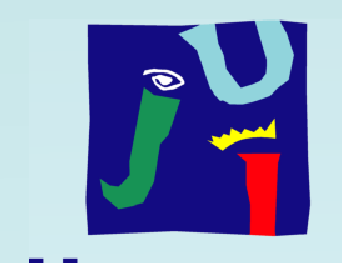

UNIVERSITAT

JAUME•I

\title{
Promoción del Emprendimiento Social y los Aprendizajes Académicos en Educación Física a través del Aprendizaje Servicio
}

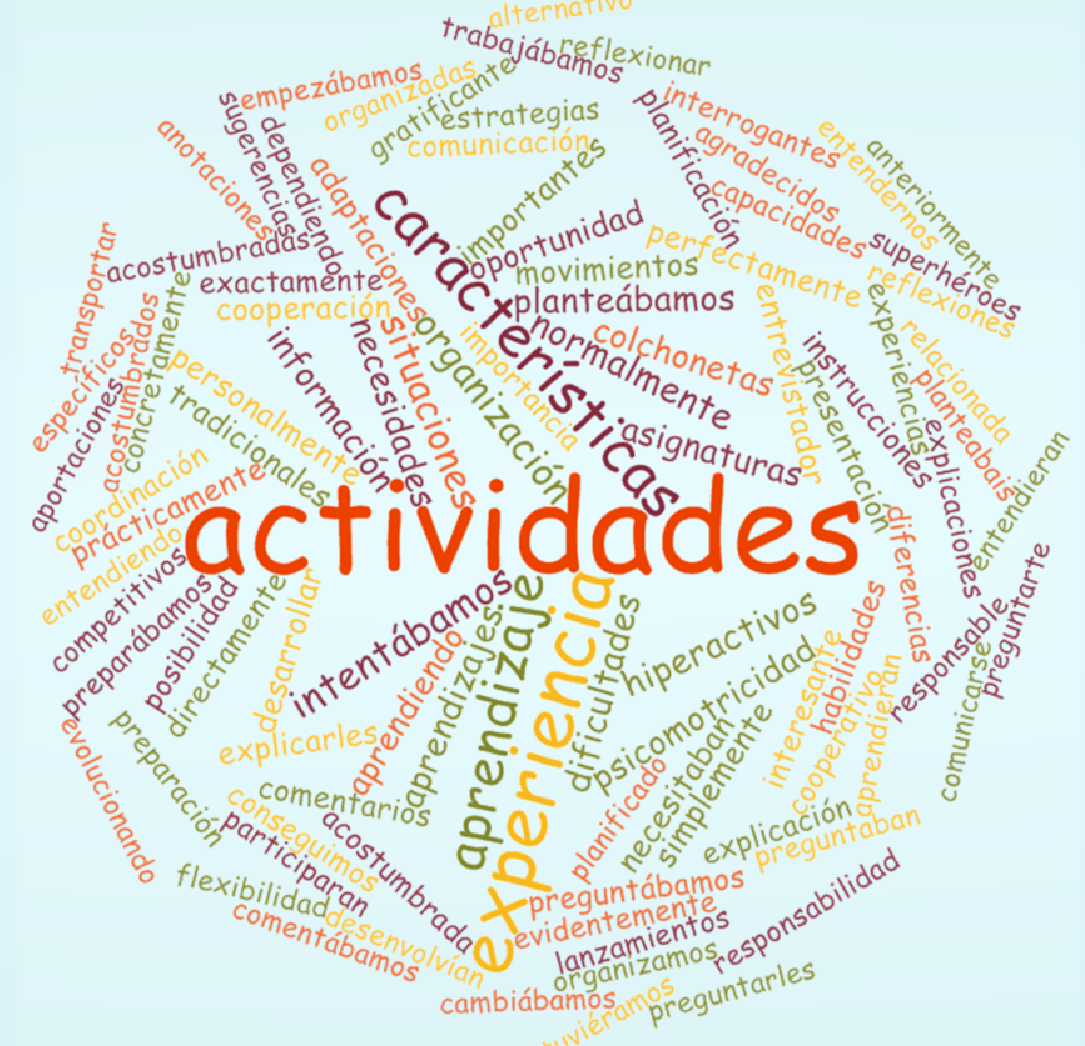

Carlos Capella Peris

Tesis Doctoral

Directores:

Dr. Jesús Gil Gómez

Mayo 2016

Dr. Manuel Martí Puig

Castellón de la Plana 


\title{
UNIVERSITAT JAUME I
}

Facultad de Ciencias Humanas y Sociales

Departamento de Educación

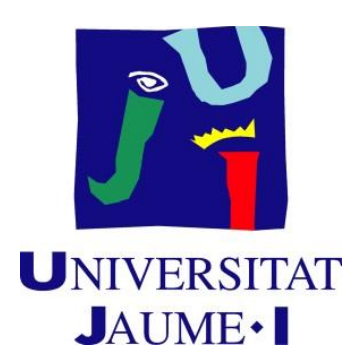

\section{Promoción del Emprendimiento Social y los Aprendizajes Académicos en Educación Física a través del Aprendizaje Servicio}

Tesis doctoral

por

\section{CARLOS CAPELLA PERIS}

\author{
Directores: \\ Dr. Jesús Gil Gómez \\ Dr. Manuel Martí Puig \\ Castellón de la Plana, 2016
}



A la memoria de mi padre.

Sigues siendo la luz que guía mi camino. 



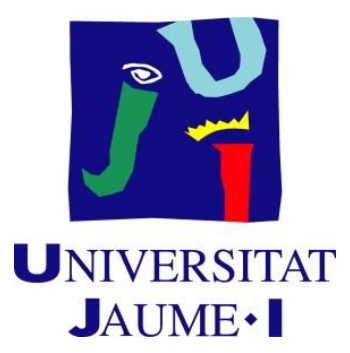

Dr. JESÚS GIL GÓMEZ, Profesor Ayudante Doctor Tipo II del Área de Didáctica de la Expresión Corporal en el Departamento de Educación de la Universitat Jaume I de Castellón, y Dr. MANUEL MARTÍ PUIG, Profesor Asociado Laboral del Área de Teoría e Historia de la Educación en el Departamento de Educación de la Universitat Jaume I de Castellón,

CERTIFICAN: Que CARLOS CAPELLA PERIS ha realizado la presente memoria, "Promoción del Emprendimiento Social y los Aprendizajes Académicos en Educación Física a través del Aprendizaje Servicio", bajo nuestra dirección en el Departamento de Educación de la Universitat Jaume I y constituye su tesis doctoral.

Y para que conste a los efectos oportunos, en cumplimiento de la legislación vigente, firmamos el presente certificado en Castellón, a trece de abril de 2016: 



\section{Tabla de contenidos}

Página

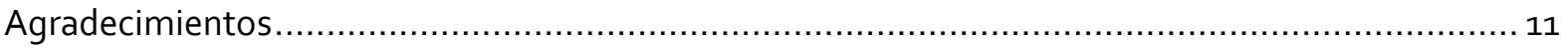

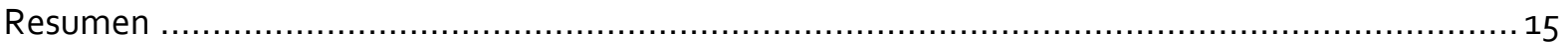

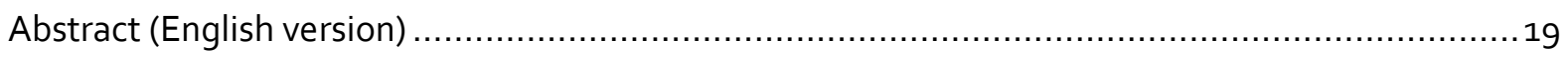

Lista de tablas, figuras, gráficos e imágenes .......................................................... 23

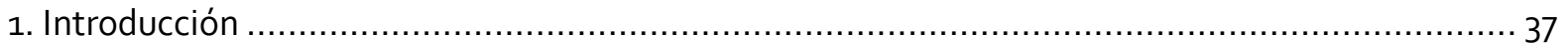

2. Aprendizaje Servicio, Educación Física e Historias de Vida .......................................... 43

2.1. Aproximación conceptual al Aprendizaje Servicio .................................................. 45

2.2. Efectos de la aplicación del Aprendizaje Servicio ................................................. 54

2.3. El Aprendizaje Servicio como estrategia de desarrollo de la competencia docente en

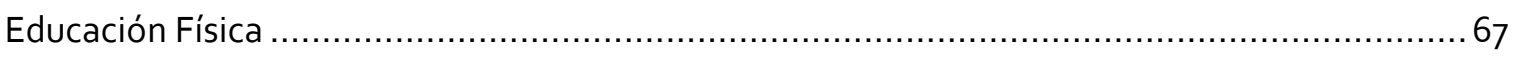

2.4. Las Historias de Vida en la investigación del Aprendizaje Servicio y el ámbito de la

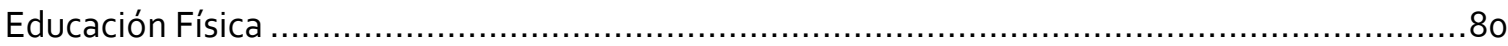

3. Emprendimiento Social y Responsabilidad Social Universitaria ........................................ 93

3.1. Concepto de Emprendimiento y peculiaridades de su vertiente social ...........................95

3.2. Estado de la cuestión respecto a Emprendimiento y Emprendimiento Social ..................117

3.3. Características y rasgos del Emprendedor Social .................................................. 128

3.4. La Responsabilidad Social Universitaria como espacio para el desarrollo del

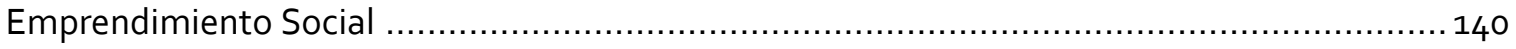

4. Programa de Aprendizaje Servicio aplicado en Educación Física .................................... 155

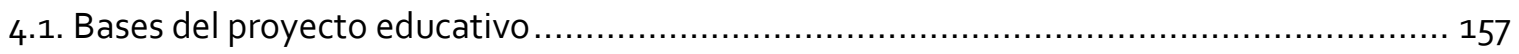

4.2. Objetivos del programa de Aprendizaje Servicio .................................................. 161

4.3. Descripción del programa de Aprendizaje Servicio ................................................. 162

4.3.1. Fase de Preparación del programa de Aprendizaje Servicio ................................. 165

4.3.2. Fase de Aplicación del programa de Aprendizaje Servicio .................................. 175

4.3.3. Fase de Reflexión del programa de Aprendizaje Servicio ............................... 183

4.4. Ámbito de aplicación del programa de Aprendizaje Servicio .....................................189

4.4.1. APADAHCAS (Asociación de Padres de Afectados por Déficit de Atención e

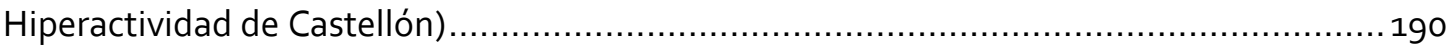

4.4.2. Centro de Educación Especial Penyeta Roja ..................................................... 191 
4.4.3. Colegio de Educación Infantil y Primaria Francesc Roca y Alcaide ........................ 193

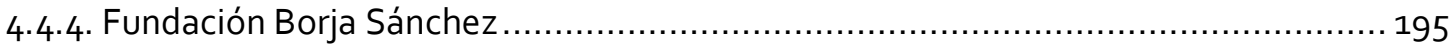

4.4.5. Fundación y Asociación Síndrome de Down de Castellón .................................. 196

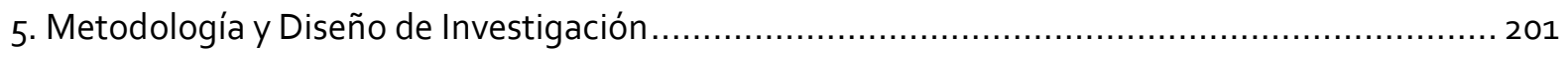

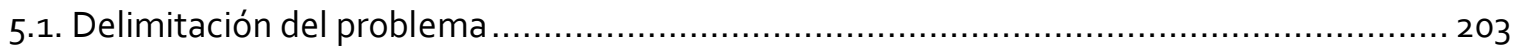

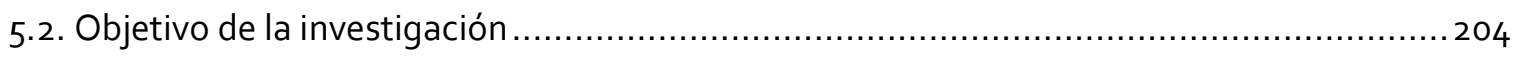

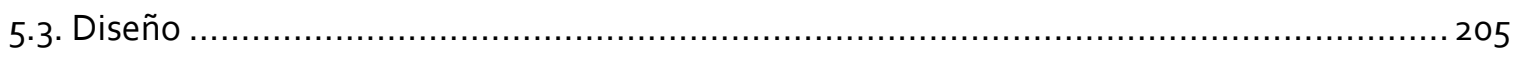

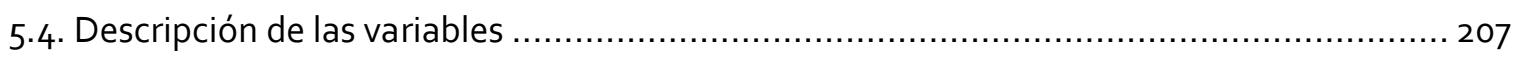

5.5. Formulación de hipótesis y preguntas de investigación .......................................... 208

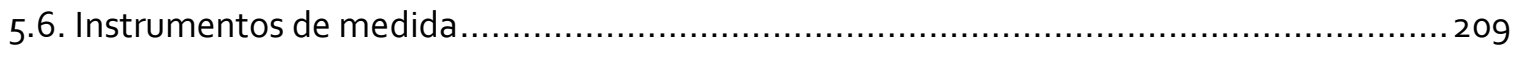

5.6.1. Rúbrica sobre conocimientos y competencias académicas .................................209

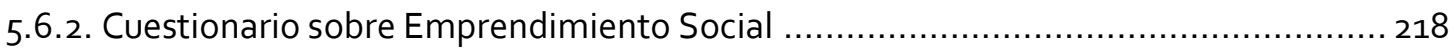

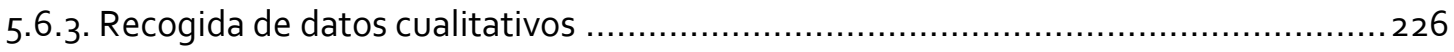

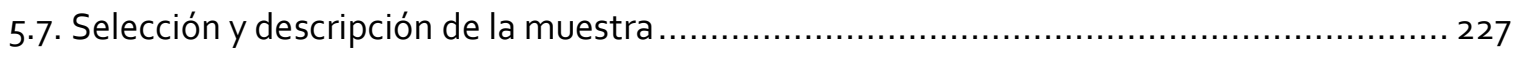

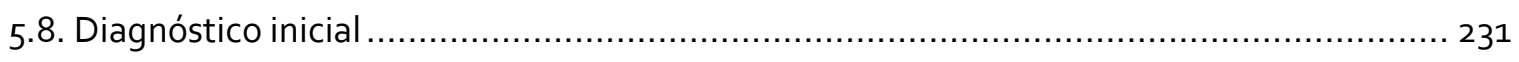

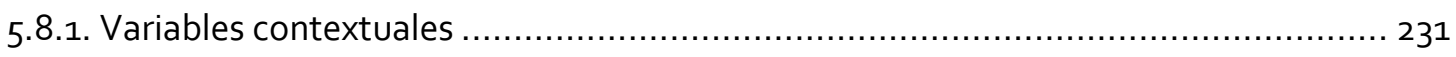

5.8.2. Procedimiento de aplicación de los instrumentos de medida ............................. 232

5.8.3. Diagnóstico de la situación inicial, Pretest de los Grupos Experimental I, Experimental

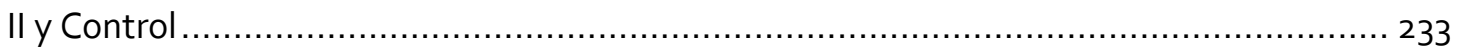

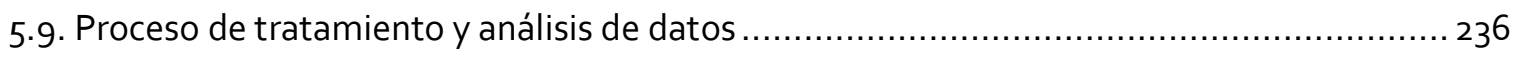

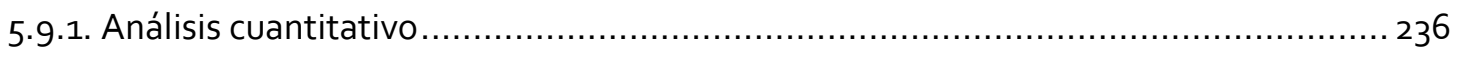

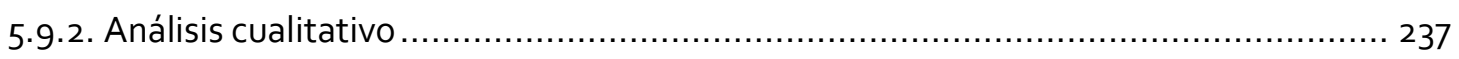

5.9.3. Expresión de los datos cualitativos de forma cuantitativa ................................ 238

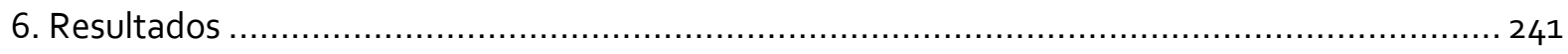

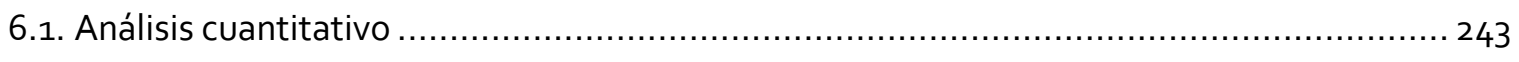

6.1.1. Variable dependiente A: conocimientos y competencias académicas ....................243

6.1.2. Variable dependiente B: competencia de Emprendimiento Social....................... 247

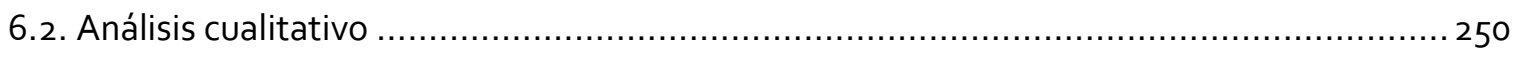

6.2.1. Variable dependiente A: conocimientos y competencias académicas ................... 251

6.2.2. Variable dependiente B: competencia de Emprendimiento Social ....................... 300

6.3. Expresión de los datos cualitativos de forma cuantitativa...................................... 345

6.3.1. Variable dependiente A: conocimientos y competencias académicas ................... 346 
6.3.2. Variable dependiente B: competencia de Emprendimiento Social ........................ 359

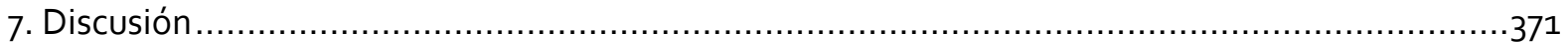

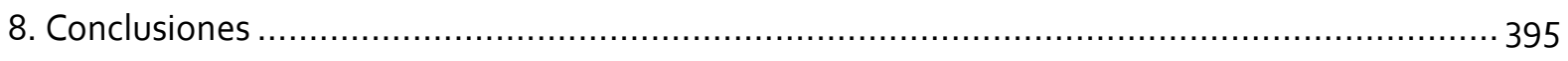

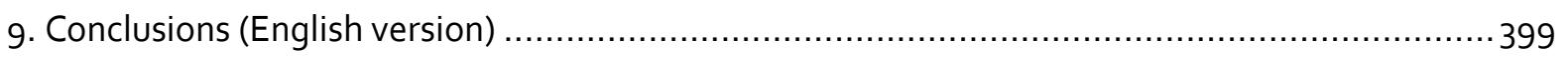

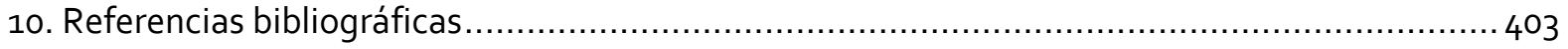

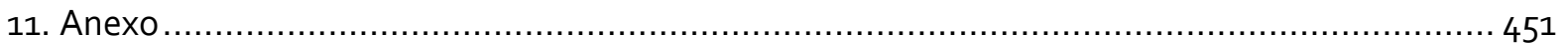





\section{Agradecimientos}

En primer lugar quisiera agradecer su ayuda a mis Directores de Tesis, los Dres. Jesús Gil y Manuel Martí, por darme la oportunidad de desarrollar este trabajo. De vuestra mano he ido dando mis primeros pasos en el ámbito docente e investigador. En este momento, con mucho por aprender todavía, soy consciente de la evolución y mejora que habéis provocado en mi capacidad para trabajar en este campo, tanto a nivel profesional como personal. Gracias por vuestras sugerencias y consejos, con vuestro apoyo hemos podido elaborar un trabajo que me provoca gran orgullo y satisfacción y que espero os despierte idénticos sentimientos.

También quisiera hacer alusión al resto de miembros del Grupo de Investigación ENDAVANT de la Universitat Jaume I, por ayudarme a progresar y compartir la difícil tarea de realizar trabajos académicos y publicaciones. Gracias por compartir vuestras ideas e integrarme en vuestros proyectos. En especial quisiera agradecer su labor a Òscar, por enseñarme que aún me queda mucho por hacer y que eso no debe desanimarme sino alentarme para seguir trabajando.

A Susana y Begoña de la secretaría del Departamento de Educación, por ayúdame a transitar por los complejos caminos de la administración. Muchas gracias por vuestra eficiencia y amabilidad pero, especialmente, por vuestra comprensión con mis innumerables dudas sobre procedimientos, formularios y requisitos. Como ya os he comentado en alguna ocasión, sois un ejemplo a seguir en cualquier puesto de la administración pública.

Al alumnado de la asignatura Fundamentos de la Expresión Corporal, Juegos motores en Educación Infantil del curso académico 2013/2014 de esta Universidad, sin cuya ayuda y colaboración no se hubiera podido desarrollar este estudio. Gracias por transmitirme vuestra pasión por la enseñanza. Igualmente, quisiera agradecer su cooperación a los distintos miembros de las entidades colaboradoras, la Asociación APADAHCAS, el CEE Penyeta Roja, el CEIP Francesc Roca $i$ Alcaide, la Fundación Borja Sánchez y la Fundación Síndrome de Down Castellón, por dejarnos entrar y trabajar en sus instituciones. En especial quisiera agradecer su participación a los niños y niñas de estas entidades, por ayudarnos a buscar nuevas formas para mejorar nuestra sociedad y recordarme que la educación debe ir más allá de la mera formación del alumnado.

A los distintos miembros de la Facultad de Educación Inicial, la Facultad de Pedagogía y Cultura Física y de la Escuela de Postgrado de la Universidad Nacional de Educación Enrique Guzmán y Valle del Perú con los que pude trabajar durante mi estancia en su país. Gracias por ofrecerme la posibilidad de integrarme en sus instituciones y aprender nuevas formas de trabajar en el ámbito académico y educativo, en especial al Dr. Luís Alberto Rodríguez, por su paciencia y comprensión con los requerimientos administrativos. También quisiera agradecer su labor a todo el personal del CEPIF de Villa El Salvador, por enseñarme a ver la docencia desde el punto de vista más humano, así como a los distintos miembros de la asociación Amigos de Villa, con quienes pude compartir vivencias de gran crudeza y emoción. Quisiera hacer especial hincapié en la figura de Elena Regalado y la Dra. Francisca Salcedo, sin cuya inestimable ayuda no hubiera podido disfrutar de una 
experiencia tan enriquecedora. Muchísimas gracias a las dos y a vuestras familias por acogerme y tratarme tan bien, nunca olvidaré las risas que nos echábamos al comprobar el contraste cultural de nuestros países. ¿Quién iba a imaginar que el simple hecho de viajar en autobús pudiera dar tanto juego?

También quisiera acordarme de todos aquellos con los que he compartido experiencias y aprendizajes sobre Educación Física a lo largo de estos años. En especial, a los profesores y compañeros del TAFAD de Benicasim y de la FCAFE de la Universidad de Valencia. Gracias por despertar mi interés por esta apasionante área de conocimiento.

En un terreno más personal, quisiera agradecer su comprensión y apoyo a todos mis amigos, en particular a los tenistas y a los vilanovins, por entender mis ausencias y, pese a ello, recibirme siempre con alegría e ilusión. Gracias por regalarme momentos inolvidables que me han ayudado y animado a seguir trabajando y mejorando como persona.

Por último, quisiera agradecer su paciencia, su confianza y su cariño a toda mi familia. En especial a Quique y Tere y a Raquel y Toni, por creer en mí desde un principio, en ocasiones incluso más que yo mismo. A toda la familia murciana, a Ramón y María José, a Pablo y Vero, y por supuesto, a Ainhoa, Martina, Irene y Julia, por regalarme momentos inolvidables llenos de alegría y emoción. A David y Bea, a Pepe y María, a Héctor y a Eva, por procurarme respaldo en los buenos y en los malos momentos, especialmente en esto últimos. Espero poder devolveros con creces el tiempo que os he robado para sacar adelante este proyecto. A mi madre, Sunin, gracias por todo el esfuerzo que has dedicado a mi educación, que ha sido mucho. Espero que esto te ayude a sobrellevar mis numerosos defectos y conseguir que estés orgullosa de mí, solo así habrá merecido la pena. Y muy en especial a mi mujer, María. Pese a trabajar en un área de conocimiento bien distinta tus consejos y sugerencias han sido de gran utilidad a lo largo de todo este proceso. Pero tu aportación va mucho más allá de la mera ayuda. Tú eres la inspiración que me ha llevado a emprender este camino, pues has generado el estímulo intelectual más potente y motivador que he recibido en toda mi vida. Gracias por ofrecerme un ejemplo de profesionalidad científica que admiro por encima de todo. No obstante, tu contribución en lo académico no puede compararse con el cariño y apoyo que me has reportado en lo personal. Muchísimas gracias, sin ti nunca hubiera llegado este momento. 




\section{Resumen}

\section{Objeto y objetivos de la investigación}

A lo largo de esta tesis presentamos y analizamos un modelo de formación universitaria, acorde con los requerimientos del Espacio Europeo de Educación Superior (EEES), basado en la metodología de enseñanza del Aprendizaje Servicio, en el que se pretende estimular las competencias del alumnado del Grado en Maestro/a de Educación Infantil, dentro del ámbito de la Educación Física, promoviendo el desarrollo del Emprendimiento Social y ofreciendo un beneficio social a través del servicio prestado en esta experiencia educativa.

Bajo esta premisa, el objetivo principal del presente trabajo es diseñar y evaluar los resultados de la aplicación de un programa de Aprendizaje Servicio en la asignatura "Fundamentos de la Expresión Corporal, Juegos Motrices en Educación Infantil". Este objetivo general se desglosa en otros dos objetivos fundamentales, que se corresponden con las dimensiones sobre las que centramos nuestro estudio:

1. Fomentar los conocimientos y competencias del alumnado sobre los contenidos de la asignatura "Fundamentos de la Expresión Corporal, Juegos Motrices en Educación Infantil".

2. Desarrollar la competencia de Emprendimiento Social en el alumnado participante.

\section{Planteamiento y metodología utilizados}

Inicialmente se ofreció al alumnado de la asignatura la posibilidad de participar en el proyecto de Aprendizaje Servicio previamente planificado. Su participación podía aplicarse en dos niveles: con dedicación completa, centrando toda la asignatura en la prestación del servicio y trabajando con una entidad colaboradora durante todo el curso académico, o con dedicación parcial, mediante una intervención reducida a 3-4 sesiones prácticas combinadas con el desarrollo normal de la asignatura. En ambos casos la función del alumnado era la de organizar, realizar y gestionar las sesiones de juegos motores y expresión corporal con los niños receptores del servicio. Con esta propuesta, se les brindó la oportunidad de practicar como docentes en esas sesiones de juegos, además de asimilar todos los beneficios adicionales que su vivencia personal les pudiera proporcionar. Siguiendo los parámetros de esta metodología didáctica, gracias a la aplicación del programa educativo, los niños y niñas de las distintas entidades colaboradoras recibieron una atención personalizada, disfrutando de una experiencia lúdica y divertida mientras desarrollaban su motricidad.

Para afrontar este estudio nos hemos decantado por un diseño de Método Mixto. Este implica el uso de las metodologías cuantitativa y cualitativa, combinándolas e integrándolas en el marco de una estructura de investigación conjunta. Aprovechando las posibilidades que nos ofrece este diseño, hemos realizado una triangulación metodológica cuyo apartado cuantitativo ha sido 
abordado a través de una investigación Multigrupo de Grupos No Equivalentes, con dos Grupos Experimentales y un Grupo Control, y medidas Pretest y Postest. Por otra parte, el aspecto cualitativo de nuestro trabajo se ha tratado empleando los métodos biográficos, a través de diversas Historias de Vida de relatos múltiples cruzados, pues es una estrategia que nos permite acceder al enorme impacto personal que generan estas prácticas educativas.

\section{Aportaciones originales}

La experiencia práctica cobra gran importancia en el campo de la Educación Física, disciplina educativa en la que se desarrolla este trabajo. Diversos autores reflexionan sobre este hecho (Gimeno, 1991; Grundy, 1991), llegando a describir la triple dimensión educativa del movimiento en la práctica: educación sobre el movimiento, educación a través del movimiento y educación en movimiento (Arnold, 1991). Por ello, teoría y práctica deben ir de la mano en este ámbito de conocimiento, promoviendo el desarrollo de un conocimiento global por parte del alumnado.

Valorando este requerimiento, consideramos que el Aprendizaje Servicio nos brinda una excelente oportunidad para desarrollar los contenidos y competencias propios de la Educación Física, a través de una formación teórico-práctica integral, ligada a una experiencia educativa de gran valor. A diferencia de otras propuestas didácticas, el Aprendizaje Servicio nos ofrece una práctica que, debido a su relación con el entorno real, aporta un doble beneficio al proceso de enseñanza-aprendizaje. En primer lugar dota de un realismo a la práctica que incrementa los beneficios de la misma en contraste con otras experiencias simuladas. $Y$, en segundo lugar, porque suma el valor educativo del contexto al proceso de enseñanza, facilitando así el tratamiento de aspectos de carácter transversal y social.

Este planteamiento nos conduce a apoyar las propuestas de formación de los aspectos de carácter social, tanto dentro como fuera de la escuela (González, 2009), pretendiendo fomentar en el alumnado el desarrollo tanto de habilidades sociales como de valores de carácter moral. En este trabajo nos hemos centrado en la promoción del Emprendimiento Social. Como señala Orrego (2009), el interés por el emprendimiento se viene evidenciando, tanto en el ambiente académico como en el empresarial, a lo largo de las últimas dos décadas en instituciones públicas, privadas y sociales. Pese a ello, Europa es una de las zonas menos emprendedoras del mundo. En España únicamente el $7,3 \%$ de la población comprendida entre 18 y 65 años participa en actividades emprendedoras de nueva creación (De la Vega, Corduras, Cruz, Justo y González, 2006). Estos autores también señalan que el porcentaje de jóvenes emprendedores menores de 25 años no supera el $10 \%$, y que la mayor parte de iniciativas emprendedoras corresponden a mayores de 35 años. Por tanto, entendemos que el emprendimiento es una competencia que debe incentivarse en los jóvenes de nuestra actual sociedad, como se refleja en la Ley Orgánica para la Mejora de la Calidad Educativa (2013). Por otra parte, fomentar el Emprendimiento Social en el ámbito educativo no solo nos permite incidir en el desarrollo de habilidades sociales y valores morales en el alumnado sino que también puede aportar su granito de arena a superar la actual crisis social que atravesamos, ya que su objetivo básico es el desarrollo y mejora de la sociedad. 
Además, cabe destacar el diseño y validación de dos instrumentos de medida diseñados ad hoc para valorar los efectos de nuestra investigación, dada la ausencia de herramientas específicas que midieran las variables analizadas en este trabajo. Por tanto, creamos una rúbrica para comprobar los aprendizajes académicos de los alumnos en cuanto al diseño y aplicación de sesiones de juegos motores y actividades de expresión corporal, y un cuestionario para medir la competencia de Emprendimiento Social del alumnado participante. Analizando la aplicabilidad de ambos instrumentos, opinamos que el valor de estas herramientas trasciende a los límites del presente estudio, pues consideramos que, en un futuro próximo, pueden ser de gran utilidad en nuevos y distintos ámbitos educativos.

\section{Conclusiones obtenidas y futuras líneas de investigación}

Los resultados obtenidos en esta investigación proporcionan evidencias sobre los efectos académicos y personales-sociales que provocan los programas de Aprendizaje Servicio. A continuación enumeramos las principales conclusiones extraídas tras la discusión de los resultados:

1. La aplicación del programa de Aprendizaje Servicio produjo una mejora significativa en los conocimientos y competencias académicas del alumnado participante sobre los contenidos de la asignatura "Fundamentos de la Expresión Corporal, Juegos Motrices en Educación Infantil".

2. La aplicación del programa de Aprendizaje Servicio produjo una mejora significativa respecto a la competencia de Emprendimiento Social del alumnado participante.

3. Los resultados obtenidos en esta investigación, respecto al desarrollo de los conocimientos y competencias académicas y el fomento de la competencia de Emprendimiento Social, están en consonancia con los trabajos teóricos de referencia y las principales revisiones sobre el Aprendizaje Servicio, así como con diversos estudios sobre los efectos de esta metodología en el campo docente de la Educación Física y el fomento del Emprendimiento Social en el ámbito educativo. Asimismo, también se aportan nuevos y destacables resultados sobre diversos aspectos de gran interés en la temática de investigación.

4. Existe una gran interrelación entre los distintos aprendizajes académicos analizados y entre los diferentes aspectos que conforman el Emprendimiento Social, poniendo de manifiesto que los elementos de ambos conceptos se desarrollan de forma conjunta.

5. La aplicación del programa de Aprendizaje Servicio provocó un notable impacto en el alumnado participante, desarrollando numerosos aprendizajes académicos y aspectos de carácter personal, social e innovador adicionales.

Las futuras líneas de investigación del presente trabajo proponen la aplicación de los instrumentos de medida creados en otros entornos educativos, para comprobar su efectividad en nuevos y variados contextos. Igualmente valoramos la posibilidad de implementar la rúbrica académica sobre la práctica del alumnado, analizar de forma continua la adquisición de conocimientos y el desarrollo de competencias a lo largo del proceso de enseñanza-aprendizaje y estudiar los efectos de esta metodología en los receptores del servicio. 



\section{Abstract (English version)}

\section{Purpose and research objectives}

Throughout this PhD Thesis we present and analyse a model of university education, according to the requirements of the European Higher Education Area (EHEA), based on the Service Learning methodology. We stimulate the skills of Pre-Service Teacher students in Early Childhood Education, in the field of Physical Education, promoting the development of Social Entrepreneurship and offering a social benefit through the service provided in this educational experience.

According to this perspective, the main objective of this work is to design and assess the results of the implementation of a Service Learning program in the subject "Body Language Basis, Motor Games in Early Childhood Education". This general objective is broken down into two basic objectives, which correspond to the dimensions on which we focused our study:

1. Promoting the student's knowledge and skills about the contents of the subject "Body Language Basis, Motor Games in Early Childhood Education".

2. Developing Social Entrepreneurship competence in the students.

\section{Approach and methodology}

Firstly we offer to the students of the subject the opportunity to participate in a Service Learning project previously planned. Their participation could be applied at two levels: through fulltime dedication, focusing all the subject development in the service provided and working with a cooperating institution throughout the entire academic year, or part-time dedication, through reduced intervention of 3-4 practical sessions combined with the regular development of the subject. In both cases the role of the students was to organize, conduct and manage sessions of motor and body language games with children receiving service. With this proposal, the students were given the opportunity to practice as teachers in those gamming sessions, and also to assimilate all the additional benefits that their personal experiences could provide to them. Following the parameters of this teaching methodology, the implementation of the educational program for children of several institutions offered them a personalized attention, enjoying a playful and fun experience while developing their motor skills.

To undertake this study we opted for a Mixed Methods design. It involves the use of quantitative and qualitative methodologies, combining and integrating them into the framework of a joint research structure. Taking advantage of the possibilities offered by this design, we made a methodological triangulation whose quantitative section has been addressed through a NonEquivalent Multi-Groups research, with two Experimental Groups and one Control Group, with Pretest and Postest measures. Moreover, the qualitative aspect of our work was treated using 
biographical methods, through several life histories of cross-multiple stories. This strategy allows us to probe the huge personal impact generated by these educational practices.

\section{Original contributions}

Practical experience has gained great importance in the field of Physical Education, the educational discipline within which this work is carried out. Several authors reflect on this fact (Gimeno, 1991; Grundy, 1991), even describing the triple educational dimension of movement in practice: education about movement, education through movement and education on movement (Arnold, 1991). Therefore, theory and practice should go hand in hand in this area, promoting the global knowledge development of the students.

Appreciating this requirement, we believe that Service Learning provides us an excellent opportunity to develop the contents and competences of Physical Education, through a theoretical and practical training, linked to a valuable educational experience. Unlike other educational proposals, Service Learning offers us a practice that, due to its relationship with the real environment, provides a double benefit to the teaching-learning process. Firstly, it gives realism to the practice that increases its benefits in contrast to other simulated experiences. Secondly, it adds the educational context value to the teaching process, thus facilitating the treatment of transversal and social aspects.

This approach leads us to support training proposals on social aspects both inside and outside school (Gonzalez, 2009), aiming to encourage the students' development of both social skills and moral values. In this work we have focused on the promotion of Social Entrepreneurship. As Orrego (2009) shows, the interest in Entrepreneurship has been arising over the past two decades both in academic and business field, and in public, private and social institutions. Nevertheless, Europe is one of the least entrepreneurial regions in the world. In Spain only 7,3\% of the population between 18 and 65 years old participate in brand new entrepreneurial activities (De la Vega et al., 2006). These authors also note that the percentage of young entrepreneurs under 25 does not exceed $10 \%$, and most entrepreneurial initiatives are carried out by people over than 35 . Therefore, we understand that entrepreneurship is a competence that should be encouraged in young people of our society, as reflected in the Spanish Law for the Improvement of Educational Quality (2013). On the other hand, promoting Social Entrepreneurship in education not only enables us to influence the development of social skills and moral values in students, but can also contribute to overcome the current social crisis we are facing, as its basic objective is the development and improvement of society.

In addition, it should be noted that we designed and validated two ad hoc measurement tools to assess the effects of our investigation, due to the absence of specific means to measure the variables analysed in this study. Hence, we created a rubric to check the student's academic learning in the design and implementation of motor games and body language activities sessions, and a questionnaire to measure the Social Entrepreneurship student's competence. Analysing the 
applicability of both instruments, we think that the value of these tools transcends the limits of this study because we believe that, in the near future, they may be useful in new and different educational levels.

\section{Conclusions and future research}

The results obtained in this research provide evidence about academic and personal-social effects caused by Service Learning programs. The following are the main conclusions drawn after discussion of the results:

1. The application of the Service Learning program produced a significant improvement in the student's academic knowledge and competences about the contents of the subject "Basis of Body Language, Motor Games in Early Childhood Education".

2. The application of the Service Learning program produced a significant improvement over the Social Entrepreneurship student's competence.

3. The results obtained in this research, regarding the development of knowledge and academic competences and the promotion of the Social Entrepreneurship competence, are in agreement with the theoretical reference works and major reviews about Service Learning as well as various studies on the effects of this methodology in teaching Physical Education and promoting Social Entrepreneurship in Education. Moreover, we provide new and outstanding results about several aspects with great interest in our field.

4. There is a strong interrelationship among the academic learning aspects analysed and among the Social Entrepreneurship features, showing that the elements of both concepts are developed jointly.

5. The application of the Service Learning program caused a significant impact on students, developing a relevant academic learning and additional personal, social, and innovative aspects.

Future research lines of this work propose the application of the measuring instruments created in other educational settings to check their effectiveness in new and varied contexts. Also, we consider the possibility of implementing the academic rubric on the pre-service teachers practice, analysing in a continuous way the acquisition of knowledge and competences development throughout the teaching-learning process or studying the effects of this methodology in the service recipients. 



\section{Lista de tablas, figuras, gráficos e imágenes}

\section{TABLAS}

Tabla 1. Etapas y fases de desarrollo de los proyectos de Aprendizaje Servicio (Puig et al., 2007). 50

Tabla 2. Diferencias entre el Prácticum y el Aprendizaje Servicio (Capella et al., 2014). ..............................52

Tabla 3. Resultados obtenidos en investigaciones cualitativas de Aprendizaje Servicio (White, 2001)................6o

Tabla 4. Impactos del Aprendizaje Servicio en los estudiantes (Furco, 2004). ..........................................6o

Tabla 5. Resultados de aprendizaje en el Aprendizaje Servicio (Yorio y Ye, 2012).....................................62

Tabla 6. Efectos del Aprendizaje Servicio según diversos meta-análisis (elaboración propia). .........................63

Tabla 7. Definiciones del término competencia (modificado de Álvarez, Pérez y Suárez, 2008)........................67

Tabla 8. Competencias profesionales en educación presentadas en el proyecto Tuning (González y Wagenaar, 2003).

Tabla 9. Competencias profesionales docentes del área de Educación Física en la titulación de Magisterio (modificado de Alonso, 2008; Romero, 2009; Romero et al., 2011).....

Tabla 10. Competencias profesionales docentes específicas del Maestro de Educación Física

(Pazo y Tejada, 2012).

Tabla 11. Pasos a seguir en el diseño de una Rúbrica

(Gallo, 2004; Suskie, 2004; Wang y Rairigh, 2006; Wolfy Stevens, 2007).

Tabla 12. Etapas para elaborar una Historia de Vida (Pujadas, 1992)

Tabla 13. Posibles enfoques del investigador al realizar Historias de Vida (Pamphilon, 1999). 86

Tabla 14. Beneficios y utilidades de la investigación narrativa en la Educación Física y el Deporte (Pérez et al., 2011).

Tabla 15. Perspectivas del Emprendimiento (Roberts y Woods, 2005).

Tabla 16. Rasgos característicos que definen la personalidad del Emprendedor Social (ampliado de Capella, Gil, Martí y Ruiz-Bernardo, en prensa).

Tabla 17. Enfoques de la Responsabilidad Social Universitaria (Gaete, 2011)........................................141

Tabla 18. Temario de la asignatura (Guía docente de la asignatura). .......................................................158

Tabla 19. Estructura organizativa de la asignatura (Guía docente de la asignatura). 159 
Tabla 20. Sistema de evaluación de la asignatura (Guía docente de la asignatura). 159

Tabla 21. Carga lectiva del Aprendizaje Servicio en la asignatura según los distintos itinerarios (elaboración propia).

Tabla 22. Sistema de evaluación de la asignatura en función de las tareas a realizar por cada grupo (elaboración propia).

Tabla 23. Duración de la fase de preparación del Aprendizaje Servicio en los equipos de trabajo del grupo A (elaboración propia).

Tabla 24. Datos sobre la fase de aplicación del Aprendizaje Servicio en los equipos de trabajo del grupo A (elaboración propia).

Tabla 25. Evaluación de la asignatura en el grupo A (elaboración propia). 184

Tabla 26. Duración de la fase de reflexión del APS en los equipos de trabajo del grupo A (elaboración propia). ...188

Tabla 27. Evaluación de la asignatura en el grupo B (elaboración propia). 188

Tabla 28. Competencias genéricas y específicas de la asignatura (Guía docente de la asignatura). 210

Tabla 29. Resultados de aprendizaje de la asignatura (Guía docente de la asignatura). 211

Tabla 30. Ítems de la rúbrica en función de los bloques de agrupación (elaboración propia). 211

Tabla 31. Relación entre los ítems de la rúbrica, las competencias y los resultados de aprendizaje (elaboración propia).

Tabla 32. Estadísticos de fiabilidad de la prueba piloto (elaboración propia). 214

Tabla 33. Kaiser-Meyer-Olkin y prueba de Bartlett (elaboración propia). 215

Tabla 34. Análisis factorial de los resultados de la prueba piloto. Matriz de estructura (elaboración propia).......215

Tabla 35. Valoración de la calidad, relevancia y comprensión por grupos de jueces (elaboración propia). 219

Tabla 36. Ítems del cuestionario en función de las categorías de agrupación (elaboración propia). 220

Tabla 37. Estadísticos de fiabilidad de la prueba piloto del cuestionario (elaboración propia). 223

Tabla 38. Kaiser-Meyer-Olkin y prueba de Bartlett (elaboración propia) 223

Tabla 39. Análisis factorial de los resultados de la aplicación del cuestionario. Matriz de estructura (elaboración propia).

Tabla 40. Distribución de los grupos en función del sexo (elaboración propia). 228

Tabla 41. Distribución de los grupos en función de la edad (elaboración propia). 228 
Tabla 42. Distribución de los grupos en función de su participación en actividades de ONG-voluntariado (elaboración propia).

Tabla 43. Distribución de los grupos en función de su nivel de formación (elaboración propia).

Tabla 44. Distribución de los grupos en función de su experiencia docente previa (elaboración propia)....... 230

Tabla 45. Agrupación de las correlaciones existentes en los resultados del Postest para la variable A (elaboración propia).

Tabla 46. Agrupación de las correlaciones existentes en los resultados del Postest para cada categoría de ítems (elaboración propia).

Tabla 47. Relación entre el objetivo principal de la investigación, los objetivos del programa de APS, las variables dependientes y las preguntas e hipótesis de investigación (elaboración propia).

Tabla 48. Estadísticos descriptivos de la prueba piloto de la rúbrica (elaboración propia). .453

Tabla 49. Análisis de los ítems si se elimina algún elemento en la rúbrica. Estadísticos total-elemento (elaboración propia).

Tabla 50. Extracción de factores comunes de la prueba piloto de la rúbrica. Varianza total explicada (elaboración propia).

Tabla 51. Estadísticos descriptivos de la prueba piloto del cuestionario (elaboración propia). 455

Tabla 52. Análisis de los ítems si se elimina algún elemento en el cuestionario. Estadísticos total-elemento (elaboración propia).

Tabla 53. Extracción de factores comunes tras el paso de la prueba piloto del cuestionario, varianza total explicada (elaboración propia).

Tabla 54. Análisis de fiabilidad de los datos de la variable A (elaboración propia).

Tabla 55. Estadísticos descriptivos de los datos de la variable A para el Grupo Experimental l en el Pretest (elaboración propia).

Tabla 56. Estadísticos descriptivos de los datos de la variable A para el Grupo Experimental II en el Pretest (elaboración propia).

Tabla 57. Estadísticos descriptivos de los datos de la variable A para el Grupo Control en el Pretest (elaboración propia).

Tabla 58. Estadísticos descriptivos de los datos de la variable A para el Grupo Experimental l en el Postest (elaboración propia). 460

Tabla 59. Estadísticos descriptivos de los datos de la variable A para el Grupo Experimental II en el Postest (elaboración propia). 
Tabla 6o. Estadísticos descriptivos de los datos de la variable A para el Grupo Control en el Postest (elaboración propia).

Tabla 61. Prueba de Kolmogorov-Smirnov para las medias de los datos de la variable A (elaboración propia)... 462

Tabla 62. Prueba de Levene para las medias de los datos de la variable A en el Pretest (elaboración propia). ... 466

Tabla 63. Prueba de Levene para las medias de los datos de la variable A en el Postest (elaboración propia). ... 466

Tabla 64. Prueba de Kruskal-Wallis para las medias de los datos de la variable A en el Pretest (elaboración propia).

Tabla 65. Prueba de Wilcoxon para las medias de los datos de la variable A en el Pretest-Postest (elaboración propia).......

Tabla 66. Prueba de Kruskal-Wallis para las medias de los datos de la variable A en el Postest (elaboración propia).

Tabla 67. Prueba de U de Mann-Whitney para las medias de los datos de la variable A en el Postest del Grupo Experimental I y el Grupo Experimental II (elaboración propia).

Tabla 68. Prueba de U de Mann-Whitney para la media de los datos de la variable A en el Postest del Grupo Experimental l y el Grupo Control (elaboración propia).

Tabla 69. Prueba de U de Mann-Whitney para las medias de los datos de la variable A en el Postest del Grupo Experimental II y el Grupo Control (elaboración propia).

Tabla 70. Prueba de Kruskal-Wallis para las medias de la categoría ajuste de los juegos al alumnado en el Postest (elaboración propia).

Tabla 71. Prueba de Kruskal-Wallis para las medias de la categoría presentación de los juegos en el Postest (elaboración propia).

Tabla 72. Prueba de Kruskal-Wallis para las medias de la categoría organización del alumnado en el Postest (elaboración propia).

Tabla 73. Prueba de Kruskal-Wallis para las medias de la categoría organización del material en el Postest (elaboración propia).

Tabla 74. Prueba de Kruskal-Wallis para las medias de la categoría organización espacio/tiempo en el Postest (elaboración propia).

Tabla 75. Prueba de Kruskal-Wallis para la medias de las categoría adaptación curricular en el Postest (elaboración propia).

Tabla 76. Prueba de Kruskal-Wallis para las medias de la categoría aspectos sociales en el Postest (elaboración propia). 
Tabla 77. Prueba de Kruskal-Wallis para las medias de la categoría juegos motores en el Postest (elaboración propia). 469

Tabla 78. Prueba de Kruskal-Wallis para las medias de la categoría juegos de expresión en el Postest (elaboración propia).

Tabla 79. Prueba de Kruskal-Wallis para las medias de la categoría otros aprendizajes académicos en el Postest (elaboración propia). 469

Tabla 80. Prueba de Pearson para las medias de los datos de la variable A por categorías de ítems en el Postest (elaboración propia).

Tabla 81. Análisis de fiabilidad de los datos de la variable B (elaboración propia).

Tabla 82. Estadísticos descriptivos de los datos de la variable B para el Grupo Experimental I en el Pretest (elaboración propia).

Tabla 83. Estadísticos descriptivos de los datos de la variable B para el Grupo Experimental II en el Pretest (elaboración propia).

Tabla 84. Estadísticos descriptivos de los datos de la variable B para el Grupo Control en el Pretest (elaboración propia).

Tabla 85. Estadísticos descriptivos de los datos de la variable B para el Grupo Experimental l en el Postest (elaboración propia).

Tabla 86. Estadísticos descriptivos de los datos de la variable B para el Grupo Experimental Il en el Postest (elaboración propia).

Tabla 87. Estadísticos descriptivos de los datos de la variable B para el Grupo Control en el Postest (elaboración propia).

Tabla 88. Prueba de Kolmogorov-Smirnov para las medias de los datos de la variable B (elaboración propia)....475

Tabla 89. Prueba de Levene para las medias de los datos de la variable B en el Pretest (elaboración propia)......478

Tabla 9o. Prueba de Levene para las medias de los datos de la variable B en el Postest (elaboración propia). ....478

Tabla 91. Prueba ANOVA para las medias de los datos de la variable B en el Pretest (elaboración propia). .........478

Tabla 92. Prueba $T$ de muestras relacionadas para las medias de los datos de la variable $B$ en el Pretest-Postest (elaboración propia).

Tabla 93. Prueba ANOVA para las medias de los datos de la variable B en el Postest (elaboración propia).

Tabla 94. Prueba de Pearson para las medias de los datos de la variable B por categorías de aspectos en el Postest (elaboración propia). 
Tabla 95. Prueba de Pearson para las medias de los datos de la variable B por aspectos característicos del Emprendimiento Social en el Postest (elaboración propia). 480

Tabla 96. Referencias sobre aprendizajes académicos en las entrevistas (elaboración propia). 482

Tabla 97. Referencias sobre aprendizajes académicos en las entrevistas por categorías (elaboración propia)... 482

Tabla 98. Referencias sobre el ajuste de los juegos al alumnado participante en las entrevistas (elaboración propia). 482

Tabla 99. Referencias sobre la presentación de los juegos en las entrevistas (elaboración propia).....................483

Tabla 100. Referencias sobre la organización del alumnado en las entrevistas (elaboración propia)...................483

Tabla 101. Referencias sobre la organización del material en las entrevistas (elaboración propia). ....................483

Tabla 102. Referencias sobre la organización espacio/temporal en las entrevistas (elaboración propia)............ 484

Tabla 103. Referencias sobre la adecuación curricular de las actividades en las entrevistas (elaboración propia). 484

Tabla 104. Referencias sobre aspectos sociales en las entrevistas (elaboración propia). 484

Tabla 105. Referencias sobre juegos motores en las entrevistas (elaboración propia). 485

Tabla 106. Referencias sobre juegos de expresión corporal en las entrevistas (elaboración propia). 485

Tabla 107. Referencias sobre otros aspectos en las entrevistas (elaboración propia). 485

Tabla 108. Referencias sobre aprendizajes académicos en la entrevista Co1 (elaboración propia). 486

Tabla 109. Referencias sobre aprendizajes académicos en la entrevista Co2 (elaboración propia)...... 486

Tabla 110. Referencias sobre aprendizajes académicos en la entrevista Co3 (elaboración propia). 486

Tabla 111. Referencias sobre aprendizajes académicos en la entrevista Co4 (elaboración propia). 487

Tabla 112. Referencias sobre los aprendizajes académicos en la entrevista Co5 (elaboración propia). 487

Tabla 113. Referencias sobre aprendizajes académicos en la entrevista Co6 (elaboración propia). 487

Tabla 114. Referencias sobre aprendizajes académicos en la entrevista Co7 (elaboración propia). 487

Tabla 115. Referencias sobre aprendizajes académicos en la entrevista Co8 (elaboración propia). 488

Tabla 116. Referencias sobre aprendizajes académicos en la entrevista Cog (elaboración propia). 488

Tabla 117. Referencias sobre aprendizajes académicos en la entrevista C10 (elaboración propia). 488 
Tabla 118. Referencias sobre aprendizajes académicos en la entrevista $C_{11}$ (elaboración propia). 489

Tabla 119. Referencias sobre aprendizajes académicos en la entrevista C12 (elaboración propia). 489

Tabla 120. Referencias sobre la competencia de Emprendimiento Social en las entrevistas (elaboración propia).

Tabla 121. Referencias sobre la competencia de Emprendimiento Social en las entrevistas por categorías (elaboración propia).

Tabla 122. Referencias sobre aspectos personales del Emprendimiento Social en las entrevistas (elaboración propia). 490

Tabla 123. Referencias sobre aspectos sociales del Emprendimiento Social en las entrevistas (elaboración propia).

Tabla 124. Referencias sobre aspectos innovadores del Emprendimiento Social en las entrevistas (elaboración propia). 491

Tabla 125. Referencias sobre la competencia de Emprendimiento Social en la entrevista Co1 (elaboración propia).

Tabla 126. Referencias sobre la competencia de Emprendimiento Social en la entrevista Co2 (elaboración propia).

Tabla 127. Referencias sobre la competencia de Emprendimiento Social en la entrevista Co3 (elaboración propia).

Tabla 128. Referencias sobre la competencia de Emprendimiento Social en la entrevista Co4 (elaboración propia).

Tabla 129. Referencias sobre la competencia de Emprendimiento Social en la entrevista Co5 (elaboración propia).

Tabla 130. Referencias sobre la competencia de Emprendimiento Social en la entrevista Co6 (elaboración propia).

Tabla 131. Referencias sobre la competencia de Emprendimiento Social en la entrevista Co7 (elaboración propia).

Tabla 132. Referencias sobre la competencia de Emprendimiento Social en la entrevista Co8 (elaboración propia).

Tabla 133. Referencias sobre la competencia de Emprendimiento Social en la entrevista Cog (elaboración propia).

Tabla 134. Referencias sobre la competencia de Emprendimiento Social en la entrevista C1o (elaboración propia). 
Tabla 135. Referencias sobre la competencia de Emprendimiento Social en la entrevista C11 (elaboración propia).

Tabla 136. Referencias sobre la competencia de Emprendimiento Social en la entrevista C12 (elaboración propia).

\section{FIGURAS}

Figura 1. Formas puras de Compromiso Social (Martin y Osberg, 2007).....................................................102

Figura 2. Constructo Multidimensional del Emprendimiento Social (Mort et al., 2003). .................................108

Figura 3. Conceptualización del Emprendimiento Social (Tan et al., 2005).................................................108

Figura 4. Conceptualización del Emprendimiento Social como Modelo Multidimensional (Weerawardena y Mort, 2006).

Figura 5. Matriz del Emprendimiento Social (Massetti, 2008).

Figura 6. Dominios conceptuales de investigación sobre el Emprendimiento Social (Short et al., 2009). 111

Figura 7. Conceptualización del Emprendimiento Social como agrupación de conceptos (Choi y Majumdar, 2014).

Figura 8. Relación de los 4 pasos de aplicación de la Responsabilidad Social Universitaria (modificado de Vallaeys et al., 2009).

Figura 9. Integración de las misiones universitarias en la perspectiva del Aprendizaje Servicio y la Responsabilidad Social (Tapia, 2010). 152

Figura 10. Diseño de la investigación (adaptado de Creswell y Plano Clark, 2007). 206

\section{GRÁFICOS}

Gráfico 1. Histograma de la prueba piloto de la rúbrica (elaboración propia). ...............................................214

Gráfico 2. Histograma de la prueba piloto del cuestionario (elaboración propia)............................................ 222

Gráfico 3. Composición de los grupos en función del sexo (elaboración propia) ............................................ 228

Gráfico 4. Composición de los grupos en función de la edad (elaboración propia). .......................................... 229

Gráfico 5. Composición de los grupos en función de su participación en actividades de ONG-voluntariado (elaboración propia).

Gráfico 6. Composición de los grupos en función de su nivel de formación (elaboración propia). 230 
Gráfico 7. Composición de los grupos en función de su experiencia docente previa (elaboración propia). 231

Gráfico 8. Resultados en el Pretest y Postest del Grupo Experimental I para la variable A (elaboración propia). 243 Gráfico 9. Resultados en el Pretest y Postest del Grupo Experimental II para la variable A (elaboración propia). 244 Gráfico 10. Resultados en el Pretest y Postest del Grupo Control para la variable A (elaboración propia). 244

Gráfico 11. Comparación de la media de los registros obtenidos en la variable A entre el Pretest y el Postest de cada uno de los grupos (elaboración propia).

Gráfico 12. Resultados en el Pretest y Postest del Grupo Experimental I para la variable B (elaboración propia).

Gráfico 13. Resultados en el Pretest y Postest del Grupo Experimental II para la variable B (elaboración propia).

Gráfico 14. Resultados en el Pretest y Postest del Grupo Control para la variable B (elaboración propia).......... 248

Gráfico 15. Comparación de la media de los registros obtenidos en la variable B entre el Pretest y el Postest de cada uno de los grupos (elaboración propia).

Gráfico 16. Referencias sobre aprendizajes académicos en las entrevistas (elaboración propia)...................... 346

Gráfico 17. Referencias sobre aprendizajes académicos en las entrevistas por categorías (elaboración propia)...347

Gráfico 18. Referencias sobre el ajuste de los juegos al alumnado participante en las entrevistas (elaboración propia).

Gráfico 19. Referencias sobre la presentación de los juegos en las entrevistas (elaboración propia). 348

Gráfico 20. Referencias sobre la organización del alumnado en las entrevistas (elaboración propia).

Gráfico 21. Referencias sobre la organización del material en las entrevistas (elaboración propia).

Gráfico 22. Referencias sobre la organización espacio/temporal en las entrevistas (elaboración propia). 350

Gráfico 23. Referencias sobre la adecuación curricular de las actividades en las entrevistas (elaboración propia).

Gráfico 24. Referencias sobre aspectos sociales en las entrevistas (elaboración propia). .351

Gráfico 25. Referencias sobre juegos motores en las entrevistas (elaboración propia). .351

Gráfico 26. Referencias sobre juegos de expresión corporal en las entrevistas (elaboración propia). .352

Gráfico 27. Referencias sobre otros aspectos en las entrevistas (elaboración propia). .352

Gráfico 28. Referencias sobre aprendizajes académicos en la entrevista Co1 (elaboración propia). 353 
Gráfico 29. Referencias sobre aprendizajes académicos en la entrevista Co2 (elaboración propia).....................353

Gráfico 30. Referencias sobre aprendizajes académicos en la entrevista Co3 (elaboración propia)....................354

Gráfico 31. Referencias sobre aprendizajes académicos en la entrevista Co4 (elaboración propia).....................354

Gráfico 32. Referencias sobre aprendizajes académicos en la entrevista Co5 (elaboración propia).....................355

Gráfico 33. Referencias sobre aprendizajes académicos en la entrevista Co6 (elaboración propia)....................355

Gráfico 34. Referencias sobre aprendizajes académicos en la entrevista Co7 (elaboración propia). ...................356

Gráfico 35. Referencias sobre aprendizajes académicos en la entrevista Co8 (elaboración propia)....................356

Gráfico 36. Referencias sobre aprendizajes académicos en la entrevista Cog (elaboración propia).................... 357

Gráfico 37. Referencias sobre aprendizajes académicos en la entrevista C10 (elaboración propia).....................357

Gráfico 38. Referencias sobre aprendizajes académicos en la entrevista C11 (elaboración propia). ....................358

Gráfico 39. Referencias sobre aprendizajes académicos en la entrevista C12 (elaboración propia)...................358

Gráfico 40. Referencias sobre la competencia de Emprendimiento Social en las entrevistas (elaboración propia).

Gráfico 41. Referencias sobre la competencia de Emprendimiento Social en las entrevistas por categorías (elaboración propia).

Gráfico 42. Referencias sobre los aspectos personales del Emprendimiento Social en las entrevistas (elaboración propia)....... 360

Gráfico 43. Referencias sobre los aspectos sociales del Emprendimiento Social en las entrevistas (elaboración propia)...... 361

Gráfico 44. Referencias sobre los aspectos innovadores del Emprendimiento Social en las entrevistas (elaboración propia)....... 362

Gráfico 45. Referencias sobre la competencia de Emprendimiento Social en la entrevista Co1 (elaboración propia). ....363

Gráfico 46. Referencias sobre la competencia de Emprendimiento Social en la entrevista Co2 (elaboración propia). 363

Gráfico 47. Referencias sobre la competencia de Emprendimiento Social en la entrevista Co3 (elaboración propia). 364

Gráfico 48. Referencias sobre la competencia de Emprendimiento Social en la entrevista Co4 (elaboración propia). 
Gráfico 49. Referencias sobre la competencia de Emprendimiento Social en la entrevista Co5 (elaboración propia). .365

Gráfico 50. Referencias sobre la competencia de Emprendimiento Social en la entrevista Co6 (elaboración propia).

Gráfico 51. Referencias sobre la competencia de Emprendimiento Social en la entrevista Co7 (elaboración propia).

Gráfico 52. Referencias sobre la competencia de Emprendimiento Social en la entrevista Co8 (elaboración propia). 366

Gráfico 53. Referencias sobre la competencia de Emprendimiento Social en la entrevista Cog (elaboración propia).

Gráfico 54. Referencias sobre la competencia de Emprendimiento Social en la entrevista C10 (elaboración propia).

Gráfico 55. Referencias sobre la competencia de Emprendimiento Social en la entrevista C11 (elaboración propia). 368

Gráfico 56. Referencias sobre la competencia de Emprendimiento Social en la entrevista C12 (elaboración propia). 368

Gráfico 57. Normalidad de la muestra del Grupo Experimental I en el Pretest para la variable A (elaboración propia).

Gráfico 58. Normalidad de la muestra del Grupo Experimental Il en el Pretest para la variable A (elaboración propia). 463

Gráfico 59. Normalidad de la muestra del Grupo Control en el Pretest para la variable A (elaboración propia). . 464

Gráfico 6o. Normalidad de la muestra del Grupo Experimental l en el Postest para la variable A (elaboración propia).

Gráfico 61. Normalidad de la muestra del Grupo Experimental Il en el Postest para la variable A (elaboración propia). 465

Gráfico 62. Normalidad de la muestra del Grupo Control en el Postest para la variable A (elaboración propia). 465 Gráfico 63. Normalidad de la muestra del Grupo Experimental I en el Pretest para la variable B (elaboración propia).

Gráfico 64. Normalidad de la muestra del Grupo Experimental II en el Pretest para la variable B (elaboración propia).

Gráfico 65. Normalidad de la muestra del Grupo Control en el Pretest para la variable B (elaboración propia) ...476 
Gráfico 66. Normalidad de la muestra del Grupo Experimental l en el Postest para la variable B (elaboración propia).

Gráfico 67. Normalidad de la muestra del Grupo Experimental Il en el Postest para la variable B (elaboración propia).

Gráfico 68. Normalidad de la muestra del Grupo Control en el Postest para la variable B (elaboración propia). . 477

\section{IMÁGENES}

Imagen 1. Contrato de aprendizaje para la participación en el programa de Aprendizaje Servicio (elaboración propia)

Imagen 2. Documento reflexivo sobre la aplicación del Aprendizaje Servicio (elaboración propia).

Imagen 3. Asignación de tareas y roles a desempeñar en las sesiones (elaborada por los equipos de trabajo del grupo A)

Imagen 4. Organización temporal de los miembros del grupo (elaborada por los equipos de trabajo del grupo A).

Imagen 5. Estructura organizativa de las tareas a realizar en cada actividad de la sesión (elaborada por los equipos de trabajo del grupo A).

Imagen 6. Autorización para hacer fotos a los niños receptores del servicio durante las sesiones (elaborada por los equipos de trabajo del grupo A).

Imagen 7. Diploma acreditativo para entregar a los niños una vez finalizada la actividad (elaborado por los equipos de trabajo del grupo $A$ ).

Imagen 8. Ficha de juego 1 (elaborada por los equipos de trabajo del grupo A).

Imagen 9. Documento de registro de roles (elaborado por los equipos de trabajo del grupo A).

Imagen 10. Documento de registro del proceso reflexivo tras la aplicación del servicio 1

(elaborado por los equipos de trabajo del grupo A).

Imagen 11. Documento de registro de la dedicación directa en el servicio 1

(elaborado por los equipos de trabajo del grupo $A$ ).

Imagen 12. Acta de registro de las reuniones realizadas a lo largo de la aplicación del servicio (elaborada por los equipos de trabajo del grupo A). 180

Imagen 13. Foto de una sesión práctica de servicio 1 (tomada por el equipo investigador). 180

Imagen 14. Foto de una sesión práctica de servicio 2 (tomada por el equipo investigador) 181 
Imagen 15. Foto de una sesión práctica de servicio 3 (tomada por el equipo investigador). .181

Imagen 16. Ficha de juego 2 (elaborada por los equipos de trabajo del grupo A). .185

Imagen 17. Documento de registro de la dedicación directa en el servicio 2

(elaborado por los equipos de trabajo del grupo A). 186

Imagen 18. Documento de registro del proceso reflexivo tras la aplicación del servicio 2 (elaborado por los equipos de trabajo del grupo $A$ ).

Imagen 19. Documento de registro del proceso reflexivo tras la aplicación del servicio 3

(elaborado por los equipos de trabajo del grupo A).

Imagen 20. Documento de registro del proceso reflexivo tras la aplicación del servicio 4 (elaborado por los equipos de trabajo del grupo A).

Imagen 21. Rubrica para valorar los conocimientos y competencias de la asignatura (Capella, Gil, Chiva y Martí, 2015).

Imagen 22. Cuestionario sobre la Competencia de Emprendimiento Social (CCES) (Capella et al., en prensa)... 225 Imagen 23. Autorización para realizar y grabar las entrevistas (elaboración propia). 

1. Introducción 

De acuerdo con la necesidad de adaptarse a los requerimientos del Espacio Europeo de Educación Superior, la Universidades españolas deben modificar sus estrategias de enseñanza, incidiendo en el desarrollo de las competencias de los estudiantes ${ }^{1}$. Diversos autores abordan las implicaciones de esta situación sobre el Grado en Maestro (Villa, Campo, Arranz, Villa y García, 2013), destacando especialmente el desarrollo de las competencias vinculadas con los contextos de intervención del alumnado (Rosales, 2013). Esta iniciativa nos lleva a pensar en la introducción de metodologías de corte activo y experiencial en la docencia de los futuros maestros, contexto de aplicación de la presente tesis, para que permitan al estudiantado aplicar sus aprendizajes en escenarios reales.

Bajo esta premisa podemos destacar el Aprendizaje Servicio como una metodología de enseñanza que procura el desarrollo de contenidos académicos a la vez que se presta un servicio a la comunidad atendiendo alguna necesidad no satisfecha. Es decir, el alumnado aprende en contextos reales movilizando capacidades complicadas de trabajar en otros ámbitos, vinculadas a contenidos curriculares, a la vez que contribuye a resolver carencias de la sociedad (Aramburuzabala y García, 2012; Gil, 2012). Así pues, el Aprendizaje Servicio supone una experiencia práctica de acción y reflexión en la que el alumnado aplica contenidos, desarrolla competencias y resuelve problemas reales, dentro de un marco académico, a través de una actividad de servicio a la comunidad. Esto implica que el alumnado debe ser socialmente activo, por lo que se presenta como un espacio idóneo para el desarrollo de valores sociales.

La experiencia práctica cobra gran importancia en el campo de la Educación Física, disciplina educativa en la que se desarrolla este trabajo. Diversos autores reflexionan sobre este hecho (Gimeno, 1991; Grundy, 1991), llegando a describir la triple dimensión educativa del movimiento en la práctica: educación sobre el movimiento, educación a través del movimiento y educación en movimiento (Arnold, 1991). Por ello, teoría y práctica deben ir de la mano en este ámbito de conocimiento, promoviendo el desarrollo de un conocimiento global por parte del alumnado.

Conjugando este requerimiento con el planteamiento anterior, consideramos que el Aprendizaje Servicio nos brinda una excelente oportunidad para desarrollar los contenidos y competencias propios de la Educación Física, a través de una formación teórico-práctica integral, ligada a una experiencia educativa de gran valor. A diferencia de otras propuestas didácticas, el Aprendizaje Servicio nos ofrece una práctica que, debido a su relación con el entorno real, aporta un doble beneficio al proceso de enseñanza-aprendizaje. En primer lugar dota de un realismo a la práctica que incrementa los beneficios de la misma en contraste con otras experiencias simuladas. $Y$, en segundo lugar, porque suma el valor educativo del contexto al proceso de enseñanza, facilitando así el tratamiento de aspectos de carácter transversal y social.

\footnotetext{
${ }^{1}$ A lo largo del documento se han tratado de utilizar términos genéricos en lo que a cuestión de género se refiere. A pesar de ello en algunas ocasiones no ha sido posible $y$, por cuestiones estilísticas, se ha utilizado indistintamente el género masculino o femenido para hacer referencia a ambos sexos sin que ello suponga una cuestión discriminatoria.
} 
Este planteamiento nos conduce a apoyar las propuestas de formación de los aspectos de carácter social, tanto dentro como fuera de la escuela (González, 2009), pretendiendo fomentar en el alumnado el desarrollo tanto de habilidades sociales como de valores de carácter moral. En este trabajo nos hemos centrado en la promoción del Emprendimiento Social. Como señala Orrego (2009), el interés por el emprendimiento se viene evidenciando, tanto en el ambiente académico como en el empresarial, a lo largo de las últimas dos décadas en instituciones públicas, privadas y sociales. Pese a ello, Europa es una de las zonas menos emprendedoras del mundo. En España únicamente el $7,3 \%$ de la población comprendida entre 18 y 65 años participa en actividades emprendedoras de nueva creación (De la Vega et al., 2006). Estos autores también señalan que el porcentaje de jóvenes emprendedores menores de 25 años no supera el 10\%, y que la mayor parte de iniciativas emprendedoras corresponden a mayores de 35 años. Por tanto, entendemos que el emprendimiento es una competencia que debe incentivarse en los jóvenes de nuestra actual sociedad, como se refleja en la Ley Orgánica para la Mejora de la Calidad Educativa (2013). Además, fomentar el Emprendimiento Social en el ámbito educativo no solo nos permite incidir en el desarrollo de habilidades sociales y valores morales en el alumnado sino que también puede aportar su granito de arena a superar la actual crisis social que atravesamos, ya que su objetivo básico es el desarrollo y mejora de la sociedad.

Buscando la forma de implementar nuestra propuesta, comprobamos que el Aprendizaje Servicio genera una serie de situaciones en el proceso de enseñanza-aprendizaje en las que se ponen en juego valores y actitudes prosociales coincidentes con los rasgos que debe tener un emprendedor social, conectando así la educación con el Emprendimiento Social desde la promoción de la participación, implicación y compromiso de los estudiantes en y con su comunidad local, como acertadamente defiende Cieza (2010).

La educación universitaria nos ofrece un espacio óptimo para la aplicación de este proyecto, la Responsabilidad Social Universitaria. Esta hace referencia a las acciones de la Universidad como institución para mejorar la sociedad desde su labor reflexiva, ética, académica, investigadora e innovadora (Vila y Martín, 2014). Esta conceptualización nos ayuda a comprender que las universidades deben emplear la Responsabilidad Social Universitaria como una herramienta útil para promover el cambio social hacia una sociedad más sostenible, con el apoyo de la gestión universitaria y su proyección social (Stephens, Hernández, Román, Graham y Scholz, 2008). De este modo se entiende que además de las responsabilidades habituales de formación, investigación y trasferencia del conocimiento y la tecnología, las universidades tienen una responsabilidad social con la comunidad.

Una de las perspectivas de actuación de la Responsabilidad Social Universitaria es la docencia, a través de la transformación social y la formación de ciudadanos responsables (Gaete, 2011). De acuerdo con este planteamiento destaca la metodología del Aprendizaje Servicio, ya que refleja este nuevo enfoque de la función del servicio de formación, cada vez más extendido y con muchos ejemplos de buenas prácticas, e implicando una forma alternativa de vinculación con la comunidad (Beltrán, Íñigo y Mata, 2014). La formación universitaria a través de esta metodología favorece la 
preparación de los estudiantes para que se inserten en la sociedad como ciudadanos responsables y contribuyan al desarrollo sostenible de la comunidad en una clara expresión de beneficio mutuo, más allá de la simple adquisición de competencias profesionales para su inserción laboral (Hervani y Helms, 2004). Por ello, los programas de Aprendizaje Servicio se presentan como una gran alternativa a la hora de implantar la Responsabilidad Social Universitaria, especialmente desde el punto de vista del desarrollo de valores cívicos y la sensibilidad social en los distintos miembros de la comunidad universitaria, ya que no solo afecta al alumnado.

Este supuesto cierra la vinculación entre los distintos elementos abordados en este trabajo. Por tanto, presentamos y analizamos un modelo de formación universitaria, acorde a los requerimientos del EEES, basado en la metodología de enseñanza del Aprendizaje Servicio, en el que se pretenden estimular las competencias del alumnado del Grado en Maestro/a de Educación Infantil, dentro del ámbito de la Educación Física, promoviendo el desarrollo del Emprendimiento Social y ofreciendo un beneficio social a través del servicio prestado en esta experiencia educativa.

Para afrontar este estudio nos hemos decantado por un diseño de Método Mixto. Este implica el uso de las metodologías cuantitativa y cualitativa, combinándolas e integrándolas en el marco de una estructura de investigación conjunta. Aprovechando las posibilidades que nos ofrece este diseño, hemos realizado una triangulación metodológica cuyo apartado cuantitativo ha sido abordado a través de una investigación Multigrupo de Grupos No Equivalentes, con dos Grupos Experimentales y un Grupo Control, y medidas Pretest y Postest. Por otra parte, el aspecto cualitativo de nuestro trabajo se ha tratado empleando los métodos biográficos, a través de diversas Historias de Vida de relatos múltiples cruzados, pues es una estrategia que nos permite acceder al enorme impacto personal que generan estas prácticas educativas. Cabe destacar el diseño y validación de dos instrumentos de medida ad hoc para valorar los efectos de nuestra investigación, dada la ausencia de herramientas específicas que midieran las variables analizadas en este trabajo. Opinamos que el valor de estas herramientas trasciende los límites del presente estudio, pues consideramos que, en un futuro próximo, pueden ser aplicadas en nuevos y distintos ámbitos educativos.

La estructura de la tesis está dividida en dos partes. En la primera se aborda el marco teórico en el que se justifica la realización de la presente investigación a través del análisis y explicación de los distintos conceptos abordados en este trabajo. La segunda parte describe el diseño, aplicación y evaluación del programa de Aprendizaje Servicio implementado en el ámbito de la Educación Física, así como el diseño del estudio realizado, los resultados registrados, la discusión de las conclusiones extraídas y las posibles líneas de investigación a seguir en el futuro. 

2. Aprendizaje Servicio, Educación Física e Historias de Vida 



\subsection{Aproximación conceptual al Aprendizaje Servicio}

Los primeros antecedentes significativos de la práctica del Aprendizaje Servicio (en adelante APS) se encuentran a finales del siglo XIX y principios del XX con la difusión del movimiento "extensión universitaria" a través de la creación del "servicio social" en universidades de México, propiciando el desarrollo de acciones sociales desde el ámbito de la educación superior (Gortari, 2004). Autores como Dewey o Freire influyeron significativamente a principios y mediados del siglo $X X$ en el desarrollo de programas y actividades basados en esta metodología; no obstante, el termino Service Learning (APS en inglés) fue utilizado por primera vez en 1967, cuando Ramsay, Sigmon y Hart lo emplearon para describir un proyecto de desarrollo local llevado a cabo por estudiantes y docentes de la Oak Ridge Associated Universities en Tennessee junto con organizaciones de la zona (Tapia, 2010). La misma autora nos indica que la expresión se consolidó tan solo dos años más tarde en la primera Service Learning Conference celebrada en Atlanta (Eberly, 1988; Jacoby, 1996; Stanton, Giles y Cruz, 1999; Titlebaum, Williamson, Daprano, Baer y Brahler, 2004). Tras esta breve aproximación sobre los inicios del APS, a continuación abordaremos la conceptualización de este término.

Según la Ley estadounidense National and Community Service Act of $1990^{2}$, el APS es un método por el cual los estudiantes o participantes aprenden y se desarrollan a través de la participación en servicios cuidadosamente organizados, que se realizan en una comunidad y se dirigen a satisfacer las necesidades de dicha comunidad; se coordina entre una escuela primaria, secundaria, una institución de educación superior o un programa de servicio comunitario y la propia comunidad; ayuda a promover la responsabilidad cívica; se integra en el currículo académico de los estudiantes o en aquellos componentes educativos del programa de servicio comunitario en el cual los participantes toman parte; por último, proporciona un tiempo estructurado para que los estudiantes o participantes reflexionen sobre la experiencia del servicio.

Por otra parte, Eyler y Giles (1999) definen el APS como una forma de educación basada en la experiencia, en la que el aprendizaje se produce a través de un ciclo de acción y reflexión gracias al cual el alumnado trabaja con otros compañeros y compañeras en un proceso de aplicación de lo que han aprendido sobre los problemas de la comunidad y, al mismo tiempo, reflexionan sobre la experiencia de perseguir objetivos reales para la comunidad e incrementar su propia comprensión y destreza. Otros autores consideran que es una metodología de enseñanza y aprendizaje mediante la cual los jóvenes desarrollan sus conocimientos y competencias a través de una práctica de servicio a la comunidad (Tapia, 2001).

En un contexto más próximo, partiendo de la idea de que la ayuda mutua es un mecanismo de progreso personal, económico y social mejor que la persecución obsesiva del provecho individual, De la Cerda, Graell, Martín, Muñoz y Puig (2009) definen el APS como una metodología que combina en una sola actividad el aprendizaje de contenidos, competencias y valores con la

\footnotetext{
${ }^{2}$ Public Law 101-610, November 16, 1990, National and Community Service Act of 1990.
} 
realización de tareas de servicio a la comunidad. En esta línea, el Centro Promotor del APS ${ }^{3}$ de Cataluña (2015) considera que es "una propuesta educativa que combina procesos de aprendizaje y de servicio a la comunidad en un solo proyecto bien articulado en el que los participantes se forman trabajando sobre necesidades reales del entorno con el objetivo de mejorarlo".

Como podemos observar existen diversas definiciones de lo que es el APS; no obstante, en los últimos años la comunidad académica ha ido convergiendo hacia algunos consensos básicos en torno a tres rasgos fundamentales: el protagonismo activo del estudiantado en el planeamiento, desarrollo y evaluación de los proyectos de APS, el desarrollo de actividades de servicio solidario orientadas a colaborar eficazmente con la solución de problemáticas comunitarias concretas y la vinculación intencionada de las prácticas solidarias con los contenidos de aprendizaje y/o investigación incluidos en el currículum académico (Tapia, 2008). En esta línea, la Writing@CSU4 de la Universidad de Colorado (2015) considera que los elementos comunes en las diferentes definiciones de este fenómeno son:

- Involucra al alumnado en actividades de servicio a la comunidad y les proporciona una experiencia para su desarrollo personal y académico.

- Surge al producirse un equilibrio entre los objetivos del aprendizaje y los resultados del servicio.

- Sus objetivos están vinculados a necesidades reales de la comunidad.

- Los materiales empleados informan al estudiantado sobre el servicio a realizar y este proporciona una formación académica mediante el diálogo y la comprensión.

- Provoca la participación del alumnado en un proceso de tres fases: preparación a través de la explicación y análisis de teorías e ideas, actividad de servicio formativo que emerge del contexto del aula y reflexión estructurada que vincula la experiencia de servicio con los objetivos de aprendizaje específicos.

Teniendo en cuenta toda esta información, entendemos el APS como una experiencia práctica de acción y reflexión en la que el alumnado aplica contenidos, desarrolla competencias y resuelve problemas reales, dentro de un marco académico, a través de una actividad de servicio a la comunidad.

Tras esta conceptualización del APS, pasamos a exponer sus principios teóricos y rasgos pedagógicos más importantes. De este modo, siguiendo a Gil (2012), consideramos que el APS se fundamenta en los siguientes principios teóricos:

- Beneficio de la sociedad. Está es una de las características principales del APS, ya que si la aplicación de un programa no provoca una mejora en la sociedad, este no puede ser considerado como APS. Sin embargo, como veremos más adelante, la importancia de este

\footnotetext{
${ }^{3}$ http://www.aprenentatgeservei.org/index.php?cm $=02$

${ }^{4}$ http://writing.colostate.edu/guides/teaching/service_learning/definition.cfm
} 
beneficio social puede darse en distintos grados, aunque siempre debe mantener la reciprocidad de aportar un beneficio mutuo al alumnado.

- Aprendizaje experiencial. La preparación y aplicación del servicio proporciona una experiencia fundamental en la metodología del APS. Según Dewey toda auténtica educación se efectúa mediante la experiencia, la cual genera cambios en la persona y en el entorno, transformando tanto el contexto físico como el social (Shook, 2000; Sleeper, 2001). Analizando estas ideas, Kraft y Sakofs (1985) plantean las siguientes bases para el aprendizaje experiencial: el alumnado debe involucrarse en lo que está aprendiendo a través de experiencias dentro y fuera del aula; el aprendizaje debe ser relevante e, igualmente, debe preparar a quienes aprenden para vivir en un mundo cambiante y en constante evolución. Como podemos ver el APS cubre todas estas premisas.

- Transformación social. Debido a la influencia del contexto en el que se aplica el APS, este aspira a provocar una transformación social (Martínez, 2015; Tapia, 2010). Obviamente, no podemos pretender provocar cambios globales e instantáneos, pero con la aplicación de cada proyecto de APS sí estamos logrando pequeños y progresivos cambios que poco a poco van teniendo un reflejo en la sociedad en la que vivimos.

- Reflexión. Este es otro de los elementos centrales en los que se fundamenta el APS ya que, si no se realiza una concienzuda reflexión sobre toda la experiencia vivida, el APS no cubrirá los objetivos pretendidos. Para aumentar los beneficios del aprendizaje, la reflexión deberá ser transversal, implicando a los diferentes miembros involucrados así como aplicándose en las distintas fases de actuación. Así pues, este proceso reflexivo deberá realizarse en las fases de preparación, aplicación y finalización del servicio, pudiendo ser individual, grupal, con los receptores del servicio, con el profesorado responsable, etc.

- Planificación y organización. Los proyectos educativos de APS plantean retos organizativos muy distintos a la educación de aula tradicional. La ruptura con el espacio físico habitual supone una gran cantidad de problemas estructurales y logísticos que solo podrán resolverse mediante una planificación y organización sin fisuras. De este modo, para poder tener éxito en cualquier programa de APS debemos planificar de antemano las fases de aplicación e imprevistos a resolver, y organizar adecuadamente los contenidos curriculares a trabajar, los objetivos educativos a conseguir y las competencias genéricas y específicas a desarrollar.

- Incremento del bienestar y de la inclusión social. Los proyectos de APS van dirigidos a cubrir necesidades sociales, trabajando en la mayoría de casos con colectivos desfavorecidos en riesgo de exclusión social. Esta situación determina la vertiente comunitaria del APS, lo cual provoca un impacto directo en las creencias y valores del alumnado así como en su forma de entender el mundo y la sociedad. Así pues, las experiencias de APS se muestran como un espacio ideal en el que desarrollar valores y principios éticos y morales aumentando el nivel de bienestar social. Por otra parte, además de fomentar la inclusión de los colectivos receptores del servicio, también aumentamos la inclusión del alumnado debido al trabajo individual, grupal y cooperativo que supone el APS al participar de forma activa en todo momento. 
- Asunción de roles significativos. Según la teoría del aprendizaje significativo de Ausubel (Ausubel, 1960, 1963, 1978; Ausubel, Novak y Hanesian, 1978), para aprender un concepto debe haber una cantidad básica de información inicial sobre el mismo. Esta actúa como material de fondo para la nueva información, reajustando y reconstruyendo el concepto en el proceso de aprendizaje. De este modo, se genera un círculo educativo en el que la estructura de los saberes previos condiciona los nuevos conocimientos y experiencias, y estos, a su vez, modifican y reestructuran la información inicial. Así pues, esta teoría considera que aprendemos mediante la construcción de redes de conceptos, añadiendo nuevos conceptos para formar mapas conceptuales más grandes. Dado la continua reflexión que implica el APS, así como el entorno contextual que lo engloba, es fácil entender el aumento de la significatividad en el proceso de enseñanza-aprendizaje, facilitando así la integración de los nuevos conocimientos por parte del alumnado.

- Constructivismo social. Según esta visión del aprendizaje, planteada por Vygotsky (1978), los nuevos conocimientos se forman en la propia persona a partir de los esquemas existentes, producto de su realidad y su comparación con los esquemas de aquellos que le rodean. Este autor confiere una gran importancia al entorno social del aprendizaje, considerando a las personas como seres principalmente sociales y postulando que solo mediante las interacciones con el contexto social se consiguen aprendizajes significativos. Por tanto, expone los siguientes principios fundamentales del constructivismo social: la sociedad tiene un rol central como elemento formativo; aprender es una experiencia social y colaborativa en la que el lenguaje, la sociedad, la cultura y la interacción social juegan un papel primordial; el aprendizaje debe situarse en un ambiente real con situaciones significativas; el conocimiento se construye a través del diálogo; por último, la adquisición de conocimientos se basa en la experimentación y en la búsqueda de soluciones a los errores cometidos. Al igual que sucedía anteriormente, el APS cumple todos estos principios ya que supone aplicaciones reales, interacciones sociales, trabajo en equipo, diálogo e interpretación social y utiliza la indagación como estrategia de actuación.

Centrándonos en los rasgos pedagógicos del APS como metodología de enseñanza-aprendizaje Puig, Gijón, Martín y Rubio (2011) opinan que todas las actividades de APS, independientemente del contenido específico que aborden, comparten determinadas condiciones pedagógicas, entre las que destacan:

- Se aprende a partir de la experiencia. Estas actividades no se centran en solventar problemas hipotéticos, estudiar casos, diseñar proyectos o llevar a cabo simulaciones, sino que se vinculan con necesidades reales sobre las que se pretende intervenir con el ánimo de mejorarlas. El establecimiento de vínculos personales que provocan las relaciones generadas a través del APS, basados en la comprensión y apertura, hace que el aspecto vivencial de la experiencia se intensifique aumentando con ello los beneficios de esta práctica.

- Se aprende de manera cooperativa. EI APS ofrece escenarios de trabajo cooperativo que permiten asumir retos ambiciosos imposibles de abordar de manera individual, generando así relaciones de interdependencia positiva entre todos los participantes. Esta cooperación se 
concreta tanto en las relaciones recíprocas entre iguales como en la articulación de las acciones con otros miembros de la comunidad.

- Se aprende reflexionando sobre la acción. Aunque la participación activa es el motor del aprendizaje, el ejercicio reflexivo necesario en todo proyecto de APS evita la actividad descontrolada. Esta reflexión, necesaria en las distintas fases de aplicación del APS, es la que permite que cada participante interiorice la experiencia de una forma significativa. Por otra parte, ofrece la posibilidad de incidir en aquellos aspectos que no se han podido desarrollar durante la intervención en el medio.

- Se aprende con la ayuda que aportan los adultos. El protagonismo del alumnado en la actividad exige a los adultos un papel diferente del habitual. Así pues, los educadores y los profesionales de entidades sociales ejercen una función menos controladora y transmisora para convertirse en guías del proceso, dirigiendo sus esfuerzos a fomentar la participación, ya sea planteando problemas, organizando la actividad o animando al joven alumnado.

Como podemos observar, estas aportaciones coinciden destacando la vertiente social y personal de esta metodología de enseñanza, aspecto de vital importancia en el proyecto planteado por la presente tesis.

Tras presentar los principios teóricos y los rasgos pedagógicos del APS, seguidamente profundizaremos en la importancia de sus dos elementos principales: el aprendizaje y el servicio. Según Batlle (2009) las características del servicio en el APS se distinguen por la realización de un trabajo, la conciencia y libre decisión, la gratuidad, el reconocimiento y, por último, la significación. Igualmente, esta autora considera que existen varias perspectivas que justifican la realización de dicho servicio: antropológica (como altruismo), política (como participación), ética (como relación interpersonal), y educativa (como prácticas de aprendizaje). En cuanto al aprendizaje a través del APS, Rubio (2009) nos indica que se caracterizará por el desarrollo de las siguientes competencias: personales, interpersonales, para el pensamiento cívico, la realización de proyectos, la ciudadanía y la transformación social, y vocacionales y profesionales. En función de estos aspectos entendemos que no hay un modelo único de APS a seguir. En esta línea, Furco (1996, 2002), Billig (2000) y Martínez-Odría (2005) sintetizan las diversas modalidades de servicio existentes en:

- Servicio directo. Esta modalidad requiere una relación directa del alumnado con las personas receptoras del servicio o las situaciones de necesidad, interviniendo directamente sobre el problema detectado. Este tipo de servicio promueve el desarrollo cognitivo, social y afectivo, desarrolla la adquisición de habilidades interpersonales y fomenta la responsabilidad social, como veremos en el siguiente capítulo, algo que gran importancia.

- Servicio indirecto. Modalidad que habitualmente se desarrolla en las instituciones académicas. El objetivo es aportar recursos, ideas y experiencias al alumnado sin entrar en contacto directo con los receptores del servicio, mejorando la situación de necesidad y colaborando con las organizaciones comunitarias que dan respuesta a la misma.

- Advocacy. Esta modalidad busca que el estudiantado contribuya a la eliminación de las causas que generan o mantienen un problema concreto de interés público que afecta a la 
comunidad. Para ello se pueden realizar campañas de concienciación y sensibilización sobre un tema, fomentando el desarrollo de habilidades negociadoras y de gobierno, el conocimiento legal sobre el funcionamiento de la sociedad y el poder público, la adquisición de compromisos sociales y el sentimiento de pertenencia a la comunidad.

- Servicio de investigación. En esta modalidad se encuentran los proyectos basados en la recopilación de información y documentación relevante para la vida de la comunidad, el conocimiento de las instancias y agentes sociales encargados de dar solución a los problemas de la misma o la detección de las principales necesidades sociales. La participación en este tipo de actividades favorece el desarrollo de habilidades de búsqueda y síntesis de la información, la capacidad de discriminación de la información, la emisión de juicios de valor sobre la documentación seleccionada y la habilidad de presentar la información a terceros.

En la elaboración de esta tesis nos hemos decantado por la modalidad del servicio directo. Con ello pretendemos fomentar la responsabilidad social, uno de los pilares de la educación universitaria actual, generar un impacto social y personal sobre el alumnado y proporcionar una experiencia práctica en la que el alumnado pueda desarrollar sus competencias docentes.

Después de profundizar en las peculiaridades de los dos elementos básicos del APS, a continuación presentamos la tabla 1 donde podemos ver las diferentes etapas y fases de aplicación que debe seguir todo programa educativo de APS (Puig, Batlle, Bosch y Palos, 2007).

Tabla 1. Etapas y fases de desarrollo de los proyectos de Aprendizaje Servicio (Puig et al., 2007).

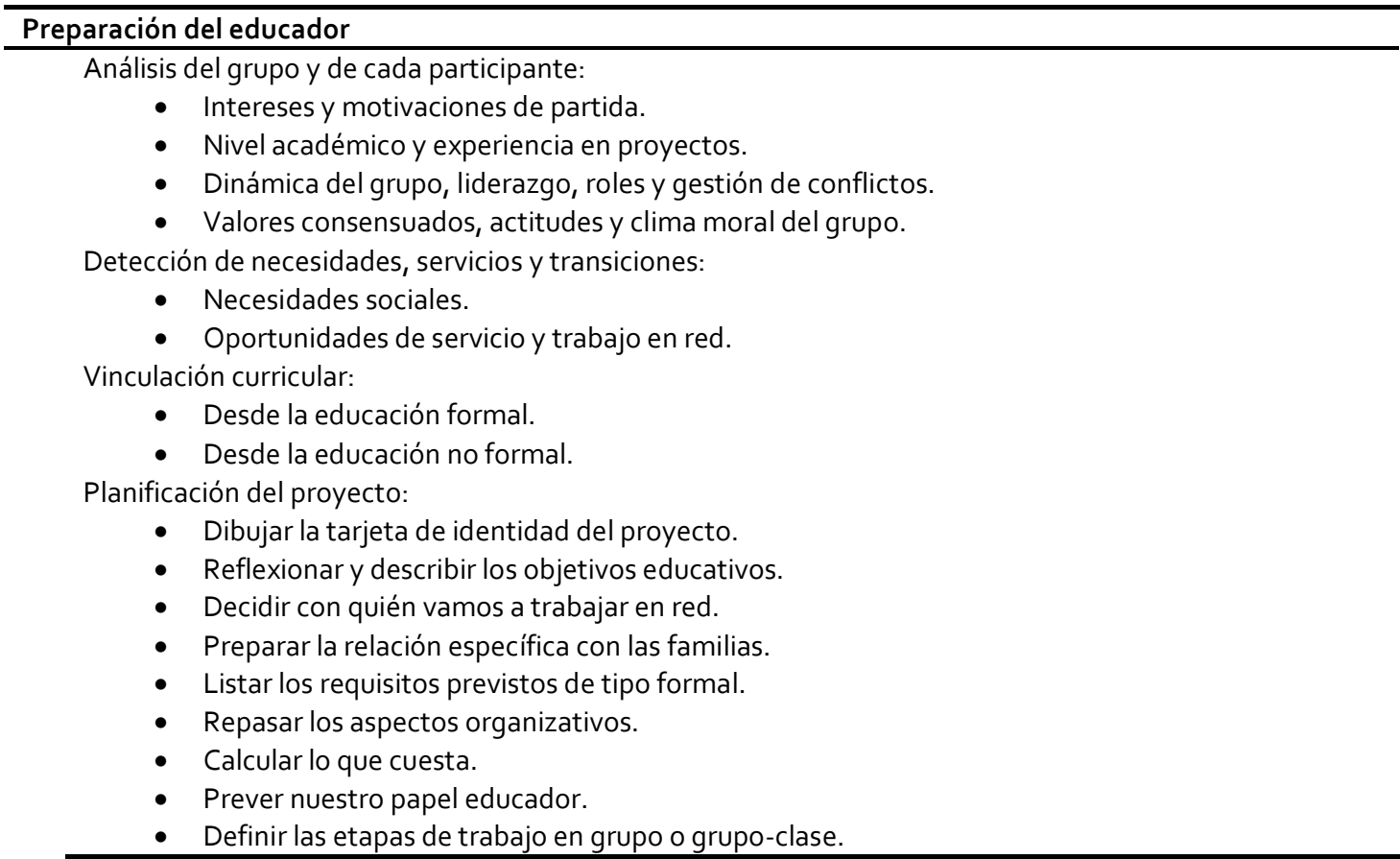




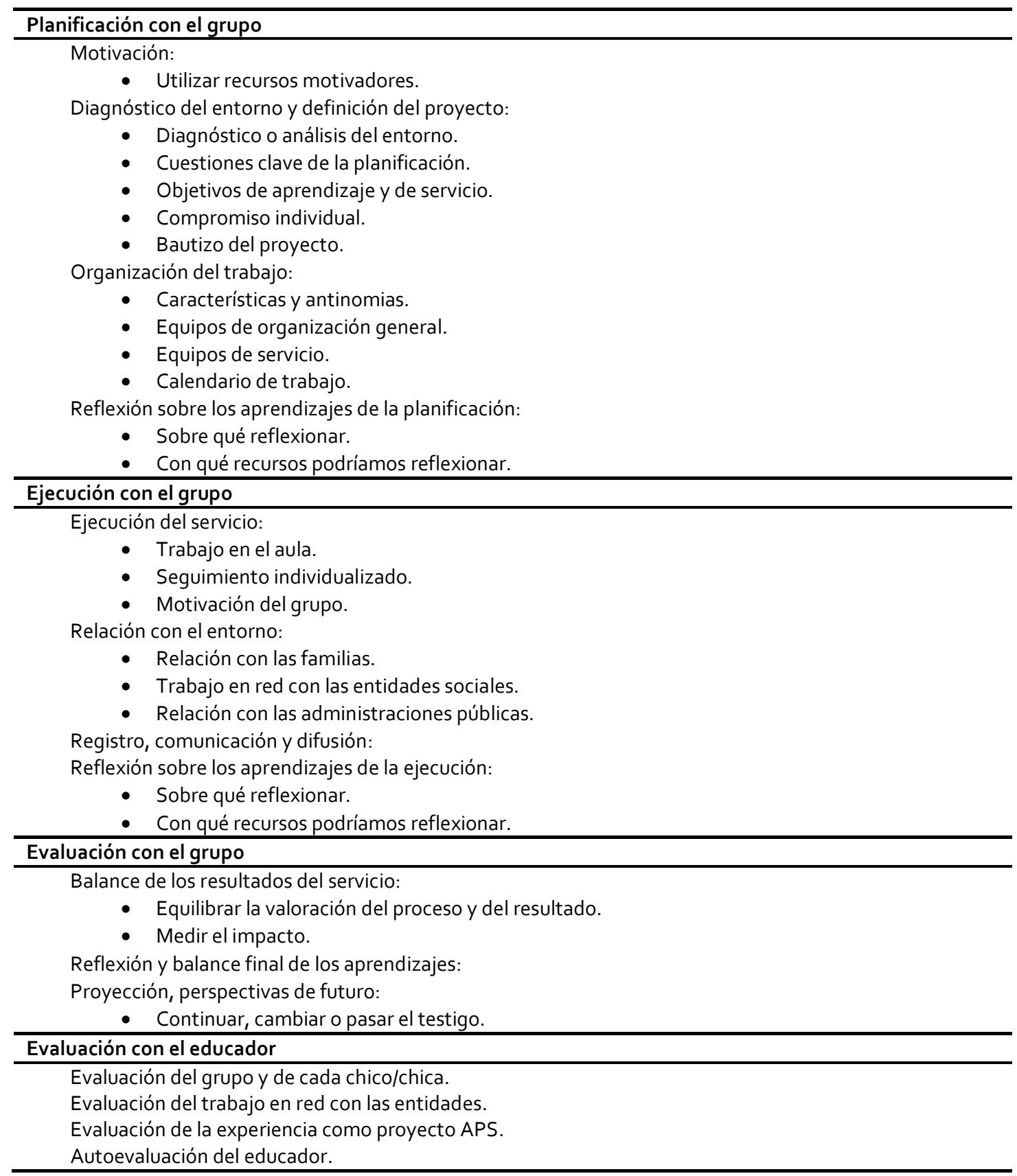

Analizando las fases expuestas en la tabla 1 , entendemos que habrá tres momentos de actuación en todo proyecto de APS: un periodo inicial que implicará la preparación del educador, el grupo de trabajo y el propio proyecto, un periodo medio de acción y, por último, un periodo final de reflexión y evaluación, coincidiendo con lo expuesto anteriormente por la Writing@CSU de la Universidad de Colorado (2015). 
Pese a toda la información aportada hasta el momento, nos gustaría resaltar las diferencias existentes entre la metodología del APS y una práctica docente y/o asignatura habitual en los estudios universitarios, las prácticas externas o Prácticum. Aunque inicialmente las diferencias entre ambos conceptos puedan parecer obvias, el Prácticum es una asignatura más del plan de estudios mientras que el APS es una metodología de enseñanza-aprendizaje que puede emplearse en cualquier asignatura, las semejanzas por compartir un fuerte carácter experiencial pueden llevar a equívocos. Así pues, recurriendo al análisis de las definiciones de estos dos términos y sus características configuradoras (Aramburuzabala y García, 2012; García, Gozálvez, Vázquez y Escámez, 2010; Gil, Francisco y Moliner, 2012; RD 1707/20115 ; Zabalza, 2011), presentamos la tabla 2 que recoge sus diferencias agrupadas en cuatro grandes categorías (Capella, Gil y Martí, 2014):

Tabla 2. Diferencias entre el Prácticum y el Aprendizaje Servicio (Capella et al., 2014).

\begin{tabular}{|c|c|c|}
\hline & PRÁCTICUM & APS \\
\hline \multirow{6}{*}{$\begin{array}{l}\text { Papel de los } \\
\text { agentes } \\
\text { implicados }\end{array}$} & Profesorado planifica & Alumnado y profesorado planifican \\
\hline & Instituciones determinan lugar y funciones & Alumnado elige o busca lugar y funciones \\
\hline & $\begin{array}{l}\text { Asimetría en las relaciones profesorado- } \\
\text { alumnado }\end{array}$ & Reciprocidad en el aprendizaje y colaboración \\
\hline & $\begin{array}{l}\text { Institución comprometida con la } \\
\text { formación }\end{array}$ & $\begin{array}{l}\text { Institución comprometida con formación y con } \\
\text { la sociedad }\end{array}$ \\
\hline & Profesorado "supervisor" & Profesorado "guía" \\
\hline & $\begin{array}{l}\text { Rol del tutor de prácticas pactado y } \\
\text { definido }\end{array}$ & $\begin{array}{l}\text { Rol del colaborador basado en su compromiso e } \\
\text { implicación }\end{array}$ \\
\hline \multirow{14}{*}{$\begin{array}{l}\text { Características } \\
\text { pedagógicas }\end{array}$} & $\begin{array}{l}\text { Receptores del Prácticum (caso de existir): } \\
\text { colectivos sin riesgos }\end{array}$ & $\begin{array}{l}\text { Receptores del servicio: colectivos en } \\
\text { desventaja social o riesgo de exclusión }\end{array}$ \\
\hline & Educación en contenidos y procedimientos & $\begin{array}{l}\text { Educación en conocimientos, procedimientos y } \\
\text { valores }\end{array}$ \\
\hline & Trabaja contenidos generales & Trabaja contenidos específicos \\
\hline & No atiende una necesidad social & Utilidad social atendiendo una necesidad \\
\hline & $\begin{array}{l}\text { Pedagogía activa y reflexiva en función de } \\
\text { variables (contexto, implicación...) }\end{array}$ & Pedagogía activa y reflexiva siempre \\
\hline & Prácticas informativas & Alumnado activo \\
\hline & Evaluación por profesorado/tutor & $\begin{array}{l}\text { Alumnado participa en la evaluación junto con } \\
\text { profesorado, colaboradores y receptores }\end{array}$ \\
\hline & Formación deontológica & $\begin{array}{l}\text { Formación deontológica, ciudadana, humana, } \\
\text { personal y social }\end{array}$ \\
\hline & $\begin{array}{l}\text { Aprendizaje ético por observación y por } \\
\text { construcción autónoma de valores }\end{array}$ & $\begin{array}{l}\text { Aprendizaje ético por observación, por } \\
\text { construcción autónoma de valores y por } \\
\text { ejercicio (o por la combinación de los tres) }\end{array}$ \\
\hline & Reproducción de modelos & Procesos de investigación-acción \\
\hline & $\begin{array}{l}\text { Construcción de conocimiento en } \\
\text { contextos habituales }\end{array}$ & $\begin{array}{l}\text { Construcción de conocimientos en contextos de } \\
\text { necesidad social }\end{array}$ \\
\hline & Reflexión sobre la práctica limitada & $\begin{array}{l}\text { Reflexión sobre la práctica continua y con } \\
\text { múltiples participantes }\end{array}$ \\
\hline & Feedback unidireccional (profesorado) & $\begin{array}{l}\text { Feedback multidireccional (profesorado, } \\
\text { receptores, agentes sociales...) }\end{array}$ \\
\hline & Elaboración individual del conocimiento & Elaboración cooperativa y colaborativa del \\
\hline
\end{tabular}

\footnotetext{
${ }^{5}$ Real Decreto $1707 / 2011$ de 18 de noviembre, por el que se regulan las prácticas académicas externas de los estudiantes universitarios.
} 


\begin{tabular}{|c|c|c|}
\hline & $\begin{array}{l}\text { generalmente } \\
\text { Saber, saber hacer } \\
\text { No análisis crítico del entorno }\end{array}$ & $\begin{array}{l}\text { conocimiento siempre } \\
\text { Saber, saber hacer, saber ser y convivir } \\
\text { Análisis crítico y social del entorno }\end{array}$ \\
\hline \multirow{5}{*}{$\begin{array}{l}\text { Adquisición de } \\
\text { competencias }\end{array}$} & Competencias profesionales & $\begin{array}{l}\text { Competencias profesionales, para la vida y la } \\
\text { ciudadanía responsable }\end{array}$ \\
\hline & Prepara profesionales & Prepara profesionales y ciudadanos \\
\hline & Crea personas competentes laboralmente & $\begin{array}{l}\text { Crea personas competentes laboralmente y con } \\
\text { conciencia social }\end{array}$ \\
\hline & Aprender a hacer, aprender a aprender & $\begin{array}{l}\text { Aprender a hacer, aprender a aprender y } \\
\text { aprender a emprender }\end{array}$ \\
\hline & $\begin{array}{l}\text { Desarrolla competencias genéricas y } \\
\text { específicas de todas las materias }\end{array}$ & $\begin{array}{l}\text { Desarrolla competencias genéricas y específicas } \\
\text { de la materia }\end{array}$ \\
\hline \multirow{5}{*}{$\begin{array}{l}\text { Papel de la } \\
\text { sociedad }\end{array}$} & $\begin{array}{l}\text { Su prioridad no es prestar un servicio a la } \\
\text { comunidad mientras se aprende }\end{array}$ & $\begin{array}{l}\text { Su prioridad es prestar un servicio a la } \\
\text { comunidad mientras se aprende }\end{array}$ \\
\hline & $\begin{array}{l}\text { No existe la necesidad de recibir la } \\
\text { prestación de un servicio }\end{array}$ & $\begin{array}{l}\text { Receptores reconocen la necesidad de la } \\
\text { prestación del servicio }\end{array}$ \\
\hline & $\begin{array}{l}\text { Su finalidad no es mejorar ni transformar } \\
\text { la sociedad }\end{array}$ & $\begin{array}{l}\text { Su finalidad es mejorar y transformar la } \\
\text { sociedad }\end{array}$ \\
\hline & $\begin{array}{l}\text { No busca la mejora del compromiso con la } \\
\text { comunidad y la justicia social del alumnado }\end{array}$ & $\begin{array}{l}\text { Busca la mejora del compromiso con la } \\
\text { comunidad del alumnado y la justicia social }\end{array}$ \\
\hline & $\begin{array}{l}\text { Su objetivo no es preparar al estudiante } \\
\text { para abordar situaciones sociales y éticas } \\
\text { en su futura profesión }\end{array}$ & $\begin{array}{l}\text { Su objetivo es preparar al estudiante para } \\
\text { abordar situaciones sociales y éticas en su } \\
\text { futura profesión }\end{array}$ \\
\hline
\end{tabular}

No podemos terminar esta aproximación conceptual sobre el APS sin exponer algunos ejemplos de su aplicación. Para hacerlo, nos remitimos a Folgueiras, Luna y Puig (2013), quienes destacan los siguientes ejemplos en el continente americano: 1983-2004 National Youth Leadership Council of Minnesota, 1985 Campus Compact, 90' Learn and Serve America's National Service Learning Clearinghouse, 90' Service Learning Research and Development Center (Berkeley), 1994 Corporation for national and community: Learn and Serve America, 2003 International Center for Service Learning in Teacher Education y Higher Education Research Institute at UCLA. Del mismo modo, estos autores también destacan las siguientes prácticas de APS en Europa: Council for Citizenship and Learning in the Community, 2002 Higher Education Active Community Fund, 2005 Service Learning: Dialogue between Universities and Communities (Proyecto Leonardo: CIVICUS), Das Hochschulnetzwerk (Red de Educación Superior), y 2007 The first international conference on Service Learning in teacher education (Bruselas). En nuestro país podemos destacar el trabajo de la Red Española de APS ${ }^{6}$, el Centro Promotor de APS ${ }^{7}$ de Cataluña, el Grupo Promotor de APS de la Comunidad Valenciana ${ }^{8}$, la fundación Zerbikas ${ }^{9}$ en Euskadi, la Red Universitaria Española de APS $(\text { ApS-U })^{10}$ y la Red APS y Educación Física ${ }^{11}$.

\footnotetext{
${ }^{6}$ http://aprendizajeservicio.net/

${ }^{7}$ http://www.aprenentatgeservei.org/index.php

8 http://apscomunitatvalenciana.net/experiencies-daps/

9 http://www.zerbikas.es/

${ }_{10}$ https://sites.google.com/site/redapsuniversitario/

${ }_{11}^{11}$ https://www.facebook.com/redapsef
} 
Tras lo expuesto, a continuación destacamos a modo de síntesis las ideas principales de este apartado:

1. Actualmente conviven multitud de definiciones sobre el APS; no obstante, existen suficientes elementos comunes entre ellas para poder limitar su conceptualización.

2. Los principios teóricos en los que se asienta el APS son el beneficio de la sociedad, el aprendizaje experiencial, la transformación social, la reflexión, la planificación y organización, el incremento del bienestar y la inclusión social, la asunción de roles significativos y el constructivismo social.

3. El APS se caracteriza pedagógicamente porque se aprende de forma cooperativa a partir de la experiencia, gracias a la ayuda de los docentes y los profesionales de las entidades colaboradoras, mediante un profundo proceso reflexivo sobre su aplicación.

4. En función del tipo de servicio prestado, las modalidades de APS serán directo, indirecto, advocacy y de investigación, y sus fases de aplicación se desarrollarán en tres grandes etapas: preparación, aplicación y reflexión-evaluación.

5. Pese a compartir algunos elementos comunes, especialmente en cuanto al valor de la experiencia, el APS es una metodología de enseñanza-aprendizaje distinta de otras estrategias educativas como las prácticas externas o el Prácticum.

6. En la actualidad se aplican diversos programas de APS en todo el mundo que pueden servir como referencia del uso de esta metodología, especialmente en el continente americano.

Tras esta aproximación conceptual sobre el APS y sus características más destacables, en el siguiente apartado analizamos los efectos que provoca el uso de esta metodología didáctica.

\subsection{Efectos de la aplicación del Aprendizaje Servicio}

Como es comprensible debido a la variedad de modalidades y posibilidades que el APS nos ofrece, los efectos de su utilización son muy distintos. Así pues, existen diferentes teorías explicativas de dichos efectos: la social cognitiva de Bandura (Bernadowski, Perry y Del Greco, 2013; Meaney, Griffin y Bohler, 2009; Meaney, Housman, Cavazos y Wilcox, 2012), el aprendizaje liberador de Chambers (Maynes, Hatt y Wideman, 2013), el modelo rizomático de Deleuze y Guattari (Carrington, 2011), la teoría constructivista de Piaget y Vygotsky (Galvan y Parker, 2011), el interaccionismo simbólico de Blumer (Chambers y Lavery, 2012), las cuatro áreas de resultados propuestas por Furco y Root (2010) (en la línea de las enunciadas por Billig 2000 y 2002; Eyler y Giles, 1999; Eyler, Giles, Stenson y Gray, 2001) y el modelo de múltiples perspectivas de Butin (Butin, 2003; Saggers y Carrington, 2008; Seban, 2013). No obstante, diversos autores nos instan a continuar profundizando en el conocimiento de los impactos provocados por las experiencias de APS (Butin, 2006; Eyler, 2000; Furco y Root, 2010; Warren, 2012). Por ello, con la intención de encontrar elementos comunes, a continuación repasamos los trabajos de diferentes autores en cuanto a los efectos provocados por el APS. 
Claus y Ogden (1999) establecen que los programas de APS hacen que el aprendizaje sea más relevante, estrechan la distancia entre las escuelas y sus comunidades, ayudan a la juventud a abordar de forma significativa cuestiones del mundo real, motivan y permiten pensar de forma crítica y contribuyen a clarificar los sentidos de identidad, autoestima, eficacia y pertenencia. Por otra parte, Billig (2000, 2002), Eyler et al. (2001), y Eyler y Giles (1999) clasifican los resultados de la aplicación de programas de APS en las siguientes categorías:

- Resultados académicos: en esta categoría se ubican los aprendizajes de carácter académico desarrollados por el alumnado. Comprende aumentos del dominio de contenidos, habilidades para solucionar problemas y actitudes hacia el aprendizaje (Furco, 2002), mejoras en escritura y en ciencias sociales (Klute y Billig, 2002), mejoras en lenguaje y ciencias (Billig, 2004), e incrementos globales de las calificaciones mejorando la conexión de los aprendizajes con el mundo que les rodea (Babcock, 2000). Por todo ello, Bransford, Brown y Cocking (2004) determinan que el APS es una estrategia efectiva para mejorar los aprendizajes académicos.

- Resultados personales: hace referencia a las mejoras desarrolladas en el aspecto personal del estudiantado. Incluye efectos positivos sobre los pensamientos, los sentimientos, la autoestima y la autoeficacia (Billig, 2002; Eyler et al., 2001; Yates y Youniss, 1996), desarrollo del compromiso académico e identificación con la escuela y la comunidad (Billig, Root y Jesse 2005; Melchior, 1999), reducción del absentismo escolar (Luchs, 1981; Shaffer, 1993; Shumer, 1994), e incremento de la asistencia a clase, la motivación respecto al aprendizaje y el respeto hacia la escuela como institución (Follman, 1998; Gallini y Moely, 2003; Hatcher, Bringle y Muthiah, 2002; Melchior y Orr, 1995; Stephens, 1995).

- Resultados sociales: abarca la valoración de cambios en las habilidades para interactuar con los demás, en los pensamientos y creencias que se tienen respecto a las personas sobre las que se presta el servicio, y en la toma de conciencia y comprensión de cuestiones sociales aceptando nuevas perspectivas y puntos de vista diferentes. Así pues, se evidencian cambios en las habilidades interpersonales y en la comprensión hacia los pensamientos y creencias de los demás (Billig, 2002; Eyler et al., 2001; Yates y Youniss, 1996), incrementos en la responsabilidad personal y social y en el sentido de la competencia educativa (Allen, Kuperminc, Philliber y Herre, 1994; Follman, 1998; Kirby, 2002, Melchior, 1999; Weiler, LaGoy, Crane y Rovner, 1998), cambios en la conciencia y comprensión de cuestiones sociales e incremento de la sensibilidad social (Covitt, 2002; Perry y Katula, 2001), mejoras en la aceptación de nuevos puntos de vista y perspectivas diferentes (Melchior, 2000; Weiler et al., 1998), y cambios en las creencias y actitudes hacia las personas a las que se presta el servicio (Conway, Amel y Gerwien, 2009).

- Resultados de ciudadanía: esta categoría engloba las creencias, intencionalidades y conductas sobre la responsabilidad personal, la participación activa en acciones que impliquen mejoras en la comunidad y la actuación ciudadana en términos de justicia social (Westheimer y Kahne, 2004). En esta línea, se destacan mejoras en la ciudadanía a nivel global (Billig, 2002; Perry y Katula, 2001; Yates y Youniss, 1996), mejoras en el ejercicio de la ciudadanía y de la responsabilidad ciudadana (Ammon, Furco, Chi y Middaugh, 2002; Astin y 
Sax, 1998; Covitt, 2002; Eyler y Giles, 1999; Kahne y Westheimer, 2002; Levine y Lopez, 2002), aumento de la conexión entre la comunidad y la escuela e incremento de la participación en ambas (Kim y Billig, 2003), mejora del autoconcepto, el compromiso político y la tolerancia hacia los demás (Morgan y Streb; 2001), y aumento de la participación política y del compromiso comunitario (Youniss, McLellan, Su y Yates, 1999). En esta categoría también se ubican las mejoras en algunos rasgos personales como el liderazgo (Ammon et al., 2002; Billig, 2002; Conrad y Hedin, 1989), la autoestima (McMahon, 1998; Melchior y Orr, 1995; Morgan y Streb, 1999; Shaffer, 1993; Switzer, Simmons, Dew, Regalski, y Wang, 1995), la percepción de uno mismo (Conrad y Hedin, 1989), el empoderamiento, la eficacia personal y la resiliencia (Billig, 2000; Batchelder y Root, 1994; Conrad y Hedin, 1989; Covitt, 2002; Furco, 2002; Leming, 2001; Melchior, 1999; McMahon et al., 1998; Morgan y Streb, 1999; Scales y Blyth, 1997), la capacidad para trabajar en equipo (Melchior y Orr, 1995) y, finalmente, las conductas prosociales (Astin y Sax, 1998; Batchelder y Root, 1994; Billig, 2000; Conrad y Hedin, 1989; Eyler y Giles, 1999; Leming, 1998; Melchior, 1999; Morgan y Streb, 1999; O'Donnell et al., 1999; Scales, Blyth, Berkas y Kielsmeier, 2000; Stephens, 1995; Yates y Youniss, 1996). Como podremos ver en el siguiente capítulo nuestra propuesta intenta desarrollar muchas de estas cualidades personales mediante el fomento del Emprendimiento Social en el alumnado.

El modelo de múltiples perspectivas de Butin considera que los efectos que se pueden derivar de la aplicación del APS se clasifican en cuatro perspectivas: técnica, cultural, política y postestructural (Butin, 2003, 2006; Chambers y Lavery, 2012; Seban, 2013). La perspectiva técnica engloba aprendizajes relativos a la eficacia, calidad, eficiencia y sostenibilidad del proceso de enseñanza-aprendizaje. Se centra en los elementos innovadores que proporciona el servicio para mejorar los resultados del estudiantado, abarcando todo lo concerniente a lo escolar en cuanto a los logros académicos del alumnado. La perspectiva cultural incluye los cambios personales provocados por la comprensión de la situación de otros individuos en un proceso de toma de decisiones. A partir de ella se produce un aumento del entendimiento, el respeto por la diversidad y, en consecuencia, se adquiere un mejor sentido de su situación en la comunidad. Hace referencia a la comprensión del mundo y de la sociedad en que vivimos, a través de los cambios producidos en el interior de cada individuo, como consecuencia de la experiencia vivida y los componentes afectivos, éticos y formativos desarrollados mediante el APS. La perspectiva política está formada por los aprendizajes relacionados con el entendimiento de la sociedad, y el desarrollo de actitudes y conductas que fomentan la participación en ella con la voluntad de transformarla. Su esencia implica dar voz a aquellas personas, colectivos y comunidades silenciadas o discriminadas por una u otra razón. Finalmente, la perspectiva postestructural abarca aquellos cambios que suponen una reconstrucción y transformación de la identidad, reinterpretando las normas con las que damos sentido al mundo y a nosotros mismos.

Para Tapia (2008) los impactos del APS en la calidad de la oferta educativa hacen referencia al aprendizaje, al desarrollo de competencias para la inserción en el mundo laboral, a la formación ética y a la participación política y social: 
- Impactos en el aprendizaje: el APS incide consistentemente en la comprensión y aplicación de los conocimientos, en el desarrollo del interés por indagar y del pensamiento reflexivo y crítico, en la percepción de las posibilidades de cambio social, en el desarrollo personal e interpersonal y en el desarrollo de la ciudadanía participativa (Eyler y Giles, 1999). En este sentido, se pueden destacar los trabajos realizados en cuanto al mayor desarrollo de conocimientos conceptuales y competencias (Markus, Howard y King, 1993; Melchior 1999; Wurr, 2002) y respecto a la mayor capacidad para analizar y sintetizar información compleja (Batchelder y Root, 1994; Eyler y Giles, 1999; Melchior y Orr, 1995; Osborne, Weadick y Penticuff, 1998; Stupik, 1996).

- Impactos en el desarrollo de competencias para la inserción en el mundo laboral: las experiencias de APS contribuyen a superar la brecha entre teoría y práctica que tantas veces es señalada como una de las carencias de la enseñanza tradicional. Por ello, constituyen una herramienta eficaz para el desarrollo de competencias básicas en ese sentido, especialmente en lo que se refiere al desarrollo de competencias para trabajar en equipo, comunicarse eficazmente, asumir responsabilidades desarrollando la capacidad de iniciativa personal y las competencias de organización y gestión (Conrad y Hedin, 1989; National Youth Leadership Council, 2004). Como veremos en el siguiente apartado, esta unión entre teoría y práctica es de vital importancia en el ámbito educativo en el que se desarrolla la presente tesis, la Educación Física (en adelante EF).

- Impactos en la formación ética: el APS propone educar no solo en la ética de los derechos sino también en la responsabilidad personal y colectiva. De este modo, permite ejercitar el juicio ético y la argumentación, la capacidad para analizar valoraciones, normas y costumbres de diversas comunidades, y participar en prácticas donde los principios de solidaridad y justicia se desarrollan a través de compromisos personales concretos. Así pues, el desarrollo de experiencias significativas de servicio, articuladas con una adecuada reflexión, nos ofrece un espacio idílico para fomentar una ética de solidaridad, cooperación, inclusión, diversidad, mediación, compromiso, etc.

- Impactos en la participación social y política: aunque la mayor parte de estudios sobre el impacto del APS en la formación para la ciudadanía han sido realizados con adolescentes, un creciente número de trabajos muestra la profunda influencia que dicho compromiso social juvenil tiene en la futura trayectoria de vida (Furco, 2004; González y Montes, 2004; Tapia, 2006). De este modo, entendemos que la aplicación de propuestas de APS mejorará la calidad de vida y el bienestar social de la comunidad futura. En el próximo capítulo justificaremos la importancia de este hecho en nuestra propuesta a través de la Responsabilidad Social Universitaria.

Intentado valorar los beneficios directos generados por las experiencias de APS, Palos (2009) considera que esta metodología facilita el aprendizaje del alumnado y refuerza los resultados positivos, promueve la mejora y el cambio metodológico del profesorado, de las diferentes profesiones que intervienen en la educación y de los propios centros educativos, favorece la relación e integración entre la escuela, la comunidad y el territorio e incide en la dimensión ética de la educación. En una línea similar, Puig et al. (2007) determinan que las finalidades de los programas 
de APS son fomentar la ciudadanía participativa, aumentar la integración y el capital social, facilitar la educación en valores y la prosocialidad $y$, por último, promover el conocimiento y la responsabilidad. Tras analizar la aplicación de una experiencia de APS, Carbonell y Carrillo (2010) consideran que estos proyectos pueden aportar los siguientes aspectos a la formación inicial:

- Significatividad de la experiencia: esta experiencia puede representar uno de los hitos más formativos de sus estudios desde el punto de vista humano y profesional, individual y colectivo, teórico y práctico. Especialmente como consecuencia del número de recursos, conocimientos, estrategias, vivencias, y procesos de adaptación, cambio y toma de decisiones en los que se ven involucrados.

- Inteligencias múltiples: antes, durante y después de esta práctica se producen numerosos episodios para el desarrollo de las capacidades cognitivas, las habilidades sociales, los compromisos éticos y solidarios, las percepciones sensoriales y el disfrute de las diversas manifestaciones artísticas.

- Globalización: en todo momento se trabaja desde una perspectiva globalizadora e interdisciplinaria. La adaptación a situaciones hasta cierto punto imprevisibles requiere el uso de conocimientos, estrategias y recursos polivalentes y transversales.

- Equipos interdisciplinarios: a diferencia de otras actividades más limitadas, en este caso se pueden combinar estudiantes de distintas especialidades estableciendo un contacto directo con profesionales de diversas disciplinas durante la experiencia.

- Planificación e improvisación: estas tareas básicas y habituales para todo profesorado, ocupan un lugar destacado en este tipo de experiencias. Inicialmente existe una fase previa de planificación para determinar las tareas y proyectos a realizar. Posteriormente, en la práctica, se exige un ejercicio constante de improvisación ante situaciones desconocidas y cambiantes. Por eso, hay que saber modificar y ajustar la planificación previa en función de las necesidades del contexto escolar y las actividades, recursos, estrategias, tiempos y espacios socioeducativos por los que transcurre la práctica.

- Inserción en los contextos escolar, familiar y comunitario: el ejercicio de observación, análisis e intervención en ámbitos micro y macroeducativos, facilita el entendimiento de las relaciones mutuas entre estos espacios, así como los comportamientos tanto del alumnado y del profesorado, como de los distintos miembros familiares y/o comunitarios involucrados.

- Trabajo en equipo: la cooperación y la colaboración constituyen uno de los pilares básicos a partir de los cuales se estructuran las distintas fases de estos proyectos. De este modo, el trabajo en pequeños y grandes grupos obliga a los participantes a orientar los procesos, regular los conflictos y ejercer la autocrítica.

- Evaluación externa y autoevaluación: estos proyectos permiten la intervención externa, a través del seguimiento y la evaluación continua y formativa, mediante la tutorización, la evaluación, la aplicación de cuestionarios de valoración, etc. Así mismo, también son totalmente compatibles con diferentes instrumentos de autoevaluación como los diarios, las memorias y las asambleas en pequeños o grandes grupos. 
- Relación permanente entre teoría y práctica: uno de los objetivos principales de estas propuestas educativas es que la teoría esté muy presente en todas las fases y momentos de aplicación práctica. De este modo se estrecha la separación entre ambos tipos de conocimiento y se facilita la reflexión global sobre el proceso educativo.

Como hemos podido constatar, existen distintos puntos de vista y focos de atención a la hora de analizar los efectos de la aplicación del APS. Por este motivo, se han realizado múltiples estudios de investigación sobre esta cuestión. Como apuntan Osborne, Hammerich y Hensley (1998) el estudio de los impactos del APS se ha concentrado en tres áreas: evaluar los resultados a largo plazo sobre grupos específicos de estudiantes (Batchelder y Root, 1994), documentar la percepción de los estudiantes sobre el impacto que el APS ha tenido en ellos (Giles y Eyler, 1994) y determinar el impacto de las experiencias de APS en el aprendizaje del alumnado respecto a los contenidos y objetivos del curso (Osborne, Weadick et al., 1998). Como veremos más adelante, nuestro trabajo discurre sobre estas dos últimas líneas de estudio.

A continuación, para profundizar en mayor medida sobre los impactos generados por las experiencias de APS, presentamos la información aportada en varios meta-análisis realizados sobre esta temática.

White (2001) profundiza en el conocimiento de las experiencias de APS en escuelas de primaria y secundaria. Para ello, analiza los estudios realizados entre 1983-2000, con los grados 5-12 de escuelas públicas y privadas. Este trabajo valora los resultados obtenidos en nueve estudios cuantitativos, doce estudios cualitativos y cinco estudios que combinan ambas metodologías de investigación. El análisis de resultados de los trabajos cuantitativos se dividió en tres categorías: progreso académico, autoconcepto y crecimiento personal y social. La categoría de progreso académico incluía resultados sobre el logro en el aula, la voluntad de aprender y la actitud positiva hacia el profesorado; en la categoría de autoconcepto aparecieron resultados referentes a la autoestima, la reducción del sentimiento de falta de adecuación y el autoconcepto; por último, la categoría de crecimiento personal y social valoraba diferentes aspectos del estudiantado como la eficacia, tanto personal como política, el sentido del deber hacia la propia comunidad, la preocupación por el bienestar de los demás, la sensación de competencia para participar dentro de la propia comunidad y la capacidad de "crear diferencias" en la comunidad. Algunas de estas cualidades medían la responsabilidad social y personal del alumnado, como ya hemos apuntado, algo de gran importancia en nuestro proyecto.

Por otra parte, el análisis de los resultados de la aplicación del APS en los estudios cualitativos se organizó en las siguientes categorías: aprecio por el valor del servicio, progreso académico y pensamiento crítico, crecimiento social y personal, tolerancia y aprecio por los demás, autoconcepto, mejora de la actitud hacia los profesores, conciencia medioambiental, y mejora del comportamiento. En la tabla 3 mostramos la lista completa de resultados obtenidos en las investigaciones cualitativas: 
Tabla 3. Resultados obtenidos en investigaciones cualitativas de Aprendizaje Servicio (White, 2001).

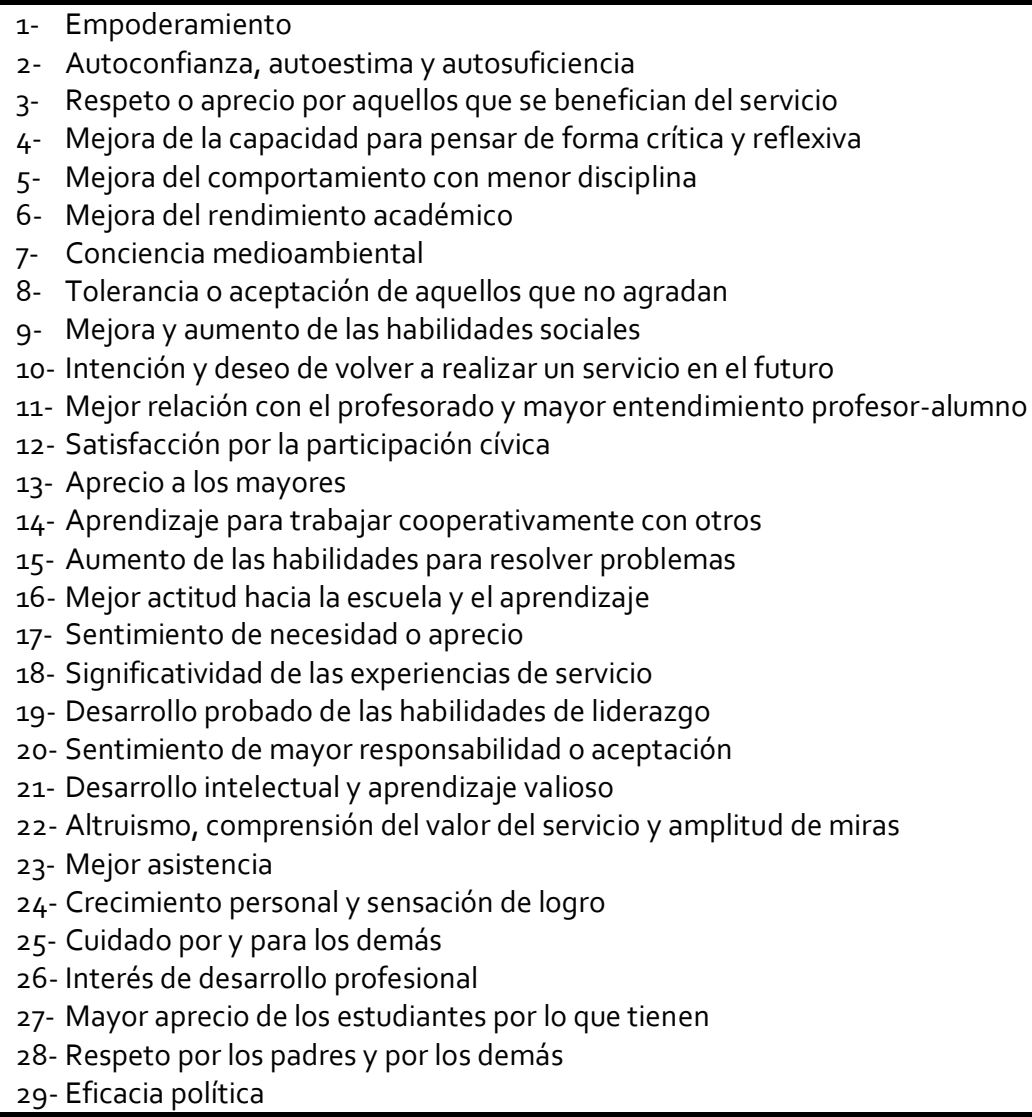

Según Furco (2004), los estudios sobre APS han encontrado impactos positivos en los estudiantes desarrollando seis campos de mejora: académico y cognitivo, cívico, vocacional y profesional, ético y moral, personal, y social. En la tabla 4 mostramos, con detalle, cada uno de los impactos producidos.

Tabla 4. Impactos del Aprendizaje Servicio en los estudiantes (Furco, 2004).

\begin{tabular}{cl}
\hline Desarrollo & Aumento del rendimiento en tests estandarizados \\
académico y & Mayor desarrollo de conocimientos conceptuales y competencias \\
cognitivo & $\begin{array}{l}\text { Mayor asistencia, motivación respecto a la escuela y retención } \\
\text { Mejores notas promedio } \\
\text { Mayor habilidad para analizar y sintetizar información compleja }\end{array}$ \\
\hline & Mayor comprensión de la política y de las actividades gubernamentales \\
Desarrollo & Mejor participación en la comunidad y en las cuestiones públicas \\
cívico & Mejor ejercicio de la ciudadanía y de la responsabilidad ciudadana \\
& Mayor conciencia y comprensión de cuestiones sociales \\
& Compromiso con el servicio comunitario \\
\hline
\end{tabular}




\begin{tabular}{|c|c|}
\hline $\begin{array}{l}\text { Desarrollo } \\
\text { vocacional y } \\
\text { profesional }\end{array}$ & $\begin{array}{l}\text { Ampliación de la conciencia y de las opciones vocacionales } \\
\text { Mejora de las competencias profesionales } \\
\text { Mayor comprensión de la ética del trabajo } \\
\text { Mejor preparación para el mundo del trabajo }\end{array}$ \\
\hline \multirow{3}{*}{$\begin{array}{c}\text { Desarrollo ético } \\
\text { y moral }\end{array}$} & Mayor exposición a nuevos puntos de vista y perspectivas \\
\hline & Cambios positivos en el juicio ético \\
\hline & $\begin{array}{l}\text { Mayor habilidad para tomar decisiones independientes respecto a } \\
\text { cuestiones morales }\end{array}$ \\
\hline \multirow{5}{*}{$\begin{array}{c}\text { Desarrollo } \\
\text { personal }\end{array}$} & Ampliación de las cualidades y competencias para el liderazgo \\
\hline & Mayor autoestima \\
\hline & Mayor conocimiento de uno mismo \\
\hline & Mayor resiliencia \\
\hline & Mayor empoderamiento y eficacia personal \\
\hline \multirow{4}{*}{$\begin{array}{l}\text { Desarrollo } \\
\text { social }\end{array}$} & Mayor camaradería entre estudiantes \\
\hline & Mayor habilidad para trabajar en equipos y/o trabajar con otros \\
\hline & Desechar prejuicios preconcebidos \\
\hline & Mejorar conductas prosociales \\
\hline
\end{tabular}

Por otra parte, Conway et al. (2009) hacen un análisis de los impactos positivos del APS y los servicios comunitarios en 103 investigaciones, siguiendo la clasificación planteada por Billig (2000, 2002), Eyler et al. (2001) y Eyler y Giles (1999). Las investigaciones seleccionadas en este metaanálisis deben realizar un Pretest y Postest utilizando idénticos diseños de medida cuantitativa, participar en servicios comunitarios entre la aplicación de Pretest y Postest, recabar suficiente información para clasificar las medidas realizadas, e incluir los datos referentes a Pretest y Postest, Desviación Estándar del Pretest, y tamaño de la muestra. Los resultados de este trabajo confirman que el APS provoca efectos positivos en los resultados académicos, personales, sociales y de ciudadanía. Profundizando en estos efectos, los autores indican que los cambios más notables se obtienen en los resultados académicos, de creencias, conocimiento, y actitudes hacia los que se sirve, señalando que los resultados personales y de ciudadanía son más discretos. Por otra parte, se apunta que la reflexión esta principalmente asociada con los cambios más destacables, que los efectos tienden a generalizarse en la educación primaria y superior, que en las poblaciones de adultos y mixtas hay una menor evidencia de cambios en los resultados personales y sociales y que los servicios no curriculares provocan unos efectos menores.

En otro meta-análisis, Celio, Durlak y Dymnicki (2011) analizan 62 estudios de investigación sobre los efectos del APS. Los criterios de selección exigen que los trabajos: deban estar realizados en Inglaterra antes del 1 de abril de 2008, evalúen programas de APS cuya definición asuma la integración del servicio con el currículum académico, involucren a estudiantes de educación elemental, secundaria y superior, utilicen un Grupo Control en el análisis de datos, e incluyan suficiente información para calcular y evaluar los efectos del APS como único componente del programa educativo. Este trabajo demuestra que la aplicación de esta metodología provoca mejoras en cinco áreas: actitudes hacia uno mismo, actitudes hacia la escuela y el aprendizaje, compromiso cívico, habilidades sociales y rendimiento académico. Las actitudes hacia uno mismo incluían la autoestima, la autoeficacia, las habilidades personales y el sentimiento de control. Las 
actitudes hacia la escuela y el aprendizaje fueron definidas por los sentimientos de los estudiantes respecto a la escuela y la clase como, por ejemplo, el compromiso académico o el disfrute del curso. El compromiso cívico mostraba cualquier resultado que estuviera directa o parcialmente relacionado con la comunidad como el altruismo, la responsabilidad cívica o la intención de voto presente y futura. Las habilidades sociales estaban representadas por cuestiones dirigidas hacia otras personas tales como la capacidad de liderazgo, la competencia cultural y la resolución de problemas sociales. Por último, el rendimiento académico reflejaba las calificaciones del alumnado o los resultados obtenidos en distintos test de valoración. Así mismo también se destaca que los programas de APS tienen una influencia positiva en la comunidad que recibe los servicios, en la institución educativa que ofrece el programa, a través de una oferta académica mejorada y más atractiva, y en los estudiantes participantes, los cuales pueden beneficiarse personal, social y académicamente (Billig, 2009; Conway et al., 2009; White, 2001). En esta línea, el alumnado demuestra aumentos en autoestima y autoconcepto, mayor interiorización de las normas morales, actitudes hacia la escuela y la educación más positivas, mayor interés, compromiso y sensibilidad hacia la comunidad y sus necesidades, mayor creencia en que se pueden crear diferencias en el mundo (Billig et al., 2005), mejora de las habilidades sociales relacionas con la comunicación, el liderazgo y la resolución de problemas, y mejora del rendimiento académico (Billig, 2009; Giles y Eyler, 1994; Markus et al., 1993).

La revisión de Yorio y Ye (2012) analiza 40 estudios de aplicación de APS. Los requisitos de selección exigen que: los trabajos sean investigaciones cuantitativas, las características del contexto de aprendizaje se ajusten a los criterios de APS propuestos por la National and Community Service Act of 1990, las variables dependientes puedan ubicarse operativamente en uno de los tres resultados de aprendizaje propuestos, y el alumnado esté cursando estudios universitarios. Esta revisión determina que el APS tiene efectos sobre diversas cuestiones de entendimiento social, elementos de la perspectiva personal de uno mismo y aspectos relacionados con el desarrollo cognitivo. En la tabla 5 exponemos los resultados destacados:

Tabla 5. Resultados de aprendizaje en el Aprendizaje Servicio (Yorio y Ye, 2012).

\begin{tabular}{|c|c|c|}
\hline $\begin{array}{l}\text { RESULTADO DE } \\
\text { APRENDIZAJE }\end{array}$ & DEFINICIÓN & ELEMENTOS MEDIDOS \\
\hline $\begin{array}{l}\text { Cuestiones de } \\
\text { entendimiento } \\
\text { social }\end{array}$ & $\begin{array}{l}\text { Marco de referencia } \\
\text { individual que guía la } \\
\text { toma de decisiones en } \\
\text { materia de cuestiones } \\
\text { sociales complejas }\end{array}$ & $\begin{array}{l}\text { Diversidad cultural, conciencia y sensibilidad social } \\
\text { Percepción de la gente sin hogar, ancianos, discapacitados, razas o } \\
\text { culturas diferentes } \\
\text { Valores éticos y morales y toma de decisiones } \\
\text { Habilidades interpersonales } \\
\text { Entendimiento de las necesidades de la comunidad } \\
\text { Entendimiento de cómo ayudar a la comunidad } \\
\text { Deseo de participar en actividades de servicio futuras en términos de } \\
\text { sentimiento de responsabilidad y compromiso para hacerlo }\end{array}$ \\
\hline $\begin{array}{c}\text { Perspectiva } \\
\text { personal }\end{array}$ & $\begin{array}{l}\text { Perspectiva individual de } \\
\text { uno mismo }\end{array}$ & $\begin{array}{l}\text { Identidad } \\
\text { Conciencia de uno mismo en términos de fortalezas y debilidades } \\
\text { Aspiraciones profesionales } \\
\text { Autoeficacia }\end{array}$ \\
\hline
\end{tabular}




\begin{tabular}{|c|c|c|}
\hline & & $\begin{array}{l}\text { Autoestima } \\
\text { Determinación } \\
\text { Persistencia }\end{array}$ \\
\hline $\begin{array}{c}\text { Desarrollo } \\
\text { cognitivo }\end{array}$ & $\begin{array}{c}\text { Desarrollo de tareas, } \\
\text { habilidades y logros } \\
\text { académicos }\end{array}$ & $\begin{array}{l}\text { Desarrollo en habilidades de gestión } \\
\text { Destreza en la escritura } \\
\text { Desarrollo de habilidades para resolver problemas } \\
\text { Desarrollo de habilidades para el pensamiento crítico } \\
\text { Promedio de calificaciones } \\
\text { Rendimiento académico }\end{array}$ \\
\hline
\end{tabular}

A continuación, a modo de resumen, presentamos la tabla 6 donde exponemos los principales efectos del APS descritos en los distintos meta-análisis revisados.

Tabla 6. Efectos del Aprendizaje Servicio según diversos meta-análisis (elaboración propia).

\begin{tabular}{|c|c|}
\hline TRABAJO & EFECTOS DEL APS \\
\hline White (2001) & $\begin{array}{l}\text { Estudios cuantitativos: progreso académico, mejoras en el auto- } \\
\text { concepto, crecimiento personal y crecimiento social. } \\
\text { Estudios cualitativos: aprecio por el valor del servicio, progreso } \\
\text { académico y del pensamiento crítico, crecimiento social y personal, } \\
\text { desarrollo de la tolerancia y el aprecio por los demás, mejoras en el auto- } \\
\text { concepto, mejora de la actitud hacia los profesores, desarrollo de la } \\
\text { conciencia medioambiental y mejora del comportamiento. }\end{array}$ \\
\hline Furco (2004) & $\begin{array}{l}\text { Desarrollo académico y cognitivo, desarrollo cívico, desarrollo } \\
\text { vocacional y profesional, desarrollo ético y moral, desarrollo personal y } \\
\text { desarrollo social. }\end{array}$ \\
\hline $\begin{array}{l}\text { Conway et al. } \\
\text { (2009) }\end{array}$ & $\begin{array}{l}\text { Efectos positivos respecto a los resultados académicos, personales, } \\
\text { sociales y de ciudadanía. }\end{array}$ \\
\hline $\begin{array}{l}\text { Celio et al. } \\
\quad(2011)\end{array}$ & $\begin{array}{l}\text { Mejoras en las actitudes hacia uno mismo, mejoras en las actitudes } \\
\text { hacia la escuela y el aprendizaje, desarrollo del compromiso cívico, } \\
\text { desarrollo de habilidades sociales y aumento del rendimiento } \\
\text { académico. }\end{array}$ \\
\hline $\begin{array}{l}\text { Yorio y Ye } \\
\text { (2012) }\end{array}$ & $\begin{array}{l}\text { Mejoras en cuestiones de entendimiento social, aumento de la } \\
\text { perspectiva personal y desarrollo cognitivo. }\end{array}$ \\
\hline
\end{tabular}

Centrándonos específicamente en el ámbito de la EF, entorno de la presente tesis, podemos destacar el trabajo de Carson y Raguse (2014). Este documento realiza una revisión de la literatura respecto a publicaciones que vinculen el APS al campo de la kinesiología, concretamente, en la actividad física de gente joven. Los criterios de selección requieren que los trabajos: analicen programas de APS de servicio directo que promocionen la actividad física desde las instituciones universitarias, incluyan solo libros y artículos sometidos a una revisión por pares y superen el mínimo de calidad académica exigido por la junta de revisión creada a tal efecto. Tras revisar los 42 trabajos seleccionados, se organizan las publicaciones existentes en tres líneas de trabajo: investigaciones, descripción de programas educativos y estrategias de implementación. Según estos autores, las investigaciones señalan el creciente interés por conocer los impactos del APS en 
los estudiantes, mientras que el resto de publicaciones describen una amplia variedad de programas educativos de APS exitosos con la intención de promover y fomentar su uso en el futuro. Al mismo tiempo, se incide en que las implicaciones de vincular el APS con la actividad física de los jóvenes siguen siendo, en gran medida, poco estudiadas.

Teniendo en consideración toda la información aportada sobre los efectos provocados por el APS, entendemos que esta metodología educativa tiene un potente impacto sobre el alumnado, principalmente a nivel académico-cognitivo y a nivel personal-social. Como ya hemos apuntado, nuestro trabajo investiga ambas temáticas. La primera, a través del desarrollo de los contenidos académicos propios de la asignatura en la que se implementa el programa de APS y, la segunda, respecto al fomento del ES por parte del alumnado participante.

Pese a lo expuesto, existen diversos factores que pueden variar o alterar algunos de los impactos descritos. Por ello, con la intención de asegurar la eficacia y unificar los efectos de la aplicación de programas de APS en la educación superior, seguimos a Howard (1993), quien describe los siguientes principios orientadores para una buena práctica:

- El crédito académico debe centrarse en el aprendizaje, no en el servicio. Cabe aclarar que este planteamiento no implica menospreciar la importancia del servicio en el programa de APS a aplicar.

- No debe comprometerse el rigor académico.

- Debe haber objetivos de aprendizaje claros para el estudiantado.

- Es necesario establecer criterios claros para seleccionar los lugares donde se desarrollará el servicio a la comunidad.

- Se deben prever mecanismos, académicamente probados, para evaluar los aprendizajes que tienen lugar en la comunidad.

- Se debe proveer a los estudiantes de herramientas para identificar los aprendizajes que desarrollan en el terreno comunitario.

- Es necesario minimizar las diferencias entre el rol del alumnado dentro y fuera del aula, debiendo ser protagonistas de sus propios aprendizajes en ambos contextos.

- El APS debe ayudar a reflexionar sobre el rol del docente.

- Es necesario prever el grado de incertidumbre y variación que generará el aprendizaje en la comunidad.

- Se debe maximizar la orientación hacia una perspectiva de responsabilidad social.

Por otra parte, la National Youth Leadership Council (2008) presenta 8 aspectos clave que determinan la calidad en la aplicación práctica del APS. Como podemos ver, muchos de estos aspectos ya han sido abordados por los teóricos del APS:

- Duración e intensidad.

- Conexión con el currículum.

- Creación de alianzas sociales. 
- Servicio útil, servicio significativo.

- Participación de los estudiantes.

- Diversidad.

- Supervisión del progreso.

- Reflexión.

En una línea similar, Tapia (2008) determina que en los últimos años el consenso académico apunta a señalar los siguientes criterios fundamentales en cuanto a la calidad de las prácticas de APS:

- Duración: este aspecto determina que el tiempo invertido en la experiencia de APS debe ser suficiente como para producir un impacto óptimo. Si bien algunos autores consideran que el tiempo necesario para empezar a advertir resultados significativos en el estudiantado debe ser de unos dos años (González y Montes, 2004), otros indican que la duración mínima de un proyecto de calidad desde el punto de vista de su impacto en el aprendizaje debería ser de seis meses (National Youth Leadership Council, 2004). De todas formas, el tiempo a dedicar específicamente al servicio no puede determinarse de forma generalizada, ya que la relación entre el tiempo y los objetivos a cumplir puede variar enormemente de un proyecto a otro.

- Intensidad: al igual que en el criterio anterior, es necesario un énfasis óptimo para aumentar la significatividad de la experiencia de APS y con ellos sus efectos sobre el alumnado. En este caso se deberá ajustar la frecuencia con la que se realiza el servicio y la cantidad de tiempo empleada en cada intervención.

- Definición: por último, para mantener la calidad en la aplicación de programas de APS, es necesario que estos presenten unos rasgos de programación bien definidos (Furco, 2004). Así pues, deben caracterizarse por el protagonismo activo del alumnado, ofrecer un servicio significativo para la comunidad y contar con una planificación que establezca espacios adecuados para la reflexión, así como vínculos bien definidos entre el servicio y los contenidos curriculares del programa educativo.

Por su parte, Celio et al. (2011) exponen cuatro recomendaciones prácticas para lograr que los programas de APS sean eficaces. En primer lugar, las experiencias de APS deben estar vinculadas al currículum, programa y objetivos académicos. Diversos estudios indican que establecer metas claras para los estudiantes y hacer conexiones explícitas entre el servicio y el aprendizaje se ha relacionado con un mayor compromiso y rendimiento académico por parte del alumnado (Billig et al., 2005), un mayor incremento de las habilidades para resolver problemas (Conrad y Hedin, 1989), y un mayor aprendizaje y satisfacción respecto al programa educativo (Hamilton y Zeldin, 1987). Del mismo modo, proporcionar oportunidades a los estudiantes para transferir o aplicar lo que han aprendido a múltiples contextos también se ha asociado con mejores resultados de aprendizaje (Boss, 1994). La segunda recomendación anima a los educadores a dar voz al alumnado en la planificación, implementación y evaluación de las experiencias de APS. Este hecho permite que los estudiantes obtengan un mayor beneficio en el comportamiento cívico (Billig et al., 2005) y desarrollen habilidades sociales como la actitud hacia otros grupos externos (Morgan y Streb, 
2001). Por otra parte, la participación en el APS ha sido un fuerte predictor de otros resultados positivos, como el desarrollo de la auto-eficacia, el aumento de la vinculación con la escuela y la comunidad, la mejora en la valoración de los académicos y el incremento del compromiso cívico en general (Melchior y Bailis, 2002; Meyer, 2006; Perry y Katula, 2001). La siguiente recomendación indica que el profesorado debe establecer alianzas comunitarias para solicitar sugerencias respecto a los elementos y objetivos de los servicios a realizar. Una experiencia de APS significativa fortalece los lazos comunitarios, genera relaciones beneficiosas, satisface algunas de las necesidades de la comunidad y beneficia por igual a los miembros de la comunidad y al estudiantado (Gray et al., 1998). Al mismo tiempo, los fuertes vínculos relacionales se asocian con la sostenibilidad del programa educativo a largo plazo (Ammon et al., 2002; Billig, 2002; Kramer, 2000). La última recomendación hace hincapié en la importancia de los procesos de reflexión en la vinculación entre la acción del servicio y la idea del aprendizaje (Billig, 2009; Eyler, Giles, y Schmiede, 1996). Asociar la reflexión con la experiencia de los estudiantes aumenta la confianza en sí mismos y la participación en la escuela, incrementa el comportamiento cívico y la responsabilidad social y mejora el cuidado de las relaciones personales (Andersen, 1998; Billig et al., 2005; Blyth, Saito y Berkas, 1997).

Con la intención de asegurar la calidad de nuestra propuesta, como podremos ver en la descripción del programa educativo implementado, hemos tenido en consideración todos estos principios, criterios y recomendaciones.

Para terminar este apartado, resumimos las ideas principales en cuanto a los efectos del uso de esta metodología educativa:

1. Actualmente conviven diversas teorías explicativas en cuanto a los efectos que provoca la aplicación de programas educativos basados en el APS.

2. EI APS provoca efectos en la comunidad, la institución educativa y el alumnado, a nivel académico, personal, social, ético, político, cívico, profesional, moral, etc.

3. Las diferentes teorías analizadas coinciden en que el APS provoca, principalmente, un notable impacto a nivel académico-cognitivo y personal-social sobre el alumnado.

4. La revisión de diversos meta-análisis sobre investigaciones en cuanto a los efectos de la aplicación del APS concuerda y refuerza la afirmación anterior.

5. Pese a lo expuesto, debido a la gran cantidad de elementos implicados en el APS, diversos factores pueden variar o alterar los efectos derivados su aplicación.

6. Para optimizar los efectos del APS debemos seguir una serie de principios, criterios y recomendaciones, aumentando así la calidad de este tipo de propuestas.

Para profundizar en el conocimiento del contexto de la presente tesis, en el siguiente apartado abordamos la relación del APS con diferentes aspectos básicos del entorno de nuestra investigación como, por ejemplo, el desarrollo de la competencia docente. Por otra parte, también tratamos la aplicación de esta metodología educativa dentro del área de conocimiento sobre el que transcurre este trabajo, la EF. 


\subsection{El Aprendizaje Servicio como estrategia de desarrollo de la competencia docente en Educación Física}

El término competencia proveniente del latín competentia y ha sido objeto de numerosos intentos de definición desde distintos ámbitos. La RAE ${ }^{12}$ presenta dos acepciones del término, en el sentido de competir y en el sentido de ser competente. Considerando el contexto en el que nos encontramos, debemos entender la competencia desde este segundo punto de vista y, más concretamente, en el sentido de "pericia, aptitud, idoneidad para hacer algo o intervenir en un asunto determinado". Como podemos ver en la tabla 7, con el paso de los años las definiciones sobre este término se han ido complementado y evolucionando progresivamente.

Tabla 7. Definiciones del término competencia (modificado de Álvarez, Pérez y Suárez, 2008).

\begin{tabular}{|c|c|}
\hline AUTOR & DEFINICIÓN DE COMPETENCIA \\
\hline Barriga (2004) & $\begin{array}{l}\text { apacidades para hacer algo de modo idóneo en un proceso complejo de asimilación de } \\
\text { aberes conceptuales, procedimentales y actitudes en el proceso de enseñanza-aprendizaje. }\end{array}$ \\
\hline Brasla & Saber hacer con saber y con conciencia respecto del impacto de ese hacer. \\
\hline Braslavsky (2001) & $\begin{array}{l}\text { Habilidades vinculadas con el desempeño autónomo, el conocimiento aplicado y aplicable, el } \\
\text { conocimiento en acción, el saber resultante de saber hacer y saber explicar lo que se hace. }\end{array}$ \\
\hline $\begin{array}{c}\text { Coll y Marcl } \\
(2007) \\
\end{array}$ & $\begin{array}{l}\text { Tener los conocimientos necesarios para desenvolverse en un ámbito y ser capaz de utilizarlos } \\
\text { actuando con eficacia en el desarrollo de actividades y tareas relacionadas con él. }\end{array}$ \\
\hline Coolahan (1996) & $\begin{array}{l}\text { Capacidad general basada en los } \mathrm{c} \\
\text { una persona ha desarrollado median }\end{array}$ \\
\hline De Kete & $\begin{array}{l}\text { Conjunto ordenado de capacidades que se ejercen sobre contenidos contextualizados dentro } \\
\text { de una categoría de situaciones para resolver los problemas que se plantean en esas } \\
\text { situaciones. }\end{array}$ \\
\hline Eury & lad o potencia para actuar de manera eficaz en un contexto determinado. \\
\hline Lasni & $\begin{array}{l}\text { lización y adecuación eficaz de } \\
\text { o sociales) y conocimientos. }\end{array}$ \\
\hline Mari & $\begin{array}{l}\text { Una competencia básica es un conjunto de conocimientos, actitudes, habilidades y destrezas } \\
\text { que permiten a un individuo responder a las demandas de una situación. Tiene un contenido } \\
\text { ético. }\end{array}$ \\
\hline Monereo (2004) & $\begin{array}{l}\text { Repertorio de estrategias coordinadas para resolver una demanda específica correspondiente } \\
\text { a un contexto habitual (educativo, familiar, profesional, personal) de la actividad humana. }\end{array}$ \\
\hline $\begin{array}{l}\text { OCDE, DeSeCo } \\
(2002)\end{array}$ & $\begin{array}{l}\text { Capacidad para responder a las demandas complejas y llevar a cabo tareas de forma } \\
\text { adecuada. Supone una combinación eficaz de habilidades prácticas, conocimientos, } \\
\text { motivación, valores éticos, actitudes, emociones y otros componentes sociales y de } \\
\text { comportamiento. }\end{array}$ \\
\hline Pérez-Gómez (2007) & $\begin{array}{l}\text { Competencia es la habilidad para afrontar demandas externas o desarrollar actividades y } \\
\text { proyectos de manera satisfactoria en contextos complejos, implica dimensiones cognitivas y } \\
\text { no cognitivas: conocimientos, habilidades cognitivas, habilidades prácticas, actitudes, valores } \\
\text { y emociones. }\end{array}$ \\
\hline Perrenoud (1997) & $\begin{array}{l}\text { Capacidad de actuar eficazmente en un número determinado de situaciones, capacidad } \\
\text { basada en los conocimientos pero que no se limita a ellos. }\end{array}$ \\
\hline $\begin{array}{l}\text { Proyecto Tuning } \\
\quad(2003)\end{array}$ & $\begin{array}{l}\text { Combinación de atributos con respecto al conocimiento y sus aplicaciones, aptitudes, } \\
\text { destrezas y responsabilidades que describen el nivel o grado de suficiencia con que se } \\
\text { desempeña. }\end{array}$ \\
\hline
\end{tabular}

${ }^{12}$ Real Academia Española. http://lema.rae.es/drae/?val=competencia 


\begin{tabular}{cl}
\hline Roegiers (2000) & $\begin{array}{l}\text { Posibilidad de movilizar un conjunto integrado de recursos con el fin de resolver una situación- } \\
\text { problema que pertenece a una familia de situaciones. }\end{array}$ \\
\hline $\begin{array}{c}\text { Spencer y Spencer } \\
\text { (1993) }\end{array}$ & $\begin{array}{l}\text { Capacidad subyacente en una persona que está causalmente relacionada con el desempeño, } \\
\text { referido a un criterio superior o efectivo, en un trabajo o situación. }\end{array}$ \\
\hline Weinert (2001) & $\begin{array}{l}\text { Sistema más o menos especializado de capacidades y destrezas que son necesarias o } \\
\text { suficientes para alcanzar un objetivo específico. }\end{array}$ \\
\hline
\end{tabular}

Repasando esta tabla, comprobamos que son muchas las perspectivas desde las que se puede abordar el término de competencia: pedagógica, curricular, sociológica, psicológica, laboral, emocional, etc. No obstante, en este trabajo nos centraremos únicamente en la visión educativa de este concepto.

Desde los inicios de la inclusión del término competencia en el ámbito educativo se considera que un alumno/a es competente cuando es capaz de aplicar los conocimientos adquiridos a las actividades, problemas cotidianos y el ambiente escolar, mediante la libertad de decisión y la toma de decisiones adecuada, como se apunta en el Informe PISA de 2006. Uno de los conceptos clave en este campo, desde un primer momento, es el de competencias básicas (key competences). El Consejo de la Unión Europea y el Parlamento Europeo (2006), en su recomendaciones para el aprendizaje permanente, definen las competencias básicas como "la combinación de conocimientos, destrezas y actitudes adecuadas a un contexto, que todo individuo necesita para su realización y desarrollo personal, ciudadanía activa, e inclusión social y laboral" (p. 13). Así pues, determina que las ocho competencias básicas son comunicación en la lengua materna, comunicación en una lengua extranjera, matemática y en ciencia y tecnología, digital, aprender a aprender, cívica y social, sentido de iniciativa y emprendimiento, y conocimiento cultural y expresión. Estas recomendaciones tienen una notable incidencia en nuestro marco educativo, influyendo tanto en la Ley Orgánica de Educación (2006) como la Ley Orgánica para la Mejora de la Calidad Educativa (2013). Prueba de ello es la proliferación de trabajos (López, 2006; Pérez, 2007; Sarramona, 2004), monográficos (Cuadernos de Pedagogía, 2007) y congresos (Congreso Internacional de Competencias

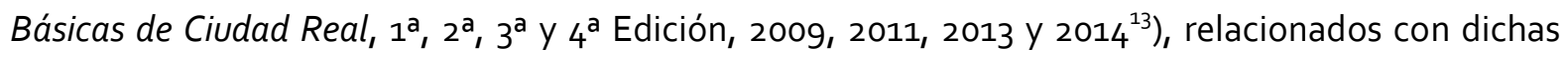
competencias básicas y su influencia en el ámbito de la docencia.

Al centrarnos en la competencia docente del alumnado del Grado en Maestro/a, foco de atención de nuestro trabajo, nos adentramos en el concepto de competencia profesional. Los trabajos de Navío (2005), Tejada (2005) y Vargas (2004) revisan las definiciones existentes sobre esta competencia para aclarar el término. De entre todas, nos decantamos por aquella que la

\footnotetext{
${ }^{13}$ Congreso Internacional de Competencias Básicas de Ciudad Real 2009, $1^{\text {a }}$ Edición. https://www.uclm.es/actividadeso8og/congresos/competencias/presentacion.asp

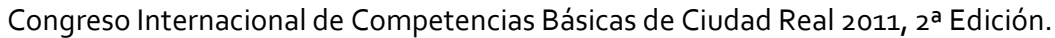
http://www.uclm.es/Actividades/repositorio/pdf/doc_3268_3922.pdf

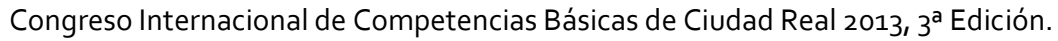
https://www.uclm.es/actividades/evento.aspx?id evento $=4291$

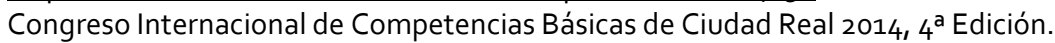
http://www.recbib.es/eventos/iv-congreso-internacional-de-competencias-basicas-competencia-digital-y-tratamiento$\underline{\text { de-la }}$
} 
interpreta como la capacidad de un individuo para realizar una tarea profesional según ciertos estándares de rendimiento, definidos y evaluados en unas condiciones específicas, a partir de un método de descomposición de funciones y tareas en niveles y unidades de comportamiento observables, dotados de criterios precisos de rendimiento (Belisle y Linard, 1996). De igual modo, numerosos autores han presentado diversas clasificaciones respecto a las competencias profesionales, por ejemplo: técnicas y sociales (Le Boterf, 2000), técnicas, metodológicas, sociales y participativas (Bunk, 1994), básicas, técnicas y transversales (Istituto per lo Sviluppo della Formazione Professionale dei Lavoratori, 1997), genéricas y específicas (Lévy-Leboyer, 1996), genéricas, técnicas y específicas (Llopart, 1997), técnicas, metodológicas, participativas y personales (Echeverría, 2002), por último, genéricas o básicas y técnicas o específicas (Cejas, 2005). Todas estas clasificaciones de competencias hacen referencia a diferentes saberes como: saber, saber hacer, saber ser y saber estar (Delors, 1996).

Uno de los referentes más notables en cuanto a las competencias profesionales en educación es el proyecto Tuning (Tuning Educational Structures in Europe) que sirve como modelo de convergencia de los nuevos planes de estudio (González y Wagenaar, 2003), provocando la adaptación de los perfiles profesionales de las titulaciones universitarias a las demandas del EEES, como indica la investigación realizada por Álvarez-Rojo et al. (2011). Así pues, el Proyecto Tuning plantea una serie de competencias profesionales a desarrollar en el campo de la educación universitaria, ver tabla 8.

Tabla 8. Competencias profesionales en educación presentadas en el proyecto Tuning (González y Wagenaar, 2003).

\begin{tabular}{cl}
\hline GRUPOS & \multicolumn{1}{c}{ COMPETENCIAS } \\
\hline & 1- Capacidad de análisis y síntesis. \\
& 2- Capacidad de organizar y planificar. \\
3- Conocimientos generales básicos. & 4- Conocimientos básicos de la profesión. \\
& 5- Comunicación oral y escrita en la propia lengua. \\
Competencias & 6- Conocimiento de una segunda lengua. \\
instrumentales & 7- Habilidades básicas de manejo del ordenador. \\
& 8- Habilidades de gestión de la información (habilidad para \\
& buscar y analizar información proveniente de fuentes \\
& 9- Resolución de problemas. \\
& 10- Toma de decisiones. \\
\hline 11- Capacidad crítica y autocrítica. \\
12- Trabajo en equipo. \\
13- Habilidades interpersonales. \\
14- Capacidad de trabajar en un equipo interdisciplinar. \\
15- Capacidad para comunicarse con expertos de otras áreas. \\
16- Apreciación de la diversidad y multiculturalidad. \\
17- Habilidad de trabajar en un contexto internacional. \\
18- Compromiso ético.
\end{tabular}




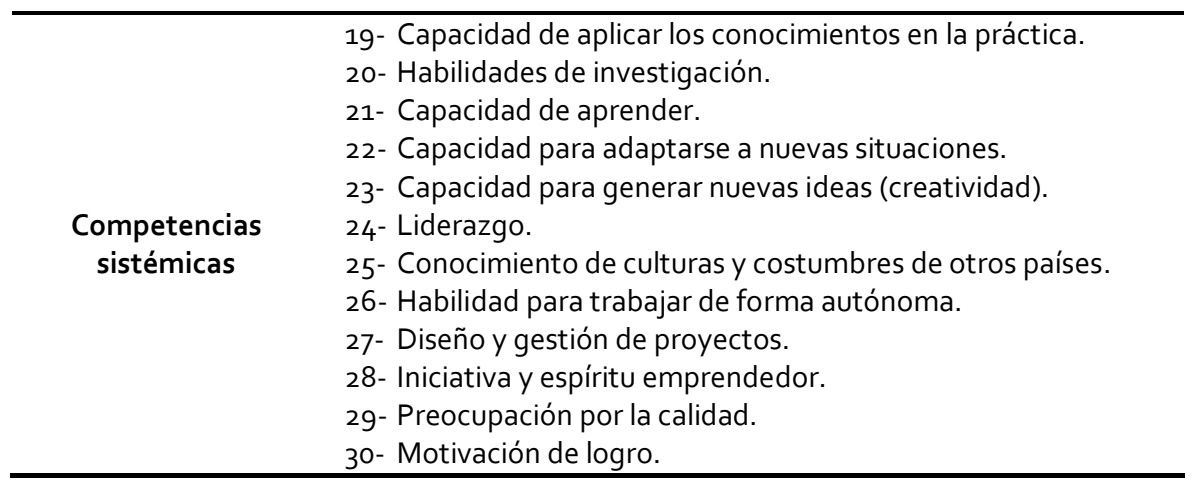

Este planteamiento establece las competencias asociadas a una determinada práctica, en base a las funciones y responsabilidades a desarrollar en los diferentes contextos sociales y profesionales (Yániz, 2008), sirviendo de referencia para fijar los objetivos formativos y los enfoques metodológicos de las nuevas enseñanzas universitarias. Así mismo, dentro del marco educativo del EEES, Corominas, Tesouro, Capell, Teixidó, Pèlach y Cortada (2006) diferencian entre competencias profesionales genéricas y específicas, indicando que las genéricas son comunes a bastantes ámbitos profesionales, mientras las específicas son saberes propios de una profesión. Por otra parte, Borrero y Contreras (2009) consideran que las primeras son aquellas comunes y exigidas en todas las materias de una titulación, mientras que las específicas son las competencias que se pretenden fomentar y desarrollar en cada asignatura. Como veremos más adelante en este trabajo valoraremos ambos tipos de competencias profesionales.

Como ya hemos apuntado, nuestro estudio pretende valorar la competencia docente del alumnado del Grado en Maestro/a. Por ello, es interesante revisar el trabajo de Pavié (2011), que profundiza en la definición de esta competencia profesional. Según este autor, la competencia profesional docente es un "grupo de conocimientos, técnicas de enseñanza y rasgos personales que, mediante su aplicación y transferencia oportuna, le permite al profesor mejorar la calidad del aprendizaje de sus alumnos en un ámbito específico del saber" (Pavié, 2011, p. 78). Entre los diferentes elementos de este concepto, destacan el carácter práctico de la función docente y el cambio que supone en la evaluación la inclusión del concepto de competencia. El primero incide en el carácter activo y experiencial de la función docente, mientras el segundo implica dotar al proceso de evaluación de un carácter formativo y continuo, y no centrarse únicamente en evaluar el resultado final. Como podemos comprobar, ambos aspectos guardan una filosofía de acción afín con la metodología educativa propuesta en este trabajo, el APS. Además, dicha compatibilidad se ve reforzada por el área de estudio en el que se desarrolla, pues la EF es una materia eminentemente práctica donde el proceso de evaluación y adquisición de los distintos aprendizajes es tan importante como el resultado final.

Tanto las competencias básicas como las competencias profesionales docentes han tenido una notable repercusión en el ámbito educativo de la EF en nuestro país. En cuanto a las primeras, son numerosas las publicaciones referentes a su inclusión en este campo de conocimiento. Podemos 
resaltar las de Blázquez y Bofill (2009), Blázquez y Sebastiani (2009), Buscà y Capllonch (2008), Calahorro, Lara y Torres-Luque (2010), Díaz et al. (2008), Jiménez (2007), Lleixà (2007), Mazón (2010), Miranda, Lara, Zagalaz y Cachón (2011), Muñoz (2007), Pacheco (2011), Vaca (2008), Zagalaz, Cachón y Lara (2008), y Zamorano (2012). Estos trabajos versan sobre las implicaciones metodológicas que supone el nuevo enfoque educativo desde un punto de vista técnico, las posibles alternativas de actuación y el análisis de las contribuciones de la EF a la adquisición y desarrollo de las competencias básicas, desde una perspectiva muy positiva. No obstante, tampoco faltan algunos trabajos críticos, como los de Fernández-Balboa (2008), Hernández y Martínez (2008), Molina y Antolín (2008) y Vicente (2011), que dudan de los beneficios del modelo de enseñanza por competencias en la EF. Por último, también debemos resaltar los estudios realizados por Barrachina y Blasco (2012) y Caballero (2013), que investigan la repercusión de incluir las competencias básicas en el área de la EF, señalando que el enfoque por competencias aún se está consolidando entre el profesorado de EF.

Respecto a la incidencia de las competencias profesionales docentes en el campo de la EF, debemos decir que tanto el proyecto Tuning como la implantación del EEES influyen en las competencias profesionales genéricas y específicas de los grados en Ciencias de la Actividad Física y el Deporte y Magisterio (ANECA, 2005a, 2005b), así como en los documentos del Programa de Convergencia Europea de las Ciencias del Deporte en el Espacio Europeo. Sobre este hecho, Romero (2004) nos indica que en ambas titulaciones encontraremos competencias profesionales básicas, referentes a la docencia en general, y competencias profesionales específicas, las cuales se centrarán en desarrollo de habilidades y contenidos propios de la EF. Obviamente, sendos estudios también incluyen competencias transversales, las cuales hacen referencia a las enseñanzas básicas y de formación general de nivel universitario.

En cuanto a trabajos que aborden la temática de las competencias profesionales docentes en EF, podemos destacar los realizados por la ANECA (2005a), Boned, Rodríguez, Mayorga y Merino (2004), Jiménez (2001), Lavega (2008), Sebastiani (2007a) y Ramiro, Sánchez-Bañuelos y GarcíaFerrando (1998) planteando diversas competencias docentes propias de la enseñanza de la EF. Mención especial merece el trabajo presentado por Sebastiani (2007b), pues revisa en profundidad dicha temática desde la perspectiva del EEES. En esta línea de trabajos, existen diversas propuestas de competencias profesionales docentes, como por ejemplo las generales de Cano (2005) y Zabalza (2005) o la específica para EF de Contreras (2012). Entre las distintas competencias profesionales docentes propuestas por estos autores, quisiéramos destacar las siguientes: capacidad de planificar y organizar el proceso de enseñanza aprendizaje, ofrecer información comprensible, gestionar adecuadamente las metodologías de trabajo didáctico y las tareas de aprendizaje, reflexionar e investigar sobre la enseñanza, establecer relaciones interpersonales constructivas, resolución de conflictos, autoevaluación constante y evaluación formativa, uso de las nuevas tecnologías, planificar los objetivos en secuencias didácticas motrices, ajustarse al nivel de las posibilidades del alumnado e incentivar la actividad física hacia la salud. 
La relación entre las competencias profesionales docentes y la EF también ha despertado el interés de diversos investigadores, prueba de ello son los trabajos de Kovač, Sloan y Starc (2008) respecto a las competencias y perspectivas de futuro en la docencia de la EF desde el punto de vista de los profesores; y Buchta (2012) sobre las competencias de los estudiantes de EF en una universidad polaca. También debemos destacar los trabajos realizados por Alonso (2008), Romero (2009) y Romero, Zagalaz, Romero y Martínez (2011), que investigan las competencias profesionales docentes de la EF dentro de la titulación de Magisterio en diferentes universidades andaluzas. A continuación mostramos la tabla 9, donde exponemos los resultados más relevantes de cada uno de estos trabajos.

Tabla 9. Competencias profesionales docentes del área de Educación Física en la titulación de Magisterio (modificado de Alonso, 2008; Romero, 2009; Romero et al., 2011).

\begin{tabular}{|c|c|}
\hline AUTOR & COMPETENCIAS \\
\hline $\begin{array}{c}\text { Alonso } \\
(2008)\end{array}$ & $\begin{array}{l}\text { Habilidades en las relaciones interpersonales. } \\
\text { Conocimiento oral y escrito en la propia lengua. } \\
\text { Capacidad de organizar y planificar. } \\
\text { Capacidad de aplicar los conocimientos en la práctica. } \\
\text { Resolución de problemas. } \\
\text { Creatividad. }\end{array}$ \\
\hline $\begin{array}{c}\text { Romero } \\
(2009)\end{array}$ & $\begin{array}{l}\text { Promover hábitos y estilos de vida saludables. } \\
\text { Relación de la actividad física con hábitos de higiene, posturales y de salud. } \\
\text { Conocer y valorar la importancia del desarrollo corporal y las posibilidades educativas que } \\
\text { ofrecen las actividades motoras. } \\
\text { Conocer el desarrollo de las capacidades y habilidades motrices y sus variables de } \\
\text { intervención educativa. } \\
\text { Capacidad para seleccionar, construir y adaptar diferentes materiales didácticos de EF y } \\
\text { utilizarlos de acuerdo con las necesidades del alumnado. } \\
\text { Saber utilizar el juego motor como recurso didáctico. } \\
\text { Conocimiento sobre aspectos de seguridad en la programación y práctica de actividades de } \\
\text { enseñanza-aprendizaje en EF. } \\
\text { Conocimiento de los fundamentos teóricos y didácticos de la EF. } \\
\text { Conocimiento de los objetivos generales de etapa y los específicos del área de EF. } \\
\text { Conocer las diversas actividades de recreación y ocio, aprovechando los recursos del } \\
\text { contexto y su relación con el centro. }\end{array}$ \\
\hline $\begin{array}{l}\text { Romero et } \\
\text { al. (2011) }\end{array}$ & $\begin{array}{l}\text { Actividad física y salud. } \\
\text { Hábitos y estilos de vida saludables. } \\
\text { El juego motor. } \\
\text { Habilidades motrices. } \\
\text { Seleccionar, construir y adaptar materiales. } \\
\text { Desarrollo corporal. } \\
\text { Fundamentos didácticos de la EF. } \\
\text { Recreación y ocio. } \\
\text { Bases biológicas y fisiológicas. } \\
\text { Objetivos de etapa y de la EF. }\end{array}$ \\
\hline
\end{tabular}

En esta línea, el trabajo de Pérez (2008) estudia las competencias que el alumnado de magisterio adquiere durante su formación inicial. Los resultados globales de este estudio indican 
que el alumnado se muestra muy competente en cuanto al respeto de las diferencias individuales, y poco competente respecto a la formación tecnológica, la investigación y la función tutorial. En el caso concreto de la especialidad en EF, los estudiantes se consideran especialmente competentes para trabajar en equipo, asumir la dimensión ética de la profesión y llevar el aula de manera autónoma. Por último, debemos señalar la investigación realizada por Pazo y Tejada (2012), donde se exponen las competencias profesionales docentes específicas del maestro de EF, según la opinión de los estudiantes del grado, sus profesores y los titulados en ejercicio (ver tabla 10).

Tabla 10. Competencias profesionales docentes específicas del Maestro de Educación Física (Pazo y Tejada, 2012).

\begin{tabular}{|c|c|}
\hline VISIÓN & COMPETENCIAS \\
\hline Alumnos & $\begin{array}{l}\text { Comprender los principios que contribuyen a la formación cultural, personal y social } \\
\text { desde la EF. } \\
\text { Adquirir recursos para fomentar la participación a lo largo de la vida en actividades } \\
\text { deportivas dentro y fuera de la escuela. } \\
\text { Regular los procesos de interacción y comunicación en grupos de estudiantes } 6-12 \\
\text { años. }\end{array}$ \\
\hline Profesores & $\begin{array}{l}\text { Conocer el currículo escolar de la EF. } \\
\text { Comprender los principios que contribuyen a la formación cultural, personal y social } \\
\text { desde la EF. } \\
\text { Adquirir un conocimiento práctico del aula y de la gestión de la misma. } \\
\text { Diseñar, planificar y evaluar la actividad docente y el aprendizaje en el aula. } \\
\text { Relacionar teoría y práctica con la realidad del aula y del centro. }\end{array}$ \\
\hline $\begin{array}{l}\text { Graduados } \\
\text { en ejercicio }\end{array}$ & $\begin{array}{l}\text { Comprender los principios que contribuyen a la formación cultural, personal y social } \\
\text { desde la EF. } \\
\text { Participar en la actividad docente y aprender a saber hacer, actuando y } \\
\text { reflexionando desde la práctica. }\end{array}$ \\
\hline
\end{tabular}

Al repasar el trato de las competencias profesionales docentes de EF, tanto en trabajos teóricos como en estudios de investigación, nuevamente comprobamos su afinidad con el APS a través de la experiencia práctica. Además, como ya hemos apuntado, esta relación va más allá del mero paralelismo, debido a que la EF es una materia eminentemente práctica donde la experiencia en primera persona no se considera un valor añadido a la enseñanza sino una necesidad imperante del aprendizaje. Seguidamente profundizaremos sobre este hecho, destacando así los beneficios de la vinculación del APS con la EF.

Diversos autores, como Ruiz-Pérez (1995), Singer (1986) y Mosston y Ashworth (1993), resaltan la importancia de la práctica como elemento indispensable en los procesos de aprendizaje y desarrollo de habilidades físico-deportivas. De este modo, es difícil concebir una EF sin una participación directa, ya que sus objetivos están directamente vinculados con la experiencia integral y vivencial, a través de la formación y el desarrollo de los aspectos esenciales de la motricidad humana (Sánchez-Bañuelos, 1996). Por ello, al igual que Fraile y Hernández-Álvarez (2006), 
consideramos que la EF está incompleta sin el conocimiento práctico, por lo que teoría y práctica deben ir de la mano en esta materia.

Este planteamiento implica entender el proceso educativo desde una perspectiva amplia que englobe ambos aspectos, teoría y práctica. Un proceso de exploración, descubrimiento e invención, donde se potencie la creatividad y la imaginación (Pérez-Tornero, 2000) y se promueva la construcción del conocimiento a partir de la interacción y la ayuda entre los alumnos a través de una experiencia social y académica de aprendizaje. Bajo este supuesto, la relación entre EF y APS a través de la práctica es clara, pues Martín (2009) expone que uno de los elementos pedagógicos característicos del APS es aprender a partir de la experiencia, argumento que otros autores utilizan para justificar el servicio como práctica de aprendizaje (Batlle, 2009). Por su parte, autores como Gimeno (1991) y Grundy (1991) defienden y reflexionan sobre la importancia de la práctica en al ámbito de la EF, siendo Arnold (1991) el que llega a describir la triple dimensión educativa del movimiento de esta práctica: educación sobre el movimiento, educación a través del movimiento y educación en movimiento. La primera hace referencia a los conocimientos teóricos relacionados con la práctica, la segunda destaca los aprendizajes adicionales que se adquieren mediante la práctica y la tercera señala el conjunto de conocimientos que se desarrollan exclusivamente a través la práctica.

Además, no solo cabe destacar la importancia de la correlación práctica entre el APS y la EF, sino también debemos ensalzar el tipo de práctica que el APS nos ofrece. Como bien nos señalan De la Cerda, Martín y Puig (2010), es preferible que la experiencia sea vivida en primera persona, pues no es lo mismo ver un documental que formar parte de la situación que se muestra, que se produzca en el interior de la misma realidad, ya que no es igual simular un caso que vivirlo de verdad, y que vaya ligada a momentos de reflexión y oportunidades de explicación, pues reflexionar y recibir información durante la práctica facilita el aprendizaje significativo y ayuda a entenderla mejor.

En base a lo expuesto, opinamos que el APS nos brinda una excelente oportunidad para desarrollar los contenidos de la EF a través de una formación teórico-práctica integral, ligados a una experiencia práctica de gran valor. Práctica que, caracterizada por su relación con el entorno social, aportará un doble beneficio al proceso de enseñanza-aprendizaje, en primer lugar por dotar de un mayor realismo a la práctica que incrementará los beneficios de la misma y, en segundo lugar, por sumar el valor educativo del contexto al propio proceso. El incremento de la realidad de la experiencia aumentará significativamente los beneficios de la misma pues, habitualmente, los propios estudiantes deben desempeñar alternativamente el rol de alumnos y de docentes a lo largo de estas sesiones prácticas. Por otra parte, respecto al valor contextual de la experiencia, consideramos que los proyectos de APS son una gran propuesta en este aspecto pues logran la acción educadora conjunta de entorno, comunidad y escuela, además de fomentar la educación en valores, como defiende Palos (2009). En una línea similar, Puig et al. (2007) apuntan que dos de las finalidades del APS son la integración y el capital social por un lado, y la educación en valores y la prosocialidad por otro, lo cual apoya nuevamente nuestro planteamiento. Así pues, estas 
experiencias prácticas, enfocadas dentro de un contexto social real, nos ayudarán a desarrollar la competencia docente del alumnado participante, tanto desde el punto de vista académico como desde la perspectiva ética y moral, objetivos fundamentales del presente trabajo.

No obstante, pese a los aparentes beneficios de la vinculación entre el APS y la EF, esta temática sigue siendo un ámbito a desarrollar, principalmente por dos motivos. Por un lado, porque la cantidad de estudios referentes al APS en el área de EF aún es escaso para establecer un marco teórico de conocimiento consolidado y contrastado; por otro lado, porque la mayoría de los trabajos realizados se han llevado a cabo en diferentes entornos culturales, básicamente en el norteamericano, lo que dificulta relacionar los resultados obtenidos con otros contextos sociales. En esta línea, podemos destacar algunos trabajos. Galvan y Parker (2011) investigan los efectos de un programa de APS sobre 3 aspirantes a maestros de EF y 15 jóvenes de origen latino de entre 6 y 13 años. El análisis de datos identifica que los candidatos a maestros adquirieron conocimientos de contenidos y protocolos técnicos establecidos además de experimentar una mayor conciencia de la competencia cultural. Al mismo tiempo, el alumnado latino mejoró sus habilidades deportivas, desarrolló la capacidad de cooperación y trabajo en equipo, y estableció relaciones positivas con personas adultas. Miller (2012) estudia a un grupo de 26 alumnos de primer curso del Grado en Maestro/a de EF participantes en un programa de APS para fomentar el desarrollo motor de niños/as de educación infantil con y sin discapacidad. Los resultados del trabajo apuntan a que el programa de APS desarrollado tiene una gran influencia positiva sobre la confianza del alumnado participante respecto a su capacidad para ensenar en EF además de prepararlos en aspectos tan importantes como la inclusión del alumnado discapacitado. Robinson y Meyer (2012) analizan una propuesta de APS centrada en la educación para la salud. Para ello, 21 estudiantes del Grado en Maestro de EF implementaron un programa educativo con 162 adolescentes (13-16 años). Las conclusiones del trabajo indican que la práctica pedagógica utilizada fue positiva tanto para los docentes de EF como para el alumnado adolescente participante. Por su parte, Pechak y Thompson (2011) se plantearon identificar y analizar las similitudes existentes entre distintos programas de APS internacional relacionados con la EF terapéutica. Gracias a la ayuda de 14 docentes participantes se concluye que, pese a no existir un modelo único de aplicación, existen similitudes en las estructuras y procesos de estos programas educativos pudiendo destacar cinco fases básicas: desarrollo, diseño, implementación, evaluación y mejora. De igual modo, también se indica que en los programas de APS analizados prestan escasa atención a los objetivos y resultados del servicio.

A continuación resaltamos aquellos trabajos que utilizan el APS específicamente en el ámbito de la docencia de la EF. Baldwin, Buchanan y Rudisill (2007) comprueban que el APS ofrece a los futuros maestros oportunidades para tener una mejor comprensión de la diversidad, la justicia social y el multiculturalismo. Bishop y Driver (2007) aplican un programa de APS con estudiantes de EF adaptada en el que ayudan a desarrollar la movilidad de personas con limitaciones motrices, aumentando notablemente el realismo de la experiencia práctica del alumnado. Domangue y Carson (2008) realizan un programa de APS de actividades físicas para niños y niñas víctimas del huracán Katrina, desarrollando diversos aspectos sociales en el alumnado como, por ejemplo, el compromiso social. Himelein, Passman y Phillips (2010), Hodges y Videto (2008) y Massey-Stokes y 
Meaney (2006) implementan programas de APS en futuros docentes para concienciar y actuar sobre la prevención de la obesidad infantil, problemática de primer nivel en los EEUU. Konukman y Schneider (2012) defienden el uso del APS en la formación del profesorado de EF basándose en los numerosos antecedentes existentes en el entorno educativo norteamericano. LaMaster (2001) lleva a cabo una propuesta de APS con futuros maestros de EF en una escuela primaria de un entorno con graves conflictos sociales y económicos, mejorando la calidad de vida de los receptores del servicio. Meaney, Bohler, Kopf, Hernandez y Scott (2008) y Meaney, Hart y Griffin (2009) desarrollan programas educativos de actividad física en los que los estudiantes podían mejorar sus competencias docentes mientras promovían estilos de vida saludable entre los niños y niñas de familias hispanas y afroamericanas con escasos recursos. Wilkinson, Harvey, Bloom, Joober y Grizenko (2013) exploran las experiencias de los estudiantes del Grado en Maestro/a de EF al aplicar un proyecto de APS con niños que presentan Trastorno por Déficit de Atención e Hiperactividad, incidiendo en el cambio de opinión respecto a los receptores del servicio, la vinculación entre teoría y práctica y los beneficios aportados a los futuros docentes de EF. Finalmente, Williams y Kovacs (2001) utilizan un programa de APS para mejorar el equilibrio y la movilidad en un grupo de personas de edad avanzada mientras el alumnado universitario, de diversos estudios relacionados con la EF y el deporte, desarrollaba competencias sociales y profesionales.

Mención especial merece la revisión de Cervantes y Meaney (2013), la cual aborda el análisis de 23 estudios, empíricos y descriptivos, sobre la aplicación del APS en futuros docentes de EF. Los trabajos descriptivos señalan que el APS facilita la consecución de objetivos en la línea de la educación superior, la existencia de una necesidad de institucionalizar el APS en el currículum y el diseño de programas de APS para satisfacer las necesidades de jóvenes marginados o en riesgo de exclusión social. Por otra parte, el análisis de los trabajos empíricos resalta las siguientes tendencias en este tipo de estudios: conceptualización del APS como una metodología de enseñanzaaprendizaje que integra un servicio a la comunidad directamente vinculada con el contenido del curso académico con el propósito de promover el aprendizaje y fortalecer la preparación de los futuros maestros, aplicación con niños de bajo estatus social o comunidades minoritarias e implementación de la modalidad de servicio directo y la metodología de investigación cualitativa. En general, los resultados de los estudios analizados demuestran un efecto positivo tanto en los futuros docentes de EF como en los receptores del servicio, incidiendo mayoritariamente en los primeros. Entre los beneficios de los estudiantes de EF destacan: aumento de la competencia percibida como docentes, uso de diversas estrategias de enseñanza y mejora de estas habilidades, incremento del componente ético y moral en la toma de decisiones, fortalecimiento de la competencia cultural para la enseñanza y desarrollo de actitudes positivas hacia la interacción con los niños con discapacidad. Entre los beneficios obtenidos por los receptores del servicio se incide en la mejora de la motivación para participar en actividades físicas y el desarrollo de los sentimientos de pertenencia, logro personal y autoconfianza. Ambos resultados están en consonancia con los trabajos expuestos anteriormente.

En nuestro contexto social, debemos señalar los trabajos de Capella et al. (2014), Chiva, Corbatón, Gil y Zorrilla (2015), Chiva, Gil y Hernando (2014), Gil (2012), Gil y Chiva (2014), Gil, Chiva 
y Martí (2014) y Gil et al. (2012) quienes han estudiado el uso del APS en la docencia de la EF. Pese a ello, consideramos que estos trabajos son insuficientes y que debemos seguir profundizando en esta cuestión, justificando así la realización de esta tesis doctoral.

Después de tratar la incidencia de las competencias básicas y las competencias profesionales docentes en el ámbito de la $\mathrm{EF}$, seguidamente exponemos cómo se aborda la compleja labor de evaluar este tipo de destrezas, fundamentando así el estudio cuantitativo de los contenidos académicos a desarrollar en nuestro trabajo. Cabe destacar en este punto que la mayor parte de trabajos que abordan esta temática se centran en el desarrollo de competencias por parte del alumnado, como el estudio de Zapatero, González y Campos (2013) que identifica los modelos e instrumentos de evaluación utilizados por los docentes de EF en la comunidad de Madrid apuntando que, pese a que estos no aplican la evaluación por competencias, esta se puede llevar a cabo de manera global e intuitiva aplicando técnicas como la observación directa. No obstante, también existen trabajos que versan sobre la adquisición de competencias docentes en la formación del profesorado: Guzmán y Marín (2011) abordan dicha temática desde un punto de vista global en el campo de la docencia, concluyendo que es necesario analizar las estrategias, criterios e instrumentos de evaluación a utilizar en la formación docente, ya que no podemos hacerlo con los dispositivos utilizados hasta la fecha; Castejón (2013) lo hace de una forma más específica respecto a la enseñanza de la EF, destacando las dificultades existentes para determinar las competencias docentes a evaluar y definir la mejor manera de hacerlo; finalmente, Lleixà, Robert y Batalla (2008) muestran las estrategias de evaluación del Blaagaard Seminarium de Copenhague como ejemplo a tener en cuenta a la hora de elaborar nuevas propuestas de evaluación en la docencia de la EF basadas en el modelo educativo por competencias. Pese a la situación expuesta, como veremos a continuación, el proceso de evaluación de la educación por competencias utiliza estrategias comunes, ya sea para valorar el desempeño del alumnado como la labor de los docentes.

La temática de la evaluación por competencias dentro de la EF tiene un valioso antecedente en el estudio de Ruiz-Pérez (1995), especialmente en lo que se refiere a la identificación de indicadores y descriptores para valorar una competencia. Esta estrategia ha sido defendida por diversos autores como Villa y Poblete (2007) o Zamorano (2011) y, especialmente, por Castejón (2010, 2013). También se han realizado diversas investigaciones sobre la evaluación en el ámbito de la $E F$, como las realizadas por Lleixà, Torralba y Abrahão (2010) mediante el diseño de procedimientos de evaluación de la EF en la etapa de primaria; Navarro y Jiménez (2012), buscando mejorar la evaluación formativa de los maestros de EF a través de un instrumento de meta-evaluación didáctica; o la tesis doctoral defendida por González (2006) respecto a la calidad de la EF en la Educación Secundaria Obligatoria en los centros de la ciudad de Barcelona.

Como nos señala Moya (2008), los indicadores hacen referencia a los criterios de evaluación fiables de una competencia y tienen que expresar los comportamientos que debe manifestar el alumnado al desarrollar unas determinadas tareas, reflejando así el nivel de dominio alcanzado en esa competencia. Los mismos autores proponen el uso de los indicadores asociándolos a la competencia que deseemos evaluar mediante la utilización de rúbricas. Según Andrade (2000) una 
rúbrica es un documento de una o dos páginas que describe diferentes niveles de calidad, de excelente a malo, para una tarea específica. Por otra parte, ya desde la perspectiva específica de la $\mathrm{EF}$, Lund (2000) considera que es un dispositivo de puntuación que incluye criterios y estándares que se utilizan para evaluar el trabajo del estudiante. Posteriormente, otros autores la describen como una guía de calificación de opciones múltiples diseñada para evaluar los resultados y rendimiento de los estudiantes, teniendo gran potencial y funcionando de diferentes formas para facilitar el aprendizaje del alumnado (Wolf y Stevens, 2007). Seguidamente profundizaremos en el conocimiento de las rúbricas como herramienta de evaluación y los procesos de creación y diseño de las mismas.

En el ámbito internacional diversos autores defienden el uso de las rúbricas como estrategia óptima para evaluar en el ámbito de la EF. Birky (2012) considera que las rúbricas facilitan el entendimiento de las exigencias del profesorado y las tareas a realizar, Mohnsen (2006) defiende el uso de las rúbricas como un método de evaluación coherente y justo que explicita los aprendizajes a alcanzar por los estudiantes, Gallo (2004) propone los pasos a seguir para crear adecuadamente una rúbrica, Lund (2000) promueve la utilización de las rúbricas en la EF Infantil, Lund (2006) profundiza en el proceso de aprobación de las rúbricas por los organismos reguladores y Wang y Rairigh (2006) destacan que para aumentar la calidad de una rúbrica ésta debe considerar los campos psicomotor, cognitivo y afectivo. También cabe reseñar las investigaciones realizadas por Williams y Rink (2003), investigando sobre la precisión de los datos de rendimiento motor presentados por los profesores de EF mediante el programa de evaluación de EF de Carolina del sur, y Dyson et al. (2011) utilizando las rúbricas para desarrollar medidas de evaluación de la EF infantil a nivel nacional en EEUU.

En nuestro entorno, Rodríguez y Fustes (2013) defienden el uso de las rúbricas como medio de evaluación y aprendizaje en la $E F$, ofreciendo una propuesta de rúbrica y planteando una serie de recomendaciones, Del Pozo (2012) reflexiona sobre la evaluación y el uso de las rúbricas, además de presentar una propuesta específica para la Expresión Corporal, y Polo (2010) ofrece una propuesta para facilitar el proceso de evaluación de las competencias motrices del alumnado mediante el uso de las rúbricas. Como destacábamos anteriormente, la mayor parte de estos trabajos se centran en evaluar la ejecución del alumnado de EF y no la labor de sus docentes. Este motivo da un nuevo aliciente a la realización del presente trabajo pues, como ya hemos apuntado, pretende valorar la competencia profesional docente en EF.

Diversos autores señalan los beneficios que aporta el uso de las rúbricas al proceso de evaluación. Los más destacables son: clarifican el objetivo del aprendizaje, dirigen el diseño y estilo metodológico, hacen que el proceso de evaluación sea más justo y preciso y proporcionan a los estudiantes una herramienta de autoevaluación y retroalimentación entre iguales. Por otra parte, también encontramos similitudes en los pasos a seguir a la hora de diseñar una rúbrica. En la tabla 11 presentamos cuatro posibles propuestas, dos de ellas enfocadas en el ámbito educativo en general (Suskie, 2004; Wolf y Stevens, 2007) y otras dos referentes específicamente al campo de la EF (Gallo, 2004; Wang y Rairigh, 2006). 
Tabla 11. Pasos a seguir en el diseño de una Rúbrica (Gallo, 2004; Suskie, 2004; Wang y Rairigh, 2006; Wolf y Stevens, 2007).

\begin{tabular}{|c|c|}
\hline Suskie (2004) & Gallo (2004) \\
\hline $\begin{array}{ll}\text { 1- } & \text { Buscar modelos. } \\
\text { 2- } & \text { Determinar la lista de cosas que se buscan. } \\
\text { 3- } & \text { Dejar espacio para lo inesperado. } \\
\text { 4- } & \text { Crear la escala de calificación. } \\
\text { 5- } & \text { Poner a prueba la rúbrica. }\end{array}$ & $\begin{array}{l}\text { 1- } \text { Establecer qué esperamos conseguir. } \\
\text { 2- } \text { Definir qué deseamos evaluar. } \\
\text { 3- } \text { Decidir cómo abordar el proyecto o habilidad. } \\
\text { 4- } \text { Presentar la rúbrica a los estudiantes. } \\
\text { 5- } \text { Aprender usando la rúbrica. }\end{array}$ \\
\hline Wolf y Stevens (2007) & Wang y Rairigh (2006) \\
\hline $\begin{array}{l}\text { 1- } \quad \text { Identificar los criterios de rendimiento. } \\
\text { 2- Configurar los niveles de rendimiento. } \\
\text { 3- } \quad \text { Crear los descriptores de rendimiento. }\end{array}$ & 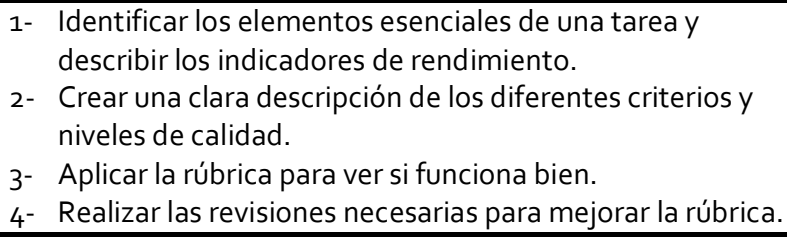 \\
\hline
\end{tabular}

Como podemos ver, estos trabajos exponen un proceso muy similar en cuanto a la elaboración de las rúbricas. En primer lugar se preparan y definen sus bases, seguidamente se especifican los criterios y niveles de valoración, y para finalizar se analizan los resultados obtenidos de su aplicación con la intención de mejorarla. En esta línea, Chiva y Gil (2012) plantean que los pasos básicos para elaborar una rúbrica son: identificar y decidir las dimensiones o aspectos que se evaluarán a partir de los objetivos planteados, determinar los niveles de logro, escribir los indicadores/descriptores de la forma más específica y precisa posible y aplicar y analizar los resultados de la rúbrica. Estos autores defienden el uso de las rúbricas como herramienta para evaluar las experiencias de APS en un contexto muy similar al de la presente tesis, estableciéndose así como un marco de referencia excelente para nuestro trabajo. Más adelante, siguiendo las recomendaciones expuestas en este marco teórico, presentaremos el proceso de elaboración de la rúbrica que valorará la competencia profesional docente del alumnado universitario para realizar sesiones de juegos motores y de expresión corporal.

Tras profundizar en las implicaciones de la inclusión de las competencias en el ámbito de la EF, como marco legal vigente en el que debe encuadrarse su docencia, y presentar la propuesta del uso de las rúbricas, como herramienta de evaluación en esta materia, consideramos necesaria la proliferación de trabajos que profundicen sobre esta temática pues, al igual que Salicetti, Campos, Jiménez, Carpio y Smith (2013), opinamos que debido a "la escasez de este tipo de instrumentos en nuestro campo, algunas veces es necesaria la creación de los mismos" (p. 212). Por ello, aunque nuestra propuesta se centre en la aplicación de juegos motores y de expresión corporal, sería igualmente interesante realizar trabajos similares en otras áreas de la EF.

Terminamos este apartado sintetizando los aspectos más importantes desarrollados a lo largo del mismo: 
1. La introducción del concepto de competencia ha supuesto un cambio notable en el enfoque tanto de la educación en general como de la EF en particular.

2. Las competencias básicas y las competencias profesionales establecen dos de los pilares fundamentales sobre los que se asienta la educación actual.

3. La perspectiva educativa de las competencias acentúa el valor práctico del aprendizaje, ofreciendo así un excelente punto de encuentro entre la EF y el APS.

4. La vinculación entre el APS y la EF sigue siendo un ámbito a desarrollar en nuestra comunidad debido a la escasez de trabajos sobre esta temática.

5. Una de las estrategias educativas más defendidas a la hora de valorar el desarrollo de las competencias es el uso de las rúbricas.

6. El proceso de elaboración de una rúbrica conlleva decidir los aspectos a evaluar, determinar los niveles de logro, describir los indicadores de forma precisa y analizar los resultados tras la aplicación de la misma.

Para concluir este capítulo, debido a la enorme carga personal que conlleva la experiencia provocada por el APS, en el siguiente apartado justificaremos el uso de las Historias de Vida (en adelante $\mathrm{HdV}$ ) como herramienta de investigación cualitativa en esta temática. Al mismo tiempo, repasaremos los antecedentes y beneficios de esta metodología de estudio en el campo de la EF.

\subsection{Las Historias de Vida en la investigación del Aprendizaje Servicio y el ámbito de la Educación Física}

Como hemos podido observar a lo largo de este capítulo, la metodología de enseñanza del APS tiene notables efectos en la esfera social y personal del alumnado involucrado, así como en los docentes y colaboradores externos. Por ello, consideramos que es interesante enriquecer nuestro estudio cuantitativo con una investigación cualitativa que nos permita acceder a las percepciones individuales de los participantes en el programa educativo objeto de estudio, entendiendo así cómo se han producido los efectos provocados. Con la intención de seleccionar el método cualitativo más adecuado para nuestra propuesta, repasamos las características básicas de algunas de las alternativas más empleadas en el ámbito educativo:

- Métodos biográficos: se centran en el estudio de las experiencias individuales resaltando así el valor de las vivencias personales. La recuperación y auge del método biográfico en los últimos años forma parte de la revalorización del actor social (individual y colectivo), no reducible a la condición de dato o variable, caracterizado como sujeto de configuración compleja y como protagonista de las aproximaciones que, desde las Ciencias Sociales, se quiere hacer de la realidad social (Pujadas, 2000).

- Estudios fenomenológicos: hacen referencia al significado de las experiencias vividas por una persona, o grupo de personas, acerca de un concepto o fenómeno (Creswell, 2007). Según Bentz y Shapiro (1998) la fenomenología no está interesada en la explicación del 
suceso sino que se preocupa por los aspectos esenciales de la experiencia. La diferencia fundamental entre este método y el anterior es que en este caso las experiencias se limitan a situaciones concretas.

- Etnografía: surge de la antropología cultural y de la sociología cualitativa, y representa el estudio descriptivo de la cultura de una comunidad, o de alguno de sus aspectos fundamentales, bajo una perspectiva de comprensión global de la misma (Aguirre, 1995).

- Teoría fundamentada: se asienta en el interaccionismo simbólico. Para Mertens (1998) es una metodología en la que las proposiciones teóricas no se postulan al inicio del estudio sino que se generalizan tras la recolección de los datos.

- Investigación-acción: su objetivo prioritario consiste en mejorar la práctica educativa en lugar de generar conocimientos. Por ello, la producción y utilización del conocimiento se subordina y condiciona a la mejora de la práctica educativa (Elliott, 1993).

- Estudio de casos: según Rodríguez, Gil y García (1996) implica un proceso de indagación que se caracteriza por el examen detallado, comprensivo, sistemático y en profundidad del caso objeto de estudio.

Tras revisar las características de las diferentes estrategias descritas, nos hemos decantado por el uso de los métodos biográficos, pues consideramos que son los que mejor se adaptan a las necesidades del presente trabajo. Esta elección nos permitirá acceder a la información referente a las vivencias individuales del alumnado participante, así como a sus impresiones y opiniones personales, información de gran valor a la hora de entender los efectos de la experiencia realizada. Según Bruner (1991), Goodson (2004), Huberman, Thompson y Weiland (2000) y Nóvoa (2003), desde principios de los años setenta se han ido produciendo una serie de cambios que han propiciado un aumento del valor de la investigación cualitativa basada en los métodos biográficos. Dentro de los métodos biográficos podemos decantarnos por distintas alternativas, entre las que Pujadas (2000) destaca las siguientes:

- Biografía: constituye un género en el que el investigador reconstruye una trayectoria individual sobre la base de documentación preferentemente escrita y con la ayuda puntual de fuentes orales cuando se trate de una persona contemporánea.

- Autobiografía: aunque el término sugiere que es el propio informante quien construye la narración, la realidad es bien distinta. El informante relata los pasajes de su vida al investigador quien habitualmente también desempeña el papel de transcriptor y traductor. Por otro lado, el texto literal se reordena para darle un hilo narrativo uniforme y se completa para evitar hiatos informativos. En este caso la información se obtiene mayoritariamente a través de fuentes orales, estrechando así la relación entre investigador e investigado.

- Documentos personales: hace referencia al uso de cualquier tipo de registro, fotografías, películas, vídeos, diarios, cartas... que posea un valor afectivo o simbólico para el sujeto analizado provocando así la rememoración de acontecimientos pasados.

- Historia oral: consiste en el trabajo histórico que, sin excluir los documentos escritos como base de evidencia, pone especial énfasis en el uso de diversos testimonios orales. 
- Relato biográfico: registro literal de las entrevistas que el investigador realiza con la persona colaboradora. Básicamente se trata de entrevistas abiertas, no directivas, en las que la labor del investigador consiste en estimular al informante para que siga el hilo de su narración, procurando no interrumpirle y manteniendo la atención para orientarle en los momentos de lapsus de memoria.

- Historia de vida: constituye el texto final que llega a las manos del lector, tras incluir la aportación del investigador al relato biográfico. Existen varias modalidades de HdV pudiendo diferenciarse entre $\mathrm{HdV}$ de relato único o de relatos múltiples $\mathrm{y}$, dentro de estas, podemos distinguir entre la $\mathrm{HdV}$ de relatos cruzados e $\mathrm{HdV}$ de relatos paralelos. El criterio diferenciador entre estas dos últimas alternativas es la existencia del sentimiento comunitario entre los narradores. Así pues, las HdV de relatos cruzados están llenas de interpretaciones compartidas, mientras que las de relatos paralelos no lo están.

Como podemos comprobar, la diferencia fundamental entre el relato biográfico y la $\mathrm{HdV}$ es que mientras el primero registra únicamente la historia contada por el entrevistado, la HdV añade la interpretación personal del investigador al reconstruir el relato (Denzin, 1989; Del Rincón, Arnal, Latorre y Sans, 1995; Hernández, 2011). Por todo ello, después de valorar las diferentes posibilidades a nuestro alcance, nos hemos decantado por el uso de las HdV como herramienta de investigación cualitativa y, debido a las características del grupo investigado, nos centraremos en el uso de la modalidad de $\mathrm{HdV}$ de relatos múltiples cruzados.

A través de la investigación con esta metodología podremos conocer, como afirma Bolívar, Domingo y Fernández (1998), el significado de los sentimientos, los deseos, las creencias y los valores compartidos y negociados en la comunidad de aprendizaje. Por ello, Ruiz e Ispizua (1989) consideran que, de todos los métodos de investigación cualitativa, las $\mathrm{HdV}$ son el que mejor permite al investigador acceder a ver cómo los individuos crean y reflejan el mundo social que les rodea, algo de gran importancia en nuestra propuesta. Otros autores defienden que esta es la elección adecuada para lograr la máxima implicación entre el investigador y la persona objeto de estudio (Santamarina y Marinas, 1995), facilitando así la producción de información y aumentando la comprensión de la misma.

Los inicios de las HdV como método de investigación datan de principios del siglo XX, cuando algunos sociólogos y antropólogos empezaron a utilizarlas en sus estudios. Entre los pioneros de esta metodología podemos destacar a autores como Boas, Thomas, Znaniecki y Dollard (Queiroz, 1991). Sin embargo, en la década de 1940 este tipo de instrumento fue relegado por el desarrollo y la gran aceptación de las técnicas estadísticas. Posteriormente, como ya hemos apuntado, se produjo un resurgimiento del uso de este tipo de técnicas debido a la importancia de la información subjetiva en las vivencias investigadas.

A continuación, siguiendo a Pujadas (1992) exponemos las diferentes etapas y pasos que debemos seguir para elaborar una $\mathrm{HdV}$, (tabla 12): 
Tabla 12. Etapas para elaborar una Historia de Vida (Pujadas, 1992).

\section{Etapa inicial}

Elaborar un marco teórico de trabajo que explicite claramente las hipótesis iniciales.

Justificar metodológicamente el porqué de la elección del método biográfico.

Delimitar con la mayor precisión posible el universo de análisis (comunidad, grupo profesional, edad, colectivo, etc.)

Explicitar el proceso de selección de los informantes (número, características, criterio de selección, etc.)

Establecer claramente la relación que se mantendrá con los colaboradores durante el trabajo:

- Finalidad de la investigación y uso de la información obtenida.

- Registro de la información y posibilidades de acceso de terceras personas a la misma.

- Confidencialidad (evitar el uso de nombres identificativos a lo largo del relato).

- Especificar la perspectiva de publicación del material.

- Compensación por el trabajo realizado (moral, material, etc.).

\section{Encuesta}

Crear las condiciones más favorables para garantizar la comodidad de nuestro informante (horario, intimidad, espacio familiar, etc.)

Estimular positivamente las ganas de hablar de nuestro informante, destacando la significación científica e importancia de su testimonio para nuestro proyecto.

Dejar hablar al colaborador e intervenir únicamente cuando sea indispensable para cerrar temas, facilitar la comprensión del diálogo o retomar el hilo principal del discurso.

Evitar dirigir excesivamente la entrevista por medio de preguntas demasiado concretas y cerradas

Tomar como punto de partida el propio relato. Empezar la entrevista repasando, completando y tratando las transcripciones de aspectos comentados con anterioridad para retomar el relato.

Iniciar nuestro trabajo realizando otro tipo de entrevistas menos personales y comprometidas.

Registro, transcripción y elaboración de los relatos

Recoger toda la información biográfica registrada a través de grabaciones y transcripciones, disponiendo del material adecuado para su posterior análisis.

Para facilitar el proceso de análisis se recomienda elaborar:

- Registro original con la transcripción literal de todas las entrevistas.

- Registro cronológico ordenando la información de acuerdo con las etapas sucesivas.

- Registro de las personas citadas, familiares, amigos, compañeros, etc.

- Registro temático agrupando la información por categorías temáticas.

Análisis e interpretación (se diferencian tres tipos de exploración analítica posibles)

Elaboración de HdV como estudio de caso único. Debe prestar atención a:

- Justificar el caso seleccionado en términos de representatividad o valor testimonial.

- Justificar la validez del estudio de caso en relación a los objetivos teóricos o temáticos de la investigación.

- Explicar el procedimiento utilizado para recopilar la narrativa con la intención de garantizar la fiabilidad del documento que se presenta.

Análisis cualitativo del contenido del texto. Registro de fenómenos sociales reducidos a categorías analíticas abstractas que permitan describir y contrastar de forma ordenada los contenidos extraídos. Debe atenderse a:

- Objetividad.

- Susceptibilidad de medición y cuantificación.

- Significación para una teoría más sistemática.

- Posibilidad de generalización.

Las diferentes etapas en las que se organiza el plan de análisis de un texto son las siguientes:

- Elaboración del texto a analizar.

- Establecimiento de los tipos de variables y categorías a analizar.

- Operacionalización de las variables mediante la asociación de los aspectos analizados con las categorías establecidas. Se puede hacer mediante:

- Unidad de registro: segmento específico del contenido situado en una categoría determinada (palabra clave cargada de significación o párrafo seleccionado).

- Unidad de contexto: extensión más amplia de contenido que puede examinarse al 
caracterizar una unidad de registro (varias respuestas o comentarios relacionados).

- Especificación de indicadores: establecen si una unidad textual concreta corresponde o no a una determinada categoría.

Análisis cuantitativo del contenido del texto. Registro de fenómenos sociales categorizados desde una perspectiva cuantitativa.

Presentación y publicación de la historia de vida

Editar el texto para presentarlo con cambios mínimos (según el apartado de registro, transcripción y elaboración de los relatos) o incorporando narraciones de otros sujetos próximos.

Introducción analítica para situar al lector sobre el contexto y las características específicas del entorno del colaborador, ilustración en profundidad del tema o problema de estudio.

Incluir notas para clarificar expresiones que se pueden hacer ambiguas, explicar el significado de algunos términos o incluir referencias a otras partes del texto que tratan temas similares.

Elaborar un glosario de términos que delimite con exactitud todas las expresiones del texto.

Adjuntar anexos para incluir el material complementario que pueda facilitar la comprensión del texto (análisis de contenido, transcripción de entrevistas, documentos personales, etc.).

Al describir los pasos y etapas a seguir en la elaboración de las HdV comprobamos que una de las etapas más delicadas es la que hace referencia al análisis e interpretación de los datos. Profundizando en esta temática, Demazière y Dubar (1997) plantean que esta labor podemos abordarla desde tres puntos de vista: ilustrativo, restituyente y analítico.

- Ilustrativo: consiste en utilizar las palabras de los colaboradores para demostrar o ilustrar los planteamientos e ideas defendidos por los investigadores. Esta perspectiva de análisis se puede abordar desde un punto de vista temático o en base al contenido. Ambas alternativas derivarán en una clasificación objetiva y sistemática de los datos obtenidos, la primera en cuanto a los temas y subtemas tratados y la segunda respecto a los elementos de significado extraídos.

- Restituyente: pretende destacar la importancia de las palabras de los entrevistados. Esta perspectiva puede tratarse desde la restitución de la sabiduría social de los sujetos o desde la transparencia de la palabra. El primer planteamiento supone que el investigador no debe, en ningún caso, proponer una interpretación autónoma, sino más bien debe esforzarse por entender el significado de cada frase en relación a una determinada situación. En la segunda opción, el investigador debe evitar cualquier etiquetamiento, limitándose a transcribir y organizar el orden de las entrevistas, ofreciendo a los lectores los instrumentos para dirigir su interés hacia los tramos de mayor pertinencia.

- Analítico: la atención del investigador debe dirigirse hacia el lenguaje de los entrevistados para entender su entorno social. De este modo, las entrevistas constituyen un conjunto de definiciones de las situaciones vividas por el colaborador. En esta perspectiva destacan el análisis proposicional del discurso de Ghiglione, Matalon y Bacri (1985) y el análisis de las relaciones por oposición de Raymond (1968). El primero se basa en el hecho de que cada narrador construye la estructura de su mundo de referencia, cuyo análisis propone una serie de relaciones entre los diversos aspectos sociales existentes. El segundo se fundamenta en la existencia de una sintaxis que estructura el discurso y organiza su significado, de este modo se atribuye un lugar de primacía a la función simbólica de la verbalización. 
Cada una de estas propuestas de análisis determina un posicionamiento del investigador con respecto al propio estudio y en cuanto a la forma de abordar los comentarios de las entrevistas. Para evitar la rigidez de este sistema, autores como Bertaux (1997) y Bichi (2002) promueven una alternativa de análisis mixto a la que denominan análisis comprensivo. Este enfoque analítico pretende hacer comprensibles los fenómenos observados en las entrevistas, con la intención de identificar las indicaciones respecto a aquello que haya influido sobre la experiencia de vida del sujeto, para reconstruir su mundo histórico-social. Por ello, este tipo de análisis considera tanto las historias narradas como lo sucedido en la propia entrevista valorando, por igual, el ciclo de vida, la vivencia concreta y la interacción en la entrevista.

Teniendo en cuenta la información expuesta debemos apuntar que nuestro planteamiento, respecto al modelo de exploración analítica de las entrevistas, se aborda desde el punto de vista ilustrativo, y dentro de este, a través del análisis temático. Así pues, apoyándonos en las categorías definidas por los instrumentos de medida cuantitativos creados ad hoc, analizamos las entrevistas del alumnado para mejorar nuestra comprensión sobre los efectos del programa educativo implementado en cada uno los temas objeto de estudio.

Para evitar que las HdV se reduzcan a un relato subjetivo es importante contextualizar social y culturalmente la información de los sujetos estudiados. En este sentido Jones (1983), reformulando y ampliando algunas aportaciones clásicas, menciona cinco criterios que el investigador debe tener en cuenta a la hora de utilizar las HdV como herramienta de investigación: la persona debe ser contemplada como miembro de una cultura, describiendo e interpretando el relato sobre su evolución en su entorno social; tenemos que reconocer el importante papel que juegan otras personas significativas en la transmisión de cultura; es necesario especificar la naturaleza de las acciones sociales y de la realidad social; el carácter continuado de la experiencia a lo largo del transcurso temporal debe ser objeto de análisis, es decir, hay que comprender cómo se constituyen cronológicamente los significados y atribuciones que el protagonista asigna a los acontecimientos que ha vivido; y, por último, el contexto social debe ser asociado permanentemente con la acción de la persona colaboradora. Con la intención de optimizar la calidad de nuestro trabajo a la hora de realizar las HdV tendremos en cuenta todas estas sugerencias.

Por otra parte, Hernández (2011) nos señala varios problemas, en términos de contradicciones y desafíos, que podemos encontrarnos al utilizar las HdV como metodología de investigación:

- El lugar del marco de la historia: debemos resaltar la importancia del contexto en el que transcurre la historia y respetar las aportaciones de los entrevistados. Para ello tenemos que evitar, en la medida de lo posible, los planteamientos preconcebidos en cuanto al análisis o la tematización de las entrevistas. No obstante, el propio autor expone que esta es una práctica muy frecuente en el ámbito sociológico.

- La relación con la historia que se nos cuenta: el investigador puede actuar como un mero comentador o ir más allá e intentar añadir un carácter contextual a la historia que se está contando. En la primera opción el investigador construye el texto dándole un valor 
preeminente a la voz del protagonista. De este modo, se comenta la experiencia utilizando un giro narrativo en el que se dice lo mismo que la persona colaboradora pero con otras palabras. La segunda propuesta trata de poner la voz del entrevistado en contexto para facilitar así la comprensión del sentido de los comentarios aportados. La elección de cualquiera de estas opciones viene condicionada, entre otros factores, por la capacidad narrativa del investigador y su conocimiento del contexto sobre el que transcurre la historia.

- La tematización y el análisis: determina el enfoque conceptual y político de la investigación. Así pues, en la medida de lo posible, debemos destacar los comentarios que nos permitan constituir la posición subjetiva o identitaria del colaborador. En esta cuestión, Pamphilon (1999) describe algunas de las posiciones que puede adoptar el investigador y los puntos de atención sobre los que debe centrarse a la hora de realizar el análisis de las HdV (tabla 13):

Tabla 13. Posibles enfoques del investigador al realizar Historias de Vida (Pamphilon, 1999).

\begin{tabular}{cl}
\hline Macro-zoom & $\begin{array}{l}\text { El foco se localiza en los discursos dominantes, la forma narrativa y el efecto cohorte de edad } \\
\text { (generacional) al que pertenece la persona sobre la que se construye la HdV. }\end{array}$ \\
\hline Meso-zoom & Presta atención al proceso narrativo, los temas de la narración y las frases clave. \\
\hline Micro-zoom & Atiende los aspectos orales del relato, en particular las pausas y las emociones. \\
\hline $\begin{array}{c}\text { Zoom } \\
\text { interaccional }\end{array}$ & $\begin{array}{l}\text { Se centra en la dinámica entre el investigador y el entrevistado, mirando de manera especial } \\
\text { las transacciones y las reacciones de ambos durante la entrevista. }\end{array}$ \\
\hline
\end{tabular}

- Convertir el relato biográfico en historia de vida: esta acción supone, como ya se ha señalado, pasar del relato de vida (life story) a la HdV (life history). En este tránsito, la posición del investigador es fundamental. Por tanto, además de dominar la técnica biográfica y las problemáticas a tratar, debe establecer una estrategia de análisis reflexiva describiendo, no solo dónde se construye la historia, sino también las decisiones que va tomando en el transcurso de la misma.

- Construir una relación: para emplear adecuadamente este tipo de investigación debemos construir, establecer y mantener una estrecha relación entre el investigador y el entrevistado durante todo el proceso a realizar. Esta premisa dificulta, en gran medida, encontrar colaboradores con los que trabajar pues supone unos niveles de vinculación y exposición considerablemente elevados.

- Una consideración que no es marginal: es recomendable que el investigador se posicione dentro de una visión epistemológica y política que le permita asumir que es posible investigar a partir de la construcción de relatos, ha de tener la suficiente empatía para entrar en un proceso de negociación y de construcción de un relato sobre y con otra persona, debe poseer un amplio conocimiento de los contextos por los que transitan las historias para poder establecer relaciones con los comentarios del colaborador y tiene que ser capaz de escribir la $\mathrm{HdV}$ de forma que el relato refleje la experiencia del colaborador consiguiendo también implicar al lector. 
Tras reflexionar sobre estas problemáticas debemos apuntar que, teniendo en cuenta la naturaleza y características de nuestro trabajo, hemos decidido situarnos en un enfoque de mesozoom a la hora de realizar las HdV, pues consideramos que es el que más se ajusta a las necesidades de esta investigación.

Otro problema habitual a la hora de hacer HdV es considerar que implica, obligatoriamente, el estudio completo de la vida de una persona. No obstante, "la expresión historia de vida se refiere a los resultados de un modelo de investigación que consiste en recoger los relatos de un individuo sobre su vida o sobre algún aspecto especial de ella" (Corradi, 1991, p. 106). De este modo, entendemos que también pueden centrarse, únicamente, en algún momento o experiencia particular de la vida del investigado. Por todo lo expuesto, es importante valorar adecuadamente todas estas cuestiones para evitar posibles problemas o conflictos metodológicos a la hora de realizar las HdV.

Aclarado en qué consiste la investigación basada en $\mathrm{HdV}$, y resaltado el valor de esa información contextual y personal, tan importante en los proyectos de APS, consideramos que dicha metodología es la elección apropiada para desarrollar nuestro trabajo, ya que nos permitirá explorar las experiencias personales del alumnado participante. Por ello, a continuación pasamos a revisar la relación existente entre las $\mathrm{HdV}$ y el campo de conocimiento que nos ocupa, la EF.

A pesar de su rápida expansión y su creciente cuerpo teórico y metodológico en las ciencias sociales, los estudios de corte narrativo como las $\mathrm{HdV}$ apenas han tenido repercusión en la EF y las Ciencias del Deporte, por lo que todavía se puede considerar como un área de producción emergente (Devís y Sparkes, 2004; López, García-Peñuela, Pérez, López y Monjas, 2004; Sparkes, 2003; Sparkes y Devís, 2008). Pese a ello, podemos destacar la figura de Andrew Sparkes como uno de los autores más prolíficos en esta materia, defendiendo y promoviendo el uso de las HdV como un medio para comprender la forma en que los docentes de EF y los deportistas construyen/reconstruyen la relación de su identidad corporal a lo largo del tiempo en unas determinadas circunstancias sociales, históricas, políticas y económicas (Sparkes, 1993, 1994a, 1994b; Sparkes y Templin, 1992). Este autor plantea que el análisis narrativo de las HdV puede abordarse desde las siguientes perspectivas (Sparkes, 2003):

- Análisis paradigmático: trata de examinar las similitudes y diferencias temáticas existentes en la narración. La mayor virtud de esta perspectiva de análisis reside en su capacidad para desarrollar un conocimiento global sobre los temas centrales que construyen el contenido de los relatos. Es la estrategia de análisis más común.

- Análisis holístico de contenido: se sirve del relato en su conjunto para compararlo individualmente con las diferentes secciones del mismo. De este modo, el investigador debe analizar el significado de cada una de las secciones por separado en relación con el contenido que emerge del resto de la historia.

- Análisis holístico de la estructura formal: esta perspectiva asume que los aspectos formales de la estructura narrativa expresan, además del propio relato, otros contenidos interesantes como la identidad, las percepciones y los valores del narrador. Así pues, analizan la estructura 
del relato para descubrir la construcción que el colaborador hace respecto a la evolución de su experiencia. De este modo, podemos valorar la progresión del argumento de la narración a lo largo del tiempo, pudiendo ser progresiva, regresiva o estable.

- Análisis de las prácticas narrativas: se centra en los aspectos formales de las diferentes secciones o categorías del relato para valorar la coherencia del mismo. La coherencia de un relato de vida no debe ser considerada como algo natural sino como un logro de la negociación entre entrevistador y entrevistado. Así pues, la coherencia de un relato viene determinada por una construcción inteligente e ingeniosa de la información que contiene.

Como podemos ver, estas perspectivas de análisis son totalmente compatibles con el planteamiento expuesto por Demazière y Dubar (1997). Igualmente, el propio autor considera interesante la posibilidad de utilizar una estrategia de análisis mixta que emplee una combinación de las diferentes alternativas propuestas. Por otra parte, Pérez, Devís, Smith y Sparkes (2011) destacan las utilidades y beneficios que aportan las $\mathrm{HdV}$, entre otras estrategias de investigación narrativa, al ámbito de la EF y el deporte. A continuación, en la tabla 14, presentamos los aspectos más destacados:

Tabla 14. Beneficios y utilidades de la investigación narrativa en la Educación Física y el Deporte (Pérez et al., 2011).

Supone una alternativa a los enfoques dominantes en la investigación de la actividad física y el deporte. Con ello, ofrece otra forma de comprender diversas experiencias corporales (lesiones, enfermedades, crecimiento, envejecimiento, etc.) y cómo las personas relacionadas con la práctica de actividad física y deportiva componen los significados de esas experiencias.

Enfatiza la importancia del componente relacional de cuestiones importantes en la práctica de la actividad física y el deporte (autoestima, percepción de la imagen corporal, salud física y mental, práctica de ejercicio físico, procesos de enseñanza, procesos de interacción social, dinámica de grupos, etc.) ayudando a comprender la forma en que las personas construyen/reconstruyen su identidad en múltiples contextos.

Permite acceder al mundo personal del profesorado, alumnado, deportistas y otras personas participantes en actividades físicas y deportivas. De este modo, se desvelan nuevas historias y se ofrecen nuevas interpretaciones sobre cómo se experimentan y se construyen las emociones y sentimientos derivados de la práctica físico-deportiva a nivel personal, colectivo y social.

Amplía los recursos narrativos disponibles de las personas vinculadas con la actividad física y el deporte, en distintas temáticas como género, etnia, clase social, etc., en la construcción de narrativas sobre la EF, el rendimiento deportivo o la práctica de actividad física saludable.

Ayuda a comprender la construcción de la identidad corporal a lo largo del tiempo, el espacio y los distintos contextos socioculturales por los que transita. De esta manera puede captarse la naturaleza y evolución de los distintos ciclos vitales (desarrollo profesional de los docentes, abandono de la práctica deportiva profesional, relación de los jóvenes deportistas con sus experiencias y expectativas, etc.) y también puede ofrecer interpretaciones sobre cómo se estructura narrativamente el tiempo en aspectos vinculados con la corporeidad y la práctica profesional.

Ofrece la posibilidad de abordar el estudio de la EF, la actividad física y el deporte entendiendo el cuerpo como una experiencia biológica y psicosocial vivida. Analizando los relatos, contados sobre y desde el cuerpo, podemos comprender mejor la vida del protagonista de la historia y entender cómo las prácticas sociales afectan a sus experiencias corporales, gratificantes o negativas (euforia, control corporal, rendimiento deportivo, estrés, ansiedad, depresión, etc.).

Concede una importancia explícita a la escritura y la representación de los resultados de la investigación narrativa en el ámbito de la actividad física y el deporte. Con ello, destaca las implicaciones teóricas, analíticas y éticas que el investigador debe considerar a la hora de comunicarse desde cualquier estrategia narrativa. 
Sirve como herramienta de reflexión en diversos campos de las ciencias de la actividad física y el deporte. El potencial de las historias para inspirar, motivar y persuadir confiere a la investigación narrativa la posibilidad de ofrecer respuestas alternativas a retos específicos, especialmente cuando nos enfrentamos a situaciones nuevas o conflictivas.

Coincidiendo con estos autores, consideramos que la investigación mediante HdV nos ayudará a comprender la dimensión relacional, el mundo personal y profesional y el fundamento sociocultural de las vivencias de nuestros colaboradores a lo largo de la experiencia propuesta. Este hecho queda patente al repasar la bibliografía sobre estudios de HdV en el ámbito de la EF y el deporte, a continuación destacamos algunos de estos trabajos.

Una de las líneas de investigación más prolíficas en esta materia se centra en la construcción de la identidad de los docentes de EF. Aldous y Brown (2010) exploran la dinámica sociológica de la transición pedagógica que se produce tras el paso de dos profesores de EF recién titulados por sus primeros puestos de trabajo. Dowling (1998) revela el significado individual de desarrollar una carrera profesional como profesor de EF en Noruega. Dowling (2001) estudia los problemas de socialización de una docente a través de su experiencia individual dentro de unas estructuras socioeconómicas y políticas más amplias. Phoenix y Sparkes (2007) investigan la influencia de las HdV en la percepción de auto-envejecimiento entre los diferentes miembros de un grupo de jóvenes. Pissanos y Allison (1996) analizan los efectos del proceso de socialización en las percepciones y acciones de un experimentado maestro de EF en relación con el aprendizaje permanente. Templin, Sparkes, Grant y Schempp (1994) ponen de manifiesto la importancia del contexto social y los diferentes eventos de la vida de un profesor/entrenador veterano en el devenir de su carrera profesional. Thorburn (2011) examina las decepciones profesionales de un docente de EF escocés tras casi cuarenta años de carrera en un mismo centro educativo.

Otro campo de estudio habitual es la influencia del género en el ámbito de la EF. Allin y Humberstone (2006) valoran la visión de la carrera profesional y la influencia del género en el desarrollo de los monitores de actividades físicas al aire libre, mostrando cómo toman decisiones en base a sus contextos socio-culturales y estructurales. Brown (1999) analiza la importancia social de la identidad masculina en la reproducción del modelo masculino dominante en la EF y el deporte escolar. Brown y Evans (2004) exploran la implicación de los profesores universitarios de EF en la construcción social de las relaciones de género en la enseñanza de la EF y deportiva. Sykes (1998, 2001a) destaca la aparición de silencios homofóbicos en las HdV de seis profesoras de EF lesbianas y heterosexuales. Sykes (2001b) estudia la construcción social de la sexualidad femenina dentro de la EF a través de la HdV de dos profesoras. Sykes y Goldstein (2004) utilizan las HdV de 8 profesores de EF homosexuales para valorar la homofobia en los programas de formación del profesorado. Wedgwood (2005) investiga el papel de un entrenador de futbol australiano en la reproducción del rol masculino dominante en el ámbito de la EF y el deporte escolar. 
También existen trabajos que abordan aspectos propios de la EF como área de conocimiento. Fry (1997) examina la influencia de las relaciones de poder y las acciones políticas en la implementación de una nueva asignatura de la EF y la salud a través de la HdV de un profesor. Keay (2006) valora la importancia del aprendizaje colaborativo en el desarrollo profesional de los docentes de EF en los primeros años de su carrera profesional. Rich (2003) estudia cómo un grupo de 10 profesoras de EF recién tituladas abordan la baja participación de las niñas en una clase de EF. Schempp (1993) describe las fuentes de información y la toma de decisiones pedagógicas utilizadas por un profesor de EF para satisfacer las demandas de un instituto público. Sparkes, Templin y Schempp (1993) exponen las HdV de varios profesores de EF con el fin de valorar los métodos de enseñanza individuales dentro de este campo.

Otras líneas de trabajo reseñables estudian cuestiones como la discapacidad o la marginación dentro de la EF. Duarte, Torres y Nieto (2010) repasan la vida de una deportista paralímpica para comprobar cómo el deporte puede ser un importante medio para transformar la vida de una persona con discapacidad. Rees, Smith y Sparkes (2003) investigan la influencia del apoyo social en la vida de 6 hombres que han sufrido una lesión medular practicando deporte. Cazers (2009) aborda la HdV de tres profesores de EF para conocer la forma en que superaron la marginación a la que fueron sometidos en sus carreras docentes. Cazers y Curtner-Smith (2013) investigan la marginación sufrida por un profesor de EF afroamericano de la universidad de Alabama por la propia sociedad sureña. Estos mismos también estudian la marginación experimentada por una profesora universitaria de EF, en lo referente al nivel de habilidad motriz, por padecer ciertas limitaciones físicas (Cazers y Curtner-Smith, 2014).

Como podemos comprobar, la mayor parte de estos trabajos se han realizado en la sociedad americana, no obstante, también destacan algunos trabajos realizados en nuestro país: Castillo y Sáenz-López (2007) investigan los hábitos de práctica de actividad física de cuatro alumnas de la Universidad de Huelva con la intención de conocer la relación con sus diferentes estilos de vida, Gallego (2008) estudia la situación de diez mujeres con distintos niveles de participación en actividades físicas y deportivas, López et al. (2004) emplean las HdV como punto de partida para comprender el desarrollo de procesos críticos y reflexivos en la formación del profesorado de EF, Pascual (2003) analiza su propia HdV para explicar las circunstancias y el contexto de su desarrollo personal y profesional como docente en la formación de profesores de EF y Torres y Lorenzo (2004) utilizan las HdV para destacar el valor formativo de un club deportivo, como contexto de animación sociocultural, para promover valores personales y sociales entre la población. Pese a ello, los únicos estudios encontrados que utilizan la metodología de las HdV para investigar los efectos de la aplicación del APS en el ámbito de la EF en nuestra sociedad, son los trabajos preliminares de la presente tesis (Capella, Gil, Chiva y Corbatón, 2015; Capella et al., 2014; Capella, Gil, Martí y Chiva, 2015). Esto nos lleva a la conclusión de que debemos seguir profundizando en esta temática, destacando la importancia de este trabajo.

Terminamos este apartado valorando las HdV como una estrategia de estudio muy útil para investigar los efectos de la aplicación de proyectos educativos de APS en el ámbito de la EF, ya que 
nos permiten adentrarnos en el terreno de los sentimientos y las emociones, tan importantes en ambos procesos, algo que ya señalaban Dowling (1996), Rovegno y Bandhauer (1997) y Devís y Sparkes (1999), indicando que gracias a la irrupción de las HdV se ha ofrecido un lugar privilegiado a las emociones en los procesos de investigación e innovación educativa en el área de la EF. Por otra parte, las HdV también recogen la información contextual necesaria para ayudarnos a comprender las experiencias vividas por el alumnado a lo largo del programa educativo.

Las ideas principales que hemos tratado a lo largo de este apartado indican que:

1. Las HdV son una metodología de investigación cualitativa perteneciente al ámbito biográfico que se caracteriza, principalmente, por incluir las interpretaciones y aportaciones del investigador.

2. Los pasos a seguir a la hora de realizar una HdV son: etapa inicial, encuesta, registro, transcripción y elaboración de los relatos, análisis e interpretación, y presentación y publicación de la HdV.

3. Al elaborar una HdV debemos determinar la posición desde la que se realiza el análisis y la interpretación, contextualizar social y culturalmente la información y resolver los problemas que puedan surgir durante su elaboración.

4. La investigación mediante $\mathrm{HdV}$ no supone, obligatoriamente, el estudio de toda la vida de una persona, pudiendo centrarse exclusivamente en alguna experiencia o momento concreto.

5. El uso de las HdV en la EF y las Ciencias del Deporte aún es incipiente, pese a ello diversos trabajos destacan las utilidades, beneficios y recomendaciones de su utilización en esta materia.

6. Los trabajos previos a la realización de esta tesis representan los únicos antecedentes respecto al uso de las HdV para investigar los efectos del APS en el campo de la EF en nuestro contexto social.

En el siguiente capítulo abordaremos el concepto de emprendimiento centrándonos especialmente en su vertiente social, sus antecedentes investigadores, las características y rasgos personales del emprendedor social, y, finalmente, la Responsabilidad Social Universitaria como posible marco de implantación. 

3. Emprendimiento Socialy Responsabilidad Social Universitaria 



\subsection{Concepto de Emprendimiento y peculiaridades de su vertiente social}

Partiendo desde una conceptualización básica nos remitimos a la Real Academia Española $(\mathrm{RAE})^{14}$ donde se indica que el emprendimiento es la "acción y efecto de emprender" o una "cualidad de emprendedor". Profundizando en estos conceptos comprobamos que emprendedor es aquel "que emprende con resolución acciones dificultosas o azarosas" y que emprender supone "cometer y comenzar una obra, un negocio, un empeño, especialmente si encierran dificultad o peligro". Como podemos comprobar, ya en estas definiciones tan básicas aparece el término negocio asociado al emprendimiento.

Para Lanzas, Lanzas y Castaño (2006) el emprendimiento hace referencia a la capacidad de generar ideas, identificar oportunidades y definir escenarios adecuados para convertirlas en realidad, teniendo una relación directa con la capacidad de adaptarse a diferentes equipos de trabajo, además de ser capaz de generar nuevos equipos y liderarlos. Además de remarcar la importancia del liderazgo, Aliaga y Schalk (2010) añaden la autonomía y la capacidad de decisión como elementos básicos del emprendimiento. Por otra parte, González y Zúñiga (2011) destacan la identificación de oportunidades, el liderazgo y la organización de recursos como características del emprendimiento que tienen el objetivo de crear valor y responder a la necesidad de fomentar el desarrollo económico. Todas estas aportaciones están enfocadas desde una perspectiva empresarial y se centran en generar beneficios económicos a través de la creación de nuevas empresas y negocios de éxito. Esto se debe a la fuerte influencia anglosajona, donde se hace referencia al empresario y al emprendedor con el mismo término, entrepreneur.

No obstante, como nos señala Velasco (2012), debemos resaltar que es posible ser emprendedor estimulando la búsqueda y el desarrollo de nuevas ideas, persiguiendo tanto objetivos individuales como sociales sin necesidad de responder a incentivos económicos. Por otra parte, Selamé (1999) aporta una dimensión más amplia al concepto de emprendimiento como el manejo del riesgo, la creatividad, la innovación, la autoconfianza y la acción a través de un sistema organizado de relaciones interpersonales, combinando recursos orientados al logro de un fin determinado, generando un nuevo valor, producto, bien o servicio. Con una visión similar, Valls, Villa, Martínez y Hernando (2009) lo entienden como: "la capacidad de iniciar, crear y poner en marcha un proyecto a través de la identificación de ideas y oportunidades, analizando los factores exógenos (económicos, sociales, ambientales y políticos) así como los endógenos (capacidad de disponer de personas así como de recursos físicos y financieros)" (p. 6).

La bibliografía citada nos ayuda a comprender que el emprendimiento es un fenómeno que se puede abordar desde diferentes perspectivas: económica, política, social, etc. Como ya hemos comentado, nuestro interés se centra en el Emprendimiento Social (en adelante ES) y en las

\footnotetext{
${ }^{14}$ http://www.rae.es/
} 
posibilidades que la educación ofrece para fomentarlo. Debemos señalar que, a día de hoy, todavía no existe un criterio unificado sobre la definición y limitaciones del ámbito del ES (Bacq y Janssen, 2011; Choi y Majumdar, 2014; Haugh, 2005; Mair y Martí, 2006; Martin y Osberg, 2007; Mort, Weerawardena y Carnegie, 2003; Roberts y Woods, 2005; Short, Moss y Lumpkin, 2009; Tan, Williams y Tan, 2005; Weerawardena y Mort, 2006). Por ello, a continuación abordaremos algunas cuestiones clave sobre el ES con la intención de esclarecer la temática y el ámbito que abarca.

Aunque el concepto de ES puede parecer novedoso, el fenómeno no lo es y, pese a no utilizar específicamente dicho término, para Dees (1998b) siempre han habido emprendedores sociales. El término emprendedor se originó en la economía francesa del siglo XVII, y se utilizaba para identificar a los individuos audaces que estimulaban el progreso económico mediante la búsqueda de nuevas y mejores formas de hacer las cosas, desplazando los recursos económicos de un área de baja productividad a una zona de mayor rendimiento (Dees, 1998b; Mort et al., 2003).

Pese al importante crecimiento de la literatura en las dos últimas décadas, Mort et al. (2003) señalan que esta sigue presentándose de forma difusa y fragmentada. Buen ejemplo de ello es el hecho de que diversos autores plantean definiciones sobre el ES que, al estar influenciadas por su propia perspectiva, no son utilizadas por otros autores. También cabe destacar que el ES se ha abordado desde diferentes dominios y con perspectivas distintas, por lo que carece de un enfoque único y coherente, poniendo así de manifiesto una deficiencia significativa en la literatura sobre este campo. Al mismo tiempo, se ha intentado avanzar hacia una conceptualización de lo que se identifica con el ES sin determinar el entorno en el que opera dicha actividad (Weerawardena y Mort, 2006), aumentando con ello la incertidumbre conceptual.

Siguiendo a Peredo y McLean (2006), comprobamos que pese a no existir un entendimiento preciso sobre esta actividad, el ES goza de una notable popularidad, tanto en el ámbito académico como en el empresarial, a través de la publicación de numerosos libros y artículos acerca de las características de las organizaciones que lo practican. Sin embargo, el ES aún no ha tenido el impacto deseado debido, en parte, a la ausencia de una definición clara de este concepto, por lo que aún tiene mucho potencial por ofrecer (Massetti, 2008). Esta disparidad terminológica no solo limita el impacto del ES, sino que también dificulta el establecimiento de un campo de estudio legítimo (Short, Payne, y Ketchen, 2008) y, por consiguiente, profundizar en el conocimiento de los antecedentes y consecuencias del ES (Short et al., 2009).

Por otra parte, el fenómeno del ES se ha ido desarrollando al mismo tiempo en diversas partes del planeta. Esto, según Bacq y Janssen (2011), ha provocado la aparición de varias corrientes de pensamiento y formas de entenderlo, debido a las diferentes concepciones del capitalismo y el papel del gobierno en las comunidades en las que se ha establecido. Este suceso pone de manifiesto la importancia del entorno en el ES, pues las proposiciones relativas en cuanto a la forma de definirlo y entenderlo se basan en los aspectos geográficos y temáticos en los que se ha desarrollado. 
Pese a lo expuesto hasta ahora, Mair y Martí (2006) señalan que uno de los temas más controvertidos es determinar si el ES es un campo de investigación independiente, pues muchos estudios sobre el ES han adoptado los conceptos y la terminología establecida en la literatura sobre el emprendimiento comercial. Además, cabe destacar en este punto la preocupación manifestada por algunos autores acerca del uso indiscriminado del término ES, considerando que esto podría socavar su significado y potencial importancia (Martin y Osberg, 2007).

Tras comprobar que no existe un criterio unificado que defina el ES, a continuación exponemos algunas de las conceptualizaciones más habituales sobre dicho fenómeno. Así pues, según Dees (1998b), la mayor parte de trabajos lo vinculan exclusivamente con organizaciones sin ánimo de lucro generadas a partir de empresas comerciales, otros lo utilizan para describir cualquier organización sin fines lucrativos, mientras hay quienes lo utilizan para referirse a las empresas comerciales que integran la responsabilidad social en sus operaciones. El mismo autor señala que el ES describe un conjunto de comportamientos excepcionales, y que estos deben ser alentados y recompensados en aquellos que tienen las capacidades y el temperamento adecuados para realizar este tipo de actividades.

Después de revisar las diferentes formas de conceptualizar el ES, tanto Tan et al. (2005) como Alvord, Brown y Letts (2004), indican que históricamente existen tres enfoques predominantes: como combinación de empresas comerciales con un impacto social (Emerson y Twersky, 1996), como innovación aplicada para provocar un cambio social (Dees, 1998a) y como efecto catalizador para la transformación social. No obstante, también hay otras concepciones menos presentes que limitan su visión al ámbito de los negocios, los servicios directos y las alianzas catalizadoras (Boschee, 1995).

Siguiendo un proceso de análisis similar, Mair y Martí (2006) consideran que un primer grupo de investigadores entiende el ES como las iniciativas sin ánimo de lucro en la búsqueda de estrategias de financiación alternativas o planes de gestión para crear valor social (Austin, Stevenson y WeiSkillern, 2003; Boschee, 1998), un segundo grupo lo identifica con la práctica socialmente responsable de las empresas comerciales que participan en asociaciones vinculadas a diversos sectores (Sagawa y Segal, 2000; Waddock, 1988), y un tercer grupo considera que el ES es un medio para aliviar los problemas sociales y catalizar la transformación social (Alvord et al., 2004). Tras este análisis, los autores identifican el ES como una forma diferente de emprendimiento que concede una mayor prioridad a fomentar el valor social y el desarrollo frente a la captación de valor económico.

Debido a la variedad de conceptualizaciones existentes, el ES puede expresarse en una amplia gama de actividades económicas, educativas, de investigación, de bienestar social, sociales y espirituales, realizadas por diferentes tipos de organizaciones (Leadbeater, 1997). Como respuesta a esta gran cantidad de posibilidades, Weerawardena y Mort (2006) intentan conceptualizar el ES en varios contextos, incluyendo el sector público, las organizaciones comunitarias, las organizaciones de acción social y las organizaciones benéficas. Así pues, según estos autores, la 
mayor parte de la literatura se ha centrado en las organizaciones no gubernamentales sin ánimo de lucro; no obstante, algunos investigadores sugieren que también pueden considerarse como ES las empresas sociales que llevan a cabo actividades con fines lucrativos para apoyar otras actividades no lucrativas (Cook, Dodds y Mitchell, 2003; Wallace, 1999) o actividades lucrativas que han tomado algún tipo de acción innovadora hacia la construcción de capital social (Canadian Centre for Social Entrepreneurship, 2001; Thompson, Alvy y Lees, 2000).

No obstante, pese a la dificultad manifiesta de conceptualizar el ES, diversos autores se aventuran a definir este complejo fenómeno. Así pues, la propuesta de Peredo y McLean (2006), entendida con la flexibilidad apropiada, concluye que el ES se ejerce cuando una persona o grupo tiene el objetivo de crear valor social, ya sea exclusivamente o por lo menos de alguna manera prominente, mostrando una capacidad para reconocer y aprovechar oportunidades, utilizando la innovación, que va desde la pura invención hasta la simple adaptación de un elemento novedoso, estando dispuesto a aceptar un grado de riesgo superior a la media, y siendo inusualmente ingenioso y relativamente inalterable a la hora de afrontar los escasos recursos disponibles para afrontar su proyecto social. Tras exponer esta idea, los autores señalan que todas estas características pueden aparecer en mayor o menor grado y que algunas deben presentarse en un grado mayor al promedio, pero que no hay forma de indicar exactamente el punto en el que se alcanza el estándar de valoración.

Por otra parte, Martin y Osberg (2007) definen el ES como aquel que, tras identificar un equilibrio estable pero intrínsecamente injusto que provoca la exclusión, la marginación o el sufrimiento de un segmento de la humanidad que carece de los medios económicos o influencia política para lograr alguna transformación en su propio beneficio, encuentra una oportunidad para desarrollar una propuesta de valor social que pone en juego la inspiración, la creatividad, la acción directa, el valor y la fortaleza, cuestionando así la hegemonía del estado estable, proporcionando un nuevo equilibrio estable que libera el potencial limitado o alivia el sufrimiento del grupo al que va dirigido, y asegurando un futuro mejor para dicho colectivo e incluso para la sociedad en general.

Sin embargo, también existen definiciones menos complejas que señalan que el ES es "el proceso de identificar, evaluar y aprovechar las oportunidades destinadas a la creación de valor social a través de actividades comerciales, basadas en actividades de mercado y el uso de una amplia gama de recursos" (Bacq y Janssen, 2011, p. 388).

Otra estrategia habitual para intentar conceptualizar el ES ha sido compararlo con su homólogo comercial. Así pues, Roberts y Woods (2005) indican que muchos de los atributos y talentos de sendos emprendedores son similares, señalando que ambos son innovadores y poseen altas cantidades de energía, tenacidad y resiliencia, y están impulsados por un ideal que siguen de modo apasionado y comprometido. Según estos autores, donde difieren es en su motivación y propósito, pues mientras los emprendedores sociales están motivados para hacer frente a una necesidad social, los emprendedores comerciales están motivados por una necesidad financiera. Así pues, 
como podemos ver en la tabla 15, analizan y comparan la visión académica y profesional de ambos tipos de emprendimiento, sintetizando su foco, interés principal y rasgos definitorios.

Tabla 15. Perspectivas del Emprendimiento (Roberts y Woods, 2005).

\begin{tabular}{|c|c|c|c|}
\hline PERSPECTIVA & FOCO & INTERÉS PRINCIPAL & RASGOS DEFINITORIOS \\
\hline $\begin{array}{l}\text { Académicos sobre el } \\
\text { emprendimiento } \\
\text { convencional }\end{array}$ & $\begin{array}{l}\text { Actividad en la esfera } \\
\text { económica }\end{array}$ & $\begin{array}{l}\text { La conexión entre una } \\
\text { oportunidad y el } \\
\text { emprendedor, se centra en } \\
\text { aprovechar oportunidades }\end{array}$ & $\begin{array}{c}\text { Cómo, a través de quién y con qué } \\
\text { oportunidades y efectos se crea un futuro } \\
\text { mejor y se descubren, evalúan y explotan } \\
\text { los servicios }\end{array}$ \\
\hline $\begin{array}{l}\text { Profesionales sobre } \\
\text { el emprendimiento } \\
\text { convencional }\end{array}$ & $\begin{array}{l}\text { Actividad en la esfera } \\
\text { económica }\end{array}$ & $\begin{array}{c}\text { Los atributos de los } \\
\text { profesionales y el proceso que } \\
\text { siguen para explotar } \\
\text { oportunidades }\end{array}$ & $\begin{array}{l}\text { Se habla de los emprendedores que están } \\
\text { ahí fuera haciéndolo, marcando una } \\
\text { diferencia en el mercado }\end{array}$ \\
\hline $\begin{array}{l}\text { Académicos sobre el } \\
\text { ES }\end{array}$ & $\begin{array}{l}\text { Actividad en la esfera } \\
\text { social basada en los } \\
\text { principios del } \\
\text { emprendimiento } \\
\text { convencional } \\
\end{array}$ & $\begin{array}{l}\text { La conexión entre el } \\
\text { emprendedor y una } \\
\text { oportunidad para cambiar la } \\
\text { sociedad }\end{array}$ & $\begin{array}{l}\text { Construcción, evaluación y seguimiento de } \\
\text { oportunidades para el cambio social }\end{array}$ \\
\hline $\begin{array}{l}\text { Profesionales sobre } \\
\text { el ES }\end{array}$ & $\begin{array}{l}\text { Actividad en la esfera } \\
\text { social basada en las } \\
\text { acciones de los } \\
\text { profesionales }\end{array}$ & $\begin{array}{l}\text { Los atributos de los } \\
\text { profesionales y el proceso que } \\
\text { siguen para cambiar la } \\
\text { sociedad }\end{array}$ & $\begin{array}{l}\text { Gente incansable con nuevas ideas para } \\
\text { abordar los principales problemas. No } \\
\text { aceptarán un no por respuesta y no se } \\
\text { darán por vencidos hasta difundir sus ideas } \\
\text { tan lejos como les sea posible }\end{array}$ \\
\hline
\end{tabular}

Como podemos ver, estos autores determinan que, desde el punto de vista académico, las definiciones del ES se basan en el proceso seguido o en los resultados que se logran al aplicarlo. Los académicos suelen estar de acuerdo en que el resultado a lograr es responder a las necesidades sociales, pero llegar a un consenso de opinión en cuanto al procedimiento es algo más problemático. Desde la visión de los profesionales, las definiciones se centran en los atributos prácticos de los emprendedores sociales y en el proceso que siguen para cambiar la sociedad.

Por otra parte, Peredo y McLean (2006) abordan esta comparativa preguntándose ¿qué hace que el ES sea emprendimiento? Tras determinar que un emprendedor es "una persona que comienza u organiza una empresa comercial, especialmente cuando involucra riesgos financieros" (Barber, 1998, p. 467), los autores entienden que el elemento emprendedor en el ES se vincula estrechamente con las perspectivas y métodos de organización y gestión dirigidos hacia y por el mercado, algo que hereda del emprendimiento comercial. Sin embargo, la diferencia substancial entre estos dos tipos de emprendimiento radica en que uno pretende aplicarlo en la esfera comercial, mientras el otro lo hace en la social, destacando el valor social de sus contribuciones.

Otros autores consideran que la distinción fundamental entre el emprendimiento comercial y el social se encuentra en la propuesta de valor en sí mismo (Martin y Osberg, 2007). Teniendo en cuenta esta premisa, la propuesta de valor para el empresario se anticipa y se organiza para servir a los mercados que puedan asumir cómodamente el nuevo producto o servicio y, por lo tanto, está 
diseñado para crear beneficio financiero. Desde el principio, la expectativa es que el empresario y sus inversores obtengan algún beneficio financiero personal; sin embargo, el emprendedor social tiene como objetivo generar valor en beneficio de un segmento importante de la sociedad o de la sociedad en general. Esta propuesta de valor social se dirige a una población marginada, descuidada o desfavorecida que carece de los medios económicos o de la influencia política necesarios para lograrlo por su cuenta. No obstante, esto no significa que estas actividades rechacen, como regla general, la posibilidad de obtener beneficios a raíz de sus labores sociales.

Por último, Bacq y Janssen (2011) van más allá y presentan un doble análisis comparativo entre el ES y el comercial. El primer análisis lo realizan desde un punto de vista académico, considerando que ha habido tres similitudes en la evolución de ambos tipos de emprendimiento. La primera hace referencia a su potencial a desarrollar, pues se ha extendido entre los profesionales antes de llamar la atención de los investigadores. La segunda es la ausencia de un paradigma unificador, permitiendo así la proliferación de múltiples definiciones. Y, la última, hace referencia a su grado de madurez académica, encontrándose aún en una etapa infantil. No obstante, mientras el emprendimiento comercial ya es reconocido como campo académico (Bruyat y Julien, 2001) y tiene una comunidad científica con un importante cuerpo de investigación (McGrath, 2003), el ES sigue en una etapa de desarrollo primaria.

El segundo análisis comparativo realizado por estos autores se centra en la perspectiva utilizada para abordar ambos tipos de emprendimiento, pues se han percibido tanto desde un punto de vista funcional como indicativo (Casson, 1982). Según los autores, desde el punto de vista indicativo los estudiosos se han centrado en las características del emprendedor. De este modo, a pesar de los intentos por aislar a los emprendedores sociales estos comparten muchas características con los emprendedores comerciales, pues tienen el mismo enfoque a la hora de ver las oportunidades y la misma capacidad para convencer y capacitar a otros para que les ayuden a convertir sus ideas en realidad (Catford, 1998). Según Dees (1998a), los emprendedores sociales son una sub-especie de la familia de los emprendedores. Sin embargo, aunque hay una gran cantidad de similitudes entre el emprendedor social y el comercial, especialmente el liderazgo, la forma de ver y manejar las situaciones y el oportunismo, la principal diferencia entre ambos es que el emprendedor social tiene una visión o motivación socio-moral, algo que le gustaría resolver en el sector social, lo cual determina su enfoque y ambición emprendedora (Nicholls, 2008). Por ello, como ampliaremos a continuación, las acciones de los emprendedores sociales siempre estarán vinculadas al objetivo de crear valor social (Sharir y Lerner 2006). Siguiendo con este enfoque, Boschee y McClurg (2003) identifican otras dos importantes diferencias entre el emprendedor social y el comercial. Por un lado, las estrategias de ingresos de los emprendedores sociales están vinculadas directamente a su misión social, mientras que los esfuerzos de un emprendedor comercial solo pueden estar unidos a un problema social de una forma indirecta. Por otro lado, los emprendedores sociales están impulsados por una doble línea de acción, una mezcla de rentabilidad financiera y social, permitiendo así reinvertir los beneficios en la misión social. Como veremos más adelante, en esta tesis abordaremos el análisis de las características del emprendedor social de acuerdo a esta perspectiva indicativa. 
Desde el punto de vista funcional, algunos trabajos hacen hincapié en el lado innovador del ES en cuanto a la recopilación, uso y combinación de recursos en la construcción, y la evaluación y búsqueda de oportunidades en una perspectiva de transformación social (Roberts y Woods, 2005). Por otro lado, según Austin, Stevenson y Wei-Skillern (2006) la distinción entre el ES y el comercial no debe ser dicotómica sino continua. Por lo tanto, proponen un enfoque sistemático para comparar el ES y el comercial basado en cuatro variables diferenciadoras: pérdidas de mercado, misión, movilización de recursos y medición del rendimiento.

Teniendo en cuenta ambos análisis comparativos, Bacq y Janssen (2011) concluyen que las principales diferencias entre el ES y comercial confluyen en dos aspectos. En primer lugar buscan objetivos bien distintos, pues mientras el ES tiene una misión social explícita y central, el comercial tiene el objetivo de lucrarse. $Y$, en segundo lugar, mientras la mayor parte del beneficio económico generado por las actividades comerciales del ES es reinvertido en la misión social, el beneficio del emprendimiento comercial se distribuye entre los accionistas o se reinvierte en las actividades comerciales de la compañía. No obstante, pese estas diferencias, existen similitudes notables entre ambos tipos de emprendimiento en términos del proceso emprendedor, es decir, el reconocimiento de oportunidades, la innovación, el liderazgo, etc.

Como acabamos de ver, uno de los elementos distintivos del ES con respecto al comercial es su misión social. Según Weerawardena y Mort (2006) la misión social para las organizaciones de ES es explícita y central, por lo que al igual que una empresa con ánimo de lucro tiene el propósito de crear un valor económico superior para su clientela, el propósito principal del emprendedor social es la creación de un valor social superior para sus clientes (Dees, 1998a). Al mismo tiempo, estos autores plantean que la capacidad de un emprendedor social para atraer recursos, capital, trabajo, equipamiento, etc., en un mercado competitivo, es un buen indicador de que la empresa representa una alternativa más productiva del uso de estos recursos frente al resto de organizaciones contra las que compite. Por último, en cuanto a la financiación, argumentan que los emprendedores sociales buscan formas innovadoras para asegurar que sus empresas tengan acceso a dichos recursos, siempre y cuando estén creando valor social. Esto destaca el papel de la innovación en las organizaciones de ES (Borins, 2000), e identifica que la capacidad de innovación, la proactividad y asunción de riesgos son sus elementos centrales (Prabhu, 1999). Otros autores consideran que el ES es un proceso de creación de valor mediante la combinación de recursos, a través de formas novedosas, principalmente destinadas a explorar y explotar las oportunidades para crear valor social, fomentando el cambio social o el compromiso con las necesidades sociales (Mair y Martí, 2006).

Siguiendo un proceso similar al expuesto anteriormente, Peredo y McLean (2006) se plantean ¿qué hace que el ES sea social? Tras comprobar que existen diversas posturas al respecto, concluyen que, en un extremo están los que sostienen que los objetivos sociales deben ser la finalidad exclusiva del ES, otro posicionamiento considera válidas a aquellas empresas que no producen beneficios sociales por sí mismas, pero que apoyan otras actividades destinadas a hacerlo (Fowler, 2000) y, la última alternativa estima que la frontera entre las actividades sin ánimo de lucro 
y las lucrativas es vaga y porosa, permitiendo la posibilidad de lucrarse a través de estas entidades, siempre y cuando los fines sociales prevalezcan. Como podemos observar, todas estas opciones describen un continuo de posibilidades que determina la importancia del elemento social en el tipo de emprendimiento que estamos analizando.

Con el objetivo de establecer los límites de actuación de la misión social de este tipo de emprendimiento respecto a otras actividades de compromiso social meritorias, Martin y Osberg (2007) presentan el siguiente esquema, figura 1, con las diferentes formas puras de compromiso social. Así pues, dependiendo de la naturaleza de acción y de los resultados producidos, podemos distinguir prestación de servicio social, activismo social y ES. Nos obstante, estos autores también advierten que pueden existir algunas formas mixtas.

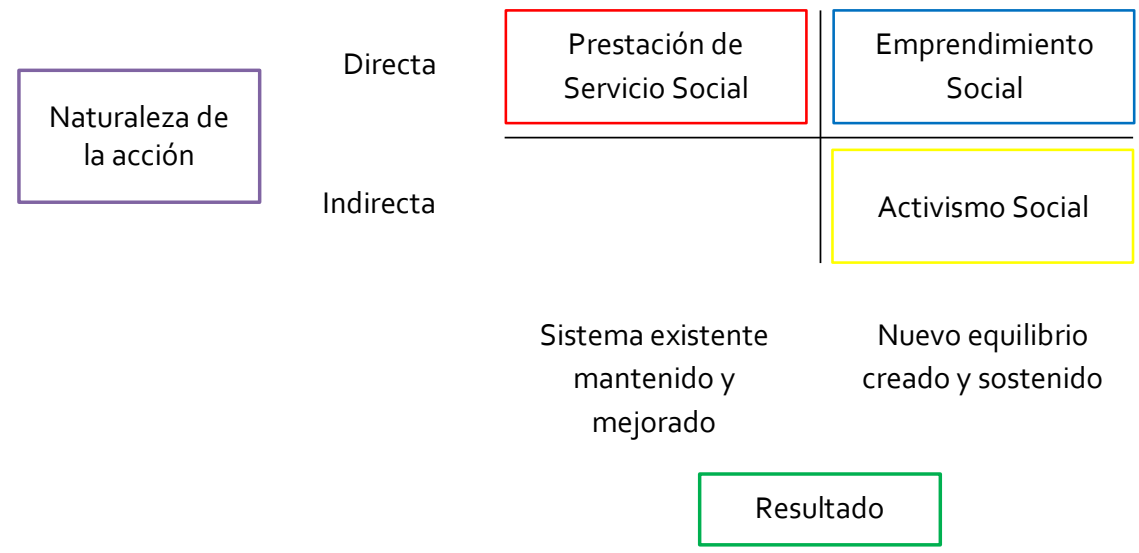

Figura 1. Formas puras de Compromiso Social (Martin y Osberg, 2007).

Otros autores nos informan de que los beneficios generados por la misión social de este tipo de emprendimiento pueden ser directos o indirectos (Tan et al., 2005). Los beneficios directos toman la forma de servicios, regalos y atención dirigida a un segmento de la sociedad, también pueden incluirse las instalaciones, becas y ayudas (asistencia), mientras los beneficios indirectos hacen referencia al empleo, ya que el proceso emprendedor puede implicar la contratación de un grupo específico de trabajadores.

No obstante, también existe cierta controversia en cuanto a la importancia de esta misión social. Por ejemplo, Roberts y Woods (2005) consideran oportuno señalar que el ES no es lo mismo que la caridad o la benevolencia e incluso que no tiene porqué ser necesariamente sin ánimo de lucro. Así pues, consideran que pese a existir una actitud benevolente, motivada por una necesidad de dar a los demás, el ES va más allá de esto. Estos autores opinan que hay muchas organizaciones caritativas que tienen una perspectiva de benevolencia similar pero que en el ES participa gente de negocios. En este sentido el ES podría ser visto como una idea o paradigma que tiene un lugar en cualquier negocio, ya sea en el sector del voluntariado como con fines de lucrativos. 
Otro aspecto por aclarar en cuanto al ES es el sector en el que actúa. Intentando resolver esta incertidumbre, Weerawardena y Mort (2006) discuten brevemente las conceptualizaciones existentes del ES para identificar que las áreas dominantes en las que se produce son el ámbito público y el privado sin ánimo de lucro. En el sector público se relaciona con el liderazgo de las organizaciones (Lewis, 1980) o el desarrollo de políticas de acción (Roberts y King, 1989). Sin embargo, el enfoque del ES en el ámbito privado sin ánimo de lucro es más amplio. En las organizaciones comunitarias se ha identificado con la mejora de la calidad de vida de los pobres y los desfavorecidos (Cornwall, 1998), facilitando así el desarrollo de la comunidad (Wallace, 1999). Dentro del contexto de la acción social se ha visto en términos de liderazgo catalizador, proporcionado cambios en las áreas de interés social, tanto en términos del área de interés como en las políticas públicas relacionadas con dicha área (Hibbert, Hogg, y Quinn, 2002; Waddock y Post, 1991). Finalmente, otros autores hacen hincapié en la diversidad de las iniciativas sociales y el impacto económico y social (Shaw, Shaw y Wilson, 2002); en definitiva, el logro de la misión social.

Según Short et al. (2009) las definiciones sobre el ES se han desarrollado principalmente desde tres ámbitos distintos: las actividades sin ánimo de lucro, las actividades con fines lucrativos y el sector público. Teniendo en cuenta este hecho, algunos autores lo limitan únicamente a las organizaciones sin ánimo de lucro (Lasprogata y Cotten, 2003). Otros consideran que hace referencia a empresas con fines lucrativos gestionadas por organizaciones sin ánimo de lucro (Wallace, 1999). También hay quienes lo describen como organizaciones que crean empresas a pérdidas (Baron, 2007), mientras otros lo equiparan a las actividades filantrópicas (Ostrander, 2007). Por último, algunos estudiosos abrazan definiciones más amplias, las cuales relacionan el ES con las personas $u$ organizaciones dedicadas a actividades empresariales con un objetivo social (Certo y Miller, 2008; Van de Ven, Sapienza y Villanueva, 2007).

Sin embargo, también existen visiones más abiertas pues, tras considerar las diferentes posibilidades del ES en cada sector, Roper y Cheney (2005) determinan que gran parte de las aplicaciones prácticas se realizan combinando los sectores público, privado y sin ánimo de lucro. Esto indica que el ES se encuentra en un punto común a todos ellos y pone de manifiesto la importancia de la capacidad de adaptación a la hora de desarrollarlo.

Tras comprobar la diversidad de conceptualizaciones existentes respecto al ES, Bacq y Janssen (2011) analizan las diferentes corrientes de pensamiento respecto a este fenómeno, información de gran utilidad ya que nos permitirá determinar las perspectivas dominantes. La revisión realizada se organiza en torno a las cuatro dimensiones del marco conceptual de Gartner (1985) para la descripción de la creación de empresas: el individuo, el proceso, la organización y el entorno. El análisis expone las diferencias y semejanzas entre los distintos planteamientos existentes, especialmente en las tres primeras dimensiones, ya que la cuarta dimensión viene reflejada por el contexto social en el que se haya desarrollado la corriente de pensamiento. Esta apreciación pone de manifiesto la importancia del entorno, algo que no debe ser ignorado a la hora estudiar este fenómeno. Tras analizar la literatura, los autores identifican tres corrientes de pensamiento básicas sobre el ES, dos en los EEUU y una en Europa: 
- La escuela de innovación social: hace hincapié en la importancia del emprendedor social como individuo y se centra en sus características.

- La escuela de la empresa social: afirma que este tipo de organizaciones sobreviven mediante la realización de actividades con fines de lucro, por lo que deben generar actividades para financiar la creación de valor social.

- La tradición europea: se acerca al ES mediante la creación de marcos jurídicos específicos para las empresas sociales. No obstante, los autores indican que también podrían coexistir otras corrientes de pensamiento en Europa.

Las principales conclusiones del análisis comparativo entre estas tres corrientes de pensamiento se comentan a continuación. Respecto al individuo, mientras la figura del emprendedor es el centro para la escuela de innovación social, en la escuela de la empresa social, la importancia del emprendedor es secundaria. Por otra parte, en la visión europea la atención se centra más bien en modelos colectivos y no tanto en sujetos individuales. En cuanto al proceso, la misión social está claramente reconocida como el principal objetivo del ES por las tres corrientes de pensamiento. No obstante, mientras la escuela de innovación social y la tradición europea requieren un vínculo directo entre la misión social de la empresa y sus actividades productivas, la escuela de la empresa social aboga por un vínculo más flexible. Por último, el análisis de la organización se centra en tres aspectos clave: la empresa, su forma legal y la distribución de beneficios. Para la tradición europea y la escuela de la empresa social la empresa es un elemento clave, mientras que para la escuela de innovación social es algo secundario. Cabe destacar en este punto que esta disparidad puede deberse a la propia controversia que suscita el concepto de empresa social, pues es probablemente el más controvertido en esta temática (Defourny y Nyssens, 2010). En cuanto a la forma legal, la escuela de la empresa social valora cualquier empresa que comercie con un propósito social y sin ánimo de lucro, mientras que la tradición europea indica algunas limitaciones en cuanto a la forma legal de este tipo de empresas. Por su parte, la escuela de innovación no tiene una idea clara en esta cuestión y considera que la elección de la forma legal debería hacerse en base a la naturaleza de las necesidades sociales a atender y la cantidad de recursos necesarios. Finalmente, la distribución de beneficios está casi totalmente prohibida por la escuela de la empresa social y parcialmente limitada en el enfoque de la tradición europea, con el fin de proteger la primacía de la misión social; en cambio, la escuela de innovación social no impone ninguna restricción.

Debemos señalar en este punto que el mayor número de fuentes bibliográficas encontradas en esta revisión de la literatura corresponden a la escuela de innovación social, lo que podría significar que es la corriente dominante en este ámbito. Por ello, más adelante nos posicionaremos en esta corriente de pensamiento para profundizar en el desarrollo de la presente tesis.

A la vista de la gran dificultad que supone delimitar la conceptualización del ES debido, en parte, a las diferentes corrientes de pensamiento existentes, debemos entender el ES desde una perspectiva más amplia. Para ello, Choi y Majumdar (2014) analizan este fenómeno desde la teoría de los conceptos esencialmente controvertidos, propuesta por Walter Bryce Gallie en 1956. En esta 
teoría, se sugiere que dichos conceptos comparten características específicas en siete condiciones clave: apreciación, complejidad interna, variabilidad descriptiva, carácter abierto, reconocimiento de usos diferenciados, ejemplo original y competencia progresiva. A continuación mostramos parte del análisis de los autores para poder entender sus posteriores conclusiones:

- Apreciación: hace referencia al significado o logro valioso acreditado. Según Dey (2006) la proliferación de narrativas sobre el ES representa una de las últimas tendencias en los discursos académicos, políticos y en los medios de comunicación, lo cual le atribuye una imagen positiva unánime. Por otra parte, Light (2009) considera el ES como uno de los términos más atractivos en el ámbito de la resolución de problemas por lo que, al utilizarlo, no solo describen propiedades específicas, sino que también se le atribuye un logro valioso.

- Complejidad interna: implica que todo su valor se atribuye a su conjunto. Varios autores reconocen esta situación en el ES, describiéndolo como un concepto multidimensional (Nicholls, 2008; Weerawardena y Mort, 2006) y un fenómeno con múltiples facetas (Bacq y Janssen, 2011). Tras revisar la bibliografía sobre esta cuestión, Choi y Majumdar (2014) plantean que los elementos a considerar en este apartado son:

- Creación de valor social: se considera un requisito previo al ES (Austin et al., 2006; Dees, 1998a; Peredo y McLean, 2006; Perrini y Vurro, 2006; Sharir y Lerner, 2006). Este aspecto ha sido abordado en las descripciones del ES vinculado a su misión social (Dees, 1998b; Lasprogata y Cotten, 2003; Mort et al., 2003; Nicholls, 2008; Seelos y Mair, 2005), la creación de riqueza social (Zahra, Gedajlovic, Neubaum y Shulman, 2009), la forma de hacer frente a las cuestiones y problemas sociales (Alvord et al., 2004; Bornstein, 2004; Light, 2006) y a la urgencia de ciertas necesidades sociales (Mair y Martí, 2006; Seelos y Mair, 2005).

- El emprendedor social: esta figura ha sido vista como un elemento central en el ES por muchos autores (Bornstein, 2004; Dees, 1998b; Leadbeater, 1997; Light, 2008; Roper y Cheney, 2005; Thompson, 2002; Thompson y Doherty, 2006; Waddock y Post, 1991).

- La organización del Emprendimiento Social: el marco organizativo del ES lo diferencia de otras iniciativas, menos estructuradas, dirigidas a provocar cambios sociales como, por ejemplo, los movimientos de activistas (Mair y Martí, 2006).

- La orientación de mercado: identificada en el ES por Nicholls y Cho (2008), se asocia a menudo con la idea de la eficiencia y la eficacia, a través de actividades comerciales (Nicholls, 2010), y con la sostenibilidad financiera y la autosuficiencia por parte de la organización de ES (Boschee y McClurg, 2003; Harding, 2004; Haugh, 2005).

- La innovación social: según Nicholls y Cho (2008), el enfoque poco convencional y novedoso del ES es lo que lo diferencia de la prestación de servicios sociales tradicionales. De este modo, muchos autores han identificado la innovación como uno de sus aspectos clave (Dees, 1998b; Peredo y McLean, 2006; Austin et al., 2006; Mair y Martí, 2006; Mair, Battilana y Cardenas, 2012; Prabhu, 1999).

- Variabilidad descriptiva: el logro acreditado puede inicialmente tener varias descripciones. Como hemos visto, actualmente coexisten múltiples formas de entender el ES, sin existir todavía una definición universalmente aceptada. Según Collier, Hidalgo y Maciuceanu (2006) 
la variabilidad descriptiva puede hacer referencia al énfasis exclusivo sobre una u otra faceta del concepto, o enfatizando distintas facetas en diferentes grados, lo que conllevaría un contraste de la importancia relativa de cada faceta. Ambas opciones se han visto reflejadas en muchas de las definiciones del ES.

- Carácter abierto: implica la posibilidad de modificación del valor acreditado en función de las circunstancias cambiantes. Para analizar este aspecto se suele recurrir a la evolución histórica, no obstante, el problema al analizar el ES es que el término se ha empezado a utilizar a partir de las últimas tres décadas (Bacq y Janssen, 2011). Pese a ello, la práctica del ES no es nueva y ha cambiado a través del tiempo en respuesta a los cambios socioeconómicos de las circunstancias, de ahí las problemáticas descritas en apartados anteriores, evidenciando con ello el carácter abierto del ES.

- Reconocimiento de usos diferenciados: esta condición establece que los diferentes grupos de usuarios de un concepto esencialmente controvertido reconocen que su propio uso es criticado por otros grupos y que su propio uso debe prevalecer en contra de esos otros usos (Gallie, 1956). Este hecho, que Collier et al. (2006) denominan como reconocimiento recíproco, aparece entre diversos usuarios del término ES. Boschee y McClurg (2003) consideran que la obtención de ingresos es algo esencial en el ES y critican directamente la definición propuesta por Dees (1998b), al considerarla no solo conceptualmente errónea, sino también psicológicamente limitante. Por su parte, Dees (2003) defiende su propuesta afirmando que a pesar de los esfuerzos para difundir una definición basada en la innovación, la mayoría de personas piensan todavía en el ES en términos de organizaciones no lucrativas que generan ingresos. Del mismo modo, Martin y Osberg (2007) defienden su uso del ES y desaprueban otros usos, argumentando que este no puede ser una inmensa tienda de campaña en el que encajen todo tipo de actividades de beneficio social. Por otra parte, tanto Nicholls y Cho (2008) como Dacin, Dacin y Tracey (2011), critican la concepción del ES que resalta el papel del emprendedor social como un salvador o héroe. Esta visión también es criticada por Dey y Steyaert (2010) al considerarla demasiado optimista y poco realista.

- Ejemplo original: viene determinado por una acción original cuya autoridad es reconocida por todos los usuarios del concepto. Probablemente el ejemplo más mencionado de ES es el del Banco Grameen creado por Muhammad Yunus, el cual recibió el reconocimiento mundial por su labor con la concesión del Premio Nobel de la Paz 2006.

- Competencia progresiva: este criterio permite que el logro se mantenga y desarrolle de forma óptima. En lo que respecta al ES, esta cualidad se ve reflejada en la continua búsqueda de conocimiento. Por ejemplo, Dacin et al. (2011) analizan las diferentes definiciones de ES y explican las similitudes y diferencias entre las conceptualizaciones del término. Nicholls (2010) identifica diversos discursos del ES promovidos por los personajes dominantes en este campo. Por su parte, Hill, Kothari y Shea (2010) reflexionan sobre los diferentes significados de ES en la literatura existente, con el fin de identificar patrones de significado comunes.

Como podemos ver, con el tiempo se ha ido clarificando de forma progresiva el concepto de ES, dando forma a un cuerpo literario que refleja su naturaleza controvertida y sus diferentes significados y enfoques. 
Tras este análisis, Choi y Majumdar (2014) concluyen que el ES puede considerarse como un concepto esencialmente controvertido. Este hecho explica por qué se sugieren diferentes significados entre los autores que lo estudian y por qué es tan difícil encontrar una definición universal sobre el término. Basándose en esta conclusión, el artículo propone una comprensión conceptual del ES como una agrupación de conceptos. Según Gaut (2000), una agrupación de conceptos es un conglomerado de ciertos conceptos, que llamaremos en este caso sub-conceptos, que representan las propiedades que definen el concepto agrupado, y en el cual puede haber distintos grados y combinaciones de los diferentes conceptos que lo forman, permitiendo así un alto grado de indeterminación. La particularidad de un concepto en agrupación de conceptos es que se puede considerar válido incluso en el caso de no mostrar todas las propiedades del concepto definido. Conceptualizar el ES entraña una gran dificultad, motivo por el cual diversos autores han abordado esta cuestión entendiendo dicho fenómeno como una agrupación de conceptos.

Para Mort et al. (2003) la dificultad de conceptualizar e investigar sobre el ES se centra en delimitar el propósito de las organizaciones y contextualizar el entorno en el que operan. La primera cuestión hace referencia a la posibilidad de incluir nuevos objetivos en los fines no lucrativos, mientras la segunda radica en la dificultad para determinar las condiciones sociopolíticas de la comunidad en la que se desarrolla, ya que se presenta en zonas bien distintas del planeta. Vista esta dificultad de análisis, se plantea que el ES es un fenómeno multidimensional, no solo debido a que el emprendimiento comercial sobre el que se funda también lo es, sino también porque sus crecientes grupos de usuarios así lo manifiestan. A continuación los autores indican las dimensiones que, a su juicio, forman el ES:

- Comportamiento emprendedor virtuoso (dentro de la esfera social). Se refiere a la presencia de virtudes positivas como los valores éticos y morales. Esta virtud debe presentarse de forma consciente, no accidentalmente, por propia elección, sin motivaciones ocultas, y debe mantenerse en el tiempo hasta ser habitual (Foot, 1978; Maclntyre, 2007).

- Capacidad de formar juicios de valor equilibrados. Supone la habilidad de exhibir un juicio equilibrado o una unidad de propósito y acción coherente frente a la complejidad.

- Reconocimiento de la oportunidad social. A diferencia del emprendimiento comercial, que es impulsado por el objetivo de crear un valor comercial superior, el ES busca oportunidades de mercado que permitan crear y aumentar el valor social.

- Tolerancia al riesgo, proactividad e innovación. Siguiendo el planteamiento de Covin y Slevin (1986) se argumenta que, al igual que en el emprendimiento comercial, la toma de decisiones se basa en estos tres aspectos pero, en este caso, expresados en el contexto social. Por otra parte, se sugiere que estas características están fuertemente asociadas con la adquisición de conocimientos a través de la exploración, la asunción de desafíos para generar aprendizaje y el rápido desarrollo de nuevos comportamientos para asentarlo (Slater y Narver, 1995). 
De este modo, el constructo multidimensional del ES planteado por Mort et al. (2003) se representaría como se muestra en la figura 2.

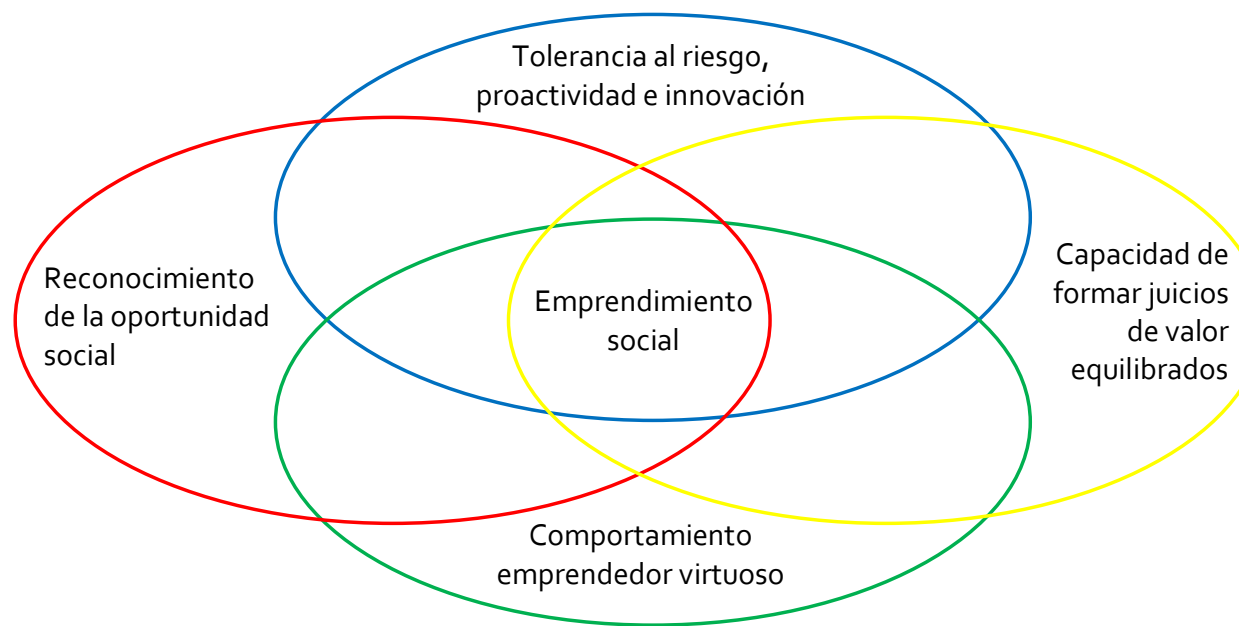

Figura 2. Constructo Multidimensional del Emprendimiento Social (Mort et al., 2003).

Por otra parte, según Tan et al. (2005) el grado de altruismo en el ES aumenta al permitir que los beneficios pretendidos incluyan no solo dinero sino también beneficios intangibles, como la mejora de la salud o, si ampliamos la sociedad beneficiaria, incluyendo diversos colectivos sociales o incluso todo el planeta. De igual modo, el nivel de altruismo también variará si el emprendedor social pretende sacar beneficios personales además de los sociales. Esta formulación puede referirse no solo a las personas individuales, sino también a entidades legales como corporaciones, asociaciones y sociedades. En la figura 3 podemos ver la representación esquemática de esta conceptualización del ES.

\begin{tabular}{|c|c|c|}
\hline Persona Legal & Proceso & Objetivo Altruista \\
\hline $\begin{array}{l}\text { Corporación } \\
\text { No corporación } \\
\text { Asociación } \\
\text { Club o Sociedad } \\
\text { (POR LA SOCIEDAD) } \\
\text { Individual }\end{array}$ & $\begin{array}{c}\text { Obtención de beneficios mediante la } \\
\text { innovación al correr riesgos } \\
+ \\
\text { Participación de un sector } \\
\text { de la sociedad } \\
\text { (PARTICIPACIÓN SOCIAL) }\end{array}$ & $\begin{array}{r}\text { Todos los beneficios } \\
\text { corresponden al mismo } \\
\text { sector de la sociedad } \\
\text { Algunos beneficios } \\
\text { corresponden al mismo } \\
\text { sector de la sociedad }\end{array}$ \\
\hline $\begin{array}{l}\text { Motivado por el } \\
\text { objetivo altruista }\end{array}$ & - (PARA & (IEDAD) \\
\hline & $\begin{array}{c}\text { En los sectores de la sociedad } \\
\text { necesarios para la obtención de } \\
\text { beneficios (EN SOCIEDAD) }\end{array}$ & \\
\hline
\end{tabular}

Figura 3. Conceptualización del Emprendimiento Social (Tan et al., 2005). 
Como ya hemos constatado, la literatura sobre el ES emerge de un gran número de dominios, está fragmentada y no viene acompañada del desarrollo de una teoría, empírica y coherente, derivada de una red de trabajo apropiada. Intentando ofrecer respuesta a esta cuestión, Weerawardena y Mort (2006) consideran que el ES debe ser conceptualizado en términos de un modelo multidimensional que represente la relación entre la capacidad de innovación, la proactividad, la gestión del riesgo, la sostenibilidad, la misión social y el entorno. Así pues, en la figura 4 , podemos ver la conceptualización gráfica del ES según este planteamiento.

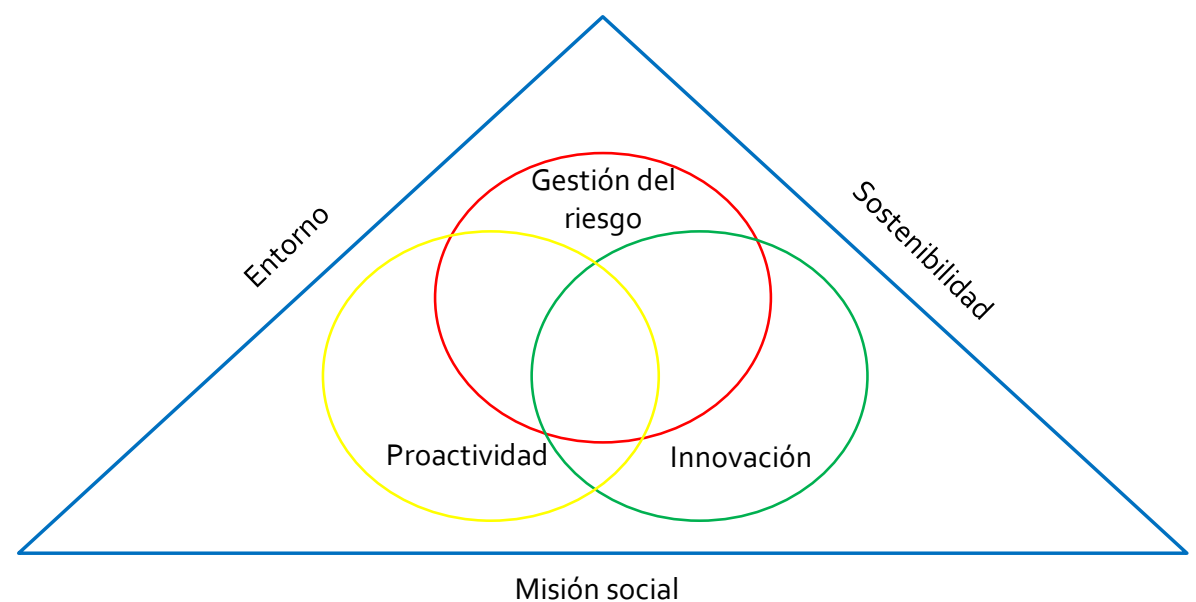

Figura 4. Conceptualización del Emprendimiento Social como Modelo Multidimensional (Weerawardena y Mort, 2006).

De igual modo, para conceptualizar el ES, Massetti (2008) se centra en dos de sus aspectos clave, su misión y sus beneficios. En ambos casos se establece una escala gradual entre la misión social, equilibrada y orientada al mercado, por un lado, y las actividades sin ánimo de lucro, los negocios sociales y las actividades con beneficios, por el otro. Teniendo en cuenta estas alternativas, la autora plantea la siguiente matriz del ES, figura 5 .

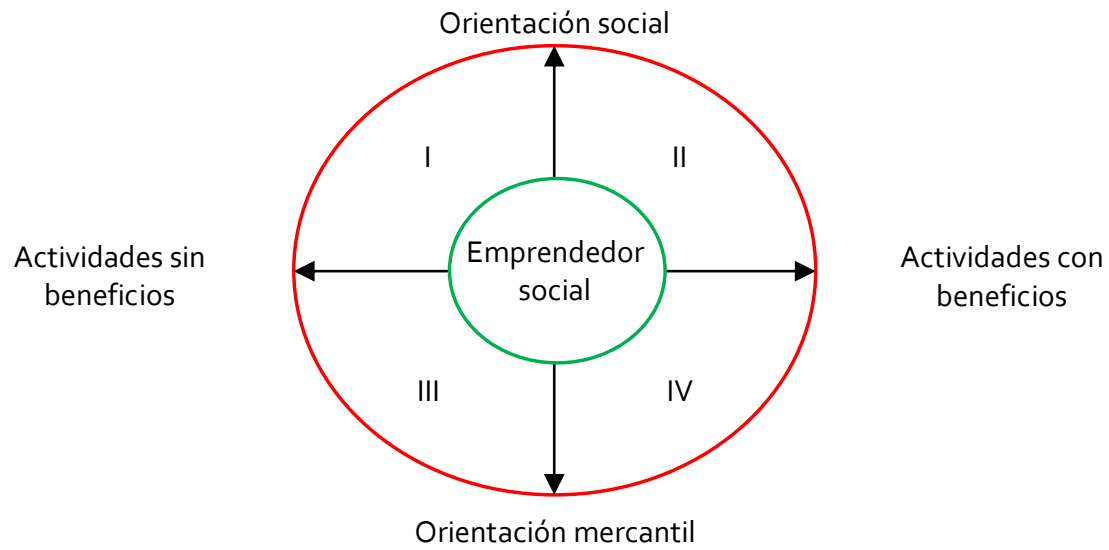

Figura 5. Matriz del Emprendimiento Social (Massetti, 2008). 
De igual modo, en base a la influencia de los diferentes conceptos incluidos en esta matriz, se plantearán las siguientes actividades de ES:

- Cuadrante I: La actividad sin ánimo de lucro tradicional. Representa a las organizaciones que están impulsadas por una misión social y no necesitan obtener un beneficio. En esta categoría se pueden encontrar fundaciones, organizaciones benéficas, museos públicos, entidades religiosas, etc., y habitualmente se centran en el uso de excedentes. Su financiación depende de fuentes externas mediante donaciones, subvenciones o el cobro de cuotas a sus miembros, aunque también pueden cobrar una tarifa por bienes o servicios con el objetivo de autofinanciarse.

- Cuadrante II: El punto de inflexión. Se identifica con organizaciones que no solo son impulsadas por motivos sociales, sino que también debe obtener beneficios para sobrevivir. Los emprendedores sociales de estas organizaciones deben lidiar con los problemas fundamentales tanto de las organizaciones sin ánimo de lucro como de las empresas lucrativas. Tratan de centrarse en satisfacer solo las demandas del mercado que beneficien a la sociedad en su conjunto y utilizan el beneficio obtenido como medida de eficiencia para asegurar que sus recursos no se desperdicien. Pueden aceptar la financiación de los sistemas tradicionales de apoyo social, pero la autogestión es más eficiente, ya que les permite centrarse en su misión social al no estar influenciados por las presiones del mercado.

- Cuadrante III: La organización temporal. Hace referencia a organizaciones que responden a las necesidades del mercado, pero sin ser impulsadas por la necesidad de obtener un beneficio. Por ello, para desempeñar su labor, deben encontrar apoyo a través de donaciones públicas y privadas, subvenciones o apoyo gubernamental. Se centran en identificar una necesidad en el mercado y utilizan los beneficios obtenidos al satisfacerla para apoyar una causa social. Como resultado, tienen que estar continuamente adaptándose a la oferta y la demanda del mercado para seguir sacando beneficios e invertir en la sociedad.

- Cuadrante IV: El negocio tradicional. Representa el enfoque más clásico de los negocios, empresas cuya misión principal está orientada hacia el mercado con la intención de obtener beneficios. EI ES en este cuadrante se aborda mediante el apoyo de actividades socialmente responsables. Algunos ejemplos podrían ser donar parte de los beneficios a una obra de caridad, la construcción de espacios verdes o el pago de primas al comprar suministros en países en vías de desarrollo. Estas acciones podrían suponer un aumento de las ventas debido a la mejora de la imagen de la marca, amortizando así el capital invertido.

Siguiendo un procedimiento similar al anterior, Short et al. (2009) revisan la bibliografía de investigación en esta materia con la intención de mejorar la comprensión de los límites del ES y sus condiciones cambiantes. Así pues, tras determinar que los tres dominios clave de este fenómeno son el emprendimiento, el sector público y sin ánimo de lucro y la gestión de los aspectos sociales, esquematizan la interrelación de estos conceptos como se muestra en la figura 6. 


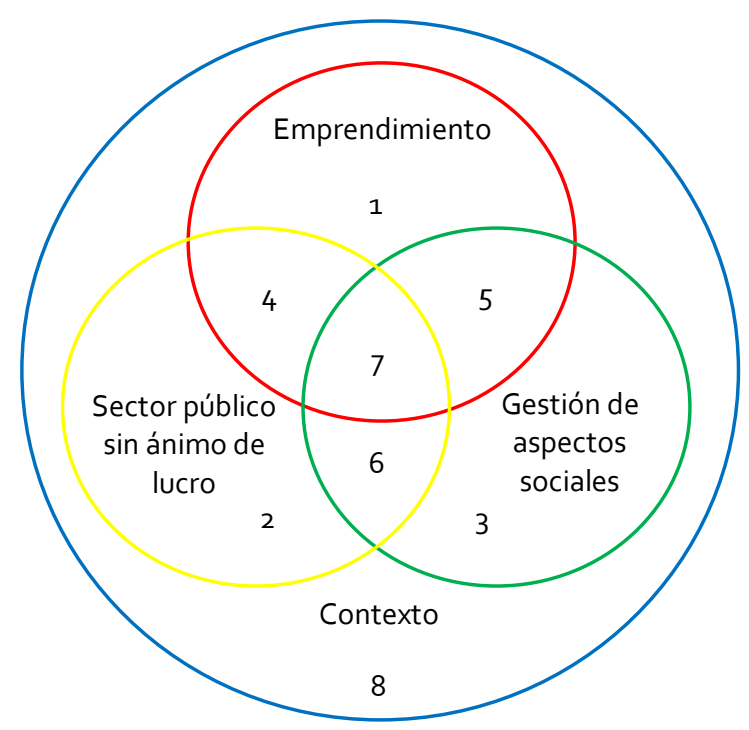

Figura 6. Dominios conceptuales de investigación sobre el Emprendimiento Social (Short et al., 2009).

De este modo, dependiendo del grado de participación de los diferentes elementos relacionados, podremos encontrarnos con los siguientes escenarios:

- Sección 1: representa únicamente al dominio del emprendimiento como campo cuyo enfoque se define por su interés en la creación de un nuevo valor. Tiene que ver con la construcción de conocimiento sobre cómo se descubren y explotan las oportunidades para crear futuros bienes o servicios.

- Sección 2: hace referencia a la gestión pública y sin ánimo de lucro, es decir, el interés inherente en el fomento de mejoras sociales en la comunidad. Tradicionalmente se ha preocupado por la reducción de las problemáticas sociales, la provisión de bienes sociales que el mercado no abastece adecuadamente, y complementar las actividades del gobierno a través de la acción de particulares (Dees, 1998a).

- Sección 3: se basa en la interacción entre las organizaciones, sus grupos de interés y varios ambientes, representando así la gestión de los temas sociales.

- Sección 4: muestra la relación entre el emprendimiento y las actividades públicas y sin ánimo de lucro. Incluye las actividades que contribuyan a la creación de nuevos valores sociales como, por ejemplo, la creación de organizaciones sin fines lucrativos que proporcionen oportunidades para satisfacer diversas necesidades sociales (Gartner, 1985).

- Sección 5: hace referencia a la conexión entre el emprendimiento y la gestión de los temas sociales. Se ocupa de la creación de nuevos valores que tienen un impacto directo en la relación entre las organizaciones y los sectores sociales interesados, siendo capaz de actuar en diversos entornos mediante nuevas estrategias.

- Sección 6: implica la coincidencia entre los ámbitos de la gestión pública y sin ánimo de lucro y la gestión de las cuestiones sociales. Representa la ejecución de políticas y programas sociales por parte de las organizaciones del sector público y sin ánimo de lucro. 
- Sección 7: muestra la relación entre los tres dominios básicos, el emprendimiento, el sector público y sin ánimo de lucro y la gestión de los aspectos sociales. Se centra en la creación y el equilibrio entre la problemática social y el valor económico, para beneficiar los intereses colectivos en lugar de los individuales.

- Sección 8: destaca la influencia del contexto en el ES, condicionando su capacidad para crear valor social a través de un negocio económicamente estable.

Cabe señalar en este punto que los propios autores advierten que, dependiendo del sector en el que nos posicionemos y la participación de los diferentes aspectos relacionados, la concepción del emprendimiento social podrá ser más o menos completa.

Por último, Choi y Majumdar (2014) consideran que los sub-conceptos que conforman el ES son los cinco elementos utilizados para analizar la complejidad interna de este fenómeno. Así pues, el ES estará determinado por la creación de valor social, el emprendedor social, la organización de ES, la orientación al mercado y la innovación social. La creación de valor social es considerada por la literatura como un requisito indispensable; no obstante, no es condición suficiente para determinar el ES, por lo que debe combinarse en mayor o menor número y grado con los otros cuatro subconceptos. A continuación exponemos la figura 7, donde podemos ver la conceptualización del ES entendido como la agrupación de estos conceptos.

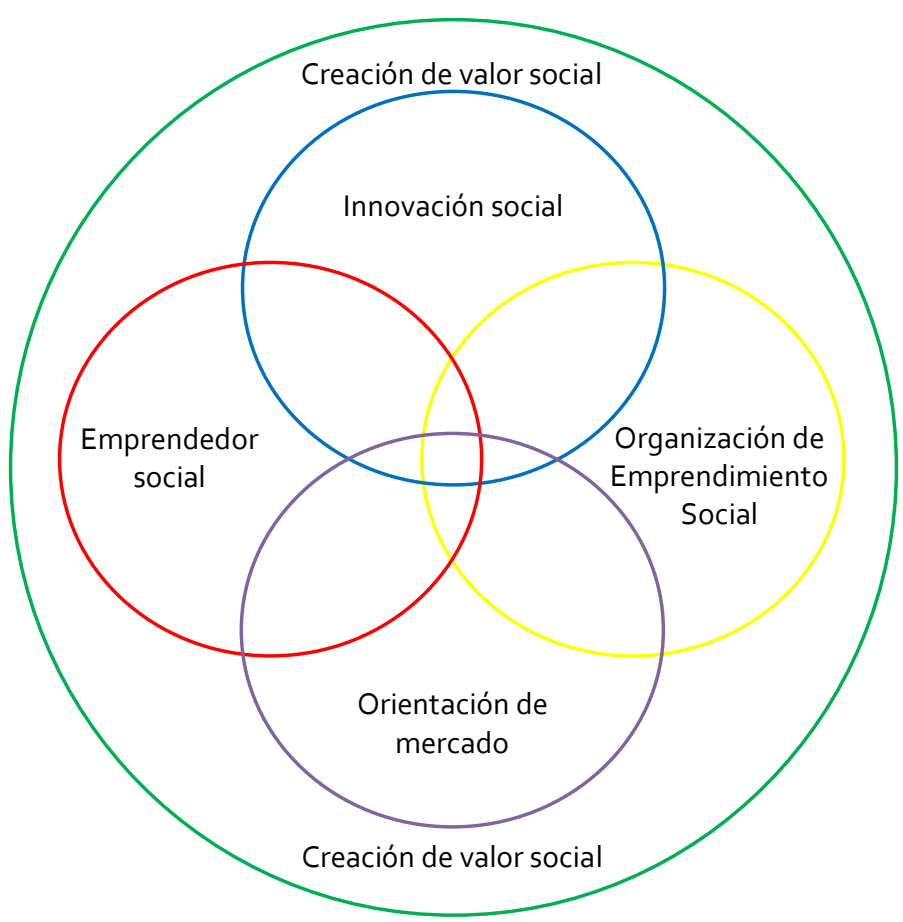

Figura 7. Conceptualización del Emprendimiento Social como agrupación de conceptos (Choi y Majumdar, 2014). 
Con el objetivo de darle mayor importancia a la conceptualización del ES como agrupación de conceptos, los autores sugieren que esta forma de entenderlo puede ayudar a avanzar tanto en su investigación como en su establecimiento como campo de estudio propio. En primer lugar, una comprensión del ES en términos de agrupación de conceptos obligaría a los investigadores a establecer de forma explícita qué sub-conceptos destacan en sus comprensiones del concepto de ES. En segundo lugar, esta perspectiva podría servir tanto para determinar las líneas de investigación en este campo, como para ayudar a localizar y organizar los trabajos ya existentes. No obstante, los autores reconocen la posible limitación de esta propuesta debido a la naturaleza compleja y controvertida de los propios sub-conceptos que podrían formar parte del ES.

Al igual que sucede con la conceptualización del ES, su aplicación también despierta opiniones contrarias. Así pues, Roberts y Woods (2005) señalan que esta es una cuestión controvertida, pues mientras los académicos argumentan que se requiere una investigación y un debate más riguroso para que el ES gane estatus y contenido, los profesionales defienden que esto es un ejercicio sin sentido, a menos que ello aporte más fondos, y sugieren que necesitan ser desarrolladas más comunidades y redes de trabajo para apoyar a otros profesionales que ya estén en el campo y así hacer crecer la preocupación general. Otros investigadores han abogado por el ES como una solución parcial a la necesidad de hacer una reforma total del estado del bienestar o como una forma de conocer las demandas sociales a través de innovaciones realizadas por los agentes emprendedores (Leadbeater, 1997; Thompson, 2002). Aunque este enfoque ha atraído considerable interés, también ha suscitado numerosas críticas al debilitar la perspectiva basada en el derecho a los servicios sociales (Cook et al., 2003).

Revisando la publicación del Canadian Centre for Social Entrepreneurship (2001), Weerawardena y Mort (2006) argumentan que no es casualidad que el ES esté recibiendo cada vez más atención, mientras el entorno competitivo y los límites tradicionales entre las actividades con y sin ánimo de lucro están cambiando. Esto supone un nuevo panorama competitivo para las actividades no lucrativas en la línea de un mercado que premia la disciplina, el rendimiento y la capacidad de organización, en lugar de valorar únicamente la misión social. Esta perspectiva ofrece, al mismo tiempo, oportunidades y amenazas para el ES. Algunos investigadores han abogado por el aumento del uso de modelos mercantiles en la gestión de las organizaciones sociales; sin embargo, esta acción dañaría seriamente los valores fundamentales del ES. Por ello, estas organizaciones deben abordar claramente un posicionamiento hacia el valor social y actuar de forma proactiva para proporcionar un servicio superior y maximizar la creación de valor social.

Otros autores advierten de la problemática que podría plantear la aplicación práctica del ES, como solución de sentido común frente a las dificultades sociales, sin considerar adecuadamente todos sus efectos (Roper y Cheney, 2005). Sin embargo, Bacq y Janssen (2011) defienden que la aplicación del ES tiene al menos dos ventajas principales que justifican su interés. En primer lugar, su capacidad de innovación en el tratamiento de los problemas sociales, que son cada vez más complejos (Thompson et al., 2000) y, en segundo lugar, porque permite desdibujar las fronteras tradicionales entre los sectores público y privado, lo que da pie al nacimiento de empresas mixtas (Wallace, 1999) que buscan la creación de un valor doble, social y económico (Alter, 2004). 
A continuación presentamos algunos ejemplos de organizaciones relacionadas con el ES proporcionados por diversos autores. Esto nos ayuda a profundizar en el conocimiento de las implicaciones de su aplicación y de las diferentes posibilidades existentes en este campo, además de ofrecernos una visión real de cómo son este tipo de entidades.

Así pues, Tan et al. (2005) describen el siguiente continuum de posibilidades: empresas basadas en la comunidad, empresas socialmente responsables, profesionales de la industria de los servicios sociales y empresas socio-económicas o dualistas. La primera categoría incluye a las organizaciones benéficas que, asumiendo cierto riesgo, utilizan métodos innovadores para llevar a cabo sus objetivos sociales. Una de estas organizaciones es la Escuela Grace Orchard. El elemento social radica en el reclutamiento de voluntarios, la participación de la comunidad local para aceptar e involucrarse con la escuela y la prestación de apoyo financiero. La segunda categoría hace referencia a empresas como la Banyan Tree Gallery, que es una extensión de los Banyan Tree Holiday Resorts. Esta entidad proporciona un bien social debido al consiguiente aumento de la producción de la riqueza creada en los pueblos de la zona y la mejora de la calidad de vida de aquellos que viven en ella. El elemento social en el proceso se puede ver en la participación de los habitantes como productores y en los beneficios que aporta a sus comunidades. La tercera categoría incluye a aquellos empresarios cuyos clientes pertenecen a la industria de los servicios sociales. Estos individuos son innovadores y asumen riesgos de negocio calculados, aunque uno de sus objetivos principales es proporcionar beneficios a la sociedad. Un ejemplo de esto es la empresa Northern Leaf Communications. Su participación va más allá de los sueldos de los profesionales de servicios sociales, sino que además implica una relación íntima, originada desde sus inicios, que hace que éstos participen como voluntarios en organizaciones benéficas. Por último, la cuarta categoría comprende empresas como la Transnational Recycling Industries. Esta entidad se especializa en el reciclaje de materiales de papel, en particular periódicos viejos, papel de oficina y residuos de papel. Su actividad vincula, de forma innovadora, la participación de los residentes en el proceso de obtener beneficios del reciclaje. Este proceso favorece a dichos residentes tanto de forma directa, al apoyar a una organización de caridad dentro de la comunidad, como indirecta, mediante la construcción de un sentido de comunidad. Pero también ofrece beneficios a nivel global en cuanto a la conservación de los recursos del planeta.

Del mismo modo, Martin y Osberg (2007) exponen algunos ejemplos de actividades de ES y sus impulsores como Robert Redford, promotor del Sundance Institute de cine independiente, Victoria Hale, que creó la primera compañía farmacéutica sin ánimo de lucro, o Muhammad Yunus, fundador del Grameen Bank que mejoró la economía y la vida de millones de personas.

No queremos cerrar este bloque sin exponer algunos aspectos que podrían ayudarnos a desarrollar, fortalecer y ampliar nuestro conocimiento sobre el ES. Para ello, seguiremos a Haugh (2005), autora que describe ocho aspectos clave a tener en cuenta para este propósito.

El primer aspecto destacado por la autora se centra en definir el alcance del ES. La investigación en esta materia se ve obstaculizada por la falta de definiciones estándar y universalmente aceptadas, por lo que sin definir claramente los límites del ámbito es complicado avanzar en su 
conocimiento. Al mismo tiempo se indica una ausencia de registros sobre las diferentes organizaciones participantes, algo que también ayudaría a comprender mejor el ámbito en el que nos movemos.

El segundo aspecto señalado es el entorno contextual. Este hace referencia a las tendencias políticas, económicas, sociales, culturales y tecnológicas que influyen en el ES. Aunque existen diversas publicaciones sobre sus orígenes en el Reino Unido, Europa y los EE.UU., aún no se ha realizado un análisis sistemático de las tendencias nacionales e internacionales relacionadas con el ES. Esto sería útil para comparar la corriente y la previsión de futuro, las tasas de creación de empresas sociales y el establecimiento de los requisitos de la red de apoyo e infraestructuras necesarias para fomentarlo.

Otro aspecto a tener en cuenta es el reconocimiento de las oportunidades y la innovación. Actualmente existen muchas oportunidades para hacer frente a la desventaja, la pobreza y la exclusión social, especialmente en las áreas de la salud, las artes, la cultura, el empleo, la vivienda, la asistencia social, la educación, el medio ambiente y los servicios de reciclaje. Según la autora, la innovación podría aprovechar estas oportunidades para generar valor ofreciendo nuevos servicios a los desfavorecidos y excluidos, identificando nuevas formas de prestación de los servicios existentes, implementando nuevas estrategias para generar ingresos, prestando servicio a nuevos colectivos o explotando nuevos recursos.

Relacionado con el punto anterior, también debemos considerar la explotación de las oportunidades. Por ejemplo, la descentralización y privatización de los servicios sociales crea oportunidades para establecer asociaciones entre personas, del mismo sector y entre sectores distintos, para prestar servicios sociales a nivel local y para ofrecer oportunidades de empleo y formación a los más desfavorecidos. También se puede aprovechar el desafío de combinar los valores competitivos del emprendimiento con una finalidad social que no tiene por qué ser rentable. De igual modo, las organizaciones de ES tienden a ser pequeñas y de influencia local, lo cual nos ofrece la posibilidad de conseguir recursos no mercantiles, ni monetarios en su creación y funcionamiento.

Las diferentes formas de organización y fuentes de adquisición de recursos representan dos nuevos apartados que debemos atender, pues la amplia variedad de ambos aspectos dificulta un conocimiento más profundo del ES. En cuanto a las formas institucionales se admiten mutuas, asociaciones, cooperativas, empresas, franquicias, organizaciones benéficas, fundaciones, fideicomisos, sociedades y compañías de interés para la comunidad. Por otra parte, la financiación del ES puede proceder del mercado (ingresos por venta de bienes y servicios), fuentes no comerciales (subvenciones del gobierno, financiación de programas y subvenciones independientes, donaciones y filantropía) y recursos no monetarios (trabajo voluntario y capital social) (The Organisation for Economic Co-operation and Development, 1999).

Otro aspecto a tener en cuenta es la medición del rendimiento o desempeño. Como ya se ha comentado, las empresas sociales operan principalmente en el ámbito local, mediante la provisión 
de bienes y servicios, lo cual tiene un impacto individual. No obstante, también debemos considerar su impacto sobre la sociedad y sus distintas comunidades al ayudar a los individuos a adquirir las habilidades necesarias para volver al trabajo y al reducir las disparidades locales en la prestación de servicios, el acceso a los mismos y los niveles de competencias, pues todo ello contribuye a la construcción de capital social y cohesión.

El último aspecto destacado por Haugh (2005) es el fomento de la formación, educación y aprendizaje sobre el ES. Mientras la enseñanza del emprendimiento comercial se ha ido consolidando progresivamente en los últimos treinta años, la vertiente social es una recién nacida, y solo se oferta un pequeño número de cursos especializados. Algunas de las Universidades más prestigiosas del mundo como Harvard y Stanford, en EEUU, o Cambridge, Oxford y Southampton, en el Reino Unido, ya ofrecen cursos de postgrado relativos al ES y comunitario. Estos cursos muestran los conceptos básicos de la creación y funcionamiento de las empresas sociales, tales como la financiación de fondos, el marketing y cómo elaborar su plan de acción. No obstante, estos cursos no suelen preocuparse por el desarrollo teórico o las implicaciones políticas del ES, lo que limita el progreso en su conocimiento.

Finalmente, nos gustaría terminar este apartado resaltando la importancia de fomentar el desarrollo del ES en cualquier sociedad ya que generará un impacto sobre el desarrollo económico, promoverá la construcción social participativa e incidirá en las cuestión de política pública (Guzmán y Trujillo, 2008).

Tras lo expuesto, a modo de síntesis, podemos decir que el ES tiene como objetivo fundamental la creación de valor social a través de propuestas innovadoras, pretendiendo con ello resolver problemas o satisfacer necesidades sociales.

De igual modo, consideramos oportuno resumir las ideas principales de este apartado:

1. El ES y el comercial se diferencian principalmente en su meta $u$ objetivo, el primero pretende crear valor social y el segundo valor económico.

2. Ambos tipos de emprendimiento comparten características similares, especialmente en cuanto al proceso de elaboración innovador.

3. Pese a los esfuerzos de múltiples autores, el concepto de ES sigue sin tener una definición clara y universalmente aceptada, poniendo de manifiesto la controversia y dificultad que suscita este término.

4. La importancia e influencia del entorno en el que se desarrolla el ES se reflejan en las diversas formas de entender este fenómeno.

5. El mejor modo de concebir el ES es de una forma amplia, como conjunto o agrupación de diversos conceptos.

6. El fomento del ES provoca un impacto en el desarrollo económico, promueve la construcción social participativa e incide en cuestiones de política pública. 
Teniendo en cuenta estas consideraciones, en el siguiente apartado analizaremos los antecedentes de investigación relacionados con el emprendimiento y su vertiente social para conocer de primera mano el estado de la cuestión así como establecer un punto de partida para la presente investigación.

\subsection{Estado de la cuestión respecto a Emprendimiento y Emprendimiento Social}

Como hemos visto, el emprendimiento puede ser tratado desde diferentes puntos de vista, motivo por el cual las investigaciones sobre este fenómeno tienen diversas perspectivas. Uno de los estudios internacionales más importantes es el proyecto Global Entrepreneurship Monitor (GEM), destinado al estudio comparativo de la creación de empresas entre los diferentes países del mundo y se lleva a cabo anualmente desde 2006 (Bygrave y Quill, 2007; Allen, Langowitz, y Minniti, 2006; Bosma y Harding, 2007). Obviamente, todas estas investigaciones tienen una clara orientación hacia el ámbito económico y financiero.

Otro ámbito en el que el emprendimiento ha despertado gran interés es el del alumnado universitario. Prueba de ello son los trabajos realizados sobre la vocación emprendedora del alumnado en dos Facultades de Ciencias Económicas y Sociales en Mar del Plata en Argentina (Graña y Fornoni, 2002), el perfil psicosocial del emprendedor en universidades de Castilla y León (Moriano, Palací y Morales, 2006), la sensibilidad sobre el emprendimiento y las intenciones emprendedoras de los estudiantes de doctorado franceses como futuros investigadores (Boissin, Castagnos y Deschamps, 2006), las relaciones entre la actividad emprendedora y el crecimiento económico en el Instituto de Estudios Empresariales de la Universidad de Montevideo (Centro de Desarrollo Emprendedor del IEEM, 2007) y el desarrollo de la actitud emprendedora de los estudiantes de la Universidad Nacional Mayor de San Marcos, en Perú, y su relación con algunas variables socio-demográficas (Loli, Dextre, Del Carpio y La Jara, 2010).

En nuestro país podemos destacar los trabajos de Corduras (2006), que describe la motivación que anima a emprender a la población española y el estado de la cultura emprendedora en España; el de Herrera (2009), que presenta una revisión de la literatura reciente sobre las redes de emprendimiento y cómo el contenido y la estructura de las redes sociales, entendidas como redes de relación personal, contribuyen al éxito de la actividad del emprendedor; el de Contín y Larraza (2010), que estudia el emprendimiento en el entorno rural y urbano y los factores que lo determinan para el caso de Navarra; el de Gessa y Toledano (2011) que investiga la relación del emprendimiento con el turismo y la sostenibilidad de los espacios naturales en la comunidad autónoma de Andalucía; y el trabajo de Espíritu (2011) que se centra en la actitud emprendedora de los estudiantes universitarios de la Comunidad de Madrid. Sin embargo, la investigación más completa es la revisión presentada por Sánchez y Gutiérrez (2011) en la que se repasan 471 trabajos, producidos en España entre 1977 y 2009, sobre el emprendimiento, sus comienzos, naturaleza y principales focos de atención. En ella, los autores destacan que existe una preferencia por el uso de 
los métodos cualitativos frente a los cuantitativos y que la mayor parte de trabajos se centran en analizar el proceso emprendedor y el estudio de las pequeñas empresas aportando diferentes contribuciones conceptuales.

Finalmente, reforzando lo expuesto en el apartado anterior, nos gustaría destacar el trabajo de Simpeh (2011), que pone de manifiesto el carácter multidisciplinar del emprendimiento a través de la revisión de las diferentes teorías existentes sobre este fenómeno. Así pues, tras presentarlas (económica, psicológica, sociológica, antropológica, basada en las oportunidades y basada en los recursos) aporta diversos estudios empíricos sobre cada una de ellas. Sus conclusiones ofrecen la oportunidad de replantear el concepto de emprendimiento a través de la integración de las distintas teorías aportadas. Al mismo tiempo, auguran un gran futuro en esta materia, tanto en la práctica como en su estudio e investigación, dada la amplia variedad de teorías explicativas. Como ya hemos visto, esta disparidad no está exenta de múltiples controversias y dificultades.

Como podemos comprobar, el principal foco de atención de estas investigaciones es el aspecto económico y financiero del emprendimiento, incluso en los trabajos que se han realizado en entornos universitarios, prestando poca atención al estudio del ES. Así pues, visto el déficit existente de trabajos que se centren en esta perspectiva del emprendimiento, especialmente en el ámbito de la educación, consideramos que es un campo a explorar, principalmente ligado a la innovación metodológica.

Seguidamente analizamos en profundidad varios estudios académicos sobre emprendimiento y ES, relacionados con el ámbito educativo, para tener una mejor idea del estado de la cuestión respecto a ambos casos. En sendos análisis comparamos los objetivos de estudio, los contextos de aplicación, la muestra empleada y las principales conclusiones extraídas en los diversos trabajos seleccionados por su especial relevancia.

En cuanto al foco de atención de los estudios educativos sobre emprendimiento, apreciamos un predominio de trabajos dedicados a investigar el desarrollo o adquisición de diversas actitudes y comportamientos relacionados con este fenómeno. Así pues, el objetivo del trabajo de Dixon, Meier, Brown y Custer (2005) es identificar los vacíos existentes entre el comportamiento deseado y el comportamiento real de la competencia emprendedora; el artículo de Ali, Topping y Tariq (2010) explora la adquisición de atributos emprendedores entre los estudiantes; Lee y Lai (2010) estudian el potencial emprendedor de los estudiantes valorando el desarrollo de diversas habilidades emprendedoras; el documento de Karlsson (2011) investiga los efectos de un programa de verano para estimular a actitud emprendedora en los jóvenes; Ram y Selvaraj (2012) indagan el impacto de la educación del emprendimiento, vía on line, mediante el desarrollo de las competencias emprendedoras; y, por último, el estudio de Ghazali, Ibrahim y Zainol (2013) pretende determinar la influencia de ciertos factores en la percepción emprendedora de los estudiantes, a través del desarrollo de diversas habilidades de emprendimiento.

No obstante, también existen trabajos que centran su atención en otros aspectos de la educación emprendedora, como el estudio de Ubah, Onwuasoanya y Eze (2012), que investiga la 
opinión de los educadores sobre el impacto de los servicios de orientación y asesoramiento en el desarrollo del emprendimiento entre los estudiantes; o el de Norasmah, Norashidah y Hariyaty (2012), que analiza la disposición de los alumnos y el contexto, en la implementación de la educación emprendedora.

Respecto al contexto de aplicación, existe una mayor presencia de trabajos realizados en el ámbito universitario frente a otras áreas educativas. De este modo, el trabajo de Ali et al. (2010) se lleva a cabo en la Islamia University of Bahawalpur, una universidad pública de Pakistán; el estudio de Lee y Lai (2010) se realiza en el departamento, dedicado el cuidado de niños, de un colegio universitario de tecnología, perteneciente al sector público de Taiwan; la investigación de Norasmah et al. (2012) se implementa en las universidades públicas de Malasia; el estudio de Ram y Selvaraj (2012) se aplica en 66 instituciones privadas de educación superior de la India; y el trabajo realizado por Ghazali et al. (2013) se desarrolla en la Universiti Sultan Zainal Abidin (UniSZA), universidad pública de Malasia. Sin embargo, también hemos encontrado estudios realizados en otros contextos educativos como las National Training Agencies de Jamaica, centros de formación emprendedora (Dixon et al., 2005), una escuela de verano para jóvenes en Suecia (Karlsson, 2011) o 10 centros de educación secundaria de Nigeria (Ubah et al., 2012).

Estos contextos de aplicación nos transmiten varias tendencias en la realización de estos estudios ya que existe una mayor elaboración de trabajos realizados en el sector público y una predominancia de investigaciones llevadas a cabo en el continente asiático. La primera tendencia puede explicarse por la falta de interés en publicar los resultados de estudios realizados en el sector privado y, la segunda, debido al periodo de crecimiento económico acontecido recientemente en esta zona del planeta. Por otra parte, también encontramos otra tendencia destacable que hace referencia a la metodología de investigación. Así pues, comprobamos que todos los trabajos analizados se decantan por utilizar una metodología cuantitativa, aplicando diversos tipos de cuestionarios. No obstante, el trabajo de Karlsson (2011) presenta una doble metodología, complementando la investigación cuantitativa con un estudio cualitativo. Dicho estudio se realizó a través de entrevistas semi-estructuradas y se completó con conversaciones, observaciones y documentos de registro. Esta ausencia pone de manifiesto la necesidad de estudiar el emprendimiento desde una vertiente cualitativa, reforzando nuestro planteamiento de analizar dicho fenómeno desde un enfoque combinado, cuantitativo y cualitativo.

El análisis de la muestra de estos estudios no presenta tendencias en cuanto al tamaño de las mismas, ya que hemos encontrado muestras pequeñas, de entre 13 y 37 sujetos, muestras intermedias, de 68 a 207 sujetos, y muestras grandes, de entre 521 a 1012 sujetos. En cambio, sí existe una tendencia en cuanto al perfil de los sujetos ya que la mayor parte de ellos se dedican a investigar sobre el alumnado (Ali et al., 2010; Ghazali et al., 2013; Lee y Lai, 2010; Norasmah et al., 2012; Ram y Selvaraj, 2012). Sin embargo, también hay estudios que se centran en otros colectivos como los gerentes y los distintos responsables de los centros de formación emprendedora (Dixon et al., 2005); políticos, funcionarios, representantes del programa emprendedor, profesores y líderes del colegio, además de los estudiantes (Karlsson, 2011); y administradores de zona, directores de colegio, orientadores y, mayoritariamente, profesores de aula (Ubah et al., 2012). 
Al igual que sucedía al comparar la motivación de estas investigaciones, existe una predominancia de resultados y conclusiones relativas al desarrollo o adquisición de diversas actitudes y comportamientos relacionados con el emprendimiento. No obstante, las diferentes particularidades de cada trabajo hacen que dicha información sea difícilmente comparable. Pese a ello, consideramos oportuno mostrar sus principales conclusiones para tener un conocimiento más preciso de los mismos.

Así pues, en los resultados del estudio realizado por Dixon et al. (2005) se considera que 39 de las 66 competencias analizadas son de vital importancia para poder desempeñar la función emprendedora de forma adecuada. Por otra parte, también concluyen que los fallos de algunos centros de formación en fomentar el espíritu emprendedor se deben, en parte, a deficiencias de los instructores. La investigación de Ali et al. (2010) destaca los registros obtenidos respecto a la autoeficacia, eficiencia y compromiso, e intenciones emprendedoras del alumnado; al mismo tiempo, también se resalta el hecho de que la mayor parte de los estudiantes mostraron atributos emprendedores positivos. Los resultados de la investigación de Lee y Lai (2010) determinan que las tres habilidades emprendedoras más destacadas fueron la colaboración, el estar a gusto con los compañeros y que su familia y amigos les apoyaran. En cambio, las habilidades con peores resultados fueron la innovación, tener dos o más compañeros y que la comunidad sea activa y útil. Finalmente, las conclusiones del trabajo indican que los futuros cuidadores de niños deben aumentar su potencial emprendedor desarrollando múltiples habilidades emprendedoras. El trabajo de Karlsson (2011) concluye que los jóvenes son más conscientes de la importancia de responsabilizarse de sus propias acciones, al mismo tiempo que han desarrollado su capacidad para resolver problemas; igualmente, se destaca el periodo de educación secundaria como el factor más influyente en su futuro.

De igual modo, los hallazgos del estudio de Ubah et al. (2012) muestran que los servicios de orientación y asesoramiento sobre emprendimiento mejoran las habilidades de los estudiantes para su desarrollo, lo cual aumenta la productividad, los medios de vida sostenible y el desarrollo del país. Según Norasmah et al. (2012) el alumnado de las universidades públicas de Malasia demuestra una fuerte disposición en términos de preparación y capacidad emprendedora. Ram y Selvaraj (2012) encontraron que las competencias genéricas que mostraron mayor diferencia en la puntuación media, a lo largo de los dos años de investigación, fueron las habilidades emprendedoras; esta situación indica un mayor énfasis educativo en dichas habilidades, dada la necesidad de garantizar la competencia y competitividad de los futuros emprendedores en un entorno global; tras analizar estos resultados, los autores consideran que la educación emprendedora vía on line debe ser implementada, de forma continua, para incentivar el interés en el emprendimiento por parte de los graduados, como una opción de carrera y desarrollo para ser más competitivos y creativos. Finalmente, los resultados de la investigación de Ghazali et al. (2013) sugieren que las mujeres tuvieron una mayor habilidad social y actitud emprendedora, y un mayor deseo de tener éxito en comparación con los estudiantes varones; otro hallazgo importante indica que aquellos que asistieron a cursos de formación sobre emprendimiento tenían una mayor habilidad social y actitud emprendedora; finalmente también se observó que tratar la habilidad de 
marketing, el deseo de éxito, la habilidad de liderazgo y la innovación y creatividad inspira a los graduados a decantarse por realizar tareas emprendedoras.

No obstante, no todo fueron resultados positivos pues en algunos trabajos no se hallaron diferencias significativas entre los atributos emprendedores positivos y los negativos, ni tampoco se encontraron impactos significativos de variables como el sexo, los ingresos o la profesión de los padres, en los atributos emprendedores de los estudiantes (Ali et al., 2010). Igualmente, tampoco se encontraron diferencias significativas con respecto a la raza, la edad, los antecedentes laborales de los padres, la participación relativa en negocios y el conocimiento previo sobre el emprendimiento, determinando que los emprendedores no se agrupaban en base a ninguna de estas variables (Ghazali et al., 2013). Por ello, se entiende que, desde la perspectiva de los estudiantes de las universidades públicas, la preparación para la educación emprendedora sigue siendo imperfecta y necesita incluir mejoras si se desea apoyar el futuro de su formación (Norasmah et al., 2012).

Por último, antes de pasar a analizar los estudios educativos sobre ES, debemos destacar la preocupación de algunos autores en cuanto a la necesidad de realizar un mayor número de investigaciones en este campo, que aborden más aspectos y que utilicen mayores muestras, para incrementar la generalización y validez de estos datos, fomentando así el mantenimiento de los programas de educación emprendedora (Lee y Lai, 2010; Karlsson, 2011). Esta sugerencia demanda la ejecución de nuevos trabajos sobre esta temática, justificando así la realización de la presente tesis.

Tras lo expuesto, podemos concluir que la tendencia dominante en los estudios educativos relacionados con el emprendimiento es investigar el desarrollo o adquisición de diversas actitudes y comportamientos relacionados con este fenómeno en el sector público universitario del continente asiático, siguiendo una metodología cuantitativa a través de la aplicación de diversos tipos de cuestionarios. En cambio, no parece haber tendencias dominantes en cuanto al tamaño de las muestras en estos trabajos.

Seguidamente analizamos con detenimiento varios estudios académicos sobre ES seleccionados por su especial relevancia en el ámbito educativo. Como en el caso anterior, en este análisis comparamos los objetivos de estudio, los contextos de aplicación, la muestra empleada y las principales conclusiones extraídas en los diversos trabajos.

Respecto al objetivo de las investigaciones, no parece existir una tendencia dominante pues los trabajos analizados tienen motivaciones muy diversas. Así pues, el estudio realizado por Alvord et al. (2004) proporciona un análisis comparativo de siete casos de ES, ampliamente reconocidos como exitosos, especialmente en lo relativo a cambios significativos en la vida social, política y los contextos económicos, para los grupos sociales pobres y marginados; el trabajo de Sharra (2005) analiza los enfoques e implicaciones de la promoción de la independencia docente y el activismo, con la intención de fomentar la innovación y provocar un cambio social; la investigación realizada por Spear (2006) compara el emprendimiento comercial y social mediante el estudio de factores 
como la innovación, los modelos de emprendimiento, el apoyo externo y el capital social, los aprendizajes y los resultados obtenidos, en diversas empresas sociales; Weerawardena y Mort (2006) llevan a cabo una investigación con 9 organizaciones sin ánimo de lucro para determinar las características del ES; Maistry y Ramdhani (2010) abordan el estudio de las experiencias del alumnado del Grado en Maestro al participar en un programa de educación emprendedora, especialmente diseñada para concienciar al alumnado del vínculo entre el emprendimiento y la responsabilidad social; finalmente, el propósito del trabajo de Kirby e Ibrahim (2011) es explorar el conocimiento del ES entre el estudiantado universitario y determinar lo que se necesita para crear más emprendedores sociales.

Al analizar los contextos de aplicación en los que se han llevado a cabo las diversas investigaciones seleccionadas, comprobamos que tampoco existen entornos dominantes debido a que los estudios se implementaron en ámbitos muy diferentes. Así pues, los trabajos se centraron en proyectos de ES implementados en Kenya, Bangladesh, E.E.U.U., México, Colombia, Perú, Burkina Faso y Francia (Alvord et al., 2004); cuatro escuelas de la república de Malaui (Sharra, 2005); diversas empresas sociales del Reino Unido que actúan en una amplia gama de sectores de actividad, ofreciendo servicios de transporte de comida, video, ordenadores, transporte, ocio y cuidado de niños (Spear, 2006); nueve organizaciones sin ánimo de lucro de Australia representadas por entidades de pequeño, mediano y gran tamaño que actúan en diversos ámbitos ofreciendo apoyo a hijos de padres adictos a las drogas, seguridad y recreación comunitaria en las playas, alojamiento y servicios legales para personas discapacitada, servicios y abogacía para personas pobres, alojamiento y servicios comunitarios para personas de edad avanzada, apoyo y financiación para actividades de ES, y servicios de desarrollo económico y comunitario (Weerawardena y Mort, 2006); un programa de APS aplicado en Sudáfrica que defiende que cualquier programa de emprendimiento debería tratar aspectos clave como la ética, los valores y la responsabilidad social (Maistry y Ramdhani, 2010); y, por último, las facultades de Ingeniería, Ciencias Computacionales y Administración de Empresas, Ciencias Políticas y Económicas de la British University de Egipto (Kirby e Ibrahim, 2011)

No obstante, donde sí encontramos una tendencia dominante es en la metodología de investigación, ya que la mayor parte de trabajos se decantaron por utiliza una metodología cualitativa. De este modo, se utilizaron la autobiografía, las entrevistas, los cuestionarios con preguntas abiertas, los informes de observadores externos e información publicada y no publicada para recoger los datos a analizar. Cabe destacar que el trabajo de Maistry y Ramdhani (2010) complementa su estudio cualitativo con una investigación cuantitativa, utilizando los cuestionarios como herramienta de investigación, y que el único estudio totalmente cuantitativo es el de Kirby e Ibrahim (2011), en el que los datos son recogidos a través de un cuestionario con preguntas abiertas y cerradas, de sí o no y de reconocer conceptos.

En cuanto a la muestra de las investigaciones, existe una predominancia de trabajos con muestras muy reducidas, especialmente en los trabajos cualitativos, donde el tamaño de muestra más elevado es de 21 sujetos. En cambio, las muestras de los estudios cuantitativos son algo mayores, 77 y 183 sujetos aunque, como ya hemos comentado, el uso de esta metodología de 
investigación es minoritario. Respecto a los sujetos de estudio, las investigaciones se centran en casos exitosos de ES, responsables de empresas sociales y organizaciones sin ánimo de lucro, profesores y estudiantes, por lo que tampoco podemos destacar tendencias en este aspecto.

El análisis de la principales conclusiones de estos trabajos revela que Alvord et al. (2004) reconocieron 3 tipos de iniciativas distintas, pudiendo centrarse en la construcción de capacidad local, la creación de movimiento o la difusión del programa realizado. Las iniciativas de construcción de capacidad se asociaron con la atención a los grupos locales y los proveedores de recursos, las iniciativas de difusión afectaban a usuarios y divulgadores, mientras que las iniciativas de creación de movimiento se centraban en las relaciones externas con posibles socios y agentes políticos. No obstante, también aparecieron factores comunes entre las distintas iniciativas, pues todas ellas demostraron el potencial de llegar a millones de personas y fomentar la transformación social a nivel cultural, económico y político. Del mismo modo, los distintos tipos de iniciativas trataron de movilizar y aprovechar los bienes de los grupos afectados para producir cambios sostenibles. Por último, se indica que la capacidad para establecer conexiones y el liderazgo adaptativo parecían estar presentes en todas las iniciativas exitosas. Por otra parte, el estudio de Sharra (2005) discute que mientras el ES comparte aspectos similares a los del activismo por la justicia social, la ética corporativa y de negocios, la idea del emprendimiento no se ajusta a las preocupaciones sociales que los maestros y otros educadores tratan en su vida diaria. Por tanto, advierte que se pueden encontrar distinciones entre la educación y el ES.

Los resultados de la investigación realizada por Spear (2006) proporcionan modelos de ES interesantes que contrastan con los modelos convencionales de las PYMEs. Así pues, se indica que las motivaciones de los emprendedores sociales eran muy diversas $y$, aunque todas ellas incluían orientaciones ideológicas, la elección institucional estaba mediatizada por los profesionales, los asesores y las organizaciones de apoyo. Por otra parte, en todas las actividades analizadas se desarrolló cierto nivel de innovación, aunque no necesariamente en la etapa de formación. El trabajo de Weerawardena y Mort (2006) determina que el ES es sensible y está limitado por el entorno contextual, la misión social y la sostenibilidad organizativa, teniendo una influencia directa sobre la búsqueda y el reconocimiento de oportunidades. Igualmente, también concluye que el ES se esfuerza por lograr la creación de valor social a través del desarrollo de la innovación, la proactividad y la gestión del riesgo.

Las conclusiones globales del estudio de Maistry y Ramdhani (2010), indican que los estudiantes demandaban un papel más importante en la planificación del proceso emprendedor, lo que habría facilitado la comunicación con los diferentes sujetos implicados, y que el programa de APS aplicado proporcionó un contexto adecuado en el que los estudiantes del Grado en Maestro iniciaron un proceso de introspección sobre su papel como maestros, generando cambios en su forma de pensar sobre el proceso pedagógico. Como podemos ver, este trabajo presenta numerosas similitudes con la presente tesis pues, al igual que los autores, estamos convencidos de las potencialidades y beneficios de la investigación sobre esta temática. Por otra parte, Kirby e Ibrahim (2011) señalan que, a pesar de que las organizaciones Ashoka Arab World, Schwab Foundation y YES Egypt hacen mucho para apoyar y promover el ES en Egipto, los estudiantes están confundidos sobre lo que es 
un emprendedor social y qué función desempeña. Por ello, la mayor parte de los estudiantes reconocía su deseo de trabajar en empresas multinacionales y el desconocimiento de la existencia de emprendedores sociales en Egipto. No obstante, una parte considerable de la muestra estaba interesada en establecer una empresa social, aunque reconocían que el principal problema que tenían para hacerlo era la falta de conocimiento e información.

Cabe destacar que algunos trabajos aportan reflexiones interesantes como que el ES analizado no era una actividad individual $y$, aunque el emprendedor desempeñe un papel central, se trabajó en equipo con otros colectivos; que el ES presenta una dimensión transitoria, desarrollándose a través de los sectores público y privado (Spear, 2006), y que el alumnado necesitaba apoyo, especialmente en cuanto a su formación y tutorización, demostrando con ello que no solo deben aprender acerca del ES, sino que también necesitan ser equipados con una serie de habilidades, destrezas y actitudes para desenvolverse adecuadamente en el ámbito del ES (Kirby e Ibrahim, 2011).

Tras todo lo expuesto, podemos concluir que la línea de actuación habitual en los estudios relacionados con el ES es la de realizar investigaciones cualitativas con muestras muy reducidas, no existiendo preferencias en cuanto al objetivo, el contexto y los sujetos de estudio. Como podemos ver, estas tendencias son muy distintas, y en algunos casos contrarias, a las expuestas en los estudios académicos vinculados con el emprendimiento en el ámbito educativo. Por ello, con la intención de clarificar estas conclusiones, a continuación destacamos dos publicaciones en las que se revisan y analizan múltiples trabajos de investigación en el ámbito del ES.

El objetivo del estudio realizado por Hoogendoorn, Pennings y Thurik (2010) es evaluar el estado de la investigación en el campo del ES. Para ello se revisan 31 estudios empíricos, realizando un análisis a nivel metodológico general y a nivel de contenido. Este análisis se hace teniendo en cuenta las distintas corrientes de pensamiento existentes respecto al ES, en base a cuatro aspectos propios de esta área. Así pues, se describen las peculiaridades de las distintas posibilidades, la escuela de innovación social, la escuela de la empresa social, la tradición europea y la escuela británica, y se analizan los trabajos en función de la perspectiva individual, el proceso, la organización y el entorno de cada investigación.

Después de analizar los resultados, se extraen las siguientes conclusiones a nivel metodológico general: hay un número limitado de estudios empíricos con un enfoque de investigación cuantitativa, principalmente de tipo exploratorio, y con tan solo un estudio que utiliza la aplicación de cuestionarios; existe una carencia de verificación de hipótesis rigurosas; se aplica poca variedad en el diseño de investigación; prevalece el uso de datos primarios; y se estudian muestras relativamente pequeñas. Respecto al contenido de los trabajos se observa que ninguna de las corrientes de pensamiento analizadas está suficientemente representada y que cada una de ellas cubre un amplio espectro de temáticas. Al mismo tiempo, la mayoría de los temas se abordan por solo unos pocos estudios y utilizando distintas muestras. Según los autores, todo esto no hace más que confirmar que la investigación científica en el ámbito del ES se encuentra en una etapa infantil, con mucho camino por recorrer pero ofreciendo numerosas posibilidades para seguir avanzando. 
Como ya hemos visto en el apartado anterior, el trabajo de Short et al. (2009) analiza el fenómeno del ES y plantea un modelo conceptual con 8 secciones interrelacionadas. En este apartado vamos a centrarnos en su profunda revisión bibliográfica para conocer más ampliamente el estado de la investigación relacionada con el ES. Para ello, los autores identifican y analizan los artículos publicados en las principales revistas de gestión y emprendimiento, donde el foco de atención estuviera centrado en el fenómeno del ES.

Tras señalar que este ámbito de estudio es relativamente reciente, los autores destacan 152 artículos pertenecientes a una amplia gama de disciplinas académicas. A continuación mostramos las distintas disciplinas con el número de artículos relacionados a cada una de ellas: gestión (40), emprendimiento (17), ciencias políticas (15), economía, (14), marketing (9), sociología (7), educación (7), derecho (2), finanzas (1) y antropología (1). También se encuentra un número importante de publicaciones relacionadas con diversas áreas del ámbito de los negocios (25) y otros ámbitos de conocimiento (14), además de destacar la ausencia de publicaciones en áreas como la contabilidad, la gestión de operaciones o la psicología. Estos datos iniciales indican que la investigación sobre ES está empezando a llegar a un amplio público y que puede haber interés suficiente para justificar la colaboración académica interdisciplinaria. También se observó que los 152 artículos analizados habían sido citados hasta la fecha en 595 ocasiones. Los artículos más citados estaban publicados en las revistas de administración pública (Public Administration Review) y gestión (Academy of Management Journal y Management Decision). También se destaca el hecho de que las citas en revistas de gestión y emprendimiento representaban un 30\% de las citas totales (179), lo que sugiere que el impacto de la investigación sobre ES en estos dos campos era considerable en comparación con el resto de disciplinas.

Entre los artículos analizados en esta revisión, se encontraron 80 de carácter conceptual (52\%) y 72 de naturaleza empírica (48\%). Siguiendo a Kerlinger (1986) y Snow y Thomas (1994), los artículos conceptuales se clasificaron en función de su propósito, obteniendo 44 explicativos $(55 \%)$, 30 descriptivos (38\%) y 6 predictivos (7\%). De entre estos 80 trabajos conceptuales, tan solo en 6 de ellos $(8 \%)$ se utilizaron hipótesis formales. Como mostramos a continuación, los 72 trabajos empíricos fueron analizados en función del uso de hipótesis formales, el método de investigación, la fuente de los datos, el marco geográfico de investigación, el tamaño de la muestra y medición del ES (Boyd, Gove y Hitt, 2005; Dean, Shook y Payne, 2007; Short, Ketchen y Palmer, 2002).

- Uso de hipótesis formales: de los 72 trabajos empíricos, tan solo 2 (3\%) establecían hipótesis operacionales que pudieran ser rigurosamente probadas, y 4 (5\%) presentaban hipótesis generales basadas en sus estudios de casos y fundamentaban teóricamente su metodología. Sumando estos registros a los datos obtenidos en los trabajos conceptuales, el total de artículos revisados que presentan el uso de hipótesis formales no llega al 8\%.

- Método de investigación: se encontraron 54 trabajos de investigación cualitativa (74\%), 16 trabajos cuantitativos (22\%) y 3 trabajos sin una metodología de investigación específica (4\%). De entre los trabajos cualitativos, $43(60 \%)$ se basaron principalmente en el estudio de casos, $8(11 \%)$ desarrollaron una teoría fundamentada sobre el ES, 2 (3\%) utilizaron el análisis 
discursivo y 1 ( $2 \%$ ) empleó métodos interpretativos. Respecto a los trabajos cuantitativos, 14 (19\%) informaron de la estadística descriptiva, 6 (8\%) reportaron correlaciones, 2 (3\%) utilizaron un análisis de regresión, 2 (3\%) emplearon el modelado de ecuaciones estructurales, 1 (2\%) informó de pruebas T, 1 (2\%) utilizó rankings y otro único artículo (2\%) realizó un análisis de agrupaciones.

- Recolección de datos: los datos de las diferentes investigaciones se obtuvieron a través de entrevistas 49 (68\%), datos secundarios 21 (29\%), encuestas 16 (22\%), observación 10 (14\%), y otras fuentes no especificadas 11 (15\%).

- Marco geográfico de investigación: el país en el que se habían llevado a cabo más estudios empíricos era el Reino Unido con 24 trabajos (33\%), seguido por los E.E.U.U. con 18 (25\%). Otros 25 artículos (35\%) estaban distribuidos entre la India con 4, Canadá y Brasil con 3 cada uno, Australia, China y Holanda con 2, e Israel, Italia, Kenya, Nepal, Nueva Zelanda, Nigeria, Noruega, Sudáfrica y España con solo 1 artículo por país. Finalmente, 5 artículos (7\%) utilizaban muestras de diversos países en la misma investigación. Cabe destacar que los estudios revisados se centraron en gran variedad de sectores sociales, entre ellos el desarrollo económico, la educación, el medio ambiente, el gobierno, la salud y los servicios sociales, la vivienda, el mobiliario, la filantropía, el capital de riesgo y la tecnología.

- Tamaño de la muestra: los trabajos empíricos analizados en esta revisión presentaban una mediana de 5 para la muestra y una media de 1149 observaciones por artículo. No obstante, al analizar con detenimiento los datos, se observa un sesgo de interpretación provocado por los 16 estudios cuantitativos, ya que al excluirlos el promedio de observaciones se reducía a tan solo 15 por artículo.

- Medición del Emprendimiento Social: se encontraron 271 medidas, bien para realizar operaciones (artículos cuantitativos) o bien considerándolas valiosas para la argumentación del trabajo sin ofrecer detalles métricos (artículos cualitativos). Los 16 artículos que utilizaron métodos cuantitativos emplearon principalmente encuestas de medida de tipo Likert sobre el apoyo gubernamental, el estatus social percibido, el número de innovaciones o la cantidad de contribuciones caritativas. De entre estos 16 trabajos, 8 examinaron el ES como una variable independiente y otros 8 como una variable dependiente. El primer grupo de artículos presentaba medidas relacionadas con los procesos y los recursos utilizados por las empresas sociales para mejorar, incluyendo la misión social y las características del emprendedor, la organización y el sector de la industria. El segundo grupo describía resultados como el impacto social o las formas en que las empresas sociales revierten en la comunidad mediante la innovación y la creación de empleo.

Basándose en los hallazgos conceptuales, los autores consideran que el progreso académico en la investigación sobre el ES no se acelerará hasta que las relaciones teóricas se hagan más explícitas para dirigir las preguntas de investigación, y la recolección de datos y los métodos analíticos sean principalmente cuantitativos, reflejando así el sentimiento de Cummings (2007).

En cuanto el análisis de los estudios empíricos, se observa que la investigación del ES se caracteriza por la predominancia de trabajos cualitativos. Siguiendo con esta argumentación, se 
indica que uno de los mayores desafíos en la investigación del ES es la recogida y medición de datos. Del mismo modo, los autores resaltan que acceder a bases de datos a gran escala ha sido particularmente difícil y que se necesitan soluciones creativas para alcanzar el tamaño de muestra necesario para la aplicación rigurosa de las técnicas multivariables. Así pues, sugieren que una vía fructífera para futuros trabajos empíricos podría encontrarse en la medición del resultado del valor social creado en áreas como la sostenibilidad del medio ambiente, el apoyo y/o donación a causas sociales, los esfuerzos de mejora de la comunidad, las innovaciones destinadas a atender las necesidades sociales o la elaboración de acciones políticas diseñadas a lograr el cambio social. Igualmente, futuros estudios sobre ES podrían evaluar si existen diferencias entre las medidas registradas en estas investigaciones en comparación con las medidas de rendimiento declaradas por las empresas sociales $u$ otras organizaciones respecto a su misión social, como plantean Palmer y Short (2008). Por otra parte, los autores demandan una mayor cantidad de trabajos de investigación rigurosos tanto cuantitativos como cualitativos. Siguiendo la argumentación de Van de Ven y Johnson (2006), una variedad de métodos y modelos de investigación aumentarán la validez, fiabilidad y aprendizaje del estudio, ya que se requiere comparar y contrastar diferentes perspectivas para discriminar la información valiosa en problemas de alta complejidad. Además se apunta que la realización de trabajos inductivos y deductivos sería beneficiosa para avanzar en la investigación del ES. De igual modo, la comparación de investigaciones que utilicen técnicas como entrevistas, encuestas o análisis de contenido narrativo revelarían si las dimensiones de la orientación emprendedora es común entre los emprendedores comerciales y sociales, y qué factores son los más asociados con las diferencias de rendimiento organizativo en cada ámbito. No obstante, los autores señalan que ningún estudio empírico sobre ES ha examinado directamente la orientación emprendedora.

Como podemos ver, ambos documentos reafirman nuestras conclusiones respecto a las tendencias de investigación en materia de ES. Así pues, teniendo en cuenta esta información, la presente tesis intenta aportar un avance novedoso y significativo en el estudio de esta materia.

Seguidamente resumimos las principales ideas extraídas en cuanto a los antecedentes de investigación sobre el emprendimiento relacionadas con el ámbito educativo, especialmente en su vertiente social:

1. La mayor parte de trabajos están relacionados con la vertiente económica, prestando una menor atención a su perspectiva social.

2. El estado de la investigación sobre el ES aún se encuentra en una etapa inicial, a la espera de realizar una mayor cantidad de estudios académicos.

3. Los estudios sobre ES carecen de una gran variedad en cuanto a la metodología de investigación, siendo estos mayoritariamente cualitativos.

4. El número de estudios cuantitativos sobre ES es muy limitado, principalmente de tipo exploratorio y con una escasa aplicación de cuestionarios.

5. Existe una carencia de trabajos rigurosos sobre ES, ofreciendo pocos estudios que utilicen la verificación de hipótesis. 
6. El tamaño de las muestras y, por consiguiente, de los datos de investigación, en los estudios relacionados con el ES, es relativamente pequeño.

Teniendo en cuenta estas consideraciones, en el siguiente apartado analizamos la figura del emprendedor social y las características que lo definen. Esto ampliará nuestra comprensión sobre el fenómeno del ES y nos ayudará a conocer los rasgos personales propios del emprendedor social, permitiéndonos así reconocerlos y valorarlos.

\subsection{Características y rasgos del Emprendedor Social}

Tras analizar el concepto de ES, así como sus antecedentes en el campo de la investigación, a continuación vamos a centrarnos en la figura del emprendedor social con la intención de conocer los rasgos de su personalidad.

Revisando algunas de las definiciones sobre los emprendedores sociales, comprobamos que Boschee $(1998$, p.2) entiende que son "ejecutivos sin ánimo de lucro que prestan cada vez más atención a las fuerzas del mercado, sin perder de vista sus misiones fundamentales, para equilibrar de alguna manera los imperativos morales y los motivos de lucro". Thompson et al. (2000) consideran que los emprendedores sociales son personas que se dan cuenta de dónde hay una oportunidad para satisfacer alguna necesidad no atendida que el sistema de bienestar social del estado no puede cubrir, y que son capaces de reunir los recursos necesarios respecto a personal, voluntarios, fondos e instalaciones, y los utilizan para crear una diferencia. Otros autores apuntan que:

"una persona jurídica es un emprendedor social solo en el caso de que intente pasar de la situación inicial a la final obteniendo beneficios para la sociedad o un segmento de ella, mediante la innovación y enfrentándose a un riesgo, de una manera que implique a la sociedad o a un segmento de ella" (Tan et al., 2005, p. 359).

Por otra parte, Martin y Osberg (2007) determinan que la actuación del emprendedor social está inspirada para revertir una situación desagradable continuada, se plantea de forma creativa y desarrolla una nueva solución que rompe radicalmente con lo existente, demuestra coraje durante todo el proceso de innovación soportando la carga del riesgo y enfrentándose directa y repetidamente a la posibilidad de fracasar, y tiene la fortaleza para manejar sus soluciones creativas a través de la aplicación y aprobación del mercado. De este modo, cuando esta acción se aplica con éxito, se genera una nueva situación estable que proporciona un nivel de satisfacción significativamente más alto para los implicados en el proceso. En cambio, Tracey y Phillips (2007) opinan que los emprendedores sociales son individuos que combinan objetivos sociales y 
comerciales, mediante el desarrollo de soluciones económicamente sostenibles para resolver problemas sociales. Mientras, otros autores indican que el emprendedor social es:

"una persona visionaria, cuyo principal objetivo es la creación de valor social, capaz al mismo tiempo de detectar y explotar oportunidades, para aprovechar los recursos necesarios para su misión social y encontrar soluciones innovadoras a los problemas sociales de su comunidad que no se encuentran adecuadamente por el sistema habitual. Esto hará que adopte un comportamiento emprendedor." (Bacq y Janssen, 2011, p. 388).

Roper y Cheney (2005) destacan la labor de los emprendedores sociales, enfatizando la orientación del valor creado y el liderazgo carismático que transmiten. Clasifican este colectivo en tres categorías: miembros de organizaciones emprendedoras, emergentes o consolidadas, innovadoras y socialmente responsables; administradores de organizaciones no lucrativas o grupos de defensa social que importan negocios y modelos basados en el mercado para mejorar el rendimiento de su organización y aumentar su longevidad; $y$, por último, grandes filántropos que se ven a sí mismos como catalizadores tanto del cambio organizativo como social.

Como podemos ver en estas definiciones, al igual que sucedía con el ES, no existe una idea clara y universalmente aceptada de cómo es un emprendedor social. Anteriormente hemos visto que la escuela de innovación social es una de las corrientes de pensamiento dominantes en el estudio del ES. Esta perspectiva hace hincapié en la importancia del emprendedor social como individuo y se centra en el estudio de sus características. Teniendo en cuenta esta visión, numerosos trabajos han analizado la figura del emprendedor social desde diversos puntos de vista. Por ello, a continuación presentamos un análisis de los rasgos característicos del emprendedor social descritos por diversos autores que siguen esta corriente de pensamiento, tanto en documentos teóricos como en artículos de investigación, con la intención de extraer los elementos comunes entre las distintas aportaciones y elaborar una definición propia. Cabe destacar que en este apartado se han incluido trabajos que analizan la personalidad emprendedora tanto desde su vertiente social como desde un punto de vista genérico pues, como ya hemos visto, ambos perfiles convergen en múltiples puntos.

Revisando la bibliografía de trabajos afines a la escuela de innovación social se observan varios patrones comunes a la hora de analizar las características del emprendedor social. Así pues, consideramos que existen tres líneas de análisis dominantes. La primera hace referencia a los aspectos de carácter personal, la segunda se centra en destacar los aspectos de carácter social y, por último, la tercera incide en los aspectos innovadores del emprendedor social.

En cuanto a la primera línea de análisis, podemos destacar el documento elaborado por Valls et al. (2009) sobre el ES juvenil, el cual determina que las características básicas del emprendedor son la iniciativa, la creatividad, el compromiso, el liderazgo, la visión de futuro, la autoconfianza, la capacidad de asumir riesgos, la tenacidad y el pensamiento positivo. Siguiendo un planteamiento 
similar, Enciso-Congote (2010) considera que las competencias que se asocian al emprendimiento son la motivación de logro, la asunción de riesgos, la autoconfianza, la tolerancia al fracaso, la habilidad para identificar oportunidades y la capacidad para aprender de las experiencias. De igual modo, en el trabajo de Ali et al. (2010) se destaca que los mayores atributos de la personalidad emprendedora son: elevado nivel de éxito, alta intención emprendedora, disposición inicial, alta aceptación emprendedora, comportamiento creativo, iniciativa, capacidad para asumir responsabilidades, capacidad para asumir riesgos, auto-confianza, lugar de control interno, autonomía y necesidad de independencia, compromiso y ejecución de tareas con energía, construcción de equipos, trabajo en equipo y de forma independiente, trabajo bajo presión, liderazgo, competencia analítica y persistencia respecto a los objetivos (Martínez, Mora y Vila, 2007; Schmitt-Rodermund, 2004). Teniendo en cuenta esta premisa, los autores elaboran un cuestionario para medir la intención emprendedora que se divide en las categorías de necesidad de éxito, lugar de control, autoeficacia, disposición inicial, cumplimiento de normas e intenciones emprendedoras.

Esta primera línea de análisis es la corriente dominante entre las tres tendencias descritas, algo que queda patente en el documento elaborado por De Pablo, Santos y Bueno (2004) sobre las dimensiones del perfil del emprendedor, donde se expone una revisión de los aspectos individuales más analizados en la literatura, presentando hasta un total de 43 . Entre ellos podemos destacar: necesidad y/o reconocimiento de logro; aceptación de riesgos moderados; creatividad, imaginación e innovación; liderazgo; orientación hacia las oportunidades; capacidad de conseguir recursos; toma de iniciativa y capacidad para asumir nuevos retos; autoconfianza y control interno; percepción del beneficio económico y ambición; patrón de factores de producción; tolerancia frente a la ambigüedad, la presión, los cambios y la incertidumbre; perseverancia y compromiso total; versatilidad y flexibilidad; receptiviad en sus relaciones sociales; energía e impulso; necesidad de independencia y autonomía; capacidad para analizar el ambiente y reflexionar; conocimiento del negocio; gerencia y administración de recursos; capacidad de decisión; orientación hacia metas específicas; planificación y seguimiento sistemático; visión comprensiva de los problemas; redes de contacto; capacidad para trabajar duro; capacidad para solucionar problemas; necesidad de escape; honestidad, integridad y confianza; responsabilidad personal; planificación con límites de tiempo; necesidad de aprobación; estabilidad emocional y autocontrol; capacidad para exigir eficiencia y calidad; necesidad de desarrollo personal; baja necesidad de poder y status; sentido de urgencia y tiempo valioso; búsqueda de información veraz; dueño de la empresa; comunicador; necesidad de cumplimiento; individualista; consideración de la opinión de los colaboradores y autoeficacia.

En cuanto a la segunda línea de análisis, aquella que se centra en los aspectos sociales del emprendedor social, el trabajo de Weerawardena y Mort (2006) indica que diversos investigadores han argumentado que los emprendedores sociales poseen varias características de liderazgo como la integridad, la credibilidad y la capacidad de generar seguidores comprometidos con proyectos enmarcados en términos de valores sociales en lugar de los puramente económicos (Borins, 2000; Lewis, 1980; Waddock y Post, 1991). Así pues, este trabajo concluye presentando un modelo multidimensional en el que indica que las características del emprendedor social son: capacidad de 
innovación, proactividad, capacidad para adaptarse a la dinámica del entorno, capacidad para gestionar el riesgo, sostenibilidad, orientación hacia la misión social y capacidad para buscar y reconocer oportunidades. Desde esta misma perspectiva, otros autores consideran que los emprendedores sociales desempeñan el papel de agentes de cambio, caracterizándose por:

"adoptar la misión de crear y sostener valor social (valor no solo privado); reconocer y perseguir de forma implacable nuevas oportunidades para servir a esa misión; participar en un proceso continuo de innovación, adaptación y aprendizaje; actuar con valentía sin estar limitado por los recursos de los que se dispone actualmente; y exponer un elevado sentido del rendimiento de cuentas a los grupos atendidos y de los resultados creados." (Dees, 1998b, p. 4).

Por último, la tercera línea de análisis resalta los aspectos innovadores de la personalidad del emprendedor social. Así pues, el trabajo de Alvord et al. (2004) determina las siguientes cualidades del emprendedor social: características de innovación, características de iniciativa, liderazgo y organización, y en el impacto de la expansión y la transformación social. La primera categoría incluye el núcleo de la innovación, la movilización de activos y capacidades para los receptores del servicio, y el énfasis en el aprendizaje continuo. La segunda categoría hace referencia a la capacidad de establecer conexiones y a los aspectos de organización operativa. Por último, la tercera categoría menciona las estrategias de expansión, la continuidad de transformación (en cuanto a estabilidad y permanencia) y el impacto global de la iniciativa.

Por otra parte, también existen trabajos que analizan varias de las líneas descritas en el estudio de la personalidad del emprendedor social, combinando la valoración de aspectos personales, sociales e innovadores. Por ejemplo, la publicación del Ministerio de Industria, Comercio y Turismo en colaboración con el Ministerio de Educación y Ciencia de España (2003), describe los nueve valores indispensables del espíritu emprendedor. Estos se presentan divididos en personales, entre los que encontramos la creatividad, la autonomía, la confianza en uno mismo, la tenacidad, el sentido de la responsabilidad y la capacidad para asumir riesgos, y sociales, donde se ubican el liderazgo, el espíritu de equipo y la solidaridad. De igual modo, tras considerar los trabajos de diferentes autores, Sánchez (2010) determina que los principales rasgos de la personalidad emprendedora son el lugar de control, la autoeficacia, la propensión al riesgo y la personalidad proactiva. Esta última es la que está más relacionada con los aspectos sociales del emprendedor social por lo que para profundizar en el conocimiento de sus características nos remitimos al texto de Moraleda, González y García-Gallo (2004) donde se destacan las siguientes actitudes y estrategias cognitivas sociales: conformidad con lo socialmente correcto, sensibilidad social, ayuda y colaboración, seguridad y firmeza en la interacción y liderazgo prosocial.

Sin embargo, estás aportaciones teóricas han tenido escasa influencia sobre los trabajos de investigación en este campo, donde se ha analizado la figura del emprendedor desde un punto de vista menos definido. Así pues, el estudio realizado por Dixon et al. (2005) pretende comprobar las 
competencias necesarias para ser emprendedor. Las 8 categorías en las que se organizaron las diferentes competencias eran: liderazgo de equipo, percepción de confiabilidad, habilidades de planificación y organización, habilidades básicas de negocio, habilidad para resolver problemas, habilidades de comunicación, rasgos personales y creatividad. Tras analizar los resultados de la investigación se destacan 39 de las 66 competencias iniciales: es diplomático en el lugar de trabajo, exige la excelencia de todos los compañeros, demuestra don de gentes, comparte información con los compañeros, es un buen mentor, no tiene miedo de cometer errores, es capaz de evaluar los riesgos, puede realizar varias tareas, está al tanto del reglamento de seguridad y salud, está comprometido con el trabajo, es capaz de cumplir los plazos de trabajo, entiende qué procesos son valiosos, demuestra buenas habilidades de análisis, tiene habilidad para gestionar problemas, es capaz de priorizar conflictos, tiene buenas habilidades de pensamiento crítico, es capaz de resolver problemas, utiliza la información para tomar decisiones, está dispuesto a escuchar a los demás, tiene buenas habilidades de comunicación, tanto verbal como escrita, posee buenas habilidades interpersonales, está orientado hacia un objetivo, desea tener éxito, posee una alta autoestima, tiene una perspectiva positiva de la vida, posee autoconocimiento, puede transferir conocimientos e ideas, tiene buenas habilidades de visualización, muestra una buena disposición para correr riesgos, es honesto, digno de confianza, integro, fiable, comprometido, leal, responsable, creativo y seguro de sí mismo.

De igual modo, las investigaciones realizadas por Harris, Gibson y Taylor (2007) y Norasmah et al. (2012) analizan el emprendimiento a partir de varios instrumentos de valoración, entre los que podemos destacar el cuestionario de orientación emprendedora elaborado por Robinson, Stimpson, Huefner y Hunt (1991). Este cuestionario analiza cuatro características básicas del emprendedor: logro, situación inicial y crecimiento; innovación y uso de métodos innovadores en sus actividades; percepción personal de control de los resultados, control individual e influencia; y percepción de autoestima, autoconfianza y competencia. No obstante, la herramienta de medida creada por Norasmah et al. (2012) es más completa y está dividida en dos grandes secciones. La primera hace referencia a la disposición de preparación hacia el emprendimiento y está compuesta por la disposición de actitud (innovación, autocontrol, logro, autoestima, control sobre el riesgo y tolerancia a la ambigüedad), la disposición de aprendizaje (iniciativas de aprendizaje y preparación de aprendizaje) y la disposición de espíritu (valores morales, buenas prácticas y confianza). En la segunda sección se enmarca la disposición de capacidad hacia el emprendimiento e incluye la disposición del pensamiento emprendedor (análisis contextual, generación de ideas y sensibilidad para el mercado), la disposición de la vocación emprendedora (habilidades de gestión de negocios, habilidades de manipulación y habilidades de marketing) y la disposición de contexto interno (profesores, currículum académico, recursos de apoyo y condiciones del campus).

Por otra parte, la investigación realizada por Lee y Lai (2010) analiza el potencial emprendedor a través del cuestionario elaborado por Macke y Markley (2003) en el que se analizan la motivación, la capacidad y el apoyo de la personalidad emprendedora. La primera categoría está compuesta por los siguientes elementos: motivación, orientación de crecimiento, creatividad, innovación, ingenio para superar las dificultades, dinamismo, capacidad para trabajar, flexibilidad respecto al cambio, 
tolerancia al riesgo, disposición para aprender y competencia y capacidad de colaboración. La segunda categoría, capacidad, incluye tanto habilidades empresariales como habilidades para trabajar con otras personas u organizaciones. Finalmente, la categoría que hace referencia al apoyo está compuesta por diversos ítems indefinidos.

Como podemos ver, estos estudios no siguen las líneas descritas en los trabajos teóricos, y analizan tanto aspectos personales, sociales e innovadores, como otros aspectos más relacionados con las habilidades empresariales y las actividades financieras. No obstante, los aspectos sociales, innovadores $y$, especialmente, los personales son abordados con gran profundidad en la mayor parte de los trabajos. Prueba de ello son los estudios realizados por Ram y Selvaraj (2012) y Ghazali et al. (2013). El primero indica que las habilidades a desarrollar en la educación del emprendimiento son la comunicación efectiva, la resolución de problemas y el pensamiento crítico, el trabajo en equipo, el aprendizaje continuo y la gestión de la información, la capacidad para emprender, la ética y moral profesional, la capacidad de gestión, el liderazgo y la orientación hacia a las operaciones internacionales. Por otra parte, el segundo trabajo utiliza un cuestionario en el que se analizan los siguientes aspectos de la personalidad emprendedora: innovación y creatividad, actitud y habilidad social, autogestión, deseo de éxito, habilidad para resolver problemas, liderazgo, capacidad de financiación, capacidad de marketing e intención emprendedora. Por otra parte, la investigación realizada por Ferrer, Cabrera, Alegre, Montané, Sánchez y Alaiz (2014) determina que las competencias que el alumnado de los Grados en Educación Social, Pedagogía y Trabajo Social de la Universidad de Barcelona consideran tener para iniciarse y aventurarse hacia el ES son: capacidad de liderazgo, habilidades sociales y comunicativas, experiencia comercial y empresarial, proactividad, creatividad e innovación, motivación, iniciativa, sensibilidad, compromiso social, confianza, trabajo en equipo y cooperación, responsabilidad, análisis y resolución de problemas y formación en gestión de proyectos.

Teniendo en cuenta la revisión bibliográfica realizada y las aportaciones de los diversos autores, a continuación presentamos la tabla $16^{15}$ donde situamos los 19 rasgos característicos que, a priori, consideramos que definen a un emprendedor social. Como se puede apreciar, la selección de dichos rasgos se ha basado fundamentalmente en su gran frecuencia de aparición en los trabajos revisados. Para facilitar la organización de esta información, la hemos clasificado en función de las tres categorías de análisis dominantes en este campo: aspectos de carácter personal, aspectos de carácter social y aspectos de carácter innovador.

\footnotetext{
${ }^{15}$ En esta tabla se ha omitido el formato abreviado de las referencias bibliográficas citadas, ya que dichas referencias representan el contenido esencial de la propia tabla.
} 
Tabla 16. Rasgos característicos que definen la personalidad del Emprendedor Social (ampliado de Capella, Gil, Martí y Ruiz-Bernardo, en prensa).

\section{CATEGORÍA 1. ASPECTOS DE CARÁCTER PERSONAL}

-[Baumol (1968); Drucker (1984); Hawkins y Turla (1987); Jarillo (1986); Nelson y Neck (1981); Timmons (1989); Welsh y White (1983)] citados en De Pablo, Santos y Bueno (2004)

-[Borins (2000); Lewis (1980); Waddock y Post (1991)] citados en Weerawardena y Mort (2006)

-Dixon, Meier, Brown y Custer (2005)

Liderazgo

-Ferrer, Cabrera, Alegre, Montané, Sánchez y Alaiz (2014)

-Ghazali, Ibrahim y Zainol (2013)

-[Martínez, Mora y Vila (2007); Ramayah y Harun (2005); Rodermund (2004)] citados en

Ali, Topping y Tariq (2010)

-Ministerio de Industria, Comercio y Turismo, y Ministerio de Educación y Ciencia (2003)

-Moraleda, González, y García-Gallo (2004)

-Ram y Selvaraj (2012)

-Valls, Villa, Martínez y Hernando (2009)

-Ali, Topping y Tariq (2010)

-Dixon, Meier, Brown y Custer (2005)

-Enciso-Congote (2010)

-Ferrer, Cabrera, Alegre, Montané, Sánchez y Alaiz (2014)

-Ghazali, Ibrahim y Zainol (2013)

-[Hawkins y Turla (1987); Hornaday y Aboud (1971); Leíbenstein (1968); Ludevid y Ollé (1993); McClelland (1961); Patel (1989); Veciana (1989); Vesper (1980)] citados en De Pablo, Santos y Bueno (2004)

Motivación al logro

-Harris, Gibson y Taylor (2007)

-[Korunka, Frank, Lueger y Mugler (2003)] citado en Sánchez (2010)

-Lee y Lai (2010)

-Macke y Markley (2003)

-[Martínez, Mora y Vila (2007); Ramayah y Harun (2005); Rodermund (2004)] citados en

Ali, Topping y Tariq (2010)

-Norasmah, Norashidah y Hariyaty (2012)

-Robinson, Stimpson, Huefher y Hunt (1991)

-Ram y Selvaraj (2012)

-Weerawardena y Mort (2006)

-[Baron y Markman (1999); Claver y Gómez (1979); Gibb y Ritchie (1982); Hawkins y Turla (1987); Hornaday y Aboud (1971); Hull, Bosley y Udell (1980); Jarillo (1986); Timmons (1989)] citados en De Pablo, Santos y Bueno (2004)

-[Covin y Slevin (1989); Das y Teng (1997); McCelland (1961); Segal, Borgia y Schoenfeld (2005); Sexton y Bowman (1983); Shepherd y Douglas (1997)] citados en Sánchez (2010)

-Dees (1998b)

-Dixon, Meier, Brown y Custer (2005)

Capacidad para

-Enciso-Congote (2010)

asumir riesgos

-Lee y Lai (2010)

-Macke y Markley (2003)

-[Martínez, Mora y Vila (2007); Ramayah y Harun (2005); Rodermund (2004)] citados en Ali, Topping y Tariq (2010)

-Ministerio de Industria, Comercio y Turismo, y Ministerio de Educación y Ciencia (2003)

-Norasmah, Norashidah y Hariyaty (2012)

-Valls, Villa, Martínez y Hernando (2009)

-Weerawardena y Mort (2006) 
-[Bandura (1997); Chen, Greene y Crick (1998)] citados en Sánchez (2010)

-[Claver y Gómez (1979); Gasse (1989); Hawkins y Turla (1987); Le Brass (1995); Nelson y Neck (1981); Timmons (1989); Veciana (1989)] citados en De Pablo, Santos y Bueno (2004)

-Dixon, Meier, Brown y Custer (2005)

-Enciso-Congote (2010)

-Ferrer, Cabrera, Alegre, Montané, Sánchez y Alaiz (2014)

Confianza

-Harris, Gibson y Taylor (2007)

-[Martínez, Mora y Vila (2007); Ramayah y Harun (2005); Rodermund (2004)] citados en Ali, Topping y Tariq (2010)

-Ministerio de Industria, Comercio y Turismo, y Ministerio de Educación y Ciencia (2003)

-Moraleda, González y García-Gallo (2004)

-Norasmah, Norashidah y Hariyaty (2012)

-Robinson, Stimpson, Huefher y Hunt (1991)

-Valls, Villa, Martínez y Hernando (2009)

-[Covin y Slevin (1989)] citado en Sánchez (2010)

-Dees (1998b)

-Dixon, Meier, Brown y Custer (2005)

-Ferrer, Cabrera, Alegre, Montané, Sánchez y Alaiz (2014)

Responsabilidad -[Harwood (1982); Ludevid y Ollé (1993); McClelland (1961); Timmons (1989)] citados en De Pablo, Santos y Bueno (2004)

-[Martínez, Mora y Vila (2007); Ramayah y Harun (2005); Rodermund (2004)] citados en Ali, Topping y Tariq (2010)

-Ministerio de Industria, Comercio y Turismo, y Ministerio de Educación y Ciencia (2003)

-Alvord, Brown y Letts (2004)

Estar integrado en $\quad$-[Collins y Moore (1970); Drucker (1984); Guerrero y Palacios (1994); Hawkins y Turla redes sociales con (1987); Hérbert y Link (1988); Leíbenstein (1968); Ludevid y Ollé (1993); Masifern (1996); acceso a información y conocimiento Meredith, Nelson y Neck (1982); Nueno (1994); Ronstadt (1984); Varela (1998); Vesper (1980)] citados en De Pablo, Santos y Bueno (2004)

-Dixon, Meier, Brown y Custer (2005) -Ghazali, Ibrahim y Zainol (2013)

-Alvord, Brown y Letts (2004)

-[Bandura (1997); Chen, Greene y Crick (1998)] citados en Sánchez (2010)

Organización -[Casson (1982); Greffe (1988); Guerrero y Palacios (1994); Hawkins y Turla (1987); Leíbenstein (1968); Ludevid y Ollé (1993); Masifern (1996); Nelson y Neck (1981); Patel (1989)] citados en De Pablo, Santos y Bueno (2004)

-Dixon, Meier, Brown y Custer (2005)

\section{CATEGORÍA 2. ASPECTOS DE CARÁCTER SOCIAL}

-Alvord, Brown y Letts (2004)

-[Baumol (1968); Hawkins y Turla (1987); Jarillo (1986); Masifern (1996); Timmons (1989)] citados en De Pablo, Santos y Bueno (2004)

-[Borins (2000); Lewis (1980); Waddock y Post (1991)] citados en Weerawardena y Mort

Conciencia social (2006)

-Dees (1998b)

-Moraleda, González y García-Gallo (2004)

-Norasmah, Norashidah y Hariyaty (2012)

-Ram y Selvaraj (2012)

-Alvord, Brown y Letts (2004)

-Dixon, Meier, Brown y Custer (2005)

-Ferrer, Cabrera, Alegre, Montané, Sánchez y Alaiz (2014)

Cooperación y

-Lee y Lai (2010)

ayuda

-Macke y Markley (2003)

-Ministerio de Industria, Comercio y Turismo, y Ministerio de Educación y Ciencia (2003)

-Moraleda, González y García-Gallo (2004)

-Norasmah, Norashidah y Hariyaty (2012)

-Ram y Selvaraj (2012) 


\begin{tabular}{|c|c|}
\hline $\begin{array}{l}\text { Coherencia y } \\
\text { compromiso }\end{array}$ & $\begin{array}{l}\text {-Alvord, Brown y Letts (2004) } \\
\text {-[Borins (2000); Lewis (1980); Waddock y Post (1991)] citados en Weerawardena y Mort } \\
\text { (2006) } \\
\text {-Dixon, Meier, Brown y Custer (2005) } \\
\text {-Ferrer, Cabrera, Alegre, Montané, Sánchez y Alaiz (2014) } \\
\text {-[Hisrich y Brush (1986); Ludevid y Ollé (1993); Nelson y Neck (1981); Timmons (1989); } \\
\text { Varela (1998)] citados en De Pablo, Santos y Bueno (2004) } \\
\text {-[Martínez, Mora y Vila (2007); Ramayah y Harun (2005); Rodermund (2004)] citados en } \\
\text { Ali, Topping y Tariq (2010) } \\
\text {-Moraleda, González y García-Gallo (2004) } \\
\text {-Valls, Villa, Martínez y Hernando (2009) }\end{array}$ \\
\hline $\begin{array}{l}\text { Convivencia y el } \\
\text { respeto por el bien } \\
\text { público }\end{array}$ & $\begin{array}{l}\text {-Ghazali, Ibrahim y Zainol (2013) } \\
\text {-Ministerio de Industria, Comercio y Turismo, y Ministerio de Educación y Ciencia (2003) } \\
\text {-Moraleda, González y García-Gallo (2004) } \\
\text {-Norasmah, Norashidah y Hariyaty (2012) }\end{array}$ \\
\hline Tolerancia & $\begin{array}{l}\text {-Dixon, Meier, Brown y Custer (2005) } \\
\text {-[Hawkins y Turla (1987); Ludevid y Ollé (1993); Timmons (1989); Welsh y White (1983)] } \\
\text { citados en De Pablo, Santos y Bueno (2004) } \\
\text {-Moraleda, González y García-Gallo (2004) } \\
\text {-Norasmah, Norashidah y Hariyaty (2012) }\end{array}$ \\
\hline & CATEGORÍA 3. ASPECTOS DE CARÁCTER INNOVADOR \\
\hline Creatividad & $\begin{array}{l}\text {-Alvord, Brown y Letts (2004) } \\
\text {-Dixon, Meier, Brown y Custer (2005) } \\
\text {-Ferrer, Cabrera, Alegre, Montané, Sánchez y Alaiz (2014) } \\
\text {-[Gasse (1989); Greffe (1988); Hornaday y Aboud (1971); Ludevid y Ollé (1993); Napoleoni } \\
\text { (1968); Nelson y Neck (1981); Nueno (1994); Ronstadt (1984)] citados en De Pablo, } \\
\text { Santos y Bueno (2004) } \\
\text {-Ghazali, Ibrahim y Zainol (2013) } \\
\text {-Harris, Gibson y Taylor (2007) } \\
\text {-Lee y Lai (2010) } \\
\text {-Macke y Markley (2003) } \\
\text {-[Martínez, Mora y Vila (2007); Ramayah y Harun (2005); Rodermund (2004)] citados en } \\
\text { Ali, Topping y Tariq (2010) } \\
\text {-Ministerio de Industria, Comercio y Turismo, y Ministerio de Educación y Ciencia (2003) } \\
\text {-Norasmah, Norashidah y Hariyaty (2012) } \\
\text {-Robinson, Stimpson, Huefher y Hunt (1991) } \\
\text {-Valls, Villa, Martínez y Hernando (2009) }\end{array}$ \\
\hline $\begin{array}{l}\text { Capacidad para } \\
\text { identificar } \\
\text { oportunidades }\end{array}$ & $\begin{array}{l}\text {-Dees (1998b) } \\
\text {-Dixon, Meier, Brown y Custer (2005) } \\
\text {-[Drucker (1984); Hawkins y Turla (1987); Leibenstein (1968); Ludevid y Ollé (1993); } \\
\text { Masifern (1996); Meredith, Nelson y Neck (1982)] citados en De Pablo, Santos y Bueno } \\
\text { (2004) } \\
\text {-Enciso-Congote (2010) } \\
\text {-[Lumpkin y Dess (1996); Shapero (1982); Stevenson y Jarillo (1990)] citados en Sánchez } \\
\text { (2010) } \\
\text {-Weerawardena y Mort (2006) }\end{array}$ \\
\hline
\end{tabular}




\begin{tabular}{|c|c|}
\hline Iniciativa & $\begin{array}{l}\text {-[Bateman y Crant (1993); Covin y Slevin (1989); Crant (1996); Korunka, Frank, Lueger y } \\
\text { Mugler (2003)] citados en Sánchez (2010) } \\
\text {-[Brown y Rose (1993); Draheim, Howell y Shapero (1966); Drucker (1984); Hawkins y } \\
\text { Turla (1987); Hornaday y Aboud (1971); Nelson y Neck (1981); Patel (1989); Timmons } \\
\text { (1989)] citados en De Pablo, Santos y Bueno (2004) } \\
\text {-Dees (1998b) } \\
\text {-Ferrer, Cabrera, Alegre, Montané, Sánchez y Alaiz (2014) } \\
\text {-[Martínez, Mora y Vila (2007); Ramayah y Harun (2005); Rodermund (2004)] citados en } \\
\text { Ali, Topping y Tariq (2010) } \\
\text {-Moraleda, González y García-Gallo (2004) } \\
\text {-Norasmah, Norashidah y Hariyaty (2012) } \\
\text {-Ram y Selvaraj (2012) } \\
\text {-Valls, Villa, Martínez y Hernando (2009) } \\
\text {-Weerawardena y Mort (2006) }\end{array}$ \\
\hline $\begin{array}{l}\text { Capacidad de } \\
\text { generar ideas }\end{array}$ & $\begin{array}{l}\text {-Dees (1998b) } \\
\text {-[Brown y Rose (1993); Claver y Gómez (1979); Leíbenstein (1968); Masifern (1996); } \\
\text { Welsh y White (1983)] citados en De Pablo, Santos y Bueno (2004) } \\
\text {-Dixon, Meier, Brown y Custer (2005) } \\
\text { - Harris, Gibson y Taylor (2007) } \\
\text {-Moraleda, González y García-Gallo (2004) } \\
\text {-Norasmah, Norashidah y Hariyaty (2012) } \\
\text {-Robinson, Stimpson, Huefher y Hunt (1991) }\end{array}$ \\
\hline $\begin{array}{l}\text { Capacidad de } \\
\text { cambio }\end{array}$ & $\begin{array}{l}\text {-[Baron y Markman (1999); Gibb y Ritchie (1982); Guerrero y Palacios (1994); Leíbenstein } \\
\text { (1968)] citados en De Pablo, Santos y Bueno (2004) } \\
\text {-[Bateman y Crant (1993); Covin y Slevin (1989)] citados en Sánchez (2010) } \\
\text {-Dees (1998b) } \\
\text {-Lee y Lai (2010) } \\
\text {-Macke y Markley (2003) } \\
\text {-Weerawardena y Mort (2006) }\end{array}$ \\
\hline $\begin{array}{c}\text { Capacidad para } \\
\text { aprender y } \\
\text { evolucionar }\end{array}$ & $\begin{array}{l}\text {-Ali, Topping y Tariq (2010) } \\
\text {-Alvord, Brown y Letts (2004) } \\
\text {-Dees (1998b) } \\
\text {-Dixon, Meier, Brown y Custer (2005) } \\
\text {-Enciso-Congote (2010) } \\
\text {-Harris, Gibson y Taylor (2007) } \\
\text {-Lee y Lai (2010) } \\
\text {-[Ludevid y Ollé (1993); Timmons (1989); Varela (1998); Welsh y White (1983)] citados en } \\
\text { De Pablo, Santos y Bueno (2004) } \\
\text {-Macke y Markley (2003) } \\
\text {-[Martínez, Mora y Vila (2007); Ramayah y Harun (2005); Rodermund (2004)] citados en } \\
\text { Ali, Topping y Tariq (2010) } \\
\text {-Norasmah, Norashidah y Hariyaty (2012) } \\
\text {-Robinson, Stimpson, Huefher y Hunt (1991) } \\
\text {-Ram y Selvaraj (2012) }\end{array}$ \\
\hline $\begin{array}{c}\text { Tolerancia al } \\
\text { fracaso }\end{array}$ & $\begin{array}{l}\text {-[Covin y Slevin (1989)] citado en Sánchez (2010) } \\
\text {-Dixon, Meier, Brown y Custer (2005) } \\
\text {-[Drucker (1984); Hawkins y Turla (1987); Le Bras (1995); Timmons (1989); Welsh y White } \\
\text { (1983)] citados en De Pablo, Santos y Bueno (2004) } \\
\text {-Enciso-Congote (2010) } \\
\text {-Lee y Lai (2010) } \\
\text {-Macke y Markley (2003) }\end{array}$ \\
\hline
\end{tabular}

Conocer esta información es de gran utilidad, pues varios trabajos concluyen que hay una relación positiva entre los rasgos de la personalidad emprendedora y el comportamiento 
emprendedor (Chell, Haworth y Brearley, 1991; Rauch y Frese, 2000). Esta relación evidencia la validez predictiva de los rasgos de personalidad (Collins, Hanges y Locke, 2004; Rauch y Frese, 2007; Stewart y Roth, 2001, 2004; Zhao y Seibert, 2006) por lo que, si conocemos los rasgos de la personalidad emprendedora social, podremos valorar y analizar dicho comportamiento en un grupo de sujetos de forma similar al proceso realizado por Sarrate, García y Pérez (2013) respecto a las competencias del animador social. Esta situación respalda la realización de trabajos como el de la presente tesis, pues nos permiten conocer y valorar con mayor exactitud la personalidad del emprendedor social.

Cabe aclarar en este punto que se pueden encontrar casos en los que se manifiesten estos rasgos característicos de diferentes formas y en diferentes grados (Choi y Majumdar, 2014; Peredo y McLean, 2006; Short et al., 2009), coexistiendo así diversas posibilidades respeto al comportamiento y personalidad del emprendedor social. No obstante, como señala Dees (1998b), cuanto más cerca esté una persona de conseguir satisfacer todas esas condiciones más se ajustará al modelo de emprendedor social propuesto.

Tras presentar las 19 características de la personalidad emprendedora social pasamos a definir cada una de ellas, así como las categorías en las que se distribuyen, para tener una idea más precisa de a qué nos estamos refiriendo en cada caso. En la descripción de estos conceptos hemos intentado reflejar tanto la aportación de los distintos autores como nuestra propia visión personal de la forma más clara y concisa posible.

- Categoría 1. Aspectos de carácter personal: hace referencia a los elementos, facetas y matices propios, pertenecientes o relativos a la personalidad del individuo.

- Liderazgo: condición de dirección que asume una persona al ejercer como jefe u orientador de un grupo.

- Motivación al logro: ensayo mental preparatorio de una acción para animar y/o animarse a ejecutarla con interés y diligencia con la finalidad de alcanzar unos objetivos determinados.

- Capacidad de asumir riesgos: aptitud, talento o cualidad que dispone a alguien para hacerse cargo, responsabilizarse y aceptar una situación de incertidumbre, duda o temor.

- Confianza: seguridad que una persona tiene en sí misma y en su propio desempeño profesional y/o personal.

- Responsabilidad: cargo u obligación que resulta para alguien el reconocer y aceptar las consecuencias de una situación o hecho realizado libremente.

- Estar integrado en redes sociales con acceso a información y conocimiento: dicho de una persona que forma parte de un grupo que le sitúa en una posición de privilegio para adquirir ciertos datos y/o saberes.

- Organización: acción y efecto de disponer en base al arreglo de unas normas o pautas.

- Categoría 2. Aspectos de carácter social: indica los elementos, facetas y matices propios pertenecientes o relativos a la personalidad del individuo en relación con la sociedad o la comunidad. 
- Conciencia social: actitud moral respecto a lo comunitario que implica reflexionar sobre las situaciones que requieren atención y actuar para mejorar la sociedad.

- Cooperación y ayuda: obrar junto a otras personas con un mismo fin, haciendo un esfuerzo y ofreciendo auxilio en el desempeño de la tarea a realizar.

- Coherencia y compromiso: actitud lógica y consecuente que vincula a una persona con una obligación o tarea contraída libremente.

- Convivencia y el respeto por el bien público: acción de vivir en compañía presentando una actitud de consideración y deferencia hacia otras personas y cosas, materiales o inmateriales, de propiedad comunitaria.

- Tolerancia: respeto a las ideas, creencias o prácticas de los demás cuando son diferentes o contrarias a las propias.

- Categoría 3. Aspectos de carácter innovador: señalan los elementos, facetas y matices propios, pertenecientes o relativos a la personalidad del individuo en relación con el potencial para descubrir, inventar y progresar.

- Creatividad: capacidad para formar nuevas ideas o proyectos, fundándolos uno mismo.

- Capacidad para identificar oportunidades: aptitud o cualidad que dispone a una persona para reconocer y aprovechar ocasiones o coyunturas.

- Iniciativa: capacidad para dar principio a algo por uno mismo, adelantándose a los demás.

- Capacidad de generar ideas: aptitud o cualidad que dispone a una persona para producir conceptos, opiniones o juicios de valor propios, con ingenio, sobre algo o alguien.

- Capacidad de cambio: aptitud o cualidad que dispone a una persona a modificar y adaptar su posición o comportamiento en función de las necesidades existentes.

- Capacidad para aprender y evolucionar: aptitud o cualidad que dispone a una persona para adquirir y asimilar el conocimiento de algo, por medio del estudio o la experiencia, produciendo un progreso en su desarrollo personal o profesional.

- Tolerancia al fracaso: capacidad para resistir, soportar y llevar con paciencia los resultados adversos en el desempeño de una tarea o acción.

Así pues, teniendo en cuenta estos rasgos característicos, nuestra definición del emprendedor social describe a un líder social que actúa con confianza y responsabilidad, capaz de organizarse y asumir riesgos en base a su motivación de logro, y que está integrado en redes sociales con acceso a información y conocimiento, procede de forma tolerante, coherente y comprometida con la comunidad, muestra una elevada conciencia social y convive en sociedad respetando el bien público al mismo tiempo que coopera y ayuda a otros, posee iniciativa y creatividad, por lo que es capaz de generar ideas e identificar oportunidades, lo que le permite cambiar, aprender y evolucionar manteniendo una buena tolerancia al fracaso.

A continuación resumimos las ideas principales de este apartado:

1. Actualmente no existe una idea clara y universalmente aceptada de cuáles son las características distintivas del emprendedor social. 
2. Tras revisar la bibliografía existente, planteamos una definición del emprendedor social en base a sus características personales, sociales e innovadoras.

3. Los aspectos personales más destacados del emprendedor social son liderazgo, confianza, responsabilidad, organización, motivación al logro, capacidad de asumir riesgos, y estar integrado en redes sociales con acceso a información y conocimiento.

4. Los aspectos sociales más destacados del emprendedor social son coherencia y compromiso, conciencia social, convivencia y el respeto por el bien público, tolerancia y cooperación y ayuda.

5. Los aspectos innovadores más destacados del emprendedor social son: iniciativa, creatividad, capacidad de generar ideas, capacidad para identificar oportunidades, capacidad de cambio, capacidad para aprender y evolucionar y tolerancia al fracaso.

6. Los rasgos de la personalidad emprendedora social pueden presentarse en distintas formas y grados, existiendo así diferentes tipos de emprendedores sociales.

Con la intención de dar continuidad al enfoque competencial ampliamente abordado en el capítulo anterior, en el apartado investigador de la presente tesis hablaremos del desarrollo de la competencia de ES en el alumnado. Con ello, pretendemos transmitir un enfoque aplicado al fomento de los rasgos característicos de la personalidad del emprendedor social descritos en este marco teórico.

Tras analizar, identificar y definir los rasgos característicos del emprendedor social, seguidamente nos adentramos en el ámbito de la Responsabilidad Social Universitaria como marco de aplicación institucional del presente trabajo en cuanto al fomento del ES.

\subsection{La Responsabilidad Social Universitaria como espacio para el desarrollo del Emprendimiento Social}

La Responsabilidad Social Universitaria (RSU en adelante) es una temática que en los últimos años ha adquirido gran notoriedad, surgiendo un debate sobre la necesidad de su implantación (Beltrán et al, 2014; Gaete, 2011). Sin embargo, al igual que sucedía en algunos de los términos abordados en apartados anteriores, una de las problemáticas habituales que debe enfrentar el análisis del concepto de RSU es la multiplicidad de definiciones e interpretaciones existentes relacionadas con dicho término (Dahlsrud, 2008; Lozano, 2009; Marrewijk, 2003; Valor y Hurtado, 2009).

Con la intención de mostrar los diferentes enfoques de la RSU en la literatura, Gaete (2011) plantea tres grandes perspectivas que orientan las propuestas existentes: gerencial, transformacional y normativa. No obstante, el propio autor recalca que estas perspectivas teóricas no siempre se presentan aisladas entre sí en las propuestas prácticas de las universidades, pudiendo coexistir una o más orientaciones en las políticas de RSU desarrolladas por cada institución. A 
continuación presentamos la tabla 17, donde podemos ver los aspectos más importantes de las diferentes perspectivas existentes.

Tabla 17. Enfoques de la Responsabilidad Social Universitaria (Gaete, 2011).

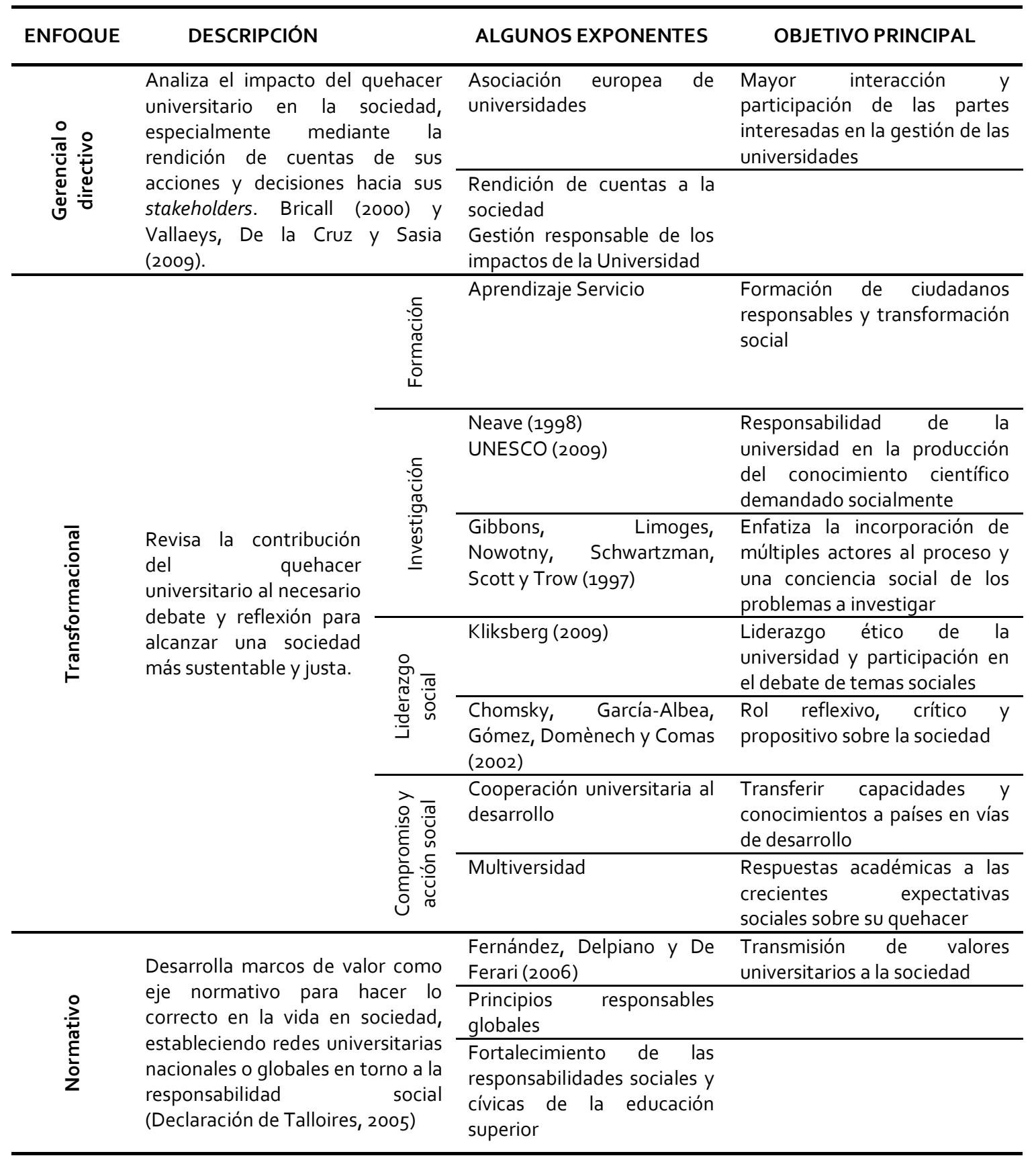

Con la intención de clarificar el término RSU, nos remitimos a la definición expuesta por Vila y Martín (2014, p. 45), los cuales entienden que es "el conjunto de discursos y acciones que genera y 
realiza la Universidad como resultado de su proyecto y proyección social como institución, de forma que trabaje para la construcción, en su seno, de las condiciones para la mejora social desde su labor reflexiva, ética, académica, investigadora e innovadora". No obstante, al contrario que en los apartados anteriores, en esta ocasión no pretendemos profundizar en las diferentes concepciones de este término ya que, al igual que Beltrán et al. (2014), entendemos que el concepto de RSU está en construcción permanente en virtud de la interacción que se establece entre universidad y sociedad. Con el paso del tiempo la visión de la responsabilidad social de toda institución va incorporando nuevas temáticas de manera que se redefinen sus prioridades y se asumen crecientes preocupaciones en concordancia con la nueva dinámica social (Reyno, 2006). Teniendo en cuenta esta consideración, suponemos que este concepto debe ser construido por cada institución a través de un proceso participativo de todos los interesados atendiendo a ciertas directrices establecidas (Villar, 2010). De igual modo, de acuerdo con Aguirre, De Pelekais y Paz (2012), para atender a las demandas del entorno las universidades deben prepararse constantemente, no solo atendiendo a los cambios, sino anticipándose a ellos para cumplir con la responsabilidad interna y externa a ella.

Por otra parte, la RSU también ha despertado el interés de los investigadores en distintas temáticas. La principales líneas de investigación en este campo son la evaluación de las percepciones de los estudiantes acerca de este concepto (Lämsä, Vehkaperä, Puttonen, y Personen, 2008), el análisis de la educación en responsabilidad social impartida por las universidades (Boks y Diehl, 2006, Lozano 2010; Lozano y Peattie, 2011) y el examen de casos específicos de RSU, sobre todo en términos ambientales (Serap y Eker, 2007; Ferrer-Balas et al., 2008; Hammond y Churchman, 2008).

Algunos trabajos destacables en esta línea se centran en la responsabilidad social desde el enfoque del compromiso que las organizaciones universitarias tienen con respecto a la sociedad en la cual interactúan (Aguirre et al., 2012), la dimensión comunitaria de la RSU en la universidad venezolana de Zulia (Bustos e Iniciarte, 2012), la transparencia informativa en temas de RSU en las políticas de comunicación online de las universidades para satisfacer las necesidades de información de los grupos de interés (Garde, Rodríguez y López, 2013), el establecimiento del compromiso cívico a través de la RSU en las universidades croatas (Ledic, Culum, Nuzdic y Jancec, 2008), el estudio de la RSU y la incidencia de la educación superior en la adquisición de comportamientos socialmente responsables (Martí, Martí-Vilar y Almerich, 2014), la RSU como elemento de unión estratégica de las funciones universitarias para fortalecer la vinculación entre esta institución y su entorno social (Martínez, Mavárez, Rojas y Carvallo, 2008), la producción científica sobre la propia RSU (Pacenza y Silva, 2013) y los aspectos relacionados con la problemática de las universidades para atender las exigencias del entorno socioproductivo (Ramos, 2010).

Del mismo modo, la RSU también ha sido objeto de estudio de diversas tesis doctorales, como las de Aldeanueva (2011), investigando sobre la consideración e integración de aspectos sociales, medioambientales, de seguridad y de salud laboral en las políticas y sistemas de gestión universitarios; De la Calle (2010), examinando la asociación entre la asignatura de responsabilidad 
social y el grado de responsabilidad social de los universitarios; o Garde (2013), analizando la comunicación y divulgación online de la RSU en el sector de la educación superior.

Esta información nos ayuda a comprender que las universidades deben fomentar la investigación sobre la RSU como una herramienta útil para promover el cambio social hacia una sociedad más sostenible, con el apoyo de la gestión universitaria y su proyección social (Stephens et al., 2008). Esto ha significado que dichas instituciones se están convirtiendo en verdaderos gestores de la responsabilidad social, liderando las acciones que promueven el nivel de desarrollo óptimo dentro de las distintas organizaciones (Lozano, Lukman, Lozano, Huisingh y Lambrechts, 2013).

Tras esta breve aproximación conceptual e investigadora sobre la RSU, nuestro interés se centra en conocer con mayor profundidad la naturaleza y peculiaridades de la RSU y cómo, a través de esta vía, podemos desarrollar e implementar proyectos educativos como el planteado en la presente tesis.

De acuerdo con lo expuesto hasta el momento, además de las responsabilidades habituales de formación, investigación y trasferencia del conocimiento y la tecnología, las instituciones universitarias tienen una responsabilidad social con la comunidad. Siguiendo a De la Cruz y Sasia (2008), entendemos que esta RSU implica responsabilidades en diferentes sentidos:

- Consecuencialista: se remite directamente a una responsabilidad asistencial y reactiva, manteniendo que la universidad debe devolver a la sociedad aquello que esta le ha otorgado. Así pues, la responsabilidad se concibe en términos de deuda con la sociedad, por lo que la universidad debe valorar aquellos aspectos que le permitan ser socialmente más responsable.

- Contractual: hace referencia al deber de la universidad de responder a las demandas sociales. De este modo, los elementos que conforman la agenda social universitaria generan una motivación en los miembros de dicha comunidad, para provocar un impacto positivo en la sociedad. Este sentido de responsabilidad supone un avance considerable respecto al anterior, especialmente en cuanto a la actitud de la universidad como entidad frente a su compromiso social.

- Prospectivo: se integra en un enfoque en el que la universidad es reconocida por la sociedad como un agente más de la misma. Esta responsabilidad implica que la universidad puede ser evaluada por terceros, manteniendo que la transparencia es un elemento fundamental en el compromiso de la institución con la sociedad.

Como veremos más adelante, nuestra propuesta pretende utilizar el APS como metodología didáctica para satisfacer los diferentes sentidos de RSU descritos. A continuación, presentamos otros dos elementos esenciales de esta temática, los impactos y espacios de aplicación de la RSU.

La acción de la universidad, como cualquier otra institución, genera una serie de impactos en la sociedad. Según Vallaeys $(2005,2007)$, uno de los autores más prolíficos en materia de RSU, estos impactos determinarán los espacios de actuación de la propia RSU, pudiendo ser: 
- Impactos de funcionamiento organizacional: como cualquier organización laboral, la universidad genera impactos en la vida de su personal administrativo, docente y estudiantil, y en el entorno medioambiental que la rodea, efectos que deberán ser gestionados por su política de bienestar social. De este modo, estos impactos hacen referencia a las "huellas" ecológicas y personales que deja esta institución como entidad educativa.

- Impactos educativos: a consecuencia de su orientación educativa, la universidad tiene un impacto directo sobre la formación de los jóvenes y profesionales, sobre su manera de entender, interpretar y relacionarse con el mundo. Esta acción tiene una influencia directa sobre la deontología profesional y orienta, de forma consciente o inconsciente, la ética profesional de cada disciplina y su rol social. Así pues, dichos impactos se ven reflejados en la formación personal y profesional de los estudiantes universitarios, ámbito en el que pretendemos actuar en el presente trabajo a través de la aplicación de un programa educativo de APS.

- Impactos cognitivos y epistemológicos: a través de la investigación, la institución universitaria orienta la producción del saber y las tecnologías, influyendo en la definición del conocimiento científico y en la selección de los temas de interés. Todo esto puede incentivar la fragmentación de los saberes al participar en la delimitación de los ámbitos de cada especialidad e, igualmente, influir en la relación entre el conocimiento y la sociedad, mediante el control y la apropiación de estos saberes. Según se gestionen ambas cuestiones, se generarán actitudes de elitismo científico o, por el contrario, se promoverá la democratización de la ciencia haciéndola extensible a la sociedad. Teniendo en cuenta lo expuesto, estos impactos de la RSU regularán el desarrollo del conocimiento a favor del interés comunitario.

- Impactos sociales: además del impacto educativo ya expuesto, mediante el cual la universidad influye directamente en los miembros de la sociedad futura, esta institución también participa en la comunidad como referente de acción social, por lo que puede promover el progreso, crear capital social, vincular la educación de los estudiantes con la realidad social exterior, hacer accesible el conocimiento a todos, etc. Considerando estas acciones es fácil reconocer el impacto de la universidad sobre el desarrollo económico, social y político de la comunidad, poniendo de manifiesto su afectación tanto sobre la entidad educativa como sobre el entorno social en la que se encuadra. Nuevamente observamos que estos impactos coinciden con los efectos provocados por el uso del APS, metodología didáctica de esta investigación.

Como ya hemos comentado, los tipos de impacto identificados sirven para definir los cuatro espacios de actuación de la RSU. No obstante, cabe destacar que este no pretende ser un modelo rígido e invariable, sino servir como marco para orientar su aplicación. Así pues, los cuatro espacios de acción de la RSU son (Vallaeys, 2005, Vallaeys et al., 2009):

- Campus responsable: este espacio está delimitado por la gestión de la organización del clima laboral, los recursos humanos, los procesos democráticos internos y el cuidado del medio ambiente. La idea es lograr un comportamiento éticamente ejemplar, a nivel 
organizativo, para la educación continua no formal de todos los integrantes de la institución universitaria. De este modo se desarrollarán tanto normas de convivencia social como de conducta ecológica.

- Formación ciudadana y profesional responsable: este espacio está definido por la gestión de la formación académica y pedagógica, tanto en su temática y organización curricular como en sus metodologías y propuestas didácticas. El objetivo es que la formación profesional y humanística se oriente realmente hacia un perfil de graduado que haya adquirido competencias ciudadanas de responsabilidad social para el desarrollo sostenible de la comunidad. Este espacio supone que la orientación curricular general y particular de los diferentes estudios tengan una estrecha relación con los problemas reales de la sociedad (económicos, sociales, ecológicos...) y puedan tratarse in situ en contacto directo con actores externos. Como ya hemos visto en los diferentes enfoques de la RSU planteados por Gaete (2011), una de las alternativas de actuación en este espacio es la metodología del APS, propuesta que coincide plenamente con el planteamiento de nuestro trabajo.

- Gestión social del conocimiento: este espacio se centra en la gestión de la producción y difusión del saber, la investigación y los modelos epistemológicos promovidos desde el aula. El propósito es orientar la actividad científica y la práctica experta, no solo a través de una negociación de las líneas de investigación universitaria con interlocutores externos, a fin de articular la producción de un conocimiento global con grandes programas sociales emprendidos desde el sector público, sino también para que los procesos de construcción de los conocimientos se den de modo participativo involucrando a miembros no académicos. Además, esta tarea supone difundir de modo comprensible los procesos y resultados de la actividad científica, ampliando la accesibilidad al conocimiento, para facilitar el ejercicio de reflexión crítica por parte de los ciudadanos.

- Comunidades de aprendizaje mutuo para el desarrollo: espacio delimitado por la gestión de la participación social de la universidad en el desarrollo humano de la comunidad. La intención es organizar proyectos con colaboradores externos a la comunicad universitaria, de tal modo que se constituyan actividades que fomenten el desarrollo social, tanto de los participantes académicos como de los no académicos, generando así capital social. Cabe destacar en este punto que bajo esta perspectiva la RSU pretende construir comunidades de aprendizaje mutuo, abiertas a cualquier ámbito de la comunidad, al mismo tiempo que se contribuye a resolver problemas sociales concretos. Este contexto de aplicación es totalmente compatible con el uso del APS, ya que ambas propuestas fomentan la acción conjunta de la institución educativa y de la sociedad para proporcionar un beneficio mutuo a los miembros de sendos colectivos.

Si analizamos con detalle los diferentes espacios de actuación de la RSU descritos, podemos comprobar cómo nuestro planteamiento de utilizar el APS como metodología didáctica para promover el ES y los conocimientos académicos del alumnado universitario, al mismo tiempo que se genera un beneficio social, actúa en todos y cada uno de ellos. Afecta a nivel personal a los diferentes miembros universitarios implicados, tanto docentes como estudiantes, emplea una metodología y un entorno de formación en contacto directo con los colaboradores externos, 
produce un conocimiento extensible al resto de la sociedad a través de su publicación en diferentes formatos y crea una comunidad de aprendizaje entre el alumnado universitario y los miembros de las entidades colaboradoras.

Aclarados los impactos y espacios de actuación de la RSU, a continuación exponemos sus objetivos y beneficios, justificando así su importancia e integración en el proyecto de nuestro trabajo, el cual expondremos con todo detalle en el siguiente capítulo. Así pues, de acuerdo con Villar (2010), entendemos que los principales objetivos de la RSU son:

- Orientar a las universidades hacia una clara conciencia de su misión social, contribuyendo al desarrollo humano, la equidad, la inclusión, el fomento de los derechos humanos, etc.

- Generar y promover políticas de acción adecuadas para dicha misión social, que aseguren la congruencia de sus procesos de docencia, investigación, extensión y gestión, dirigiendo su capital humano, relacional, intelectual, económico y tecnológico.

- Propiciar una adecuada concepción de la autonomía universitaria, enfatizando la capacidad de tomar sus propias decisiones, responsabilizándose de los impactos derivados de su actuación y atendiendo a los requerimientos, interpelaciones y necesidades de todos los colectivos sociales.

- Generar y promover una cultura de análisis, interno y externo, que diagnostique la evaluación de sus procesos, acciones e impactos, presentes y futuros, tanto cognitivos como educativos, sociales y medioambientales.

- Fomentar la transparencia y la rendición de cuentas tanto a la comunidad universitaria como a la sociedad en general.

- Permitir la integración curricular de la responsabilidad social en el modelo educativo, desarrollando programas específicos de ética aplicada y responsabilidad social, metodologías pedagógicas y procesos evaluativos creados ex profeso.

Una vez más apreciamos numerosas similitudes en el propósito de aplicación de la RSU respecto al uso del APS. Por otra parte, la consecución de los objetivos conllevará una serie de beneficios a toda la comunidad. Según Vallaeys et al. (2009) estos beneficios, a corto y largo plazo, serán:

- Coherencia e integración institucional: articulará las funciones universitarias de docencia, investigación y extensión mediante una política transversal que impregnará toda la institución y alineará los diversos procesos, académicos y no académicos, con un enfoque de gestión ética responsable. Con ello, aumentará la coherencia entre la declaración de intenciones, respecto a la misión, visión y valores institucionales de la universidad, y la práctica cotidiana en el campus.

- Pertinencia y permeabilidad social: vinculará a la entidad educativa con su entorno social, invitando a colaboradores externos a participar en los procesos académicos y organizativos internos, y orientando la gestión, la formación y la investigación hacia la solución de 
problemas sociales concretos. Este hecho fomentará el tratamiento de cuestiones de gran relevancia como, por ejemplo, la enorme desigualdad social actual.

- Dinámica institucional hacia la innovación: permitirá que la universidad sea una organización inteligente, actuando de forma transparente y democrática, e implementando procesos de mejora continua que faciliten iniciativas creativas en los ámbitos académico y de gestión.

- Racionalización de la gestión universitaria: mejorará el desempeño de los diversos procesos de la institución universitaria como, por ejemplo, la gestión racional del campus, el incremento de la motivación personal, el aumento del rendimiento académico, tanto educativo como investigador, o la creación de valor social.

Nuevamente observamos que los beneficios de aplicar la RSU convergen con el uso del APS como metodología didáctica, ya que su implantación aumenta la coherencia e integración institucional de una entidad al servicio de la sociedad, incrementa la pertinencia y la permeabilidad social de la Universidad como parte de la comunidad, fomenta el cambio institucional a través de la innovación docente y promueve la gestión racional de los recursos disponibles para aumentar los efectos positivos de su aplicación.

Teniendo en cuenta los beneficios de aplicar la RSU, es fácil entender por qué los centros de educación superior están incorporando principios de responsabilidad social tanto en el diseño de su oferta formativa e investigadora (De la Calle, García y Giménez, 2007; Martínez, 2010), como en su misión, visión y planificación estratégica (Núñez y Alonso, 2009; y Ramos, 2010). Estos principios de responsabilidad social deben traducirse en acciones específicas (Mulder, 2010; Nicolaides, 2006; Vallaeys, 2005), dando lugar a programas concretos como los que, a modo de ejemplo, exponemos en el siguiente punto. Siguiendo a Díaz (2008), a continuación mostramos algunas de las iniciativas de RSU que han sido propuestas a nivel nacional e internacional por todo el mundo:

- Reino Unido: HE21 colección de buenas prácticas (1999-2000), HEPS asociación de 18 Universidades para la sostenibilidad y Learning for sustainable development action plan. Estos programas generaron espacios de debate sobre RSU, para lograr la transferencia interdisciplinar de conocimientos, hábitos y competencias en todas las áreas y comunidades de influencia, así como para desarrollar un plan de promoción de proyectos de protección ambiental y uso eficiente de los recursos naturales.

- Holanda: Programa intersectorial de aprendizaje para la sostenibilidad y educación formal y no-formal desde preescolar hasta las universidades (2002-2006). Pretendía formar personal que colaborara con el desarrollo de conocimientos y tecnología ambiental en busca de una reducción en el consumo de recursos naturales y la producción de residuos, así como el cuidado de los parques y espacios ecológicos de los campus universitarios.

- EE UU: New Jersey HEPS, asociación de 34 instituciones de educación superior (2001-2005). Buscaba definir e incentivar la participación de los stakeholders (grupos de interés), así como la comunicación interna y externa al campus, para promocionar una red de universidades 
responsables que buscaran optimizar sus recursos y fomentar criterios éticos, sociales y medioambientales.

- Nueva Zelanda: Learning and education for sustainability, informe del departamento de medioambiente (2004). Se centraba en la transferencia de conocimientos de diferentes disciplinas que buscaban promover la formación y la investigación en materia medioambiental, trabajando en la creación de modelos de actuación para el desarrollo sostenible.

\section{- Iniciativas internacionales:}

- Década para la educación para el desarrollo sostenible (2005-2015) (Naciones Unidas, UNESCO). El objetivo es movilizar a toda la sociedad en la relación del hombre con el medio ambiente. Pretende generar cambios en el estilo de vida a partir de la reflexión crítica, implicando a los individuos en la toma de decisiones para trabajar de forma activa desde todos los grupos sociales, en la construcción de un mundo cada vez más sostenible.

- Global Higher Education for Sustainability Partnership (UNESCO, IAU, ULSF). La razón de la asociación es el consenso de que la educación superior debe jugar un papel central en el proceso global de lograr un desarrollo sostenible.

- Global University Network for Innovation. Proporciona experiencias personales que van más allá de la mera elaboración de prácticas de compromiso social, basando sus modelos institucionales en criterios éticos diseñados para encajar en sus comunidades.

- European Academy for Business in Society. Alianza de empresas, escuelas de negocios e instituciones académicas, con el apoyo de la comisión europea, comprometida con la integración de estas empresas en la sociedad en cuestión de negocios.

- Centros de Excelencia en Educación para el Desarrollo Sostenible (UPC, ESADE). Resalta la importancia de la educación para el desarrollo sostenible en el ámbito tecnológico.

Además de los ejemplos expuestos, debemos resaltar el desarrollo de la RSU en Latinoamérica, donde en la última década se ha generado gran cantidad de literatura sobre esta temática y se han elaborado numerosos programas de RSU. Los más destacables son el proyecto Universidad Construye País de Chile, los trabajos de la red de RSU de la asociación AUSJAL y la labor llevada a cabo por el Banco Interamericano de Desarrollo (Martí y Martí-Vilar, 2013). El primero se centra en el desarrollo de principios y valores en los planos personal, social y universitario, tanto por parte de instituciones públicas como privadas; el segundo pretende potenciar la habilidad y efectividad de las universidades jesuitas de América Latina para responder a las necesidades de transformación de la sociedad en clave de justicia, solidaridad y equidad; y, finalmente, el tercero se lleva a cabo mediante la red universitaria de ética y desarrollo, fomentando la integración de la Universidad de las Américas Puebla.

En nuestro país, la RSU encuentra sus orientaciones más importantes en la Estrategia Universidad 2015 (Gaete 2011; Garde, 2013), consensuando la adaptación de las universidades españolas al Espacio Europeo de Educación Superior (EEES), especialmente en lo referente a la internacionalización de las universidades y su competitividad a nivel mundial. Este documento determina que la RSU goza de gran relevancia debido a la clara vocación y orientación social de las 
universidades (Ministerio de Ciencia e Innovación, 2009). En España, la responsabilidad social ha despertado el interés universitario en diversos campos como, por ejemplo, el del grupo de investigación SOGRES ${ }^{16}$ de la Universitat Jaume I, centrado en la sostenibilidad de las organizaciones y la gestión de la responsabilidad social, o el de la Universidad Internacional de Andalucía ${ }^{17}$, elaborando la memoria de responsabilidad social donde da a conocer los resultados y avances en esta materia en lo relativo a sus indicadores de desempeño económico, social, laboral y medioambiental.

Como hemos podido comprobar, existen numerosas iniciativas de RSU en diversas partes del mundo. En nuestra opinión este hecho debe incentivar la propagación de nuevas propuestas en esta línea, especialmente en los momentos de crisis económica y social. Así pues, la elaboración del presente trabajo pretende cimentar un nuevo espacio de implantación de la RSU a través del uso del APS. Por ello, seguidamente nos centramos en el procedimiento a seguir a la hora de implementar este tipo de iniciativas. Según Vallaeys et al. (2009) los pasos de aplicación de la RSU son: compromiso, autodiagnóstico, cumplimiento y rendición de cuentas. Como vemos a continuación los autores plantean una evolución lineal de estos aspectos, pudiendo establecerse una relación cíclica entre los tres últimos pasos.

- Primer paso: compromiso. Pretende articular la RSU con el proyecto institucional, la misión y los valores de la universidad. Exige una clara implicación de toda la comunidad universitaria así como la creación de un equipo rector a cargo del tema.

- Segundo paso: autodiagnóstico. Presenta las herramientas cuantitativas y cualitativas para establecer la situación de los cuatro ámbitos clave de las universidades: gestión de la organización, formación educativa, conocimiento e investigación, y participación social.

- Tercer paso: cumplimiento. A partir de los resultados del diagnóstico, planifica las áreas de mejora y ejecuta los proyectos de responsabilidad social con la más amplia participación, tanto de los miembros de la comunidad universitaria como de los colaboradores externos pertinentes.

- Cuarto paso: rendición de cuentas. Ofrece ideas para evaluar y comunicar los resultados de los proyectos de responsabilidad social, con el objetivo de afinar las estrategias y reiniciar el ciclo centrándose especialmente en los aspectos que hayan presentado dificultades.

El planteamiento de nuestro trabajo, en el que se aplica un programa educativo de APS fundamentado en la implantación de la RSU, tiene en consideración todos los pasos descritos. No obstante, discrepamos con los autores en cuanto a la distribución de los mismos pues consideramos que se le debe otorgar una mayor importancia al compromiso a lo largo de todo este proceso. Así pues, en la Figura 8, se puede apreciar que nuestra visión propone una vinculación más estrecha y continua entre el compromiso y el resto de pasos a seguir a la hora de aplicar las iniciativas de RSU.

\footnotetext{
${ }^{16}$ http://www.sogres.uji.es/

${ }^{17} \mathrm{http}$ ://www.unia.es/planificacion-y-calidad/modelo-responsabilidad-social
} 


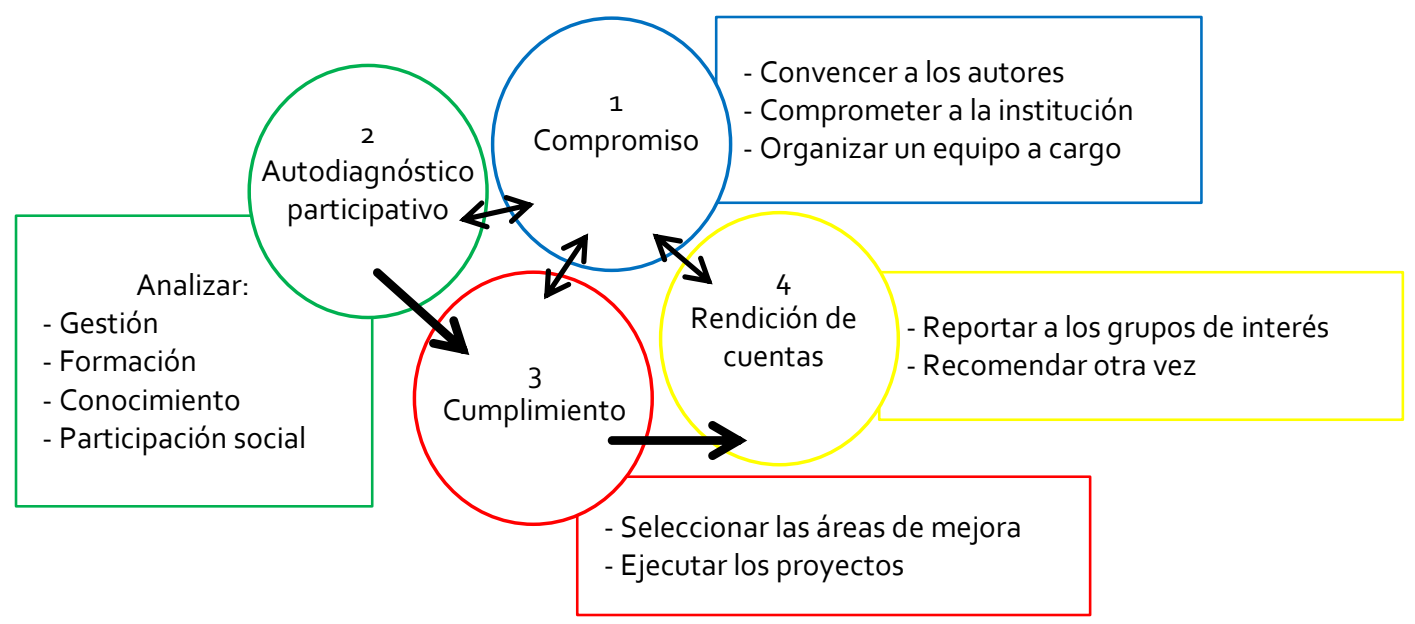

Figura 8. Relación de los 4 pasos de aplicación de la Responsabilidad Social Universitaria (modificado de Vallaeys et al., 2009).

Tras finalizar esta aproximación sobre las diferentes peculiaridades de la RSU, seguidamente abordamos la relación de este concepto con el fenómeno del ES y la metodología del APS respectivamente, dos aspectos fundamentales del presente trabajo.

En este capítulo hemos definido al emprendedor social como un líder social que actúa con confianza y responsabilidad, capaz de organizarse y asumir riesgos en base a su motivación de logro, y que está integrado en redes sociales con acceso a información y conocimiento, procede de forma tolerante, coherente y comprometida con la comunidad, muestra una elevada conciencia social y convive en sociedad respetando el bien público al mismo tiempo que coopera y ayuda a otros, posee iniciativa y creatividad, por lo que es capaz de generar ideas e identificar oportunidades, lo que le permite cambiar, aprender y evolucionar manteniendo una buena tolerancia al fracaso.

Como podemos apreciar esta definición contiene numerosas similitudes con la idea de la RSU expuesta en el presente apartado, especialmente en lo referente a los aspectos de carácter personal y social. Debido a dichas semejanzas, no es difícil imaginar que los proyectos de RSU sean un buen vivero en el que implementar actividades de promoción de ES desde las instituciones universitarias. En esta línea el trabajo de Saldaña y Coutiño (2010) pretende resaltar la importancia y contribuciones de la RSU en el ámbito del ES, delimitando su campo de actuación y la vinculación entre ambos conceptos. Para ello analizan el caso del Tecnológico de Monterrey a través de su misión del año 2015, buscando establecer centros de transferencia de conocimiento y aplicación, mediante la figura del instituto para el desarrollo social sostenible. No obstante, este no es el único trabajo que relaciona la RSU con el emprendimiento, también podemos destacar la investigación de Casilla y Camacho (2012) sobre la evaluación de programas de RSU como alternativa para mejorar los procesos interactivos con la comunidad y renovar la calidad de respuesta a la construcción de nuevas maneras de vinculación más pertinentes y emprendedoras; o la de 
Rodríguez y Larrota (2012) sobre las estrategias y logros de varios programas de promoción emprendedora a través de la RSU en la Universidad de la Salle de Bogotá.

El planteamiento de esta tesis mantiene una perspectiva similar a la de estos trabajos, considerando que la RSU es un espacio óptimo para el desarrollo de acciones de fomento del ES. Igualmente, como hemos visto a lo largo de este apartado, consideramos que el uso del APS se postula como una herramienta de implantación adecuada de la RSU desde el ámbito de la docencia. Por ello, a continuación profundizamos en la relación de ambos conceptos, RSU y APS.

La tendencia actual desde la perspectiva de la comunidad universitaria supone la asunción de una responsabilidad cada vez mayor en materia de formación, investigación, estudio y servicios de orientación, transferencia de tecnología y educación permanente (Ramalho y Beltrán, 2012). En esta línea, dentro del marco de la formación práctica, cada vez son más frecuentes las experiencias de servicio de los estudiantes implicándose en una comunidad local. Hasta hace bien poco, estas actividades formativas de servicio se centraban únicamente en la educación de los estudiantes más que en el beneficio que podían ofrecer a la sociedad. No obstante, la manera en que la formación del estudiantado se lleva a cabo a través de estas experiencias reales y de servicio a la comunidad está cambiando (Aponte, 2007). Un buen ejemplo de estas políticas prácticas de responsabilidad social podemos encontrarlo en las universidades americanas, las cuales se distinguen por su compromiso de servir a la comunidad (Decter, 2009).

De acuerdo con este planteamiento destaca la metodología del APS, estrategia ampliamente abordada en el capítulo anterior. Según Beltrán et al. (2014), el APS refleja este nuevo enfoque de la función del servicio de formación, cada vez más extendido y con muchos ejemplos de buenas prácticas, implicando una forma alternativa de vinculación con la comunidad. Así pues, los procesos de formación basados en el APS favorecen directamente la preparación de los estudiantes para que se inserten en la sociedad como ciudadanos responsables y, a la vez, contribuyan al desarrollo sostenible de la misma en una clara expresión de beneficio mutuo, más allá de la simple adquisición de competencias profesionales para su futura inserción laboral como principal resultado de su paso por las aulas universitarias (Boyle, 2007; Gronski y Pigg, 2000; Hervani y Helms, 2004; Martínez, 2010; Newman, 2008). De este modo, los programas de APS se presentan como una gran opción a la hora de implantar la RSU, especialmente desde el punto de vista del desarrollo de valores cívicos y la sensibilidad social en los miembros de la comunidad universitaria.

Debemos aclarar que, según lo expuesto por Tapia (2010), esta concepción de la RSU no actúa de forma filantrópica, sino que parte de examinar el currículum de la universidad para revisar los valores éticos que se incorporan a la formación profesional y desarrolla un movimiento de reforma integral, incluyendo la participación de estudiantes y docentes en iniciativas sociales así como el desarrollo de investigaciones orientadas al desarrollo sostenible. Este modelo implica profundos cambios en la organización de la universidad, reconociéndola como parte del conjunto de la comunidad sin mostrarse aislada ni supeditada a las demandas externas. De igual modo, la sociedad ya no es vista como un cliente o destinatario pasivo sino como un espacio donde se aprende, se investiga y se construyen alianzas institucionales a través de iniciativas solidarias. Este 
planteamiento, como muestra la figura 9, establece la integración de las misiones primarias de RSU desde la perspectiva del APS, manteniendo una clara identidad educativa y presentando unas fronteras permeables a las diferentes demandas sociales existentes.

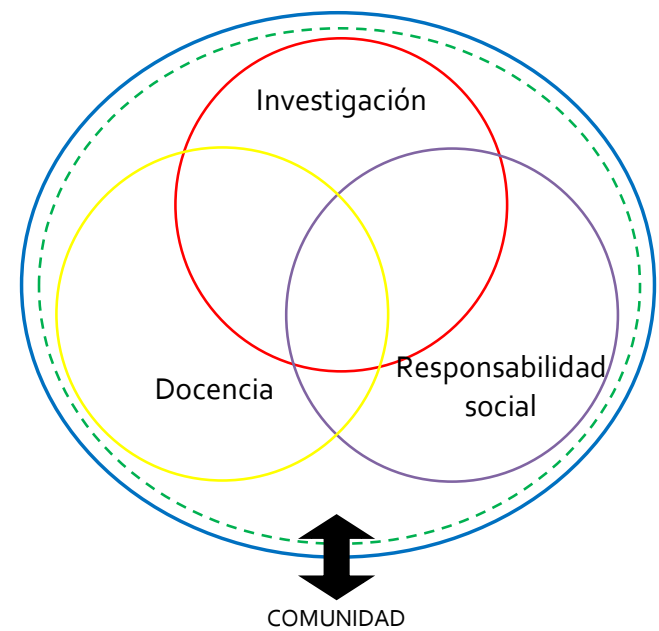

Figura 9. Integración de las misiones universitarias en la perspectiva del Aprendizaje Servicio y la Responsabilidad Social (Tapia, 2010).

Siguiendo este modelo dinámico y dialéctico, el aprendizaje, la investigación y la intervención social tienen un fuerte impacto sobre el proceso de enseñanza-aprendizaje, ya que al involucrarse en la resolución de problemas reales de una comunidad específica, la universidad trabaja con realidades complejas que aumentan la riqueza y significatividad de todo este proceso.

En resumen, las ideas principales de este apartado son:

1. El ámbito de la RSU está obteniendo una creciente importancia en los últimos años, despertando el interés tanto de académicos como de investigadores.

2. Las acciones de RSU generan impactos de funcionamiento organizativo, educativos, sociales, cognitivos y epistemológicos, los cuales determinan los espacios de actuación en esta temática.

3. La implementación de proyectos de RSU generan beneficios a nivel de coherencia e integración institucional, pertinencia y permeabilidad social, dinámica institucional hacia la innovación y racionalización de la gestión universitaria.

4. Existen numerosas propuestas en relación a la RSU, tanto a nivel nacional como internacional, manifestando una mayor presencia en el continente americano.

5. Los principales pasos de actuación a la hora de aplicar propuestas de RSU son compromiso, autodiagnóstico, cumplimiento y rendición de cuentas, manteniendo una estrecha relación entre ellos a lo largo de todo el proceso de aplicación.

6. Las acciones de RSU ofrecen un espacio óptimo para fomentar el desarrollo del ES a través de programas de formación universitaria basados en la metodología educativa del APS. 




\section{Programa de Aprendizaje Servicio aplicado en Educación Física}



Este capítulo está dedicado a definir las características del programa educativo sobre el que se ha desarrollado la investigación. En primer lugar, sentamos las bases de la propuesta educativa implementada, enmarcándola dentro de la asignatura en la que se desarrolló. Más adelante, determinamos los objetivos generales y específicos que se deseaban alcanzar a través de su aplicación. Seguidamente describimos el programa de APS implementado, exponiendo sus distintas fases y grupos de aplicación, además de aportar diversos documentos para ilustrar las labores desempeñadas por el alumnado participante. Finalmente esbozamos el contexto de aplicación del mismo, describiendo las características de las entidades colaboradoras.

\subsection{Bases del proyecto educativo}

Como ya hemos señalado, esta tesis pretende medir los efectos de un programa de APS en el ámbito de la EF. Por la facilidad de acceso al alumnado, el contexto de aplicación de nuestro trabajo es la asignatura Ml 1019, "Fundamentos de la Expresión Corporal, Juegos Motrices en Educación Infantil". Esta asignatura pertenece al $2^{\circ}$ curso del Grado en Maestro o Maestra de Educación Infantil de la Universidad Jaume I de Castellón. Su docencia recae sobre el área de Didáctica de la Expresión Corporal del Departamento de Educación de esta universidad y se cursa de forma anual, con carácter obligatorio y una carga lectiva de 6 créditos ECTS.

Siguiendo la guía docente de la asignatura ${ }^{18}$, se justifica su inclusión en el plan de estudios por la necesidad manifiesta del ser humano de expresarse a lo largo de la vida. Es así como los niños, a partir de la necesidad de comunicarse, imaginan y encuentran elementos de comprensión del mundo que les rodea, entre ellos la familia, la sociedad y el entorno. En esta necesidad, el cuerpo y el movimiento juegan un papel fundamental, especialmente en la etapa de o a 6 años, cuando la comunicación verbal no es totalmente efectiva. La expresión corporal es el medio por el que el ser humano exterioriza sensaciones, emociones, sentimientos y pensamientos con su cuerpo. Por tanto, se entiende ligada al desarrollo de las cualidades físicas básicas (fuerza, flexibilidad, resistencia y velocidad) y derivadas (coordinación, equilibrio, agilidad, etc.), dentro de lo se denomina la EF de base, desde la perspectiva de su uso para comunicarse, expresarse y socializarse. Además, el desarrollo del movimiento es fundamental para estimular y consolidar los procesos de aprendizaje futuros. Igualmente, la manera adecuada de trabajar dichos aspectos a lo largo de esta etapa es mediante el juego, ya que la riqueza psicomotriz que ofrece su uso hace que sea la herramienta adecuada para tal fin. En consecuencia, los futuros maestros tienen que ser capaces de trabajar la expresión corporal con el cuerpo y el movimiento como protagonistas, entendiendo que en la etapa de infantil es de especial relevancia dotar a los niños de este lenguaje corporal que facilitará su futura socialización.

Esta asignatura, fundamental en la formación de los maestros, toma como base los conocimientos trabajados en su predecesora de primer curso del Grado Ml 1010, "El Desarrollo

${ }^{18}$ https://eujier.uji.es/pls/www/gri_www.euji22883_html?p_curso_aca=2013\&p_asignatura_id=Ml1019\&p_idioma=CA\&p_ titulacion $=217$ 
Motriz, Salud y Crecimiento", y está relacionada con las asignaturas vinculadas al desarrollo psicológico y al aprendizaje de niños entre o y 6 años, Ml 1003 "Psicología de la Educación en la Escuela Infantil y Primaria", Ml 1004 "Psicología del Desarrollo (o-6 años)" y Ml 1026 "Trastornos del Desarrollo (o-6 años)".

Según lo expuesto, la asignatura pretende desarrollar los siguientes contenidos: (1) la expresión corporal, evolución, investigaciones y tendencias actuales; (2) bases y contenidos de la expresión corporal; (3) características de las actividades de expresión corporal; (4) la expresión corporal en la infancia, evolución del gesto expresivo; (5) el juego como elemento educativo; y (6) organización de los juegos, criterios didácticos de elección. Para logarlo, se establece el trabajo del alumnado alrededor del temario expuesto en la tabla 18:

Tabla 18. Temario de la asignatura (Guía docente de la asignatura).

\begin{tabular}{|c|c|c|}
\hline $\begin{array}{c}\text { Tema } 1 \\
\text { Expresión corporal. Fundamentos } \\
\text { teóricos }\end{array}$ & $\begin{array}{c}\text { Tema } 2 \\
\text { Contenidos de la expresión corporal }\end{array}$ & $\begin{array}{c}\text { Tema } 3 \\
\text { Las actividades en la expresión } \\
\text { corporal }\end{array}$ \\
\hline $\begin{array}{l}\text { - Expresión y expresión corporal. } \\
\text { - Conceptualización. Definición por } \\
\text { diferentes autores. } \\
\text { - Fundamentos y funciones de la } \\
\text { expresión. } \\
\text { - Objetivos generales. } \\
\text { - Tendencias actuales dentro de la } \\
\text { expresión corporal. } \\
\text { - La expresión corporal en la } \\
\text { educación. }\end{array}$ & $\begin{array}{l}\text { - El cuerpo y sus posibilidades } \\
\text { expresivas: cabeza y cara, mano, } \\
\text { tronco, piernas y pies, tono } \\
\text { muscular y esquema corporal. } \\
\text { - El espacio y el tiempo como } \\
\text { elementos clave en la expresión. } \\
\text { - El ritmo como contenido } \\
\text { expresivo. Ritmos simples y } \\
\text { compuestos. Cadencias. } \\
\text { - La coordinación en la expresión. } \\
\text { Coordinación dinámica general, } \\
\text { coordinación segmentaria. }\end{array}$ & $\begin{array}{l}\text { - Los cuentos motores. } \\
\text { - Las canciones con componente } \\
\text { motriz: danzas y juegos cantados } \\
\text { y danzados. } \\
\text { - Actividades de representación. } \\
\text { Clasificación. Títeres y mimo. } \\
\text { - Las dramatizaciones. Elementos } \\
\text { de una dramatización. Recursos } \\
\text { dramáticos. } \\
\text { - La creatividad en la expresión } \\
\text { corporal. }\end{array}$ \\
\hline $\begin{array}{c}\text { Tema } 4 \\
\text { El juego motriz }\end{array}$ & $\begin{array}{c}\text { Tema } 5 \\
\text { Organización de los juegos }\end{array}$ & $\begin{array}{c}\text { Tema } 6 \\
\text { Análisis de conductas y } \\
\text { movimientos en la expresión } \\
\text { corporal y el juego }\end{array}$ \\
\hline $\begin{array}{l}\text { - Etimología, definición y } \\
\text { naturaleza del juego. } \\
\text { - Evolución del juego según las } \\
\text { etapas educativas. } \\
\text { - Clasificación de los juegos: según } \\
\text { las etapas evolutivas, según su } \\
\text { aplicación práctica (organización, } \\
\text { interacción social, utilidad, etc.), } \\
\text { juegos modificados, juegos } \\
\text { tradicionales y populares, juegos } \\
\text { predeportivos, juegos recreativos, } \\
\text { etc. } \\
\text { - El juego como elemento } \\
\text { educativo: roles, características, } \\
\text { pautas metodológicas, } \\
\text { evaluación. }\end{array}$ & $\begin{array}{l}\text { - La ficha y el fichero de juegos. } \\
\text { - La sesión de juegos. } \\
\text { - Criterios didácticos de elección. } \\
\text { - Medios, instalaciones, materiales. }\end{array}$ & $\begin{array}{l}\text { - Determinación de pautas de } \\
\text { actuación adecuadas a la edad de } \\
\text { los niños. } \\
\text { - Valoración de actuación en la } \\
\text { expresión corporal. } \\
\text { - Valoración de actuación en los } \\
\text { juegos motrices. } \\
\text { - Elaboración de informes sobre el } \\
\text { estado de desarrollo del } \\
\text { alumnado en función de la } \\
\text { actuación. } \\
\text { - Aplicación de las valoraciones en } \\
\text { el ámbito educativo. Diagnóstico } \\
\text { y propuestas de mejora. }\end{array}$ \\
\hline
\end{tabular}


Como ya hemos indicado, la carga lectiva de la asignatura es de 6 créditos ECTS, por lo que cursarla supone realizar $60 \mathrm{~h}$. presenciales y $90 \mathrm{~h}$. no presenciales, sumando un total de $150 \mathrm{~h}$. En la tabla 19 presentamos la estructura organizativa de la asignatura, donde se muestra el desglose de tareas ubicadas en cada sección:

Tabla 19. Estructura organizativa de la asignatura (Guía docente de la asignatura).

\begin{tabular}{lcc}
\hline \multicolumn{1}{c}{ ACTIVIDADES } & $\begin{array}{c}\text { HORAS } \\
\text { PRESENCIALES }\end{array}$ & $\begin{array}{c}\text { HORAS NO } \\
\text { PRESENCIALES }\end{array}$ \\
\hline Enseñanzas teóricas & 10 & 0 \\
Enseñanzas prácticas (problemas) & 10 & 0 \\
Enseñanzas prácticas (laboratorio) & 10 & 0 \\
Seminarios & 6 & 0 \\
Tutorías & 4 & 0 \\
Evaluación & 20 & 0 \\
Trabajo personal & 0 & 60 \\
Trabajo de preparación de los exámenes & 0 & 30 \\
\hline Total por sección & 60 & $\mathbf{9 0}$ \\
\hline Carga lectiva total de la asignatura & \multicolumn{150}{c}{} \\
\hline
\end{tabular}

Partiendo de estos parámetros, el sistema de evaluación de la asignatura se plantea de la siguiente manera, tabla 20:

Tabla 20. Sistema de evaluación de la asignatura (Guía docente de la asignatura).

\begin{tabular}{lc}
\hline \multicolumn{1}{c}{ TIPO DE PRUEBA } & PORCENTAJE \\
\hline Elaboración y/o exposición de trabajos & $30 \%$ \\
Observación/ejecución de tareas y prácticas & $30 \%$ \\
Examen escrito (test, desarrollo y/o problemas) & $30 \%$ \\
Resolución de ejercicios y problemas & $10 \%$ \\
\hline Total & $\mathbf{1 0 0 \%}$ \\
\hline
\end{tabular}

Cabe destacar en este punto que, para poder ser evaluados, los alumnos deben realizar obligatoriamente todas las actividades de evaluación planificadas, excepto el apartado de resolución de ejercicios y problemas (10\%), que es optativo. Por otra parte, para superar la asignatura es necesario conseguir una puntuación de al menos un 50\% en cada apartado de los considerados obligatorios: elaboración y/o exposición de trabajos, observación/ejecución de tareas y prácticas, y examen escrito, test, desarrollo y/o problemas. 
En cuanto a la metodología didáctica empleada, el programa de la asignatura indica el uso de diferentes estrategias en el proceso de enseñanza-aprendizaje. Así pues, se combinan métodos directos y de descubrimiento en función del tipo de contenido a aprender, el objetivo a conseguir y la tarea a realizar. En todo caso, se destaca el protagonismo del alumnado en el proceso enseñanzaaprendizaje, ofreciendo la opción de participar en la mayor cantidad de decisiones posibles en cuanto al desarrollo de la asignatura. Con ello, se pretende implicar al alumnado en la asignatura, intentando mejorar su resultado académico. Por último, se resalta que la innovación metodológica es otro de los principios plateados por la asignatura. En este sentido, se oferta la posibilidad de participar en aplicaciones de APS, trabajos cooperativos y metodologías basadas en problemas como estrategias innovadoras.

Con el desarrollo de la asignatura se pretende fomentar en el alumnado la adquisición de las siguientes competencias genéricas y específicas:

- Planificar las actividades educativas en función de la progresiva cohesión-integración del grupo/clase (adaptación, consolidación, cohesión...).

- Potenciar el uso del lenguaje corporal para conseguir una mejor expresión, respetar el trabajo propio y desarrollar habilidades sociales.

- Promover el juego simbólico y de representación de roles como principal medio de conocimiento de la realidad social.

- Crear propuestas motrices adecuadas a cada grupo de edad en la etapa de educación infantil.

- Desarrollar los hábitos de autonomía personal y el respeto a las normas de convivencia en sus alumnos.

- Seleccionar materiales y espacios adecuados para la realización de los juegos motrices en educación infantil.

- Utilizar el juego como principal recurso didáctico, así como diseñar actividades de aprendizaje basadas en principios lúdicos.

Asimismo, al finalizar el curso se esperan alcanzar los siguientes resultados de aprendizaje:

- Aplicar un amplio abanico de propuestas de trabajo de la expresión corporal.

- Planificar el trabajo de expresión corporal dentro de la programación general de la etapa de Educación Infantil.

- Transmitir valores a los niños a través del trabajo de los contenidos de la expresión corporal y el juego (cooperación, solidaridad, respeto...).

- Trabajar la expresión corporal adecuadamente al nivel de desarrollo de los niños/as.

- Utilizar el juego motriz de forma adecuada en función de las intencionalidades educativas que se persiguen.

- Utilizar el movimiento como herramienta de aprendizaje y de socialización, entendiendo la importancia del mismo en la etapa de infantil. 
Como ya hemos indicado, dentro de la estructura básica expuesta existe la posibilidad de participar en aplicaciones de APS. Así pues, la implementación del programa educativo que se presenta más adelante se llevó a cabo respetando todos los parámetros de la guía docente anteriormente descritos.

\subsection{Objetivos del programa de Aprendizaje Servicio}

Como hemos aportado en el marco teórico, la aplicación de este tipo de proyectos educativos provoca efectos sobres aspectos académicos, personales y sociales en el alumnado. Por ello, los objetivos planteados en la aplicación de este programa de APS se refieren a dichos aspectos. Así pues, los objetivos generales de esta propuesta didáctica eran los siguientes:

1. Desarrollar los aprendizajes del alumnado sobre los contenidos de la asignatura "Fundamentos de la Expresión Corporal; Juegos Motrices en Educación Infantil", incrementando su competencia docente en este ámbito.

2. Fomentar el Emprendimiento Social del alumnado a través del desarrollo de los distintos aspectos de carácter personal, social e innovador que lo conforman.

De igual modo, se formularon una serie de objetivos específicos que detallaban diversas cuestiones relativas a estos objetivos generales.

Debido a la concreción en el contexto de aplicación del programa formativo, los objetivos específicos vinculados a los aprendizajes académicos debían ajustarse a la guía docente de la asignatura en la que se iba a implementar el APS. Como podemos comprobar, estos objetivos específicos hacían referencia a las competencias y resultados de aprendizaje anteriormente descritos:

- Planificar las actividades educativas en función de la progresiva cohesión-integración del grupo/clase (adaptación, consolidación, cohesión...).

- Potenciar el uso del lenguaje corporal para conseguir una mejor expresión, respetar el trabajo propio y desarrollar habilidades sociales.

- Promover el juego simbólico y de representación de roles como principal medio de conocimiento de la realidad social.

- Crear propuestas motrices adecuadas a cada grupo de edad en la etapa de educación infantil.

- Desarrollar los hábitos de autonomía personal y el respeto a las normas de convivencia en sus alumnos.

- Seleccionar materiales y espacios adecuados para la realización de los juegos motrices en educación infantil.

- Utilizar el juego como principal recurso didáctico, así como diseñar actividades de aprendizaje basadas en principios lúdicos.

- Aplicar un amplio abanico de propuestas de trabajo de la expresión corporal. 
- Planificar el trabajo de expresión corporal dentro de la programación general de la etapa de Educación Infantil.

- Transmitir valores a los niños a través del trabajo de los contenidos de la expresión corporal y el juego (cooperación, solidaridad, respeto...).

- Trabajar la expresión corporal adecuadamente al nivel de desarrollo de los niños/as.

- Utilizar el juego motriz de forma adecuada en función de las intencionalidades educativas que se persiguen.

- Utilizar el movimiento como herramienta de aprendizaje y de socialización, entendiendo la importancia del mismo en la etapa de infantil.

Por otra parte, los objetivos específicos vinculados con el fomento del ES hacían mención a los distintos aspectos personales que hemos indicado en el marco teórico que lo definen ${ }^{19}$. Así pues, se formularon los siguientes objetivos específicos relativos al ES:

- Desarrollar la capacidad de liderazgo.

- Aumentar la confianza.

- Mejorar la responsabilidad.

- Orientar al alumnado hacia una motivación al logro.

- Incrementar su capacidad para asumir riesgos.

- Facilitar su integración en redes sociales con acceso a información y conocimiento.

- Estimular la coherencia y el compromiso social.

- Intensificar la conciencia social.

- Reforzar la convivencia y el respeto por el bien público.

- Potenciar la capacidad de cooperación y ayuda.

- Incentivar la iniciativa.

- Enriquecer la creatividad.

- Acrecentar la capacidad para generar ideas.

- Favorecer la capacidad para identificar oportunidades.

- Amplificar la capacidad de cambio.

- Perfeccionar la capacidad para aprender y evolucionar.

- Fortalecer la tolerancia al fracaso.

\subsection{Descripción del programa de Aprendizaje Servicio}

En primer lugar debemos resaltar que el programa de APS implementado se elaboró siguiendo las directrices generales de este tipo de propuestas, presentadas en el marco teórico de este trabajo, respetando en todo momento los criterios, principios y recomendaciones de aplicación de

\footnotetext{
${ }^{19}$ En esta lista no aparecen dos de los aspectos descritos en el marco teórico: tolerancia y organización. Como veremos en el siguiente capítulo, ambos fueron eliminados tras someter el cuestionario a un juicio de expertos.
} 
esta metodología didáctica (Celio et al., 2011; Howard, 1993; National Youth Leadership Council, 2008; Tapia, 2008).

Inicialmente se realizó una presentación previa en la que se informó al alumnado de las distintas alternativas para cursar la asignatura en cuanto a organización, metodología de trabajo, valoración, requisitos a cumplir, tareas a realizar, trabajos voluntarios, etc. De este modo, se ofertaron tres itinerarios a seguir. Los dos primeros, grupos A y B, se caracterizaban por la aplicación de sendos proyectos de APS vinculados al desarrollo de la asignatura. En cambio, el itinerario del grupo $C$ seguía el desarrollo habitual de la asignatura hasta la fecha, realizando clases magistrales, sesiones prácticas y trabajos teórico-prácticos, sin verse involucrado en ninguna de las dinámicas expuestas más adelante. Tras plantear las distintas alternativas, se formaron los grupos de alumnos por orden de solicitud de los estudiantes interesados hasta completar el número de participantes en cada uno de los itinerarios propuestos. Esta situación de libre elección nos ofreció una primera muestra de la buena acogida que tuvieron los itinerarios formativos vinculados con el APS por parte del alumnado ya que, pese a desconocer en gran medida sus características, los estudiantes se mostraron muy motivados hacia el uso de esta metodología de participación activa.

Como hemos apuntado, la característica diferenciadora del programa formativo de los grupos A y B era que incluían la participación en un proyecto educativo de APS. En ambos casos la aplicación del servicio se llevó a cabo mediante la modalidad de servicio directo. En el marco teórico hemos visto que dicha modalidad requiere una relación directa de los alumnos con las personas receptoras del servicio, acción que nos permitiría influir en el alumnado universitario tanto a nivel académico como personal.

Debido a la especificidad de contenidos a desarrollar en la asignatura, se buscaron centros en los que se trabajara con niños que presentaran alteraciones de la motricidad para que los alumnos pudieran aplicar sesiones de juegos motores y expresivos. Además, bien por el exceso de niños, por la falta de profesionales en la materia o por limitaciones en cuanto a la disposición de recursos, existía una necesidad social no cubierta. Siguiendo las indicaciones de Puig et al. (2007), durante el proceso de elaboración del programa formativo, el profesorado estableció un acuerdo de colaboración con distintas entidades y asociaciones de la provincia de Castellón que cumplieran estos requisitos. De este modo, se pudo atender a más de 150 niños y niñas pertenecientes a la Asociación APADAHCAS (Asociación de Padres de Afectados por Déficit de Atención e Hiperactividad de Castellón), el Centro de Educación Especial del complejo Socio-Educativo Penyeta Roja, el Colegio de Educación Infantil y Primaria Francesc Roca i Alcaide, la Fundación Borja Sánchez y la Fundación Síndrome de Down Castellón. Como hemos señalado, el común denominador de estas entidades es que todas ellas trabajan con niños que presentan alteraciones en su motricidad. Por tanto, la participación de estos niños en sesiones de juegos motores y expresivos representaba una mejora considerable en la atención recibida por este colectivo infantil. Al final de este capítulo exponemos detalladamente las peculiaridades y características propias de cada una de estas entidades colaboradoras. 
La función primordial del alumnado universitario durante la prestación del servicio era la de organizar, aplicar y gestionar distintas sesiones de juegos motores y expresivos planificadas con anterioridad, estimulando así el desarrollo motor y social de los niños, atendiendo a sus diversas necesidades. Pese a que había dos itinerarios formativos vinculados con el APS, la carga lectiva de ambos grupos era bien diferente. Como vemos en la tabla 21, mientras el grupo A cursó el 100\% de la asignatura utilizando la metodología didáctica del APS, el grupo B dedicó exclusivamente un 30\% de la asignatura a esta actividad formativa, la correspondiente a la observación/ejecución de tareas y prácticas.

Tabla 21. Carga lectiva del Aprendizaje Servicio en la asignatura según los distintos itinerarios (elaboración propia).

\begin{tabular}{lccc}
\hline & GRUPO A & GRUPO B & GRUPO C \\
\hline Carga lectiva asignatura & $150 \mathrm{~h}$. & $150 \mathrm{~h}$. & $150 \mathrm{~h}$. \\
Carga lectiva APS & $150 \mathrm{~h} .(100 \%)$ & $45 \mathrm{~h} .(30 \%)$ & o h. (0\%) \\
\hline
\end{tabular}

Pese a la notable diferencia en cuanto a la dedicación en el servicio, los dos grupos, A y B, debían trabajar de manera conjunta en la aplicación de las sesiones prácticas de juegos motores y expresivos con los niños de las entidades colaboradoras. No obstante, mientras los alumnos del grupo A intervinieron directamente en la realización de todas las sesiones aplicadas a lo largo del curso académico, los miembros del grupo $B$ participaron únicamente en la aplicación directa de 3-4 sesiones prácticas de 1-2 horas de duración, en base a las posibilidades de acción con cada entidad. En ambos casos, la carga de trabajo que suponía el APS no se limitaba únicamente a las horas computables de servicio directo, sino que incluía la realización de múltiples tareas como, por ejemplo, tutorías conjuntas e individuales, conocimiento y análisis de las entidades y niños receptores del servicio, preparación de las actividades, aplicación directa de las tareas propuestas, análisis de las sesiones, periodos de reflexión individuales y grupales, etc.

Cursar la asignatura mediante cualquiera de las alternativas ofertadas era totalmente voluntario, por tanto el alumnado que no deseara participar en las actividades de servicio tenía la opción de seguir el itinerario habitual en el grupo C. Trasladando la dedicación del alumnado en las actividades de servicio al sistema de evaluación de la asignatura, comprobamos como dicha experiencia determinó el 70\% de la nota de los integrantes del grupo A ya que, a excepción del examen final de la asignatura, desarrollaron todas las tareas a valorar mediante el APS. En cambio, la evaluación del programa formativo de APS de los miembros del grupo B supuso tan solo el 30\% de su calificación. Así pues, en la tabla 22 apreciamos la distribución del sistema de evaluación de la asignatura en base a las tareas a realizar por cada grupo. 
Tabla 22. Sistema de evaluación de la asignatura en función de las tareas a realizar por cada grupo (elaboración propia).

\begin{tabular}{|c|c|c|c|c|}
\hline ÁREAS DE EVALUACIÓN & VALOR & GRUPO A & GRUPO B & GRUPO C \\
\hline $\begin{array}{l}\text { Elaboración y/o ejecución de } \\
\text { trabajos }\end{array}$ & $30 \%$ & \multirow{3}{*}{ APS } & Trabajos teóricos & Trabajos teóricos \\
\hline $\begin{array}{l}\text { Observación/ejecución de } \\
\text { tareas y prácticas }\end{array}$ & $30 \%$ & & APS & Trabajos prácticos \\
\hline $\begin{array}{l}\text { Resolución de ejercicios y } \\
\text { problemas }\end{array}$ & $10 \%$ & & $\begin{array}{c}\text { Trabajos teórico- } \\
\text { prácticos }\end{array}$ & $\begin{array}{c}\text { Trabajos teórico- } \\
\text { prácticos }\end{array}$ \\
\hline $\begin{array}{l}\text { Examen escrito: test, } \\
\text { desarrollo y/o problemas }\end{array}$ & $30 \%$ & Examen final & Examen final & Examen final \\
\hline
\end{tabular}

Durante la prestación del servicio, el papel del profesorado era el de coordinar y gestionar la actividad. Por ello, debía aconsejar al alumnado sobre la aplicación de las sesiones diseñadas y sobre su interacción con los distintos colectivos implicados, manteniéndose en un segundo plano y cediendo el protagonismo a los alumnos durante el proceso formativo. Esta situación justifica que, pese a seguir unos patrones de aplicación comunes, cada grupo de trabajo pudiera gestionar el servicio de forma libre e independiente permitiendo que, como veremos a continuación, aparecieran notables diferencias en cuanto a la aplicación de sus propuestas a través de esta experiencia educativa.

A continuación pasamos a describir el programa de APS aplicado en cada uno de los grupos vinculados con esta metodología, grupos A y B. Como hemos expuesto en el marco teórico, un elemento común en las definiciones del APS es que provoca la participación del alumnado en un proceso de tres fases: preparación a través de la explicación y análisis de teorías e ideas, actividad de servicio formativo que emerge del contexto del aula y reflexión estructurada que vincula la experiencia de servicio con los objetivos de aprendizaje específicos (Writing@CSU, Universidad de Colorado, 2015). Siguiendo estas indicaciones, secuenciamos la presentación de las distintas actividades realizadas por el alumnado en las fases de preparación, aplicación y reflexión. Igualmente, debido a que la acción de los dos grupos de alumnos, A y B, coincidía en diversos momentos, primero aportamos las actividades realizadas de forma conjunta $y$, seguidamente, indicamos las tareas propias de cada grupo en cada una de las fases descritas.

\subsubsection{Fase de Preparación del programa de Aprendizaje Servicio}

Esta fase comenzó al principio del curso académico y hace mención a las labores previas a la aplicación del servicio. El primer día de clase, el 10 de septiembre de 2013, se expuso al alumnado los posibles itinerarios para cursar la asignatura y se dejó una semana de tiempo para que fueran transmitiendo al profesorado sus preferencias. Así pues, el día 17 de septiembre, se cerraron las distintas agrupaciones de alumnos, estableciendo finalmente los integrantes de los grupos A, B y C e iniciando las actividades propias de cada grupo. 


\section{- Preparación del Aprendizaje Servicio en el Grupo A}

Tras establecer los miembros pertenecientes al grupo A, se inició el desarrollo del programa educativo propiamente dicho. Durante esta fase se realizaron inicialmente 10 sesiones teóricoprácticas en las que se informó y formó al alumnado sobre todos los aspectos básicos relacionados con el servicio. Primeramente se amplío el conocimiento de los integrantes de este grupo sobre la metodología didáctica del APS, sus peculiaridades y requisitos. Al mismo tiempo, se hizo especial hincapié en la pertinencia de actuar siguiendo los postulados del aprendizaje cooperativo. Para ello, se expusieron las características y ventajas de esta forma de trabajar así como de sus procesos de aplicación, incidiendo en la distribución de roles, las responsabilidades de cada miembro, las funciones que cada rol lleva implícitas, las tareas de seguimiento a realizar, etc. Con ello se pretendía procurar un funcionamiento armónico y adecuado de todos los miembros del grupo. Igualmente, se ayudó a planificar la asignación de roles y se incidió en la necesidad de establecer una ejecución rotativa de estas funciones. El objetivo de esta acción era que todos los integrantes desempeñaran todos los roles establecidos de una forma equilibrada.

Una vez asentadas las directrices del proyecto educativo, se formalizó un contrato de aprendizaje entre los alumnos y el equipo docente de la asignatura. Esta acción sirvió para definir y exponer claramente los compromisos asumidos en el programa de APS, tanto por parte del alumnado como del profesorado. Como podemos ver en la imagen 1, este contrato constaba de diez cláusulas y debía ser firmado por ambas partes, asumiendo individualmente el cumplimiento de cada una de ellas. 
CONTRATO DE APRENDIZAJE PARA LA PARTICIPACIÓN EN LA ORGANIZACIÓN DE UN PROGRAMA DE APRENDIZAJE-SERVICIO

Este contrato se ejecutará a través de las siguientes cláusulas:

Primera: el participante se compromete a asistir a las actividades presenciales programadas y cumplir con el desarrollo de las actividades del curso en un nivel superior al $90 \%$.

Segunda: el participante se compromete a mantener un clima de respeto y consideración, con el organizador, con sus compañeros de curso, con las actividades y con las instituciones.

Tercera: el participante se compromete a mantener una actitud proactiva y a convertirse en un agente facilitador del desarrollo del curso y de su propio aprendizaje. Cuarta: el participante se compromete a cumplir con seriedad y profundizar con todas las estrategias de aprendizaje propuestas en el programa del curso y con las actividades de evaluación acordadas o establecidas en el mismo.

Quinta: el participante se compromete a participar activa y responsablemente en las actividades cooperativas previstas en las diferentes fases del curso.

Sexta: el organizador se compromete a mantener un trato de igualdad con el grupo de participantes con respecto al resto del alumnado, asegurando unas pautas de actuación, contenidos y criterios de evaluación equivalentes de acuerdo con la guía docente de la asignatura.

Séptima: el organizador se compromete a mantener una actitud seria, responsable, de colaboración y apoyo en todo momento.

Octava: el organizador se compromete a constituirse en un guía, asesor y orientador académico, para solventar las dificultades propias del proceso de aprendizaje, atendiendo a las consultas e inquietudes que los participantes planteen en las actividades presenciales o a través de medios electrónicos.

Novena: el organizador se compromete a entregar de forma oportuna el material e información necesaria para la realización de las diferentes actividades propuestas.

Décima: el organizador se compromete a administrar este curso con responsabilidad y profundidad, procurando en todo momento elevar la calidad y fomentar el aprendizaje del alumnado.

Participante: LORENA
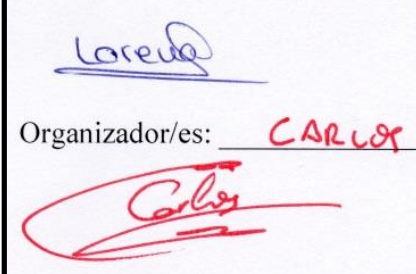

Lugar: CASTELLÓN

Fecha: 26 de SEPTIEMBRE de 2013

Imagen 1. Contrato de aprendizaje para la participación en el programa de Aprendizaje Servicio (elaboración propia).

Seguidamente se informó al alumnado sobre las características de las diferentes entidades colaboradoras y sus niños, para que se distribuyeran de forma libre y equilibrada, escogiendo la entidad con la que querían colaborar. Así pues, se formaron 5 equipos de trabajo, uno para cada entidad colaboradora. La distribución de los alumnos del grupo A en estos equipos de trabajo era la siguiente: APADAHCAS 5 miembros, Centro de Educación Especial Penyeta Roja 7 miembros, Colegio de Educación Infantil y Primaria Francesc Roca i Alcaide 7 miembros, Fundación Borja 
Sánchez 5 miembros y Fundación Síndrome de Down Castellón 4 miembros. Una vez establecida la vinculación entre los alumnos y las entidades colaboradoras, cada equipo de trabajo se responsabilizó de todas las actividades a realizar en su correspondiente entidad a lo largo de la prestación del servicio. De este modo, se pretendía fomentar la aparición de distintas actuaciones a la hora de preparar, adaptar y aplicar el servicio. Finalmente, se proporcionaron los datos de contacto de los responsables de las entidades colaboradoras para que cada equipo de trabajo empezara a actuar cuando lo considerara oportuno.

En las siguientes sesiones el profesorado expuso los contenidos y competencias a trabajar en la prestación del servicio, sirviendo de orientación para las actividades a desarrollar por cada equipo de trabajo. Básicamente se presentaron las siguientes recomendaciones prácticas en cuanto a la estructura de las sesiones de juegos motores y expresivos:

- Adaptar las actividades a las características de los niños participantes.

- Ajustar las propuestas a un ratio adecuado de docentes y alumnos.

- Maximizar el tiempo de compromiso motor durante las sesiones.

- Optimizar la organización interna del grupo repartiendo responsabilidades.

- Maximizar el provecho de las instalaciones y el material disponible.

- Aplicar juegos que desarrollen las habilidades motrices básicas: caminar, correr, saltar, mantener el equilibrio, coger, atrapar o recibir, lanzar, golpear y patear.

- Aplicar juegos que desarrollen las habilidades de expresión corporal: simbolismo, comunicación, representación de roles, relajación, etc.

- Adaptarse correctamente al contexto educativo de cada grupo de niños.

- Utilizar recompensas y estímulos para mantener motivado al alumnado.

- Implementar el uso de material novedoso y asequible: lana, papel higiénico, globos, botellas, cartón, periódicos, tizas, ceras, gomas elásticas, etc.

- Fomentar la plena participación de los niños evitando los juegos de eliminación.

- Evitar los tiempos de espera o filas en el desarrollo de las actividades.

- Utilizar estructuras grupales simples y divisibles en el transcurso de las sesiones.

- Mantener un mínimo de seguridad en las actividades a realizar.

Tras estas recomendaciones prácticas, el profesorado proporcionó al alumnado un modelo de ficha de juegos para que cada equipo de trabajo pudiera recopilar y analizar todas las actividades aplicadas durante el servicio. Esta ficha de juegos era orientativa y cada grupo podía modificarla o adaptarla. En ella se podía indicar la siguiente información:

- Habilidades motrices desarrolladas en el juego: habilidades fundamentales como caminar, correr, saltar, mantener el equilibrio, atrapar, coger, lanzar, golpear, patear y habilidades avanzadas.

- Nivel de dificultad del juego: elemental, intermedio, complejo y adaptable.

- Datos del juego: nombre, material, agrupaciones, espacio, desarrollo, variantes y representación gráfica. 
- Análisis de la aplicación práctica del juego en base a los siguientes ítems:

- Se adapta con coherencia al desarrollo de las habilidades planteadas.

- El ritmo e intensidad del juego son adecuados a las necesidades y capacidades de los jugadores.

- La organización del juego fomenta un alto tiempo de compromiso motor.

- Las reglas son fácilmente entendidas por la mayoría de jugadores.

- El planteamiento resulta motivante y fomenta la implicación y atención de los jugadores.

- El uso del material es adecuado tanto a nivel pedagógico como de seguridad.

- Fomenta valores individuales como el autoconcepto y la autoestima.

- Promueve valores sociales relacionados con la integración y la cooperación.

- Impulsa el desarrollo de la autonomía motriz de los jugadores.

- Es fácil de adaptar y modificar mediante pequeñas variantes.

- Valoración final del juego según el número de ítems cumplidos: <5 (desechable), de 5 a 7 (mejorable), de 7 a 9 (aprovechable) y 10 (óptimo).

- Otra información: observadores, directores del juego, jugadores, fecha de aplicación y otras observaciones.

Al mismo tiempo, también se facilitaron tres modelos de registro en los que el alumnado podía recabar la información relativa a la aplicación del servicio, los roles desempeñados y las reuniones realizadas. En cuanto a la aplicación del servicio, el documento incluía los siguientes aspectos: fecha, actividad, participantes, dedicación temporal, acciones destacables y número de registro. La hoja de registro de roles recababa datos como la fecha, la actividad realizada y el rol de cada uno de los participantes entre las siguientes opciones iniciales: ayudante, mensajero, animador, secretario/moderador, distribuidor/revisor e informador. Finalmente, en el acta de reuniones se podía registrar: fecha, número de registro, tema de la reunión, dedicación temporal, enfoque de la situación, posibles alternativas, principales reflexiones, acuerdos y decisiones finales. Al igual que en el caso anterior, los alumnos eran libres de modificar o adaptar cualquiera de estos tres documentos si lo consideraban necesario.

Por último, con la intención de estimular el proceso de reflexión durante la aplicación del servicio, también se proporcionó un modelo en el que el alumnado podía registrar esta importante labor. En la imagen 2 podemos comprobar que dicho documento incluía los siguientes datos: número de sesión, fecha, componentes del equipo de trabajo, instrucciones de uso y pautas para analizar la actividad. 


\section{Documento reflexivo sobre la aplicación \\ Sesión $n^{\circ}:$ Fecha: Componentes Grupo:}

\section{INSTRUCCIONES:}

Este documento persigue conseguir una constancia escrita y seguimiento de las actividades realizadas en el servicio a la comunidad prestado en la asignatura MI1019, de los contenidos curriculares trabajados y de los objetivos académicos conseguidos. Además pretende hacer consciente al alumno/a de la dimensión social del servicio que se presta (se trabaja con personas que tienen necesidades especiales) a la vez que se aprenden contenidos de la asignatura. Sirve además para recoger las opiniones del alumnado sobre el trabajo realizado.

Debéis rellenarlo al acabar la sesión de práctica por grupos de trabajo. Una persona debe encargarse de informatizarlo y recopilarlo para posteriormente entregárselo al responsable de la asignatura.

Haced la reflexión entre todos los miembros del grupo y plasmad las sensaciones que experimentéis y las ideas que os surjan, tanto a nivel académico como personal. Este apartado es especialmente importante, ya que vuestras opiniones nos sitúan en el proceso de aprendizaje.

Reunión para analizar la actividad.

Dificultades y problemas encontrados en la realización:

(Ejemplo: no ha dado tiempo a realizar todos los ejercicios planificados, los ejercicios eran demasiado complejos, no acabamos de entender bien sus problemas y necesidades, no sabemos interactuar con ellos/as...)

\section{Diálogo sobre la propia acción y conclusiones más relevantes:}

(Ejemplo: la próxima sesión realizaremos menos actividades pero las trabajaremos más intensamente, profundizaremos en las características de sus problemáticas y en conocer sus limitaciones en la vida diaria para poder comunicarnos mejor con ellos, estableceremos estrategias para empatizar, etc.)

\section{Sensaciones experimentadas:}

(Ejemplo: ha sido gratificante trabajar con estos alumnos ya que hemos tenido la sensación de hacer cosas muy provechosas para ellos y para nosotros, mediante el diálogo les hemos transmitido confianza en que pueden integrarse perfectamente en la sociedad, etc.)

Imagen 2. Documento reflexivo sobre la aplicación del Aprendizaje Servicio (elaboración propia).

Como se puede apreciar, estos documentos recaban información sobre los efectos académicos y personales que el programa de APS iba provocando en el alumnado, abarcando así los ejes fundamentales del proyecto educativo y sirviendo para evaluar el cumplimiento de los objetivos generales y específicos descritos en el apartado anterior. 
Tras entregar estos documentos y aclarar las dudas existentes respecto a sus posibilidades de uso, el profesorado y todos los miembros del grupo hicieron un análisis del trabajo a realizar con las entidades colaboradoras, determinando los primero pasos de cada equipo de trabajo. En este análisis se valoraron los siguientes aspectos:

- Características de las entidades colaboradoras y sus niños.

- Estrategias de comunicación con los responsables de los centros.

- Recursos disponibles en cada entidad.

- Detección de necesidades específicas a cubrir en cada caso.

- Posibles dificultades a afrontar durante la prestación del servicio.

- Habilidades de los integrantes en cada equipo de trabajo.

Después de esta valoración inicial, cada equipo de trabajo procedió a delimitar sus líneas de acción en cuanto a los objetivos generales del servicio y su relación con el resto de implicados en el mismo: profesorado, profesionales de las entidades, niños receptores del servicio, familiares de los niños, compañeros universitarios, etc.

A lo largo de toda la fase de preparación los distintos equipos de trabajo del grupo A debían responsabilizarse de las siguientes tareas vinculadas a su entidad colaboradora:

- Determinar los principios básicos del servicio.

- Contactar con los responsables de las entidades colaboradoras.

- Definir las responsabilidades y obligaciones de los distintos colectivos implicados.

- Establecer la duración e intensidad del servicio.

- Organizar los horarios del servicio con los responsables del centro colaborador.

- Definir los objetivos específicos de las sesiones de juegos.

- Preparar todas las actividades y tareas vinculadas directa o indirectamente con la aplicación del servicio.

- Determinar los materiales y espacios a utilizar.

- Establecer los distintos grupos de trabajo.

- Distribuir a los miembros del grupo B.

- Facilitar los conocimientos adquiridos sobre el centro colaborador y las características de los niños a los miembros del grupo B.

- Fijar las pautas y normas de funcionamiento durante el servicio.

- Seleccionar las estrategias metodológicas a aplicar en función de las actividades.

- Predecir las posibles trabas administrativas o logísticas a solventar y elaborar respuestas a las mismas.

Como podemos apreciar, con el cumplimiento de estas labores se pretendía estimular el desarrollo de los aprendizajes académicos y de los aspectos personales vinculados con el ES. A continuación, presentamos varios ejemplos que aportan una idea más clara de la labor del alumnado en el desempeño de estas funciones. Para ello, mostramos una asignación de tareas y 
roles a desempeñar en el desarrollo de las sesiones (imagen 3), una organización temporal de los miembros del grupo B (imagen 4), una estructura organizativa de las tareas a realizar por los asistentes a la sesión en cada actividad (imagen 5), una autorización para poder hacer fotos a los niños receptores del servicio durante el desarrollo de las propuestas a aplicar (imagen 6) y un diploma acreditativo para entregar a los niños una vez finalizada la actividad (imagen 7).

\section{PAUTAS A SEGUIR EN LAS SESIONES}

-Portavoz: es el encargado de explicar y dirigir el juego.

-Animador: se asegura de que todos los niños participen.

-Ayudante: se asegura de que al portavoz no le falte ningún recurso humano y material.

-Observador del juego*: analiza y observa el funcionamiento del juego, tomando notas.

-Controlador del tiempo: controla el tiempo, ajustándolo a los intereses de los niños.

-Preparador del siguiente juego*: recoge el material que ya no se vaya a utilizar a lo largo del juego presente y prepara el siguiente juego al completo.

\section{${ }^{\text {*NOTA: }}$ No se podrá participar en el juego hasta que el rol se} haya cumplido.

Imagen 3. Asignación de tareas y roles a desempeñar en las sesiones (elaborada por los equipos de trabajo del grupo A).

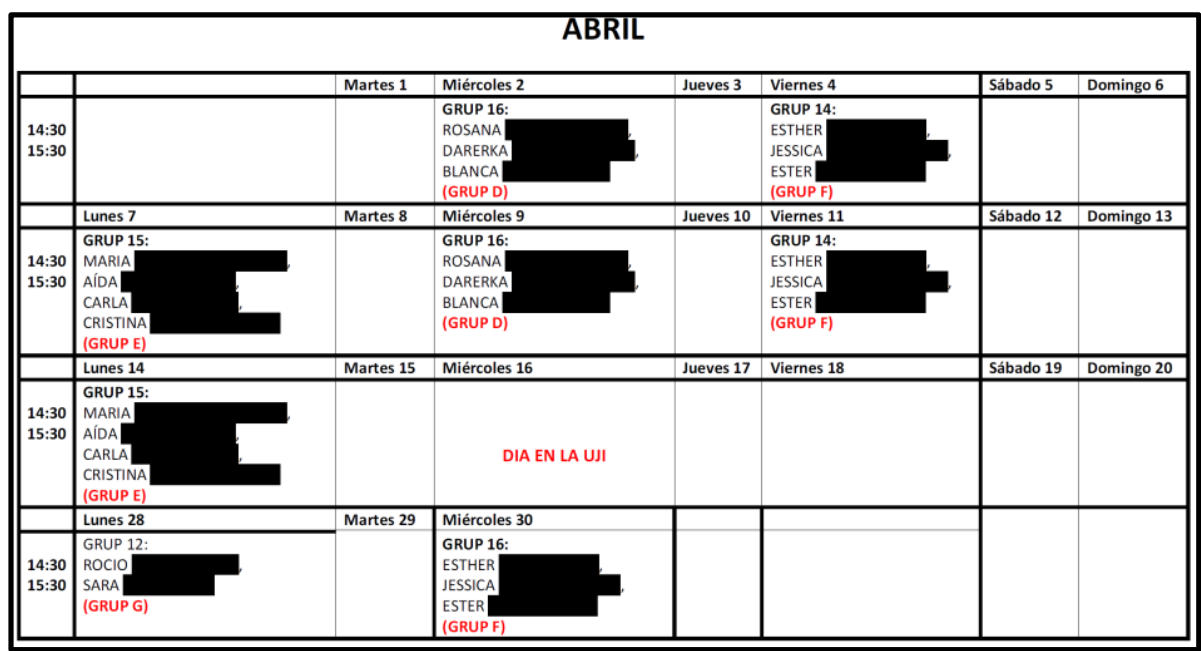

Imagen 4. Organización temporal de los miembros del grupo (elaborada por los equipos de trabajo del grupo A). 


\begin{tabular}{|l|c|c|c|c|}
\hline & $\begin{array}{c}\text { Presentamos la } \\
\text { sesión }\end{array}$ & $\begin{array}{c}\text { Hacemos } \\
\text { grupos }\end{array}$ & Expedición & $\begin{array}{c}\text { Recolecta de } \\
\text { cocos }\end{array}$ \\
\hline Portavoz & Carlos & Juanmi & Esme & Albal \\
\hline Animador & Marta & Lorena & Rosa & Jesi \\
& Rosa & Carlos & Juanmi & Esme \\
\hline Ayudante & Alba & Marta & Lorena & Rosa \\
& Jesi & Jesi & Carlos & Juamni \\
\hline Control tiempo & Esme & Alba & Marta & Lorena \\
\hline Preparar juego & Juanmi & Esme & Alba & Marta \\
& Lorena & Rosa & Jesi & Carlos \\
\hline Portavoz & Almuerzo & Rompe hojas & Supervivencia & Carrera \\
\hline Animador & Marta & Lorena & Rosa & Jesi \\
\hline Ayudante & Carlos & Juanmi & Esme & Alba \\
\hline Control tiempo & Alba & Marta & Marta & Rosa \\
\hline Preparar juego & Jesi & Carlos & Juanmi & Esme \\
\hline & Lorena & Albal & Lorena & Lorena \\
\hline
\end{tabular}

Imagen 5. Estructura organizativa de las tareas a realizar en cada actividad de la sesión (elaborada por los equipos de trabajo del grupo A).

Estimados padres;

Somos el grupo de estudiantes del Grado de Magisterio Infantil que durante el periodo lectivo 2013-2014, vamos a compartir el tiempo con vuestros hijos durante las sesiones que se realizarán los sábados en la Universitat Jaume I.

Durante esas sesiones, seremos los responsables de que sus hijos disfruten y aprovechen el tiempo al máximo. Para ello, prepararemos diferentes actividades, con el fin de trabajar de una manera lúdica, diferentes aspectos psicosociales relevantes en su desarrollo.

Debido a que somos estudiantes, a nosotros nos sirve esta experiencia para aprender a ser buenos profesionales en el futuro, es por ello que debemos de realizar un trabajo de todo lo realizado para que nuestros profesores nos puedan evaluar adecuadamente.

Con el fin de que nuestro trabajo sea completo, necesitaremos realizar algunas fotografias de las dinámicas que hemos preparado, es por eso que dado que el derecho a la propia imagen está reconocida en el artículo 18 de la Constitución Española y regulado por la Ley $1 / 1982$ de 5 de Mayo, sobre el derecho al honor, a la intimidad personal y familiar, y a la propia imagen, y la Ley 15/1999 de 13 de diciembre, sobre Protección de Datos de Carácter Personal, os pedimos el consentimiento para poder publicar las imágenes en las cuales aparezcan vuestros hijos, que con carácter psicopedagógico se puedan realizar a los que participen en actividades organizadas.

Si nos da su consentimiento nos comprometemos a regalarle un $\mathrm{CD}$ con las imágenes tomadas y así podrán tener un magnifico recuerdo de las mismas.

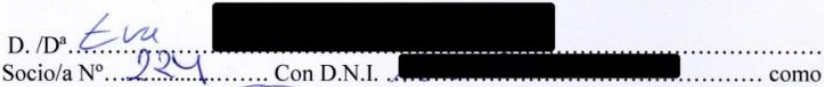

persona fisica y/o padre madre o tutor legal del menor

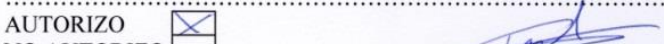

NO AUTORIZO

Al grupo de estudiantes de Magisterio Infantil responsables de las sesiones realizadas durante 2013-2014, a usar las fotografias tomadas durante esas sesiones, únicamente para el trabajo académico correspondiente a esas sesiones.

Imagen 6. Autorización para hacer fotos a los niños receptores del servicio durante las sesiones (elaborada por los equipos de trabajo del grupo A). 


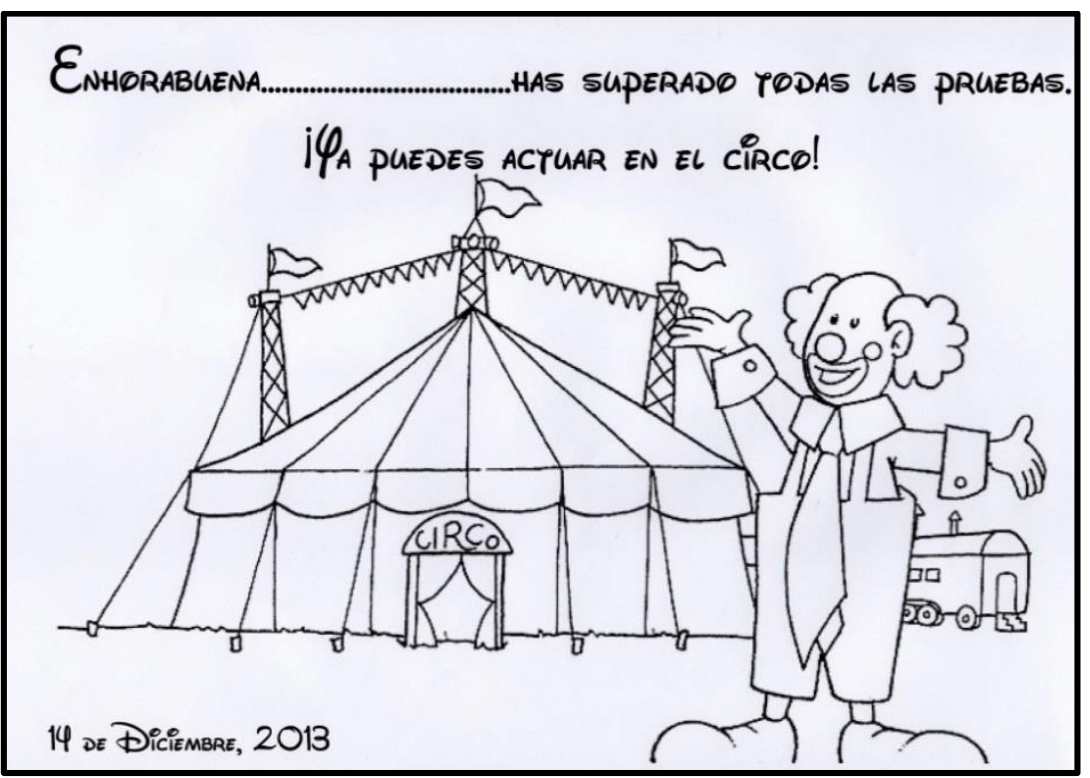

Imagen 7. Diploma acreditativo para entregar a los niños una vez finalizada la actividad (elaborado por los equipos de trabajo del grupo A).

Como ya hemos apuntado, la libertad de acción de los equipos de trabajo provocó la aparición de numerosas variantes en cada aplicación. Entre ellas podemos destacar los diferentes periodos de acción en las distintas fases del programa de APS, provocada por las diferentes necesidades y disponibilidades de los centros colaboradores en cuanto a la prestación del servicio. No obstante, el profesorado veló por la participación equilibrada de los alumnos involucrados en función de los parámetros estipulados en los itinerarios ofertados. En la tabla 23 exponemos la duración de la fase de preparación en cada uno de los equipos de trabajo del grupo A, la cual varió entre unas pocas semanas y varios meses.

Tabla 23. Duración de la fase de preparación del Aprendizaje Servicio en los equipos de trabajo del grupo A (elaboración propia).

\begin{tabular}{llllll}
\hline $\begin{array}{l}\text { Equipo de } \\
\text { trabajo }\end{array}$ & $\begin{array}{c}\text { Asociación } \\
\text { APADAHCAS }\end{array}$ & CEE Penyeta Roja & $\begin{array}{l}\text { CEIP Francesc } \\
\text { Roca i Alcaide }\end{array}$ & $\begin{array}{c}\text { Fundación Borja } \\
\text { Sánchez }\end{array}$ & $\begin{array}{c}\text { Fundación } \\
\text { Síndrome de } \\
\text { Down Castellón }\end{array}$ \\
\hline $\begin{array}{l}\text { Duración de } \\
\text { la fase }\end{array}$ & $\begin{array}{l}\text { Del 17/9/2013 } \\
\text { al 19/10/2013 }\end{array}$ & $\begin{array}{l}\text { Del 17/9/2013 } \\
\text { al 17/2/2014 }\end{array}$ & $\begin{array}{l}\text { Del 17/9/2013 } \\
\text { al 13/11/2013 }\end{array}$ & $\begin{array}{l}\text { Del 17/9/2013 } \\
\text { al 9/11/2013 }\end{array}$ & $\begin{array}{l}\text { Del } 17 / 9 / 2013 \\
\text { al 13/11/2013 }\end{array}$ \\
\hline
\end{tabular}




\section{- Preparación del Aprendizaje Servicio en el Grupo B}

Tras determinar los integrantes de este colectivo, los miembros del grupo B iniciaron la docencia de la asignatura con total normalidad, realizando las actividades teóricas y prácticas asociadas a cada apartado de la misma. Tras dos semanas de clase, se informó al alumnado de las entidades colaboradoras en las que podían realizar el servicio y las características de sus niños. Al igual que en el grupo anterior, se permitió que el alumnado se distribuyera de forma libre y equilibrada, escogiendo la entidad con la que querían colaborar. De este modo, los distintos equipos de trabajo del grupo $B$, de 3 a 5 personas cada uno, quedaron vinculados a una entidad colaboradora y a su correspondiente equipo de trabajo del grupo A. Siguiendo el calendario establecido, los equipos de trabajo de ambos grupos, A y B, trabajaron conjuntamente para preparar las sesiones de juegos motores y expresivos en las que tenían que participar. Como ya hemos indicado, ambos colectivos eran responsables de organizar y aplicar las sesiones de juegos motores y expresivos con los niños de las entidades colaboradoras. Las funciones y responsabilidades de ambos colectivos durante la preparación de las sesiones eran exactamente las mismas, ya descritas en el correspondiente apartado del grupo A. No obstante, mientras los equipos de trabajo del grupo $\mathrm{A}$ intervinieron directamente en la organización y aplicación de todas las sesiones realizadas a lo largo del curso académico, los equipos de trabajo del grupo B participaron únicamente en la organización y aplicación directa de 3-4 sesiones prácticas de 1-2 horas de duración, en base a las posibilidades de acción con cada entidad. Por ello, los equipos de trabajo del grupo $B$ se dejaron guiar y aconsejar por sus homónimos del grupo $A$, ya que tenían un mayor conocimiento y experiencia respecto a las necesidades del servicio a realizar y las características de los niños. Esta fase implicaba que ambos equipos de trabajo se reunieran 2 o 3 veces antes de la aplicación de las sesiones de juegos. En el primer encuentro se establecían las pautas de actuación, las necesidades a cubrir y los objetivos a alcanzar en el servicio y, en los siguientes, se presentaban y analizaban conjuntamente las propuestas iniciales a realizar durante la ejecución del servicio.

Una vez definidas las labores realizadas durante la preparación del servicio pasamos a exponer las tareas relativas a su aplicación.

\subsubsection{Fase de Aplicación del programa de Aprendizaje Servicio}

Esta fase hace referencia a la prestación directa del servicio. Al igual que en el caso anterior, los periodos de aplicación del APS en cada equipo de trabajo variaron en función de las necesidades y disponibilidades de su entidad colaboradora. De este modo, mientras unos grupos empezaron a las pocas semanas tras iniciar el curso académico, en los meses de octubre y noviembre, otros tuvieron que esperar hasta el mes de febrero para poder empezar a aplicar el servicio. 


\section{- Aplicación del Aprendizaje Servicio en el Grupo A}

La función básica de cada equipo de trabajo a lo largo de esta fase era la de aplicar correctamente las sesiones de juegos motores y expresivos planificadas con anterioridad. Para lograrlo, el alumnado debía prever y solventar cualquier incidencia que pudiera alterar el desarrollo normal de la práctica.

De hecho, debemos destacar que durante este periodo de aplicación los miembros del grupo A no solo se dedicaron a prestar el servicio directo, sino que también debían adaptar y ajustar las distintas actividades en función de dicha aplicación. Este hecho nos ayuda a comprender que, pese a encontrarse en el periodo de aplicación, el servicio fue evolucionando en base a los resultados de su puesta en práctica. Por ello, gran parte de las funciones organizativas expuestas en la fase de preparación también se manifestaron en esta fase de aplicación. Igualmente entendemos que, pese a la división realizada para presentar el programa de APS, el desarrollo de estos proyectos educativos sigue un proceso lineal en el que muchas funciones se entrelazan o extienden a lo largo de las distintas etapas del mismo.

Otro elemento fundamental que aumenta su protagonismo en esta fase de aplicación es el seguimiento del trabajo de los alumnos por parte del equipo docente. Con esta acción el profesorado debía guiar y orientar la labor de los distintos equipos de trabajo en base a los objetivos del programa formativo. De este modo se entiende que las adaptaciones y ajustes realizados a lo largo de la aplicación del servicio se llevaron a cabo bajo la atenta supervisión del equipo docente. Para ejercer esta función el profesorado empleó las reuniones de tutoría correspondientes, individuales y grupales, el contacto diario mediante el uso del correo electrónico, las visitas a las entidades colaboradoras durante el desarrollo de las sesiones y las reuniones con los distintos profesionales responsables de dichos centros. Como hemos apuntado en el párrafo anterior, esta no es una función exclusiva de la fase de aplicación sino que también está presente durante la preparación y la reflexión del APS.

Igualmente, a lo largo de la fase de aplicación se incrementa la importancia de los periodos de reflexión, un elemento decisivo en los programas de APS. Este proceso es esencial para llevar al plano consciente aquello que se está aprendiendo durante la aplicación del servicio, asentando así los conocimientos que guiarán las acciones futuras. A lo largo de esta fase, además de la reflexión conjunta realizada al finalizar las sesiones prácticas, también se llevaron a cabo reflexiones adicionales en las sesiones de tutoría con el profesorado. En ambos casos, se efectuaron dos tipos de reflexiones: una a nivel de aprendizajes en cuanto a los conocimientos académicos adquiridos a lo largo del programa formativo y otra sobre los aspectos personales vinculados con el ES.

Así pues, las funciones básicas de los distintos equipos de trabajo a lo largo de esta fase de aplicación se centraron en: la organización, aplicación y adaptación de las sesiones de juegos motores y expresivos, el seguimiento del servicio junto con el profesorado de la asignatura y los procesos de reflexión derivados de la aplicación del servicio. Para llevar a cabo estas acciones, el alumnado utilizó las distintas herramientas proporcionadas al inicio del programa formativo por 
parte del equipo docente: ficha de juegos, modelos de registro y documento reflexivo. Seguidamente, mostramos varios ejemplos gráficos de las labores desempeñadas por los equipos de trabajo a lo largo de esta fase. Para ello, aportamos la ficha de un juego aplicado durante la prestación del servicio (imagen 8), un documento de registro de los roles desempeñados en las distintas labores desempeñadas (imagen 9), un documento de registro del proceso reflexivo tras la aplicación del servicio (imagen 10), un documento de registro de la dedicación directa en el servicio (imagen 11), un acta de registro de las distintas reuniones realizadas a lo largo de la aplicación del servicio (imagen 12) y tres fotos de distintas sesiones prácticas de servicio (imágenes 13, 14 y 15).

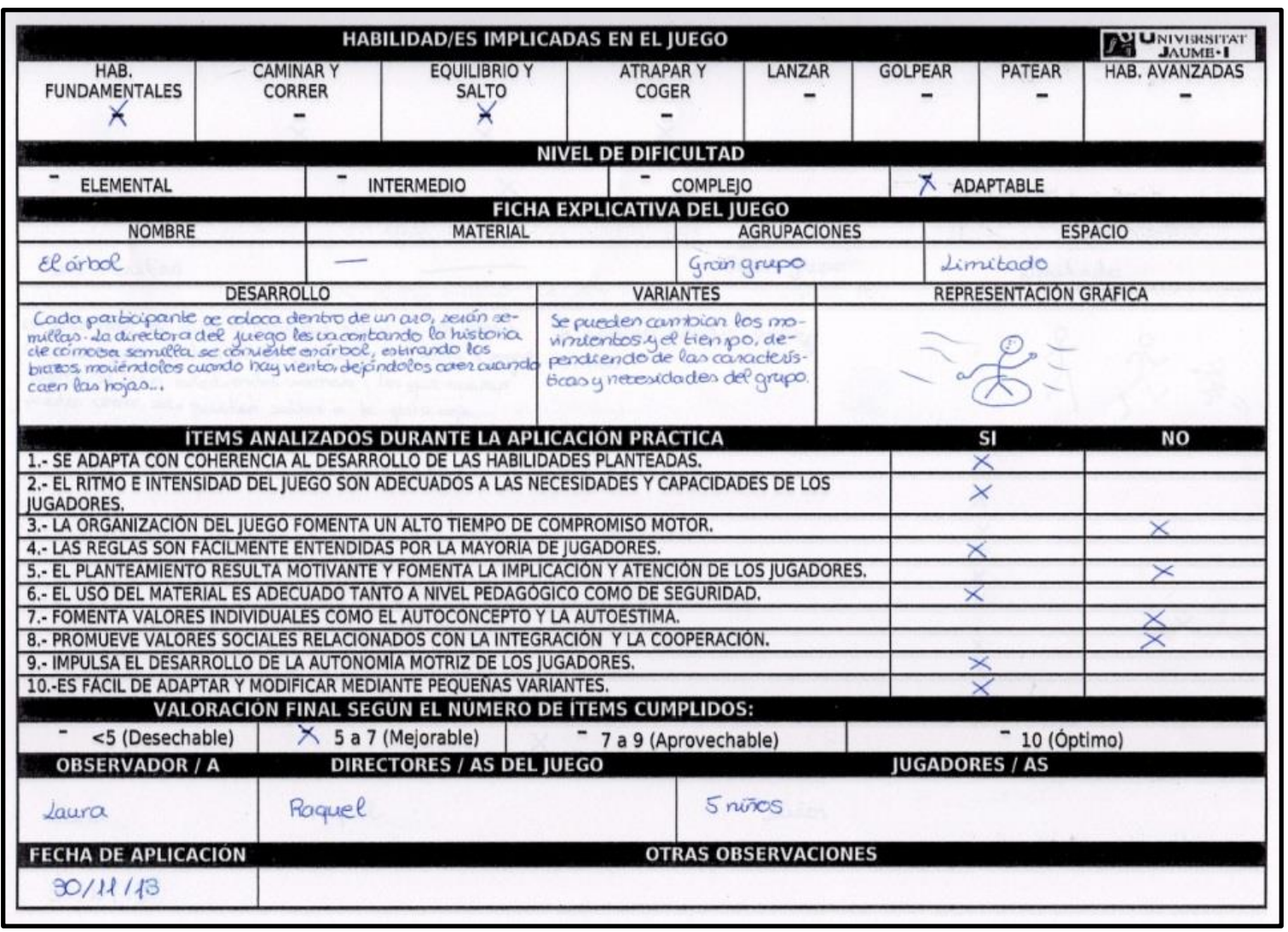

Imagen 8. Ficha de juego 1 (elaborada por los equipos de trabajo del grupo A). 


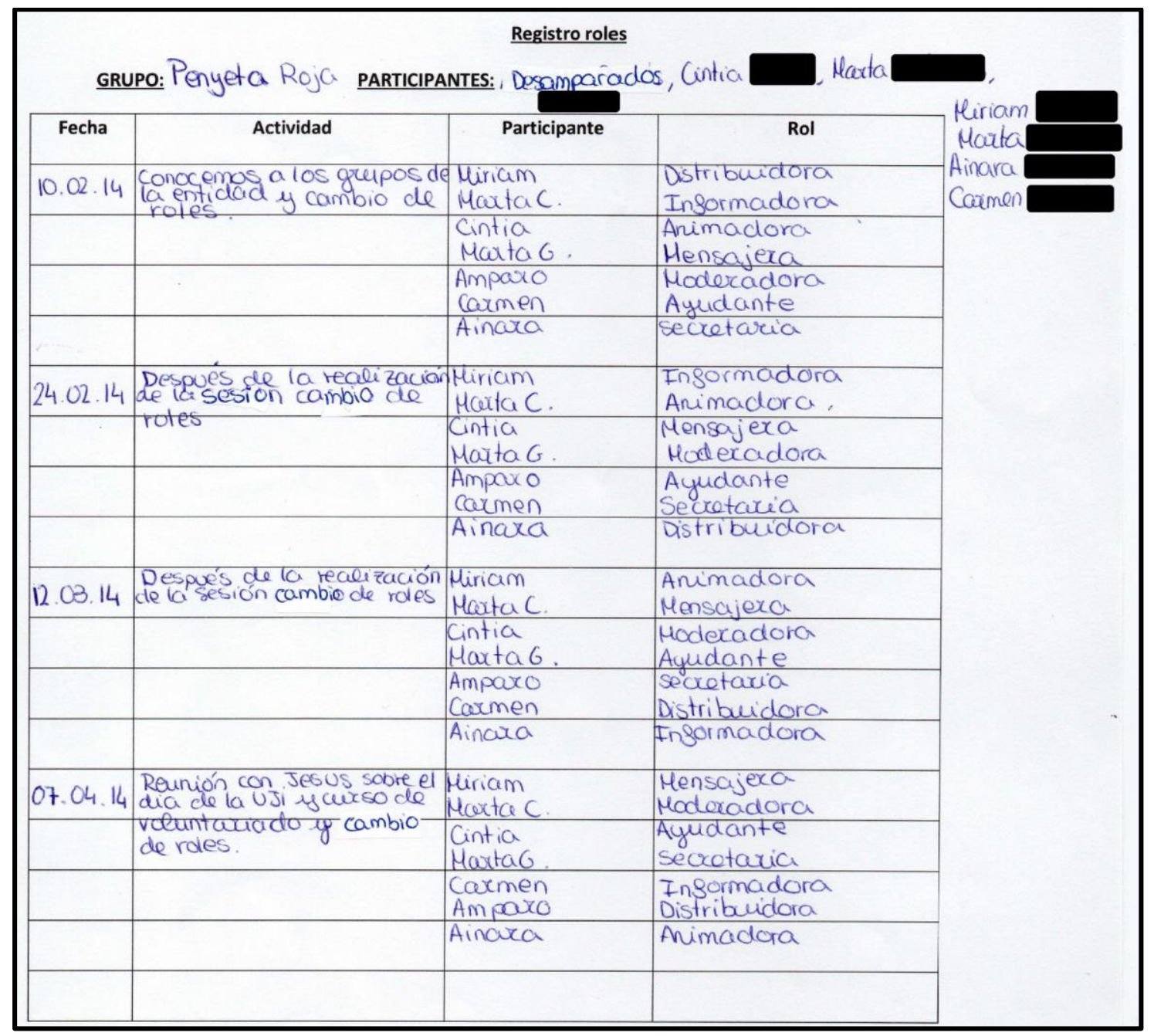

Imagen 9. Documento de registro de roles (elaborado por los equipos de trabajo del grupo A).

Diálogo sobre la propia acción y conclusiones más relevantes:

En las planificaciones de las próximas sesiones, aportaremos al resto de grupos, los conocimientos que hemos adquirido sobre los niños/as para que las sesiones se puedan llevar a cabo de manera factible.

Para ello, profundizaremos en las características físicas y mentales de los componentes de cada grupo de niños/as e intentaremos que nuestros compañeros/as empaticen ante las necesidades de los niños.

Cabe decir que, hemos observado que con el grupo de los pequeños ha sido complicado llevar a cabo una sesión propiamente dicha, les iba mejor hacer actividades de estimulación y espontáneas, ya que es un grupo con diferentes dificultades y al ser los más pequeños les cuesta mucho entender las explicaciones de nuestras compañeras. 
Sensaciones experimentadas:

Nos ha sido gratificante trabajar con estos alumnos, ya que hemos tenido la sensación de ayudar y que pasaran buenos momentos en los juegos.

En un principio había gente de nuestro grupo que no estaba muy cómoda con este tipo de niños y niñas pero poco a poco han mejorado sus impresiones y sensaciones respecto a la primera idea que tenían.

Todos los niños se alegran mucho cuando llegamos al centro para hacer las actividades, eso nos llena de satisfacción al ver que disfrutan jugando con las sesiones preparadas.

Hemos podido observar que con los mayores se pueden hacer más juegos motores ya que sus problemas no son físicos por lo tanto nos alegra, ya que la sesión que preparamos se puede llevar a cabo con facilidad.

Imagen 10. Documento de registro del proceso reflexivo tras la aplicación del servicio 1 (elaborado por los equipos de trabajo del grupo A).

\begin{tabular}{|c|c|c|c|c|c|}
\hline \multicolumn{2}{|c|}{ GRUPO: CAES Burriana } & \multicolumn{2}{|c|}{ PARTICIPANTES: Miriam } & 1, Raquel Lucia & \multirow{2}{*}{ Registro } \\
\hline Fecha & Actividad & Participantes & Dedicación (h) & Acciones destacables & \\
\hline $31 / 10 / 13$ & Reunión & $\begin{array}{l}\text { Jesús + } \\
\text { grupo }\end{array}$ & 1 hora & $\begin{array}{l}\text { Hablamos de la sesión motriz } \\
\text { para la clase y de los } \\
\text { alumnos de tercero }\end{array}$ & Reunión 1 \\
\hline $13 / 11 / 13$ & Reunión & $\begin{array}{l}\text { Jesús + } \\
\text { grupo }\end{array}$ & 1 hora & Hablamos de la sesión motriz & Reunión 2 \\
\hline $7 / 11 / 13$ & Reunión & $\begin{array}{l}\text { Jesús + } \\
\text { Carlos + } \\
\text { grupo }\end{array}$ & 1 hora & $\begin{array}{l}\text { Hablamos del colegio de } \\
\text { Burriana }\end{array}$ & Reunión 3 \\
\hline $19 / 10 / 13$ & Reunión & $\begin{array}{l}\text { Jesús + } \\
\text { grupo }\end{array}$ & 15 minutos & $\begin{array}{l}\text { Hablamos de las alumnas de } \\
\text { tercero }\end{array}$ & Reunión 4 \\
\hline $6 / 11 / 13$ & Reunión & $\begin{array}{l}\text { Víctor + } \\
\text { grupo }\end{array}$ & 1 hora & $\begin{array}{l}\text { Conocemos los horarios del } \\
\text { colegio y acordamos las } \\
\text { sesiones }\end{array}$ & Reunión 5 \\
\hline $13 / 11 / 13$ & Sesión Burriana & $\begin{array}{l}\text { Victor + } \\
\text { grupo }\end{array}$ & 2 horas & Conocemos a los niños & Sesión 1 \\
\hline $20 / 11 / 13$ & Sesión Burriana & $\begin{array}{l}\text { Víctor + } \\
\text { grupo }\end{array}$ & 2 horas & Impartimos las clases & Sesión 2 \\
\hline $27 / 11 / 13$ & Sesión Burriana & $\begin{array}{l}\text { Victor + } \\
\text { grupo }\end{array}$ & 2 horas & Impartimos las clases & Sesión 3 \\
\hline $4 / 12 / 13$ & Sesión Burriana & $\begin{array}{l}\text { Víctor + } \\
\text { grupo }\end{array}$ & 2 horas & Impartimos las clases & Sesión 4 \\
\hline $11 / 12 / 13$ & Sesión Burriana & $\begin{array}{l}\text { Víctor + } \\
\text { grupo }\end{array}$ & 2 horas & Impartimos las clases & Sesión 5 \\
\hline $18 / 12 / 13$ & Sesión Burriana & $\begin{array}{l}\text { Victor + } \\
\text { grupo }\end{array}$ & 2 horas & Impartimos las clases & Sesión 6 \\
\hline $23 / 01 / 14$ & Reunión & $\begin{array}{l}\text { Grupo + } \\
\text { grupo clase }\end{array}$ & 1 hora & $\begin{array}{l}\text { Información Burriana y } \\
\text { sesiones }\end{array}$ & Reunión 6 \\
\hline $3 / 02 / 14$ & Reunión & $\begin{array}{l}\text { Grupo + } \\
\text { grupo clase }\end{array}$ & 1 hora & Informar sesiones & Reunión 7 \\
\hline $5 / 02 / 14$ & Sesión Burriana & $\begin{array}{l}\text { Victor }+ \\
\text { grupo }+ \\
\text { grupo clase }\end{array}$ & $\begin{array}{l}2 \text { horas y } \\
\text { media }\end{array}$ & $\begin{array}{l}\text { Observamos e impartimos } \\
\text { clase. Valoración final }\end{array}$ & Sesión 7 \\
\hline $12 / 02 / 14$ & Sesión Burriana & $\begin{array}{l}\text { Victor + } \\
\text { grupo }+ \\
\text { grupo clase }\end{array}$ & $\begin{array}{l}2 \text { horas y } \\
\text { media }\end{array}$ & $\begin{array}{l}\text { Impartimos clase y } \\
\text { observamos. Valoración final }\end{array}$ & Sesión 8 \\
\hline $19 / 02 / 14$ & Sesión Burriana & $\begin{array}{l}\text { Victor + } \\
\text { grupo + }\end{array}$ & $\begin{array}{l}2 \text { horas y } \\
\text { media }\end{array}$ & $\begin{array}{l}\text { Observamos sesión grupo } \\
\text { clase. Valoración final }\end{array}$ & Sesión 9 \\
\hline
\end{tabular}

Imagen 11. Documento de registro de la dedicación directa en el servicio 1 (elaborado por los equipos de trabajo del grupo A). 


\begin{tabular}{|c|c|c|c|c|c|}
\hline \multicolumn{6}{|c|}{ Registro actas reuniones } \\
\hline GRUPO:APADAHCAS & \multicolumn{3}{|c|}{ PARTICIPANTES: } & 1. BÁRBARA; & BEATRIZ; \\
\hline FECHA: 19/11/2013 & \multicolumn{3}{|c|}{ REGISTRO: $21 / 10 / 2013$} & & \\
\hline Tema & $\begin{array}{c}\text { Dedicación } \\
\text { (m) }\end{array}$ & Enfoque & Alternativas posibles & Principales reflexiones & Acuerdos $y$ decisiones \\
\hline $\begin{array}{l}\text { ORGANIZACIÓN DE ROLES } \\
\text { PARA LLEVAR A CABO LAS } \\
\text { SESIONES }\end{array}$ & 30 & grupal & $\begin{array}{l}\text {-Se quede una } \\
\text { persona observando y } \\
\text { controlando el tiempo. } \\
\text {-cada miembro del } \\
\text { grupo dirija un juego. } \\
\text {-todos tenemos que } \\
\text { saber los juegos. }\end{array}$ & $\begin{array}{l}\text { En la sesión hubo falta de } \\
\text { coordinación y comunicación por } \\
\text { parte de los miembros del grupo, } \\
\text { por lo que los niños se } \\
\text { dispersaban un poco, sobre todo } \\
\text { en la hora del almuerzo. Además } \\
\text { algunos miembros del grupo no } \\
\text { se sabian los juegos por lo que las } \\
\text { que dirigian el juego casi siempre } \\
\text { eran las mismas personas y } \\
\text { finalmente hubo juegos que no } \\
\text { cumplian la seguridad y otros que } \\
\text { no eran motivadores para la } \\
\text { tipologia de niños. }\end{array}$ & $\begin{array}{l}\text { No dejar materiales preparados para no se } \\
\text { distraigan. } \\
\text { Dejar claras las normas y la zona de } \\
\text { almuerzo. } \\
\text { Cuando hay un juego en funcionamiento no } \\
\text { tiene se tiene que empezar otro. } \\
\text { Los juegos tienen que ser dirigidos y } \\
\text { seleccionados por los monitores. } \\
\text { Los niños no son los que mandan que juego } \\
\text { hay que hacer. } \\
\text { Los juegos tienen que ser cooperativos. }\end{array}$ \\
\hline CAMBIO DE ROLES & 60 & Grupal & $\begin{array}{l}\text {-todos los miembros } \\
\text { del grupo rodarán } \\
\text { según los roles de } \\
\text { juego. }\end{array}$ & $\begin{array}{l}\text { Para poder llevar a cabo una } \\
\text { adecuada sesión hay que } \\
\text { establecer una serie de roles, de } \\
\text { este modo todos los miembros } \\
\text { del grupo sabrán que tienen que } \\
\text { hacer en cada momento. }\end{array}$ & $\begin{array}{l}\text { Se realizarán } 4 \text { roles } \\
\text { 1. Director del juego } \\
\text { 2. Ayudante/animador. } \\
\text { 3. Controla el tiempo } \\
\text { 4. Prepara el siguiente juego }\end{array}$ \\
\hline
\end{tabular}

Imagen 12. Acta de registro de las reuniones realizadas a lo largo de la aplicación del servicio (elaborada por los equipos de trabajo del grupo A).

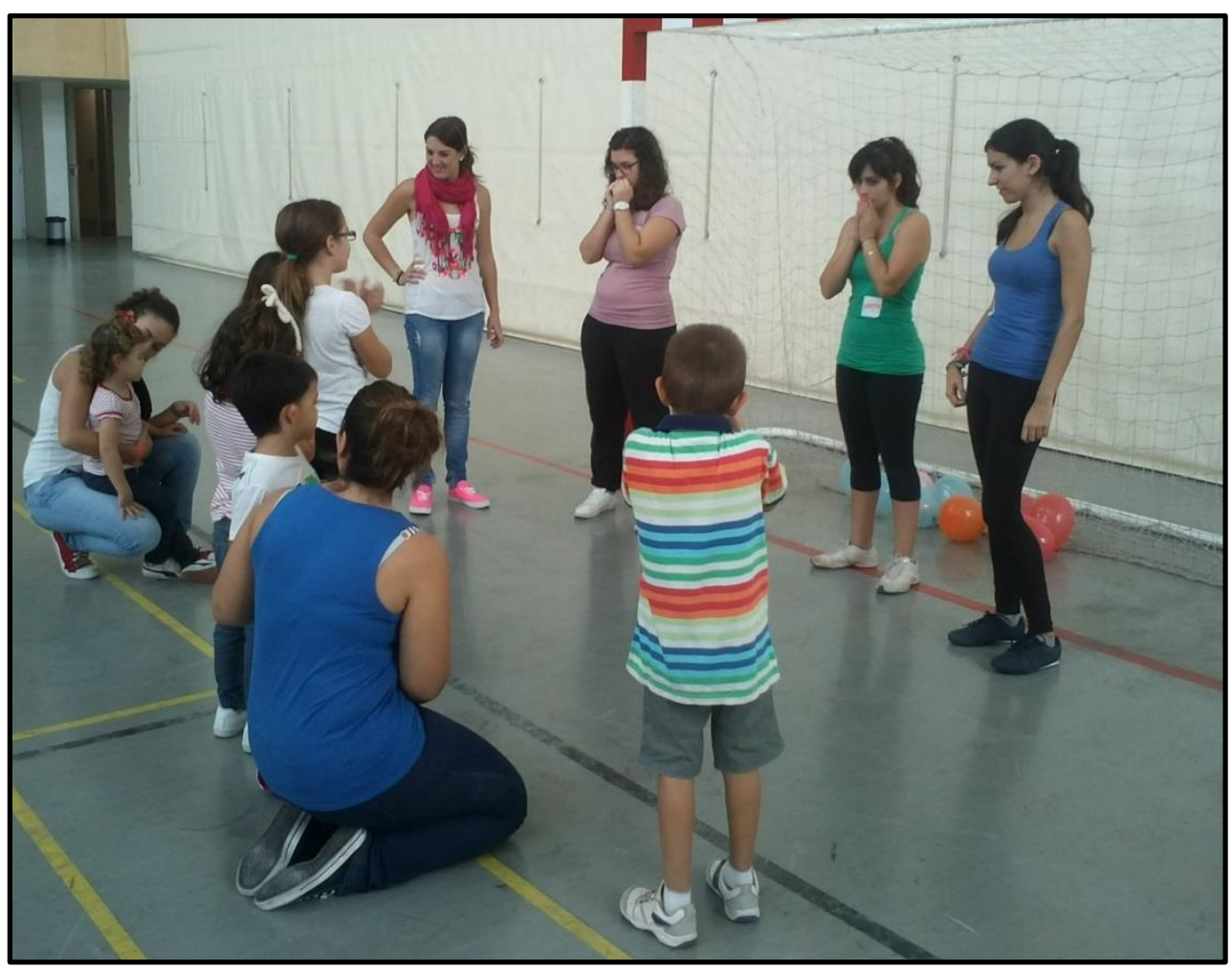

Imagen 13. Foto de una sesión práctica de servicio 1 (tomada por el equipo investigador). 


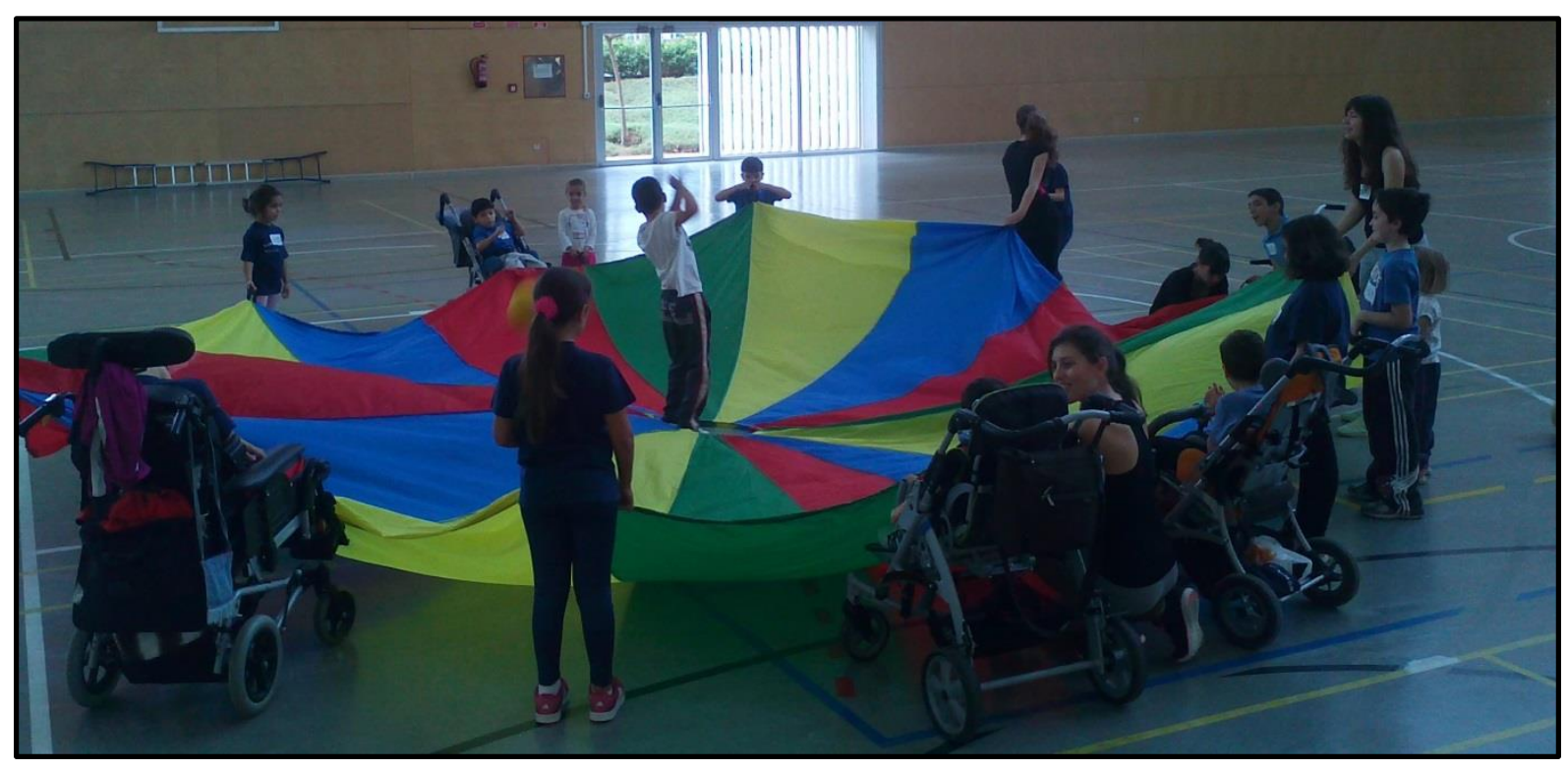

Imagen 14. Foto de una sesión práctica de servicio 2 (tomada por el equipo investigador).

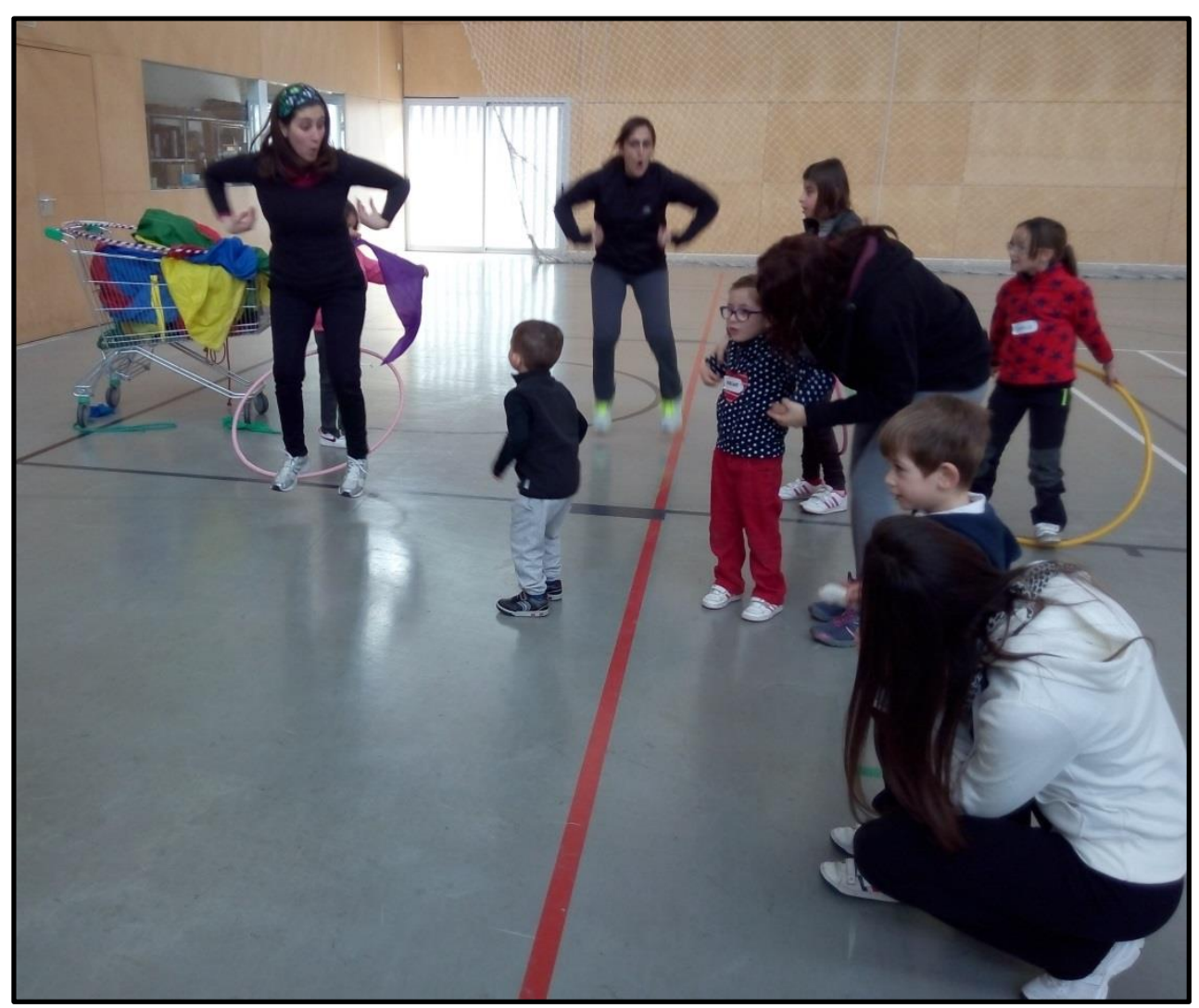

Imagen 15. Foto de una sesión práctica de servicio 3 (tomada por el equipo investigador). 
Al igual que en la caso anterior los distintos equipos de trabajo presentaron diferencias notables en cuanto a los tiempos de ejecución de esta fase. En la tabla 24 exponemos el periodo de la fase de aplicación en cada uno de los equipos de trabajo del grupo A. Igualmente, se incluyen algunos datos relativos a la ejecución del servicio: número de sesiones, horario, duración, periodicidad y lugar de aplicación. Como anteriormente, el profesorado procuró la participación equilibrada de los alumnos a lo largo de esta fase, adaptando la duración de las distintas labores a realizar en base a la dedicación de cada equipo de trabajo.

Tabla 24. Datos sobre la fase de aplicación del Aprendizaje Servicio en los equipos de trabajo del grupo A (elaboración propia).

\begin{tabular}{|c|c|c|c|c|c|}
\hline $\begin{array}{l}\text { Equipo de } \\
\text { trabajo }\end{array}$ & $\begin{array}{l}\text { Asociación } \\
\text { APADAHCAS }\end{array}$ & CEE Penyeta Roja & $\begin{array}{l}\text { CEIP Francesc } \\
\text { Roca i Alcaide }\end{array}$ & $\begin{array}{c}\text { Fundación Borja } \\
\text { Sánchez }\end{array}$ & $\begin{array}{c}\text { Fundación } \\
\text { Síndrome de } \\
\text { Down Castellón }\end{array}$ \\
\hline $\begin{array}{l}\text { Duración de la } \\
\text { fase }\end{array}$ & $\begin{array}{c}\text { Del 19/10/2013 } \\
\text { al 14/6/2014 }\end{array}$ & $\begin{array}{c}\text { Del 17/2/2014 } \\
\text { al 16/5/2014 }\end{array}$ & $\begin{array}{c}\text { Del 13/11/2013 } \\
\text { al 7/5/2014 }\end{array}$ & $\begin{array}{c}\text { Del 9/11/2013 } \\
\text { al 17/5/2014 }\end{array}$ & $\begin{array}{c}\text { Del 13/11/2013 } \\
\text { al 7/5/2014 }\end{array}$ \\
\hline $\begin{array}{l}\text { Número } \\
\text { sesiones }\end{array}$ & 10 & 29 & 16 & 16 & 13 \\
\hline $\begin{array}{l}\text { Horario y } \\
\text { Duración }\end{array}$ & $\begin{array}{c}\text { De 10:00 a 12:00 } \\
(2 \mathrm{~h})\end{array}$ & $\begin{array}{c}\text { De 14:30 a 15:30 } \\
\text { (1h) }\end{array}$ & $\begin{array}{c}\text { De 15:00 a 17:00 } \\
(2 \mathrm{~h})\end{array}$ & $\begin{array}{c}\text { De 10:00 a 12:00 } \\
(2 \mathrm{~h})\end{array}$ & $\begin{array}{c}\text { De 10:00 a 12:00 } \\
(2 \mathrm{~h})\end{array}$ \\
\hline Periodicidad & $\begin{array}{c}1 \text { día semana } \\
\text { (Sábado) }\end{array}$ & $\begin{array}{c}3 \text { días semana } \\
\text { (Lunes, miércoles } \\
\text { y viernes) }\end{array}$ & $\begin{array}{l}1 \text { día semana } \\
\text { (Miércoles) }\end{array}$ & $\begin{array}{c}1 \text { día semana } \\
\text { (Sábado) }\end{array}$ & $\begin{array}{c}1 \text { día semana } \\
\text { (Sábado) }\end{array}$ \\
\hline $\begin{array}{l}\text { Lugar de } \\
\text { aplicación }\end{array}$ & $\begin{array}{c}\text { Pabellón } \\
\text { polideportivo } \\
\text { Universitario } \\
\text { (Castellón) }\end{array}$ & $\begin{array}{l}\text { CEE Penyeta Roja } \\
\text { (Castellón) }\end{array}$ & $\begin{array}{c}\text { Colegio Francesc } \\
\text { Roca i Alcaide } \\
\text { (Burriana) }\end{array}$ & $\begin{array}{c}\text { Pabellón } \\
\text { polideportivo } \\
\text { Universitario } \\
\text { (Castellón) }\end{array}$ & $\begin{array}{c}\text { Pabellón } \\
\text { polideportivo } \\
\text { Universitario } \\
\text { (Castellón) }\end{array}$ \\
\hline
\end{tabular}

Un aspecto destacable de este periodo de acción es el total cumplimiento de las horas de servicio directo programadas por parte del alumnado. Cabe añadir que, además de la realización de todas las sesiones formativas, los alumnos universitarios también participaron en otras actividades extracurriculares que se fueron desarrollando de forma voluntaria. Con estas colaboraciones pretendían aumentar la ayuda prestada al colectivo de niños receptores del servicio y mejorar su relación con el centro al que pertenecían. Estas labores adicionales se realizaron en diferentes horarios y espacios, fuera del marco académico de la asignatura. Entre estas actividades podemos destacar la participación en diversas sesiones y fiestas de las entidades colaboradoras, el acompañamiento en visitas a otros centros y lugares y la asistencia y apoyo en varias reivindicaciones y manifestaciones. Estas dos situaciones vuelven a destacar la buena acogida del programa de APS por parte del alumnado así como su elevado grado de compromiso con los niños receptores del servicio. 


\section{- Aplicación del Aprendizaje Servicio en el Grupo B}

En esta segunda fase los equipos de trabajo del grupo B debían participar en la organización, aplicación y adaptación de las sesiones de juegos motores y expresivos junto a sus compañeros del grupo A. Así pues, ambos colectivos eran igualmente responsables en las labores relativas a la aplicación del servicio, ya descritas en el correspondiente apartado del grupo A. Sin embargo, como ya hemos indicado, su participación se limitaba a 3-4 sesiones prácticas de 1-2 horas de duración, en base a las posibilidades de acción con cada entidad. Al igual que en la fase anterior, durante esta aplicación los integrantes del grupo B se dejaron guiar y aconsejar por sus compañeros del grupo A por su mayor conocimiento y experiencia respecto a las necesidades del servicio y las características de los niños. No obstante, con el paso de las sesiones fueron tomando mayor protagonismo. De este modo, mientras los miembros del grupo $A$ eran los encargados de dirigir las primeras sesiones de juegos, con la ayuda de sus compañeros del grupo $B$, en las siguientes prácticas se invirtieron los papeles, permitiendo así la participación equilibrada de los dos equipos de trabajo. Igualmente, los miembros de este grupo participaron activamente en los procesos de seguimiento y reflexión derivados de la aplicación del servicio, ya descritos en el apartado del grupo A.

Terminada esta fase de aplicación pasamos a describir la última fase del programa de APS.

\subsubsection{Fase de Reflexión del programa de Aprendizaje Servicio}

Esta fase hace mención a las actividades realizadas tras la aplicación del servicio. De acuerdo con el marco teórico de este trabajo, las tareas fundamentales de esta última fase abarcan: demostración de los aprendizajes desarrollados, evaluación del proyecto educativo, reconocimiento del servicio prestado, reflexión final y valoración del programa de APS aplicado. Debido a la continuidad del proceso educativo algunas de estas acciones se fueron desarrollando simultáneamente desde las últimas etapas de la fase anterior hasta el final del programa formativo fechado el 20 de junio de 2014, día en el que finalizaba el periodo de evaluación optativo para los estudios de grado.

\section{- Reflexión del Aprendizaje Servicio en el Grupo A}

El primer aspecto destacable de esta fase hace referencia a la demostración de los aprendizajes adquiridos. Al tratarse de un servicio directo el espacio de aplicación del mismo representaba un escenario único en el que el alumnado podía mostrar día a día sus aprendizajes al trabajar con el colectivo de niños receptores del servicio, especialmente en lo relativo a los aprendizajes académicos. Igualmente, los numerosos espacios de reflexión generados a los largo del proceso didáctico permitieron al profesorado comprobar el desarrollo de numerosos aprendizajes por parte de los alumnos, tanto académicos como personales. Del mismo modo, las distintas tareas de

evaluación, expuestas a continuación, también ofrecieron entornos adecuados para que el 
alumnado pusiera de manifiesto los aprendizajes adquiridos a lo largo de esta experiencia educativa.

Respecto a la evaluación del proyecto educativo, el profesorado optó, principalmente, por realizar una evaluación continua a lo largo de todo el proceso educativo. Este sistema de evaluación supuso el $70 \%$ de la calificación de los integrantes del grupo A. En esta evaluación continua se valoró la información aportada en los diferentes documentos de registro, las tareas realizadas en la organización y aplicación del servicio y las valoraciones expuestas en los distintos espacios de reflexión facilitados. Las labores relativas a cada una de estas tareas, definidas en apartados anteriores, hacían referencia tanto a aprendizajes académicos como a aspectos personales vinculados con ES. Con esta información se cubrieron respectivamente los apartados de elaboración y/o ejecución de trabajos, observación/ejecución de tareas y prácticas y resolución de ejercicios y problemas. Por último, para cubrir el 30\% restante de la calificación, los miembros del grupo A realizaron el examen escrito final. En la tabla 25 presentamos el sistema de evaluación de la asignatura en el grupo $\mathrm{A}$ en el que se indican las áreas, tareas, valores y métodos de evaluación.

Tabla 25. Evaluación de la asignatura en el grupo A (elaboración propia).

\begin{tabular}{|c|c|c|c|}
\hline ÁREAS DE EVALUACIÓN & TAREAS DE EVALUACIÓN & VALOR & MÉTODO DE EVALUACIÓN \\
\hline $\begin{array}{c}\text { Elaboración y/o ejecución de } \\
\text { trabajos }\end{array}$ & $\begin{array}{c}\text { Información de los } \\
\text { documentos de registro }\end{array}$ & $30 \%$ & \multirow{3}{*}{ Evaluación continua } \\
\hline $\begin{array}{c}\text { Observación/ejecución de } \\
\text { tareas y prácticas }\end{array}$ & $\begin{array}{c}\text { Organización y aplicación del } \\
\text { servicio }\end{array}$ & $30 \%$ & \\
\hline $\begin{array}{c}\text { Resolución de ejercicios y } \\
\text { problemas }\end{array}$ & $\begin{array}{c}\text { Valoraciones en los espacios } \\
\text { de reflexión }\end{array}$ & $10 \%$ & \\
\hline $\begin{array}{c}\text { Examen escrito: test, } \\
\text { desarrollo y/o problemas }\end{array}$ & Examen final & $30 \%$ & Examen escrito (desarrollo) \\
\hline
\end{tabular}

En cuanto al reconocimiento del servicio prestado, tanto el profesorado como los distintos miembros de las entidades colaboradoras, responsables, profesionales, familiares, niños, etc., procuraron destacar la labor desempeñada por los distintos equipos de trabajo, demostrando así su agradecimiento y satisfacción por la atención recibida a lo largo de todo el programa de APS.

Como ya hemos apuntado en el apartado anterior, los procesos reflexivos representan un aspecto esencial en esta clase de proyectos educativos. Estos ayudan a que el alumnado interiorice tanto los aprendizajes académicos como los aspectos personales que se han puesto en juego durante el APS, en nuestro caso relativos a la aplicación de juegos motores y expresivos y al ES, respectivamente. Por ello, además de las reflexiones realizadas a lo largo de la fase anterior, en esta fase se llevaron a cabo varias reflexiones finales de mayor profundidad. En primer lugar se realizó una reunión final, en la que estuvieron presentes todos los alumnos vinculados con el APS, para comentar y reflexionar sobre los aspectos globales del programa educativo. Seguidamente se efectuó una reflexión con los miembros del grupo $A$, en la que se debatieron cuestiones relativas a 
la organización del servicio prestado. Más adelante se hizo una tutoría final con cada equipo de trabajo, en las que se trataron los aspectos específicos de cada una de las entidades colaboradoras. Finalmente, se proporcionó un espacio individual para que los alumnos del grupo pudieran expresar, tras una profunda reflexión interna, sus impresiones sobre todo lo sucedido a lo largo de su experiencia educativa. Para lograrlo, se realizaron entrevistas individuales con cada uno de los miembros de este grupo, en las que se animó al alumnado a exponer, con total libertad, los aspectos académicos y personales desarrollados a lo largo del curso académico.

Por último, la valoración del programa de APS se obtuvo a través de los numerosos encuentros con todos los implicados en el servicio. Así pues, gracias a la información aportada en las reuniones, tutorías, sesiones prácticas, momentos de reflexión, etc., se pudo valorar la opinión de los niños receptores del servicio, sus familiares, los responsables de las entidades colaboradoras, los propios estudiantes universitarios, el equipo docente, etc. Sobre esta cuestión, se puede destacar el alto grado de satisfacción de todos los participantes en el programa de APS implementado. No obstante, con la intención de mejorar el proyecto educativo, también se ofrecieron diversas críticas constructivas como, por ejemplo, la vinculación fija de los alumnos con las entidades colaboradoras, el aumento de la duración del servicio, la posible coordinación entre los distintos equipos de trabajo, etc.

A continuación aportamos varios ejemplos gráficos de las labores realizadas o valoradas en el transcurso de esta fase. Aportamos la ficha de uno de los juegos valorados en los aprendizajes académicos (imagen 16), un documento de registro de la dedicación directa en el servicio (imagen 17) y tres documentos de registro del proceso reflexivo tras la aplicación del servicio (imágenes 18, 19 y 20$)$.

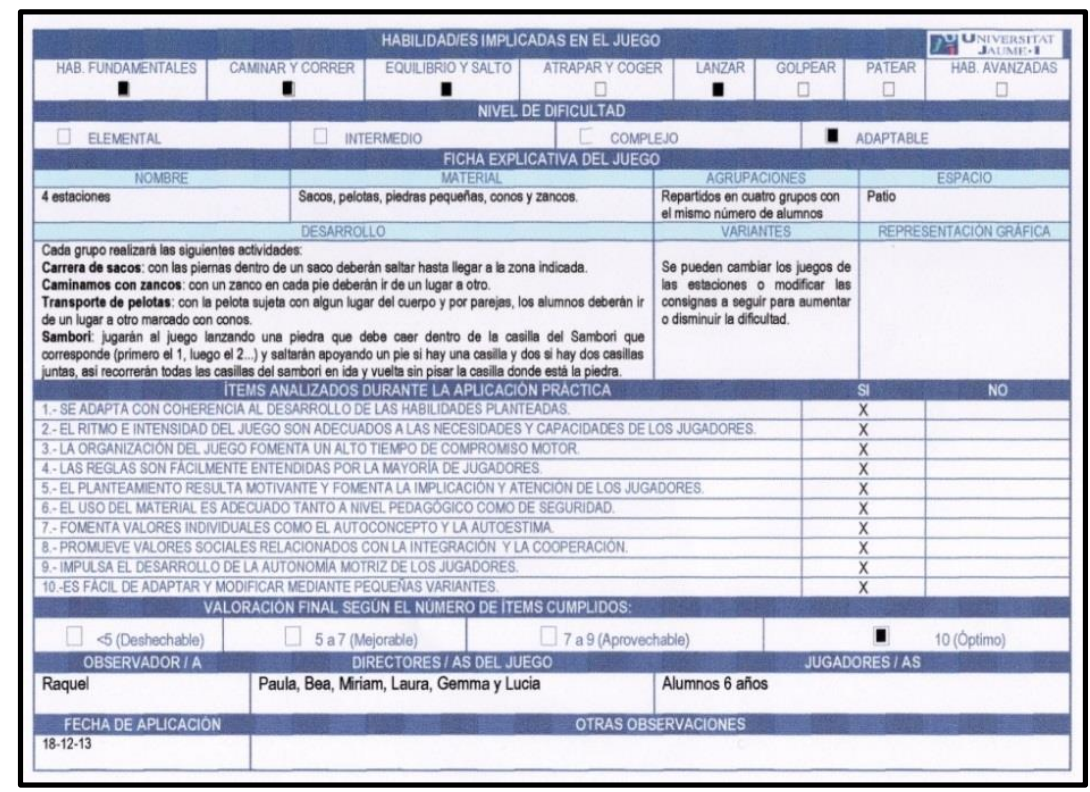

Imagen 16. Ficha de juego 2 (elaborada por los equipos de trabajo del grupo A). 


\begin{tabular}{|c|c|c|c|c|c|}
\hline \multicolumn{6}{|c|}{$\begin{array}{l}\text { Registro dedicación aplicación } \\
\text { Marta Miriar }\end{array}$} \\
\hline Fecha & Actividad & Participantes & Dedicación (h) & Acciones destacables & Registro \\
\hline $16 \cdot 10.13$ & Reunión con Jesus & $\begin{array}{l}\text { GRUPO + } \\
\text { coordinador }\end{array}$ & 1 hora & $\begin{array}{l}\text { - Explecación y oricita- } \\
\text { cion del curso y del tipo } \\
\text { de asignatura que hemos }\end{array}$ & 1 \\
\hline 31.10 .13 & Clase Teórica & $\begin{array}{l}\text { TODOS LOS } \\
\text { GRUPOS } \\
\text { coordinador }\end{array}$ & 1 hora & $\begin{array}{l}\text { - Explicacoún de las } \\
\text { hojas de registric distribu } \\
\text { conderoles y ficha de jueg }\end{array}$ & 1 \\
\hline 05.11 .13 & Reunión de grupo & GRUPO & 2 hores & $\begin{array}{l}\text { - Planificación de la } \\
\text { sesión. }\end{array}$ & 1 \\
\hline 06.11 .13 & Tutoría con Jesus & $\begin{array}{l}\text { GRUPO + } \\
\text { coordinador }\end{array}$ & 1 hora & $\begin{array}{l}\text { - Revisión de la sesión } \\
\text { planficada. Orientación para mejorar }\end{array}$ & 2 \\
\hline 07.11 .13 & Clase Teórica & $\begin{array}{l}\text { TOCOS LOS } \\
\text { GR PRS } \\
\text { COordinador }\end{array}$ & 1 hora & 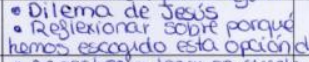 & \\
\hline 14.11 .13 & Clase Teórica & $\begin{array}{l}\text { TODOS LOS } \\
G R \text { ROS } \\
\text { coordinador }\end{array}$ & 1 hora & 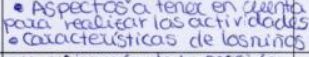 & $c$ \\
\hline $19 \cdot 11 \cdot 13$ & Reunión de grupo & GRUPO & 1 hora $30 \mathrm{~min}$. & $\begin{array}{l}\text { - Hodificación de la sessión. } \\
\text { - Elaboracion de gichas ae } \\
\text { juegos. }\end{array}$ & 2 \\
\hline 21.11 .13 & Clase Teórica & $\begin{array}{l}\text { TODOS LOS } \\
\text { GRUPOS } \\
\text { cordinador }\end{array}$ & 1 hora & $\begin{array}{l}\text { - Caracieństicas de los niños } \\
\text { de cacta centro y propesta } \\
\text { de activicades segun las caract }\end{array}$ & eristicas \\
\hline 27.11 .13 & Tutoría con Jesus & $\begin{array}{l}\text { GRUPO + } \\
\text { coordinador }\end{array}$ & 1 hora & $\begin{array}{l}\text { - Revisión de la sesiógondeligi- } \\
\text { ada, para la case dia }\end{array}$ & 3 \\
\hline 28.11 .13 & Clase Teórica & $\begin{array}{l}\text { TODOS LOS } \\
\text { GRUPOS } \\
\text { CoOrdinador }\end{array}$ & 1 hora & 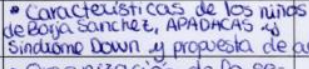 & 5 \\
\hline 02.12 .13 & Reunión de grupo & GRUPO & 4 horas & $\begin{array}{l}\text { - Organización de la se- } \\
\text { sion y distrioucion dep tia- } \\
\text { bois paila la sesión. }\end{array}$ & 3 \\
\hline 03.12 .13 & Sesión práctica & $\begin{array}{l}\text { GRUPO + alum } \\
\text { nos universitorio } \\
+ \text { coordinadar }\end{array}$ & sishora & $\begin{array}{l}\text { - Puesta en practica de la } \\
\text { session planteada con an- } \\
\text { Terioridad. }\end{array}$ & 1 \\
\hline 03.12 .13 & Reunión de grupo & GRUPO & 1 hora & $\begin{array}{l}\text { - Planteamiento de juegos } \\
\text { delaptados a eos niños } \\
\text { de mustra enticad. }\end{array}$ & 4 \\
\hline 05.12 .13 & Clase Teórica & $\begin{array}{l}\text { T000S LOS } \\
\text { GRUPOS } \\
\text { coordinador }\end{array}$ & 1 hora & 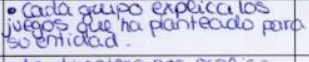 & 6 \\
\hline 27.01 .14 & Visita Entidad & $\begin{array}{l}\text { GRUPO + } \\
\text { ENTIDAD }\end{array}$ & Thora $30 \mathrm{~min}$ & 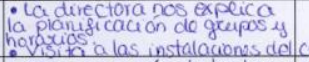 & centro. \\
\hline 30.01 .14 & Reunión de Gropo & GRUPO & 1 hora & 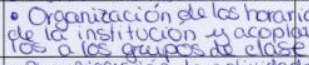 & 5 \\
\hline 05.02 .14 & Reunión de Grupo & GRUPO & 1 hora & 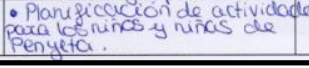 & 6 \\
\hline
\end{tabular}

Imagen 17. Documento de registro de la dedicación directa en el servicio 2 (elaborado por los equipos de trabajo del grupo A).

\begin{abstract}
Reflexión:
En la sesión de hoy, día 7/05/14, las dificultades a la hora de planearla no han sido demasiadas puesto que uno de los objetivos primordiales que teníamos era el de hacer una despedida divertida para los alumnos de los dos cursas ya que era nuestro último dia de aprendizaje-servicio en el CAES de Burriana.

En la reunión para organizar la sesión, hemos planteado muchas actividades que cumplieran los requisitos de desarrollar habilidades motrices pero que también fueran más motivadoras para los alumnos y que disfrutaran siendo el último día. Finalmente decidimos las que se explican en las fichas de juegos.

Hemos observado que al realizar la sesión, algunas de las actividades se han alargado más de lo esperado, como por ejemplo el Paracaídas, que les ha gustado mucho y hemos podido disfrutar haciendo diferentes juegos solo con este elemento. También que al realizar todas las actividades hemos intentado tener un ambiente más relajado para que pudieran disfrutar todo lo posible.
\end{abstract}

Imagen 18. Documento de registro del proceso reflexivo tras la aplicación del servicio 2 (elaborado por los equipos de trabajo del grupo A). 


\section{SESIÓN 6 (01/03/14)}

Esta sesión ha resultado muy motivante para los niños, ya que hemos partido de una temática de animales y cada uno podía elegir el que quisiera, además de pintarles la cara para caracterizarlos que es algo que hemos aprendido que les encanta. Los únicos problemas que hemos tenido han sido en relación a la propia organización del grupo, ya que además contábamos con un nuevo grupo de compañeras de clase y siempre nos cuesta coordinarnos en la primera sesión, pero han sido mucho menores que en otras semanas y por tanto no han afectado al desarrollo de la sesión.

Las actividades han tenido, como casi siempre, un hilo conductor que ha ayudado a que los niños siguieran conectados al grupo, en esta ocasión incluso los que normalmente tienden a separarse y vagar por el pabellón. Esto nos ha enseñado que si en el grupo se realizan actividades que resultan motivantes (bien por la naturaleza de la propia actividad, bien por la temática), es posible que todos los niños participen.

Nos ha dejado una sensación en general bastante buena, tanto por la sesión en sí como con nuestras nuevas compañeras. Los niños han disfrutado con la sesión y nosotras empezamos a ver muchas mejoras tanto en su actitud como en sus capacidades, ya que aunque no producimos en ellos ningún cambio significativo (tampoco aspiramos a ello) sí vemos que pierden el miedo a los compañeros que no conocían, los materiales más "peligrosos" como el trampolín o caminar sobre los bancos suecos.

Imagen 19. Documento de registro del proceso reflexivo tras la aplicación del servicio 3 (elaborado por los equipos de trabajo del grupo A).

Documento reflexivo sobre la aplicación
Sesión n०:8 Fecha:12 abril $2014 \quad$ Componentes Grupo:Beatriz. Marta.
Bárbara. Carlos. Lorena. Carolina. Alba. Rosa.
Reunión para analizar la actividad.
La sesión ha ido especialmente bien. Los niños/as han respetado la norma
de "no tocar los globos" en todo momento, a pesar de tenerlos al alcance.
Además, en el tiempo establecido se ha podido llevar a cabo la grabación del
LipDub.
No pretendíamos realizar un LipDub perfecto, solo que los niños/as
disfrutaran de una experiencia nueva. Al final, se han tenido ambas.
Dificultades y problemas encontrados en la realización:
Un niño no quería pintarse la cara como el resto. Al final, como era el único
día que iba a venir y era una sesión para pasarlo especialmente bien, lo hemos
permitido.
Diálogo sobre la propia acción y conclusiones más relevantes:
La conclusión más relevante es que podemos confiar en los niños/as, puesto
que han respondido muy bien a la actividad y todos han mostrado mucho interés y
participación. Nadie se ha ido por su cuenta a "explorar" el pabellón.
Sensaciones experimentadas:
Ha funcionado muy bien, estamos muy orgullosas de los niños/as, ya que en
dos horas se ha podido explicar el LipDub, pintarles la cara y grabarlo
correctamente.

Imagen 20. Documento de registro del proceso reflexivo tras la aplicación del servicio 4 (elaborado por los equipos de trabajo del grupo A). 
Como en las fases anteriores, los equipos de trabajo del grupo A presentaron notables diferencias respecto a los tiempos de ejecución de esta fase. En la tabla 26, presentamos su duración en cada uno de los equipos de trabajo de este grupo.

Tabla 26. Duración de la fase de reflexión del APS en los equipos de trabajo del grupo A (elaboración propia).

\begin{tabular}{lccccc}
\hline $\begin{array}{l}\text { Equipo de } \\
\text { trabajo }\end{array}$ & $\begin{array}{c}\text { Asociación } \\
\text { APADAHCAS }\end{array}$ & CEE Penyeta Roja & $\begin{array}{c}\text { CEIP Francesc } \\
\text { Roca i Alcaide }\end{array}$ & $\begin{array}{c}\text { Fundación Borja } \\
\text { Sánchez }\end{array}$ & $\begin{array}{c}\text { Fundación } \\
\text { Síndrome de } \\
\text { Down Castellón }\end{array}$ \\
\hline $\begin{array}{l}\text { Duración de } \\
\text { la fase }\end{array}$ & Del 14/6/2014 & Del 16/5/2014 & Del 7/5/2014 & Del 17/5/2014 & Del 7/5/2014 \\
al 20/6/2014 & al 20/6/2014 & al 20/6/2014 & al 20/6/2014 & al 2014 \\
\hline
\end{tabular}

\section{- Reflexión del Aprendizaje Servicio en el Grupo B}

Como en el grupo anterior, los aspectos más relevantes de esta última fase fueron la demostración de los aprendizajes desarrollados, la evaluación del proyecto educativo, el reconocimiento del servicio prestado, las reflexiones finales y la valoración del programa de APS aplicado. Todas estas labores se desarrollaron de forma conjunta con sus compañeros del grupo A, por lo que siguieron los mismos procesos de ejecución descritos en el correspondiente apartado de dicho grupo. El único punto discordante aparece en la evaluación ya que, acorde a su participación, la puntuación reservada al programa de APS en los miembros de este grupo representaba un 30\% del total de la asignatura. En la tabla 27 exponemos el sistema de evaluación de la asignatura para los alumnos del $\mathrm{B}$ en el que se indican las áreas, tareas, valores y métodos de evaluación.

Tabla 27. Evaluación de la asignatura en el grupo B (elaboración propia).

\begin{tabular}{cccc}
\hline ÁREAS DE EVALUACIÓN & TAREAS DE EVALUACIÓN & VALOR & MÉTODO DE EVALUACIÓN \\
\hline $\begin{array}{c}\text { Elaboración y/o ejecución de } \\
\text { trabajos }\end{array}$ & Trabajos teóricos & $30 \%$ & $\begin{array}{c}\text { Valoración de los trabajos } \\
\text { entregados }\end{array}$ \\
\hline $\begin{array}{c}\text { Observación/ejecución de } \\
\text { tareas y prácticas }\end{array}$ & $\begin{array}{c}\text { Organización y aplicación del } \\
\text { servicio }\end{array}$ & $30 \%$ & Evaluación continua \\
\hline $\begin{array}{c}\text { Resolución de ejercicios y } \\
\text { problemas }\end{array}$ & Trabajos teórico-prácticos & $10 \%$ & $\begin{array}{c}\text { Valoración de los trabajos } \\
\text { entregados }\end{array}$ \\
\hline $\begin{array}{c}\text { Examen escrito: test, } \\
\text { desarrollo y/o problemas }\end{array}$ & Examen final & $30 \%$ & Examen escrito (desarrollo) \\
\hline
\end{tabular}




\section{4. Ámbito de aplicación del programa de Aprendizaje Servicio}

Pese a las notables ventajas de utilizar el APS, descritas en el marco teórico de este trabajo, la realidad es que pueden aparecer resistencias iniciales cuando se plantea la posibilidad de aplicar programas como el presente, ya que implican la entrada de elementos ajenos a la vida de los centros. Así pues, se deben respetar las normas y espacios de actuación para poder interactuar sin crear alteraciones indeseables. Igualmente, la colaboración de los profesionales de estas entidades es primordial en el programa educativo, ya que sin ellos no serían viables. Por ello, se deben presentar proyectos bien estructurados, con una fundamentación sólida y con una viabilidad de ejecución palpable, que fomenten la participación y colaboración de estos centros con las instituciones educativas.

Como ya hemos apuntado, debido la especificidad del contenido a desarrollar a través del programa de APS, se contactó con centros que trabajaran con niños que presentaran diversas alteraciones motrices para que los alumnos pudieran realizar las sesiones de juegos motores y expresivos. Cabe destacar que, en muchos de los casos, dichas alteraciones suponían un riesgo de exclusión social añadido a las distintas limitaciones o dificultades que ya padecían estos niños, reforzando así el aspecto social del proyecto educativo planteado. En este contacto inicial el profesorado presentó el proyecto de APS a los responsables de las entidades, explicando que consistía en la realización de sesiones prácticas de trabajo directo con sus usuarios, con el objetivo de mejorar a grandes rasgos la situación de los receptores del servicio, mientras el alumnado aplicaba y aprendía los contenidos fundamentales de la asignatura con la que se vinculaba. Además, se profundizó en el otro objetivo perseguido con esta aplicación metodológica, el fomento del ES, aspecto que se pretendía estimular en base a la interacción con colectivos que tienen dificultades de exclusión social y/o necesidades educativas especiales en su vida cotidiana. Tras confirmar su conformidad de colaboración trasladamos la propuesta de participación al alumnado universitario.

En este punto, cabe destacar el elevado nivel de compromiso e implicación mostrado por los distintos profesionales de estas entidades, acogiendo de buen grado la incorporación e intervención del alumnado universitario en sus centros, algo que facilitó enormemente el desarrollo del programa educativo. A continuación, pasamos a describir las cinco entidades en las que el alumnado de los grupos A y B prestó el servicio correspondiente a la aplicación metodológica del APS. 


\subsubsection{APADAHCAS (Asociación de Padres de Afectados por Déficit de Atención e Hiperactividad de Castellón)}

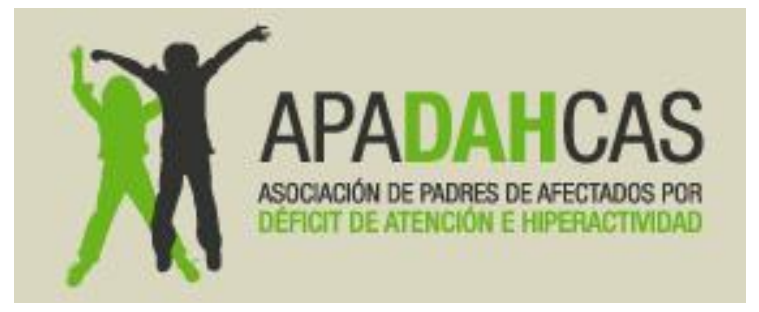

APADAHCAS ${ }^{20}$ surge ante la inquietud de algunos padres y profesionales, que ven la necesidad de unir y concienciar a las familias de niños con este trastorno, para buscar mecanismos de intervención que ayuden a mejorar sus dificultades de adaptación. El objetivo de la asociación es orientar, asesorar, investigar y colaborar en áreas educativas y científicas de personas, centros o profesionales, dedicados al estudio del déficit de atención e hiperactividad.

Entre las distintas actividades y servicios que oferta podemos destacar la escuela de padres, el taller de habilidades socioemocionales, talleres de lectoescritura y matemáticas, técnicas de estudio, grupo de ocio para jóvenes, terapias individuales, evaluaciones y diagnósticos, estudios neuropsicológicos, atención neurológica y neuropediátrica, charlas informativas en centros escolares e intervención escolar individualizada y actividades de formación para profesionales en contacto con el Trastorno por Déficit de Atención e Hiperactividad (TDA-H). Esta entidad cuenta con la colaboración del Dr. Jesús García, médico especializado en neuropediatría.

La intención de la asociación APADAHCAS es unir voces para conseguir toda la fuerza posible y lograr que el TDA-H deje de ser invisible en nuestra sociedad. Por ello, ofrece numerosas ventajas a sus asociados, como:

- Información y asesoramiento sobre los temas administrativos relacionados con el TDA-H como educación, obtención de becas, medicación, impuestos, tratamiento, discapacidad psíquica, etc.

- Información sobre los resultados de investigaciones relacionadas con el TDA-H.

- Posibilidad de utilizar la biblioteca de la asociación en la que disponen de libros especializados sobre TDA-H.

- Asistencia gratuita a las jornadas anuales que se celebran en la Universitat Jaume I de Castellón.

- Asistencia a talleres organizados por la asociación.

- Asistencia a los congresos organizados por la Federación Española de Ayuda al Déficit de Atención e Hiperactividad con descuentos especiales.

\footnotetext{
${ }^{20}$ http://www.apadahcas.org/
} 
Por otra parte, esta entidad también ofrece algunos servicios a los propios niños con TDA-H:

- Posibilidad de participación en estudios relacionados con el TDA-H.

- Asistencia gratuita a campamentos de verano organizados por la Universitat Jaume I de Castellón.

- Atención gratuita a los niños que estén cursando infantil o primaria mientras se desarrollan las actividades de la escuela de padres.

La experiencia de APS desarrollada con esta entidad se centra en el trabajo psicomotriz de los niños con TDA-H. Así pues, el servicio pretendía ayudar a los niños de la asociación a controlar su motricidad debido al exceso de actividad que provoca este trastorno. Para ello, los alumnos universitarios implementaron sesiones de juegos motores y expresivos en las que se fomentaba el control del tono muscular, la relajación, los contrastes en la intensidad de ejecución motriz, la motricidad fina, los distintos tipos de coordinación específica, etc., de casi 30 niños de la asociación. El programa de APS aplicado contó con la supervisión de varios miembros de la junta directiva de esta asociación, participando en numerosas actividades de colaboración mutua.

\subsubsection{Centro de Educación Especial Penyeta Roja}
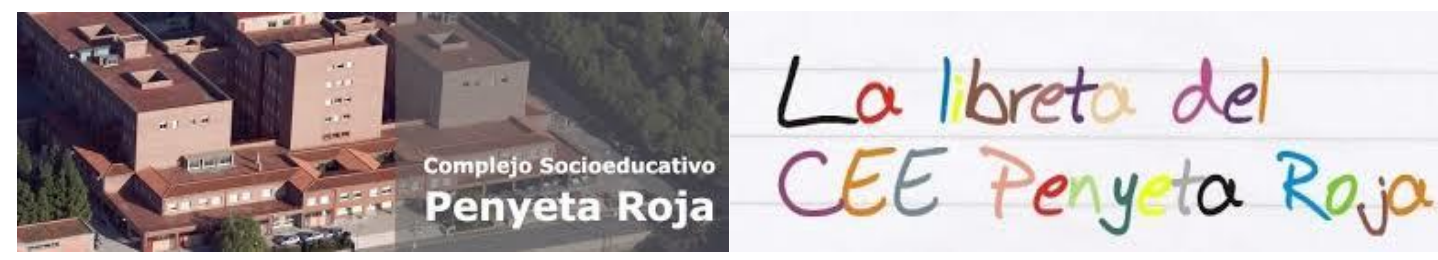

El Centro de Educación Especial Penyeta Roja ${ }^{21}$ atiende a alumnos con discapacidades psíquicas, motrices o con plurideficiencias cuya situación no permite su escolarización en centros ordinarios. Este centro se encuentra dentro del Complejo Socio-Educativo Penyeta Roja, el cual constituye la expresión de los esfuerzos de la Diputación Provincial de Castellón por proporcionar un apoyo social y docente a esta provincia. De esta forma, en el año 1979 nació este Complejo Socio-Educativo, que poco a poco iría acogiendo los diversos servicios socio-educativos que lo configuran en la actualidad. Así pues, además del Centro de Educación Especial, este complejo cuenta con un Centro de Acogida, un Servicio Psicopedagógico Escolar, una Escuela Infantil, un Centro de Iniciación Técnico Deportiva, un Colegio-IES de enseñanza reglada y varias residencias de estudiantes.

Concretamente, el Centro de Educación Especial Penyeta Roja atiende a niños y jóvenes de o a 24 años que presentan necesidades educativas especiales. Sus etapas de actuación se dividen en

${ }^{21}$ http://penyetaroja.dipcas.es/educacion-especial/

http://www.dipcas.es/es/complejo-socio-educativo-penyeta-roja/ 
atención temprana de o a 3 años, educación infantil de 3 a 6 años, escolarización obligatoria de 6 a 21 años, primaria, secundaria y transición a la vida adulta y programas de cualificación inicial profesional (PCPI) desde los 16 hasta los 24 años. El alumnado de este centro accede por dictamen de escolarización, realizado por el Servicio Psicopedagógico Escolar (SPE) correspondiente y remitido desde la Dirección Territorial de Educación de Castellón al SPE del Centro. El objetivo fundamental del centro es fomentar el desarrollo integral del alumnado, potenciando al máximo sus capacidades en sus aspectos afectivos, físicos, cognitivos y sociales.

Dado que el alumnado que escolariza este centro presenta necesidades educativas especiales graves y permanentes, derivadas de discapacidad intelectual o trastornos graves de conducta, el centro desarrolla los procesos de enseñanza-aprendizaje en base a las siguientes áreas de atención preferente:

- Comunicación: expresar sentimientos y necesidades a través del gesto, la palabra o la imagen.

- Autonomía personal/hogar: adquirir hábitos de higiene y de alimentación, de trabajo, de orden, etc.

- Motora: desplazarse de forma autónoma, andando o con los medios necesarios.

- Uso de recursos comunitarios: parques y plazas, bibliotecas, medios de transporte, etc.

- Académico-funcional: leer, escribir, sumar, restar, etc.

- Habilidades sociales: saludar, despedirse, normas de cortesía, etc.

- Laboral: destinada a los alumnos de secundaria, T.V.A y PCPI, y enfocada a la adquisición de hábitos y conocimientos específicos en relación a un área laboral determinada, jardinería, hogar, carpintería o cerámica.

Para desempeñar estas labores el centro cuenta con profesores de pedagogía terapéutica, profesores técnicos de formación profesional, educadores, fisioterapeutas, logopedas, psicólogos, un profesor de psicomotricidad y EF, un profesor de música, una trabajadora social y un celador.

La finalidad del centro es perseguir los mismos objetivos educativos que se establecen en la enseñanza ordinaria, aunque en ocasiones se deben priorizar objetivos de etapas anteriores. Así pues, en Educación Infantil se priorizan aprendizajes relacionados con las áreas de comunicación, desarrollo motor, hábitos básicos de higiene y alimentación y uso de recursos próximos, colegio y casa. En Educación Primaria se amplía el número de actividades fuera del centro, se inicia el trabajo del área académico-funcional y se refuerzan y amplían las habilidades sociales. En Educación Secundaria se refuerzan los aprendizajes más básicos para ampliarlos, en la medida de lo posible, y se introducen en el área laboral, asistiendo a los talleres ofertados. Con todo ello, esta entidad busca la mayor funcionalidad en los aprendizajes, es decir, que lo que aprendan los alumnos les sea útil en la mayor parte de lugares donde se desenvuelven. Por ello, se organizan actividades con variedad de ambientes: contexto aula/trabajo, contexto parques y excursiones, piscina, teatro, museos, etc. Además, el centro está abierto como recurso educativo, participando en distintos programas y proyectos ofertados por otras entidades: Cruz Roja, ayuntamientos, universidad, etc. 
Entre los distintos servicios disponibles en el centro podemos destacar los de Fisioterapia y Psicopedagogía. El Servicio de Fisioterapia apoya y participa con los tutores y el Servicio Psicopedagógico Escolar en la identificación y valoración de las necesidades educativas especiales del alumnado vinculadas con el desarrollo motor, asesora al resto de profesionales que trabajan con los alumnos en todos aquellos aspectos relacionados con su especialidad y participa en la propuesta y/o realización de las ayudas técnicas necesarias para el acceso del alumnado al currículum. Conjuntamente con los tutores, establece criterios de observación y evaluación del proceso de desarrollo motor de los alumnos y elabora y lleva a cabo el programa de educación y/o habilitación física específica e individual que necesite cada alumno, a fin de conseguir el máximo desarrollo de sus posibilidades motoras de acuerdo a los objetivos establecidos en el currículum. Por último, colabora con el responsable de la tutoría en el asesoramiento, información y orientación a la familia para que las actividades del hogar favorezcan el desarrollo motor del alumno. Por otra parte, el Servicio Psicopedagógico Escolar tiene como finalidad detectar las necesidades psicopedagógicas, diseñar y aplicar instrumentos de prevención y tratamiento de las dificultades de desarrollo personal y aprendizaje, aplicar pruebas y elaborar informes, así como el asesorar a familias y profesionales.

Toda esta información nos permite apreciar las notables necesidades y limitaciones, tanto físicas como cognitivas, que padecen los alumnos del centro debido a patologías de distinta índole. Por ello, a través del desarrollo de juegos motores y expresivos, el programa de APS aplicado pretendía estimular sus habilidades motrices y psicomotrices básicas, el control postural, la coordinación global y específica, las habilidades sociales, etc. Esta actividad de servicio se aplicó sobre un colectivo de unos 40 niños de la entidad divididos, por el profesorado del centro, en tres grupos de trabajo en base a su edad y competencia psicomotriz. Para ello, contamos con la colaboración y seguimiento de distintos miembros del centro como la directora, los profesores de pedagogía terapéutica, el profesor de psicomotricidad y EF y diversos educadores.

\subsubsection{Colegio de Educación Infantil y Primaria Francesc Roca y Alcaide}

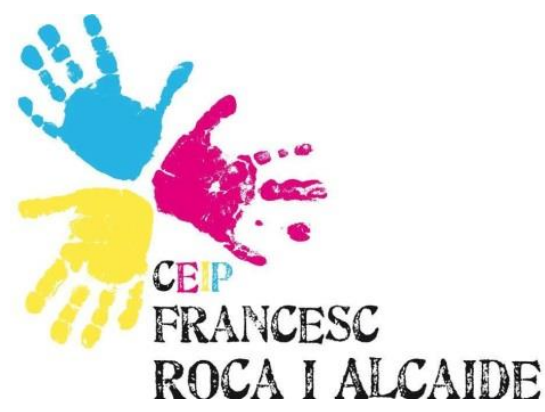


El Colegio de Educación Infantil y Primaria Francesc Roca i Alcaide ${ }^{22}$ de Burriana es un centro escolar público. Su oferta educativa comprende las etapas y/o niveles educativos de Educación Infantil de segundo ciclo, de 3 a 6 años, y Educación Primaria. El colegio se fundó en 1948 con el nombre del historiador Rafael Martí Viciana, pero en los años 80 con la construcción y desplazamiento al nuevo centro pasó a llamarse Francesc Roca i Alcaide. Actualmente cuenta con 75 alumnos de infantil y 250 de primaria, gestionados por un equipo docente de 3 y 10 miembros, respectivamente. Este colegio se caracteriza por ser un Centro de Acción Educativa Singular (CAES), por lo que tiene más del 30\% de alumnado con necesidades de educación compensatoria. Por tanto, está dirigido a niños en situación de desventaja respecto al acceso, permanencia y promoción en el sistema educativo, pertenecientes a minorías étnicas o culturales en situaciones de desventaja socioeducativa y otros colectivos socialmente desfavorecidos que presenten un desfase escolar significativo, alumnos que por razones personales, familiares o sociales no puedan seguir un proceso normalizado de escolarización, e inmigrantes y refugiados con desconocimiento de la lengua vehicular del proceso de enseñanza.

Además de situarse en un barrio periférico de la ciudad, debemos señalar que prácticamente la totalidad del alumnado del colegio procede de familias inmigrantes de distintas etnias en clara situación de desventaja sociocultural, lo cual aumenta el desfase educativo de sus alumnos. Así pues, con la intención de superar las desigualdades educativas existentes el centro implementa medidas de compensación educativa con los siguientes objetivos:

- Garantizar la escolarización en condiciones de igualdad de oportunidades del alumnado con necesidades de compensación educativa.

- Favorecer la incorporación e integración social y educativa de todo el alumnado perteneciente a sectores sociales desfavorecidos y a minorías étnicas.

- Potenciar los aspectos de enriquecimiento que aportan las diferentes culturas.

- Fomentar la asistencia continuada y evitar el abandono escolar del alumnado.

- Crear líneas de coordinación con instituciones públicas, administraciones, asociaciones y organizaciones no gubernamentales sin ánimo de lucro.

- Desarrollar estrategias organizativas y curriculares para la consecución de los objetivos educativos por parte de su alumnado.

Este centro está altamente comprometido e implicado en la mejora e innovación educativa, abierto a la colaboración con otras entidades para mejorar la formación de su alumnado y menguar las dificultades derivadas de su situación social. Prueba de ello son los distintos programas educativos aplicados en los últimos años, como las comunidades de aprendizaje, el proyecto musical europeo Mus-e, o el propio programa de APS aplicado en este caso. Igualmente, está inmerso en el programa de plurilingüismo de enseñanza en Valencià en la etapa de infantil y en los programas de plurilingüismo de enseñanza en valenciano e inmersión lingüística en la etapa de primaria.

\footnotetext{
${ }^{22}$ https://www.facebook.com/ceip-francesc-roca-i-alcaide-227856350612015/ http://www.ceice.gva.es/ocd/areacd/es/centro.asp?codi=12000625
} 
Como podemos observar, la principal necesidad de este centro parte del desfase educativo de sus integrantes, algo que se manifiesta tanto a nivel cognitivo como motor. Por ello, la intención del alumnado universitario participante en la propuesta de APS era la de paliar o mejorar esta situación mediante la aplicación de numerosas sesiones de juegos motores y expresivos. Así pues, entre sus objetivos destacaban acrecentar sus recursos motores, desarrollar sus habilidades sociales, generar la adquisición de hábitos saludables, mejorar su desempeño en las habilidades motrices básicas, fomentar la expresión oral y corporal, etc. En esta actividad participaron más de 45 niños divididos en dos grupos: último curso de infantil y primero de primaria. Igualmente, el servicio prestado contó con la colaboración de los dos profesores del área de EF, así como de otros miembros del equipo docente y del equipo directivo del centro.

\subsubsection{Fundación Borja Sánchez}

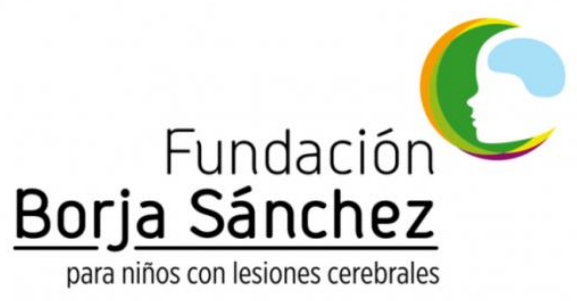

La misión de esta fundación es prestar el más amplio rango de asistencia posible a niños que padezcan una lesión cerebral; divulgar, compartir y aplicar el conocimiento, los procedimientos y los métodos médicos existentes para tratar de obtener, en la medida de lo posible, una recuperación de los efectos producidos por las distintas lesiones cerebrales. Así pues, su principal objetivo es asistir a niños en edad pediátrica que sufran cualquier tipo de lesión cerebral y brindar apoyo y ayuda a sus familias. La Fundación Borja Sánchez ${ }^{23}$ para Niños con Parálisis Cerebral Infantil de la Comunidad Valenciana se constituyó el 6 de octubre de 2010 en Castellón de la Plana.

La constatación de la mejora que tienen los niños con lesiones cerebrales cuando se les presta la debida atención y se les aplican las soluciones médicas adecuadas, fue determinante para crear la asociación. A partir de ese momento, consideran que la aportación y ayuda de todos es imprescindible para avanzar juntos en busca de soluciones cada vez más avanzadas. La Fundación Borja Sánchez es una organización de interés social, sin ánimo de lucro, que pretende dar respuestas a necesidades sociales relacionadas con la parálisis cerebral. Trabaja con el convencimiento de llegar a ser un referente profesional de compromiso social en la investigación y la aplicación práctica de los conocimientos médicos, estableciendo para ello todo tipo de relaciones y alianzas con organizaciones y asociaciones afines. Así pues, opera como una organización de gran

\footnotetext{
${ }^{23}$ http://www.fundacionborjasanchez.org/areas/index.php
} 
implantación social, promotora de proyectos que hagan la vida más fácil a estos niños y a sus familias. Entre estos proyectos podemos destacar la disponibilidad de una cámara hiperbárica, la implementación de un aula multisensorial, la creación de la clínica de la fundación o la adquisición del Pediatric Lokomat ${ }^{\circledR}$, primer soporte ortopédico de marcha accionada que automatiza la terapia de locomoción intensiva para niños con parálisis cerebral.

Además, esta entidad ofrece un servicio médico y psicológico a todos aquellos niños con lesiones cerebrales que estén censados y asociados a la fundación. Así pues, conscientes de la situación y las circunstancias por las que se atraviesa ante una lesión cerebral infantil, ofrecen su apoyo y ayuda para orientar tanto en la faceta médica como psicológica. Por ello, apuestan por un servicio de asesoramiento médico, que les permite ofrecer consejos, recomendaciones y una segunda opinión sobre los diagnósticos ofrecidos. Cuentan con el asesoramiento de un especialista en tratamientos de hidroterapia y brindan apoyo psicológico a las familias, incidiendo especialmente en la figura del cuidador, aquella persona o personas sobre las que recae la responsabilidad de asumir una nueva situación y planificar un nuevo proyecto de vida. Por ello, indican que es muy importante ser consciente de la nueva situación y no caer en sentimientos erróneos que dificulten y empobrezcan el alcance de la calidad de vida tanto de los niños afectados como de sus cuidadores. Finalmente, también ofrecen un servicio de consulta y asesoramiento telefónico, para aquellas personas que no puedan desplazarse a su sede o tengan dudas concretas que puedan resolverse por esta vía.

Vista la necesidad de este colectivo, el programa de APS pretendía atender las limitaciones motrices de casi 20 niños de la fundación, provocadas directamente por lesiones cerebrales. Así pues, el alumnado universitario desarrolló juegos motores y expresivos en los que se pretendía estimular la movilidad, el equilibrio, la marcha, la relajación, la coordinación global, etc. Este servicio formativo contó con el seguimiento de los responsables de la fundación, llegando incluso a colaborar con el alumnado universitario en diversas actividades extracurriculares.

\subsubsection{Fundación y Asociación Síndrome de Down de Castellón}

\section{sindrome Dawn castellón}

Esta entidad atiende a personas afectadas por distintas patologías, especialmente a personas con Síndrome de Down, y a sus familias procedentes de distintas poblaciones de la provincia de 
Castellón. La Asociación Síndrome de Down de Castellón ${ }^{24}$ fue fundada en 1995 y los objetivos específicos que persigue son:

- Potenciar el desarrollo cognitivo, social y afectivo que permita a las personas con Síndrome de Down y/o discapacidad intelectual, su plena realización personal.

- Sensibilizar y concienciar al resto de la sociedad de la realidad de estas personas, logrando así, su plena inclusión.

- Defender la integración escolar, porque de ella se benefician no solo los niños/as con Síndrome de Down y/o discapacidad intelectual, sino todos sus compañeros.

- Activar su inclusión laboral para conseguir una imagen positiva y útil de uno mismo y un conocimiento y respeto de los demás.

- Fomentar la atención médica, reivindicando sus derechos como persona.

Su fundación, instaurada un año más tarde, tiene como objetivo fundamental la promoción y realización de cuantas actividades contribuyan a la mejora de la calidad de vida de las personas con Síndrome de Down y de aquellas con otros tipos de discapacidad psíquica, favoreciendo así su integración social en todos los ámbitos, formación, empleo, recursos sociales, ocio, etc., para que puedan disfrutar de una vida normalizada a la que tienen derecho como cualquiera de nosotros. Esta entidad cuenta con un Centro de Desarrollo Infantil y Atención Temprana (CDIAT), cofinanciado por la Conselleria de Bienestar Social de la Comunidad Valenciana, que cuenta con un equipo interdisciplinar de profesionales del desarrollo infantil: pedagogas, logopeda, psicóloga y fisioterapeuta. En dicho centro se atiende a niños de o a 4 años con necesidades transitorias o permanentes, considerando su globalidad y actuando en el entorno familiar, educativo, sanitario y social en el que se desenvuelven, proporcionando información, asesoramiento y apoyo. Se puede acceder al centro a través de: centros sanitarios y hospitalarios públicos o privados, pediatras o médicos especialistas, servicios sociales, centros educativos o escuelas infantiles, equipos municipales de base o solicitando los padres o tutores cita previa por teléfono o correo electrónico. EI CDIAT ofrece diferentes tratamientos integrales en el ámbito del desarrollo infantil, entre los que destacan:

- Terapia de estimulación cognitiva a través del juego.

- Fisioterapia y psicomotricidad.

- Logopedia y terapia de la comunicación y el lenguaje.

- Regulación de hábitos y conductas disruptivas.

- Escuela de padres.

- Talleres: técnicas respiratorias, masaje infantil, terapia miofuncional, etc.

La experiencia de APS desarrollada con esta entidad se contextualiza en el marco de acción de la psicomotricidad establecido por el CDIAT. Así pues, el servicio pretendía atender las limitaciones motrices de cerca de 20 niños de la fundación, provocadas por las alteraciones cognitivas de padecían. Para ello, los alumnos de la universidad aplicaron juegos motores y expresivos en los que

${ }^{24}$ http://www.downcastellon.com/ 
se incentivara el desarrollo de la lateralidad, la orientación espacio-temporal, la motricidad global y específica, la expresión corporal, etc. El programa de APS fue supervisado por varios miembros de esta asociación no lucrativa, contando con la colaboración de profesores, psicopedagogas, familiares, etc., durante la prestación del servicio. 


5. Metodología y Diseño de
Investigación 

Este capítulo está dedicado a definir las cuestiones relacionadas con la metodología que se ha empleado en la investigación. En primer lugar, delimitamos las variables, presentamos las preguntas de investigación a las que daremos respuesta y planteamos las hipótesis que aceptaremos o rechazaremos en función de los resultados obtenidos. Más adelante, se expone el proceso de elaboración de los instrumentos de medida a emplear, el procedimiento de recogida de datos, la selección de la muestra y el diagnóstico inicial en las dos variables objeto de estudio. Finalmente, dedicamos un epígrafe a describir el proceso de tratamiento y análisis de datos expuesto en el próximo capítulo.

\subsection{Delimitación del problema}

En el marco teórico de la presente tesis hemos presentado el estado de la investigación sobre la aplicación de programas de APS y los impactos que produce su uso. Según lo expuesto, el APS provoca efectos en la comunidad, la institución educativa y el alumnado. Bajo esta premisa, nuestro propósito es indagar en los frutos de su aplicación en el alumnado universitario. Las diferentes teorías analizadas en el marco teórico sobre los efectos del APS, la social cognitiva de Bandura, el aprendizaje liberador de Chambers, el modelo rizomático de Deleuze y Guattari, la teoría constructivista de Piaget y Vygotsky, el interaccionismo simbólico de Blumer, las cuatro áreas de resultados propuestas por Furco y Root y el modelo de múltiples perspectivas de Butin, coinciden en que esta metodología provoca, principalmente, un notable impacto a nivel académico-cognitivo y personal-social sobre el alumnado, por lo que en este trabajo pretendemos medir elementos de ambos contextos. Así pues, investigamos el impacto del programa de APS aplicado sobre los conocimientos y competencias académicas y el desarrollo del ES del alumnado. En la revisión teórica realizada apenas hemos encontrado trabajos que profundicen en el desarrollo de los conocimientos académicos a través de esta metodología en nuestro país, más aún si nos limitamos al ámbito de nuestro trabajo, la EF. De igual modo, se ha detectado una ausencia de trabajos que empleen el APS para fomentar el desarrollo del ES en este contexto, lo cual incrementa aún más el interés de esta investigación. De esta escasez de trabajos y antecedentes, nace el reto de aportar nuevos datos sobre los efectos de esta metodología en nuestra sociedad, basándonos en investigaciones estructuradas que contribuyan a demostrar su operatividad en las dos dimensiones que abarca, los conocimientos académicos y el beneficio social.

Así pues, este es el problema de investigación que nos planteamos, ya que tratamos de demostrar la validez del APS como metodología que permite avanzar hacia lo que entendemos que ha de ser la universidad, una institución académica y formadora de ciudadanía crítica, en consonancia con los principios rectores del EEES. Este enfoque concuerda a la perfección con el concepto de RSU, el cual supone que dentro de las funciones habituales de esta entidad, formación, investigación, estudios y servicios de orientación, transferencia de la tecnología y educación permanente, se incluye un carácter de responsabilidad social que afecta a todas sus acciones y actividades institucionales. Por ello, consideramos que el APS puede ser una herramienta 
metodológica muy adecuada para la docencia universitaria, en base a sus principios fundamentales y a los planteamientos actuales de estas instituciones. De igual modo, opinamos que también sería interesante promover su uso en otras áreas y niveles educativos.

Como hemos visto en la revisión bibliográfica, el estado de la investigación sobre el APS a nivel internacional está mucho más avanzado en el continente americano, en consonancia con los años que llevan utilizando esta metodología, por lo que se han publicado numerosos estudios sobre distintos aspectos del uso del APS y sus efectos. Sin embargo, es difícil trasladar los resultados de estos estudios a nuestra sociedad debido a las notables diferencias socio-cultuales entre ambos contextos. Por ello, consideramos que debemos desarrollar trabajos propios que indaguen en los efectos del APS en nuestro entorno social. Esta investigación pretende contribuir al avance en esta línea, abordando el tema empíricamente y tratando de identificar las aportaciones que el uso de esta metodología genera, desde la perspectiva de aplicar un método que conjuga una forma de aprender activa, una necesidad imperiosa en $\mathrm{EF}$, y una formación en el ámbito de los valores. Como ya hemos apuntado, consideramos que se debería promover el uso de esta metodología en el resto del sistema educativo español. Por ello creemos que la realización del presente trabajo podría contribuir doblemente a incentivar dicho proceso, por un lado mediante la difusión de sus conclusiones finales y, por otro, a través de la aplicación del APS en otros contextos, ya que el futuro ámbito profesional del alumnado participante en esta investigación es la docencia. El reto radica en conseguir que su filosofía se propague por el contexto educativo de nuestro país, con el objetivo de buscar un beneficio recíproco entre las instituciones formativas y la sociedad. Con ello se contribuiría a derribar las barreras existentes en cuanto a la aplicación de este tipo de innovaciones didácticas, concienciando a distintos agentes educativos y superando así las reticencias actuales.

Además, pensamos que esta investigación puede servir de ejemplo en cuanto a la aplicación del APS nuestro contexto social, proporcionando una guía práctica sobre su uso para todos aquellos que quieran vincular su docencia con la mejora de la sociedad a través de la promoción de cambios en las actitudes y valores de su alumnado ante las distintas problemáticas sociales existentes. Así pues, esperamos poner al alcance del profesorado una serie de datos y procedimientos prácticos que estimulen la aplicación del APS en el ámbito de la EF universitaria y, a ser posible, en otros niveles y áreas educativas. Igualmente, confiamos en concienciar a los docentes que accedan a este documento para que se replanteen su labor educativa como un servicio de mejora de la sociedad en la que vivimos, intentando reportar el máximo beneficio social desde nuestro campo de acción, la educación.

\subsection{Objetivo de la investigación}

Partiendo de la argumentación teórica expuesta en el bloque inicial de este trabajo, donde se profundiza en el proceso de adquisición de conocimientos académicos a través del uso del APS, y los efectos personales y sociales que esta metodología provoca, explicitamos los objetivos de 
nuestra investigación. Así pues, pretendemos evaluar el uso del APS desde el supuesto de que su aplicación provocará efectos positivos sobre el aprendizaje de los contenidos y competencias académicas y sobre el fomento del ES del alumnado implicado en el programa educativo descrito. Por tanto, la finalidad de esta investigación queda concretada en el siguiente objetivo general:

Diseñar y evaluar los resultados de la aplicación de un programa de APS en la asignatura "Fundamentos de la Expresión Corporal, Juegos Motrices en Educación Infantil".

Este objetivo general se desglosa en otros dos objetivos fundamentales, que se corresponden con las dimensiones sobre las que centramos nuestro trabajo. Así pues, estos dos objetivos se definen de la siguiente manera:

$\mathrm{O}_{1}$ - Fomentar los conocimientos y competencias del alumnado sobre los contenidos de la asignatura "Fundamentos de la Expresión Corporal, Juegos Motrices en Educación Infantil".

$\mathrm{O}_{2}$-- Desarrollar la competencia de Emprendimiento Social en el alumnado participante.

\subsection{Diseño}

Nuestra investigación combina el uso de las metodologías cuantitativa y cualitativa. Así pues, el diseño de esta investigación se ubica en los denominados Métodos Mixtos (Mixed Methods). Para explicar por qué nos hemos decantado por esta opción, nos remitimos a Todd, Nerlich y McKeown (2004) los cuales, tras revisar las aportaciones de otros autores, concretan las principales ventajas del uso de estos métodos en los siguientes aspectos:

- La perspectiva es más completa, integral y holística, explorándose diversos niveles o dimensiones del problema objeto de estudio.

- Se facilita la formulación del problema y su encuadre conceptual.

- La riqueza de los datos es notablemente mayor, dado que no existe limitación en cuanto a la diversidad de las fuentes de procedencia y a la naturaleza de la información.

- Se potencia la creatividad teórica con numerosos procedimientos de valoración crítica.

- Aumentan las posibilidades de ampliar las dimensiones de un estudio.

- Se consigue una mayor y mejor exploración y explotación de los datos, así como una presentación más sugerente de los resultados.

Cabe aclarar que estos métodos mixtos suponen una recogida y un uso riguroso de los datos, tanto cuantitativos como cualitativos, combinándolos e integrándolos en el marco de un 
determinado diseño y dentro de una estructura de investigación más amplia. Por el contrario, un estudio multi-método, que no implicase utilizar métodos mixtos, se limitaría únicamente a la yuxtaposición de datos cuantitativos y cualitativos (Bazeley, 2009), sin que exista ningún proceso de combinación o integración entre ellos, o sin ubicarlos en un marco de investigación más amplio (Brannen, 2005). Esta combinación de datos puede lograrse por dos vías, integrando coherentemente la interpretación de resultados a partir de análisis separados o efectuando transformaciones entre los datos, convirtiendo los resultados cualitativos en cuantitativos o a la inversa (Creswell y Plano Clark, 2007). Con la intención de aprovechar al máximo el diseño escogido, en el presente trabajo emplearemos ambas estrategias, por lo que, además del correspondiente análisis cuantitativo y cualitativo de los datos, también analizaremos los resultados cualitativos desde una perspectiva cuantitativa y haremos una interpretación conjunta de todos los resultados obtenidos, tanto cuantitativos como cualitativos.

Aunque todavía no es una corriente dominante, los métodos mixtos ya tienen importantes referentes en el ámbito de las Ciencias de la Educación Física y el Deporte en nuestro país, como pueden ser los trabajos de Anguera, Camerino, Castañer y Sánchez-Algarra (2014), Camerino, Castañer y Anguera (2012) y Castañer, Camerino, Anguera (2013).

Dentro de los métodos mixtos podemos distinguir entre diseños de triangulación, dominancia, exploración secuencial y explicación secuencial (Creswell y Plano Clark, 2007; Teddlie y Tashakkori, 2010). Dada la naturaleza y necesidades de nuestro trabajo nos hemos decantado por un diseño de triangulación, ya que consiste en la confrontación de diversos datos complementarios sobre un mismo episodio con el propósito de comprenderlo mejor (Morse, 1991; Riba, 2007). Dentro de este diseño encontramos triangulación de datos, de investigadores, de teorías y metodológica (Denzin, 1970). En este caso nos hemos decantado por una triangulación metodológica, la cual utiliza distintos métodos e instrumentos para un mismo problema de investigación. Así pues, hemos abordado la adquisición de los conocimientos académicos de la asignatura y el desarrollo del ES en el alumnado utilizando métodos e instrumentos de investigación tanto cuantitativos como cualitativos.

Por tanto, nuestro trabajo responde a un método mixto con triangulación metodológica. Por tanto, el diseño de esta investigación se expresa de la siguiente forma, figura 10.

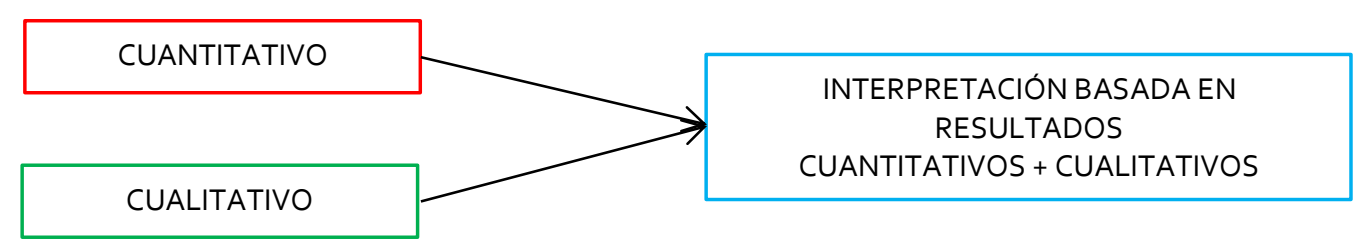

Figura 10. Diseño de la investigación (adaptado de Creswell y Plano Clark, 2007). 
El apartado cuantitativo de nuestro diseño lo hemos abordado a través de una investigación Multigrupo de Grupos No Equivalentes, con dos Grupos Experimentales y un Grupo Control, y medidas Pretest y Postest. A los tres grupos se les tomó una medida inicial sobre las variables dependientes, Pretest. A continuación, llevamos a cabo dos intervenciones distintas sobre los Grupos Experimental I y Experimental II, mientras que el tercero sirvió de Grupo Control. Después de la intervención, volvimos a medir las variables dependientes en los tres grupos, Postest. El esquema que sintetiza la investigación es el siguiente:

\begin{tabular}{lccc} 
Grupo Experimental I & $O_{1}$ & $X_{1}$ & $O_{2}$ \\
Grupo Experimental II & $O_{1}$ & $X_{11}$ & $O_{2}$ \\
\hdashline Grupo Control & $O_{1}$ & & $O_{2}$
\end{tabular}

Los símbolos $\mathrm{O}_{1}$ y $\mathrm{O}_{2}$ representan las puntuaciones obtenidas en el Prestest y Postest para cada uno de los grupos participantes en el estudio. Por otra parte, las $X_{1}$ y $X_{\| 1}$ hacen referencia a las dos intervenciones realizadas mediante el programa educativo basado en la metodología del APS. EI Grupo Control se mantuvo al margen de ambas intervenciones para contrastar que los resultados obtenidos eran debidos al proyecto educativo aplicado.

El apartado cualitativo de nuestro diseño se abordó mediante una investigación basada en los métodos biográficos a través de diversas Historias de Vida de relatos múltiples cruzados. Finalmente contrastamos y comparamos los datos registrados en ambas vertientes de nuestro diseño, cualitativa y cuantitativa, para hacer una interpretación conjunta de los resultados obtenidos y extraer las conclusiones globales de nuestra investigación.

\subsection{Descripción de las variables}

- Variables Independientes:

- Variable Independiente 1: Programa de APS A.

- Variable Independiente 2: Programa de APS B.

- Variables Dependientes:

- Variable Dependiente A: conocimientos y competencias del alumnado sobre los contenidos académicos de la asignatura "Fundamentos de la Expresión Corporal, Juegos Motrices en Educación Infantil".

- Variable Dependiente B: competencia de Emprendimiento Social. 


\subsection{Formulación de hipótesis y preguntas de investigación}

- H1: La aplicación del programa de APS A producirá en el alumnado del Grupo Experimental I una mejora estadísticamente significativa $(p<0,05)$ en sus conocimientos académicos y competencias sobre los contenidos de la asignatura "Fundamentos de la Expresión Corporal, Juegos Motrices en Educación Infantil", que diferirá y será superior a la obtenida por el Grupo Control.

- H2: La aplicación del programa de APS B producirá en el alumnado del Grupo Experimental II una mejora estadísticamente significativa $(p<0,05)$ en sus conocimientos académicos y competencias sobre los contenidos de la asignatura "Fundamentos de la Expresión Corporal, Juegos Motrices en Educación Infantil", que diferirá y será superior a la obtenida por el Grupo Control.

- H3: La aplicación del programa de APS A producirá en el alumnado del Grupo Experimental I una mejora estadísticamente significativa $(p<0,05)$ en sus conocimientos académicos y competencias sobre los contenidos de la asignatura "Fundamentos de la Expresión Corporal, Juegos Motrices en Educación Infantil", que diferirá y será superior a la obtenida por el Grupo Experimental II.

- $\mathrm{H}_{4}$ : La aplicación del programa de APS A producirá en el alumnado del Grupo Experimental I una mejora estadísticamente significativa $(p<0,05)$ respecto a su competencia de Emprendimiento Social, que diferirá y será superior a la obtenida por el Grupo Control.

- H5: La aplicación del programa de APS B producirá en el alumnado del Grupo Experimental II una mejora estadísticamente significativa $(p<0,05)$ respecto a su competencia de Emprendimiento Social, que diferirá y será superior a la obtenida por el Grupo Control.

- H6: La aplicación del programa de APS A producirá en el alumnado del Grupo Experimental I una mejora estadísticamente significativa $(p<0,05)$ respecto a su competencia de Emprendimiento Social, que diferirá y será superior a la obtenida por el Grupo Experimental II.

- P1: ¿El programa de APS implementado aumenta los conocimientos y competencias de la asignatura "Fundamentos de la Expresión Corporal, Juegos Motrices en Educación Infantil" en el alumnado participante?

- P2: ¿El programa de APS implementado desarrolla la competencia de Emprendimiento Social en el alumnado participante? 


\subsection{Instrumentos de medida}

Debido a la ausencia de herramientas adaptadas al contexto de nuestra investigación, así como a la especificidad de los objetivos establecidos, nos planteamos el diseño y validación de dos instrumentos de medida, uno para cada una de las dimensiones que pretendemos medir:

- Conocimientos y competencias del alumnado sobre los contenidos de la asignatura "Fundamentos de la Expresión Corporal, Juegos Motrices en Educación Infantil".

- Competencia de Emprendimiento Social del alumnado participante.

Siguiendo lo expuesto en el marco teórico de este trabajo consideramos que una buena alternativa para medir los conocimientos y competencias del alumnado sobre la asignatura objeto de estudio puede ser a través del uso de una rúbrica. Por otra parte, para medir los efectos del programa educativo implementado sobre la competencia de ES del alumnado optamos por un cuestionario de valoración que analizara los diferentes aspectos que hemos fundamentado que lo definen.

Previamente a la elaboración de ambos instrumentos realizamos una revisión de la bibliografía que reveló la ausencia de investigaciones similares que hubieran utilizado y/o validado algún instrumento de medida en este campo. Por tanto constatamos la necesidad de crear instrumentos propios ad hoc que midieran específicamente los aspectos de las variables sobre las que íbamos a incidir, ya que no encontramos instrumentos que se ciñeran concretamente a nuestros objetivos. Cierto es que algunos se aproximaban en diversos aspectos, pero consideramos que era necesario establecer un proceso de diseño y validación de instrumentos propios para mejorar la calidad de nuestro trabajo. De este modo, nos aseguramos de que los instrumentos de medida se ajustaban a las características de nuestra población y a nuestros objetivos, además de crear unos instrumentos que pueden ser útiles tanto a nivel docente como investigador.

Así pues, para medir la variable dependiente A diseñamos, validamos y aplicamos una rúbrica de evaluación sobre los conocimientos y competencias de la asignatura. Por otra parte, para medir la variable B diseñamos, validamos y aplicamos el cuestionario CCES (Cuestionario sobre la Competencia de Emprendimiento Social).

\subsubsection{Rúbrica sobre conocimientos y competencias académicas}

En el proceso de diseño y validación de la rúbrica para valorar los conocimientos y competencias académicas se realizaron las siguientes acciones: (1) creación de la rúbrica, (2) aplicación de la rúbrica en una prueba piloto y (3) revisión empírica de la rúbrica con los datos obtenidos en dicha aplicación. 


\section{- Creación de la rúbrica sobre conocimientos y competencias académicas}

Siguiendo los pasos descritos en el marco teórico por Chiva y Gil (2012), para elaborar una rúbrica debemos identificar y decidir las dimensiones o aspectos que se evaluarán a partir de los objetivos planteados, determinar los niveles de logro, escribir los indicadores/descriptores de la forma más específica y precisa posible, aplicar la rúbrica y analizar los resultados obtenidos. De acuerdo con estas directrices, pasamos a describir el proceso de creación de la rúbrica.

Nuestro programa educativo se enmarca en la asignatura "Fundamentos de la expresión corporal: juegos motrices en Educación Infantil", perteneciente al $2^{\circ}$ curso del Grado en Maestro o Maestra de la Universidad Jaume I de Castellón". Nuestro planteamiento pretende medir los conocimientos y competencias adquiridas por el alumnado sobre esta asignatura. Para ajustarnos correctamente a este marco académico de aplicación, nos centramos en desarrollar las diferentes competencias genéricas y específicas requeridas para superar la asignatura, así como en fomentar los resultados de aprendizaje que se esperan alcanzar, información que concretamos a través de la guía docente de la asignatura, tablas 28 y 29 . En este punto cabe destacar que, aun siendo una rúbrica planteada para una asignatura concreta, su alcance transciende a la misma ya que además de las competencias específicas valora competencias genéricas de titulación y analiza la aplicación de un recurso didáctico primordial en el ámbito de la EF, el juego motor y expresivo (Alonso, 2008; García, 2011; Navarro, 2011; Romero, 2009; Romero et al., 2011).

Tabla 28. Competencias genéricas y específicas de la asignatura (Guía docente de la asignatura).

\begin{tabular}{cl}
\hline CÓDIGO $^{25}$ & \multicolumn{1}{c}{ COMPETENCIA } \\
\hline DDUJ188 & $\begin{array}{l}\text { Planificar las actividades educativas en función de la progresiva cohesión-integración } \\
\text { del grupo/clase (adaptación, consolidación, cohesión...). }\end{array}$ \\
\hline DDUJ199 & $\begin{array}{l}\text { Potenciar el uso del lenguaje corporal para conseguir una mejor expresión, respetar el } \\
\text { trabajo propio y desarrollar habilidades sociales. }\end{array}$ \\
\hline DDUJ120 & $\begin{array}{l}\text { Promover el juego simbólico y de representación de roles como principal medio de } \\
\text { conocimiento de la realidad social. }\end{array}$ \\
\hline DDUJ/21 & $\begin{array}{l}\text { Ser capaz de crear propuestas motrices adecuadas a cada grupo de edad en la etapa de } \\
\text { educación infantil. }\end{array}$ \\
\hline DDUJ/22 & $\begin{array}{l}\text { Ser capaz de desarrollar los hábitos de autonomía personal y el respeto a las normas de } \\
\text { convivencia en sus alumnos. }\end{array}$ \\
\hline DDUJ123 & $\begin{array}{l}\text { Ser capaz de seleccionar materiales y espacios adecuados para la realización de los } \\
\text { juegos motrices en educación infantil. }\end{array}$ \\
\hline DD23 & $\begin{array}{l}\text { Saber utilizar el juego como principal recurso didáctico, así como diseñar actividades de } \\
\text { aprendizaje basadas en principios lúdicos. }\end{array}$ \\
\hline
\end{tabular}

\footnotetext{
${ }^{25}$ Los códigos de las competencias son los descritos en la guía docente de la asignatura. Estos se exponen para poder identificarlos fácilmente al escribir los indicadores/descriptores de la rúbrica.
} 
Tabla 29. Resultados de aprendizaje de la asignatura (Guía docente de la asignatura).

\begin{tabular}{cl}
\hline CÓDIGO $^{26}$ & RESULTADO DE APRENDIZAJE \\
\hline RA1 & Ser capaces de aplicar un amplio abanico de propuestas de trabajo de la expresión corporal. \\
\hline RA2 $\begin{array}{l}\text { Ser capaces de planificar el trabajo de expresión corporal dentro de la programación general de la } \\
\text { etapa de Educación Infantil. }\end{array}$ \\
\hline RA3 $\begin{array}{l}\text { Ser capaces de transmitir valores a los niños a través del trabajo de los contenidos de la expresión } \\
\text { corporal y el juego (cooperación, solidaridad, respeto...). }\end{array}$ \\
\hline RA4 & Ser capaces de trabajar la expresión corporal adecuadamente al nivel de desarrollo de los niños/as. \\
\hline RA5 $\begin{array}{l}\text { Ser capaces de utilizar el juego motriz de forma adecuada en función de las intencionalidades } \\
\text { educativas que se persiguen. }\end{array}$ \\
\hline RA6 $\begin{array}{l}\text { Ser capaces de utilizar el movimiento como herramienta de aprendizaje y de socialización, } \\
\text { entendiendo la importancia del mismo en la etapa de infantil. }\end{array}$ \\
\hline
\end{tabular}

Seguidamente, determinamos los ítems que debían formar parte de la rúbrica para valorar adecuadamente estas competencias y resultados de aprendizaje. En este caso no era necesario realizar una revisión lógica o validez de contenido mediante un juicio de expertos, ya que dicho contenido venía determinado por la guía de la asignatura. Pese a ello, presentamos 60 ítems iniciales al profesorado de la asignatura para que nos diera su opinión al respecto con la intención de mejorar el instrumento final. Estos docentes nos aconsejaron replantear o fusionar algunos ítems con el propósito de simplificar la rúbrica y facilitar su futura aplicación. Así pues, siguiendo estas indicaciones, confeccionamos una batería de 40 ítems distribuidos en diez bloques de cuatro ítems cada uno. En la tabla 30 mostramos la relación de ítems en función de los distintos bloques de asociación.

Tabla 30. Ítems de la rúbrica en función de los bloques de agrupación (elaboración propia).

\begin{aligned} & \hline \multicolumn{1}{c}{ BLOQUE } \multicolumn{1}{c}{ ITEMS } \\ & \hline Ajuste de los juegos al a1) Edad \\ & alumnado propuesto b1) Periodo \\ & c1) Necesidades educativas \\ & d1) Seguridad \\ & \hline a2) Descripción \\ & Presentación b2) Estructura \\ & c2) Comprensión de las normas \\ & d2) Representación gráfica \\ & \hline a3) Participación \\ & Organización del b3) Distribución de roles \\ & alumnado c3) Trabajo individual / grupal \\ & d3) Control del respeto por las normas \\ & \hline a4) Uso del material \\ & Organización del b4) Variedad de material \\ & material c4) Optimización \\ & d4) Distribución \\ & \hline\end{aligned}

\footnotetext{
${ }^{26}$ Los códigos de los resultados de aprendizaje se han creado específicamente en este caso. Estos se exponen para poder identificarlos fácilmente al escribir los indicadores/descriptores de la rúbrica.
} 


\begin{tabular}{|c|c|}
\hline $\begin{array}{l}\text { Organización } \\
\text { espacio-temporal }\end{array}$ & $\begin{array}{l}\text { a5) Optimización/adaptación temporal } \\
\text { b5) Equilibrio temporal } \\
\text { c5) Optimización/adaptación espacial } \\
\text { d5) Equilibrio espacial }\end{array}$ \\
\hline Adecuación curricular & $\begin{array}{l}\text { a6) Relación contenidos-objetivos } \\
\text { b6) Consecución de los objetivos } \\
\text { c6) Progresión } \\
\text { d6) Valor educativo }\end{array}$ \\
\hline Aspectos sociales & $\begin{array}{l}\text { a7) Atención a la diversidad } \\
\text { b7) Transmisión de valores sociales } \\
\text { c7) Normas de convivencia } \\
\text { d7) Fomento de la cohesión-integración }\end{array}$ \\
\hline Juegos motores & $\begin{array}{l}\text { a8) Desarrollo de la motricidad fina } \\
\text { b8) Desarrollo de la motricidad gruesa } \\
\text { c8) Desarrollo de la coordinación global } \\
\text { d8) Desarrollo de la coordinación específica }\end{array}$ \\
\hline $\begin{array}{r}\text { Juegos de expresión } \\
\text { corporal }\end{array}$ & $\begin{array}{l}\text { ag) Representación de roles } \\
\text { bg) Simbolismo } \\
\text { cg) Desarrollo de la expresión } \\
\text { dg) Comunicación corporal }\end{array}$ \\
\hline Otros & $\begin{array}{l}\text { a10) Carácter innovador y originalidad } \\
\text { b10) Valor lúdico } \\
\text { c10) Variedad de juegos } \\
\text { d10) Evaluación de la propuesta }\end{array}$ \\
\hline
\end{tabular}

A continuación, en la tabla 31, comprobamos cómo cada uno de estos bloques hacía referencia a una o varias competencias de la guía docente de la asignatura y se asociaba con uno o dos de los resultados de aprendizaje esperados.

Tabla 31. Relación entre los ítems de la rúbrica, las competencias y los resultados de aprendizaje (elaboración propia).

\begin{tabular}{|c|c|c|}
\hline BLOQUES DE ÍTEMS & CÓDIGOS DE LAS COMPETENCIAS & $\begin{array}{l}\text { RESULTADOS DE } \\
\text { APRENDIZAJE }\end{array}$ \\
\hline 1.- Ajuste de los juegos al alumnado & DDUJ/21 & $\mathrm{RA}_{2}, \mathrm{RA}_{4}$ \\
\hline 2.- Presentación & DDUJI21, DD23 & $\mathrm{RA}_{4}$ \\
\hline 3.- Organización del alumnado & DDUJ/21,DDUJ/22, DD23 & $\mathrm{RA}_{4}$ \\
\hline 4.- Organización del material & DDUJl23 & $\mathrm{RA}_{2}, \mathrm{RA} 5$ \\
\hline 5.- Organización espacio/temporal & DDUJ/23 & $\mathrm{RA}_{2}, \mathrm{RA}_{5}$ \\
\hline 6.- Adecuación curricular & DDUJI21, DD23 & $\mathrm{RA}_{2}, \mathrm{RA} 5$ \\
\hline 7.- Aspectos sociales & DDUJ118, DDUJ/19, DDUJ/22 & $\mathrm{RA}_{3}, \mathrm{RA} 6$ \\
\hline 8.- Juegos motores & DDUJ/21, DD23 & $\mathrm{RA}_{5}, \mathrm{RA} 6$ \\
\hline 9.- Juegos de expresión corporal & DDUJl19, DDUJl20, DD23 & $\mathrm{RA}_{1}, \mathrm{RA}_{4}$ \\
\hline 10.- Otros: carácter innovador, etc. & DDUJ118, DDUJ/21, DD23 & $\mathrm{RA}_{1}, \mathrm{RA} 5$ \\
\hline
\end{tabular}

Para finalizar el proceso de diseño de la rúbrica determinamos los niveles de logro y redactamos los descriptores de forma específica y precisa. A tal efecto adjuntamos una escala de valoración de tipo Likert de 1 a 5, donde 1 indicaba el valor más bajo de consecución, muy mal, y 5 el más alto, muy bien. A continuación elaboramos los indicadores de valoración de cada ítem en función de 
estos 5 niveles de consecución. Por ejemplo en el ítem (a1), "ajuste de los juegos a la edad del alumnado participante", los indicadores de valoración eran los siguientes:

1- Ningún juego se ajusta a la edad del alumnado.

2- Pocos juegos se ajustan a la edad del alumnado.

3- Algunos juegos se ajustan a la edad del alumnado.

4- Muchos juegos se ajustan a la edad del alumnado.

5- Todos los juegos se ajustan correctamente a la edad del alumnado.

Este proceso se realizó con cada uno de los ítems de la rúbrica.

\section{- Aplicación de la rúbrica en una prueba piloto}

Una vez finalizada la rúbrica se elaboró un supuesto práctico que incluía las competencias a desarrollar en la misma, para así ponerla a prueba mediante su aplicación. Dicho supuesto planteaba la realización de una sesión de juegos motrices y de expresión corporal, de una hora de duración, para un grupo de 23 alumnos y alumnas de 5 años, 17 niñas y 6 niños. Entre el alumnado participante había un niño con problemas de actitud, agresividad, exceso de competitividad y tendencia a transgredir las normas. En cuanto al material se indicaba que disponían de 15 pelotas de espuma de tamaño normal, 2 pelotas gigantes hinchables, 10 aros, 18 conos, 10 pelotas de minibásquet, 4 balones de fútbol, 30 pañuelos de diversos colores, 9 colchonetas, 3 telas de $3 \times 3$ metros cada una de un color, tizas de colores, papel de periódico, globos de colores y ceras especiales para pintar la piel. Respecto a las instalaciones se contaba con un espacio al aire libre de $20 \times 20$ metros, de suelo de hormigón fino, rodeado por un muro en una parte y sin límites por las otras tres. Asimismo, se indicaba que la sesión tenía lugar a finales del mes de mayo. Se incluyeron dos premisas a cumplir: la primera implicaba plantear tanto juegos motrices como de expresión corporal, buscando trabajar los dos bloques de contenidos fundamentales de la asignatura; la segunda premisa requería añadir juegos que fomentaran la autonomía y la cooperación, promoviendo así el desarrollo de estos valores. Finalmente se indicaron los siguientes contenidos a desarrollar: coordinación y control de las habilidades motrices de carácter fino y grueso y percepción de los deseos y de los estados de ánimo, su manifestación y comunicación. Ambos fueron extraídos del currículum de Educación Infantil de la Conselleria de Educación de la Comunidad Valenciana ${ }^{27}$. Seguidamente, presentamos este supuesto práctico a un grupo de 160 alumnos que habían cursado previamente la asignatura para que el equipo docente de la misma, dos profesores especialistas en la materia, valorara las respuestas elaboradas utilizando la rúbrica creada. Por tanto, el muestreo para esta prueba fue de tipo no probabilístico incidental.

\section{- Revisión empírica de la rúbrica con los resultados de la prueba piloto}

Una vez realizada la aplicación de la rúbrica recogimos los datos resultantes para realizar el análisis estadístico de los mismos utilizando el paquete estadístico SPSS versión 21 . En el anexo

\footnotetext{
${ }^{27}$ Decreto 38/2008 de 28 de marzo; Currículo del segundo ciclo de la Educación Infantil en la Comunitat Valenciana 2008. DOCV Conselleria de Educación. Recuperado de http://www.docv.gva.es/datos/2008/04/03/pdf/2008_3838.pdf
} 
mostramos los estadísticos descriptivos que nos permiten conocer en profundidad los datos registrados (tabla 48). Podemos destacar que el registro más bajo para la media era 1,28 (ítem d2) y el más alto 3,29 (ítem b8), obteniendo una media total de 2,53 tal como muestra el gráfico 1. En él presentamos el histograma que muestra la distribución de los sujetos según el grado de competencia alcanzado.

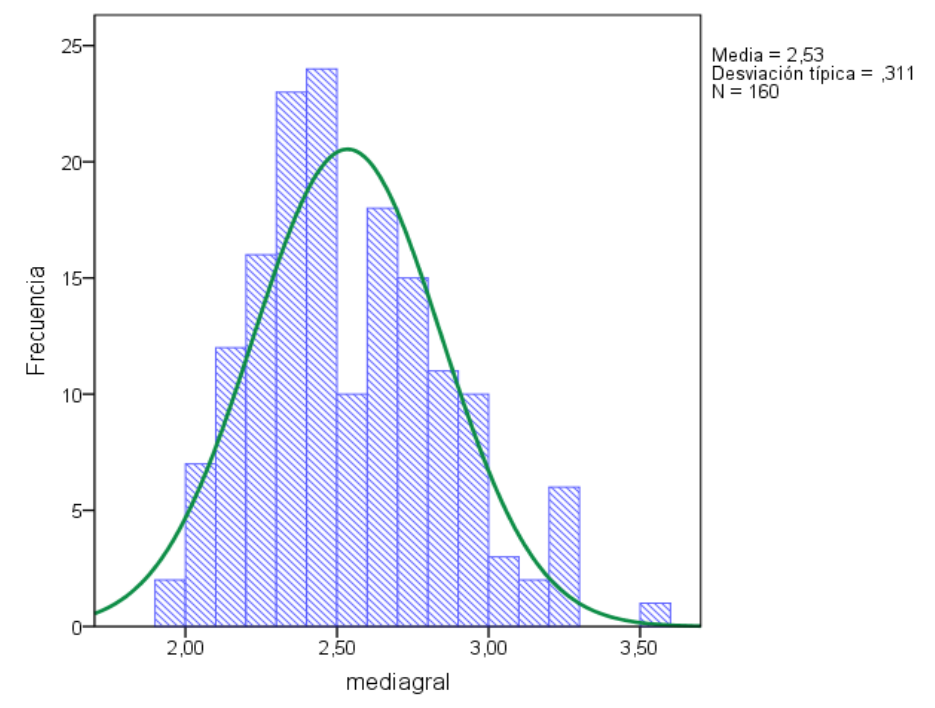

Gráfico 1. Histograma de la prueba piloto de la rúbrica (elaboración propia).

El método de consistencia interna basado en el Alfa de Cronbach nos permitió estimar la fiabilidad del instrumento de medida a través de un conjunto de ítems que se espera que midan el mismo constructo o dimensión teórica. La medida de la fiabilidad mediante este estadístico asume que los ítems miden un mismo constructo y que están altamente correlacionados (Welch y Comer, 1988). Cuanto más cerca se encuentre el valor del alfa a 1, mayor es la consistencia interna de los ítems analizados. Como podemos ver en la tabla 32, nuestro estudio obtuvo un valor de 0,908, por lo que, según la categorización realizada por George y Mallery (2014), al ser superior a 0,9 su fiabilidad puede calificarse de excelente.

Tabla 32. Estadísticos de fiabilidad de la prueba piloto (elaboración propia).

\begin{tabular}{|ccc|}
\hline Alfa de Cronbach & $\begin{array}{c}\text { Alfa de Cronbach basada en } \\
\text { los elementos tipificados }\end{array}$ & N de elementos \\
\hline 1908 & 1910 & 40 \\
\hline
\end{tabular}


En la tabla 49 del anexo mostramos la relación del Alfa de Cronbach con cada uno de los ítems. En ella podemos apreciar que todos los ítems eran importantes al valorar los conocimientos y competencias para realizar sesiones de juegos motrices y de expresión corporal, situación que se corrobora claramente al observar que, si se elimina algún ítem, el Alfa de la escala en general no mejoraba significativamente. Por tanto, puede afirmarse que la rúbrica creada permite medir correctamente los conocimientos y competencias de la asignatura

Respecto al análisis factorial, el resultado para la medida de adecuación muestral de KMO (Kaiser-Meyer-Olkin) era de 0,795 y el registro de la prueba de esfericidad de Bartlett de o,000 (ver tabla 33). Al obtenerse un registro superior a 0,6 e inferior a 0,05 respectivamente se demostró que había una correlación interna significativa en las respuestas de la aplicación de la rúbrica.

Tabla 33. Kaiser-Meyer-Olkin y prueba de Bartlett (elaboración propia).

\begin{tabular}{|lrr|}
\hline Medida de adecuación muestral de Kaiser-Meyer-Olkin. &, 795 \\
& Chi-cuadrado aproximado & 4727,875 \\
Prueba de esfericidad de Bartlett & gl & 780 \\
& Sig. &, 000 \\
\hline
\end{tabular}

En cuanto a la extracción de factores comunes, en la tabla 50 del anexo comprobamos que los ítems se agrupaban en diez categorías, algo que concuerda con nuestro planteamiento teórico inicial. Asimismo, esta agrupación explicaba el 70,26\% de la varianza acumulada. Este análisis nos permite observar la estructura interna de la rúbrica, identificando las categorías en las que se agrupaban los ítems. A continuación, en la tabla 34, mostramos el análisis de componentes principales, con rotación de normalización Oblimin con Kaiser, ya que esta tiene una función exploratoria. Igualmente, en esta tabla podemos ver los ítems que saturaban en cada categoría (resaltados en color azul).

Tabla 34. Análisis factorial de los resultados de la prueba piloto. Matriz de estructura (elaboración propia).

\begin{tabular}{|c|c|c|c|c|c|c|c|c|c|c|}
\hline \multirow[t]{2}{*}{ Ítem } & \multicolumn{10}{|c|}{ Componente } \\
\hline & 1 & 2 & 3 & 4 & 5 & 6 & 7 & 8 & 9 & 10 \\
\hline a1 &, 415 &, 045 & 164 &, 069 &,- 017 & 256 & 273 & 101 &,- 072 & 793 \\
\hline$b_{1}$ &, 240 &, 081 &, 114 &, 041 & 154 & 152 & 144 &, 098 &,- 117 &, 814 \\
\hline $\mathrm{C} 1$ &, 564 &, 211 & ,297 & 071 & 317 & 152 &, 098 & 191 &, 087 &, 564 \\
\hline $\mathrm{d}_{1}$ & 144 &, 163 &, 034 & 146 & ,104 &, 082 &,- 025 & 371 &, 294 &, 587 \\
\hline $\mathrm{a} 2$ &, 165 &, 057 &, 052 &, 067 &, 283 &, 838 &, 076 & 164 &, 134 & 151 \\
\hline b2 & 307 &, 136 & 123 & 187 &, 628 &, 560 &, 211 & 345 &, 205 & 159 \\
\hline $\mathrm{C} 2$ &, 253 &, 030 &, 230 & 180 & 277 &, 743 & 397 &, 361 &, 046 &, 247 \\
\hline $\mathrm{d}_{2}$ &,- 011 &,- 015 & 168 &, 074 &,- 017 & 142 &, 069 &, 117 &, 500 &,- 038 \\
\hline a3 &, 410 &, 052 &, 212 &, 063 & 309 & 178 &, 351 &, 477 &,- 499 & 307 \\
\hline b3 & 399 & 101 &, 426 & 176 &, 362 & 241 &, 220 &, 592 &,- 246 &, 414 \\
\hline c3 & ,499 &, 025 & ,359 & 173 & ,393 & 117 &, 228 & ,617 &,- 253 & 370 \\
\hline$d_{3}$ &, 417 &,- 067 & 290 &, 084 & 113 &, 474 & 319 &, 343 & -180 &, 082 \\
\hline
\end{tabular}




\begin{tabular}{|lllllllllll|} 
a4 &, 427 &, 130 &, 200 &, 137 &, 254 &, 225 &, 492 &, 563 &, 336 &, 372 \\
b4 &, 430 &, 271 &, 067 &, 145 &, 169 &, 137 &, 403 &, 116 &, 457 &, 270 \\
c4 &, 142 &, 064 &, 078 &, 107 &, 272 &, 114 &, 085 &, 775 &, 074 &, 063 \\
d4 &, 380 &, 239 &, 118 &, 177 &, 158 &, 215 &, 390 &, 649 &, 100 &, 185 \\
a5 &, 239 &, 202 &, 144 &, 098 &, 911 &, 129 &, 267 &, 196 & -146 &, 034 \\
b5 &, 263 &, 190 &, 139 &, 116 &, 906 &, 145 &, 300 &, 188 & -148 &, 034 \\
C5 &, 274 &, 193 &, 097 &, 142 &, 227 &, 142 &, 936 &, 183 &, 047 &, 124 \\
d5 &, 282 &, 224 &, 092 &, 155 &, 229 &, 140 &, 926 &, 149 &, 038 &, 099 \\
a6 &, 924 &, 161 &, 217 &, 323 &, 214 &, 178 &, 317 &, 268 &,- 036 &, 313 \\
b6 &, 931 &, 094 &, 222 &, 313 &, 205 &, 160 &, 341 &, 227 &,- 055 &, 271 \\
c6 &, 739 &,- 002 &, 273 &, 332 &, 278 &,- 013 &, 198 &, 216 &, 011 &, 135 \\
d6 &, 755 &, 175 &, 349 &, 405 &, 344 &, 222 &, 247 &, 424 &, 002 &, 395 \\
a7 &, 280 &, 166 &, 602 &, 062 &, 207 &,- 079 &, 086 &, 097 &, 075 & -130 \\
b7 &, 214 &, 053 &, 946 &, 120 &, 115 &, 072 &, 072 &, 132 &, 044 &, 135 \\
C7 &, 267 &,- 015 &, 902 &, 109 &, 139 &, 174 &, 044 &, 070 &,- 026 &, 127 \\
d7 &, 169 &, 008 &, 916 &, 113 &, 031 &, 016 &, 115 & 175 &, 074 &, 132 \\
a8 &, 042 &, 794 &,- 024 &, 077 &, 117 &, 178 &, 179 &,- 137 &,- 047 &, 146 \\
b8 &, 081 &, 914 &, 018 &,- 112 &, 142 &, 051 &, 207 &, 148 &, 071 &, 080 \\
c8 &, 101 &, 913 &, 044 &,- 094 &, 144 &, 062 &, 218 &, 166 &, 072 &, 084 \\
d8 &, 201 &, 780 &, 163 &, 098 &, 162 &,- 058 &, 098 &, 077 &, 123 &, 077 \\
a9 &, 362 &,- 008 &, 218 &, 837 &, 086 &, 009 &, 076 &, 146 &, 009 &, 129 \\
b9 &, 201 &, 053 &,- 006 &, 745 &, 100 &,- 063 &, 241 &, 073 &, 156 &,- 047 \\
c9 &, 222 &,- 036 &, 089 &, 883 &, 133 &, 109 &, 112 &, 067 &, 017 &, 007 \\
d9 &, 231 &,- 086 &, 115 &, 895 &, 116 &, 097 &, 009 &, 099 &, 065 &, 105 \\
a10 &, 399 &, 108 &, 239 &, 534 &, 487 &, 339 &, 291 &, 223 &, 201 &, 324 \\
b10 &, 439 &, 317 &, 189 &, 484 &, 378 &, 096 &, 310 &, 235 &, 309 &, 396 \\
c10 &, 223 &, 028 &, 126 &, 190 &, 687 &, 184 &, 049 &, 377 &, 301 &, 303 \\
d10 &, 218 &,- 226 &, 159 &, 047 &, 187 &,- 458 &, 068 &, 331 &,- 081 &,- 142 \\
\hline
\end{tabular}

Aunque las diez categorías en las que se agrupaban los ítems no coincidían completamente con nuestra sugerencia inicial, cabe destacar la existencia de numerosas semejanzas. Los bloques de ítems 1, 6, 7, 8 y 9 se ubicaban en la misma categoría, los bloques 4 y 5 se situaban en dos categorías distintas y solo los ítems de los bloques 2, 3 y 10 se ubicaban en tres categorías diferentes, no existiendo ningún caso en el que cada ítem de un mismo bloque se situara en una categoría distinta. Esta asociación no distaba mucho de la planteada inicialmente, pues los bloques 1, 6, 7 y 8 quedarían tal cual se sugirieron originalmente; el bloque 9 estaría formado por los cuatro ítems iniciales además de los ítems a1o y b10; el bloque 4 se formaría con tres de sus ítems iniciales, a4, $\mathrm{c}_{4}$ y $\mathrm{d}_{4}$, a los que se añadirían dos ítems del bloque anterior, b3 y c3; el bloque 2 se constituiría con dos de sus ítems iniciales, a2 y c2, y otros dos ítems, d3 y d10; el bloque 5 estaría formado tan solo por la mitad de sus ítems iniciales, $c_{5}$ y d 5 ; la otra mitad del bloque 5 , ítems a 5 y b5, se uniría a otros dos ítems, b2 y c10, para formar un nuevo bloque; y, finalmente, obtendríamos un último bloque como resultado de la combinación de varios ítems de diversos bloques, sus ítems serían a3, b4 y d2. Teniendo en cuenta estas semejanzas, consideramos apropiado no modificar la estructura organizativa de los ítems de la rúbrica inicial, puesto que no aumentaría la calidad de la misma ni aportaría beneficios en cuanto a su aplicación o análisis. Igualmente, esta situación mantendría la relación entre los bloques de la rúbrica y las competencias y resultados de aprendizaje de la guía docente anteriormente descrita. 
Tras revisar la bibliografía referente a las competencias profesionales docentes en el ámbito de la EF (Contreras, 2012; Sebastiani, 2007b), así como las posibilidades y beneficios didácticos que nos ofrecen las rúbricas en el proceso de evaluación (Salicetti et al., 2013; Wolf y Stevens, 2007), concluimos que la herramienta creada responde a las necesidades manifestadas al respecto por la literatura (Castejón, 2010, 2013; Guzmán y Marín, 2011; Lleixà et al., 2008; Moya, 2008). Asimismo, la rúbrica presenta una solidez estadística adecuada para ser utilizada como instrumento de medida de los conocimientos y competencias necesarios para el diseño y aplicación de sesiones de juegos motores y expresivos para niños en edad infantil, aunque nuevamente destacamos la posibilidad de utilizarla en otros contextos dada la importancia y utilidad del juego motor y expresivo en el ámbito de la EF. A continuación presentamos la rúbrica creada en el formato de uso empleado para la presente tesis, imagen 21 :

\begin{tabular}{|c|c|c|c|c|c|}
\hline \multicolumn{3}{|c|}{$\begin{array}{l}\text { Fundamentos de la expresión corporal; juegos motrices en educación infantil } \\
\text { NOMBRE: }\end{array}$} & \multicolumn{3}{|c|}{ DNI } \\
\hline $\begin{array}{l}\text { VALORACIÓN DEL SUPUESTO } \\
\text { PRÁCTICO }\end{array}$ & $\underset{1}{\text { Muy Mal }}$ & $\begin{array}{c}\text { Mal } \\
2\end{array}$ & $\underset{3}{\text { Regular }}$ & $\begin{array}{c}\text { Bien } \\
4\end{array}$ & $\underset{5}{\text { Muy Bien }}$ \\
\hline $\begin{array}{l}\text { 1.- Ajuste de los juegos al alumnado propuesto: } \\
\text { a1) Edad: } \\
\text { b1) Periodo: } \\
\text { c1) Necesidades educativas: } \\
\text { d1) Seguridad: }\end{array}$ & & . & & & - \\
\hline $\begin{array}{l}\text { 2.- Presentación: } \\
\text { a2) Descripción: } \\
\text { b2) Estructura: } \\
\text { c2) Comprensión de las normas: } \\
\text { d2) Representación gráfica: }\end{array}$ & & & & & \\
\hline $\begin{array}{l}\text { 3.- Organización del alumnado: } \\
\text { a3) Participación: } \\
\text { b3) Distribución de roles: } \\
\text { c3) Trabajo individual / grupal: } \\
\text { d3) Control del respeto por las normas: }\end{array}$ & & & & & \\
\hline $\begin{array}{l}\text { 4.- Organización del material: } \\
\text { a4) Uso del material: } \\
\text { b4) Variedad de material: } \\
\text { c4) Optimización: } \\
\text { d4) Distribución: }\end{array}$ & & & & & \\
\hline $\begin{array}{l}\text { 5.- Organización espaciotemporal: } \\
\text { a5) Optimización/adaptación temporal: } \\
\text { b5) Equilibrio temporal: } \\
\text { c5) Optimización/adaptación espacial: } \\
\text { d5) Equilibrio espacial: }\end{array}$ & & & & & \\
\hline $\begin{array}{l}\text { 6.- Adecuación curricular: } \\
\text { a6) Relación contenidos - objetivos: } \\
\text { b6) Consecución de los objetivos: } \\
\text { c6) Progresión: } \\
\text { d6) Valor educativo: }\end{array}$ & & & & & \\
\hline $\begin{array}{l}\text { 7.- Aspectos sociales: } \\
\text { a7) Atención a la diversidad: } \\
\text { b7) Transmisión de valores sociales: } \\
\text { c7) Normas de convivencia: } \\
\text { d7) Fomento de la cohesión-integración: }\end{array}$ & & & & & \\
\hline $\begin{array}{l}\text { 8.- Juegos motores: } \\
\text { a8) Desarrollo de la motricidad fina: } \\
\text { b8) Desarrollo de la motricidad gruesa: } \\
\text { c8) Desarrollo de la coordinación global: } \\
\text { d8) Desarrollo de la coordinación específica: }\end{array}$ & & & & & \\
\hline $\begin{array}{l}\text { 9.- Juegos de expresión corporal: } \\
\text { a9) Representación de roles: } \\
\text { b9) Simbolismo: } \\
\text { c9) Desarrollo de la expresión: } \\
\text { d9) Comunicación corporal: }\end{array}$ & & & & & \\
\hline $\begin{array}{l}\text { 10.- Otros: } \\
\text { a10) Carácter innovador y originalidad: } \\
\text { b10) Valor lúdico: } \\
\text { c10) Variedad de juegos: } \\
\text { d10) Evaluación de la propuesta: }\end{array}$ & & & & & \\
\hline
\end{tabular}

Imagen 21. Rubrica para valorar los conocimientos y competencias de la asignatura (Capella, Gil, Chiva y Martí, 2015). 


\subsubsection{Cuestionario sobre Emprendimiento Social}

Igual que en el caso anterior, en el proceso de diseño y validación del cuestionario para medir la competencia de ES se realizaron las siguientes acciones: (1) creación del cuestionario realizando una revisión lógica de validez de contenido, (2) aplicación en una prueba piloto y (3) revisión empírica del mismo con los datos obtenidos de su aplicación.

\section{- Creación del cuestionario sobre Emprendimiento Social}

Para la elaboración de este instrumento de medida partimos de la revisión bibliográfica mostrada en el marco teórico, en la que hemos acotado los 19 rasgos característicos que, a priori, caracterizan al emprendedor social: confianza, responsabilidad, liderazgo, organización, motivación al logro, capacidad para asumir riesgos, estar integrado en redes sociales con acceso a información y conocimiento, tolerancia, cooperación y ayuda, coherencia y compromiso, conciencia social, convivencia y respeto por el bien público, creatividad, iniciativa, capacidad para identificar oportunidades, capacidad para generar ideas, capacidad de cambio, capacidad para aprender y evolucionar y tolerancia al fracaso.

Tras definir estos aspectos, realizamos una búsqueda bibliográfica de cuestionarios ya existentes que los midieran. Entre los instrumentos encontrados podemos destacar los siguientes: cuestionario para medir la capacidad emprendedora (Kafati, 2012), Test de perfil emprendedor (Centros Europeos de Empresas Innovadoras, 2012), Entrepreneurial inclinations of prospective teachers (Ali, Topping y Tariq, 2009) y Entrepreneur attitude orientarion (Huefner, Hunt, y Robinson, 1996). Finalmente, para resaltar la importancia del componente social del emprendimiento, tuvimos en consideración el test AECS: Actitudes y Estrategias Cognitivas Sociales (Moraleda et al., 2004) en la parte dedicada a la prosocialidad, y el cuestionario de actitudes hacia la responsabilidad social (Alonso, 2004). De entre todos estos test, seleccionamos aquellos ítems que hacían referencia a alguno de los 19 rasgos característicos del emprendedor social descritos anteriormente, formando así el cuestionario inicial con 96 ítems sobre el que iniciaríamos el proceso de validación.

Aunque los ítems seleccionados provenían de instrumentos ya validados, consideramos necesario someterlos a un nuevo proceso de validación en el que se analizaran conjuntamente en este nuevo contexto. Así pues, para llegar al cuestionario piloto evaluamos la validez de contenido o validez lógica del cuestionario inicial a través de un juicio de expertos (Ding y Hershberger, 2002; González, Sánchez y Jornet, 2011). En la configuración de este grupo de 6 expertos se tuvieron en cuenta los criterios de Skjong y Wentworht (2001), destacando la experiencia e imparcialidad como factores más importantes. Para que el equipo de expertos valorara adecuadamente el cuestionario inicial, al seleccionarlos tuvimos en cuenta qué queríamos medir y dónde lo íbamos a aplicar tal como sugieren Escobar y Cuervo (2008). Por ello, ya que el cuestionario pretendía medir la competencia de ES y su aplicación se iba a llevar a cabo en el entorno educativo universitario, se formaron dos subgrupos de jueces. El primero estaba formado por un experto en ES con numerosas publicaciones y actividades al respecto, un miembro de diversas asociaciones de carácter social 
habituado al trato humano y solidario y un miembro de un equipo de formación para la inclusión y la participación social. El segundo subgrupo de jueces lo formaron tres docentes universitarios con experiencia en APS, formación e innovación docente y ES: un profesor titular, un contratado doctor y un profesor asociado.

Este juicio de expertos valoró la calidad, relevancia, comprensión y dimensión a la que debía asociarse cada ítem del cuestionario inicial. La calidad se valoraba en una escala de uno a tres donde uno correspondía a mucha calidad, dos a una calidad regular y tres a poca calidad. La relevancia se escalaba igualmente en uno (muy relevante), dos (relevante) y tres (nada relevante). La comprensión se valoró en fácil comprensión (uno), comprensión media (dos) y difícil comprensión (tres). Por último, en la dimensión asociada, los expertos debían relacionar cada ítem con la dimensión a la que consideraban que hacía referencia el mismo dentro de los aspectos propuestos que conforman el ES. Así pues, el formulario de valoración que se utilizó para la consulta a los jueces constaba de una primera parte que incluía las dimensiones, los aspectos a evaluar y los criterios de evaluación, y de una segunda parte que incluía el cuestionario inicial que constaba de 96 ítems, los cuales estaban repartidos en 19 dimensiones.

Para medir el nivel de acuerdo entre los jueces utilizamos el Coeficiente de Concordancia de Kendall (W), pues este coeficiente muestra el acuerdo o, mejor dicho, la concordancia entre los jueces en función del criterio consultado, en relación a todas las valoraciones de los ítems del instrumento. Esta prueba determina que los valores iguales o por debajo de 0,20 muestran una concordancia pobre, entre 0,21 y 0,40 débil, entre 0,41 y 0,60 moderada, entre o,61 y o,8o buena y entre 0,81 y 1 muy buena. Seguidamente presentamos los resultados obtenidos en las categorías de calidad, relevancia y comprensión, presentándolos en conjunto y por subgrupos de jueces (ver tabla 35). Como veremos más adelante, el aspecto sobre la dimensión a la que debía asociarse cada ítem se valoró a través de la moda por tratarse de datos nominales.

Tabla 35. Valoración de la calidad, relevancia y comprensión por grupos de jueces (elaboración propia).

\begin{tabular}{|lccc|}
\hline Criterio & $\begin{array}{c}\text { Todos los jueces W } \\
\text { de Kendall }\end{array}$ & $\begin{array}{c}\text { Subgrupo de jueces } \\
\text { Universitarios } \\
\text { W de Kendall }\end{array}$ & $\begin{array}{c}\text { Subgrupo de jueces } \\
\text { expertos en ES } \\
\text { W de Kendall }\end{array}$ \\
\hline Calidad &, 233 & 1391 & 1376 \\
Relevancia & 1313 & 1446 & 1444 \\
Comprensión &, 219 &, 408 &, 336 \\
\hline
\end{tabular}

El resultado de la W de Kendall para la valoración de la calidad determinó que existía acuerdo entre jueces y que este era débil pero significativo en todos los casos. En cuanto a la valoración de la relevancia, los datos indicaban que existía acuerdo entre jueces, siendo significativo en todos los casos, débil para el conjunto de todos los jueces y moderado en los subgrupos por separado. Respecto a la comprensión, la W de Kendall indicaba que había acuerdo entre jueces, de nuevo significativo en todos los casos, débil para todos los jueces y los expertos en ES y moderado para los 
jueces universitarios. Como también se observa en la tabla 35 , eran más concordantes los subgrupos de expertos entre sí que de forma conjunta. Esto podemos atribuirlo a la misma dualidad que le da sentido a la formación de estas agrupaciones, es decir, al tratar de conjugar la formación y la experiencia profesional de cada ámbito.

Tras analizar los datos aportados por el juicio de expertos se estableció un procedimiento para el filtrado de los ítems más apropiados en función de tres criterios. El primer criterio requería que la media de resultados debía ser menor o igual que 1,5, descartando todos los ítems con una media mayor. Esto se debe a que la escala priorizaba el 1 como el más importante y el 3 como el menos importante. Esta acción nos aseguraría que los ítems seleccionados tuvieran una elevada puntuación en los tres primeros aspectos valorados. El segundo criterio hacía referencia al coeficiente de variación, descartando todos aquellos ítems con registros superiores a un 37\%, ya que a partir de dicha cifra la distribución empieza a ser heterogénea. Esta acción nos garantizaría una distribución homogénea de los ítems seleccionados. Por último, el criterio utilizado para filtrar los ítems en cuanto a la dimensión asociada sería la moda. Así pues, se descartaron aquellos ítems que no tuvieran al menos un $50 \%$ de acuerdo en cuanto a la dimensión asociada a la que hacían referencia. Por ello, para seleccionar un ítem, al menos tres de los seis jueces tenían que asociarlo a la misma dimensión.

Tras el filtrado descrito pasamos de un cuestionario inicial de 96 ítems que representaba los 19 rasgos característicos del emprendedor social, distribuidos en tres grandes categorías, a un cuestionario piloto con tan sólo 30 ítems. Pese a la notable reducción de ítems, tan sólo se descartaron dos de los rasgos característicos planteados inicialmente, ya que ninguno de los ítems que hacían referencia a dichos aspectos superó los criterios de selección anteriormente descritos. El primer rasgo característico descartado fue la organización, perteneciente a la categoría de aspectos de carácter personal, mientras que el segundo fue la tolerancia, ubicado en la categoría de aspectos de carácter social. Cabe destacar que la distribución de los 30 ítems seleccionados era muy equilibrada, ya que cinco aspectos estaban representados por un solo ítem, otro aspecto estaba representado por tres ítems y los once aspectos restantes estaban representados por dos ítems cada uno. En la tabla 36 mostramos la relación de ítems seleccionados en función de las distintas categorías y aspectos a los que se asocian.

Tabla 36. Ítems del cuestionario en función de las categorías de agrupación (elaboración propia).

\begin{tabular}{|c|c|c|}
\hline CATEGORÍA & ASPECTO & ÍTEMS \\
\hline \multirow{3}{*}{$\begin{array}{r}\text { Aspectos } \\
\text { de carácter } \\
\text { personal }\end{array}$} & Liderazgo & $\begin{array}{l}\text { i1) Me gusta trabajar con un equipo de personas a las que coordinar } \\
\text { i2) Cuando se trabaja en grupo, prefiero ser el/la líder }\end{array}$ \\
\hline & Motivación al logro & $\begin{array}{l}\text { i3) Soy una persona decidida a lograr mis objetivos } \\
\text { ig) Me considero autosuficiente para poder conseguir lo que me } \\
\text { propongo }\end{array}$ \\
\hline & $\begin{array}{r}\text { Capacidad de } \\
\text { asumir riesgos }\end{array}$ & $\begin{array}{l}\text { i4) Pienso que es necesario arriesgarme para progresar } \\
\text { i5) Creo que las personas que se arriesgan tienen más } \\
\text { probabilidades de tener éxito que las que no lo hacen } \\
\text { i6) Me qusta tomar riesaos calculados con las nuevas ideas }\end{array}$ \\
\hline
\end{tabular}




\begin{tabular}{|c|c|c|}
\hline & Confianza & $\begin{array}{l}\text { i7) Me veo capacitado/a para enfrentarme a la mayoría de } \\
\text { situaciones } \\
\text { i8) Creo en mis posibilidades }\end{array}$ \\
\hline & Responsabilidad & $\begin{array}{l}\text { i10) Asumo las consecuencias de lo que he dicho o hecho } \\
\text { i11) Hago cada trabajo tan a fondo como sea posible }\end{array}$ \\
\hline & $\begin{array}{r}\text { Integrado en redes } \\
\text { sociales con acceso } \\
\text { a información y } \\
\text { conocimiento }\end{array}$ & $\begin{array}{l}\text { i12) Prefiero trabajar con más personas } \\
\text { i13) Tengo acceso a información de apoyo para comenzar a } \\
\text { emprender proyectos }\end{array}$ \\
\hline \multirow{4}{*}{$\begin{array}{r}\text { Aspectos } \\
\text { de carácter } \\
\text { social }\end{array}$} & Conciencia social & $\begin{array}{l}\text { i14) Me encantaría colaborar gratuitamente en una O.N.G. } \\
\text { i16) Las personas que ayudan a los demás son un ejemplo a seguir }\end{array}$ \\
\hline & $\begin{array}{r}\text { Cooperación- } \\
\text { Ayuda }\end{array}$ & i15) Me gusta ayudar a mis amigos de clase/trabajo \\
\hline & $\begin{array}{l}\text { Coherencia y } \\
\text { compromiso }\end{array}$ & $\begin{array}{l}\text { i17) Por lo general cumplo muy bien con mi parte en cualquier } \\
\text { proyecto en el que estoy involucrado/a }\end{array}$ \\
\hline & $\begin{array}{r}\text { Convivencia y } \\
\text { respeto por el bien } \\
\text { público }\end{array}$ & i18) Los problemas de convivencia se solucionan dialogando \\
\hline \multirow{7}{*}{$\begin{array}{l}\text { Aspectos } \\
\text { de carácter } \\
\text { innovador }\end{array}$} & Creatividad & $\begin{array}{l}\text { i19) Consigo hacer las cosas de manera imaginativa y diferente a } \\
\text { como lo hacen otras personas } \\
\text { i20) Veo nuevas utilidades en objetos comunes }\end{array}$ \\
\hline & $\begin{array}{r}\text { Capacidad para } \\
\text { identificar } \\
\text { oportunidades }\end{array}$ & i21) Puedo crear oportunidades y aprovecharlas \\
\hline & Iniciativa & $\begin{array}{l}\text { i22) He intervenido alguna vez en la puesta en marcha de proyectos } \\
\text { de grupo o asociaciones } \\
\text { i23) He considerado seriamente iniciar mi propio negocio después } \\
\text { de graduarme }\end{array}$ \\
\hline & $\begin{array}{r}\text { Capacidad para } \\
\text { generar ideas }\end{array}$ & $\begin{array}{l}\text { i24) Soy capaz de formular sugerencias para mejorar los proyectos } \\
\text { en los que participo } \\
\text { i25) Disfruto encontrando buenas soluciones a los problemas que } \\
\text { nadie ha resuelto todavía }\end{array}$ \\
\hline & $\begin{array}{r}\text { Capacidad de } \\
\text { cambio }\end{array}$ & $\begin{array}{l}\text { i26) Cuando los planes se cambian improviso sin dificultad } \\
\text { i27) Soy bueno/a manejando situaciones imprevistas }\end{array}$ \\
\hline & $\begin{array}{r}\text { Capacidad para } \\
\text { aprendery } \\
\text { evolucionar }\end{array}$ & $\begin{array}{l}\text { i28) Busco siempre el lado positivo en una situación mala } \\
\text { i29) Analizo mis errores para aprender de ellos }\end{array}$ \\
\hline & $\begin{array}{r}\text { Tolerancia al } \\
\text { Fracaso }\end{array}$ & $\begin{array}{l}\text { izo) Pienso que se pueden extraer oportunidades de los problemas o } \\
\text { situaciones difíciles }\end{array}$ \\
\hline
\end{tabular}

Para finalizar el proceso de diseño de este cuestionario determinamos los distintos niveles de respuesta adjuntando una escala de valoración de tipo Likert de 1 a 5 . Así pues, las posibles respuestas eran 1 muy en desacuerdo, 2 en desacuerdo, 3 indeciso, 4 de acuerdo y 5 muy de acuerdo.

\section{- Aplicación del cuestionario sobre Emprendimiento Social mediante una prueba piloto}

Una vez definido el cuestionario piloto realizamos una aplicación del mismo con una muestra de 188 sujetos. Para valorar adecuadamente la muestra debemos tener en consideración que el presente cuestionario pretendía medir los efectos del APS sobre el alumnado universitario en cuanto a su competencia de ES en la realización de actividades pertenecientes al ámbito de la EF. 
Por ello, la muestra debía haber participado en actividades de este carácter, por lo que nos remitimos al colectivo de alumnos del curso anterior. Con ello, aseguramos la similitud de la muestra de esta aplicación del cuestionario piloto con los participantes de nuestra investigación. Así pues, la muestra de esta prueba piloto estaba formada por un colectivo de 188 sujetos pertenecientes al Grado en Maestro/a de Educación Infantil, que habían participado en programas de APS relacionados con la EF en sus primeros años de formación. Por tanto el muestreo fue de tipo no probabilístico incidental.

\section{- Revisión empírica del cuestionario con los resultados de la prueba piloto}

Una vez realizada la aplicación del cuestionario, recogimos los datos resultantes para realizar el análisis estadístico de los mismos utilizando el paquete estadístico SPSS versión 21. En la tabla 51 del anexo mostramos los estadísticos descriptivos que nos permiten conocer en profundidad los datos registrados. Los datos revelan que el registro más bajo para la media era 2,63 puntos (ítem 2) y el más alto 4,64 puntos (ítem 16), obteniendo una media total de 3,82 puntos, como podemos ver en el gráfico 2. En él presentamos el histograma con la distribución de los sujetos según los registros obtenidos. Estos datos ponen de manifiesto los elevados registros obtenidos al pasar el cuestionario.

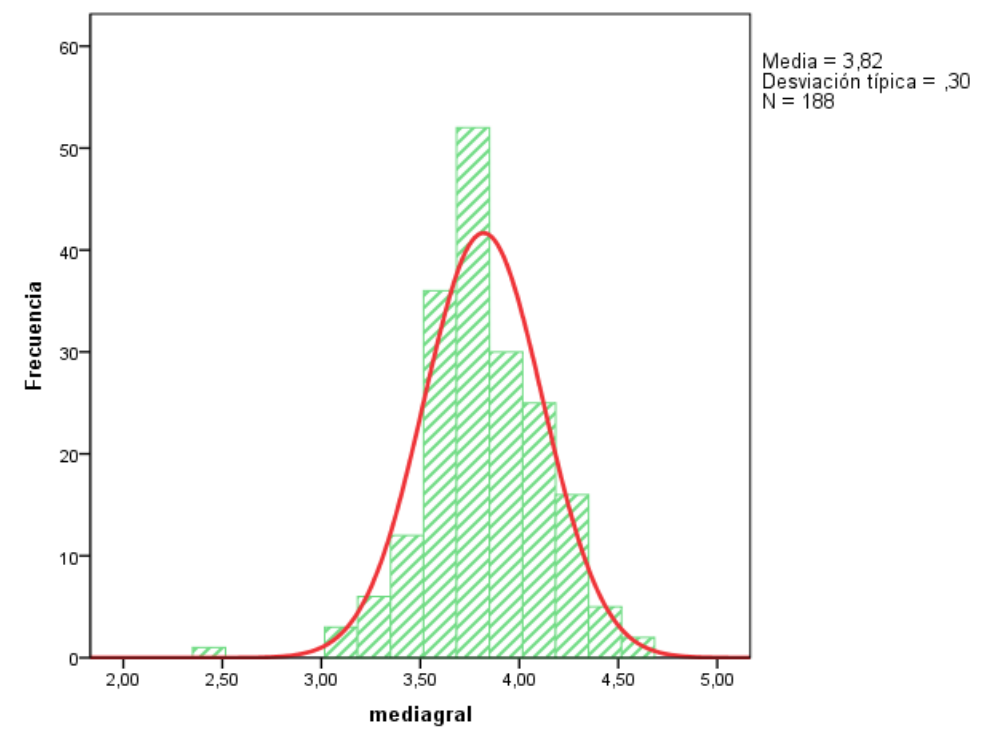

Gráfico 2. Histograma de la prueba piloto del cuestionario (elaboración propia).

Como en el caso anterior, utilizamos el Alfa de Cronbach para valorar la fiabilidad del instrumento de medida. El resultado en esta prueba fue de 0,809 (ver tabla 37), asegurando la buena solidez interna del cuestionario por encima del valor 0,7 que determina la aceptación de la confiabilidad de la prueba (George y Mallery, 2014). 
Tabla 37. Estadísticos de fiabilidad de la prueba piloto del cuestionario (elaboración propia).

\begin{tabular}{|ccc|}
\hline Alfa de Cronbach & $\begin{array}{c}\text { Alfa de Cronbach basada en } \\
\text { los elementos tipificados }\end{array}$ & N de elementos \\
\hline, 809 &, 836 & 30 \\
\hline
\end{tabular}

Posteriormente se comprobó que el Alfa de la escala en general no mejoraba significativamente si se eliminaba alguno de los ítems. Así pues, se puede apreciar que todos los ítems eran importantes para valorar la competencia de ES y que el cuestionario creado permitía medir dicha competencia (tabla 52 del anexo).

Respecto al análisis factorial, el resultado para la medida de adecuación muestral de KMO fue de 0,754 y el registro de la prueba de esfericidad de Bartlett de $p=0,000$; es decir, al obtenerse un registro superior a 0,6 e inferior a 0,05 respectivamente, se demostró que existían correlaciones internas significativas en las respuestas de la aplicación del cuestionario (ver tabla 38).

Tabla 38. Kaiser-Meyer-Olkin y prueba de Bartlett (elaboración propia).

\begin{tabular}{|lrr|}
\hline Medida de adecuación muestral de Kaiser-Meyer-Olkin. &, 754 \\
& Chi-cuadrado aproximado & 1795,329 \\
Prueba de esfericidad de Bartlett & gl & 435 \\
& Sig. &, 000 \\
\hline
\end{tabular}

En cuanto a la extracción de factores comunes, en la tabla 53 del anexo vemos que los ítems se agrupaban en tres categorías, algo que concuerda con nuestro planteamiento teórico inicial. Asimismo, esta agrupación explicaba el 34,93\% de la varianza acumulada. Este análisis nos permitió observar la estructura interna del cuestionario, identificando las categorías en las que se agrupaban los ítems. A continuación, mostramos el análisis de componentes principales con rotación de normalización Oblimin con Kaiser, donde podemos ver los ítems que saturaban en cada categoría (resaltados en color azul), tabla 39.

Tabla 39. Análisis factorial de los resultados de la aplicación del cuestionario. Matriz de estructura (elaboración propia).

\begin{tabular}{|cccc|}
\hline Ítem & \multicolumn{3}{c|}{ Componente } \\
& $\mathbf{1}$ & $\mathbf{2}$ & $\mathbf{3}$ \\
\hline i1 &, 426 &, 079 &,- 064 \\
i2 &, 259 &, 159 &,- 186 \\
i3 &, 334 &,- 132 &,- 720 \\
i4 &, 245 &,- 034 &,- 635 \\
i5 &, 247 &,- 167 &,- 363 \\
i6 &, 224 &, 009 &,- 587 \\
i7 &, 212 &, 257 &,- 714 \\
\hline
\end{tabular}




\begin{tabular}{|llll|} 
i8 &, 183 &, 200 &,- 704 \\
i9 &, 194 &, 287 &,- 746 \\
i10 &, 560 &, 017 &,- 426 \\
i11 &, 496 &,- 083 &,- 232 \\
i12 &, 291 &, 221 &, 134 \\
i13 &, 215 &, 341 &,- 046 \\
i14 &, 298 &, 019 &,- 160 \\
i15 &, 653 &,- 081 &,- 252 \\
i16 &, 568 &,- 358 &,- 147 \\
i17 &, 578 &, 000 &,- 365 \\
i18 &, 638 &,- 179 &,- 167 \\
i19 &, 524 &, 262 &,- 215 \\
i20 &, 443 &, 548 &, 099 \\
i21 &, 379 &, 537 &,- 206 \\
i22 &,- 091 &, 508 &, 066 \\
i23 &,- 140 &, 270 &, 130 \\
i24 &, 563 &, 068 &,- 058 \\
i25 &, 519 &, 127 &,- 182 \\
i26 &, 164 &, 559 &,- 307 \\
i27 &, 178 &, 631 &,- 321 \\
i28 &, 165 &, 443 &,- 347 \\
i29 &, 560 &, 189 &,- 201 \\
i30 &, 534 &, 213 &,- 258 \\
\hline
\end{tabular}

Como podemos apreciar, las tres categorías en las que se agrupaban los ítems no coincidían completamente con las planteadas de inicio. La nueva categoría 1 presentaba una mezcla de las categorías 1 y 2 iniciales, la categoría 2 actual se asemejaba mucho a la anterior categoría 3 y, finalmente, la nueva categoría 3 incorporaba tres de los rasgos ubicados inicialmente en la categoría 1. Por tanto, esta nueva clasificación no distaba mucho de la propuesta inicialmente, por lo que consideramos que podía deberse a cuestiones meramente terminológicas o de interpretación de los rasgos característicos analizados. Por ello, consideramos apropiado no modificar la organización de los ítems del cuestionario inicial, puesto que esto no aumentaría la calidad del mismo ni aportaría beneficios en cuanto a su posterior aplicación o análisis.

Después de revisar la bibliografía referente al ES, consideramos que el cuestionario creado responde a las necesidades manifestadas por la literatura en esta cuestión, pues recoge la totalidad de los rasgos del emprendedor social definidos por autores como Bacq y Janssen (2011), Choi y Majumdar (2014), Weerawardena y Mort (2006) y Haugh (2005). Por ello, tras el proceso de elaboración expuesto, concluimos que el cuestionario presenta una solidez estadística adecuada para ser utilizado como instrumento de medida del ES mediante la aplicación de programas de APS con alumnado universitario en el ámbito de la EF, contexto de nuestra investigación. No obstante, considerando los datos obtenidos y la fundamentación teórica del mismo, creemos que también podría ser útil para medir el ES en diferentes entornos sociales, con otro tipo de colectivos y mediante otras actuaciones pedagógicas. A continuación presentamos el cuestionario creado en el formato de uso empleado para la presente tesis, imagen 22: 


A continuación vas a encontrar una serie de frases que hacen referencia al emprendimiento soc
\begin{tabular}{|lll|}
\hline $\mathbf{1}$ si con lo que dice la frase estás & MUY EN DESACUERDO \\
$\mathbf{2}$ si con lo que dice la frase estás & EN DESACUERDO \\
$\mathbf{3}$ si con lo que dice la frase estás & INDECISO \\
$\mathbf{4}$ si con lo que dice la frase estás & DE ACUERDO \\
$\mathbf{5}$ si con lo que dice la frase estás & MUY DE ACUERDO
\end{tabular}

Por favor, contesta a todas ellas aunque en alguno de los casos te resulte difícil. Señala con una cruz la respuesta que corresponda. Gracias por tu colaboración.

\begin{tabular}{|c|c|c|c|c|c|c|}
\hline & & 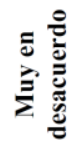 & 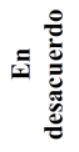 & 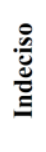 & 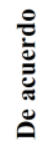 & 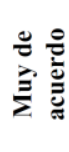 \\
\hline 1 & Me gusta trabajar con un equipo de personas a las que coordinar. & 1 & 2 & 3 & 4 & 5 \\
\hline 2 & Cuando se trabaja en grupo, prefiero ser el/la líder. & 1 & 2 & 3 & 4 & 5 \\
\hline 3 & Soy una persona decidida a lograr mis objetivos. & 1 & 2 & 3 & 4 & 5 \\
\hline 4 & Pienso que es necesario arriesgarme para progresar. & 1 & 2 & 3 & 4 & 5 \\
\hline 5 & $\begin{array}{l}\text { Creo que las personas que se arriesgan tienen más probabilidades } \\
\text { de tener éxito que las que no lo hacen. }\end{array}$ & 1 & 2 & 3 & 4 & 5 \\
\hline 6 & Me gusta tomar riesgos calculados con las nuevas ideas. & 1 & 2 & 3 & 4 & 5 \\
\hline 7 & $\begin{array}{l}\text { Me veo capacitado/a para enfrentarme a la mayoría de } \\
\text { situaciones. }\end{array}$ & 1 & 2 & 3 & 4 & 5 \\
\hline 8 & Creo en mis posibilidades. & 1 & 2 & 3 & 4 & 5 \\
\hline 9 & $\begin{array}{l}\text { Me considero autosuficiente para poder conseguir lo que me } \\
\text { propongo. }\end{array}$ & 1 & 2 & 3 & 4 & 5 \\
\hline 10 & Asumo las consecuencias de lo que he dicho o hecho. & 1 & 2 & 3 & 4 & 5 \\
\hline 11 & Hago cada trabajo tan a fondo como sea posible. & 1 & 2 & 3 & 4 & 5 \\
\hline 12 & Prefiero trabajar con más personas. & 1 & 2 & 3 & 4 & 5 \\
\hline 13 & $\begin{array}{l}\text { Tengo acceso a información de apoyo para comenzar a } \\
\text { emprender proyectos. }\end{array}$ & 1 & 2 & 3 & 4 & 5 \\
\hline 14 & Me encantaría colaborar gratuitamente en una O.N.G. & 1 & 2 & 3 & 4 & 5 \\
\hline 15 & Me gusta ayudar a mis amigos de clase/trabajo. & 1 & 2 & 3 & 4 & 5 \\
\hline 16 & Las personas que ayudan a los demás son un ejemplo a seguir. & 1 & 2 & 3 & 4 & 5 \\
\hline 17 & $\begin{array}{l}\text { Por lo general cumplo muy bien con mi parte en cualquier } \\
\text { proyecto en el que estoy involucrado/a. }\end{array}$ & 1 & 2 & 3 & 4 & 5 \\
\hline 18 & Los problemas de convivencia se solucionan dialogando. & 1 & 2 & 3 & 4 & 5 \\
\hline 19 & $\begin{array}{l}\text { Consigo hacer las cosas de manera imaginativa y diferente a } \\
\text { como lo hacen otras personas. }\end{array}$ & 1 & 2 & 3 & 4 & 5 \\
\hline 20 & Veo nuevas utilidades en objetos comunes. & 1 & 2 & 3 & 4 & 5 \\
\hline 21 & Puedo crear oportunidades y aprovecharlas. & 1 & 2 & 3 & 4 & 5 \\
\hline 22 & $\begin{array}{l}\text { He intervenido alguna vez en la puesta en marcha de proyectos } \\
\text { de grupo o asociaciones. }\end{array}$ & 1 & 2 & 3 & 4 & 5 \\
\hline 23 & $\begin{array}{l}\text { He considerado seriamente iniciar mi propio negocio después de } \\
\text { graduarme. }\end{array}$ & 1 & 2 & 3 & 4 & 5 \\
\hline 24 & $\begin{array}{l}\text { Soy capaz de formular sugerencias para mejorar los proyectos en } \\
\text { los que participo. }\end{array}$ & 1 & 2 & 3 & 4 & 5 \\
\hline 25 & $\begin{array}{l}\text { Disfruto encontrando buenas soluciones a los problemas que } \\
\text { nadie ha resuelto todavía. }\end{array}$ & 1 & 2 & 3 & 4 & 5 \\
\hline 26 & Cuando los planes se cambian improviso sin dificultad. & 1 & 2 & 3 & 4 & 5 \\
\hline 27 & Soy bueno/a manejando situaciones imprevistas & 1 & 2 & 3 & 4 & 5 \\
\hline 28 & Busco siempre el lado positivo en una situación mala. & 1 & 2 & 3 & 4 & 5 \\
\hline 29 & Analizo mis errores para aprender de ellos. & 1 & 2 & 3 & 4 & 5 \\
\hline 30 & $\begin{array}{l}\text { Pienso que se pueden extraer oportunidades de los problemas o } \\
\text { situaciones dificiles. }\end{array}$ & 1 & 2 & 3 & 4 & 5 \\
\hline
\end{tabular}

Imagen 22. Cuestionario sobre la Competencia de Emprendimiento Social (CCES) (Capella et al., en prensa). 


\subsubsection{Recogida de datos cualitativos}

Para extraer los datos cualitativos de nuestra investigación analizamos el contenido de entrevistas personales realizadas con el alumnado. Para ello, utilizamos la metodología de investigación cualitativa de las Historias de Vida, siguiendo las indicaciones expuestas en el marco teórico de este trabajo. A continuación, exponemos las indicaciones previas facilitadas al alumnado en cuanto a la realización de estas entrevistas:

- La entrevista era abierta, por lo que no tenía preguntas preparadas, aunque sí se podían hacer preguntas para recuperar o ampliar la información sobre cualquier comentario o aspecto.

- El alumnado debía preparar la entrevista como una historia contada a un amigo, familiar o alguien conocido. Todo aquello que prepararan podría ser utilizado durante la entrevista: guías, reflexiones, comentarios, recordatorios, etc.

- La entrevista debía elaborarse siguiendo dos ejes principales, aspectos académicos y personales, expresando en ambos casos sus aprendizajes, resultados, habilidades, experiencias, etc. Con ello pretendíamos recabar información sobre los dos objetivos fundamentales de la investigación, el desarrollo de contenidos académicos y la competencia de ES del alumnado.

- Aparte de estos dos ejes principales, se debían aportar dos nuevos matices: información contextual que facilitara la comprensión de sus cometarios y otros aprendizajes, sugerencias, opiniones, críticas, etc., que consideraran importantes.

- La entrevista debía intentar organizarse en orden cronológico: planteamiento, inicio, sesiones de preparación, contacto con el centro, inicio del servicio, coordinación con los compañeros, finalización, etc.

- Los entrevistados no debían preocuparse si se hacían anotaciones o se escribía durante la entrevista ya que, en caso de hacerlo, era para seguir el hilo de los comentarios y recordar lo importante por si era necesario retomar algún tema.

Tras exponer estas indicaciones, se plantearon y resolvieron las posibles dudas existentes sobre la realización de las entrevistas. Igualmente, se solicitó una autorización para realizarlas y grabarlas en formato de audio y video. En este punto se insistió en el hecho de que el objetivo de estas grabaciones era meramente investigador y que primaría en todo momento el derecho a la intimidad de todos los participantes. Seguidamente aportamos una de estas autorizaciones, imagen 23: 


\begin{abstract}
D. $/ \mathrm{D}^{\mathrm{a}}$. marta
D.N.I.

CONSIENTO voluntariamente a participar en la entrevista de investigación sobre las actividades de Aprendizaje Servicio llevadas a cabo durante el curso 2013-2014 en el marco de la asignatura MI 1019 Fundamentos de la expresión corporal: juegos motrices en Educación Infantil, perteneciente al $2^{\circ}$ curso del grado de Magisterio Infantil de la Universitad Jaume I de Castellón. Dicha entrevista será registrada en formato de audio y video.

AUTORIZO a los miembros del grupo de investigación ENDAVANT de la Universitat Jaume I de Castellón a utilizar la información recabada en dicha entrevista tanto para su trabajo académico como para posibles publicaciones en el ámbito educativo. El grupo de investigación velará, en todo momento, por respetar el derecho a la propia imagen reconocido en el artículo 18 de la Constitución Española y regulado por la Ley 1/1982 de 5 de Mayo, sobre el derecho al honor, a la intimidad personal y familiar, y a la propia imagen; y la Ley 15/1999 de 13 de diciembre, sobre Protección de Datos de Carácter Personal.
\end{abstract}

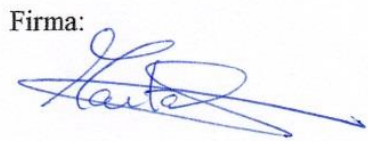

Imagen 23. Autorización para realizar y grabar las entrevistas (elaboración propia).

Una vez registradas las entrevistas en formato de audio y video, procedimos a la transcripción de las mismas para poder analizar su contenido y extraer los resultados pertinentes. Como veremos más adelante, el proceso de análisis de los datos extraídos se llevó a cabo utilizando el programa informático NVivo 10. En el próximo capítulo mostramos y analizamos ampliamente estos resultados.

\title{
5.7. Selección y descripción de la muestra
}

La selección de la muestra participante en la investigación corresponde a un grupo natural, es decir, ya existente como tal. Este colectivo constituía el grupo-clase de segundo curso del Grado en Maestro o Maestra de Educación Infantil, del curso académico 2013/2014, en la asignatura "Fundamentos de la Expresión Corporal, Juegos motores en Educación Infantil". Por tanto el muestreo fue de tipo no probabilístico incidental.

En esta investigación han participado un total de 173 alumnos. La muestra total se distribuye de la siguiente manera: 16,2\% $(n=28)$ Grupo Experimental I, 39,3\% $(n=68)$ Grupo Experimental II y 
$44,5 \%(n=77)$ Grupo Control. Además, se recogieron datos socio-demográficos de la muestra para tener un mayor conocimiento de sus características en función de los siguientes parámetros: sexo, edad, participación en actividades de voluntariado o pertenencia a asociaciones U ONG's, formación y experiencia docente previa.

En la tabla 40 podemos ver la distribución de los distintos grupos en función del sexo. Estos datos se ven reflejados en el gráfico 3, donde vemos la composición de cada grupo:

Tabla 40. Distribución de los grupos en función del sexo (elaboración propia).

\begin{tabular}{|lccc|}
\hline SEXO & GRUPO EXPERIMENTAL I & GRUPO EXPERIMENTAL II & GRUPO CONTROL \\
\hline Hombre & 1 & 0 & 2 \\
Mujer & 27 & 59 & 66 \\
\hline
\end{tabular}

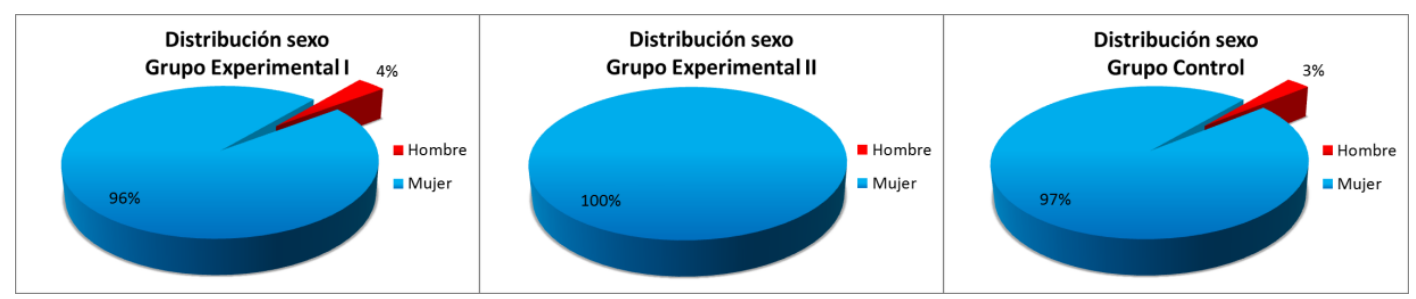

Gráfico 3. Composición de los grupos en función del sexo (elaboración propia).

Como podemos apreciar hay una enorme diferencia entre el número de hombres y mujeres en todos los grupos participantes. Así pues, vemos que prácticamente la totalidad de la muestra está formada por mujeres, un $98 \%$ del total, mientras que la representación de los hombres es muy minoritaria, un $2 \%$ del total. Esta distribución es bastante similar en todos los grupos del estudio.

Seguidamente, en la tabla 41, presentamos la distribución de la muestra de los distintos grupos en base a la edad de los participantes. Con estos datos se configura el gráfico 4, el cual muestra la composición de cada grupo en función de este parámetro.

Tabla 41. Distribución de los grupos en función de la edad (elaboración propia).

\begin{tabular}{|cccc|}
\hline EDAD & GRUPO EXPERIMENTAL I & GRUPO EXPERIMENTAL II & GRUPO CONTROL \\
\hline $\mathbf{1 8}$ & 4 & 5 & 10 \\
$\mathbf{1 9}$ & 7 & 20 & 21 \\
$\mathbf{2 0}$ & 4 & 9 & 5 \\
$\mathbf{2 1}$ & 2 & 7 & 6 \\
$\mathbf{2 2}$ & 5 & 6 & 12 \\
$\mathbf{2 3}$ & 5 & 6 & 3 \\
$\mathbf{2 4}$ & 2 & 2 & 2 \\
$\mathbf{2 5}$ & 1 & 1 & 2 \\
$\mathbf{2 6}$ & 0 & 1 & 3
\end{tabular}




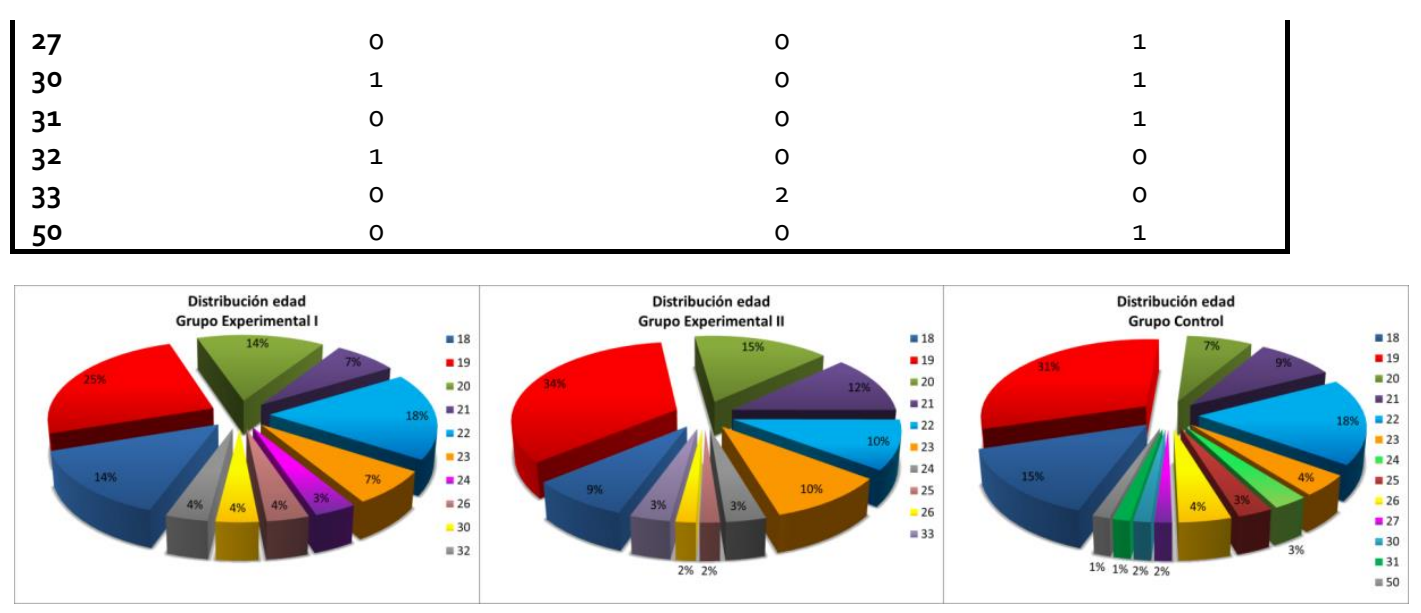

Gráfico 4. Composición de los grupos en función de la edad (elaboración propia).

Como se puede comprobar, la distribución del alumnado en función de la edad es más variable. No obstante, gran parte del alumnado se sitúa entre los 18-19 años, un 43\% del total. También se distinguen otros dos grupos destacables entre los 20-21 y los 22-23 años, con un 22\% del total de participantes respectivamente. Por último, tan solo el 13\% de los integrantes en el estudio tenía 24 años o más. Al igual que en el caso anterior, esta distribución era muy similar a la de todos los grupos de trabajo.

A continuación vemos la participación de los miembros de cada grupo en actividades de voluntariado o colaboración con ONG's, tabla 42 y gráfico 5 .

Tabla 42. Distribución de los grupos en función de su participación en actividades de ONG-voluntariado (elaboración propia).

\begin{tabular}{|lccc|}
\hline PARTICIPACIÓN & GRUPO EXPERIMENTAL I & GRUPO EXPERIMENTAL II & GRUPO CONTROL \\
\hline $\mathrm{Si}$ & 5 & 14 & 16 \\
$\mathrm{No}$ & 23 & 45 & 52 \\
\hline
\end{tabular}

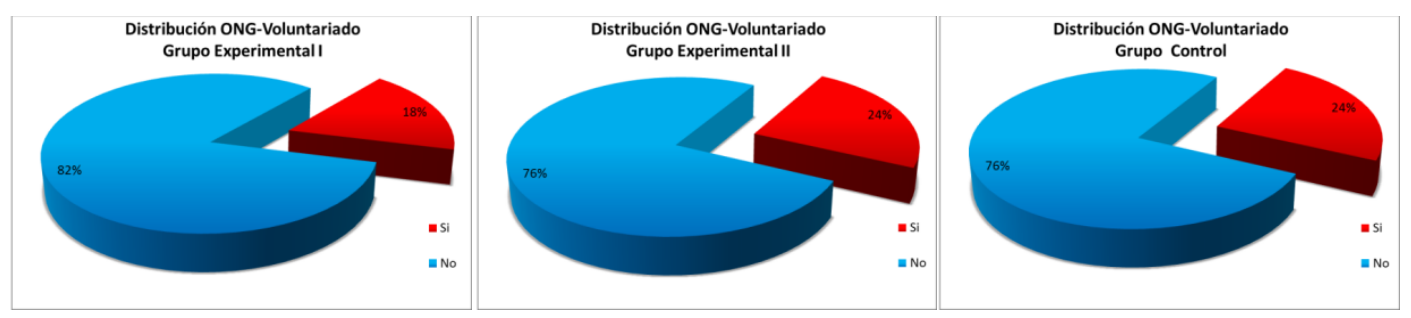

Gráfico 5. Composición de los grupos en función de su participación en actividades de ONG-voluntariado (elaboración propia). 
Esta información nos ayuda a comprender que gran parte de la muestra no había participado previamente en actividades de voluntariado ni había colaborado con ONG's, un $77 \%$ del total de la muestra. Solo el $23 \%$ de los participantes habían realizado alguna de estas tareas. Una vez más, observamos cómo esta distribución es muy similar en los tres grupos objeto de estudio.

En este caso mostramos los distintos niveles de formación de los alumnos participantes en el estudio, tabla 43 y gráfico 6 :

Tabla 43. Distribución de los grupos en función de su nivel de formación (elaboración propia).

\begin{tabular}{|lccc|}
\hline NIVEL DE FORMACIÓN & GRUPO EXPERIMENTAL I & GRUPO EXPERIMENTAL II & GRUPO CONTROL \\
\hline Bachiller & 12 & 31 & 37 \\
Formación Profesional & 8 & 9 & 10 \\
Bachiller y Formación & 7 & 18 & 18 \\
Profesional & 1 & 1 & 3 \\
Titulación Universitaria & & & 3 \\
\hline
\end{tabular}

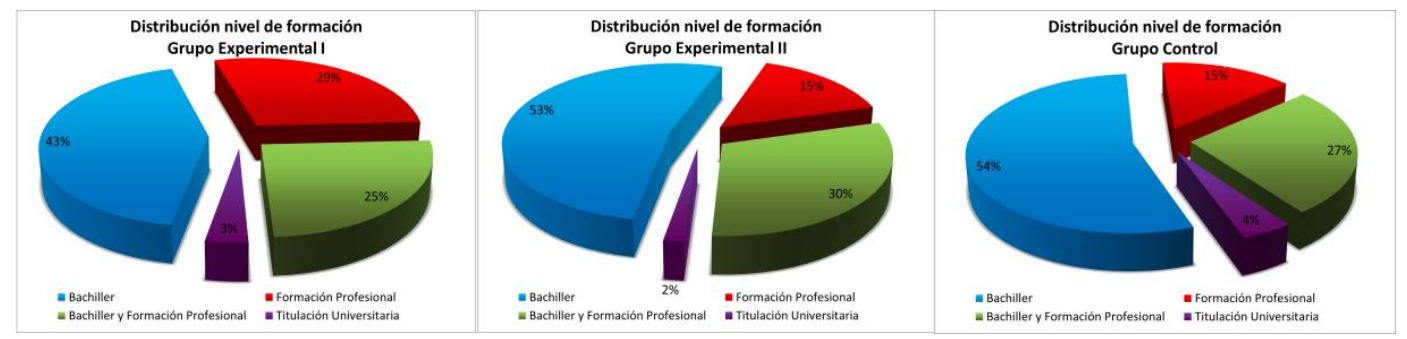

Gráfico 6. Composición de los grupos en función de su nivel de formación (elaboración propia).

Este gráfico nos permite ver que el $52 \%$ de los alumnos tenía el título de bachiller, el $17 \%$ era titulado en formación profesional y un $28 \%$ poseía ambas titulaciones. Solo el $3 \%$ de los participantes eran titulados universitarios. Esta tendencia global se mantiene en los Grupos Experimental II y Control; en cambio, en el Grupo Experimental I hay una mayor presencia de alumnos con titulaciones de formación profesional en detrimento de la titulación de bachiller.

Finalmente, también se recogió información sobre la experiencia docente de la muestra. Así pues, en la tabla 44 y el gráfico 7 comprobamos la experiencia docente previa de los participantes en esta investigación:

Tabla 44. Distribución de los grupos en función de su experiencia docente previa (elaboración propia).

\begin{tabular}{|lccc|}
\hline EXPERIENCIA & GRUPO EXPERIMENTAL I & GRUPO EXPERIMENTAL II & GRUPO CONTROL \\
DOCENTE PREVIA & GRO \\
\hline Si & 16 & 31 & 31 \\
No & 12 & 28 & 37 \\
\hline
\end{tabular}




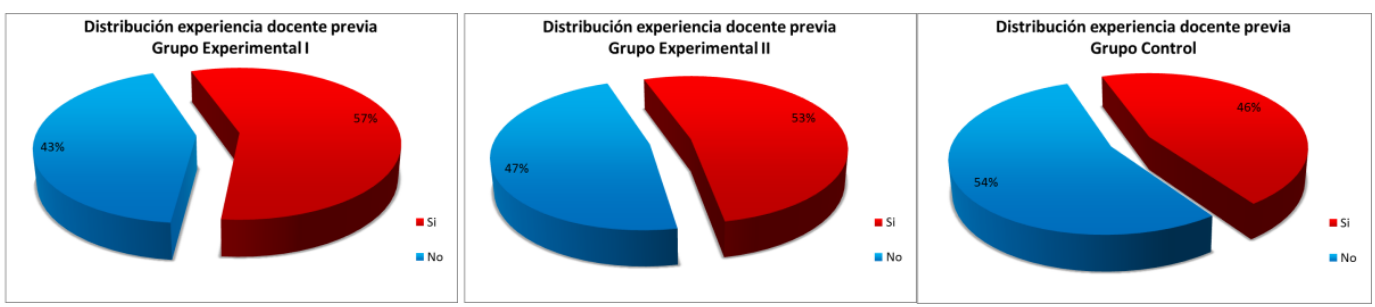

Gráfico 7. Composición de los grupos en función de su experiencia docente previa (elaboración propia).

En este caso la muestra está dividida a partes iguales con cerca de un $50 \%$ del total de los participantes entre las dos respuestas posibles. Esta situación se refleja de forma similar en los tres grupos objeto de estudio, con una ligera predominancia de aquellos que sí tienen experiencia docente previa en los Grupos Experimentales I y II, y a favor de aquellos que no la tienen en el Grupo Control.

Con todo esto podemos considerar que el alumno tipo de este estudio es una mujer de $21,15 \pm$ 3,79 años de edad, que no ha participado anteriormente en actividades de voluntariado o colaborado con ninguna ONG, con el título de bachiller y sin una tendencia definida en cuanto a experiencias docentes previas. Este alumno tipo responde a la realidad de las aulas del Grado en Maestro o Maestra en Educación Infantil, por lo que es una muestra representativa de esta población.

\subsection{Diagnóstico inicial}

En este apartado pretendemos establecer el punto de partida de nuestra investigación. Esto nos permitirá anticipar algunas variables o factores que puedan incidir en los resultados de nuestro trabajo.

\subsubsection{Variables contextuales}

Estas variables pretenden describir el entorno en el que vamos a intervenir, determinando las condiciones objetivas que afectarán a la aplicación del programa educativo propuesto. Considerando las diversas entidades colaboradoras con las que debía coordinarse el alumnado, la cantidad de miembros de los Grupos Experimentales I y II, la diversidad de horarios en la prestación del servicio y el número de receptores del mismo, es fácil intuir que la logística de esta propuesta formativa fue notablemente compleja. Como hemos visto en el capítulo anterior, en la aplicación del programa educativo colaboramos con 5 entidades, 96 alumnos universitarios participaron en el programa de APS descrito, el horario de las actividades abarcó una franja horaria muy amplia, de 
lunes a sábado y desde las 10 hasta las 17 horas, se utilizaron multitud de instalaciones y materiales y se realizaron sesiones de juegos con más de 150 niños receptores del servicio. A pesar de esta enorme complejidad estructural, gracias al trabajo previo de planificación y a la colaboración de los profesionales de las entidades, así como del alumnado participante, la actividad se pudo desarrollar con total normalidad. En consecuencia, no hemos encontrado limitaciones contextuales destacables en la aplicación práctica del programa de APS descrito para los Grupos Experimentales I y II en ninguna de las cinco entidades receptoras. En cambio, sí advertimos varios elementos positivos que han facilitado en gran medida la aplicación del programa de APS, entre los que podemos destacar:

- Profesionales del ámbito educativo y miembros de las entidades colaboradoras dispuestos a implicarse en el desarrollo del programa formativo propuesto.

- Centros educativos e instituciones formativas con una adecuada dotación de materiales e infraestructuras para la realización de las sesiones propuestas.

- Niños con distintas limitaciones o afectaciones motoras dispuestos a participar en las actividades propuestas por el alumnado universitario.

- Familiares comprometidos con la realización de estas actividades y agradecidos por la prestación del servicio.

- Alumnos universitarios motivados a participar en una propuesta de innovación educativa que les proporcione una experiencia práctica.

La descripción de estas condiciones contextuales nos aporta una idea más definida del entorno en el que hemos aplicado el programa de APS descrito. Esta información adquiere gran relevancia en este tipo de proyectos educativos, ya que el marco contextual de aplicación influye notablemente en los efectos de su implementación, cuestión que abordan diversos autores (Carbonell y Carrillo, 2010; Martínez, 2015; Tapia, 2010).

Una vez expuestas las variables contextuales que delimitan la aplicación del programa educativo propuesto, pasamos a presentar el diagnóstico inicial de nuestra investigación, obtenido mediante la aplicación Pretest de los instrumentos de medida.

\subsubsection{Procedimiento de aplicación de los instrumentos de medida}

Para realizar un primer diagnóstico, procedimos a la aplicación inicial de los dos instrumentos descritos, la rúbrica sobre conocimientos y competencias académicas y el cuestionario para medir la competencia de ES. Este diagnóstico inicial se realizó durante la última semana del mes de septiembre de 2013, al inicio del curso académico, una vez conformados los distintos grupos de investigación y antes de iniciar el programa educativo basado en la metodología de APS. A continuación presentamos los resultados del Prestest y el análisis de los mismos en los distintos grupos. 


\subsubsection{Diagnóstico de la situación inicial, Pretest de los Grupos Experimental I, Experimental II y Control}

En primer lugar, se extrajeron los estadísticos descriptivos de los datos registrados en los grupos Experimental I, Experimental II y Control, en el Pretest, respecto a los conocimientos académicos y la competencia de ES.

Antes de realizar el diagnóstico inicial testamos la equivalencia de los grupos participantes en las dos variables objeto de estudio, para determinar si la situación de partida era la misma en todos ellos.

En cuanto a los conocimientos académicos, la comparación de las puntuaciones medias de los tres grupos en el Pretest mediante la prueba de Kruskal-Wallis para 3 muestras independientes, al no poder utilizar pruebas paramétricas, demostró que no había diferencias significativas, obteniéndose un valor $\mathrm{P}$ de 0,989 (tabla 64 en anexo). Al registrar un valor mayor de 0,05 podemos considerar que el Grupo Experimental I, el Experimental II y el Control eran inicialmente equivalentes en cuanto a conocimientos y competencias específicas de la asignatura "Fundamentos de la Expresión Corporal, Juegos Motores en Educación Infantil".

Respecto a la competencia de ES, la comparación de las puntuaciones medias de los tres grupos en el Pretest mediante una prueba ANOVA para 3 muestras independientes, al poder utilizar pruebas paramétricas, mostró que no habían diferencias significativas, obteniéndose un valor $\mathrm{P}$ de 0,905 (tabla 91 en anexo). Al registrar un valor superior a 0,05 podemos considerar que el Grupo Experimental I, el Experimental II y el Control eran inicialmente equivalentes en cuanto a la competencia de ES.

\section{- Diagnóstico inicial respecto a la variable A: conocimientos y competencias académicas}

En primer lugar analizamos los registros obtenidos por el alumnado del Grupo Experimental I en los 40 ítems que conforman la rúbrica para medir esta variable, correspondientes al Pretest, a través de la media obtenida por el total de los miembros del grupo en cada ítem. Siguiendo la escala de valoración de la rúbrica, estos registros se gradúan de la siguiente forma: 1 muy mal, 2 mal, 3 regular, 4 bien y 5 muy bien. Revisando estos datos, expuestos en la tabla 55 del anexo, vemos que, de los 40 ítems que componen la rúbrica, 5 presentaban un índice de respuesta entre el 1 y el 2, muy mal y mal respectivamente, destacando el ítem d2 con el valor mínimo de 1,21; la mayor parte de ítems, 27 en total, se situaba entre 2 y 3 , mal y regular respectivamente; y 8 ítems mostraron registros entre 3 y 4 , regular y bien para cada caso, destacando el ítem b8 como el mejor valorado con una puntuación de 3,57. Finalmente, no hubo ningún ítem con registros superiores a 4, entre 
bien y muy bien. Por bloques de ítems comprobamos que el bloque 8 era el que mejores datos registraba, mientras el bloque $g$ fue el que peores resultados obtuvo.

Seguidamente analizamos los registros del Pretest obtenidos por el alumnado del Grupo Experimental II en los 40 ítems que conforman la rúbrica. Analizando los datos, aportados en la tabla 56 del anexo, observamos que, de los 40 ítems de la rúbrica, 5 ítems presentaban un índice de respuesta entre el 1 y el 2, destacando el ítem d2 con un valor mínimo de 1,25; la mayor parte de ítems, 30, se situaba entre 2 y 3 ; y 5 ítems mostraron registros entre 3 y 4 , destacando los ítems b8 y c8 como los mejor valorados con una puntuación de 3,18. Finalmente, no hubo ningún ítem con registros superiores a 4 . Nuevamente, los bloques de ítems 8 y 9 fueron los que mejores y peores resultados presentaron, respectivamente.

Finalmente analizamos los registros obtenidos en el Pretest por el alumnado del Grupo Control en los 40 ítems de la rúbrica para medir los conocimientos y competencias académicas. En estos resultados (tabla 57 del anexo) apreciamos que 5 ítems presentaban un índice de respuesta entre el 1 y el 2, destacando el ítem ag con el valor mínimo de 1,3; la mayor parte de ítems, 28 en total, se situaba entre 2 y 3 ; y 7 ítems mostraron registros entre 3 y 4 , destacando el ítem b8 como el mejor valorado con una puntuación de 3,28 . Nuevamente, no hubo ningún ítem con registros superiores a 4. Una vez más, por bloques de ítems comprobamos que el 9 era el peor valorado mientras el mejor volvía a ser el bloque 8 .

Comparando los resultados de los tres grupos, podemos apreciar que los datos obtenidos en el Prestest respecto a la variable $A$ fueron muy similares. Los tres grupos registraron 5 ítems con un índice de respuesta entre 1 y 2 , destacando el ítem d 2 como el peor valorado en global. Igualmente, los tres grupos ubicaron más de la mitad de los ítems de la rúbrica entre los valores 2 y 3 . En el rango de valoración entre 3 y 4 , se situaron entre 5 y 8 ítems, destacando el ítem b8 como el mejor valorado en el total de los grupos. Ningún grupo obtuvo puntuaciones superiores al 4 en la valoración de toda la rúbrica y, por bloques de ítems, los tres grupos coincidieron en registrar los valores más bajos en el bloque 9 y los más altos en el bloque 10. Igualmente, todos ellos presentaron unas valoraciones globales bajas.

Por todo ello, podemos concluir que la situación inicial de los tres grupos respecto a los conocimientos y competencias académicas era muy parecida, ya que obtuvieron resultados muy similares en el análisis de los datos del Pretest respecto a dicha variable. Además, revisando la correlación de estos registros con los ítems de la rúbrica, apreciamos que el ítem con peor valoración global hace referencia a la representación gráfica, mientras el ítem con mejores registros se centra en el desarrollo de la motricidad gruesa. De igual modo, el bloque de ítems peor valorado fue el de los juegos de expresión corporal, mientras que el bloque que analiza los juegos motores obtuvo los mejores resultados en los tres grupos. 


\section{- Diagnóstico inicial respecto a la variable B: competencia de Emprendimiento Social}

En primer lugar, analizamos los registros obtenidos por el alumnado del Grupo Experimental I en los 30 ítems que conforman el cuestionario para medir esta variable, correspondientes al Pretest. Siguiendo la escala de valoración del cuestionario, los registros se gradúan de la siguiente forma: 1 muy en desacuerdo, 2 en desacuerdo, 3 indeciso, 4 de acuerdo y 5 muy de acuerdo. Gracias a los datos obtenidos, los cuales se muestran en la tabla 82 del anexo, podemos concluir que, de los 30 ítems que componen el cuestionario, tan solo 2 ítems se situaban por debajo del valor 3 , abarcando las categorías muy en desacuerdo, en desacuerdo e indeciso, destacando el ítem i2 como el valor mínimo con una puntuación de 2,36; gran parte de los ítems, 15 en total, se situaba entre el 3 y el 4, indeciso y de acuerdo respectivamente; y 13 ítems mostraron registros entre 4 y 5 , de acuerdo y muy de acuerdo para cada caso, destacando los ítems i16 e i18 como los mejor valorados con una puntuación de 4,71 . En cuanto a los resultados por categorías no apreciamos tendencias dominantes destacables.

Seguidamente analizamos los registros del Pretest obtenidos por el alumnado del Grupo Experimental II en los 30 ítems que conforman el cuestionario para medir el ES. Analizando los datos, aportados en la tabla 83 del anexo, observamos que, de los 30 ítems del cuestionario, 3 ítems se situaban por debajo del valor 3 , destacando el ítem i2 con un valor mínimo de 2,63; 13 ítems se situaban entre el 3 y el $4 i$ y otros 14 ítems mostraron registros entre 4 y 5 , destacando los ítems i 6 e i3 como los mejor valorados con una puntuación de 4,54. Nuevamente, en cuanto a los resultados por categorías, no se apreciaron predominancias positivas ni negativas.

Finalmente analizamos los registros obtenidos en el Pretest por el alumnado del Grupo Control en los 30 ítems del cuestionario de ES. En estos resultados (tabla 84 del anexo) apreciamos que tan solo 2 ítems se situaban por debajo del valor 3 , destacando el ítem i2 como el valor mínimo con una puntuación de 2,$54 ; 17$ ítems se ubicaban entre el 3 y el $4 ;$ y 11 ítems mostraron registros entre 4 y 5 , destacando el ítem i16 como el valor máximo con una puntuación de 4,59. Una vez más, no encontramos tendencias dominantes en cuanto a los resultados por categorías.

Comparando los resultados de los tres grupos, podemos apreciar que los datos obtenidos en el Prestest respecto a la variable $B$ son muy similares. Los tres grupos registraron un número de ítems muy reducido por debajo del valor 3, destacando el ítem i2 como el peor valorado en los tres grupos. Igualmente, los tres grupos ubicaron gran cantidad de ítems entre los valores 3 y 4 y 4 y 5 , respectivamente, existiendo una mayor presencia de ítems en la primera franja en los grupos Experimental I y Control y en la segunda en el Grupo Experimental II. El ítem i16 fue el más valorado en los tres grupos, aunque en dos de los casos con idéntica puntuación que los ítems iz e i18, respectivamente. En cuanto a los resultados por categorías, no se apreciaron tendencias dominantes destacables en ninguno de los grupos. Igualmente, todos ellos registraron valores notablemente elevados en cuanto a la competencia de ES.

Por todo ello, podemos concluir que la situación inicial de los tres grupos respecto a la competencia de ES era muy parecida, ya que obtuvieron resultados muy similares en el análisis de 
los datos del Pretest respecto a dicha variable. Además, revisando la correlación de estos registros con los ítems del cuestionario, apreciamos que el ítem con peor valoración global hace referencia al liderazgo, mientras el ítem con mejores registros se centra en medir la conciencia social. De igual modo, dos ítems sobre la motivación al logro y la convivencia y respeto por el bien público, respectivamente, también obtuvieron puntuaciones muy elevadas.

\subsection{Proceso de tratamiento y análisis de datos}

Una vez recogidos los datos correspondientes al Pretest y el Postest de los tres grupos, iniciamos el proceso de tratamiento de los mismos a efectos de contrastar las hipótesis y preguntas de investigación establecidas para el presente trabajo. Para ello utilizamos el paquete estadístico SPSS versión 21. Así mismo, tras implementar el programa educativo, se recabaron los datos cualitativos, extraídos de las entrevistas realizadas al alumnado participante, para proceder al análisis de su contenido utilizando el programa de análisis cualitativo NVivo 10.

\subsubsection{Análisis cuantitativo}

El análisis cuantitativo de ambas variables se realizó aplicando el siguiente procedimiento:

- Comprobación de la fiabilidad de la muestra: prueba del Alfa de Cronbach.

- Extracción de los estadísticos descriptivos: registros de cada grupo y observación.

- Determinación del uso de pruebas paramétricas o no paramétricas:

- Comprobación de la asignación y selección aleatoria de los grupos.

- Comprobación de la medida intervalar o de razón de las variables.

- Comprobación de la normalidad de la muestra: prueba de Kolmogorov-Smirnoff.

- Comprobación de la homocedastidad de la muestra: prueba de Levene.

- Comprobación de la equivalencia/igualdad inicial para muestras independientes: comparación de los resultados Pretest de los tres grupos a través de una prueba ANOVA o la prueba de Kruskal-Wallis, en función de si se deben aplicar pruebas paramétricas o no paramétricas, respectivamente.

- Comparación de las muestras Pretest-Postest para muestras relacionadas: comparación de los resultados Pretest-Postest en cada uno de los grupos mediante una prueba T para muestras relacionadas o la prueba de Wilcoxon, en función de si se deben aplicar pruebas paramétricas o no paramétricas.

- Comparación de las muestras Postest-Postest para muestras independientes: comparación de los resultados Postest de los tres grupos a través de una prueba ANOVA o la prueba de Kruskal-Wallis, en función de si se deben aplicar pruebas paramétricas o no paramétricas. 
- Comparación de las muestras por niveles: en caso de que no se encuentren diferencias significativas en las pruebas anteriores o deseemos profundizar en la comparación de los resultados se repetirán las comparaciones Pretest-Postest y Postest-Postest respetivamente, por categorías o bloques.

- Prueba de asociación de resultados (correlaciones): prueba de Pearson.

\subsubsection{Análisis cualitativo}

El análisis de los datos cualitativos extraídos de las entrevistas se realizó utilizando el programa informático Nvivo 10. Así pues, se aplicó un procedimiento deductivo para analizar la información registrada, en cada entrevista seleccionada al azar, a través de los aspectos que conforman la rúbrica académica y el cuestionario sobre la competencia de ES, respectivamente. Por tanto, los focos de atención en el análisis de ambas variables fueron los siguientes:

- Variable $A$, conocimientos y competencias académicas:

- Ajuste de los juegos al alumnado: edad, periodo, necesidades educativas y seguridad.

- Presentación: descripción, estructura, comprensión de las normas y representación gráfica.

- Organización del alumnado: participación, distribución de roles, trabajo individual/grupal y control del respeto por las normas.

- Organización del material: uso del material, variedad de material, optimización y distribución.

- Organización espacio/temporal: optimización/adaptación temporal, equilibrio temporal, optimización/adaptación espacial y equilibrio espacial.

- Adecuación curricular: relación objetivos-contenidos, consecución de los objetivos, progresión y valor educativo.

- Aspectos sociales: atención a la diversidad, transmisión de valores sociales, normas de convivencia y fomento de la cohesión-integración.

- Juegos motores: desarrollo de la motricidad fina, desarrollo de la motricidad gruesa, desarrollo de la coordinación global y desarrollo de la coordinación específica.

- Juegos de expresión corporal: representación de roles, simbolismo, desarrollo de la expresión y comunicación corporal.

- Otros: carácter innovador y originalidad, valor lúdico, variedad de los juegos y evaluación de la propuesta.

\section{- Variable B, competencia de Emprendimiento Social:}

- Liderazgo.

- Motivación al logro.

- Capacidad para asumir riesgos.

- Confianza.

- Responsabilidad. 
- Integración en redes sociales con acceso a información y conocimiento.

- Conciencia social.

- Capacidad de cooperación y ayuda.

- Coherencia y compromiso.

- Convivencia y respeto por el bien público.

- Creatividad.

- Capacidad para identificar oportunidades.

- Iniciativa.

- Capacidad para generar ideas.

- Capacidad de cambio.

- Capacidad para aprender y evolucionar.

- Tolerancia al fracaso.

\subsubsection{Expresión de los datos cualitativos de forma cuantitativa}

Siguiendo las indicaciones de Creswell y Plano Clark (2007), respecto a la combinación de datos en el diseño de triangulación metodológica, efectuamos una transformación de resultados cualitativos expresados de forma cuantitativa. Así pues, realizamos un análisis de frecuencia, en las entrevistas registradas, sobre cada uno de los aspectos estudiados en este trabajo, tanto para los aprendizajes académicos como respecto a la competencia de ES.

Tras exponer los pasos a seguir en el análisis de datos, en el siguiente capítulo procedemos a mostrar los resultados obtenidos en este proceso. 


6. Resultados

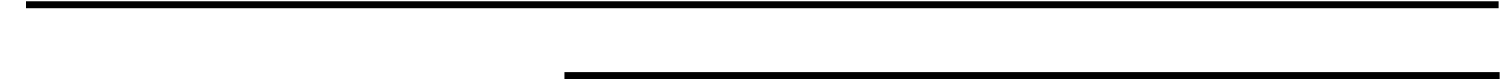



En el presente capítulo exponemos los resultados extraídos en el proceso de análisis realizado. Como ya hemos comentado, en el análisis de los datos cuantitativos utilizamos el paquete estadístico SPSS versión 21. En cambio los datos cualitativos se analizaron con el programa informático NVivo 10.

\subsection{Análisis cuantitativo}

El análisis cuantitativo de las variables A y B se realizó aplicando el proceso descrito en el capítulo anterior. En este apartado se indican los objetivos de los procedimientos realizados, las pruebas aplicadas, los resultados obtenidos y las correspondientes referencias a las distintas tablas y gráficos extraídos en cada caso.

\subsubsection{Variable dependiente A: conocimientos y competencias académicas}

- Comprobación de la fiabilidad de la muestra. Para verificar que la muestra registrada era fiable aplicamos la prueba del Alfa de Cronbach. Esta prueba determina que cuanto más se acerca el valor del alfa a 1 mayor fiabilidad presentan los datos. Nuestro estudio obtuvo un valor $\mathrm{P}$ de 0,955 , como podemos comprobar en la tabla 54 del anexo, por lo que al ser superior a 0,9 su fiabilidad puede calificarse de excelente.

- Extracción de los estadísticos descriptivos. Para iniciar el análisis de los datos registrados realizamos un estudio descriptivo de los mismos para cada grupo y observación. Los gráficos 8,9 y 10 muestran las puntuaciones medias del Pretest y el Postest en cada grupo. En el anexo adjuntamos los estadísticos descriptivos indicando: ítem analizado, casos válidos, registro mínimo, registro máximo, media, desviación típica y varianza (tablas de la 55 a la 60).

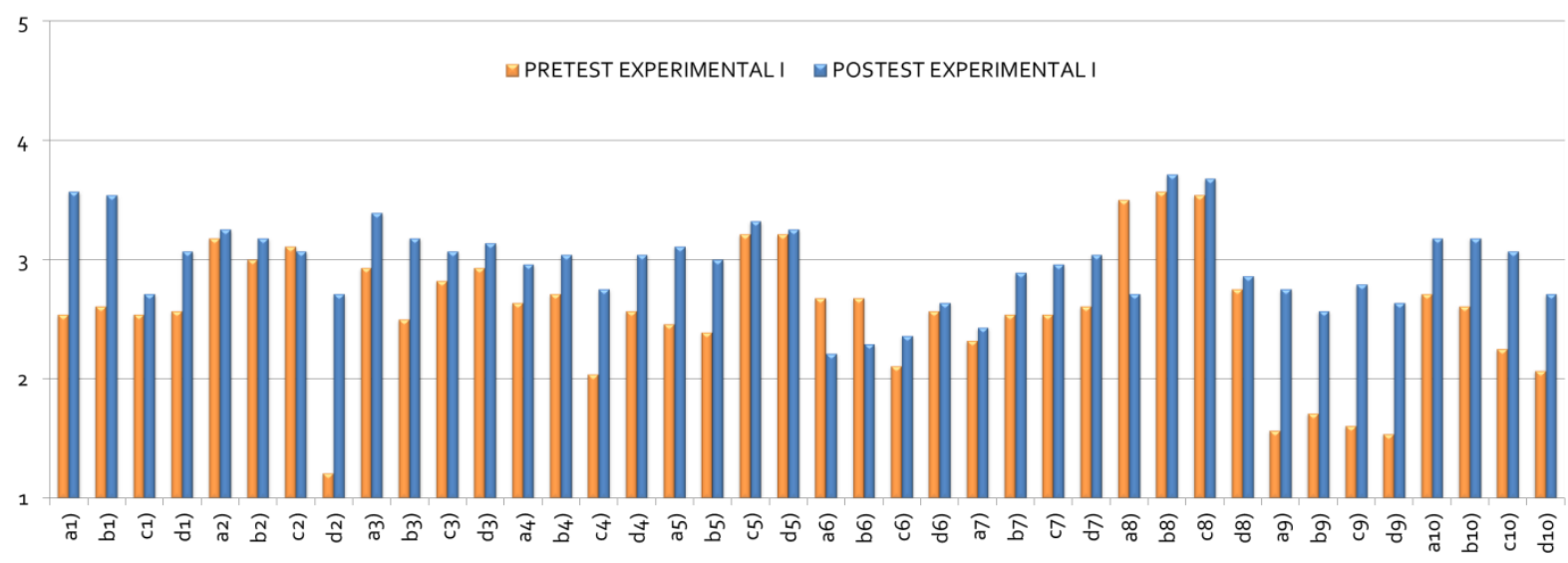

Gráfico 8. Resultados en el Pretest y Postest del Grupo Experimental I para la variable A (elaboración propia). 


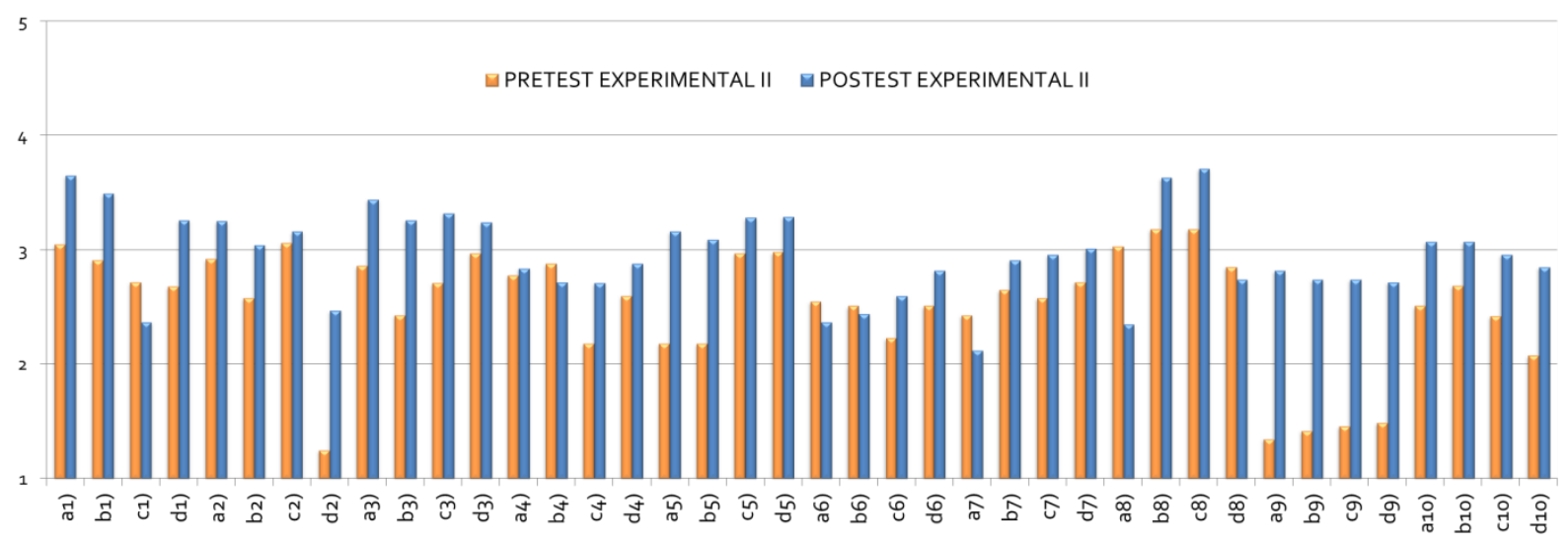

Gráfico 9. Resultados en el Pretest y Postest del Grupo Experimental Il para la variable A (elaboración propia).

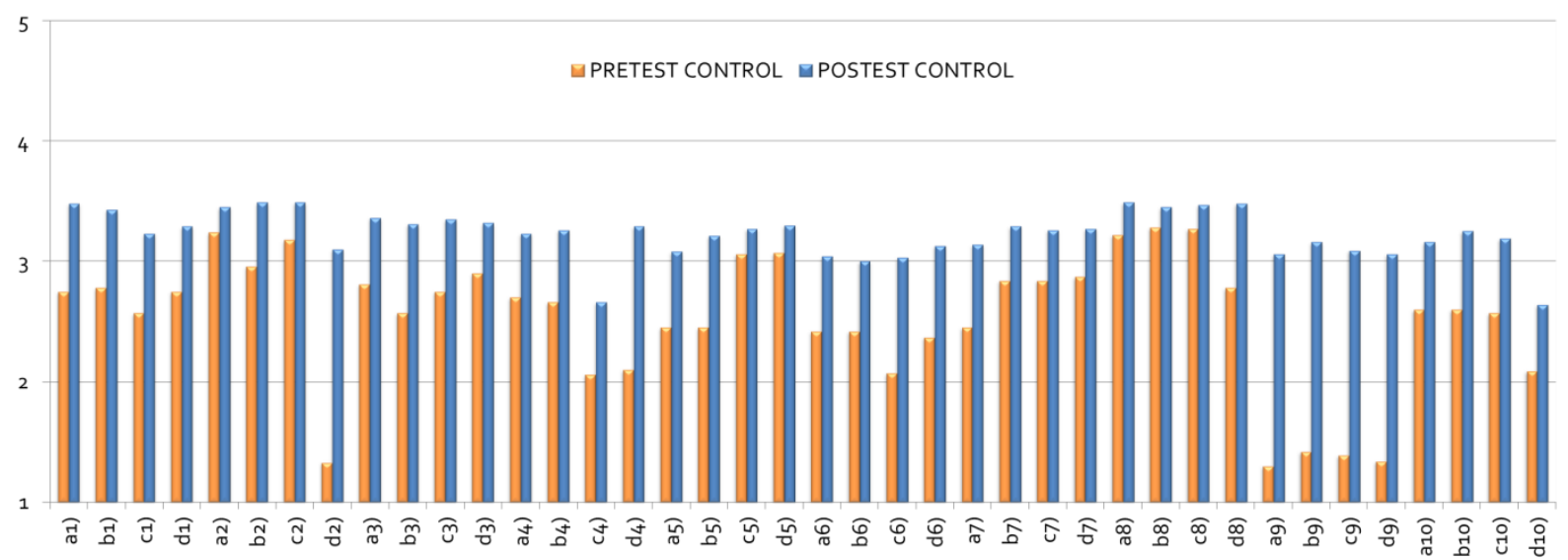

Gráfico 10. Resultados en el Pretest y Postest del Grupo Control para la variable A (elaboración propia).

- Determinación del uso de pruebas paramétricas o no paramétricas. Para verificar si debíamos utilizar pruebas paramétricas o no paramétricas en nuestro análisis estadístico comprobamos si se cumplían los siguientes requisitos:

- Comprobación de la asignación y selección aleatoria de los grupos. Debido a que los distintos grupos del estudio se formaron aleatoriamente verificamos que se cumplía la asignación y selección aleatoria de los grupos.

- Comprobación de la medida intervalar o de razón de las variables. Debido a que los datos registrados sobre la variable dependiente A se podían expresar en una escala de 1 a 5 verificamos que se cumplía la medida intervalar o de razón de esta variable.

- Comprobación de la normalidad de la muestra. Para verificar que la muestra era normal aplicamos la prueba de Kolmogorov-Smirnov. Esta prueba determina que si el valor obtenido es de p>0,05 la muestra analizada es normal. Como podemos ver en la tabla 61 del anexo, los valores P obtenidos para el Grupo Experimental I, el Grupo Experimental II y 
el Grupo Control fueron de 0,287, 0,177 y 0,200 en el Pretest, y 0,849, 0,972 y 0,846 en el Postest, respectivamente. Como todos los registros fueron superiores al valor de 0,05 verificamos que la muestra era normal en todos los casos. Para tener una imagen visual de esta normalidad de la muestra en el anexo incorporamos los gráficos del 57 al 62.

- Comprobación de la homocedastidad de la muestra. Para verificar que las muestras presentaban una varianza homogénea entre ellas aplicamos la prueba de Levene. Esta prueba determina que si el valor obtenido es de $p>0,05$ las muestras analizadas presentan una varianza homogénea. Como podemos ver en las tablas 62 y 63 del anexo, los valores $P$ obtenidos fueron de $0,685,0,780$ y 0,909 en el Pretest, y 0,887, 0,000 y 0,000 en el Postest, respectivamente. Como los dos últimos registros fueron inferiores al valor de 0,05 verificamos que había una varianza heterogénea entre las muestras.

Debido a que no se cumplían todos los requisitos necesarios para poder utilizar pruebas paramétricas continuamos el análisis de la variable $\mathrm{A}$ aplicando pruebas no paramétricas.

- Comprobación de la equivalencia/igualdad inicial para muestras independientes. Para verificar que las 3 muestras iniciales eran iguales aplicamos la prueba de Kruskal-Wallis. Esta prueba determina que si el valor obtenido es de $p>0,05$ las muestras analizadas son iguales. Como podemos ver en la tabla 64 del anexo el valor $\mathrm{P}$ obtenido fue de 0,989 , por lo que verificamos que las muestras iniciales eran iguales.

- Comparación de las muestras Pretest-Postest para muestras relacionadas. Para verificar si había diferencias significativas entre el Pretest y el Postest en cada uno de los 3 grupos aplicamos la prueba de Wilcoxon. Esta prueba determina que si el valor obtenido es de $p<0,05$ existen diferencias significativas entre la comparación del Pretest y el Postest de las muestras analizadas. Como podemos ver en la tabla 65 del anexo los valores $P$ obtenidos en cada caso fueron de 0,000, 0,000 y 0,000 respectivamente, por lo que verificamos que había diferencias significativas entre el Pretest y el Postest en cada uno de los grupos analizados. A continuación presentamos el gráfico 11, donde podemos ver la comparación de las puntuaciones medias obtenidas en cada uno de los casos.

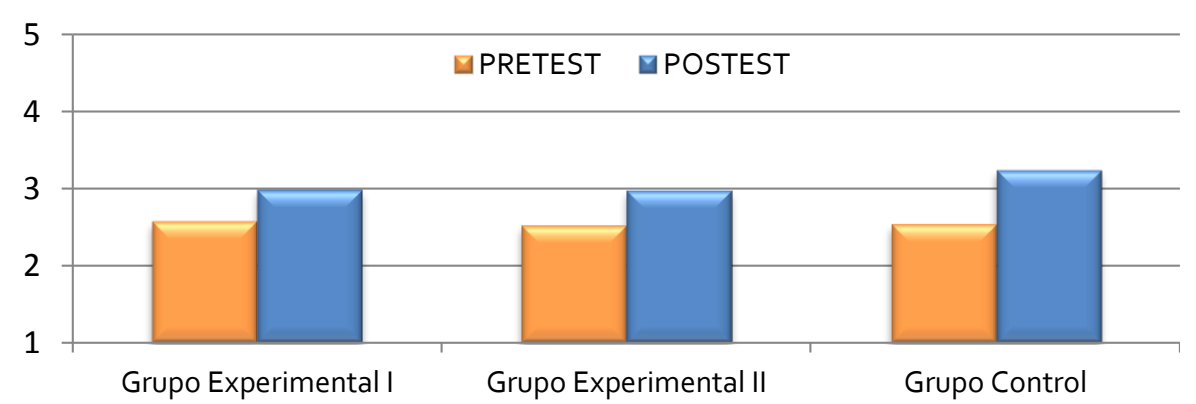

Gráfico 11. Comparación de la media de los registros obtenidos en la variable A entre el Pretest y el Postest de cada uno de los grupos (elaboración propia). 
- Comparación de las muestras Postest-Postest para muestras independientes. Para verificar si había diferencias significativas entre los registros del Postest de los 3 grupos aplicamos la prueba de Kruskal-Wallis. Esta prueba determina que si el valor obtenido es de $p<0,05$ existen diferencias significativas en las muestras analizadas. Como podemos ver en la tabla 66 del anexo el valor $\mathrm{P}$ obtenido fue de 0,000, por lo que verificamos que había diferencias significativas entre los registros del Postest de los grupos analizados. Para determinar las muestras que eran significativamente diferentes aplicamos la prueba $U$ de Mann-Whitney, emparejando las muestras. Esta prueba determina que si el valor obtenido es de $p<0,05$ existen diferencias significativas entre las 2 muestras analizadas. Como podemos ver en la tabla 67 del anexo, entre las muestras de los dos Grupos Experimentales se obtuvo un valor $\mathrm{P}$ de 0,988 , por lo que se verificó que no había diferencias significativas entre los Postest de estos dos grupos. En cambio el registro de esta prueba entre cada uno de los Grupos Experimentales y el Grupo Control obtuvo un valor $P$ de 0,000 y 0,000 respectivamente, como podemos ver en las tablas 68 y 69 del anexo. Estos registros indican que había una diferencia significativa entre los datos del Postest del Grupo Control respecto a los dos Grupos Experimentales, en favor del primero. No obstante, al analizar los registros del Postest para cada uno de los grupos por categorías, mediante la prueba de Kruskal-Wallis, comprobamos que estas diferencias significativas tan solo se mantenían en 3 de los 10 bloques de ítems analizados (tablas de la 70 a la 79 del anexo). Estos bloques hacen referencia a la adaptación curricular $(P=0,015)$, los aspectos sociales $(P=0,024)$ y los juegos de expresión corporal $(P=0,022)$.

- Prueba de asociación de resultados (correlaciones). Para verificar si había relación entre los registros obtenidos en el Postest en las distintas categorías aplicamos la prueba de Pearson. Esta prueba determina que si el valor obtenido es de $p<0,05$ existen correlaciones entre las muestras analizadas. Por otra parte, si el grado de correlación es de $x>0$ indica que la relación entre las muestras analizadas es positiva. En cambio, si este registro es de $x<0$ indica que la relación entre las muestras es negativa. Como podemos ver en la tabla 80 del anexo, encontramos 45 registros significativos de 45 posibles entre las distintas categorías analizadas, todos ellos positivos. Para tener una mejor idea del grado de correlación de estos registros en la tabla 45, agrupamos estos datos en función del coeficiente de correlación obtenido en cada caso. Esta agrupación se realizó siguiendo la siguiente escala: de 1 a 0,8 correlación muy alta, de o,8 a o,6 correlación alta, de 0,6 a 0,4 correlación moderada, de 0,4 a 0,2 correlación baja y de 0,2 a o correlación muy baja.

Tabla 45. Agrupación de las correlaciones existentes en los resultados del Postest para la variable A (elaboración propia).

\begin{tabular}{|cc|}
\hline NIVEL CORRELACIÓN & NÚMERO DE CORRELACIONES \\
\hline Muy alta & 0 \\
Alta & 3 \\
Moderada & 30 \\
Baja & 12 \\
Muy baja & 0 \\
\hline
\end{tabular}




\subsubsection{Variable dependiente B: competencia de Emprendimiento Social}

- Comprobación de la fiabilidad de la muestra. Para verificar que la muestra registrada era fiable aplicamos la prueba del Alfa de Cronbach. Esta prueba determina que cuanto más se acerca el valor del alfa a 1 mayor fiabilidad presentan los datos. Nuestro estudio obtuvo un valor $\mathrm{P}$ de 0,827 , como podemos comprobar en la tabla 81 del anexo, por lo que al ser superior a 0,8 su fiabilidad puede calificarse de buena.

- Extracción de los estadísticos descriptivos. Para iniciar el análisis de los datos registrados realizamos un estudio descriptivo de los mismos para cada grupo y observación. Los gráficos 12, 13 y 14 muestran las puntuaciones medias del Pretest y el Postest en cada grupo. En el anexo adjuntamos los estadísticos descriptivos indicando: ítem analizado, casos válidos, registro mínimo, registro máximo, media, desviación típica y varianza (tablas de la 82 a la 87).

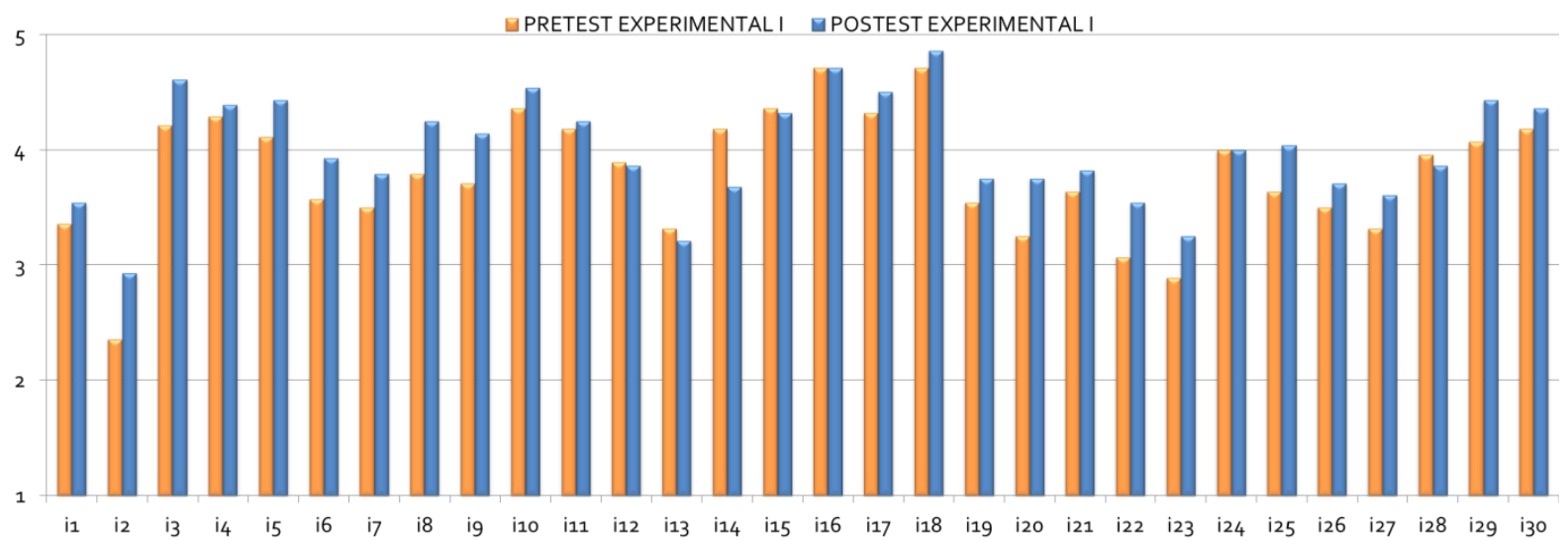

Gráfico 12. Resultados en el Pretest y Postest del Grupo Experimental I para la variable B (elaboración propia).

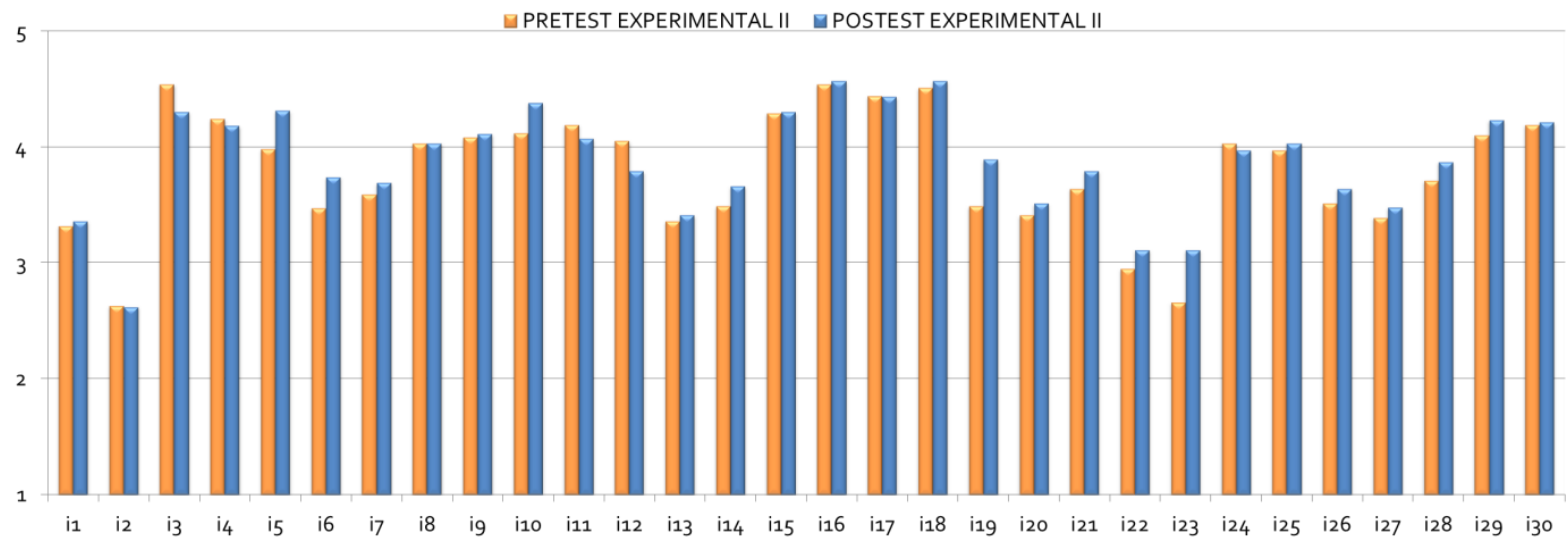

Gráfico 13. Resultados en el Pretest y Postest del Grupo Experimental Il para la variable B (elaboración propia). 


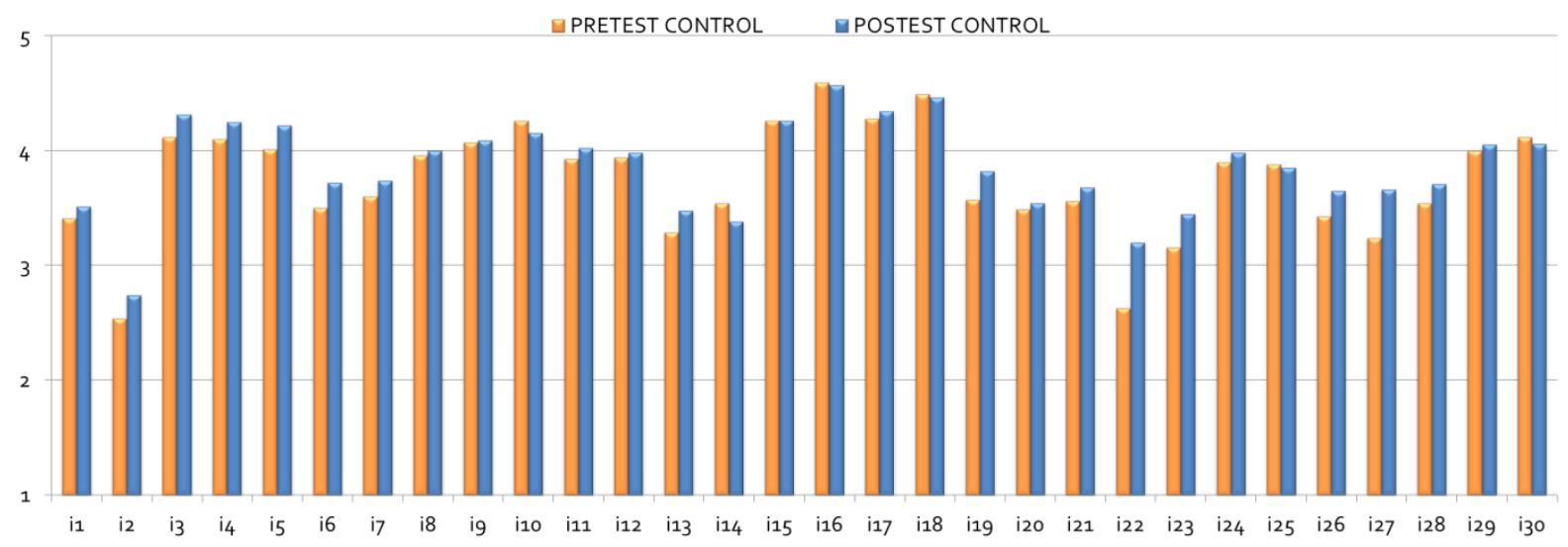

Gráfico 14. Resultados en el Pretest y Postest del Grupo Control para la variable B (elaboración propia).

- Determinación del uso de pruebas paramétricas o no paramétricas. Para verificar si debíamos utilizar pruebas paramétricas o no paramétricas en nuestro análisis estadístico comprobamos si se cumplían los siguientes requisitos:

- Comprobación de la asignación y selección aleatoria de los grupos. Debido a que los distintos grupos del estudio se formaron aleatoriamente verificamos que se cumplía la asignación y selección aleatoria de los grupos.

- Comprobación de la medida intervalar o de razón de las variables. Debido a que los datos registrados sobre la variable dependiente $B$ se podían expresar en una escala de 1 a 5 verificamos que se cumplía la medida intervalar o de razón de esta variable.

- Comprobación de la normalidad de la muestra. Para verificar que la muestra era normal aplicamos la prueba de Kolmogorov-Smirnov. Esta prueba determina que si el valor obtenido es de $\mathrm{p}>0,05$ la muestra analizada es normal. Como podemos ver en la tabla 88 del anexo, los valores $P$ obtenidos fueron de 0,955, 0,400 y 0,592 en el Pretest, y 0,918, 0,952 y 0,819 en el Postest, respectivamente. Como todos los registros fueron superiores al valor de 0,05 verificamos que la muestra era normal en todos los casos. Para tener una imagen visual de esta normalidad de la muestra en el anexo incorporamos los gráficos del 63 al 68.

- Comprobación de la homocedastidad de la muestra. Para verificar que las muestras presentaban una varianza homogénea entre ellas aplicamos la prueba de Levene. Esta prueba determina que si el valor obtenido es de p>0,05 las muestras analizadas presentan una varianza homogénea. Como podemos ver en las tablas 89 y 90 del anexo, los valores $P$ obtenidos fueron de 0,986, 0,693 y 0,700 en el Pretest y 0,310, 0,220 y 0,885 en el Postest, respectivamente. Como todos los registros fueron superiores al valor 0,05 verificamos que había una varianza homogénea entre las muestras.

Como se cumplían todos los requisitos necesarios para poder utilizar pruebas paramétricas continuamos con el análisis de la variable $B$ aplicando este tipo de pruebas. 
- Comprobación de la equivalencia/igualdad inicial para muestras independientes. Para verificar que las 3 muestras iniciales eran iguales aplicamos una prueba ANOVA. Esta prueba determina que si el valor obtenido es de $p>0,05$ las muestras analizadas son iguales. Como podemos ver en la tabla 91 del anexo el valor $\mathrm{P}$ obtenido fue de 0,905 por lo que verificamos que las muestras iniciales eran iguales.

- Comparación de las muestras Pretest-Postest para muestras relacionadas. Para verificar si había diferencias significativas entre el Pretest y el Postest en cada uno de los 3 grupos aplicamos la prueba $\mathrm{T}$ de muestras relacionadas. Esta prueba determina que si el valor obtenido es de $p<0,05$ existen diferencias significativas entre la comparación del Pretest y el Postest de las muestras analizadas. Como podemos ver en la tabla 92 del anexo los valores $\mathrm{P}$ obtenidos en cada caso fueron de 0,000, 0,009 y 0,000, respectivamente, por lo que verificamos que había diferencias significativas entre el Pretest y el Postest en cada uno de los grupos analizados. A continuación presentamos el gráfico 15 , donde podemos ver la comparación de las puntuaciones medias obtenidas en cada uno de los casos.

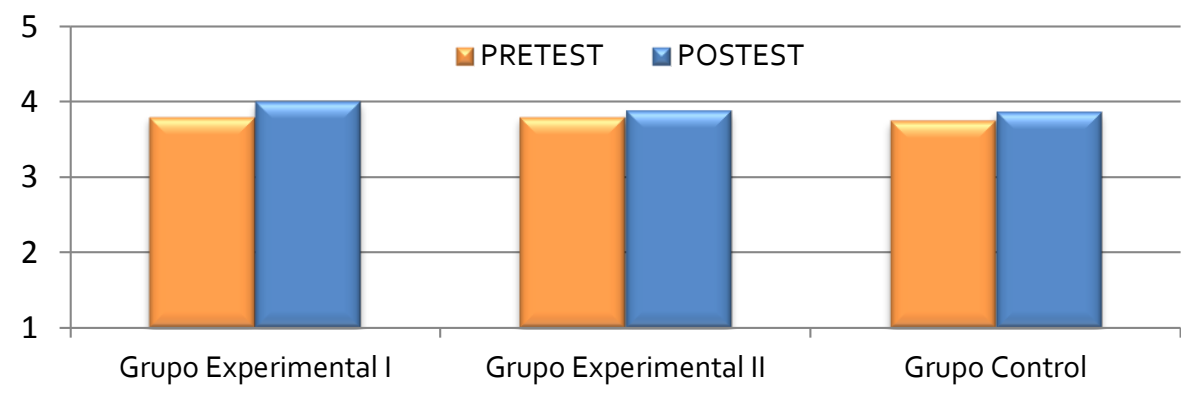

Gráfico 15. Comparación de la media de los registros obtenidos en la variable B entre el Pretest y el Postest de cada uno de los grupos (elaboración propia).

- Comparación de las muestras Postest-Postest para muestras independientes. Para verificar si había diferencias significativas entre los registros del Postest de los 3 grupos aplicamos una prueba ANOVA. Esta prueba determina que si el valor obtenido es de $p<0,05$ existen diferencias significativas en las muestras analizadas. Como podemos apreciar en la tabla 93 del anexo el valor $\mathrm{P}$ obtenido fue de 0,419 , por lo que verificamos que no había diferencias significativas entre los registros del Postest de los grupos analizados. No obstante, al comparar los registros globales del Postest en cada uno de los grupos verificamos que el Grupo Experimental I fue el que mejor resultado había obtenido ( $x=$ 4,0020), seguido del Grupo Experimental II $(x=3,8787)$ y, por último, el Grupo Control obtuvo la peor puntuación de los tres grupos analizados $(x=3,8623)$ (tabla 88 del anexo).

- Prueba de asociación de resultados (correlaciones). Para verificar si había relación entre los registros obtenidos en el Postest en las distintas categorías aplicamos la prueba de Pearson. Esta prueba determina que si el valor obtenido es de $p<0,05$ existen correlaciones entre las 
muestras analizadas. Por otra parte, si el grado de correlación es de $x>0$ indica que la relación entre las muestras analizadas es positiva. En cambio, si este registro es de $x<0$ indica que la relación entre las muestras es negativa. Como podemos ver en la tabla 94 del anexo, encontramos 3 registros significativos de 3 posibles entre las distintas categorías analizadas, todos ellos positivos. Siguiendo la escala de agrupación expuesta anteriormente comprobamos que dos de estas correlaciones eran moderadas, mientras la tercera era alta. De igual modo analizamos la correlación de los distintos aspectos que conforman la variable dependiente B. En la tabla 95 del anexo, se aprecian los 99 registros significativos encontrados de 136 posibles entre los distintos aspectos analizados, todos ellos positivos. Para tener una mejor idea del grado de correlación de estos registros en la tabla 46, agrupamos estos datos en función del coeficiente de correlación obtenido en cada caso siguiendo la escala expuesta anteriormente.

Tabla 46. Agrupación de las correlaciones existentes en los resultados del Postest para cada categoría de ítems (elaboración propia).

\begin{tabular}{|cc|}
\hline NIVEL CORRELACIÓN & NÚMERO DE CORRELACIONES \\
\hline Muy alta & 0 \\
Alta & 1 \\
Moderada & 11 \\
Baja & 70 \\
Muy baja & 17 \\
\hline
\end{tabular}

\subsection{Análisis cualitativo}

Como hemos indicado anteriormente, el análisis cualitativo se aplicó mediante diversas Historias de Vida de relatos múltiples cruzados con 12 de las entrevistas realizadas. Para seleccionar estas entrevistas hicimos dos tipos de muestreo: por cuota y por cadena de referencia. En el muestreo por cuota se seleccionaron 8 entrevistas representativas atendiendo a los parámetros de: sexo, edad, participación en actividades de voluntariado o pertenencia a asociaciones u ONG's, formación y experiencia docente previa. En el muestreo por cadena de referencia se seleccionaron las 4 entrevistas restantes atendiendo a las sugerencias de los 8 estudiantes seleccionados previamente. Siguiendo las recomendaciones de implementación de esta metodología de investigación, las Historias de Vida, aplicamos un procedimiento deductivo para analizar la información registrada a través de los aspectos que conforman la rúbrica académica y el cuestionario sobre la competencia de ES, respectivamente.

Inicialmente aportamos la definición de la categoría analizada, en base a lo expuesto en la guía docente de la asignatura y el marco teórico de este trabajo. A continuación se presenta la información relativa a las citas seleccionadas en cada caso, incluyendo la interpretación del investigador a raíz del comentario del alumno, seguida de la cita textual del mismo. Igualmente, 
también se aporta el código generado por el programa informático utilizado donde se muestra la referencia de cada comentario. Cabe señalar que la selección de estas citas responde a la importancia y profundidad de las mismas, intentando destacar el impacto del programa de APS en el alumnado sobre cada uno de los aspectos analizados. Al final de cada categoría incluimos una valoración global sobre los resultados extraídos en cada caso.

\subsubsection{Variable dependiente A: conocimientos y competencias académicas}

\section{- Ajuste de los juegos al alumnado participante.}

Siguiendo la estructura de la rúbrica creada sobre los conocimientos y competencias académicas de la asignatura, el primer bloque de resultados trata el ajuste de los juegos al alumnado, comprobando la relación entre las actividades realizadas y las características de los niños participantes.

\section{- Edad del Alumnado.}

El primer aspecto de este bloque hace referencia a la edad del alumnado, valorando el ajuste de los juegos propuestos al periodo formativo de los niños.

Como consecuencia de la dificultad que supone organizar tareas colectivas con niños de corta edad, el alumnado universitario se decantó por realizar diversas actividades con grupos menos numerosos. La experiencia pone de manifiesto el gran aporte que supuso el servicio en esta cuestión, ya que de lo contrario no se hubieran podido realizar este tipo de estrategias debido a la gran cantidad de recursos humanos necesarios.

"... algunas de las actividades de las que hicimos con estos grupos, por ejemplo... porque estos grupos estaban muy, porque eran los más pequeños, entonces estaba muy dividido no podías hacer un grupo cohesionado había como grupitos." <Elementos internos||Entrevistas ||C 05> - Referencia 8.

Los condicionantes existentes, a la hora de seleccionar los juegos, obligaron a los alumnos universitarios a ajustarse tanto a la edad de los niños como a la programación establecida en el momento de planificar las sesiones a realizar.

"...con los pequeños sí que no tenía una planificación de... este semestre vamos a hacer esto, luego esto, luego esto. Pero con los de primero si y sí que nos teníamos que adaptar los juegos a lo que él tenía en su programación porque claro no podía saltársela." <Elementos internos\|Entrevistas\|C o8> Referencia 2.

La simplicidad de los juegos realizados, debido a la gran dependencia de los niños más pequeños, no deja lugar a dudas respecto a la consideración de los alumnos universitarios en cuanto a las necesidades educativas de los receptores del servicio. Igualmente nos permite apreciar cómo trataban a estos niños para poder desarrollar las actividades con normalidad.

"...al principio, los niños eran muy pequeños y muy dependientes, no podían hacer ellos solos las cosas. Luego les explicabas los juegos y tampoco entendían las órdenes. Eran juegos muy... tenían que ser juegos muy, muy, muy simples (...) los niños estos necesitaban órdenes claras y simples, sencillas." $<$ Elementos internos $\|$ Entrevistas $\| C$ 10> - Referencia 2. 
La aplicación de algunos ejercicios específicos para fomentar el autocontrol de los niños más pequeños fue de gran importancia, ya que sin dicha cualidad no hubieran podido realizar otro tipo de tareas de mayor autonomía. Esta observación del alumnado demuestra el desarrollo de su capacidad analítica respecto a las necesidades educativas de los niños.

"Nos dimos cuenta un poco que con los de cuatro años quizá era un poco el pararlos era algo que... como que no sabían, entonces planteamos también algunos días ejercicios que uno de los objetivos era que aprendiesen un poco el autocontrol de pararse." <Elementos internos\|Entrevistas ||C 11> Referencia 3.

Siguiendo las indicaciones del profesorado del centro educativo, los alumnos universitarios elaboraron tareas que no requerían el uso de material para no estimular en exceso a los niños más pequeños. Al mismo tiempo observamos cómo utilizaron estrategias como la expresión corporal para comunicarse con ellos, exponiendo así las limitaciones existentes debido a la corta edad de los niños participantes.

"...con los pequeños, siempre... al principio siempre jugábamos o a la caja mágica o a la araña, o a la cadena, o algo. Eran actividades que no tenían ningún material, porque $V$---- nos los dijo, dice... si sacáis algún material los vais a distraer, se van a centrar en el material, no van a hacer caso (...) y súper sencillos de pocas órdenes y gestualizando nosotras para que lo entendieran." <Elementos internos $\|$ Entrevistas $\| C$ 12> - Referencia 7.

\section{- Periodo del curso.}

La adaptación al periodo del curso analiza el ajuste de los juegos realizados a la etapa del programa educativo aplicado.

Adecuar el espacio de las actividades en función de la estación del año denota el ajuste de las propuestas al periodo del curso. De este modo, se aprecia cómo las primeras prácticas se realizaron en un espacio interior, ya que fuera hacía frio, y con el paso del tiempo y la llegada del calor pasaron a hacerse las sesiones en el patio exterior. Como veremos más adelante, este aprendizaje es de gran valor en el ámbito de la EF debido a que su práctica no se desarrolla en el aula ordinaria.

"...empezamos a mitad de Febrero. Esos días con los más pequeños por ejemplo y más que nada porque había mucho carro también, pues nos quedamos en el módulo. Pero luego a partir ya de Marzo, ya nos hemos ido al patio..." <Elementos internos $\mid$ Entrevistas ||$C$ o1 $>$ - Referencia 1.

La progresión organizativa alcanzada a lo largo del programa educativo fue tan grande que al final llegaron a realizar una propuesta tan compleja como un Lipdub, un vídeo musical en el que niños y alumnos universitarios cantaban y coordinaban sus movimientos con una canción a través de un plano secuencia de una sola toma. Este logro nos demuestra el gran nivel organizativo adquirido por los alumnos a lo largo del servicio, pues evidentemente es una actividad que no hubieran podido aplicar durante las primeras sesiones.

"De hecho en la evolución de los juegos y en la organización y todo mira si yo creo que ha sido un progreso muy grande que hemos llegado a hacer un Lipdup que eso necesita mucha organización. Entonces en la última que hemos hecho ha sido el Lipdub." <Elementos internos ||Entrevistas\|C o3> Referencia 1. 
El aumento gradual de la exigencia motriz de las actividades, a consecuencia del avance en el proyecto educativo, nos permite entender que el alumnado asimiló un concepto básico para cualquier proceso de enseñanza-aprendizaje, incrementar progresivamente la dificultad de las tareas a realizar. Este aprendizaje viene reforzado por la mejora en la confianza de los alumnos universitarios, tanto en las capacidades de los niños como en su propio desempeño.

"...al principio sí que mirábamos pues... vamos a hacer cosas que no se tengan que mover casi, vamos a hacer algo que estén sentados, vamos a hacer... Pero ahora ya, aparte de que ellos también han mejorado y ya se mueven más y tal también nosotras, yo qué sé, que no nos cortamos tanto, como que les pedimos un poco más porque sabemos que pueden llegar." <Elementos internos ||Entrevistas ||C 05> - Referencia 3.

La falta de confianza inicial del alumnado universitario, por tener que enfrentarse a una situación desconocida, hizo que empezaran el servicio realizando las tareas más sencillas y seguras posibles. Como en el caso anterior, fueron aumentando progresivamente la dificultad de las actividades pero, en esta ocasión, en base a la mejora de su competencia docente.

"...entonces esos primeros pasitos te hicieron pensar de ¿cómo plantearías las actividades con ellos? Y claro pues las primeras fueron en plan de a lo seguro. Si V---- estaba haciendo la caja mágica vamos a hacer la caja mágica nosotras. Fueron como unas prácticas para nosotras no para los niños ¿no? De a ver nosotras cómo nos desenvolvemos en ese aspecto." <Elementos internos $\mid$ Entrevistas $\| C$ 11> Referencia 1.

Con el paso de las sesiones, los alumnos universitarios fueron incluyendo progresivamente materiales en la aplicación de los juegos. Así pues, mientras las actividades iniciales carecían de material, para no estimular en exceso a los niños, poco a poco fueron incorporando diversos materiales en sus propuestas, muestra de su evolución en este sentido.

"...estuvimos desde Noviembre hasta Diciembre haciendo esos juegos. En Diciembre dijimos, como era la despedida, le dijimos a V----... V---- jvamos a hacer una fiesta! (...) Entonces al ver que con los, que sacando los globos no se distraían ni nada y que podían hacer bien la actividad pues ya dijimos pues al volver de Navidad, ivamos a hacer actividades con material!" <Elementos internos||Entrevistas ||C 12> - Referencia 2.

\section{- Necesidades educativas del alumnado.}

El aspecto de las necesidades educativas del alumnado hace alusión a la adecuación de los juegos propuestos con los requerimientos formativos de los niños.

En función de las características de cada grupo de niños, los alumnos universitarios realizaban un tipo de actividades $u$ otras. Este es un aprendizaje vital para cualquier docente pues, pese a la existencia de elementos comunes, cada conjunto de niños precisa una atención formativa específica y diferenciada.

"...dependiendo de la clase había que hacer algo más tranquilo o más movidito pero... eso siempre era por las características de los niños. En verdad eso lo hemos tenido muy... muy en cuenta." <Elementos internos $\|$ Entrevistas $\| C$ o1> - Referencia 4.

La aplicación de algunos juegos de presentación para desarrollar la expresión oral de los niños nos ayuda a apreciar la problemática existente en cuanto a comunicación verbal. Por ello, el alumnado universitario desarrolló diferentes tareas en las que se fomentara este aspecto. Su reflexión nos permite entender que el hecho de que un grupo de niños presente 
una carencia específica no quiere decir que debamos obviarla, al contrario, tenemos que estimularla para intentar alcanzar un nivel más elevado.

"...en general a todos les costaba mucho el tema del lenguaje oral, o sea, expresión verbal mal. Y entonces había que tenerlo mucho en cuenta porque por ejemplo cuando no los conocíamos las primeras sesiones que eran de presentación por así decirlo había muchos juegos que era imprescindible para el juego (...) eso no quiere decir que no haya que trabajarlo para nada con ellos." <Elementos internos $\|$ Entrevistas $\| C$ o6> - Referencia 3.

Uno de los objetivos básicos del servicio era fomentar el desarrollo motor de los niños a través de la selección y adaptación de las actividades en función de sus necesidades motrices. Esta premisa educativa fue una de las más atendidas, hecho que demuestra la coherencia curricular de las propuestas planteadas por los alumnos.

"...hemos intentado tanto como que desarrollaran actividades tipo un circuito, que desarrollaran varias actividades juntas, por ejemplo saltar, había niños que no sabían saltar y tenías que cogerles las manos para que ellos saltaran, otros que no tenían equilibrio. Entonces hemos intentado, viendo las deficiencias que tenían los niños y lo que les faltaba, hemos intentado adatar los juegos." < Elementos internos $\|$ Entrevistas $\| C$ o8> - Referencia 3.

Con el paso del tiempo y el conocimiento de los niños, el alumnado fue mejorando la atención personalizada a los receptores del servicio. Este hecho es fundamental en todo proceso educativo, pues el avance global del grupo está relacionado con la mejora individual de cada uno de sus miembros.

"Entonces pues durante las siguientes sesiones pusimos en práctica todo esto y como venían siempre los mismos niños pues nos resultaba mucho más fácil planificar las sesiones porque ya los conocíamos bien. Y pues realmente me di cuenta de que cada uno es diferente y necesitan unos estímulos diferentes porque tienen distintas necesidades, y bueno pues eso." <Elementos internos||Entrevistas $\| C$ og> Referencia 4 .

Debido a su exceso de rigidez, estos niños requerían un trabajo de desarrollo motor muy específico. Gracias al análisis de movimientos, el alumnado fue conociendo sus limitaciones y pudo adaptarse mejor a sus requerimientos. Esta labor es una de las más importantes en la función docente y demuestra el gran interés de los alumnos universitarios por conseguir mejoras en los niños receptores del servicio.

"Algunos niños eran muy rígidos (...) Entonces a la hora de ir haciendo las actividades en el momento ibas observando (...) cómo actuaba cada uno a la hora de hacer la actividad y poco a poco conforme los observábamos es lo que nos ha ido enseñando. Porque tú preparabas la sesión y luego llegabas allí y a lo mejor no sabía o no podían hacerlo por su movilidad." <Elementos internos\|Entrevistas\|C 10> Referencia 15.

\section{- Seguridad de los juegos.}

La seguridad de los juegos estudia el grado de peligrosidad existente de las propuestas a aplicar en función de los participantes.

La valoración del terreno de juego, como aspecto a considerar en cuanto a la seguridad de las actividades, es de gran importancia en educación infantil, ya que con estos niños las caídas son habituales. Por ello, siempre es preferible desarrollar las sesiones en terrenos blandos o 
acolchados en lugar de suelos duros y rugosos, consiguiendo así minimizar las dolencias ocasionadas por cualquier impacto.

"...era asfalto, bueno era... no sé cómo se dice ¿cemento? Ya... eso también se tenía en cuenta. Por ejemplo si tenían que correr o algo les decíamos... no corráis a todo lo que os da, más que nada por si se caían seguro que se hacían algo." <Elementos internos||Entrevistas ||C 01> - Referencia 4.

La intervención del alumno para evitar que dos niños pudieran hacerse daño mientras jugaban nos hace pensar en la atención que merecen aquellos participantes que, por cualquier motivo, puedan tenerse cierta antipatía. Como docentes debemos valorar adecuadamente estos conflictos para anticiparnos a la aparición de problemas mayores.

"...el sábado pasado se fueron, o sea, él se fue y ella le siguió y se fueron a una colchoneta que habíamos utilizado y que luego habíamos apartado un poquito. Y claro, yo para que se mataran entre ellos porque se estaban revolcando por el suelo y digo... ;aquí vamos a acabar mal! Pues me fui con ellos." <Elementos internos $\|$ Entrevistas $\| C$ o2> - Referencia 1.

El alumnado universitario valoró seriamente la seguridad de las propuestas y la participación de los niños como dos pilares básicos del programa educativo a aplicar. Estas premisas destacan su responsabilidad a la hora de planificar las sesiones de juegos.

"A la hora de plantear las dinámicas y los juegos siempre teníamos tres instrucciones básicas. Que no esperaran, también evidentemente el tema de la seguridad, que no llevaran los ojos vendados, y que no hiciéramos filas, cosas asi.." <Elementos internos $\|$ Entrevistas $\| C 0_{4}>$ - Referencia 3.

La atención personalizada sobre el nivel de excitación de un niño, para que no representara un riesgo durante el desarrollo de las actividades, supuso un aprendizaje muy importante para los alumnos universitarios. Esto cobra mayor importancia, si cabe, en este tipo de propuestas en las que los niños padecen trastornos que puede hacerlos más proclives a manifestar estas conductas.

"...muchas veces él sobrepasaba sus límites y se alteraba mucho y nosotras teníamos que controlarle. (...) Si estás haciendo un juego movido y este chico se altera mucho luego tienes que hacer un juego pausado para que vuelva a la calma (...) porque cuando se excitaba pues a lo mejor te cogía y te podía hacer daño. Entonces eso también lo teníamos que tener muy en cuenta." <Elementos internos $\|$ Entrevistas $\|$ C 05> - Referencia 2.

Debido a las limitaciones motoras de los niños, los alumnos universitarios consideraron necesario reducir la dificultad de ejecución de un juego para hacerlo más seguro. En un entorno educativo ordinario la zona de equilibrio de la actividad hubiera estado formada por bancos o alguna superficie elevada. No obstante, apreciamos cómo rebajaron dicha zona al nivel del suelo para desplazarse simplemente por encima de una cuerda. Incidimos en el acierto de esta decisión, pues es una adaptación muy apropiada teniendo en cuenta las características de los niños participantes.

"...lo que les hacíamos era ponerles cuerdas y poníamos pues como una ciudad y otra ciudad y que esto era el río, y entonces si se caían pues se los comían los tiburones. Entonces les poníamos simplemente cuerdas para que fueran por encima de las cuerdas con un pie delante del otro y que no cayeran." <Elementos internos||Entrevistas $\| C$ 07> - Referencia 11.

En este apartado hemos visto que el programa de APS generó numerosas situaciones en las que el alumnado universitario debía adaptar las actividades en base a las características de los 
receptores del servicio. Este aprendizaje es de vital importancia en cualquier proceso de enseñanzaaprendizaje ya que puede condicionar notablemente el éxito o fracaso del mismo.

\section{- Presentación de los juegos.}

En este bloque abordamos el análisis de la presentación de los juegos, apartado que estudia el modo en que los alumnos universitarios trasladaban sus propuestas a los niños de la entidad colaboradora.

\section{- Descripción de los juegos.}

La descripción de los juegos valora la explicación de las actividades propuestas por parte del alumnado universitario.

El alumnado indicó a los compañeros universitarios que describieran los juegos como si ellos mismos no supieran jugar, destacando la importancia de exponer todos los detalles de las actividades sin presuponer que los niños conocían el desarrollo de las mismas y asegurando la completa descripción de sus propuestas didácticas. Este ejercicio puede ser de gran utilidad para futuros docentes, ya que al conocer las dinámicas a realizar se pueden obviar algunas indicaciones necesarias para la correcta aplicación de las actividades.

"...las explicaciones les decíamos a las chicas, siempre se lo recalcábamos... explicarlo como si nosotras no supiéramos jugar. Explicarlo todo, paso por paso, detalle por detalle, no deis nada por hecho sino que..." <Elementos internos $\|$ Entrevistas $\| C$ o1 $>$ - Referencia 5.

La descripción de una actividad siguiendo unas pautas muy determinadas nos permite apreciar cómo este alumno elaboró una guía en la que no había dejado nada al azar para explicar un juego. Aunque esta estrategia es tremendamente costosa y difícilmente aplicable en el total de las actividades, puede ser de gran ayuda para aquellos docentes que se sientan inseguros por cualquier motivo, como iniciar su labor docente, cambiar de grupo de alumnos, trabajar en un nuevo centro, etc., ya que aporta una enorme seguridad durante este proceso de explicación.

"...traía mi guion como si fuera esto una obra de teatro de... actividad uno, nombre, dos puntos, palabras textuales con las que tenía que explicar la actividad, transición ¿cómo la hacemos? yo me pongo en la rayita que vamos a marcar con un aspa, los niños se van a poner aquí, la no sé quién del grupo aquí, no sé quién no sé cuántos, el niño $A$ aquí, el niño $B$ aquí, voy a hacer el ejemplo con el niño C." <Elementos internos\|Entrevistas $\| C$ o2> - Referencia 1.

Cuando los alumnos no lograban exponer los juegos de forma clara y concisa, el desarrollo de las actividades se veía muy perjudicado, llegando incluso a no poder aplicarse algunas tareas. Este hecho destaca la importancia de realizar una descripción adecuada de los juegos, acción que se puede facilitar en gran medida mediante la representación de los mismos.

"...cuando tú estás explicando el juego, tú tienes que prepararlo, pensarlo bien, o sea, no puedes llegar ahí a lo que me salga para contárselo porque tienes que explicárselo muy concisamente, es... ¡hay que hacer esto, ya! Porque si no luego no, de verdad que se les iba, o sea, cada uno se iba a una punta a 
jugar (...) no es explicárselo... ¡hala y ahora lo haces jejeje! Muchas veces teníamos que hacer nosotras lo que había que hacer." <Elementos internos\|Entrevistas ||C o6> - Referencia 3.

Debido a las limitaciones motrices existentes, los alumnos universitarios explicaban los juegos como si los niños fueran mucho menores, exponiendo la necesidad de adaptar la descripción de las actividades a las características de los participantes. No obstante, tras las indicaciones de sus familiares fueron corrigiendo este trato, lo que destaca la importancia de presentar las actividades según la capacidad intelectual de los participantes y no en base a sus competencias motrices.

"... al principio sí que como para niños de dos años, todo explicarlo, explicarlo muy bien, explicarlo dos veces. Pero es que luego los padres nos dijeron... no, es que ellos no hablan, ipero ellos te entienden perfectamente! Entonces claro pues empezamos a tratarlos pues como niños de su edad y ya está. Y vimos que vamos, que hablar no hablaran pero que lo entienden todo perfectamente. Entonces explicarlo todo igual y ya está, todo bien, claro y bien, pero no repetirlo veinte veces." <Elementos internos\|Entrevistas\|C 07> - Referencia 10.

Escenificar el desarrollo de las actividades de forma repetida, hasta comprobar que los niños eran capaces de jugar de forma independiente, destaca el beneficio de complementar la descripción de los juegos con una representación gráfica. Esta situación refuerza la relación positiva entre la explicación de las tareas y la ejemplificación de las mismas. Igualmente incide en la utilidad del aprendizaje por imitación, resaltando el valor del elemento visual de las explicaciones. Por último, se puntualiza que las indicaciones debían ser sencillas y cortas, facilitando así el entendimiento de las mismas. Este aporte también relaciona la descripción de los juegos con la comprensión de las normas, otro importante aspecto de este bloque.

"...era gestualizar mucho y repetir, repetir, repetir. Cuando veíamos que ellos ya por imitación lo hacian ya nos apartábamos un poco para ver si de verdad lo habían comprendido y ya es cuando lo comprendían (...) aparte de que eran órdenes muy sencillas, muy... frases cortas, lo hacíamos nosotras mucho para que ellos nos vieran y por imitación lo aprendieran." <Elementos internos $\|$ Entrevistas $\mid C$ 12> - Referencia 6.

\section{- Estructura de la sesión.}

La estructura de la sesión hace referencia a la coherencia organizativa de las actividades durante las prácticas.

Para ajustarse al grupo con TDAH, los alumnos universitarios realizaron juegos de alta exigencia motriz seguidos por otras tareas de baja activación. En un principio esta estructura organizativa sería poco adecuada con otro tipo de niños, pero conociendo las características de este colectivo entendemos que es una decisión muy acertada, pues les ayudó a regular su nivel de activación a través del marcado contraste de las actividades.

"...intento preparar juegos que sean más movidos, a lo mejor, que más pausado. Que también hay que haber... claro en este tipo de niños hay que hacer actividades de subida y de bajada, que los niños estos son picos. Entonces haces sube y baja, sube y baja, sube y baja, y al final para que ya entre ellos tengan una estabilidad."<Elementos internos $\|$ Entrevistas $\| C$ o3>- Referencia 1.

La importancia de realizar un juego de poca intensidad previo a la parada para almorzar, consiguiendo que los niños se relajaran antes de comer algo, nos transmite la preocupación 
del alumnado por seguir una progresión adecuada de las actividades a lo largo de la sesión. Igualmente se indicó la posibilidad de aprovechar estas situaciones para realizar aquellos juegos que ofrecieran algunas dudas respecto al éxito de su aplicación.

"Entonces considerábamos que antes del almuerzo hay que hacer siempre un juego de relajación, bueno no de relajación sino un juego que el nivel de activación sea bajo. $Y$, a lo mejor, pues sabiendo que tienes que poner un juego de ese estilo pues pones algo no muy convencido pero porque te preocupa o te interesa que se baje la activación aunque el juego no lo veas muy atractivo." < Elementos internos $\|$ Entrevistas $\| C$ o4> - Referencia 8.

Los alumnos universitarios consideraron necesario aplicar juegos de relajación, en la última parte de las sesiones, para que los niños no se fueran a casa demasiado excitados. Esta propuesta concuerda a la perfección con las sugerencias básicas en cuanto al desarrollo de la $E F$, coincidiendo estos ejercicios de baja activación con las comúnmente conocidas actividades de vuelta a la calma.

"...la cuestión que siempre les planteábamos a todos los grupos es que si ellos pensaban que es importante hacer un poco de relajación al final. Porque nosotras pensábamos que era necesario hacerlo en todos los grupos (...) en todas las sesiones se ha hecho la relajación. Creíamos que era una cosa buena para los niños también porque no se iban tan alterados de las sesiones." <Elementos internos $\|$ Entrevistas $\| C_{05}>-$ Referencia 5.

La distribución del trabajo del alumnado, en cuanto a la estructura de la sesión, muestra que cada alumno universitario era responsable de uno de los juegos de la sesión, mientras actuaba de apoyo en el resto de actividades. Esta estrategia fue de gran utilidad para reducir los tiempos muertos entre las distintas propuestas a realizar, destacando así la relación de este aspecto con la optimización del tiempo, otra importante cuestión analizada en este trabajo.

"Entonces pues mientras una se encargaba un juego y todo lo que eso conlleva que sería describirlo, controlar a los niños, estar pendiente del tiempo... pues otra podría estar organizando ya su actividad. Entonces pues ya no se perdería el tiempo entre las actividades y todo estaría más fluido y también pensábamos que así el tiempo de compromiso motor sería más alto." <Elementos internos $\|$ Entrevistas $\| C$ og> - Referencia 1.

El uso de una temática común a lo largo de la sesión, para mantener un elevado nivel de motivación en los niños, nos ayuda a entender que este hilo conductor no solo afectaba al entorno contextual de las prácticas sino que también influía en su estructura organizativa. Por ello, este tipo de dinámicas deben estar perfectamente dirigidas desde la programación de las actividades, evitando así la aparición de conflictos durante la aplicación de las sesiones.

"...nosotras al principio lo que solíamos hacer era buscar algún hilo conductor para tenerlos más motivados y todo eso. (...) aparte las actividades con los niños de cuatro años tienen que ser muy, muy simples." <Elementos internos $\|$ Entrevistas $\| C$ 12>- Referencia 3.

\section{- Comprensión de las normas.}

La comprensión de las normas comprueba el entendimiento de la dinámica de las actividades por parte de los jugadores.

El alumnado utilizó una sencilla estrategia para verificar si los niños habían entendido el desarrollo de las tareas, preguntándoles directamente o pidiéndoles que lo explicaran ellos 
mismos. Esta acción representa una herramienta útil para cualquier docente, ya que le permite comprobar de forma rápida si los niños han asimilado cualquier explicación o concepto.

"...les explicábamos todo el reloj, todos los momentos y cuando eso... para verificar que los niños lo habían entendido pues siempre preguntábamos... a ver ¿lo habéis entendido? Si, a ver ¿quién me lo explica otra vez? Y entonces salía un voluntario $y$ lo explicaba todo." <Elementos internos $\|$ Entrevistas $\| C_{03}>$ - Referencia 1.

Los alumnos universitarios fueron incluyendo las reglas de los juegos, de forma progresiva con el desarrollo de las actividades, para facilitar su entendimiento por parte de los niños. Con ello lograron aumentar poco a poco la complejidad de sus propuestas, implantando la siguiente norma una vez comprobado que habían entendido y asimilado la anterior. Este aumento gradual en la dificultad de las tareas es la base de todo proceso educativo.

"...iban dando pautas cortas a mitad del juego. Por ejemplo que cuando una persona lanzara todos tienen que estar quietos o que no se tenía que hablar o (...) ahora avanzamos un poco a la pata coja. Pero siempre iban dando... no daban las instrucciones todas juntas sino que iban dando las instrucciones un poco conforme iba avanzando la actividad para que ellos lo pudieran hacer. Porque si les decías todo luego hacían lo que querían." <Elementos internos ||Entrevistas \|C 05> - Referencia 16.

Cuantas más normas tenía un juego más complejo era su entendimiento y viceversa. Esto incide en la relación existente entre la proporción de reglas a seguir y la dificultad de una actividad. Conocer la dependencia de estos aspectos es de gran utilidad, ya que modificando la cantidad de exigencias de un juego podemos variar la dificultad del mismo a nuestro interés.

"...si veíamos un juego que era muy complicado porque requería hacer muchas cosas o estar atento a muchas cosas con eso no nos hemos atrevido normalmente o los hemos reducido o simplificado. $O$ si... no sé, el número de normas y el número de cosas para hacer, eso lo hemos tenido muy en cuenta, y luego también la dificultad de lo que había que hacer." <Elementos internos\|Entrevistas\|C o6> Referencia 29.

Los alumnos universitarios indicaron a sus compañeros que el ritmo de asimilación, respecto a las pautas a seguir en los juegos, era mucho más lento con estos niños, advirtiendo que una mala valoración, en cuanto al entendimiento de las normas, podía tener un efecto negativo en el desarrollo de las actividades. Esta situación tuvo una gran influencia sobre la organización temporal de la sesión, ya que ralentizó notablemente todos los procesos a realizar a lo largo de la misma, de ahí su importancia.

"...al principio las chicas que venían sí que hacían sesiones como en un colegio y lo explicaban muy rápido y les tenías que decir... no, que no lo entienden, les cuesta más. Entonces claro a lo mejor ellas llevaban programadas cinco o seis actividades que duraban para ellas diez minutos, pero para estos niños a lo mejor duraban veinte minutos porque entre que se lo explicabas, lo entendían, luego si no lo entendían se lo tenías que volver a explicar entonces el tiempo era más largo que los otros niños en un colegio que tú lo explicas y enseguida lo hacen." <Elementos internos\|Entrevistas $\| C$ 10> - Referencia 15.

Pese al entendimiento de las actividades, la implantación progresiva de las normas, como consecuencia de la falta de confianza existente, muestra las reticencias de los niños al realizar las tareas por no sentirse cómodos con el contexto. Por ello, ir introduciendo reglas de forma 
paulatina puede ser una buena opción para solventar esta clase de cuestiones, ya que ofrece más tiempo a los niños para adaptarse y familiarizarse con el entorno de la actividad.

"...la dificultad que tenían era entendernos o que participaran, porque si no vienen a clase, no tienen confianza entre ellos, no tienen confianza contigo, les cuesta un poco más lanzarse. Pues un poco sí que intentábamos siempre salvar ese aspecto de... vamos a decirles solo esto y luego ya les decimos otra cosa. ¡Venga, ahora vamos a saltar! cuando ya lo habías hecho dos o tres veces... vale chicos y ahora mirad atención, ivamos a hacer esta otra cosa! e introducías otra norma. Como ya habían hecho la primera ya la tenían como asimilada entonces la segunda era más... la captaban." < Elementos internos\|Entrevistas $\|$ C 11> - Referencia 20.

\section{- Representación gráfica.}

La representación gráfica es el aspecto que analiza la información visual aportada en la presentación de las actividades.

Este alumno indicó a sus compañeros que una buena visualización de las tareas puede facilitar enormemente la descripción de las mismas, destacando la relación que existe entre la representación gráfica y la comprensión de las normas. Este hecho, sumado a los ya expuestos con anterioridad, pone de manifiesto la gran coherencia e interrelación entre los distintos aspectos de este apartado.

"...y luego poned ejemplos, que os vean... todo visualizado porque así lo cogerán a la primera, más que en veinte explicaciones." $<$ Elementos internos $\|$ Entrevistas $\| C$ o1> - Referencia 2.

La representación gráfica aplicada a una actividad de baile nos ayuda a entender cómo se situó el alumnado, en el terreno de juego, para facilitar la adquisición de los distintos pasos del baile por parte de los niños. No obstante, comprobamos que no todos los movimientos eran dirigidos, ya que dejaron algunos momentos para la libre actuación de los participantes, fomentando así su intervención en estas actividades de expresión corporal.

"...éramos tres así y las otras en frente, y los niños detrás para que cogieran los pasos. Entonces poníamos la música y dependiendo del momento de la música (...) pues hacían unos pasos u otros. Era muy sencillo, era pues caminar hacía un lado, caminar hacia el otro, hacia adelante, hacia atrás, con diferente ritmo (...) luego nos juntábamos todos y escuchando la canción a cada uno se le daba su momento de baile (...) así una ronda de baile individual." <Elementos internos\|Entrevistas\|C o3> Referencia 2.

Incluir referencias visuales en la descripción de los juegos facilitó la organización de los niños y los mantuvo más atentos durante las explicaciones. Esta situación destaca la importancia de atraer el interés de los jugadores en la presentación de las actividades. Igualmente la relación entre la representación gráfica y la organización del alumnado demuestra la vinculación de este aspecto con otros elementos de este análisis.

"Y también como veían también el dibujito pues la explicación también se hacía más corta porque en realidad ellos ya se hacen a la idea de qué vamos a hacer, que en plan organización con ellos sí que nos ayudó mucho. Sí a tenerlos centrados." <Elementos internos $\|$ Entrevistas $\|$ C o6> - Referencia 5.

El uso de diversos tipos de información visual, para simplificar la presentación de los juegos y facilitar el entendimiento de las normas, no deja lugar a dudas en cuanto a la intención del alumnado al incluir imágenes y representaciones a modo de ejemplos. Esta acción nos permite apreciar cómo fueron capaces de escenificar las actividades a realizar con tal de 
asegurar el entendimiento de las mismas por parte de los niños del centro colaborador. Nuevamente comprobamos la vinculación de este aspecto con el resto del bloque.

"...muchas veces poníamos ejemplos, o sea, lo estábamos explicando y había dos chicas haciendo el ejemplo para que observaran cómo se hacía o con imágenes también muchas veces para que lo vieran en la imagen y no solo... o ellos mismos, cogíamos dos de ejemplo y nosotros les ayudábamos a realizarlo. Hacíamos uno de prueba para que lo vieran y si no lo habían entendido lo volvíamos a repetir hasta que lo entendieran." <Elementos internos $\|$ Entrevistas $\| C$ 10>- Referencia 1.

La representación gráfica fomentó el aprendizaje por imitación de los participantes, aprendiendo el desarrollo de los juegos a base de mirar y repetir lo que hacían los alumnos universitarios. Esta alternativa puede ser especialmente útil cuando hay serias dificultades en la comunicación verbal entre docente y alumnado. Asimismo se estimula la expresión corporal de los niños a través de esta relación no verbal.

"Nosotras llegábamos allí y la explicación era... como si estuviéramos haciendo un teatro, igual, no parábamos de gestualizar para que ellos lo vieran. Por ejemplo el juego del pollito inglés, que lo hicimos con los pequeños. Pues lo explicamos gestualizando nosotras, haciendo un ejemplo y nos pusimos a jugar y no lo hacían y a base de repetir, repetir, repetir (...) nos imitaban, y a raíz de imitarnos han aprendido ellos a jugar. Porque al final ya no nos poníamos y ellos lo hacían bien." <Elementos internos $\|$ Entrevistas $\| C$ 12>-Referencia 2.

El análisis de la presentación de los juegos pone de manifiesto la notable interrelación entre los distintos elementos de este apartado, remarcando la gran coherencia interna del mismo. Por ello, la mejora individual de alguno de estos aspectos afectará positivamente al resto de elementos de esta categoría, mejorando en su conjunto la exposición de las actividades.

\section{- Organización del alumnado.}

A continuación abordamos la organización del alumnado, bloque que hace alusión al modo en que los alumnos universitarios coordinaron y gestionaron a los niños durante la aplicación de las actividades.

\section{- Participación del alumnado.}

La participación del alumnado estudia el grado de intervención de los niños en las propuestas motrices y expresivas aplicadas.

Los alumnos universitarios dejaban que los niños decidieran el juego final de la sesión si intervenían adecuadamente en el transcurso de la clase, incentivando así su participación. Pese a que en este caso la estrategia tuvo éxito, debemos advertir que estas técnicas no siempre son efectivas. Por ello, es aconsejable desarrollar otras alternativas para fomentar la participación de los niños.

"...para que también ellos se involucren de alguna manera y estén un poquito más atentos al desarrollo de las sesiones siempre les dejamos unos cinco o diez minutos, al final prácticamente, para que ellos perciban un poco el control de lo que están haciendo allíy puedan elegir de los juegos que hemos hecho anteriormente cuál quieren repetir. <Elementos internos\||Entrevistas $\| C$ 04>-Referencia 3. 
Vista la dificultad de una niña para tomar parte en numerosas actividades, los alumnos decidieron elaborar una propuesta adaptada a sus necesidades y preferencias para asegurar su intervención. Esta acción pone de manifiesto la capacidad del alumnado universitario para reconocer los intereses de esta niña, así como el deseo de integrarla en el resto de actividades a través de esta primera propuesta. No obstante, esa estrategia solo debería emplearse mientras no perjudique a ninguno de sus compañeros.

"...había una niña que tenía dificultades para... siempre se quería coger de ti, no quería ir, no quería andar sola entonces propusimos una actividad para esta niña que fuera de... como por ejemplo subir las escaleras y bajar la rampa, de estas de madera, para que ella sola pudiera hacer la actividad. Entonces la actividad esta de subir escaleras y bajar la acoplamos a todo el grupo para que esta niña en concreto la pudiera realizar." <Elementos internos $\|$ Entrevistas $\| C$ 05> - Referencia 7.

Los alumnos universitarios encuadraron las sesiones de juegos en distintos contextos atractivos para fomentar la intervención de los niños. Esta actuación demuestra su capacidad para identificar temáticas que motivaran la participación en las actividades propuestas.

"Por ejemplo iba muy bien con ellos tener como un hilo conductor, como tener una temática en la sesión, para centrarlos mucho y sobre todo también porque ahí puedes jugar con escoger un tema que a ellos les motive mogollón. Entonces también pues con eso pues ya consigues que participen más o que estén más." <Elementos internos\|Entrevistas $\| C$ o6> - Referencia 2.

El objetivo de mantener un elevado nivel de compromiso motor, durante la aplicación de los juegos, supo evitar aquellas propuestas en las que los niños debían esperar para intervenir. Esta situación distingue la participación activa de la mera intervención en las actividades, hecho que nos hace reflexionar sobre ambos conceptos. Por ello, para alcanzar un grado de participación adecuado debemos obtener resultados positivos en ambos supuestos, consiguiendo que los niños tomen parte en las actividades propuestas y que su nivel de participación activa sea el más elevado posible

"...también vimos que era importante que los niños estuvieran haciendo algo en todo momento, que no plateáramos actividades que tuvieran que estar esperando a su turno y que la mayor parte del tiempo estuvieran parados. Por lo mismo de siempre, para que el grado de compromiso motor fuera alto, que eso para ellos era, o sea, era importante." <Elementos internos ||Entrevistas ||C og> - Referencia 2.

El alumnado universitario tuvo muchos problemas para integrar a los niños en una misma actividad, pues presentaban características muy dispares. Con el paso de las sesiones lo fueron consiguiendo, situación que demuestra el gran esfuerzo realizado así como el buen resultado obtenido, gracias a la adquisición de importantes estrategias como la introducción de variantes en el desarrollo de las actividades.

"Aunque tenían la misma edad y estaban todos con más o menos entre la franja de edades todos en el mismo grupo pero las características podías encontrar uno con autismo, otro en silla de ruedas, otro con parálisis... entonces, otro con síndrome... Entonces tenías que hacer una actividad que pudieran jugar todos a la vez y que aunque necesitara ayuda participaran todos juntos en la actividad (...) al principio nos centrábamos solo en una actividad y no sabíamos sacarle variantes a esa actividad para que pudieran jugar todos. Y ahora ya sabemos cómo organizarlo de manera que puedan participar todos a la vez." <Elementos internos $\|$ Entrevistas $\| C$ 10> - Referencia 4. 


\section{- Distribución de roles.}

La distribución de roles comprueba la asunción de distintas actuaciones por parte de los niños durante el transcurso de los juegos realizados.

La aplicación de una actividad muy popular en la que los niños debían asumir dos roles bien diferenciados, perseguidor y perseguidos, nos deja ver que los alumnos no tuvieron problemas en recurrir a juegos conocidos para tratar de alcanzar los objetivos propuestos.

"Vamos a jugar al pilla pilla." <Elementos internos $\|$ Entrevistas $\mid C$ 01> - Referencia 1.

La realización de un juego original basado en la interpretación de distintos roles, distribuidos en función de la edad de los participantes, nos lleva a pensar en su mayor adaptación a las capacidades de cada uno de los niños. Igualmente debemos resaltar la interacción cooperativa entre los diferentes papeles desarrollados, algo que aporta un nuevo beneficio social a empleo de esta actividad.

"...en este juego concretamente de la natación cogimos a los dos más grande y tenían que... los demás tenían que disfrazar al grande." <Elementos internos $\|$ Entrevistas $\mid C$ O3> - Referencia 1.

La posible evolución de las actividades, a raíz de introducir cambios en los roles de los jugadores, nos hace pensar en la gran cantidad de variantes que se pueden ofrecer en una misma actividad gracias a esta estrategia. Esta acción incrementa el número de experiencias motrices y amplía el tiempo útil de aplicación, potenciando notablemente la riqueza de los juegos.

"... al final había que poner normas nuevas o cambiar el tipo de juego de una sola cosa que era... jugar a uno se mete por debajo y ahora aparece por arriba pero el otro le quiere quitar, pues vamos a jugar a pillar, pues ahora te cambias el papel y ahora eres tú el de abajo y ahora eres tú el de arriba, pues ahora sois dos debajo. Cosas así (...) ir variando el juego." <Elementos internos\|Entrevistas\|C o6> Referencia 9.

En función de las posibilidades y limitaciones de los niños, los alumnos universitarios les asignaron un papel $u$ otro en el desarrollo de los juegos. Aunque esta acción pueda resultar encomiable, debemos recomendar el desempeño de los distintos roles de la actividad por parte de todos los jugadores. Con ello se aumentaría la exigencia motriz de la propuesta y se incrementarían las experiencias de los participantes.

"...la actividad de los refugios la hemos utilizado bastante porque ahí colocábamos a cada niño digamos lo que mejor se le daba a cada uno y así sacar el máximo partido. Porque por ejemplo J---- M--- que no anda pero sí los brazos y lanzar le gusta pues a él lo poníamos a lanzar los balones. Luego B---con nuestra ayuda llevándolo un poco nosotras pero andando él y A---- y C---- pues iban corriendo y huyendo de las pelotas (...) Cada uno adaptarlo a lo que más, mejor le veía." <Elementos internos $\|$ Entrevistas $\|$ C 07> - Referencia 1.

Un juego, en el que dependiendo del desarrollo del mismo los niños debían cambiar el rol a desempeñar, nos hace reflexionar sobre la importancia de identificar correctamente estos momentos durante la explicación de las actividades. De lo contrario, la aplicación de las propuestas podría estar llena de problemas y errores asociados a esta incertidumbre.

"Hubo una vez que jugábamos a (...) unos eran grillos y otros eran ranas jejeje y era cuando una rana tocaba al grillo o algo así, el grillo se transformaba en rana, más o menos. Entonces era un poco 
relacionar el que si te había tocado el compañero tú tenías que cambiar, no podías seguir siendo lo que eras ¿no? el cambiar el chip ese de..." <Elementos internos $\|$ Entrevistas $\| C$ 11> - Referencia 7.

\section{- Trabajo individual/grupal.}

El trabajo individual/grupal valora la aplicación de actividades en las que los niños intervengan de forma individual y/o colectiva durante las sesiones de juegos.

El alumnado universitario aprovechó la buena afinidad entre dos niños para fomentar su actuación conjunta durante las actividades. Este hecho nos lleva a reflexionar sobre la influencia de la intervención individual de cada niño sobre el resto de jugadores como, en este caso, en lo referente a su participación en los juegos.

"...uno de los mayores que viene así súper cañero de hacer todas las actividades y además las hace con muchas ganas también se lleva bien con una nena pequeñita que por ejemplo a él le gusta mucho bailar y entonces cuando hay que hacer algo de bailar la coge y se pegan ahí unos bailes (...) nos gusta ponerlos juntos porque a ella le gusta recibir ayuda y a él le gusta ayudar." <Elementos internos $\|$ Entrevistas $\| C$ 02 $>$ - Referencia 4.

A consecuencia de su situación de benjamín en el grupo, un niño debía asumir ineludiblemente un importante rol en un momento concreto del juego. Esta hábil estrategia no solo aseguró su participación en el desarrollo de la actividad sino que, además, le ofreció la opción de ganarse el respeto y admiración del resto de sus compañeros, facilitando así su socialización e integración en el grupo.

"La pista la tenía que coger el más pequeñito, para hacerle partícipe también." <Elementos internos $\|$ Entrevistas $\|$ C $03>-$ Referencia 8.

Los alumnos fomentaron la participación grupal de los niños, a través de una actividad cooperativa en la que debían colaborar entre ellos, para conseguir las piezas de un atuendo vinculado con la temática de la sesión. Esta propuesta utiliza un estímulo competitivo para generar un sentimiento de grupo y mejorar la intervención conjunta de los jugadores. Por ello, se debe incidir en la importancia de la actuación cooperativa frente al resultado final de la competición, para que este elemento no condicione en exceso el desarrollo del juego.

"Hubo un juego cooperativo que también lo hemos utilizado dos veces, adaptado de dos formas diferentes pero muy similar. Que era que entre ellos tenían que competir, o sea, por grupos tenían que cooperar cada grupo pero compitiendo respecto al otro para ir consiguiendo partes de un disfraz y acabar generándose ellos un disfraz identificado a la temática de ese día." <Elementos internos $\|$ Entrevistas $\| C$ 04> - Referencia 7.

La dificultad de realizar actividades colectivas con el grupo de niños más pequeños nos ayuda a entender el fracaso del alumnado universitario en la aplicación de una propuesta. Por ello, optaron por desarrollar actividades en pequeños grupos por niveles de competencia. Esta acción demuestra su capacidad de análisis y su habilidad para agrupar a los participantes, ya que no se limitaron a realizar trabajos individuales.

"Intentábamos plantear una actividad, por ejemplo un circuito, para ver si todos los niños del grupo podían hacer la actividad esa. Pero algunas actividades en algunos grupos, por ejemplo en el de los pequeños, nos dimos cuenta cuando realizamos esta actividad de que no se podía hacer una actividad para todos." <Elementos internos $\|$ Entrevistas $\| C$ 05> - Referencia 8. 
La necesidad de organizar a los niños tanto de forma individual como colectiva nos transmite la atención del alumnado en esta cuestión, destacando la importancia de coordinar adecuadamente la aplicación de ambas propuestas.

"...organizar a los niños de forma individual y de forma colectiva, como te estaba diciendo."

$<$ Elementos internos\|Entrevistas $\|$ C og $>$ - Referencia 3.

\section{- Control del respeto por las normas.}

El control del respeto por las normas hace referencia a las estrategias utilizadas por los alumnos para asegurar el cumplimiento de las reglas establecidas por parte de los niños.

El proceder del alumnado cuando los niños no seguían las normas indicadas se basaba en cambiar de juego para evitar la continuidad de dicha problemática. Pese a servir como medida evasiva, esta acción debe ir acompañada de un proceso de reflexión en el que se expliciten los motivos por los que se sustituye el juego, de lo contrario no se entenderá el porqué del cambio de actividad.

"...cuando nos dábamos cuenta de esto... es que los niños no están haciendo caso, se están rebotando, cada uno va a su bola, decíamos... mirad cambiad de juego." <Elementos internos||Entrevistas ||C o1> Referencia 5.

Los alumnos actuaron con mucha permisividad cuando algún niño no quería participar en una actividad, dejando que se incorporaran al juego según su propio interés. Este proceder es muy comprensivo con sus deseos y sentimientos. Sin embargo, no debemos supeditar la participación a su propio criterio, por lo que, siempre que la situación lo permita, se recomienda el uso de una estrategia más persuasiva.

"...el niño que no quiera participar pues su tiempo fuera y que ya decidirá él cuando... o sea, no forzar ¿no? tampoco. Que ellos tomaran la decisión de ver que si los demás se lo pasaban bien pues podían participar libremente cuando ellos quisiesen y no tener que estar nosotros ahi." <Elementos internos $\|$ Entrevistas $\| C$ 04> - Referencia 2.

El procedimiento a seguir si los niños se alteraban o no atendían al juego era progresivo, primero reducían el volumen de la canción, luego detenían la actividad y, si seguían sin prestar atención, reiniciaban el juego describiéndolo desde el principio. Estas acciones muestran el buen hacer del alumnado en la resolución de este conflicto, pues cada una de ellas responde a distintas posibilidades de inatención, como dejarse llevar por el ritmo de la música, presentar un exceso de agitación que impida el progreso habitual de la actividad o no estar atento durante la explicación del juego.

"...bajar la música o pararla y volver a empezar o volver a explicarles el juego, normalmente bajábamos un poco la música y ya se relajaban." <Elementos internos||Entrevistas||C o8> - Referencia 5.

Debido al gran número de alumnos presentes, decidieron crear una figura que se dedicara única y exclusivamente a controlar el respeto de las normas durante las sesiones. Esta decisión nos transmite la importancia que el alumnado le daba a este aspecto en el global de la actividad, algo que se ve reforzado al comprobar su insistencia por conseguirlo.

"Habían dos en primero que eran bastante cañeros de... poco compañerismo o... Entonces pues como también a lo mejor éramos más, siempre había alguna que estaba un poco más encima de que... controlar que no se fueran de madre ¿no? de... iyep, relax, control! Eso nos ayudaba, pero como éramos 
muchas no damos tampoco tiempo a que se descuadrara todo (...) vuélvelo a decir. ¿Sabes? En plan de... ¡no lo han captado, repitamos! Y la repetición también la usábamos mucho." < Elementos internos $\|$ Entrevistas $\| C$ 11> - Referencia 8.

El proceder de este alumno, al reprender una conducta inapropiada de los niños, nos ayuda a ver cómo fue capaz de enfrentarse a sus propios compañeros para conseguir el respeto necesario y mantener una disciplina mínima durante el desarrollo de las actividades. Alabamos este proceder, pues la discrepancia con el resto de alumnos universitarios dificulta enormemente que se puedan aplicar este tipo de medidas. También queremos destacar la profundidad de su reflexión sobre esta situación, gracias a una convincente argumentación que no deja lugar a dudas en cuanto a la pertinencia de su actuación.

"...como al principio no nos hacían caso, les dijimos eso y seguían sin hacernos caso, pues ya al final cogí la pelota y dije... ¿qué estáis haciendo? Y me dice, y me decían... hemos ido a quitarla, digo... ipues hale, id a coger las bolsas que hemos acabado de jugar hoy! (...) Y estas me decían... que mala eres, digo... mala no, pero es que al final nos, se van a burlar de nosotros (...) mala no pero así es como de verdad ellos se darán cuenta de que lo que estaban haciendo está mal. Porque si tú lo están haciendo y aún les recompensas siguiendo jugando..."<Elementos internos $\|$ Entrevistas $\mid C$ 12> - Referencia 2.

Gracias a este apartado hemos comprobado que la práctica de APS generó numerosos aprendizajes en cuanto a la gestión de los receptores del servicio. La realidad del contexto de acción nos ayuda a ver las notables diferencias en esta cuestión respecto a la aplicación de prácticas simuladas con compañeros universitarios.

\section{- Organización del material.}

Seguidamente abordamos el análisis de la organización del material, apartado que examina el modo en que el alumnado universitario gestionó los recursos materiales disponibles durante las actividades.

\section{- Uso del material.}

El uso del material estudia la adecuación en la aplicación de los juegos respecto al empleo de los recursos materiales.

Utilizar materiales específicos, relacionados con la temática de la actividad, nos hace pensar en la posibilidad de emplear objetos poco comunes, gracias a la creación de un entorno educativo acorde con cada situación. De este modo, seríamos capaces de aprovechar cualquier material con la adecuada ambientación contextual.

"...por ejemplo en la sesión que hicimos de piratas con bandanas y todos disfrazados y además luego sacamos las espadas." <Elementos internos $\|$ Entrevistas $\| C$ 02 $>$ - Referencia 1.

Emplear un material con un objetivo muy distinto del que se le supone nos muestra la viabilidad de encontrar nuevas formas para aprovechar los objetos disponibles. Así pues, ponerse un cono en la cabeza fue de gran utilidad en un ejercicio de equilibrio, ya que era susceptible de cualquier variación en cuanto a la estabilidad de su portador. Igualmente su 
posición era fácilmente reconocible, por lo que no generó problemas al observar a los participantes desde una distancia relativamente lejana. Este uso alternativo del material también demuestra la creatividad del alumnado en este aspecto, algo que puede mejorar notablemente la optimización de estos recursos.

"Entonces con el cono encima de la cabeza, un poco de equilibrio, pues también iban saltando."

$<$ Elementos internos||Entrevistas $\|$ C 03>-Referencia 10.

No es de extrañar que las actividades que implicaran el uso de pelotas con estos niños fueran todo un éxito, ya que este material les resultaba muy atractivo. Por ello, se aprovechó su carácter motivador para incentivar la participación de los jugadores en aquellas actividades o tareas que inicialmente no eran de su agrado. Sin embargo, no se debe abusar del empleo de estos objetos, ya que podrían monopolizar la atención de los participantes.

"...todo lo que llevaba balón, siempre, todos los juegos que llevaban balones, vamos esos éxito total, pero tampoco hemos abusado mucho de ellos." <Elementos internos\||Entrevistas ||C o4>-Referencia 4.

El gran despliegue de recursos materiales necesarios para desarrollar una actividad con multitud de tareas nos ayuda a entender la compleja dinámica del circuito realizado. El éxito de esta actividad estaba supeditado a la correcta distribución del material y a la optimización del mismo. Esta situación demuestra la estrecha relación entre las distintas categorías de este bloque, poniendo de manifiesto su gran coherencia interna.

"...normalmente poníamos primero una colchoneta para que hicieran la voltereta. (...) luego hacíamos un banco para que aguantaran el equilibrio (...) las escales para que subieran hasta arriba ellos solos y saltaron, o sea, y saltaran (...). Luego había unos círculos, unos medios círculos, para que pasaran por el medio (...). Luego hay los gusanos estos que son de tela que le pones la forma que quieres y tienen que pasar por dentro (...). Al final sí que poníamos, por ejemplo, la canasta para que (...) tuvieran un aliciente a acabar el circuito (...) se lo pasaban bien y nunca querían acabar el circuito." < Elementos internos $\|$ Entrevistas $\| C$ o8> - Referencia 10.

El escaso uso de un paracaídas, objeto poco común y lleno de posibilidades educativas, hizo reflexionar al alumnado sobre la importancia de aprovechar adecuadamente todos los materiales disponibles a su alcance. Con ello se vuelve a incidir en la optimización de estos recursos para elaborar sesiones con gran variedad de estímulos.

"...yo personalmente había oído hablar de él pero no había visto el juego en directo. Entonces me gustó y de hecho ahora en prácticas lo he puesto en la semana pascuera que vamos a hacer una yincana y eran todo juegos tradicionales típicos. Y yo he dicho... ¡hombre! Sacar el paracaídas aún que lo tenéis ahí guardado en una bolsa, ipor favor! Jejeje." <Elementos internos\|Entrevistas $\mid C$ 11> - Referencia 6.

\section{- Variedad de material.}

La variedad de material analiza el empleo de diversos objetos en el desarrollo de las sesiones realizadas.

El uso de diferentes tipos de materiales en el transcurso de una actividad pone de manifiesto la riqueza de las propuestas aplicadas, así como la gran cantidad de estímulos provocados en los niños de la entidad a la hora de relacionarse con todos y cada uno de estos objetos.

"...al principio de cada ladrillo había cuerdas, habían palos, habían aros, habían pelotas..." < Elementos internos $\|$ Entrevistas $\| C$ 01> - Referencia 3. 
Utilizar una gran cantidad de objetos permitió al alumnado universitario atraer la atención de los niños, despertar su interés y mejorar su participación en las actividades propuestas. No obstante, debemos evitar el uso de esta estrategia en colectivos con TDAH, ya que un elevado número de estímulos pueden generar una sobrexcitación poco deseable para el desarrollo de la sesión.

"El material, o sea, nosotros teníamos siempre unas cantidades de material tremendas ¿por qué? porque queremos que su atención, o sea, queríamos llamar su atención siempre, sorprender y..." $<$ Elementos internos\|Entrevistas $\|$ C 04> - Referencia 5.

El alumnado complementó el instrumental del centro colaborador con nuevos elementos que incrementaron la variedad de recursos materiales disponibles. Este hecho nos lleva a pensar en la importancia que le daban a esta riqueza de materiales, algo que aumentaría las posibilidades de trabajo con los niños. Igualmente destaca el interés de los alumnos por prestar un servicio de calidad más allá de las posibilidades del centro colaborador.

"...casi todos los grupos han utilizado el material de alli porque para las sesiones que habían preparado no necesitaban nada más. Pero muchos grupos sí que, aparte de lo que había allí, llevaban más cosas como botellas por ejemplo para jugar a los bolos (...) llevaban material alternativo pero como para complementarlo." <Elementos internos $\|$ Entrevistas $\|$ C 05> - Referencia 19.

Los alumnos universitarios se decantaron por el uso de un balón de gran tamaño para solventar las limitaciones de un niño al agarrar una pelota pequeña, así lograron que participara en el juego con el resto de sus compañeros. Esta experiencia nos indica que disponer de una gran variedad de materiales no solo brinda la posibilidad de generar más estímulos sino que también permite responder a una mayor cantidad de exigencias a lo largo de las actividades. Igualmente queremos destacar el carácter social de esta acción en cuanto a la atención de las necesidades educativas del niño.

"...les hacíamos una que era de lanzar, cogimos en general pelotas de espuma y conos. $Y$ entonces tenían que lanzar y tirar el cono (...). Pero como J---- M---- por ejemplo, la pelota le costaba cogerla pues a él le poníamos la azul más grande de goma, entonces esa con las dos manos sí que ya le daba y vamos y él se pegaba una alegría cada vez que tiraba el cono." <Elementos internos ||Entrevistas ||C 07> - Referencia 7.

La presencia del alumnado universitario en el centro colaborador permitió a los niños realizar actividades con materiales que aún no habían utilizado hasta la fecha. Esta situación demuestra su enorme carácter servicial más allá de cumplir con una actividad curricular de su formación. De igual modo, apreciamos su interés por aprovechar al máximo los recursos disponibles en el centro, otro aspecto analizado en este bloque.

"...creemos que a modo de servicio, a los niños más que al cole (...) lo hacemos a todos ¿no? pero yo me centro más en los niños. Es poder usar la cantidad de material que tienen allí, porque la verdad es que tienen mucho material (...). Los primeros días ni nos dábamos cuenta pero ya cuando llevábamos tres o cuatro empezamos a entrar ahí a hurgar por las cajas (...) imira pues si hay sacos, mira pues hay patines, mira pues hay...! Y ya empezamos a trabajar también con el material." <Elementos internos $\|$ Entrevistas $\| C_{11}>$ - Referencia 3. 


\section{- Optimización del material.}

La optimización del material valora el provecho que se extrae de los objetos disponibles en el transcurso de las actividades.

Aprovechar un mismo objeto para desarrollar diferentes juegos permitió al alumnado aplicar distintas propuestas sin tener que cambiar de material. Este hecho maximizó la duración de la sesión al no perderse tanto tiempo entre juego y juego. No obstante, este beneficio no debe perjudicar en ningún momento el uso de materiales variados, otra cualidad a tener en cuenta a lo largo de las sesiones.

"Implica que tienes que (...) preparar material cada vez material un juego diferente y en cambio con lo del paracaídas que era una cosa tan sencilla como pasar de jugar a, yo que sé, a abanicarlo así a que una se pusiera por debajo y los pille, a que ahora los tengas que pillar pero haciendo no sé qué." $<$ Elementos internos\|Entrevistas $\|$ C 06>-Referencia 1.

El alumnado utilizó diferentes tipos de aros para elaborar dos propuestas que fomentaran el lanzamiento en los niños de la entidad. Resaltamos el doble provecho de esta acción pues, aunque empleaban un mismo material para diferentes ejercicios, el uso de este objeto era muy diferenciado en ambas propuestas. Así pues, mientras los aros servían de diana en un juego, en el otro se utilizaban como objeto a lanzar. Con esta acción se logró un desarrollo motor variado respecto al uso de este material.

"...queremos preparar algo para lanzar. Y entonces pues dijimos... pues lanzar, vale, la canasta está muy alta entonces ahí no llegan. Y pensamos... ostras, pues si tenemos aros y tenemos cuerdas, ipor qué no colgamos aros y que cada uno...! U otro por ejemplo, con conos, también para lanzar. Cogíamos conos los poníamos en el suelo y cogíamos los aros sensoriales, estos que son chiquititos, pues también para que lanzaran ahí, no sé, cosas asi.."<Elementos internos\|Entrevistas\|C o7> - Referencia 9.

Los alumnos montaron dos circuitos diferenciados e hicieron que los niños los utilizaran de forma no consecutiva, aprovechando el mismo material en diferentes momentos de la actividad. Esta situación maximizó nuevamente el tiempo disponible para la sesión, ya que todas las propuestas a realizar se construyeron en el mismo momento. Por otra parte, el uso alternativo del material podría aumentar el tiempo útil de las actividades, ya que al no permitir la ejecución repetida de las mismas tareas se dificultaría la automatización de movimientos.

"...intentábamos que fueran distintos para luego cambiarse, o sea, hacer el circuito este grupo este y luego el otro el otro y cuando acabaran los dos pues cambiar y que fuera otro distinto para que no se aburrieran." <Elementos internos $\|$ Entrevistas $\| C$ o8> - Referencia 8.

Las diferentes características de los niños no impidieron el uso de los mismos objetos en el desarrollo de las actividades, gracias a la adaptación de las tareas en función de las capacidades de los participantes. Esta habilidad es de gran importancia, pues no solo demuestra el uso variado del material sino que también denota la capacidad para modificar los juegos en base a las posibilidades de actuación de los jugadores.

"...saltar a la comba. Decías... ¡no, son niños que no pueden saltar a la comba pero a lo mejor en vez de saltar pues mover en plan como la serpiente, moverla y que pasen primero un pie y pasen luego otro! ¡Ah, sí! O cuando dijeron... ijugar a la bomba! Pues en vez de jugar a la bomba que se pasen el balón y vayan botándolo o cosas así, ir adaptándolo." <Elementos internos\|Entrevistas $\mid C$ 10>-Referencia 15. 
El uso de todos los elementos disponibles durante las sesiones nos transmite el provecho obtenido por los niños al emplear la mayor cantidad de materiales posible. Igualmente se incide en el valor de utilizar un mismo objeto con distintos propósitos. Ambas estrategias maximizan el uso de estos recursos, algo de gran importancia en entornos educativos con escasez de materiales.

"...tienen mucho material que a lo mejor no pueden usar, ahora que estoy haciendo prácticas en un cole me doy cuenta o busco más, me fijo en esas cosas de... ¿a ver qué material tenéis? Porque quizá no lo estéis usando y podamos utilizarlo para algo y hacer cosas diferentes o nuevas (...) a veces es como que entras dentro de una rutina y te cuesta introducir cosas nuevas. " <Elementos internos $\|$ Entrevistas $\| C$ 11> - Referencia 7.

\section{- Distribución del material.}

La distribución del material aborda la correcta ubicación de los objetos en función de las necesidades de uso.

El desarrollo de una actividad en la que el material estaba ubicado en el centro del espacio de juego nos ayuda a entender por qué los niños se desplazaban en círculos. Esta disposición fue acertada, ya que si hubiera estado repartido por todo el terreno disponible los participantes hubieran tenido más dificultades para encontrar los objetos indicados por la música.

"...luego también por ejemplo... bueno hicieron un cuadrado y dentro imágenes y luego con cuerdas, bueno el cuadrado era con cuerdas y alrededor iban dando vueltas. Se ponía una música y bueno... paquito el chocolatero pues una taza de chocolate. Tenías que buscar esa imagen y los niños ponerse encima." <Elementos internos $\|$ Entrevistas $\| C$ o1 $>$ - Referencia 1.

Los alumnos aprendieron la importancia de no exponer el material hasta el momento de su uso debido a los problemas ocasionados en las primeras sesiones por sacarlo al inicio de las actividades. Este hecho nos enseña cómo un recurso facilitador de los juegos puede ser perjudicial para el desarrollo de la sesión, solo por el hecho de no situarlo adecuadamente en el terreno de juego.

"...otra cosa, que es muy básica pero se nota muchísimo que lo hemos aprendido a la primera, que el material el justo y necesario enfrente de ellos y ya está." <Elementos internos||Entrevistas||C o2> Referencia 1.

Una actividad, cuyo objetivo era modificar la ubicación de diversos objetos, nos permite ver cómo aprovecharon este recurso motivador para desarrollar diferentes habilidades y tareas a través de un circuito. Esta propuesta estaba ambientada en una dinámica cooperativocompetitiva, lo que añadía a la actividad todos los beneficios de este tipo de juegos.

"...hay un circuito y en el circuito tienen que llevar una serie de material a un punto concreto del patio."

<Elementos internos\|Entrevistas $\|$ C 05>-Referencia 2.

La distribución diversificada de los materiales en un juego denota la riqueza motriz del mismo, debido a que los objetivos estaban situados en planos distintos. Esta disposición implicaba el uso diferenciado de los objetos por parte de los niños. Igualmente cabe destacar la diferencia de roles desempeñados por estos materiales durante la actividad, ya que mientras la pelota hacía de móvil el resto de objetos se utilizaban como blanco de lanzamiento. 
"Por ejemplo, el... hicimos un día, les pusimos los ladrillos con los palos estos de plástico y de la canasta colgamos una pelota de estas grandes atada arriba. Entonces tenían que golpear la pelota e intentar tirar los conos, bueno los palos, y no sé, ese por ejemplo." <Elementos internos\|Entrevistas\|C op> Referencia 4.

El cambio de ubicación de un material, para facilitar el desarrollo inicial de un juego, nos permite comprender cómo utilizaron ciertos objetos para delimitar más claramente las posibilidades de movimiento de algunos participantes. Este recurso es de gran utilidad para crear límites físicos que condicionen el desplazamiento de los jugadores, en lugar de demarcaciones virtuales o menos visibles. No obstante, debemos incidir en la importancia de evolucionar rápidamente hacia el desarrollo natural del juego, evitando que este aspecto se interiorice en los jugadores y dificulte su futura progresión.

"...el de la araña, que es un juego básico, pero sí que era un poco de... al principio con colchonetas marcadas en el suelo, estar encima de la colchoneta y no poder bajarse de ahí, o sea, no era una línea y ya está (...) Era ahí un poco que físicamente y visualmente que tuviesen... de aquí no podéis bajar. Y eso luego fue eliminándose y al final era una línea como el juego digamos original." <Elementos internos $\|$ Entrevistas $\| C$ 11> - Referencia 9.

A lo largo de este apartado hemos visto la notable interrelación entre los distintos elementos asociados con la organización del material. Sin embargo, también destaca la influencia de estos aspectos con otras categorías de este análisis, como por ejemplo la organización espacio-temporal, bloque que analizamos a continuación.

\section{- Organización espacio/temporal.}

En este apartado analizamos la organización espacio/temporal, bloque que hace alusión al modo en que los alumnos gestionaron los recursos temporales y espaciales disponibles en el transcurso de las sesiones.

\section{- Optimización/adaptación temporal.}

La optimización/adaptación temporal juzga la utilidad y adecuación de los juegos en función del tiempo disponible para realizar las actividades.

La creación de un instrumento que informaba a los niños sobre la estructura de la sesión proporcionó una imagen visual clara sobre la dedicación temporal de cada tarea, facilitando así la comprensión de los distintos tiempos de trabajo. Esta acción también sirvió para mantener la atención de los receptores del servicio ya que al tratarse de niños con TDAH tendían a despistarse con facilidad.

"...elaboramos un reloj con los diferentes momentos de la actividad... pues el momento de la asamblea que es cuando entran, cuando pasamos a lo mejor lista, porque hay niños que a veces son nuevos, no son siempre los mismos. Entonces también los tienes ahí un poco y captas su atención que eso es muy importante en estos niños el captar la atención. Luego nada les explicábamos todo el reloj, todos los momentos." <Elementos internos $\|$ Entrevistas $\| C$ o3 $>$ - Referencia 2. 
Debido a que la dinámica de las actividades era muy lenta y que cada niño necesitaba del apoyo de un alumno universitario para poder llevarlas a cabo, los equipos de trabajo decidieron hacer varias actividades en pequeños grupos para que la sesión no se hiciera tan pesada. De este modo consiguieron optimizar el tiempo de práctica y la atención prestada, ya que las actividades se ajustaron a cada grupo de participantes. Esta nueva estructura organizativa también implicó un uso equilibrado del tiempo para que cada grupo de niños pudiera participar en todas las tareas propuestas.

"...yo sí que me di cuenta que por ejemplo que las actividades de los niños más pequeños las chicas como el juego era más libre se les hacía muy larga la hora (...) proponíamos que, por ejemplo que se los llevaran a todos juntos a otro sitio o que les propusieran como rincones de... por ejemplo en un rincón papeles de periódico, en otro serpentinas de estas de los árboles de navidad, en el otro papeles del baño para estirar. Que lo distribuyeran así para que no se les hiciera tan pesada la hora, para que estuvieran un ratito en cada lugar y no estuvieran siempre todos juntos en el mismo lugar." <Elementos internos $\|$ Entrevistas $\| C_{05}>-$ Referencia 6.

La adaptación temporal de los juegos, en función del grado de diversión que proporcionaban, permitió al alumnado universitario exprimir al máximo las propuestas educativas más exitosas y evitar la pérdida de tiempo al aplicar actividades con escasa aceptación. Esta experiencia nos ofrece una idea del carácter servicial de los alumnos, al tener muy en cuenta el grado de satisfacción de los niños a la hora de desarrollar las actividades.

"...había juegos que enseguida se cansaban, como el de tierra no sé qué... ese juego era un rollo. Pues había otros que podían estar mucho tiempo jugando como ese o el de los circuitos que les gustaban mucho saltar y hacer cosas." <Elementos internos\|Entrevistas $\| C$ o6> - Referencia 7.

Los alumnos universitarios evitaron perder tiempo en las distintas etapas de transición de las sesiones como, por ejemplo, en los cambios de juego o al parar a almorzar. Gracias a la reducción de estos tiempos muertos consiguieron maximizar el tiempo útil de práctica, destacando la importancia de la participación activa de los niños. Este aprendizaje es muy valioso en cualquier campo docente y, especialmente, en el ámbito de la EF, ya que debido al desplazamiento de los niños desde el aula ordinaria a la zona destinada para esta materia cuenta con un tiempo de práctica más reducido.

"No perdimos tiempo entre juego y juego, también dedicamos menos tiempo al almuerzo, porque J---nos decía que no era importante, que lo realmente importante era hacer juegos y trabajar." < Elementos internos\|Entrevistas $\| C$ og > - Referencia 2.

El alumnado recomendó a sus compañeros universitarios que prepararan una cantidad de juegos adaptada al tiempo disponible. Igualmente les aconsejaron elaborar varios juegos adicionales a modo de reserva. Esta acción simplificaría los cambios a realizar en caso de que una actividad no tuviera éxito y, si no fuera necesario aplicarlos, facilitaría la elaboración de la próxima práctica.

"...había gente que en vez de llevar cinco a lo mejor llevaban un juego o dos para toda la hora, entonces también se quedaban cortos. Entonces siempre les decíamos que llevaran preparados juegos, si les sobraban pues para la siguiente sesión como estaban bien los juegos ya los tenían y más o menos podían servir. Pero que siguieran pensando más juegos." <Elementos internos $\|$ Entrevistas $\| C$ 10> Referencia 19. 


\section{- Equilibrio temporal.}

El equilibrio temporal es el aspecto que estudia si el uso del tiempo entre las actividades realizadas es proporcionalmente equitativo.

Gracias al aporte de otra profesora del grado, los alumnos conocían la importancia de gestionar adecuadamente los distintos tiempos de juego con los niños que tenían TDAH. Esta organización temporal hace referencia a distintos aspectos como, por ejemplo, especificar claramente los cambios de dinámica, informar de las distintas actividades a realizar a lo largo de la sesión o adecuar el tiempo de juego a las necesidades de los participantes.

"...una profesora, M---- J---- de dificultades de aprendizaje, ella en un momento dado estábamos trabajando el TDAH en clase, y nos dijo... bueno, yo sé que.... pues que claro, que tienen que tener los de TDAH tienen que tener una organización temporal." <Elementos internos\|Entrevistas $\mid C$ o3> . Referencia 1.

Este alumno reflexionó sobre la importancia de saber estructurar apropiadamente el tiempo disponible para las actividades, considerando que puede facilitar la gestión de otras cuestiones de interés como la organización del alumnado. Su razonamiento demuestra la trascendencia de estructurar equitativamente el tiempo en las distintas actividades a realizar. Al mismo tiempo, nos lleva a pensar en la relación de este uso equilibrado del tiempo y la optimización del mismo.

"Pues yo me voy a quedar, sobre todo, a saber cómo estructurar el tiempo. Porque para mí es algo muy importante la organización temporal y en este caso si lo tienes todo bien estructurado y bien organizado llega un momento que da igual que tengas diez que veinte niños. ¿Por qué? pues porque sabes en cada momento qué hay que hacer." <Elementos internos\|Entrevistas $\| C$ o4>- Referencia 6.

El alumnado disponía de sesenta minutos de trabajo con los niños de la entidad, determinando así el equilibro temporal en cuanto a la duración de las sesiones. Esta circunstancia no es de extrañar, pues seguramente sería el tiempo que dicha institución estipulaba que debían durar las actividades. No obstante, podemos destacar el hecho de que todos los alumnos dedicaran el mismo tiempo a realizar ejercicios de relajación al final de la sesión, cinco minutos. Esta situación nos lleva a suponer que utilizaron una distribución temporal muy similar.

"...casi todas las sesiones han durado lo mismo porque tenían una hora. Lo que pasa que siempre todos dejaban cinco minutos al final para relajación." <Elementos internos||Entrevistas ||$C$ 05> - Referencia 2.

La evolución de los alumnos en cuanto a la gestión equitativa del tiempo nos permite ver cómo intentaban seguir la programación elaborada para mantener el equilibrio temporal entre las actividades. Su reflexión señala el valor de este aspecto aunque también se apunta la posibilidad de introducir algunos cambios en función del resultado de los juegos. Esta capacidad de cambio es muy importante en los docentes ya que permite aprovechar las propuestas exitosas o evitar que se pierda más tiempo en aquellas abocadas al fracaso.

"... al principio era un poco desorden pero ahora ya es, estamos haciendo uno y cuando pasa el tiempo

(...) acabamos y empezamos el que tenemos pensado y todo como muy dinámico y muy ordenado (...)

si vemos que va pues a lo mejor decimos... iva, pues tres minutos más, pero tres, no unos sí y otros no! Y si vemos que no va, pues se corta." <Elementos internos $\|$ Entrevistas $\| C$ 07>-Referencia 2. 
El apoyo prestado entre los alumnos, a la hora de vigilar la duración de los juegos, muestra la necesidad de mantener el equilibrio temporal de la sesión para poder aplicar todas las actividades. Este hecho nos hace pensar en la dificultad de controlar un recurso tan básico como el tiempo, ya que se debe prestar atención a multitud de aspectos.

"... a mí también me gusta controlar el tiempo (...) y sí que es verdad que a veces te hace falta tener a alguien que te recuerde... ioye faltan diez minutos! porque tenías pensado hacer una cosa y desde fuera estás viendo que se está alargando y no te va a dar tiempo a acabarla y entonces vas y le avisas de... ¡oye faltan diez minutos lo acabamos aquí y tal! Entonces sí que nos dábamos un poco, entre las chicas del grupo, ese apoyo de mira veo que tal acabamos aquí ya y así llegaremos a tiempo." <Elementos internos $\|$ Entrevistas $\| C_{11>}$ - Referencia 1.

\section{- Optimización/adaptación espacial.}

La optimización/adaptación espacial valora el provecho y ajuste de las propuestas aplicadas sobre los recursos espaciales disponibles.

El alumnado recordó a sus compañeros universitarios que tuvieran en cuenta el espacio de aplicación de sus propuestas al elaborarlas, destacando así la importancia de conocer el terreno de juego en el proceso de planificación de las actividades. Esta situación nos hace pensar en el valor de recabar la máxima información posible sobre los condicionantes de la práctica antes de iniciar la programación de las sesiones, algo que nos permitirá sacar el máximo partido al espacio disponible.

"Pero antes de ir a (...) o sea, antes de planificar ya les decíamos... pensad dónde queréis hacerlo. Y bien. Y la mayoría se han hecho fuera." <Elementos internos||Entrevistas ||C 01> - Referencia 7.

El desarrollo de una actividad nos muestra cómo los alumnos distribuyeron aros por el terreno de juego para que los niños fueran entrando en ellos a cada cambio de música. Además de hacer un uso muy provechoso del espacio, este juego también nos permite trabajar otros aspectos como el espacio próximo individual o el contacto físico entre compañeros, algo que en edad infantil debe tratarse con especial atención.

"...hubo un juego que quisimos hacer de espacios de... que poníamos unos aros y ellos tenían que meterse dentro de un aro (...) ellos tenían que eso... ;ocupa tu espacio que tu espacio es este aro $y$ metete dentro del aro y cuando cambie la canción tienes que coger y buscarte otro aro!" <Elementos internos $\|$ Entrevistas $\| C$ o4> - Referencia 5.

Las sesiones de observación inicial se desarrollaron en el aula de psicomotricidad, mientras que las prácticas del alumnado universitario se aplicaron en el patio exterior de la entidad. Esta situación nos ayuda a comprender que supieron sacar partido de los distintos espacios disponibles, ajustándose perfectamente a las necesidades de las propuestas a realizar.

"Al aula de psicomotricidad solo fuimos tres veces que fueron las tres sesiones que fuimos nosotras $e$ hicimos las tres sesiones para ver cómo se desenvolvían (...) Pero mayormente las actividades se han realizado en el exterior, por eso, porque las tutoras de los grupos nos decían que ellas preferían que los sacáramos al patio porque se sentían mejor en el patio." <Elementos internos\|Entrevistas\|C 05> Referencia 21.

El desarrollo de un juego en diferentes espacios de acción, realizando las distintas pruebas en las zonas reservadas para cada una de ellas, nos transmite la gran cantidad de recursos 
espaciales que requería. Esto demuestra el enorme provecho que sacaron los alumnos universitarios del espacio disponible. Igualmente la distribución equitativa de las diferentes tareas destaca el gran equilibro espacial de la actividad.

"...hicimos una actividad pero tipo yincana. Entonces con el dado pusimos diferentes actividades ya hechas, cuando llegaron ya las tenían montadas y preparadas, y cada actividad tenía un número. Entonces los dividimos para que no tuvieran que estar tanto rato esperando y tal en cada actividad e iban y tiraban el dado y con el dado se iban a hacer una actividad u otra, y cada actividad si la hacían bien les dábamos una prenda de disfraces que hay en el poli, y cuando acababan (...) tenían que coger a uno y disfrazarlo."<Elementos internos $\|$ Entrevistas $\| C$ 07> - Referencia 10.

Mientras las sesiones con los niños más pequeños se desarrollaron en el módulo interior, las actividades con el grupo de mayor edad se realizaron en el patio exterior. Este hecho indica que los alumnos supieron sacar el máximo partido a las instalaciones disponibles, ajustándose en cada caso a las distintas necesidades de los participantes. De este modo, consiguieron que los niños más mayores disfrutaran más de los juegos aplicados, mientras que las actividades realizadas con el grupo de menor edad se aplicaban en un entorno mucho más seguro.

"...ellos lo disfrutan mucho más estando fuera, las actividades eran más amplias, tenían más espacio...

Si planteábamos cosas con las pelotas, claro ellos también tienen... al lanzar, por ejemplo, pueden lanzar más lejos no es lo mismo que con los de cuatro. Tener esta diferencia de edad nos hacía a veces ver esas cosas de... claro, es que aquí este espacio que considerábamos se nos queda pequeño porque para estos bien pero para aquellos no." <Elementos internos $\|$ Entrevistas $\| C 11>-$ Referencia 11.

\section{- Equilibrio espacial.}

El equilibrio espacial comprueba si el uso del terreno en los juegos planteados se da en una proporción equitativa.

El uso del patio exterior, cuando hacía buen tiempo, y del módulo interior, cuando hacía demasiado frío o llovía, nos lleva a entender cómo se aprovecharon equitativamente los espacios disponibles, adaptándose a las exigencias ambientales. Aunque esta acción está sujeta a la disponibilidad del centro educativo destacamos su interés en el ámbito de la EF, ya que al no desarrollarse en el aula ordinaria supone un aprendizaje de gran utilidad.

"...estos días que hacía buen tiempo siempre hemos ido al patio. Pero los días así de febrero que hacía frío sí que lo hacíamos en el... un módulo que había alli." <Elementos internos||Entrevistas\|C 01> Referencia 1.

El desarrollo de un juego nos ayuda a ver cómo se aprovecharon los distintos terrenos disponibles, tanto interiores como exteriores. Esta situación nos lleva a reflexionar sobre el uso equitativo del espacio, ya que cada fase de la actividad se realizaba en una zona distinta.

"Entonces en cada punto del pabellón, salimos fuera o sea era... por ejemplo fuera era Winnie the Pooh y lo que tenían que hacer era ponerse los zancos hasta una cierta distancia y luego ir a buscar la miel, era una fotito con la miel." <Elementos internos||Entrevistas $\mid C$ o3 $_{3}$ - Referencia 4.

El empleo de diferentes espacios en función de la edad de los niños nos muestra cómo aprovecharon tanto el módulo interior como el patio exterior, a lo largo de las diferentes actividades de servicio realizadas, de forma equilibrada. 
"Algunas sesiones, las de infantil que son los chicos pequeños y las de primaria, se realizaban en el módulo, todas las demás salían al exterior." <Elementos internos||Entrevistas||C 05> - Referencia 17.

El uso equilibrado del espacio disponible nos permite apreciar cómo los niños tenían que pasar por las distintas zonas de juego, a lo largo de un circuito, mientras realizaban las tareas requeridas. Esta actividad pone de manifiesto la relación existente entre este aspecto y la distribución de los recursos materiales. Por ello, sin una disposición adecuada del material difícilmente podríamos hacer un uso equilibrado del espacio en la aplicación de propuestas.

"...en dos sesiones diferentes había dos circuitos diferentes (...) había que pasar por los aros que estaban puestos de manera que tú cada pierna la ponías en un aro (...) luego era hacer equilibrio en el banquito, cruzarlo haciendo equilibrio, luego había que rodar en una colchoneta y luego había que saltar de un trampolín abajo (...) era como una colchonetita, ese era uno." <Elementos internos\|Entrevistas\|C 06>-Referencia 14.

Un juego basado en el uso equilibrado del espacio, a través de la división de los participantes en dos equipos bien diferenciados, nos muestra que los jugadores debían subir a un taburete $\mathrm{u}$ otro en función del grupo al que pertenecieran. Esta dinámica nos lleva a pensar en la aplicación de propuestas similares en las que los niños se vieran obligados a hacer un uso equitativo del espacio disponible, como por ejemplo el popular juego de las cuatro esquinas.

"Un juego que hicimos fue de los de bancos (...) era de ordenarse por ejemplo por la altura, por la edad (...) dividimos el banco en dos colores. Pues no eran capaces de ponerse la mitad en un color y la otra mitad en el otro (...) les decíamos... itodos en el color rojo con una mano! Y no, no podían, no se organizaban (...) la organización de organizarse ellos no." <Elementos internos\|Entrevistas\|C o8> Referencia 3 .

Este apartado demuestra la interrelación entre dos aspectos básicos en la aplicación de actividades en EF, el espacio y el tiempo. La gestión adecuada de ambos recursos permite mejorar notablemente el desarrollo de las dinámicas ya que, junto a la organización de los materiales y la gestión de los niños, establece los puntos de apoyo sobre los que trabajar.

\section{- Adecuación curricular.}

A continuación tratamos la adecuación curricular, analizando la relación entre las tareas realizadas y el marco curricular de las sesiones.

\section{- Relación objetivos/contenidos.}

La relación entre los objetivos y los contenidos hace referencia al ajuste de las actividades en relación con las metas que se pretenden alcanzar.

Uno de los propósitos del servicio era que los niños se divirtieran durante las sesiones. La relación existente entre esta meta y el tipo de actividades realizadas demuestra que los alumnos tuvieron en cuenta dicho objetivo recreativo al elaborar sus propuestas.

"...los juegos que se han hecho y tal... es que han sido con el objetivo lúdico." <Elementos internos\|Entrevistas $\| C$ 01>- Referencia 2. 
Planificar las actividades siguiendo el currículum académico establecido supuso una experiencia primordial en la formación del alumnado, ya que como docentes deberán ajustarse al marco educativo vigente en todas sus propuestas. Igualmente resaltamos la adquisición de este aprendizaje en un entorno real, lo cual aumenta la significatividad y beneficio del mismo, una característica básica del APS.

"... a nivel personal he podido ver que si que he aprendido es el planificar a partir de unos contenidos dados del currículum." <Elementos internos $\|$ Entrevistas $\|$ C 03> - Referencia 1.

A lo largo de las sesiones prácticas se realizaron tanto juegos de carácter motor como expresivos. Ambas propuestas se ajustan a la perfección a los requerimientos del programa educativo, pues desarrollan los contenidos básicos de la asignatura.

"...se ha centrado más en los juegos motores. Han sido más todo juegos motores que de expresión corporal."<Elementos internos\|Entrevistas $\| C_{05}>-$ Referencia 5.

La existencia de objetivos transversales y propios de cada sesión, como el desarrollo del habla a través de los juegos motores y expresivos y el aprendizaje de los colores, respectivamente, proporcionó al alumnado una idea clara de los diferentes niveles de concreción a la hora de planificar las actividades, un valioso aprendizaje para su futuro docente.

"...personalmente creo que ha sido una gran experiencia personal de poder ayudar a niños que sí que tienen unos problemas para hablar y eso. Uno de nuestros objetivos es que los juegos tuvieran algo de hablar para que fueran desarrollándolo. (...) cada sesión intentábamos tratar un tema por ejemplo los colores." <Elementos internos $\|$ Entrevistas $\| C$ o8> - Referencia 1.

Uno de los objetivos a conseguir con la aplicación del servicio era aumentar el tiempo de acción motriz de los niños atendiendo a sus necesidades individuales. Esta situación incide en la importancia de especificar las metas a alcanzar por cada uno de los participantes, otra cuestión clave en la planificación de las actividades didácticas.

"Y bueno pues aquí ya, con este tercer grupo lo que nos proponíamos más que nada era pues eso, aumentar el grado de compromiso motor, trabajar más, más específicamente con nada niño las necesidades que tuviera y eso." <Elementos internos $\|$ Entrevistas $\| C$ og>- Referencia 4.

\section{- Consecución de objetivos.}

La consecución de objetivos examina el logro de las metas propuestas a través del desarrollo de las actividades.

El gran nivel de alegría y satisfacción de los niños, respecto a las sesiones de juegos realizadas, nos permiten comprobar que los alumnos universitarios alcanzaron uno de los objetivos primordiales del servicio, conseguir que se divirtieran y se lo pasaran bien durante el desarrollo de las actividades.

"... a los niños por ejemplo al acabar las sesiones, las sesiones que nos habían quedado así bonitas que se lo habían pasado bien, les preguntábamos... ¿os lo habéis pasado bien? y todos... isiii! palmas y todo." <Elementos internos $\|$ Entrevistas $\|$ C 02 $>$ - Referencia 2.

La participación de los niños en las actividades era otro objetivo básico de las sesiones. Por ello, el hecho de que intervinieran en las tareas propuestas representa un resultado positivo 
en este aspecto, indicando que los juegos tenían un elevado componente motivador. Este importante aspecto ya ha sido abordado con anterioridad.

"...hubieron más pruebas y con el objetivo final que todos tenían que encontrar una taquilla donde allí estaba el regalo final. Entonces pues ya llegan al sitio y... creo que pusimos o chucherías o monedas (...) todos tuvieron su recompensa por haber participado." <Elementos internos\|Entrevistas\|C 03> Referencia 9.

Debido a las problemáticas que afrontaban estos niños, no estaban tan integrados como otros colectivos infantiles. La necesidad de incentivar este aspecto social demuestra la importancia de alcanzar este objetivo a través de una actividad lúdica y divertida como las sesiones de juegos realizadas.

"...en ese sentido yo creo que un factor que se nos incidió que era el tema de que ellos necesitan socializarse, se ha cumplido bastante." <Elementos internos $\|$ Entrevistas $\| C$ o4 $>$ - Referencia 2.

Los juegos musicales tuvieron gran acogida por parte de los niños, algo que queda reflejado al ver cómo se involucraban en el desarrollo de estas propuestas. La consecución de este objetivo está vinculada con la motivación y la participación, dos aspectos ya mencionados.

"...juegos que han ido bien, por ejemplo los juegos que hemos hecho que tenían algo de música, algo de baile, algo de eso, eso con los nuestros iba muy bien, enseguida les motivaba y enseguida lo hacían bien." <Elementos internos $\|$ Entrevistas $\| C$ o6> - Referencia 2.

Otro de los objetivos principales del servicio era desarrollar la motricidad de los niños. A través de la búsqueda de numerosas propuestas estimulantes se logró un gran avance en esta difícil labor, demostrando así la consecución de este objetivo.

"G---- bueno es un niño que puede hacer muy poca cosa, pero la verdad es que le hemos visto evolución, que ahora ya camina un poco. Y claro al principio (...) no hablaba, ni caminaba, ni nada. Entonces pues veíamos que su padre pues siempre le hacía cosquillas o le tocaba el pelo y entonces síque se reía, pues para contentarlo y para también trabajar lo que vienen siendo la parte del abdomen y eso pues le hacíamos cosquillas o también con pelotitas con las manos para que también empezara a desarrollar lo que es la prensión y eso." <Elementos internos\|Entrevistas \|C og> - Referencia 7.

\section{- Progresión de las actividades.}

La progresión de las actividades valora la adecuación metodológica a lo largo de las sesiones en cuanto a la evolución de las tareas propuestas.

La ubicación de un juego de presentación al inicio de la práctica fue todo un acierto. Esta estrategia no solo sirvió para relajar la tensión inicial de niños y alumnos universitarios sino que también facilitó el desarrollo de las distintas propuestas iniciales.

"...algo muy importante, juego de presentación al principio. No lo he dicho antes pero es algo que nos ha venido siempre muy bien para romper ese hielo y que también empezáramos a meternos en la dinámica." <Elementos internos $\|$ Entrevistas $\| C$ o4 $>$ - Referencia 4.

La progresión en el nivel de exigencia física de las sesiones queda patente al ver cómo se aumentaba poco a poco la intensidad de los juegos a realizar. Esta acción pretende evitar la aparición de molestias o lesiones en los participantes por no haber alcanzado una temperatura corporal adecuada, aprendizaje básico en cualquier actividad de EF. 
"También muchas veces se nota que al principio preparan unos juegos, al principio de la sesión los juegos eran más tranquilos para ir aumentando la intensidad conforme iba avanzando la sesión." $<$ Elementos internos\|Entrevistas \|C 05> - Referencia 4.

Las situaciones acontecidas durante el calentamiento de las sesiones nos ayudan a comprender cómo el alumnado aprovechó estos ejercicios introductorios para desarrollar otras tareas, como por ejemplo observar el nivel de desarrollo motor de los niños. De igual modo, debemos destacar la importancia de hacer ejercicios variados para mantener un elevado nivel de motivación y diversión en los participantes.

"...en las sesiones antes de empezar hacian como un calentamiento. Entonces se ponían todos en círculo y tú les ibas dando normas (...) ahí veía que trabajábamos varias cosas y (...). Además ahí ibas viendo a qué niño tienes que ir ayudando porque están todos en el círculo, qué no hacen, qué si hacen. Y eso, no sé, eso les gustaba. Porque como vas cambiando la norma a cada rato y cada vez tienen que mover una cosa también no se aburrían." < Elementos internos $\|$ Entrevistas $\| C$ o6>-Referencia 2.

Un ejercicio de relajación aplicado al final de las actividades nos permite entender que para acabar la sesión siguieron una progresión inversa a la del calentamiento. Con esta acción rebajaron el nivel de activación de los niños mientras seguían disfrutando y divirtiéndose, alcanzando así un objetivo principal ya mencionado.

"Cuando quedan diez minutos ponemos la música, la cambiamos y ponemos música más relajante y los ponemos a todos, menos a M---- y a J---- M----, en la colchoneta grande y a estos dos en las más finitas (...) para que no se den entre ellos. Y con plumas, con las pelotas de espuma y con globos, y ellos pues eligen lo que quieren les hacemos un masaje por todo el cuerpo con la pelota y eso (...) en general es la que más les gusta, porque se relajan, se les nota y se relajan." <Elementos internos\|Entrevistas ||C 07> - Referencia 2.

La progresión de las actividades a lo largo de las sesiones hizo reflexionar al alumnado sobre la evolución natural de las propuestas prácticas con el paso del tiempo. Este aprendizaje fue útil tanto para las sesiones de forma individual como para todo el conjunto de prácticas del programa formativo. Cabe resaltar que parte de este avance progresivo fue debido a la mejora en el trato directo con los niños como consecuencia de la confianza adquirida en el proceso.

"...eso te hace plantearte un poco, a la hora incluso de planificar de... los primeros ejercicios nunca son iguales que los que cuando ya te conocen. Al principio siempre intentas entrar con cosas... primero que sean como... presentación (...). Hablar, no entrar directamente a hacer un ejercicio, sino entrar a modo... mira ¿qué tal?, ¿cómo ha ido el día? Ahora ya íbamos a cogerlos y veníamos ya con ellos cantando ¿sabes?"<Elementos internos $\|$ Entrevistas $\mid C$ 11> - Referencia 2.

\section{- Valor educativo.}

El valor educativo de las actividades comprueba el nivel de interés didáctico de los juegos desarrollados a lo largo de las sesiones.

La aplicación de actividades para fomentar el conocimiento de los diferentes segmentos corporales desarrolló un valioso aspecto en los niños de la entidad colaboradora. Este aprendizaje adquiere un gran valor en el periodo formativo infantil, dada su importancia y protagonismo en las primeras experiencias vitales. 
"...se han hecho juegos en plan para el reconocimiento del cuerpo y todo... entonces yo creo que eso ha sido un refuerzo." <Elementos internos ||Entrevistas ||C o1> - Referencia 4.

En consonancia con los objetivos didácticos del servicio, el alumnado universitario realizó juegos con multitud de estímulos motrices, reforzando así la riqueza de las actividades en este aspecto. Igualmente se distingue la aplicación de tareas individuales y grupales, acción que fomentó doblemente el desarrollo motor de los niños participantes al tener que ajustar su ejecución tanto a las consignas indicadas como a sus compañeros de juego.

"...luego cogíamos aros y también que lanzaran igual, poníamos la música y en el momento de la música... pues nos vamos a coger todos en cadena y vamos a ir pues corriendo por las diferentes... o ¡andando de cangrejo hacia atrás! Diferentes consignas... y ¡cuando pare la música tenéis que parar y meter la pelota dentro del aro!" <Elementos internos $\|$ Entrevistas $\| C$ o3> - Referencia 3.

El desarrollo de la rapidez y el lenguaje son dos valiosas experiencias que fomentaron la adquisición de distintos aprendizajes. La primera tiene valor en sí misma en el ámbito de aplicación, los juegos motores y expresivos. En cambio la mejora del lenguaje aporta un valor educativo añadido a las tareas realizadas, pues no es un contenido específico del área de EF.

"Intentábamos que durante los juegos pues hablaran que es lo que más necesitaban. Y luego los motrices que, o sea, hicieran movimientos rápidos que... la rapidez de pensar y hacer. Que eso sí que les costaba y... muy pasotas, y... ipues ahora salto y salto una vez! Pero que fueran más rápidos. Sí que... eso, lo del lenguaje intentamos." <Elementos internos $\|$ Entrevistas $\mid C$ C $8>$ - Referencia 5.

El fomento de distintos valores educativos durante la realización de los juegos motores nos ayuda a comprender cómo se desarrollaron aspectos tan importantes como la cooperación y el trabajo en equipo a lo largo de las sesiones. Asimismo, destacamos el buen hacer de los alumnos al impedir la promoción de otras cuestiones negativas a esta edad, como por ejemplo la rivalidad. Ambas situaciones nos llevan a pensar que estas actividades ofrecen un entorno óptimo para trabajar el desarrollo de valores y actitudes en los niños.

"...teníamos que tener en cuenta en los juegos que no fueran competitivos entre ellos que no ganara y perdieran unos ya que estos niños no entienden el perder (...) los niños querían, o sea, juegos, variantes en las que colaboraran todos, no estuvieran en fila y fueran pasando de uno en uno, que participaran todos a la vez en un grupo." <Elementos internos $\|$ Entrevistas $\| C$ 10>-Referencia 1.

Analizar el valor adicional de las actividades realizadas nos permite apreciar, aparte del contenido propio de $E F$, el nivel de concienciación del alumnado sobre este importante aspecto. Así pues, fomentaron el desarrollo de nuevos aprendizajes, como el conocimiento de distintos medios de locomoción, a través de tareas propias de esta disciplina. Esta actitud es de vital importancia en la perspectiva de la educación transversal.

"...hicimos un día de orientación espacial pero introduciendo también contenido en este caso de medios de transporte, para también un poco globalizar ahí. Que no solo tienes que hacer cosas físicas y ya está, sino que dentro de lo físico y de que estás haciendo orientación espacial (...) introducir a lo mejor eso, ejercicios con contenido también." <Elementos internos $\|$ Entrevistas $\| C 11>$ - Referencia 1.

El análisis de este apartado nos permite ver la conexión de sus elementos con distintos aprendizajes académicos como, por ejemplo, el fomento del desarrollo motor, el componente lúdico de los juegos, la organización y participación del alumnado, etc. Igualmente se aprecian 
relaciones positivas con otros aprendizajes valiosos que no son propios de la EF, como el desarrollo del lenguaje, resaltando la utilidad educativa de este tipo de propuestas.

\section{- Aspectos sociales.}

Seguidamente afrontamos el análisis de los aspectos sociales de los juegos, estudiando la adecuación de las actividades realizadas respecto a distintas cuestiones de interés social.

\section{- Atención a la diversidad.}

La atención a la diversidad analiza si los juegos propuestos responden de forma adecuada a la heterogeneidad existente entre los niños participantes.

La consideración del alumnado respecto a dos niños con deficiencias sensoriales muestra cómo tuvieron en cuenta estas grandes limitaciones a la hora de planificar y seleccionar las actividades. Igualmente percibimos el deseo de que estos niños pudieran participar en los juegos con normalidad, lo que nos hace pensar que desarrollaron numerosas adaptaciones para responder adecuadamente a las necesidades de los participantes.

"...que lo pudieran realizar por el hecho de que... por ejemplo la de la vista o un nene que estaba sordo, bueno que está sordo. Entonces claro eso lo teníamos en cuenta, las dificultades... las necesidades..." <Elementos internos\|Entrevistas $\|$ C o1> - Referencia 4.

El texto no deja lugar a dudas en cuanto a la progresión de un niño con déficit de atención e hiperactividad en diversos aspectos como la integración y la intervención en los juegos. Esta apreciación nos permite comprender que los alumnos fueron capaces de valorar su participación de forma global y no únicamente en cuanto a la aplicación de los juegos.

"...justamente de ese niño que es el que tiene TDAH sí que hemos podido ver la gran evolución que ha hecho ese niño en cuanto a socialización, en todo, o sea, en implicación en los juegos... es una cosa increíble. Es donde más nos hemos... donde más demuestra el gran trabajo que hemos podido realizar." $<$ Elementos internos\|Entrevistas $\|$ C o3> - Referencia 3.

La atención prestada a una niña con serios problemas de comportamiento nos ayuda a ver el gran servicio realizado en ese caso, muy por encima de lo esperado por los familiares de la propia niña. Por otra parte, el comentario sobre la dificultad de incorporar a un nuevo niño, cuando la propuesta ya estaba en marcha, nos demuestra la capacidad reflexiva del alumnado universitario en esta delicada cuestión.

"M---- ha llegado hace poco, sí que... no conflictiva, pero a lo mejor como que ya estábamos muy bien con todos, que ya todo iba bien y los conocíamos y eso y llegó $M$---- que se nos tiraba al suelo y todo y decíamos... ostras, ahora que ya los tenemos a todos más o menos i¿qué hacemos?! Pero enseguida también hemos sabido qué hacerle a ella y todo y ahora ya ni se tira al suelo ni nada y se pasa toda la hora andando que su padre ni se lo cree." <Elementos internos\|Entrevistas $\|$ C 07> - Referencia 9.

Las actividades realizadas por un niño con importantes alteraciones motoras ponen de manifiesto tanto la capacidad analítica del alumnado, en cuanto a los aspectos motrices a desarrollar, como su interés por mejorar la movilidad de los receptores del servicio a través de 
los juegos. Ambas situaciones exponen su deseo de aprender y servir, cumpliendo así el compromiso asumido mediante el APS.

"...por ejemplo lo que te comentaba que B---- cruzaba las piernas pues cogíamos un banco y lo hacíamos caminar por encima o por encima de cuerdas ayudándole para hacer eso que no cruzara las piernas a la hora de caminar. O (...) siempre utilizaba el mismo brazo para hacer las cosas pues hacerle lanzar con el otro brazo porque le costaba más." <Elementos internos\|Entrevistas \|C og> - Referencia 4.

Los alumnos universitarios emplearon distintas estrategias para atender la necesidad de un niño a la hora de agarrar objetos. Primero, modificaron la tarea a realizar, después propusieron una actividad alternativa $y$, por último, fomentaron específicamente su desarrollo en esa acción concreta. Estas propuestas destacan el gran servicio prestado en este caso.

"Pues por ejemplo en un niño que tenía que lanzar una pelota vimos que el lanzar la pelota con la mano no podía entonces intentamos que la cogiera con las dos manos (...) $O$ en vez de lanzar una pelota le dábamos como unos bloques y los metía en un cajón (...) le dabas agarre con la mano entera y al principio no lo sujetaba y conforme se lo ibas haciendo más veces iba aprendiendo a coger, entonces le estimulabas el cogerlo con una mano." <Elementos internos $\mid$ Entrevistas $\| C 10>$ - Referencia 11.

\section{- Transmisión de valores.}

La transmisión de valores examina si las propuestas realizadas incentivan el desarrollo de distintos valores sociales en los niños participantes.

El comportamiento de los alumnos respecto al controvertido valor de la competitividad muestra cómo evitaron el desarrollo de este aspecto entendido como rivalidad u oposición entre adversarios. No obstante, esta compleja disyuntiva, muy habitual en la EF, puede ser abordada desde un punto de vista positivo, siempre que se vincule con la mejora o superación en lugar de la pugna o enfrentamiento.

"...se han hecho bastantes circuitos, luego... pero no competitivos, siempre han evitado eso más que nada porque había algún grupo que habían niños muy competitivos. Entonces siempre les hemos dicho... ievitadlo! Que sí que llegue uno primero si queréis pero el otro también ha sido ganador." <Elementos internos\|Entrevistas $\|$ C o1> - Referencia 2.

El deseo de fomentar la cooperación entre los niños mediante las actividades propuestas no deja lugar a dudas en cuanto al valor social de esta acción. Así pues, además de promover la participación en actividades conjuntas en lugar de distintas tareas individuales, el alumnado universitario incidió en que los niños se ayudaran mutuamente en el desarrollo de los juegos.

"Nosotras queríamos que hubiera un poco de aprendizaje cooperativo que se ayudaran los unos a los otros y que no tuviéramos que estar una con cada niño si no que se pudieran ayudar entre ellos." $<$ Elementos internos\|Entrevistas $\| C$ 02> Referencia 2.

El trato del desarrollo de valores se apreció en un juego concreto en el que los alumnos escribieron los distintos aspectos fomentados gracias al APS para mostrarlos mientras la actividad era grabada en video. Esta acción nos ayuda a ver que podemos concienciar a los niños de los aspectos trabajados explicitándolos mediante una sencilla propuesta.

"Luego hicimos carteles pues con diferentes palabras pues, por ejemplo, motivación, esfuerzo, comprensión... diferentes carteles así con diferentes valores, no sé, que consideramos nosotros que 
eran importantes que salieran en el video, y más o menos todo lo que ha supuesto toda la práctica, toda la práctica con ellos." <Elementos internos $\|$ Entrevistas $\| C$ 03>- Referencia 12.

El fomento de la responsabilidad en los niños más mayores, durante la aplicación de los juegos, fue aprovechado por los alumnos universitarios para gestionar las diferencias existentes entre los participantes. Esta hábil decisión nos lleva a entender cómo afrontaron esta situación, obteniendo beneficios adicionales mientras lo hacían.

"Una que nos funcionó, a mí me suele funcionar bien, es pues que a lo mejor a esos niños que son un poquito más mayores les planteas el tema de que para ese juego tengan un papel un poco más responsable y entonces entienden que tienen que tener esa responsabilidad por ser más mayores y que claro pues tienen que ayudar un poquito a esos niños más pequeños ¿no?" <Elementos internos $\|$ Entrevistas $\| C_{04}>$ - Referencia 2.

El APS tiene un gran impacto social en todos los implicados, consideración que sale reforzada al comprobar los distintos valores sociales desarrollados a través de esta actividad. Además, el hecho de que fuera el propio alumno universitario el que reflexionara y señalara esta situación proporciona una nueva dimensión a la significatividad de esta vivencia.

"...además pues también me gustaría destacar que también he desarrollado muchos aspectos sociales sobre todo la atención a la diversidad, la transmisión de valores como la cooperación y la integración." $<$ Elementos internos\|Entrevistas $\|$ C og>-Referencia 1.

\section{- Normas de convivencia.}

El aspecto de las normas de convivencia valora si las tareas realizadas fomentan la adquisición de pautas para vivir en sociedad.

La asimilación de diferentes reglas de comportamiento por parte de los niños dirigió su actuación en distintos momentos de las sesiones. Este aspecto cobra mayor importancia cuando se trata de colectivos con problemas añadidos, como por ejemplo los niños con TDAH, a los cuales les cuesta mucho cumplir las normas establecidas debido a su condición.

"... a medida que iban pasando las sesiones ya los niños ya conocían las rutinas que he explicado antes, a la entrada pues dejar las mochilas en un lado, sentarse, es que ya lo hacían directo no tenías que decirles nada, dejaban la mochila y se sentaban en el banco, ahí y el reloj. Y ya... y luego en el almuerzo también ellos sabían que cuando tocaba el silbato o cuando se decía almuerzo era almorzar ahí sentaditos y ninguno se desperdigó por ahi." <Elementos internos||Entrevistas\|C o3> - Referencia 2.

La ubicación del momento para comer algo a lo largo de las sesiones nos ofrece una idea de la organización temporal de las mismas. Con ello vemos que fueron bastante equilibradas, ya que dejaron el mismo tiempo para la primera parte de la práctica que para la segunda. Este importante aspecto organizativo ya ha sido analizado en categorías anteriores.

"...el almuerzo siempre entre las dos horas. Hacemos diez minutos justo en la mitad, es decir, si es de diez a doce pues a las once menos cinco paran y hasta las once y cinco, once y diez." <Elementos internos $\|$ Entrevistas $\| C_{04}>$ - Referencia 5.

El alumnado universitario consideró que los grupos de menor edad podían tener una normativa más laxa que el resto debido a su menor nivel de activación. No obstante, incidieron en el valor de las normas de convivencia independientemente de la edad de los 
niños. Esta situación refuerza dos aspectos ya analizados: la atención a las necesidades educativas de los niños y el ajuste de las actividades a la edad de los participantes.

"...sí que tienes que ir ya dando pautas porque algunos a lo mejor son más excitados, algunos niños, y sí que tienes que controlarlos un poco e ir poniendo como unas reglas, no puedes dejarlos tan libres como a los pequeños. Porque a los pequeños les podías dejar libres, aunque les dabas reglas, pero como son más quietos no suponía tanto esfuerzo."<Elementos internos $\|$ Entrevistas $\| C$ 05> - Referencia 1.

La aplicación de diversos hábitos de conducta, relativos al principio de las sesiones prácticas, facilitó el inicio de las actividades propuestas, tanto por parte del profesor como de los alumnos universitarios. Igualmente se aprecia cierta admiración del alumnado respecto al buen hacer del docente de la entidad en esta cuestión.

"...ellos siempre cuando entran a clase vamos en el tren, y cuando entran a clase se ponen contra la pared $y$ se sientan en el suelo para explicarles los juegos. $Y$ eso sí que lo tienen muy... muy concienciados de que cuando entren tienen que ponerse en la pared para que les expliquemos el juego, pero eso ya lo tenían de $V$----." <Elementos internos $\|$ Entrevistas $\| C$ o8> - Referencia 3.

La siguiente experiencia realza el valor de fomentar el desarrollo de hábitos higiénicos en los niños, un aspecto habitualmente asociado al ámbito de la EF. De igual modo, distinguimos la especial situación de este colectivo, ya que por tener una relación más distante con el agua presenta una mayor dificultad a la hora de afianzar este tipo de pautas.

"...los mayores siempre tienen que acabar diez minutos antes porque tienen que ir a asearse y todo eso.

$Y(\ldots)$ la otra profesora, nos decía que (...) son cosas que con ellos lo tienes que hacer más aún que con... que en otras situaciones porque por ejemplo cuando fueron a la piscina había un niño que no sabía ducharse, y se metía con la toalla en la ducha." <Elementos internos\|Entrevistas ||C 12>-Referencia 1.

\section{- Fomento de la cohesión/integración.}

El fomento de la cohesión e integración comprueba la estimulación de las relaciones de los participantes a través de los juegos realizados.

La integración de un niño en las actividades por medio de la relación con su hermana nos deja ver cómo consiguieron mejorar su participación, comunicación y vinculación con el resto del grupo gracias a esta estrategia. La acción demuestra que los alumnos supieron aprovechar todos los recursos disponibles a su alcance para mejorar la situación de los niños. Al mismo tiempo, debemos señalar la importancia de este aprendizaje en cualquier dinámica grupal, ya que a través de los líderes se puede dirigir la participación del resto del grupo.

"...tenemos a uno que es así también muy paradito que vienen con la hermana y entonces la hermana claro ya está acostumbrada a ayudarle a hacer cosas, y pues nos sirve de mucha ayuda porque sabe comunicarse con él para que haga las cosas." <Elementos internos $\mid$ Entrevistas $\mid C$ 02> - Referencia 3.

Debido a las distintas opiniones existentes sobre la dificultad y las posibles estrategias a la hora de fomentar la cohesión del grupo, el alumnado fue tanteando diferentes alternativas para promover esta unión. Su actuación espontánea nos lleva a pensar que no existe una respuesta única para afrontar esta problemática y que gracias al método de ensayo-error se puede resolver este asunto en los distintos contextos en los que se presente.

"Otra situación que también llamó la atención fue pues lo típico ¿no? es el primer día unos niños no querían implicarse en la dinámica. Y ¿qué hacemos ahí?, ¿los forzamos?, ¿los dejamos estar? Creo que 
entre todos, cada uno fue adoptando un rol pero sin ni siquiera comentarlo pero yo me decanté más por intentar convencerlos, otra compañera veía que lo mejor o lo que creía más conveniente que había que hacer era dejarlos estar."<Elementos internos\|Entrevistas $\| C$ O4> - Referencia 1.

El esfuerzo del alumnado por integrar en los juegos a un niño con serias limitaciones motoras nos lleva a entender la importancia moral de esta cuestión, así como la dificultad que entraña. Igualmente achacamos su acción a una mejora en cuanto a la comprensión de las necesidades del niño, gracias al desarrollo de diversos aspectos sociales como la solidaridad o la empatía.

"...no podíamos realizar las actividades para que él desenvolviera su movilidad (...) para que se arrastrara por el suelo tampoco nos parecía como muy adecuado. Cuando nos planteábamos eso de cómo hacer para que el niño se sienta integrado en el grupo y no que se vea como él haciendo actividades aparte y todos sus compañeros haciendo todas las actividades conjuntamente. Pues intentábamos integrarlo para que se sintiera uno más en el juego." < Elementos internos||Entrevistas\|C 05>-Referencia 1.

El alumnado introdujo distintas adaptaciones en un circuito para integrar a un niño con el resto de sus compañeros. Estas modificaciones se encajaron únicamente en aquellas tareas que no era capaz de hacer por el mismo. La importancia de este aprendizaje es fundamental, ya que si se cambia por completo el ejercicio podría considerar que está realizando una actividad distinta a la de sus iguales y que se están mermando sus posibilidades de mejora al rebajar la exigencia de la tarea. De igual modo, un cambio de dinámica afectaría a todos los participantes.

"...hicieron un circuito las chicas, e iba uno en silla de ruedas (...) como este niño no lo podía hacer pues nosotras con la silla de ruedas íbamos esquivando los ladrillos en vez de saltarlos (...) Luego sí tenían que lanzar la pelota y él no podía lanzarla tan fuerte pues le poníamos una caja cerca y entonces con la mano el llevaba la pelota a la caja (...) él iba haciendo detrás de los compañeros el recorrido con nuestra ayuda, pero había sitios que estaban adaptados para que él pudiera. En otros sí que él podía hacerlo como todos." <Elementos internos\|Entrevistas $\| C$ 10>-Referencia 1.

Un alumno consideraba apropiado estimular la conexión entre los niños tanto a nivel global como en pequeños grupos. Su comentario nos lleva a reflexionar sobre la dificultad que implica esta labor ya que, si no lo hacemos correctamente, cohesionar distintos subgrupos podría jugar en nuestra contra a la hora de conseguir un sentimiento colectivo de unión social.

"...puedes fomentar la cohesión de grupos pequeños o como sea, pero fomentar una cohesión de grupo. Pues plantearte cosas que fomentaran eso por ejemplo la actividad que hicieron estas chicas que nos gustó tanto y que salió tan bien." <Elementos internos $\|$ Entrevistas $\mid C$ 11> - Referencia 2.

El aspecto más destacable de este apartado es su relación con el elemento social de la educación. Esta situación es doblemente importante en este caso ya que a su valor como aprendizaje académico hay que sumar su efecto en cuanto al fomento de la competencia de ES, manifestando así su estrecha vinculación con este otro objetivo fundamental del presente trabajo. 


\section{- Juegos motores.}

En este bloque abordamos el análisis de los juegos motores, apartado que estudia el componente motriz de las actividades realizadas por los niños.

\section{- Motricidad fina.}

La motricidad fina hace referencia a la participación de los grupos musculares de menor tamaño en el desarrollo de los juegos propuestos.

La necesidad de realizar un trabajo de motricidad fina adicional con un niño hizo que los alumnos recomendaran a sus familiares el refuerzo de esta habilidad en su propia casa. Esta experiencia muestra cómo los beneficios del servicio pueden trasladarse incluso más allá de la actividad realizada en el centro educativo, incrementando con ello las aportaciones sobre los receptores del mismo.

"ile vendría bien reforzar la motricidad fina en casa a ver si le hacéis no sé qué!" <Elementos internos $\|$ Entrevistas $\|$ C o2>-Referencia 1.

La participación de la motricidad fina en el transcurso de una actividad más elaborada queda patente al desatar unos materiales a lo largo del juego. Esto nos hace reflexionar sobre la importancia de fomentar de forma específica y aislada los distintos tipos de coordinación a desarrollar, lo cual no está reñido con aprovechar la posibilidad de trabajarlos también de una forma conjunta en otras propuestas.

"Luego por ejemplo de la de Winnie the Pooh era el libro de la selva ¿vale? pusimos para poder encontrar la pista que le llevara al siguiente juego en pañuelos atados, pues entre todos tenían que desatarlos y tenían que sacar la pista." <Elementos internos $\|$ Entrevistas $\| C$ o3 $>$ - Referencia 2.

La incompetencia motriz de los niños de menor edad, al ejecutar tareas de motricidad fina, destaca la dificultad de desarrollar esta coordinación en dicho colectivo. Esto se debe tanto a la precisión que requieren los movimientos como a la falta de madurez cognitiva de estos niños, por lo que es una situación que podemos ubicar dentro de la normalidad.

"Cuando hemos planteado ejercicios que implican unas exigencias motrices más finas, por así decirlo, los niños, evidentemente más pequeños, los ves más torpes. Vamos pero es que eso es así." <Elementos internos\|Entrevistas $\| C_{04}>-$ Referencia 1.

Dado que un niño no participaba del resto de actividades, los alumnos aprovecharon su preferencia por realizar una acción de motricidad fina para desarrollar diversas tareas basadas en ese movimiento. Esta experiencia nos enseña cómo el alumnado universitario aprovechó los deseos y posibilidades de los niños para proponer alternativas adaptadas a sus necesidades, otro aspecto analizado en este trabajo.

"...un niño con silla de ruedas que el profesor nos dijo que él solo se entretenía jugando con meter cosas dentro de un bote." <Elementos internos $\|$ Entrevistas $\| C$ 05>- Referencia 1.

El alumnado universitario intentó dirigir la acción motriz de una niña para sensibilizarla sobre su uso discrecional de la motricidad fina y evitar que la empleara únicamente bajo su propia disposición. Esto nos lleva a recapacitar sobre la voluntariedad y participación de los niños en las actividades, algo que debemos considerar en todo momento a la hora de elaborar 
nuestras propuestas. Por ello, opinamos que siempre serán mejor recibidas aquellas tareas que vayan en consonancia con sus preferencias y aspiraciones, que al contrario. Obviamente, esto no quiere decir que debamos supeditar la planificación educativa a los deseos de los niños.

\begin{abstract}
"M----, por ejemplo, las manos también... no hacía nada, a no ser que ella quisiera, si ella te quería coger o te quería estirar del pelo o que fuera entonces ella sí que hacía fuerza pero de por sí ella no. Y queríamos que no solo tenía que hacerlo cuando ella quisiera que era algo que tenía que hacer siempre, entonces pues también pues le hacíamos ejercicios con pelotas sensoriales para que también las apretara o con otros tipos de pelotas." <Elementos internos $\|$ Entrevistas $\| C$ og > - Referencia 2.
\end{abstract}

\title{
- Motricidad gruesa.
}

La motricidad gruesa analiza la intervención de los grupos musculares de gran tamaño durante la aplicación de las actividades realizadas.

La ejecución de diversas tareas de motricidad gruesa mediante la aplicación de un circuito nos ayuda a comprender cómo desarrollaron esta habilidad de una forma específica y controlada. Estas actividades son más adecuadas para el trabajo de la coordinación específica, por lo que para estimular la motricidad gruesa nos decantaríamos, preferiblemente, por el uso de ejercicios más abiertos en forma de juegos. No obstante, esta alternativa podría ser de gran utilidad en aquellos casos en los que necesitáramos controlar la ejecución de los niños para aumentar la seguridad de la propuesta.

"...hacíamos como circuitos por ejemplo de saltar los aros, lo de subir escaleras y bajar, dar vueltas así como croquetas por las colchonetas..." < Elementos internos ||Entrevistas $\| C$ 05> - Referencia 10.

Los alumnos diseñaron una original actividad para promover el trabajo de la motricidad gruesa en los niños. Consideramos que esta propuesta tiene una mayor riqueza motriz que la anterior por desarrollarse de forma libre en forma de juego y no estar limitada a la ejecución cerrada de un circuito. Por otra parte, debemos resaltar el gran componente lúdico de esta iniciativa, el cual aumenta la motivación de los niños para participar en la misma.

"...el juego de lo... igual que lo de las sillas, de cada vez vas quitando, pero con los aros y al revés. $O$ sea, en vez de que cada vez se quita una silla y entonces alguien se queda sin sitio esa persona no juega porque solo cabe una persona por silla, pues en el aro lo que hacíamos era que cada vez más personas tenían que estar dentro de un aro. Y eso les gustaba, iba bien. No sé, ese juego salía bien, además había musiquita mientras se movían y tal. Ese iba bien, a ese hemos jugado varias veces." < Elementos internos $\|$ Entrevistas $\|$ C 06> - Referencia 9.

Durante el desarrollo de un juego de motricidad gruesa aparecieron algunos problemas que hacían referencia a la dificultad de los niños por reconocer el número de integrantes en el que debían agruparse y a su preferencia por asociarse según su afinidad en lugar de seguir las pautas indicadas. Ambas situaciones señalan la necesidad de reforzar la identificación de los números básicos y trabajar la socialización del grupo para poder aplicar la actividad correctamente.

"El último día hicimos un juego que era de... ¡ahora nos ponemos por parejas, ahora nos ponemos por tríos, de tres en tres, de cuatro en cuatro! Y no, no sabían contar, no entendían, querían estar entre sus amigos, no querían ponerse con otra gente." <Elementos internos $\mid$ Entrevistas ||$C$ o8>-Referencia 4. 
Utilizar un trabajo de motricidad gruesa exigente, con la intención de relajar a los niños de la entidad, sirvió para modular su nivel de excitación. Recomendamos que estas propuestas vayan acompañadas de trabajos de interiorización en los que se identifiquen las diferentes sensaciones experimentadas. Con ello se facilitaría su reconocimiento en futuras vivencias.

"Luego, han hecho también juegos de correr un montón, porque había niños que nos decían que necesitaban soltar en ese momento la adrenalina que llevaban para luego llegar a clase y estar más relajados. Entonces hacíamos juegos movidos y el último juego de relajación para que cuando fueran a clase fueran más relajados." <Elementos internos $\|$ Entrevistas $\| C$ 10>-Referencia 16.

Un ejercicio que fomentaba el equilibrio de los niños, a través de una propuesta de motricidad gruesa, nos permite comprobar cómo se elaboraron tareas que desarrollaban distintas coordinaciones y trabajos motores en una sola actividad. Igualmente debemos destacar la aplicación de este planteamiento siguiendo las recomendaciones del profesor, ya que de lo contrario malograría toda su adecuación curricular.

"V---- también iba guiándonos un poco de la temática que él estaba dando. En primero nos dijo... ¡ahora vamos hacer un poco de equilibrio! Entonces nosotras buscábamos cosas un poco de equilibrio. $Y$ de hecho planteamos a modo recorrido de cosas para hacer con equilibrio con las cuerdas, ir por encima de la cuerda, ir por encima de los bancos. "<Elementos internos $\|$ Entrevistas $\| C 11>$ - Referencia 4.

\section{- Coordinación global.}

La coordinación global aborda la ejecución de actividades que impliquen la acción coordinativa conjunta de numerosos grupos musculares.

El desarrollo de un juego motor muy popular nos permite entender el trabajo coordinativo que supuso su aplicación. Así pues, además del fomento de la coordinación global, promovido por los desplazamientos de los participantes, también destaca el estímulo de la coordinación específica, asociado al lanzamiento y recepción del objeto protagonista en la actividad. Este hecho nos hace reflexionar sobre la posibilidad de incentivar conjuntamente las coordinaciones global y específica, aumentando así la riqueza de nuestras propuestas.

"Luego hemos hecho el típico de balón-tiro, el típico juego del balón-tiro." <Elementos internos||Entrevistas $\|$ C 01> - Referencia 2.

La ejecución de diferentes tareas de coordinación global, durante el transcurso de una actividad musical, incentivó la coordinación de los niños a raíz de las indicaciones y requisitos establecidos por los alumnos universitarios. El valor de esta propuesta se establece al asegurar la vivencia de unas experiencias mínimas en los participantes.

"...durante la música pues hacíamos (...) diferentes consignas... ipues ahora cuando suene la música tenemos que ir tocándonos la nariz o ir a gatas o en cuclillas!" <Elementos internos||Entrevistas||C 03> - Referencia 4.

El alumnado universitario iniciaba las sesiones con un juego de coordinación global de gran exigencia física. Esta elección toma sentido al saber que los niños participantes tenían TDAH, un colectivo caracterizado por su gran despliegue físico y dificultad para regular sus niveles de excitación motriz. La aplicación inicial de estas propuestas ayudó a reducir el nivel de estrés de los niños, facilitando así su intervención durante el resto de la práctica. 
"...después de esas presentaciones iniciales, el típico juego de sacar la energía ¿no? que le llamábamos nosotros. Y casi todos eran juegos de pillar, con sus diferentes variantes adaptadas a lo que era la temática de ese día, pero eran juegos en los que veías que físicamente se iban a cansar." <Elementos internos $\|$ Entrevistas $\| C$ o4 > - Referencia 6.

El objetivo principal de un juego de coordinación global era el fomento del equilibrio. Esta situación nos hace valorar el tratamiento de diferentes habilidades motrices a través de la ejecución de distintas tareas coordinativas. De este modo, podríamos ofrecer experiencias motrices llenas de vivencias y conocimientos prácticos.

"Más actividades que realizamos con estos grupos... por ejemplo de hacer equilibrio (...) sobre unas... hay como si fueran unas piedras que tienen las bases de diferentes tamaños. Pusimos eso e intentamos que los niños fueran pasando por estas bases y al final por dentro de los aros que los enganchábamos en unas cosas que tenían alli." < Elementos internos $\|$ Entrevistas $\| C$ 05> - Referencia 8.

El gran componente motor de las actividades aplicadas señala la predominancia de este tipo de tareas durante prestación del servicio. Esto nos lleva a pensar en la inmensa cantidad de propuestas que incentivaron el desarrollo de diferentes movimientos, provocando así la acción conjunta de los distintos elementos analizados a lo largo de este bloque.

"...el otro día hicieron un circuito e hicieron como una especie de yincana. Entonces claro eran los mayores y a ellos les gustaba mucho correr, saltar, movimiento y la verdad es que trabajaron todo tipo de saltos, con un pie, con otro, escalada, o sea, reptar, ir a gatas, no sé. Hicieron también el pase de balón, lanzamientos hacia delante, lanzamientos hacia atrás. Entonces lo que más han hecho en las sesiones ha sido motor." <Elementos internos\|Entrevistas $\| C$ 10> - Referencia 7.

\section{- Coordinación específica.}

La coordinación específica hace alusión al desarrollo de un número reducido y concreto de grupos musculares a través de las actividades.

El circuito elaborado fomentaba el trabajo de la coordinación óculo-manual y la óculo-pédica, desarrollando así las dos coordinaciones específicas más importantes. Esta propuesta tenía una gran riqueza motriz, tanto por el avance en estas dos coordinaciones, como por el hecho de hacerlo estimulando distintas habilidades básicas como la conducción, el agarre, el lanzamiento y la recepción.

"...luego los típicos circuitos han sido de... llevar la pelota por medio de los conos con el pie. Luego la cogemos con la mano y la vamos botando por encima de los aros. Luego la lanzamos y la intentamos meter en la canasta." <Elementos internos $\|$ Entrevistas $\mid C$ O1> - Referencia 5.

El desarrollo de un juego en el que los participantes debían trasladar un objeto, con la limitación de hacerlo utilizando únicamente una de sus manos, estimuló su libertad de movimientos respecto a la coordinación específica. Esta estrategia es muy adecuada para niños en edad infantil, ya que fomenta el desarrollo coordinativo de forma independiente a través de la experimentación individual y colectiva, lo que aporta un nuevo aliciente a este tipo de propuestas.

"...están tratando de transportar un globo sin que caiga al suelo utilizando solo la mano izquierda pues ellos se fijan en qué estrategias están utilizando para que no se le caiga." <Elementos internos $\|$ Entrevistas $\| C_{04}>$ - Referencia 3. 
El trabajo de diversas coordinaciones específicas asociadas a varios deportes nos permite ver cómo se desarrollaron estas habilidades a través de diferentes juegos. Pese a la falta de originalidad de estas propuestas, cabe señalar el estímulo coordinativo que suponen, algo que se incrementa al comprobar la variedad de actividades realizadas.

"...juegos de jugar a fútbol, de baloncesto y de tenis." <Elementos internos\|Entrevistas \|C 05> Referencia 5.

Gracias a la ejecución de una actividad divertida, como el uso de la cinta de gimnasia rítmica, los niños de la entidad desarrollaron la coordinación específica asociada con esta tarea, tanto de forma libre como siguiendo las indicaciones del alumnado. De este modo, promovieron la actuación autónoma de los niños, asegurándose el despliegue de ciertos movimientos básicos.

"...yo recuerdo que el día de las olimpiadas lo de las cintas les volvía locos jejeje les gustaba un mogollón. Y ahí pues, ahí sí que podías ir, no sé, añadiendo normas... y iahora con la mano izquierda, ahora con la otra, ahora...! Y la cinta les gustaba mucho." <Elementos internos ||Entrevistas\|C o6> Referencia 3.

La aplicación de numerosos juegos motores que fomentaban distintas coordinaciones específicas nos da una pista de la gran labor coordinativa realizada a través del servicio. Esta acción favoreció enormemente la motricidad de los niños del centro colaborador.

"Lo que más hemos hecho es... juegos motores (...) han hecho muchos circuitos, muchos de lanzamientos, de coger, de coordinación de ojo-mano, ojo-pie." <Elementos internos\|Entrevistas\|C 10>-Referencia 3 .

Este bloque revela el trabajo conjunto de sus distintos elementos mediante la aplicación de las propuestas del alumnado. Igualmente, la riqueza motriz de las actividades realizadas se establece como el aspecto más destacable del servicio prestado, lo cual determina la consecución de varios objetivos básicos del programa de APS como la mejora de la motricidad de los niños o el desarrollo del contenido motor de la asignatura por parte de los alumnos universitarios.

\section{- Juegos de expresión corporal.}

A continuación pasamos al análisis de los juegos de expresión corporal, bloque que valora el contenido expresivo de las propuestas aplicadas.

\section{- Representación de roles.}

La representación de roles examina la aplicación de actividades en las que se trabaja la interpretación expresiva de los participantes.

A través de un juego de persecución, el alumnado fomentó la representación de dos roles habituales bien marcados: perseguidor y perseguidos. Igualmente destaca su flexibilidad al realizar esta actividad, siendo capaces de modificarla en función del transcurso de la misma, una habilidad esencial en el ámbito de la EF donde pueden aparecer numerosas situaciones que desvirtúen o alteren el objetivo inicial de las propuestas aplicadas. 
"Con el paracaídas pues empezamos a hacer el juego de (...) peces y tiburones o algo así le llamábamos a ese. Nada, lo que hacíamos era pues asignar roles y dependiendo un poco de cómo veías a esos niños esos días (...) tienes que ser flexible y si te piden ese protagonismo pues lo das. Pero claro, cuando ya te das cuenta de que todo el rato quiere ser él el tiburón, pues lo que haces es cambiar el nombre al juego. Ya no estás jugando a tiburones y a peces, y estás jugando al salvamento de personas que se están, con un terremoto, hundiendo en charco o algo asi." <Elementos internos $\|$ Entrevistas $\| C$ o4>-Referencia 2.

La representación de varios roles a través de un juego de relajación demuestra la vinculación de este aspecto con el resto de elementos del bloque. Advertimos que para tener éxito al conjugar esta cualidad expresiva con la relajación debemos aprovechar la interpretación de comportamientos de escasa movilidad para así reducir adecuadamente el nivel de actividad corporal de los niños, de lo contrario estaríamos provocando el efecto inverso al deseado.

"...todos los de relajación han ido más o menos en la misma línea porque a lo mejor les decían que estaban en la ducha o que eran árboles. Como daban instrucciones ellos en su cuerpo tenían que hacer la expresión." <Elementos internos $\|$ Entrevistas $\| C$ 05> - Referencia 1.

El desarrollo de un elaborado juego en el que se interpretaban diferentes tipos de roles transcurría en dos momentos bien diferenciados. Debemos destacar el buen hacer del alumnado en la confección de esta tarea, gracias a la cual se pudieron extraer multitud de propuestas, utilizando la imaginación de los niños para definir la representación de diversas situaciones. El valor de estas actividades reside en su capacidad para incentivar la expresividad individual de los participantes con ciertos márgenes de libertad.

"...se llama terremoto, que es que tú les das cualquier norma, la que sea... pues ahora vais andando cada uno libremente o corriendo o saltando o lo que sea y cuando alguien dice terremoto (...) se tienen que juntar, hacer una casa y uno se esconde debajo y se protege en la casa. Y entonces tienes que buscarte o una pareja para hacer la casa o una casa donde esconderte y ese le gustaba. Ese también estuvieron mucho rato jugando." <Elementos internos\|Entrevistas $\| C$ o6> - Referencia 2.

La representación de roles, mediante el seguimiento de las indicaciones de una canción, establecía que todos los participantes debían ejecutar los mimos movimientos en determinados momentos. Este es un recurso eficaz para que los niños aprendan a través de sus compañeros, adaptando y ajustando su ejecución a la del resto del grupo. Igualmente puede ser una alternativa útil en aquellos casos en los que se observen reticencias a la representación individual, gracias a la acción conjunta de los participantes.

"iPues bailarla, o sea, hacerlo, expresarlo y avant! No sé, hacer la tetera, la cuchara, el cucharón.

Entonces cada una de estas cosas pues tiene su, no sé, la forma de representarla digamos."

$<$ Elementos internos $\|$ Entrevistas $\|$ C 07> - Referencia 2.

Un juego de expresión corporal, ambientado en la representación de animales, nos ayuda a entender cómo se trabajaron diversos desplazamientos específicos. Este hecho nos lleva a reflexionar sobre la capacidad del alumnado para fomentar distintos aspectos motores a través de diferentes propuestas representativas. La importancia de esta estrategia se manifiesta al ofrecernos un recurso de trabajo múltiple.

"De expresión también, por ejemplo el de los animales. Se despertaban y hacían $X$ animal, la serpiente, el canguro, el no sé qué... que también relacionan un poco pues que el canguro va saltando, que la serpiente va arrastrándose por el suelo..." <Elementos internos $\|$ Entrevistas $\| C$ 11> - Referencia 2. 


\section{- Simbolismo.}

El simbolismo estudia el significado de las propuestas de expresión corporal realizadas por los niños.

Una actividad en la que dos niños actuaban como si fueran el rey de la selva nos ayudar a ver el simbolismo de la tarea al representar el comportamiento de estos animales en sus diferentes facetas. Vuelve a destacar el uso del mundo animal para fomentar la expresión corporal, un entorno muy apropiado para la edad de los receptores del servicio. Igualmente se aprecia la vinculación de este aspecto representativo con el resto del bloque analizado.

"...él empezó que era un león ¿vale? y ella le siguió porque cuando quiere imita muy bien las cosas. Y estaban los dos de leones, tirados por el suelo de leones, y entonces él me quería cazar a mí y yo digo... vale pues me vas a cazar, los dos me cazáis." <Elementos internos\|Entrevistas\|C o2>-Referencia 1.

Esta situación presenta una tarea muy similar a la anterior pero enmarcada dentro de una actividad mucho más ambiciosa, un Lipdub. Pese a tener una esencia común, la diferencia fundamental entre ambas recae en el entorno de esta última, el cual limita y pauta el simbolismo en la representación de los niños. Deducimos que este condicionamiento no solo fue gestual sino también temporal, ya que esta actividad engloba diferentes momentos de actuación consecutivos.

"Nos dividimos en dos grupos, el primer grupo pues salía al principio del video, por ejemplo... nos pintamos todas las caras de león todos, todos, todos, todos, todos, y en el principio era todo muy suave, movimientos muy suaves para llegar... eso fue en el pabellón." <Elementos internos $\|$ Entrevistas $\|$ C o3> - Referencia 1.

En este juego los niños representaron a un extraterrestre que debía montar su nave para volver al espacio exterior. Además del contexto lúdico de esta propuesta, podemos resaltar el hecho de que representaran a un ente del que no tenían referencias reales, condicionante que aumentó el factor simbólico de la actividad realizada.

"Hicimos una hace poco que iba de ayudar a un marcianito a montar su nave y eso le gustó mucho, jugar y tener... porque se trajeron además el personaje y eso les gustó un montón. Tener un personaje que... a este personaje tenéis que ayudar jeje." <Elementos internos $\|$ Entrevistas $\| C$ o6>-Referencia 2.

Una tarea ambientada en un contexto determinado nos permite comprobar cómo los niños participaron en diversos circuitos cargados de significado. Gracias a este original recurso los alumnos pudieron dirigir la acción motriz de los participantes en una actividad muy atractiva. Una vez más nos vemos obligados a señalar la inmensa cantidad de posibilidades que ofrece esta estrategia al ámbito de la EF.

"...ponían a lo mejor dos circuitos para que jugaran todos a la vez. Entonces ponían aros, conos en forma de zigzag y que se pasaran la pelota, cuerdas para como si fuera un río, luego ponían, había una especie de piedras, y tenían que pasar por encima sin caer abajo y les decían que abajo había agua. Luego (...) lanzaban la pelota al aro (...) Luego colchonetas y reptaban por las colchonetas y pañuelos (...) como si fueran piratas que van en un barco. Entonces les ibamos poniendo en situación." $<$ Elementos internos $\|$ Entrevistas $\| C$ 10> - Referencia 1.

Conociendo el desarrollo de una actividad simbólica muy popular, el juego de las estatuas, percibimos el componente significativo de la tarea realizada. Igualmente, las indicaciones del 
alumno nos llevan a comprender cómo utilizaron esta actividad para fomentar la expresión de los niños mientras se familiarizaban con los participantes. Esta estrategia puede ser de gran utilidad al iniciar el contacto con cualquier grupo de niños.

"...lo de las estatuas lo hicimos y sí que veías un poco... ibas conociendo también al grupo." < Elementos internos $\|$ Entrevistas $\| C$ 11> - Referencia 1.

\section{- Expresión.}

El aspecto que hace referencia a la expresión analiza la aplicación de las diversas actividades y juegos de carácter expresivo.

Una conocida actividad, que utiliza el recurso de la música para guiar la representación de diversos objetos, nos lleva a reflexionar sobre el enorme potencial de la relación entre la expresión corporal y la música, pudiendo proporcionarnos infinitas posibilidades de trabajo.

"Han hecho coreografías. Y... pero en plan imitando lo que la canción decía. De esta... la típica la de, soy una taza, soy una tetera..." <Elementos internos||Entrevistas||C o1> - Referencia 2.

La siguiente actividad expresiva destaca por la enorme dificultad que supone su aplicación debido a la gran complejidad organizativa que conlleva. Debemos destacar el buen hacer del alumnado universitario en su ejecución, ya que se consiguió desarrollar de forma satisfactoria con los niños con TDAH, un colectivo caracterizado por su incapacidad para esperar o estar concentrado mucho tiempo, cualidad esencial en el transcurso de esta actividad.

"El baile este que era una serie de pasos con la música del libro de la selva, y luego hemos hecho lo del Lipdub que también es de expresión corporal." <Elementos internos\|Entrevistas $\| C$ o3> - Referencia 4.

La dificultad de fomentar la expresión corporal en los niños más mayores provenía de la sensación de bochorno que experimentaban al trabajarla junto a sus compañeros de menor edad. La experiencia nos anima a desarrollar este tipo de actividades en grupos de edades similares, evitando así el afloramiento de este sentimiento negativo.

"...al principio, cuando queríamos hacer alguna canción así un poco más de animar... pues jvamos a hacer una canción entre todos! Pues no, ahí los que eran ya más de seis, siete años, como los pequeñitos sí que lo hacían pues los más mayores pues para mí que tenían vergüenza de que los pequeñitos sí que lo hacían y pues lo pasaban mal." <Elementos internos\|Entrevistas\|C o4> Referencia 4 .

Un juego expresivo, basado en la representación de diversos animales, era tan estimulante que llegaron a realizar una sesión completa utilizando dicho reclamo. Igualmente destaca el uso de estas actividades de expresión corporal en lugar de otras tareas verbales. Con ello, los alumnos incentivaron el desarrollo de este aspecto clave en el servicio mientras sorteaban una problemática existente en cuanto a la comunicación verbal.

"...si se podía sustituir por expresión corporal, mejor. Los jueguitos estos de... hicieron una sesión toda de animales de... pues ;ahora vamos a hacer cómo si fuésemos no sé qué! Y que eso les iba mejor que presentarse, hablar, expresar cosas hablando." <Elementos internos\|Entrevistas $\mid C$ o6> - Referencia 1.

La propuesta siguiente pretendía que la expresión corporal de los niños se ajustase al ritmo y velocidad de varias canciones. Valoramos la gran cantidad de posibilidades que nos ofrece 
esta estrategia. Sin embargo, debemos aprender a utilizarla de forma correcta, ya que si no lo logramos podría ser ineficaz o incluso perjudicial, como sucede en este caso.

"...sí que intentábamos que a través de la música se movieran o que expresaran a través de la música. Si era más deprisa, o sea, si era rápida que fueran rápido, si era lenta que fueran lento, si se paraba que se pararan, y expresar bailando (...) Lo que pasa es que si la poníamos muy fuerte notamos que se alteraban y (...) ya se les olvidaba el juego de lo que estaban jugando." <Elementos internos $\|$ Entrevistas $\| C$ o8> - Referencia 4.

\section{- Comunicación corporal.}

La comunicación corporal valora el desarrollo de actividades que fomenten el intercambio de información o diálogo a través del cuerpo.

En este sencillo juego los niños debían realizar una acción $u$ otra en respuesta a las indicaciones mímicas del alumno que dirigía la actividad. Esta estrategia nos ofrece un espacio útil para fomentar el diálogo gestual entre los participantes, pudiendo maximizar su beneficio si otorgamos una mayor importancia e independencia a los jugadores durante el desarrollo de la actividad.

"...luego por ejemplo, se ponían en, todos en fila y una de las chicas si daba una palmada era por ejemplo saltar, si daba dos darse la vuelta y así." <Elementos internos ||Entrevistas\|C o1> - Referencia 2.

El hecho de que los propios niños expusieran los movimientos a repetir por el resto de compañeros no solo incentivó el dialogo corporal mediante una actividad musical sino que también promovió el desarrollo de la expresividad individual en todos los participantes, otro importante aspecto de este apartado.

"En un grupo sí que se hicieron tipo, tenían que hacer una coreografía, y se ponía una música. Cada alumno hacía un paso de baile, el que quisiera, y luego todos... luego se juntaban todos, los iban repitiendo todos y al final colocaban una música y se hacía eso." <Elementos internos ||Entrevistas |IC 05>-Referencia 1.

La aplicación de varios juegos, basados en el intercambio de información no verbal, nos ayuda a ver cómo se fomentó este importante aspecto. Como en el caso anterior, estas actividades tenían una gran carga expresiva y representativa, muestra de la vinculación entre los diferentes apartados de este bloque.

"...si que hemos hecho actividades de expresión corporal y pues eran más que nada actividades en grupo (...) bueno actividades de representar. Llevaban por ejemplo tarjetas y un niño tenía que representar y los otros tenían que adivinar que era aquello que estaba representando, o simplemente nosotras decíamos... iahora representaremos esto!" <Elementos internos||Entrevistas\|C og> Referencia 1.

Un juego de presentación fomentó la comunicación gestual de los participantes y desarrolló otros aspectos relacionados con su expresión corporal. La actividad solo se realizó con un grupo de chicas, hecho que achacamos al prejuicio común que tiene el alumnado masculino sobre la participación en tareas de carácter expresivo. Como ya hemos apuntado, es necesario realizar un trabajo equilibrado de cualquier actividad en ambos colectivos. 
"De expresión corporal con el grupo de las chicas (...) sí que hicimos como una especie de baile, luego juegos de presentación en los que expresaran con movimientos quién eran, entonces... pero lo que más se ha hecho es juego motor." <Elementos internos\|Entrevistas $\mid C$ 10> - Referencia 1.

El transcurso de una actividad de comunicación corporal, centrada en la representación de los diferentes estados de ánimo, nos permite entender el desarrollo de este juego. Asimismo se aprecia cómo aprovecharon esa tarea para trabajar sobre el reconocimiento de las distintas situaciones emocionales que se pueden manifestar, evidenciando así el carácter educativo de la actividad más allá de su componente expresivo.

"...también hicimos una que era... es que no, ahora mismo no me acuerdo, pero era algo de... también que pues a lo mejor, estamos cansados y es... y que hicieran que estaban cansados, ahora estamos muy contentos y tal." <Elementos internos $\|$ Entrevistas $\| C$ 12> - Referencia 1.

Aunque el desarrollo de actividades relacionadas con la expresión corporal no tuvo una presencia tan notable en el servicio como los juegos motores, este apartado nos muestra la aplicación de numerosas y variadas propuestas que estimularon los distintos elementos de este bloque, completando así el desarrollo de los contenidos básicos de la asignatura.

\section{- Otros aspectos.}

Por último analizamos el bloque que hace mención a otros aspectos, abordando diferentes cuestiones genéricas que no han podido formar un apartado específico.

\section{- Carácter innovador y originalidad.}

El carácter innovador y originalidad comprueba la creatividad y novedad de los juegos aplicados.

El desarrollo de un juego, creado expresamente para el servicio, nos muestra cómo los niños más pequeños tenían que utilizar el material disponible para caracterizar a dos compañeros más mayores siguiendo una dinámica de ambientación acuática. Esta original y novedosa propuesta no deja lugar a dudas en cuanto al carácter creativo de los alumnos. Igualmente se aprecia cómo a través de su ejecución también se fomentaba la creatividad de los participantes. Cabe destacar que el carácter cooperativo de esta actividad también permite trabajar numerosas cuestiones sociales durante su aplicación.

"...nos salió un juego súper chulo que era... como si estuviéramos nadando y en medio teníamos ropa diferente de baño de pantalones, gafas, gorro, toalla ¿no? y dos de los niños que escogimos nosotros (....) en este juego concretamente de la natación cogimos a los dos más grandes y tenían que... los demás tenían que disfrazar al grande. Entonces con una serie de normas pues... eran dos equipos también y unos disfrazaban al contrario. Iban poniéndole ropa y ya está." <Elementos internos $\|$ Entrevistas $\| C_{03}>$ - Referencia 1.

La originalidad de las actividades quedó patente en el contexto temático de las diferentes sesiones realizadas, ya que las clases prácticas estuvieron ambientadas con distintos entornos atractivos para los niños, como los Juegos Olímpicos, el circo, los premios de 
Hollywood, animales en libertad, etc. Este original reclamo no solo permitió englobar los juegos aplicados cada día en una misma temática sino que también consiguió aumentar la motivación de los niños, mejorando su nivel de participación en las tareas propuestas.

"... a lo largo de cada sesión hemos tocado un montón de temáticas: las Olimpiadas, el circo, los Óscar, animales de la selva..." <Elementos internos $\|$ Entrevistas $\| C$ o4> - Referencia 2.

La aplicación del juego espontáneo incentivó la libertad de los niños a través del uso de nuevos materiales, estimulando también su creatividad. No obstante, cabe destacar que los alumnos universitarios fueron dirigiendo la actividad de los niños para que se ajustara a los requisitos del servicio, reforzando así el carácter educativo de las propuestas desarrolladas.

"...ha habido un poco de todo. Juego libre ha habido por ejemplo como te he comentado con los pequeños como un poco espontáneo. Ellas traían material y los niños jugaban con ese material. También a partir de ese juego espontáneo lo dirigían un poco." <Elementos internos\||Entrevistas\|C 05> - Referencia 1.

El alumnado diseñó una elaborada propuesta, repleta de originalidad, a partir de una dinámica muy popular. Así pues, utilizando el conocido reclamo de ir a pillar crearon una actividad de estrategia basada en un juego de mesa. Además del carácter innovador de esta tarea, debemos resaltar el gran papel que puede jugar en el ámbito de la EF, ya que nos permite enriquecer la motricidad de los niños a través de los diferentes desplazamientos asociados a cada pieza.

"Era un juego de pillar pero con una serie de normas porque era como jugar al ajedrez, eso era con los mayores que era un juego muy complicado. Había dos equipos, cada equipo era una pieza y cada pieza tenía por así decirlo una norma, entonces uno de un lado salía a pillar a alguien sin saber que pieza le había tocado y entonces tocaba a quien fuera y la norma era que según la pieza que era salía más gente o menos detrás de ti a pillarte." <Elementos internos ||Entrevistas $\| C$ 06> - Referencia 8.

La reflexión de un alumno sobre la progresión de las actividades nos transmite la dificultad de aplicar nuevas propuestas con esta clase de niños, incluso utilizando juegos muy conocidos. Pese a esta complejidad, intentaron innovar a través de la ejecución de nuevas tareas una vez asimilados los juegos básicos. Esta acción habla por sí sola de su intención de aportar elementos originales al ejercer como docentes durante el servicio.

"...juego que planteamos era el de la cadena y cogerse de la mano no, no. Ellos no se centraban en cogerse de la mano, cada uno se iba, el que pillaba luego se iba allí ya no pillaba (...) la semana siguiente seguimos con el mismo juego y ya pues parecía que más o menos empezaban a entenderlo. $Y$ luego la sesión que lo repetimos no fue la siguiente fue otra y ya sí que perfecto. Y a partir de esa sesión pues ya intentamos innovar con juegos." <Elementos internos $\mid$ Entrevistas $\| C$ o8> - Referencia 2.

\section{- Valor lúdico.}

El valor lúdico examina el componente recreativo de los juegos y tareas realizadas con los niños.

El siguiente alumno destaca el entretenimiento de los participantes a lo largo de las sesiones. Además, no solo incide en el regocijo percibido en los niños sino que apoya esta afirmación con el análisis de otras conductas, como por ejemplo el hecho de que fueran cariñosos con 
ellos. Esta acción demuestra su capacidad para analizar el comportamiento de los niños en su conjunto y no únicamente en cuanto a la respuesta inmediata tras la aplicación de los juegos.

"...se lo pasaban bien luego te dan besos, te abraza, te buscan, es que te buscan (...) yo por ejemplo con algunas niñas síque es que lo noto mogollón que te buscan." <Elementos internos||Entrevistas ||$C$ o3> Referencia 21.

Los conflictos existentes, a la hora de utilizar un material divertido dentro de una actividad dirigida, hablan del enorme componente lúdico de las propuestas realizadas. Esta experiencia nos muestra cómo una diversión desmedida puede ser perjudicial en la aplicación de las sesiones. Por ello, los alumnos debían controlar el nivel de excitación de los niños de modo que mantuvieran un alto grado de motivación sin provocar una sobre-estimulación.

"...el paracaidas les gusta un montón, recuerdo que nos cuesta mucho conseguir un juego organizado, por así decirlo, de ahí (...) ellos ven el paracaídas y se vuelven locos pero ponerlos a jugar a algo es muy difícil, o sea, que en ese momento cada uno hace lo que quiere, y se meten todos debajo y luego sácalos jeje. Y el último día sí que conseguimos porque establecíamos turnos." <Elementos internos $\|$ Entrevistas $\|$ C o6>-Referencia 9.

Los alumnos utilizaron diversos juegos tradicionales con el propósito de asegurar el componente lúdico de algunas sesiones. Igualmente, se aprecia cómo introdujeron modificaciones en el desarrollo de estas actividades para incidir en aquellos movimientos que consideraban más importantes. Este hecho demuestra su intención de alcanzar los dos objetivos fundamentales del servicio, fomentar la diversión y el desarrollo motor de los niños.

"También han hecho juegos tradicionales pero, o sea, poniendo reglas nuevas en plan de si era el del pollito inglés pues ir a la pata coja con la izquierda o ir a la pata coja con la derecha, o ir botando el balón con una mano." <Elementos internos $\|$ Entrevistas $\| C$ 10> - Referencia 3.

El uso de distintos objetos provocó una respuesta lúdica en los niños del centro colaborador debido al carácter novedoso de los materiales. Esta situación nos hace reflexionar sobre la diversión que puede aportar cualquier variante en la dinámica de las sesiones. No obstante, debemos estudiar adecuadamente estas modificaciones, ya que no todos los cambios implican una respuesta positiva en cuanto a la recreación de los participantes.

"Y cuando introdujimos los globos igual, los globos se lo pasaron pipa. Era material nuevo dentro de... entre comillas. También les gustaba, a los de cuatro, les gustaba mucho cuando sacábamos cosas de para hacer psicomotriz de esta que es como esponjita que son cubos o un túnel, y... también sacamos eso." < Elementos internos $\|$ Entrevistas $\| C$ 11>-Referencia 11.

El alumnado consideró que aplicar juegos bajo las mismas premisas de forma continua podía acabar desmotivando a los niños. Por ello, fueron introduciendo variantes en la dinámica de las actividades para aumentar el carácter recreativo de las mismas. Además, observamos que aprovecharon esta ocasión para fomentar la adquisición de otros conocimientos, reforzando así el valor educativo de sus propuestas.

"...nosotras intentábamos hacerlas porque (...) jugar a la zapatilla por detrás nos parece (...) no sé cómo decirlo, un poco chorra. Nos parecía un poco muy, muy aburrido. (...) y lo hicieron. Y me dijeron... pues ha salido superbién, los ha motivado un montón (...) porque la hicimos con transportes. En vez de a la zapatilla... en vez de cantar la canción pues hacíamos... jel camión, camión, coche! Cuando decías el coche pues tenían que salir corriendo." <Elementos internos $\mid$ Entrevistas ||$C$ 12> - Referencia 3. 


\section{- Variedad.}

La variedad de los juegos analiza la diversidad de las propuestas aplicadas durante el servicio.

El uso de una temática global, para ampliar la variedad de tareas en las sesiones, permitió que se aplicaran propuestas que en un principio provocaban una respuesta negativa de los participantes. Esta estrategia no solo muestra su capacidad para incrementar la diversidad de sus clases sino que también transmite su competencia para motivar a los niños a participar en actividades que inicialmente no eran de su agrado, una cualidad esencial en todo docente.

"...con una serie de consignas que les dimos los niños lo hicieron genial (...) normalmente cuando propones así algo de algún baile o algo de cantar normalmente los niños... i¿ahora tenemos que cantar?, ¿ahora tenemos que bailar?! Se desmotivan un poco, pero como era la dinámica del juego pues estuvo bien, estuvo genial. No nos dijeron ninguno... pues iyo no voy a jugar a bailar! No, todos siguieron..." < Elementos internos\|Entrevistas $\| C$ o3> - Referencia 14.

La introducción de algunos cambios y consignas en los juegos, para aumentar la variabilidad de los mismos, nos enseña cómo exprimían el uso de algunas actividades exitosas, a través de la modificación de ciertos aspectos que hacían que el juego siguiera resultando divertido y motivador para los niños. Esta capacidad para introducir variantes puede emplearse con multitud de objetivos como alterar el juego, adaptarlo a las condiciones existentes, cambiar su objetivo, introducir nuevos elementos, etc., de ahí el gran valor educativo de este aprendizaje.

"...ese tipo de juegos, los de pillar con algunas instrucciones más concretas, o sea, con algunas consignas cambiadas, adaptadas a lo que eran las temáticas, funcionaban." <Elementos internos\|Entrevistas\|C 04> - Referencia 12.

La reflexión del siguiente alumno sobre la importancia de aplicar juegos y propuestas distintas a lo largo de las sesiones, nos permite apreciar el valor de esta premisa, no solo en cuanto a la variedad de actividades ofertadas sino por los distintos estímulos y respuestas que esta diversidad provoca en los participantes. Esta situación aumenta notablemente la riqueza del proceso de enseñanza-aprendizaje.

"Que fueran haciendo varios tipos de juegos y que no hicieran siempre el mismo esquema, para que ellas también aprendieran de esa situación. Porque si todos los juegos que nos proponían en las fichas veíamos que eran muy parecidos o que eran todos del mismo tipo les decíamos pues que eso, que cambiaran un poco para que ellas pudieran ver también desde su punto de vista cómo afectan todos los tipos de juegos a estos niños." <Elementos internos||Entrevistas ||C 05> - Referencia 7.

El alumnado universitario utilizó la variedad de juegos como alternativa para evitar algunos conflictos, en el desarrollo de las actividades, cuando los niños no entendían la dinámica de las propuestas. Así pues, cambiaron el juego conflictivo por otras tareas de similares características, por lo que los participantes no se vieron perjudicados por estas modificaciones. Por otra parte, destacamos la rapidez con la que cambiaban de dinámica, lo cual indica su intención por perder el menor tiempo posible en estas acciones.

"...si por ejemplo jugaban a la bomba, por ejemplo, y no lo entendían en ese momento cambiar enseguida y jugar a otro juego, jugar a pared o jugar a pasar el balón." <Elementos internos\|Entrevistas\|C 10> - Referencia 13. 
La gran variedad de actividades realizadas a lo largo de todo el servicio no deja lugar a dudas en cuanto a la riqueza y diversidad de propuestas aplicadas en el transcurso del programa formativo. Conociendo la dinámica de los juegos motores y expresivos descritos, comprobamos cómo se fomentó el desarrollo de muchos de los aspectos abordados en este análisis como la coordinación específica, la motricidad fina, el uso de varios materiales, las distribución de roles, etc.

"...con los mayores... al principio también hicimos circuitos (...) Luego trabajamos las estatuas. Jugamos (...) a béisbol. Hemos jugado también a bolos. Las canicas. Las chapas. Los juegos tradicionales. Hemos saltado a la comba. (...) También hemos hecho bailes con ellos. También hemos jugado al sobre sobre. Hemos jugado con la pelota gigante." <Elementos internos||Entrevistas ||C 12> Referencia 12.

\section{- Evaluación de las actividades.}

La evaluación de las actividades propuestas valora el resultado de aplicación de los juegos en función de los objetivos iniciales.

Los alumnos no dudaron en preguntar directamente a los niños si les habían gustado las tareas aplicadas o incluso qué actividades querían realizar. Con esta sencilla acción supieron rápida y eficazmente si los juegos cubrían el componente recreativo esperado, asegurando así la consecución del objetivo lúdico del servicio.

"...les preguntaban ¿os ha gustado? Mil cosas. ¿Qué queréis hacer el próximo día? Más que nada para tener una base, por si estás ahí obligando a los niños a jugar a algo y se aburren más que una patata." $<$ Elementos internos\|Entrevistas $\|$ C 01>-Referencia 1.

El dominio alcanzado, en cuanto a la gestión del colectivo con el que realizaron el servicio, demuestra el conocimiento adquirido por los alumnos universitarios respecto a las características y necesidades de los niños con TDAH. Este aprendizaje es la base de toda acción docente, ya que cuanta más información tengamos sobre las exigencias y tipología del alumnado al que va dirigida la práctica, mejor resultado se podrá obtener de su aplicación.

"...la tercera sesión yo ya tenía... a ver, no quiero ahí decir que tenía súper dominado lo que era el grupo de hiperactivos, pero ya había llegado a descubrir qué funcionaba, qué no y qué cosas se podían mejorar con ese grupo." <Elementos internos\|Entrevistas $\| C$ o4>- Referencia 5.

Tras identificar la motivación que el estímulo sonoro producía en los niños, los alumnos no dudaron en integrarlo en sus propuestas para conseguir que participaran y se divirtieran durante las actividades. Este hecho revela su buen hacer en cuanto al reconocimiento de los intereses de los participantes. Por otra parte, su acción también fomentó el éxito de los juegos realizados, gracias a la atracción que las distintas canciones despertaban en los jugadores.

"También ha habido juegos con música, en muchas sesiones se ha utilizado la música para muchos juegos porque les llamaba mucho la atención, les gustaban mucho los juegos para bailar." < Elementos internos $\|$ Entrevistas $\| C_{05}>$ - Referencia 5.

La capacidad del alumnado para evaluar sus propias propuestas les ayudó a reconocer aquellos juegos que provocaban una mejor aceptación de los participantes. Esta acción es mucho más sutil que preguntar directamente a los niños, aunque aporta exactamente los 
mismos beneficios. El éxito de estas actividades radicaba en su gran valor lúdico, destacando así otro de los elementos de esta categoría.

"...el de los refugios porque es el que tenemos que hacerlo más porque es que les encanta y lo piden, 0 sea, igual que la relajación que hacemos al final que $B$---- entra a las diez y media y se pasa la hora diciendo... ¿Cuándo va relajación?" <Elementos internos\|Entrevistas $\| C$ 07> - Referencia 6.

La deficiente implementación de una actividad de bate y campo no deja lugar a dudas en cuanto al fracaso del alumnado universitario en la aplicación de algunas propuestas prácticas. Sin embargo, esta situación les aportó un aprendizaje valioso, ya que no solo fueron capaces de reconocer el poco éxito de la misma sino que también identificaron los motivos que provocaron este resultado negativo. Esto puede ayudarles a modificar futuras propuestas para que tengan mejor acogida y evitar dinámicas similares que puedan ser igualmente improductivas.

"...jugamos a béisbol y no había forma de que cuando cogieran la pelota se la pasaran. Y cogían la pelota y salían corriendo y se tiraban unos encima de otros, todos querían la pelota. Al final tuvimos que marcar una línea y para que de ahí no pudieran pasar y que se la tuvieran que lanzar al compañero. $Y$ nos pusimos una de nosotras dentro para que no... porque se peleaban." <Elementos internos $\|$ Entrevistas $\| C$ o8> - Referencia 6.

Pese a que este bloque engloba diversos aspectos inicialmente independientes, hemos comprobado que igualmente presentan cierta interrelación entre ellos, así como con otros aprendizajes académicos como la participación del alumnado, la consecución de objetivos, el ajuste a las necesidades educativas de los participantes, la variedad de materiales, etc. Esta situación refuerza la inclusión de los elementos de este bloque en el análisis realizado.

\subsubsection{Variable dependiente B: competencia de Emprendimiento Social}

\section{- Aspectos personales.}

Siguiendo la estructura del cuestionario para medir la competencia de ES, la primera categoría de resultados de esta variable trata los aspectos de carácter personal. Estos hacen referencia a los elementos, facetas y matices propios, pertenecientes o relativos a la personalidad del individuo.

\section{- Liderazgo.}

El liderazgo hace alusión a la condición de dirección que asume una persona al ejercer como líder $\mathrm{u}$ orientador de un grupo.

Este alumno dirigió las actividades con los niños por conocerlos con anterioridad. Con ello tomó el liderazgo dentro del equipo de trabajo, asumiendo una responsabilidad mayor que el resto de compañeros, con la intención de mejorar las actividades del servicio.

"...al yo conocerlos... si yo no los hubiera conocido yo creo que las sesiones nos hubieran salido más mal. Porque es así y porque no íbamos desde cero, mis compañeras me preguntaban ¿qué es lo que le pasa a este niño? o ¿hasta dónde puede llegar?" <Elementos internos||Entrevistas||C 01> - Referencia 6. 
El siguiente alumno buscó de forma autónoma una serie de actividades a realizar en función de los objetivos propuestos, dirigiendo así las tareas del equipo de trabajo sin mermar la participación de sus compañeros, una actitud deseable al actuar como líder en cualquier situación.

"...como había encontrado actividades interesantes de motricidad y todo eso y por ejemplo canciones y tal, pues propuse que hiciéramos aquí una sesión de animales y traje unas actividades y... canciones." $<$ Elementos internos\|Entrevistas $\| C$ 02> - Referencia 1.

El liderazgo asumido por los alumnos hace referencia al grupo de compañeros universitarios con los que debían trabajar. Sus palabras nos ayudan a entender que realizar esta labor no siempre es sencillo, ya que se pueden presentar algunas dificultades en cuanto al seguimiento de las normas establecidas, especialmente cuando se trata de una relación entre iguales.

"...nosotros les dijimos... pues es esto, esto, esto y esto ¿no? Y si, se supone que lo tenían claro pero luego en el momento de la sesión pues no, cada uno iba a su bola, no cumplía el rol que tocaba (...) a lo mejor le tocaba preparar el juego y estaba jugando o le tocaba ser la portavoz y (...) no cumplieron sus roles. Entonces de aquí ¿qué aprendimos? pues a poner unas normas." <Elementos internos $\|$ Entrevistas $\| C_{03}>-$ Referencia 4.

El primer contacto de un alumno universitario con los niños de la entidad generó una situación con la que no estaba familiarizado hasta ese momento, de ahí la tremenda exigencia que sintió al asumir la dirección del trabajo con los niños. Este hecho destaca el valor de la vivencia experimentada en su formación como futuro docente.

"...cada vez empecé a ver más niños ¿no? (...) Y claro ahí empezaba a notar, digo... ya es responsabilidad mía, bueno y de mis compañeros, el control un poco de que estos niños están aquí ahora. Y nunca había estado yo al frente de niños en ese sentido." < Elementos internos $\mid$ Entrevistas $\mid C$ o4>-Referencia 1.

La posición asumida como miembro del equipo de trabajo nos lleva a comprender la gran responsabilidad adquirida en cuanto a la realización de las tareas y la gestión de los recursos humanos disponibles, una cualidad que más adelante abordaremos en este mismo análisis.

"...muchas veces nos pasó cuando íbamos que algunos alumnos no querían jugar entonces se quedaban aislados y nosotras no sabíamos cómo reaccionar (...). Y nosotras siempre estábamos pensando en eso ¿cómo hacer para que el niño pueda jugar? O ¿qué hacer para que el niño se motive? E intentábamos transmitirlo a las chicas que planteaban la sesión." <Elementos internos||Entrevistas||C 05> Referencia 13.

La dirección de los juegos con los niños de la entidad es una situación crítica en la aplicación de las actividades que, de no ser gestionada adecuadamente, puede conllevar consecuencias muy negativas para el desarrollo normal de la sesión.

"... a veces es muy caótico y cuando terminas un juego tienes que reunirlos ¿no? todos para escuchar otra vez y explicar otra vez el juego... esos son momentos críticos ¿eh? Porque si se te van ahí se te van, y luego reúnelos a todos otra vez para contar lo que hay que hacer." <Elementos internos $\|$ Entrevistas $\| C$ 06> - Referencia 3.

La problemática surgida al trabajar con los compañeros de clase nos hace pensar que una de las claves del liderazgo es hacerlo desde una posición comprensiva y dialogante, intentando 
ofrecer libertad a todos los implicados para participar en la toma de decisiones, de lo contrario podrían aparecer numerosas disputas y conflictos.

"...ellas fueron a J---- y se le quejaron de que lo tenían que hacer todo ellas cuando el primer día lo hicimos con ellas, el segundo lo hicimos nosotras, ellas hicieron el tercero y el cuarto lo hicimos nosotras. Y que no les habíamos dicho nada, y que les habíamos dicho que era así y ya está y no les habíamos dado a elegir (...) si nos hubieran dicho... inos parece mal, hagámoslo de otra forma! Tampoco les hubiéramos dicho que no." <Elementos internos $\|$ Entrevistas $\mid C$ o $7>$ - Referencia 3.

La responsabilidad asumida por el alumno universitario al sacar a los niños del aula le causó ciertos reparos al inicio de la actividad. No obstante, con el paso del tiempo consiguió familiarizarse con este tipo de labores $y$, finalmente, fue capaz de liderar a los niños sin ningún temor, demostrando así su evolución en esta importante cuestión.

"... a mí por ejemplo no me resulta ya difícil llegar y hablar yo con ellos. Por ejemplo de la clase siempre los saco yo, y hacemos el tren y ya... y siempre los saco yo, y cantamos la cancioncita y yo no tengo ningún problema en estar con ellos." <Elementos internos $\|$ Entrevistas $\| C$ o8> - Referencia 6.

La decisión tomada por el equipo de trabajo, en cuanto al inicio de las actividades, nos hace entender que retrasando la participación de sus compañeros de clase, en vistas a conocer en mayor profundidad el contexto de la actividad a realizar, consiguieron ofrecer un servicio de más calidad por adaptarlo mejor a las necesidades educativas de los niños.

"...habíamos preparado la sesión pero no habíamos estado en contacto con ningún niño (...) decidimos que hasta que no tuviéramos los grupos claros, decidimos hacer la primera sesión nosotras para tener un primer contacto con las familias y los niños, y a partir de la próxima semana ya empezar con el primer grupo y así pues también saber más o menos cómo están las cosas." <Elementos internos $\|$ Entrevistas $\|$ Cog $>$ - Referencia 2.

Las distintas labores realizadas por los alumnos al liderar el servicio de sus compañeros nos llevan a pensar que, pese a todas las acciones que suponía gestionar esta actividad, seguían considerando que la participación en esta clase de proyectos era muy positiva para su formación práctica, destacando nuevamente este tipo de aprendizajes frente a aquellos de carácter teórico.

"...hemos planificado los horarios, hemos hablado con las alumnas, hemos encuadrado todas las horas para que no perjudicara a nadie y pudiéramos todas trabajar bien y la verdad es que en ese sentido sí que recomiendo que se elija esta asignatura para... porque aprendes más que en las clases teóricas, ya que pones en práctica todo lo teórico." <Elementos internos $\|$ Entrevistas $\| C$ 10>-Referencia 3.

La falta de autoridad existente al liderar a un grupo de iguales hizo reflexionar a un alumno sobre la desventaja de su posición con respecto a la de un profesor. No obstante, su conocimiento del grupo le permitió gestionar adecuadamente este conflicto, otra cualidad analizada más adelante.

"...yo me encargué bastante de confeccionar los horarios con los de tercero que tenían que venir al cole también. Y fue interesante también hacer eso porque (...) tú proponías una cosa pero no tenías ninguna autoridad para los que tenían que recibirla jejeje. (...) Entonces me ayudaba un poco el que conocía a gente pero claro no tenía esa autoridad que puede tener un profesor de decirles no, no, jes que esto es así! o... ise han planteado estos horarios!" <Elementos internos $\|$ Entrevistas $\mid C$ 11> - Referencia 2. 
La queja del siguiente alumno por la falta de implicación del resto de compañeros nos ayuda a ver cómo se sentía al comprobar la escasa voluntad de participación. Por ello, decidió comunicárselo al resto de miembros del equipo de trabajo con la intención de conseguir una respuesta positiva por su parte. La estrategia para hacerlo fue a través del uso de la empatía, una cualidad recomendable tanto a nivel social como personal.

"Y hubo un día que también me quede sola. Y yo digo (...) entiendo que una se tenga que ir a Valencia, la otra tenga médico, la otra... pero tenéis que poneros en mi lugar, de que yo ahora tengo una sesión con veinte niños (... ) ¿Qué hago? i¿Le digo a V----... V---- que esta semana no podemos ir?! Digo... o voy yo y me lo como yo sola. Total que al final como dije eso pues dos chicas de las que se iban pues dijeron... ipues va, nos vamos a quedar! (...) yo pienso que fue eso, que al principio todas estaban muy ilusionadas y tal. Y conforme pasa el tiempo (...) parece que se escaquean... no sé." <Elementos internos $\|$ Entrevistas $\| C$ 12> - Referencia 5.

\section{- Motivación al logro.}

La motivación al logro hace referencia al ensayo mental preparatorio de una acción para animar y/o animarse a ejecutarla con interés y diligencia con la finalidad de alcanzar unos objetivos determinados.

El deseo del alumno por participar en el servicio, ofreciendo una prestación adecuada, no solo hizo que se esforzara en rendir a buen nivel durante la actividad sino que también aumentó la intensidad de la experiencia vivida, maximizando así los efectos del su participación en el programa de APS.

"...yo lo cogí con muchas ganas, por eso yo creo que lo he vivido de una manera muy intensa, de decir tiene que salir bien, tiene que salir bien." <Elementos internos $\|$ Entrevistas $\mid C$ 01> - Referencia 6.

La preocupación por ofrecer un servicio de calidad de un alumno se manifiesta en el agradecimiento por el alto grado de participación e interés mostrado por los padres y madres de los niños receptores del servicio.

"...aquí por suerte hemos tenido padres que se han interesado muchísimo y de verdad. Que al final de cada sesión nos preguntan... ¿qué tal ha ido? y ¿ha trabajado? y ¿se lo ha pasado bien? y ¿qué tal ha estado con los compañeros?"<Elementos internos\|Entrevistas\|C 02> - Referencia 2.

Faltar a algunas clases para disponer de más tiempo en la preparación del servicio destaca la motivación del alumnado por prestar un servicio apropiado.

"Si veíamos que en esa clase no era importante que estuviéramos presentes, pues no nos importaba salir de esa clase, no hacerla, luego pedir apuntes, lo que fuera para poder preparar la sesión. Porque claro las sesiones hay que prepararlas bien." <Elementos internos||Entrevistas ||C 03>-Referencia 4.

Pese a la incertidumbre que generaba el desconocimiento de la metodología del APS, la iniciativa fue bien recibida por los alumnos ya que representaba un cambio sustancial respecto al modelo educativo tradicional.

"...yo lo vi bien. De entrada me pareció muy atractiva la idea. Consideraba que era algo diferente a lo que se estaba haciendo y que como nunca lo había realizado pues me motivó, me motivó el interesarme y el lanzarme en ese proyecto, por así decirlo."<Elementos internos ||Entrevistas\|C 04>-Referencia 1. 
La mejora del alumno en su capacidad para preparar las sesiones de juegos con los niños se fundamentaba en el análisis de las propuestas aplicadas, perfeccionando progresivamente la elaboración de nuevos planteamientos.

"...yo pienso que... el aprender a hacer una sesión es preparándotela tú y ver todas las dificultades que tienes cuando la expones en prácticas. Entonces cuando tú la pones en práctica y ves todo lo que te ha salido mal a la próxima ya mejoras todo lo que no te ha salido bien en esta y poco a poco (...) vas avanzando con todas las sesiones." <Elementos internos\|Entrevistas \|C 05> - Referencia 20.

El agradecimiento del siguiente alumno por recibir una formación previa a la realización del servicio muestra su interés por prepararse adecuadamente para participar en la actividad, demostrando así su motivación por cumplir satisfactoriamente con el servicio. También se aprecia una crítica del sistema educativo, el cual podría estar obviando la adquisición de ciertos aprendizajes a lo largo de su formación como docente.

"Lo de las sesiones teóricas del principio a mí también me pareció muy buena idea porque mucha gente da por sentado que tú te apuntas a magisterio y ya sabes un montón de niños ¿no sé por qué? (...) Y yo pues mucha experiencia con los niños tampoco he tenido. Entonces que sí que me pareció muy buena idea que no fuera directamente... ihala, con los niños! (...) No sé, que me da como un poco de seguridad también." <Elementos internos $\|$ Entrevistas $\|$ C 06> - Referencia 3.

El empeño del alumnado por adaptar las actividades a las características de los niños nos indica su deseo de atender las necesidades educativas de los receptores del servicio, fomentando así la mejora en su capacidad de cambio de las actividades, otra cualidad destacable de este análisis.

"...bastante cambio pero (...) aún no nos ha salido ninguna sesión perfecta de lo que hemos planificado, pero que ya al planificarlas pues ya sabemos más pues $B$---- necesita esto, $B$---- aquello, $M$---- esto. Entonces ya las sabemos adaptar mejor a ellos y en caso de que alguna actividad (...) falla pues ya como que reaccionamos un poco antes y sabemos mejor cómo cambiarla." <Elementos internos $\|$ Entrevistas $\|$ C 07> - Referencia 7.

La ilusión por iniciar su participación en el proyecto educativo lo antes posible hizo que el alumnado se desplazara a la entidad colaboradora mucho antes de lo programado, permitiéndoles conocer al profesorado del centro, observar el desarrollo de las sesiones, examinar las características de los niños, familiarizarse con el entorno, etc. Esto les ayudó a preparar la actividad de una forma más adecuada.

"...la primera sesión que fuimos, que empezamos cuanto antes, nos distéis el número y le llamamos y la semana siguiente ya estábamos allí, porque teníamos ganas de empezar, teníamos ganas, la ilusión. $Y$ la primera sesión fuimos a ver lo que hacía él."<Elementos internos $\|$ Entrevistas \|C o8>-Referencia 1.

La actitud del alumno nos ayuda a comprender que más allá de su propio aprendizaje tenía una motivación desinteresada por servir a los niños de la entidad, mostrando así su compromiso con la actividad a realizar. Esta conducta también destapa otras cualidades de tinte ético-moral como la conciencia social o la cooperación y ayuda, aspectos que analizamos más adelante.

"...yo vi que ellas no estaban muy motivadas ni interesadas en hacerlo, pero yo vi que lo estaban haciendo porque tenían que hacerlo porque formaba parte de la asignatura, pero yo veía que ellas no lo veían como yo, que era algo que les gustaba realmente y que querían hacerlo porque sí, para ayudar a 
los niños y todo eso. Entonces la verdad es que todo lo planificamos un poco con prisas y no se hizo como a mí sí que me habría gustado hacerlo." <Elementos internos\||Entrevistas\|C og>-Referencia 8.

La satisfacción por el éxito de la experiencia realizada muestra el deseo del alumno de tomar parte en futuros proyectos de similar calado, recomendando la continuidad de este tipo de propuestas así como la participación de nuevos estudiantes.

"Yo repetiría, no me arrepiento de elegir esta opción, si al año que vienen tuviera que elegir otra vez la opción la elegiría porque me ha ayudado bastante y es lo que yo quiero hacer y en lo que quiero trabajar (...) la verdad es que me ha gustado bastante. Y lo recomiendo para que lo haga la gente y se haga más años." <Elementos internos $\|$ Entrevistas $\| C$ 10> - Referencia 13.

El efecto positivo que aportó este proyecto a todos los implicados provocó la felicidad de los alumnos universitarios al comprobar el logro de sus propuestas con los niños, destacando el beneficio obtenido por la participación en el servicio y el provecho proporcionado a los niños de la entidad.

"...un poco compartías esa felicidad ¿no? de que... tú estabas contenta porque había salido bien y porque también habías aprendido algo nuevo y las que estaban haciendo la práctica, las compañeras de segundo, estaban contentas porque lo que habían planteado les había salido bien ¿no? Y era de... era un cúmulo, una cadena de estar ahí contentas." <Elementos internos\|Entrevistas\|C 11> Referencia 6.

La motivación de este alumno por ir más allá de los límites de la actividad de servicio, sumado a la gran cantidad de beneficios obtenidos, nos da una pincelada de su elevado nivel de satisfacción respecto al programa de APS realizado.

"...hay veces que estás en casa y lo estás pensando y... aparte de que te acuerdas de ellos ¿no? y tienes ganas de que llegue el miércoles para ir a darles clase. Y estás pensando y... yo por lo menos, yo estoy contenta de lo que hemos hecho. A parte de que creo que estamos ayudándoles a ellos porque lo necesitan, creo que nos estamos ayudando a nosotros mismos también. Porque yo por ejemplo no sabía ni hacer una sesión, no sabía planificar (...). Yo vamos no me veía capaz de dar una clase con veinte niños (...) y en cambio ahora me doy cuenta que no, que cuando me he dado cuenta estoy yo sola dando la clase y no sé, es mucho más fácil de lo que tú te piensas al principio." <Elementos internos $\|$ Entrevistas $\| C_{12}>$ - Referencia 3.

\section{- Capacidad para asumir riesgos.}

Concebimos la capacidad para asumir riesgos como la aptitud, talento o cualidad que dispone a alguien para hacerse cargo, responsabilizarse y aceptar una situación de incertidumbre, duda o temor.

La inquietud experimentada por empezar la actividad más tarde que el resto de compañeros pone de manifiesto el miedo afrontado a no tener sesiones suficientes para desarrollar el servicio correctamente.

"...fueron pasando los días y también dejamos de ir los jueves y veíamos que todas las instituciones (...) ya habían empezado y todo y nosotras sin nada. Sí que nos decíais empezaréis más tarde (...) pero claro pasaba el tiempo y nos poníamos nerviosas (...) es que nos va a coger el toro... nadie nos decía nada y... sí que nos pusimos un poco histéricas." <Elementos internos $\|$ Entrevistas $\| C$ o1> - Referencia 2.

La preocupación inicial del siguiente alumno debido a la inseguridad que le transmitía el servicio se tradujo en ilusión por poder trabajar en un entorno real y realizar actividades 
directamente con los niños, destacando su participación en la experiencia en primera persona.

"... al principio estaba asustada porque no tenía ni idea de cómo podía salir esto. Pero a medida que pasaban los días era como que me daba más ilusión el decir... ivoy a tener niños de verdad y va a ser una cosa de verdad, lo voy a poder ver!" <Elementos internos $\|$ Entrevistas $\| C$ o2 $>$ - Referencia 1.

El riesgo asumido por el alumno al comprometerse a participar en el programa de APS, teniendo que compaginarlo con sus obligaciones laborales, nos permite ver que el foco de su preocupación se centraba en saber si sería capaz de cumplir con sus propias exigencias de implicación, lo que demuestra su interés por ofrecer un servicio de calidad.

"...al principio pues estabas así un poco dudosa... ¿lo habré hecho bien, lo habré hecho mal? yo no sé si habré escogido bien porque pues claro por temas de trabajo porque si luego no puedo dar lo que tengo que dar de mi." <Elementos internos $\|$ Entrevistas $\|$ C $03>$ Referencia 1.

La incertidumbre por tener que escoger un equipo de trabajo sin conocer a ninguno de sus futuros compañeros fue superada por la confianza que transmitía participar en la actividad al considerarla interesante para su formación.

"...me decanté por el tema de hiperactivos sin conocer a ningún compañero de clase ni nada. O sea, yo iba ahí a ciegas porque mi situación es un poco diferente porque yo este año estoy cursando primero y como tenía una disponibilidad horaria pues me cogí unos créditos de más y cogí estas asignaturas de segundo (...) y digo... a ver en qué grupo caigo, y todo lo demás." < Elementos internos $\|$ Entrevistas $\mid C$ 04>-Referencia 3.

La inseguridad experimentada por los alumnos, antes de empezar a realizar los juegos con los niños, fue apaciguada por la elaboración de nuevas tareas, a modo de alternativas, en el caso de que las propuestas iniciales no se desarrollaran de la forma esperada. Esta situación también les permitió ir un paso por delante de cualquier problema que pudiera aparecer.

"...nosotras preparábamos un juego a lo mejor, a ver, pensábamos que... teníamos la incertidumbre de que algunos de los niños no lo pudieran realizar (...). Entonces nos poníamos... como actividades (...). Si había algún niño que por ejemplo no quería jugar o que se abstenía del grupo como podíamos nosotras, para ayudar a las chicas que estaban alli, integrar a este alumno o intentar hacer que este alumno se sintiera en el juego." <Elementos internos $\|$ Entrevistas $\| C$ 05> - Referencia 19.

El temor provocado por tener que elaborar una sesión informativa para los padres y madres sirvió al alumno para superar su miedo a tener que relacionarse con los progenitores de los niños, uno de los temores más habituales de aquellos que afrontan la docencia en educación infantil, primaria o secundaria por primera vez.

"...la fundación Síndrome de Down nos pidió que hiciésemos una charla para los padres. Y estábamos súper nerviosas, pero luego vimos que era una cosa muy sencilla, que ya está, que son personas como tú, tú les cuentas lo que vas a hacer y punto. Y la verdad es que eso me gustó mucho." <Elementos internos $\|$ Entrevistas $\| C$ 06> - Referencia 2.

El miedo de este alumno a realizar un examen sin haber seguido el itinerario habitual, a través de las clases teóricas, desapareció al verificar que el trabajo desarrollado en estas clases no era muy distinto de lo que había hecho en el programa de APS. Esto destaca la dificultad que supone realizar una innovación metodológica pues, aunque el propio alumnado la reclame, también presenta reservas y temores debido a la educación tradicional recibida. 
"...nos da un poco de miedo por el examen porque no sabemos si... bueno, yo he ido a clases y los días que he ido hacen más o menos lo mismo (...) Entonces eso me alegró un poco porque yo pensaba que si ellas están dando teoría y están dando cosas y J---- está explicando y nosotras lo único que tenemos es lo nuestro, pues no sabía cómo estaríamos. Pero (...) ahí ya me alegré un poco." <Elementos internos $\|$ Entrevistas $\| C_{07>}$ - Referencia 4.

El riesgo asumido por el alumnado al introducir innovaciones respecto a los juegos de las sesiones pone de manifiesto su carácter atrevido al modificar el sistema establecido. Con ello pretendían aportar mejoras al programa educativo y plantear nuevos retos a los niños receptores del servicio.

"...estábamos casi en Noviembre y estaba en tres juegos desde Septiembre que empezó. Porque no, los niños no, dice que no acababan de entenderlo y que estaba con ese juego. Y llegamos allí y esos tres juegos los llevaban bien. Y la semana siguiente nosotras llegamos y los juegos los repetimos, pero como nos salieron bien pues dijimos... iva, a la semana siguiente innovamos y hacemos otros juegos con los niños! y esa semana fue un caos." <Elementos internos $\mid$ Entrevistas $\| C$ o8> - Referencia 3.

La preocupación de este alumno al responsabilizase de una actividad que desconocía nos transmite la inquietud e inseguridad asumidas por no saber si sería capaz de realizar el servicio adecuadamente. Gracias a ello podemos ver el elevado nivel de compromiso que supone este tipo de proyectos, demandando un grado de implicación muy por encima de lo habitual.

"...nos dijeron que a partir de ahí que nosotras seríamos las que se encargarían de todo. Entonces pues primero estaba preocupada y agobiada porque no sabía muy bien cómo teníamos que llevarlo ya que nunca habíamos hecho algo así. Entonces pues me acuerdo de que casi todos los días estábamos en el despacho de J----, pues diciéndole que... cómo se hacía esto, que cómo se hacía lo otro, que estábamos preocupadas, que no nos saldría bien." <Elementos internos $\|$ Entrevistas $\mid C$ og > - Referencia 2.

Pese al nerviosismo experimentado durante la realización del servicio, originado por la responsabilidad que conllevaba el programa educativo, los alumnos intentaron resolver los problemas encontrados por ellos mismos, prueba de que comprendían y asumían las exigencias que esta metodología de enseñanza supone.

"... al ser esto Aprendizaje Servicio de hacerlo por tu cuenta no queríamos, queríamos hacerlo nosotros y sacar las cosas nosotras mismas. Pero había momentos en que nos agobiábamos, no sabíamos por dónde salir, se nos amontonaba la faena y nos bloqueábamos y ya no sabíamos. (...). Entonces llegabas allí con un poco de miedo de que no saliera bien la sesión o que hubiera problemas con los niños." $<$ Elementos internos $\|$ Entrevistas $\| C$ 10>-Referencia 4.

El éxito en la aplicación de un juego con elevados niveles de inseguridad en su ejecución nos lleva a reflexionar sobre el valor de realizar algunas tareas pese a no confiar totalmente en su viabilidad.

"...plantearon, unas chicas en concreto, una actividad que era ahí todos los aros en grupo e iban quitando aros poco a poco y claro todo el grupo de niños cada vez iba pegándose más. Y era un poco de... ivy, madre mía estos se van a quedar ahí todos matados! Pero no, salió genial esa actividad. (...) o sea, sí que la veíamos viable les dijimos... no, probadla a ver... pero, no sé, igual tal. Pero poníamos pegas (...). Y claro, luego nos quedamos todas como... iguau, qué bien ha salido!" <Elementos internos $\|$ Entrevistas $\| C$ 11> - Referencia 6. 
Los prejuicios sobre el barrio en el que estaba el colegio generaron una inseguridad inicial que condicionó las primeras acciones del alumnado. Con el paso del tiempo estos temores desaparecieron al entender que era un contexto educativo comparable a cualquier otro.

"El colegio yo personalmente tenía miedo. Porque yo, mi abuela vive en un barrio así y he tenido más de un caso en el que... pues no sé, que ha habido conflictos y yo tenía miedo de decir... a ver si algún niño, se nos... yo que sé, me daba miedo. Por el... por la zona en la que estaba. Pero luego que va, para nada. Cuando hemos llegado allí hemos visto que no, que son niños normales y corrientes." <Elementos internos $\|$ Entrevistas $\| C_{12}>$ - Referencia 4.

\section{- Confianza.}

Entendemos la confianza como la seguridad que una persona tiene en sí misma y en su propio desempeño profesional y/o personal.

La confianza ganada por el alumno tras participar en la experiencia de APS hizo que no solo se viera capaz de planificar una sesión de juegos motores, ajustada a un tipo específico de niños, sino que también considerara que podía hacerlo rápidamente y sin ningún tipo de ayuda. Todo ello gracias al conocimiento práctico adquirido a lo largo del programa educativo propuesto.

"...ahora yo pienso que si me dices... iplanifícame una sesión para mañana para estos niños! yo creo que sin ayuda lo sabría hacer." <Elementos internos\|Entrevistas||C o1> - Referencia 2.

El aumento de la seguridad en su propio desempeño a la hora de realizar las sesiones denota un incremento de la confianza de los alumnos forjado a partir de la adquisición de nuevos conocimientos, considerándose preparados para afrontar cualquier eventualidad que pudiera surgir durante las clases.

"...entonces ahora (...) como nos conocemos entre nosotras, conocemos al grupo, tenemos más confianza, sabemos qué podemos hacer, o sea, no nos ponemos tan nerviosas porque nos falle algo. $Y$ es como que ya sabemos salir un poco del bache que tengamos." <Elementos internos\|Entrevistas $\mid C$ o2> - Referencia 3.

El siguiente alumno alaba su capacidad para reconocer si el nivel de participación en un juego es o no adecuado. Pese a que argumenta que esta cualidad se debe a su propia forma de ser, entendemos que la vivencia de APS la ha reforzado, además de aportarle otras habilidades que han aumentado su confianza en sí mismo, como la capacidad de cambiar un juego por otro más adecuado en función de las circunstancias.

"...y luego por ejemplo cuando un juego es muy parado o que no hay mucho interés por parte de los niños, yo también sé detectarlo rápido. No sé si es porque... no sé, porque soy una persona así más activa y pienso... iuy, esto, yo aquí si fuera un niño o incluso de mayor me aburro! Entonces eso también... se cambiar el chip rápido."<Elementos internos $\|$ Entrevistas $\| C$ 03>-Referencia 5.

La reflexión de este alumno le llevó a decantarse por un equipo de trabajo al considerar que su formación previa le haría más útil en este colectivo. Sus palabras desvelan la doble vertiente de esta confianza, pues además de pensar que sería más valioso en este entorno también le transmitía una mayor seguridad en su propio desempeño.

"...debido también un poco a mi formación anterior de psicólogo, al oír el tema de la posibilidad de hacer el trabajo o el servicio con hiperactivos, pues también un poco por seguridad mía o por sentirme 
yo con más confianza, pensé que mis conocimientos psicológicos podrían ser más aplicables en el colectivo de hiperactivos." $<$ Elementos internos $\|$ Entrevistas $\| C$ O4 $>$ - Referencia 1.

El buen hacer de los alumnos a la hora de planificar las actividades nos muestra la seguridad que tenían en su propio criterio para seleccionar los juegos que harían con los niños. Cabe destacar que en ningún momento tuvieron que realizar modificaciones importantes respecto al planteamiento inicial, resaltando así el acierto de sus decisiones.

"Yo no sé si en otras sesiones a lo mejor sí que se ha replanteado, pero en todas las sesiones yo creo que como nosotras teníamos todo escrito, las características de los niños... se han adaptado bastante a eso, no se ha tenido que replantear luego." <Elementos internos ||Entrevistas $\mid C$ 05 $^{>}$- Referencia 8.

El programa de APS mejoró la confianza de los alumnos respecto al trato con niños que presentan necesidades educativas especiales. Esta situación es notablemente importante, ya que gran parte del futuro profesorado no tiene la posibilidad de entrar en contacto con este tipo de niños, limitándose únicamente al trabajo con alumnado ordinario.

"...también seguridad a la hora de estar en una clase en la que hayan niños que tengan dificultades de este tipo. Porque aunque sea en un grado pequeño pero yo ya he tratado con ellos y ya he tenido que enfrentarme a jugar con ellos y a plantear cosas para ellos. Entonces ya sé más o menos (...) qué cosas les cuestan más y qué cosas les cuestan menos de hacer. Entonces eso, por una parte un poco de seguridad y un poco de conocimiento de... pues de este tipo de niños." <Elementos internos $\|$ Entrevistas $\|$ C 06> - Referencia 7.

La seguridad adquirida en cuanto a la capacidad para dirigir sesiones de juegos motores pone de manifiesto que esta confianza se centra en la habilidad para asumir cambios y adecuarse o responder correctamente ante estos, otro aspecto analizado en el presente trabajo.

"...respecto a aprendizajes que he tenido pues eso a ajustar la ayuda, a adaptar las sesiones, a saber reaccionar, si algo está saliendo mal pues cambiarlo y mejorarlo y adaptarlo, no sé, la verdad que bien." $<$ Elementos internos\|Entrevistas $\|$ C 07> - Referencia 2.

Un alumno destaca su buen hacer al hablar delante de los niños o explicarles las actividades a realizar, indicando que se sentía más seguro que algunos de sus compañeros. Otra fuente de seguridad fue el apoyo que se prestaban mutuamente cuando aparecía algún problema durante las sesiones, algo que sería imposible si se tratase de una práctica individual.

"...yo nunca he tenido ningún problema pero sí que hay gente que le resulta... le paraba tener a tantos niños mirándote y ser tú la que tienes que hacer que ellos te entiendan. Explicarles un juego y (...). Pero siempre si te quedabas en blanco, si no sabías qué decir siempre estaba alguien que te decía la palabra o... como estábamos todas siempre había alguna que decía... ipues sí, tenemos que hacerlo así! (...) si hemos visto a alguna apurada en algún momento la hemos ayudado." <Elementos internos $\|$ Entrevistas $\|$ C 08> - Referencia 8.

La compenetración existente entre los alumnos del equipo de trabajo posibilitó la aparición de resultados muy positivos en la aplicación del servicio, algo que pone de manifiesto la importancia de organizarse adecuadamente a la hora de realizar cualquier actividad de carácter grupal.

"...con el tercer grupo la verdad es que también fue muy bien, trabajamos mucho y los niños estaban muy activos, participativos y la verdad es que salían muy contentos y nosotras también estábamos bien organizadas (...) realmente pues eso también vimos que habíamos mejorado y pues salimos más contentas de estas sesiones." <Elementos internos $\|$ Entrevistas $\mid C$ og> - Referencia 5. 
La confianza mostrada por los miembros de la entidad en el equipo de trabajo aumentó notablemente la seguridad en su propio desempeño. Esta situación también hizo que se plantearan las diferencias existentes entre el conocimiento teórico y el práctico.

"... al ser de prácticas a nosotros nos han dado la confianza de que nos dejaban a los niños y que tú trabajaras. Ellos mismos (...) nos decían que como mejor se aprende es practicando con ellos. Entonces que ellos te dieran la confianza a la hora de ir allí y que tú ibas con un poco de miedo por lo que estabas haciendo y que ellos confiaran plenamente en ti eso te ayudaba bastante." <Elementos internos $\|$ Entrevistas $\| C$ 10> - Referencia 4.

Realizar actividades prácticas en un espacio abierto entraña mayor dificultad en cuanto al control del alumnado que hacerlo en un lugar cerrado. Por ello, el hecho de que fueran capaces de pasar del interior del polideportivo a un terreno al aire libre muestra el aumento de su confianza en cuanto al manejo de esta cuestión.

"...con los de primero también empezamos a salir fuera al patio exterior, que los primeros días estábamos un poco como encajetadas allí dentro del poli. Y yo creo que también era un poco la evolución nuestra de ir sintiéndonos más seguras." <Elementos internos\|Entrevistas\|C 11> Referencia 5 .

La seguridad del alumno a la hora de mantener el orden en el desarrollo de los juegos era tal que incluso llegó a detener la actividad para indicar a los niños una falta de disciplina durante el juego, aconsejando a su maestro que actuara del mismo modo para reconducir esta conducta.

"...al principio eran súper buenos, súper buenos y ahora están súper revolucionados y yo digo... no sé por qué motivo es pero sí que es verdad que ahora cuesta más y están más alterados (...) siempre o cambiábamos a otro juego (...) o les reñíamos pero de decirles que no estaba bien lo que estaban haciendo pero nunca habíamos parado, el último día fue el único día que yo dije, cogí la pelota y dije... ¡Hale, iros que se ha acabado! Y por eso le dije a V---- (...) ¡ríñeles que ha pasado esto!" <Elementos internos $\|$ Entrevistas $\| C$ 12> - Referencia 8.

\section{- Responsabilidad.}

La responsabilidad es el cargo $\mathrm{u}$ obligación que resulta para alguien el reconocer y aceptar las consecuencias de una situación o hecho realizado libremente.

La responsabilidad demandada por el alumno, en cuanto al trato con una niña que presentaba un problema en la vista, nos ayuda a ver cómo hizo extensible al resto de compañeros el compromiso de tratar de una forma adecuada y adaptada a cada niño de la entidad. Al mismo tiempo, también demuestra su capacidad de atender a la diversidad, aprendizaje académico que abordaremos más adelante.

"...había una niña que tenía dificultad visual, jtenedla en cuenta! La niña ha llegado a decir... jes que yo no veo bien! O sea, que te lo tenga que decir la niña cuando ya te hemos dicho nosotras... itiene esto, procura estar pendiente de ella y tal!"<Elementos internos $\|$ Entrevistas $\| C$ 01> - Referencia 1.

El alumnado universitario se encargó de informar de ciertas acciones a los padres y madres de los niños receptores del servicio. Aunque esto parezca no tener un efecto formativo entendemos que cobra gran importancia en el futuro de los docentes, ya que será una tarea habitual en su desempeño profesional. 
"...nos exigían que hiciéramos nosotras la circular para informar a los padres, que hiciéramos una presentación en PowerPoint porque teníamos que hacer una reunión con los padres." <Elementos internos $\|$ Entrevistas $\| C$ o2> - Referencia 1.

La responsabilidad del siguiente alumno al mediar en un conflicto aparecido durante la sesión le hizo intervenir en una discusión. En este caso consideró apropiado no participar en la disputa, intentando trasladar el enfrentamiento al término de la sesión con el objetivo de continuar realizando las actividades sin perjudicar a los niños de la entidad.

"Luego a lidiar conflictos grupales. Hay a veces que en el grupo pues ha habido así un poquito de conflictos incluso en las sesiones, pues nada se han puesto a discutir... pues, claro tienes que hacer un poco de mediador y decir... hombre este no es el momento ¿no?" <Elementos internos||Entrevistas\|C o3> - Referencia 12.

Un equipo de trabajo demostró su responsabilidad al preparar los juegos para las sesiones del servicio. La situación nos permite intuir su capacidad para anticiparse a la aparición de ciertos problemas, una cualidad fundamental en el desarrollo de cualquier docente. Asimismo denota un buen dominio del aspecto temporal de la sesión, otro factor importante en el apartado académico del presente trabajo.

"Eso ahora no ocurre, ahora nosotros por ejemplo siempre tenemos una bolsa de juegos, una bolsa me refiero de que nos entran a lo mejor seis o siete en una sesión y... pero siempre hay dos o tres que se pueden, o sea, que se tienen a mano por si alguno de ellos por lo que sea no sale o dura menos de lo previsto o mil cosas." <Elementos internos $\|$ Entrevistas $\|$ C o4 $>$ - Referencia 7.

El afán de superación de este alumno le hizo responsabilizarse del trabajo con sus compañeros universitarios, ayudándoles a desempeñar correctamente las distintas labores del equipo de trabajo y evitando la intervención del responsable de la entidad, muestra del grado de responsabilidad adquirido en el cumplimiento de sus funciones.

"Y cuando planteábamos las sesiones todo esto se lo decíamos a las chicas porque creíamos que eran las cosas más relevantes que se tenían que cuestionar ellas, como si les sucedía una situación de estas qué es lo que tenían que hacer para poderlo sobrellevar, para que no se les fuera de las manos y no quedarse por ejemplo en blanco o que tuviera que intervenir mucho la tutora." <Elementos internos $\|$ Entrevistas $\|$ C 05> - Referencia 8.

Un alumno no tuvo reparos en mostrar su total aprobación del proyecto realizado pese a que la propuesta educativa demandaba obligaciones adicionales. Esta situación destaca los aspectos positivos de ese grado superior de responsabilidad así como el tener que enfrentarse por sus propios medios a las problemáticas surgidas durante la realización del servicio.

"... a mí del contacto con la entidad y todo lo que me ha pasado es que he tenido que ser muy responsable, cosas que otras veces no se me piden, y bueno eso, que también me ha gustado pues eso que tienes que sacarte tú las castañas del fuego y seguir con todo adelante a pesar de que pues tienen más dificultades que otras personas o que la entidad no está ayudando." <Elementos internos $\|$ Entrevistas $\| C$ 06> - Referencia 1.

Fomentar el desarrollo motor de los niños con actividades adecuadas, sin que esto representara un peligro para los mismos, muestra la responsabilidad del alumnado al 
respetar acertadamente el criterio de seguridad de los juegos. Más adelante, abordaremos este aspecto con mayor profundidad.

"...pusimos para los que andaban así un poco mejor un banco y tenían que ir por encima del banco para, como cruzan tanto los pies, para que supieran poner los pies uno delante del otro. Y los que nos daban así un poco más de miedo por si se caían o algo, aunque fuéramos con ellos pero por si acaso, pues pusimos dos bancos muy juntos. "<Elementos internos $\|$ Entrevistas $\| C$ o7> - Referencia 1.

La responsabilidad compartida por el equipo de trabajo, a la hora de presentar sus propuestas, nos ayuda a entender el modo en el que se distribuían las distintas tareas a realizar de una forma organizada y equilibrada, ayudándose entre ellos y trabajando de forma cooperativa, otra cuestión de especial relevancia en el presente trabajo.

"...planificar las actividades las planificábamos todas, las sesiones allí nos dividiamos tu explicas esta actividad yo explico esta, tú ayudas a explicar esta, ellas van a hacerlo gráfico para que ellos lo vieran y... sí que hemos tenido buena compenetración entre todas. " < Elementos internos ||Entrevistas \|C o8> Referencia 3.

Atender de forma personalizada las diferentes necesidades de los niños nos ayuda a ver la responsabilidad con la que respondieron a las demandas existentes y cómo fueron capaces de entrar en el terreno personal de los niños, reconociendo sus preferencias y deseos para mantenerlos motivados. Esta cualidad adquiere gran valor en cualquier ámbito educativo ya que mejora el contexto del proceso de enseñanza-aprendizaje.

"...cuando nos quedamos a hablar con J---- y con C---- pues fue cuando me di cuenta de todo esto que te estoy diciendo (...) pues realizar ejercicios más específicos con cada niño porque, por ejemplo, ya nos dábamos cuenta de que $B$---- cruzaba las piernas al caminar, o de que en un brazo tenía más fuerza que en el otro o que lo movía más (...) a $B$---- le encantaba la música, que era lo único que la motivaba, 0 que a B---- le encantaban los coches." <Elementos internos $\|$ Entrevistas $\| C$ og> - Referencia 5.

El elevado nivel de concienciación social de los alumnos universitarios ante la falta de responsabilidad de algunos de sus compañeros muestra el compromiso global de los equipos de trabajo para superar cualquier conflicto con tal de no perjudicar a los niños receptores del servicio.

"A la hora de quedar con ellas pues acabamos, o sea, decidimos hacerlo por correo ya que no, nos ponían pegas entonces no podíamos trabajar bien con ellas. $Y$ con las de mi grupo al ser siete trabajábamos cinco, entonces siempre trabajábamos las mismas, y eso al final te acaba cansando. Pero como por querer sacar adelante y porque los niños no tienen culpa de los problemas que puedan haber de fuera, siempre acabas solucionándolo y todo para que ellos tengan la sesión porque ellos son a los que les beneficia o perjudica si nosotros tenemos problemas o no." <Elementos internos $\|$ Entrevistas $\| C$ 10> - Referencia 2.

La responsabilidad compartida por el equipo de trabajo se manifestó gracias a la cooperación y colaboración existentes. Esto posibilitó que los alumnos participaran en el servicio de una forma más relajada de lo habitual, aportándoles nuevas experiencias y sensaciones respecto al trabajo en grupo.

"...me considero bastante responsable entonces igual al ver... si en algún grupo la carencia esa de guía o de responsabilidad pues la iba cogiendo yo, en este grupo me he sentido en plan... no necesito ser así porque entre todas conseguimos, o sea, llegamos a donde tenemos que llegar, colaboramos todas (...). Todas tenemos un poco en mente el tener esa responsabilidad." <Elementos internos| Entrevistas $\mid C$ 11>- Referencia 5 . 
La responsabilidad grupal asumida por uno de los alumnos muestra su fuerte compromiso con la actividad al aconsejar personalmente al grupo de compañeros con el que debía colaborar, una obligación que correspondía a todo el equipo de trabajo. Esta cualidad se aborda con mayor profundidad en el apartado social de estos resultados.

"...el grupo que está a hora... no sé porque pero tienen mi número, y entonces pues me llaman... mira es que estamos aquí que hemos quedado para no sé qué. Y quieras o no, pues soy yo la que estoy haciendo la sesión con ellas ¿no? mi grupo no sabe nada. Pero porque ellas me llaman a mí (...) me llamaban a mí y yo pues les ayudaba y eso, y nada, bien." <Elementos internos $\mid$ Entrevistas $\mid C$ 12>-Referencia 9.

\section{- Estar integrado en redes sociales con acceso a información y conocimiento.}

El aspecto relativo a estar integrado en redes sociales con acceso a información y conocimiento hace mención a una persona que forma parte de un grupo que le sitúa en una posición de privilegio para adquirir ciertos datos y/o saberes.

Haber trabajado con la entidad colaboradora durante su formación en cuidado con personas dependientes situaba al alumno en una posición aventajada respecto al conocimiento del personal, los niños, el contexto social del centro, etc., algo que favoreció notablemente las labores del equipo de trabajo.

"...dio la casualidad de que yo he hecho atención socio-sanitaria e hice allí las prácticas entonces los conocía, porque he estado... tenía una clase, pero cuando faltaba un profesor o algo me enviaban a las otras clases entonces ya quieras o no sabía hasta donde podía llegar y podíamos ayudar." < Elementos internos $\|$ Entrevistas $\|$ C 01> - Referencia 7.

Empezar más tarde su actividad de servicio no supuso una desventaja para estos alumnos, ya que supieron aprovechar la experiencia previa de sus iguales para obtener información sobre las labores a realizar.

"...como nosotras, por ejemplo, empezamos con mucho retraso pues nos vino bien gente que ya había empezado que nos contara cómo les estaba yendo y si estaban teniendo problemas, si respondían bien los niños y todo eso." <Elementos internos $\|$ Entrevistas $\| C$ o2> - Referencia 6.

La información obtenida a través de las sesiones de preparación para el servicio proporcionó al alumnado consejos sobre cómo trabajar con todas las entidades colaboradoras, ampliando enormemente el aprendizaje en esta experiencia por no limitarse exclusivamente al trabajo con su entidad.

"...también nos enseñaron y pudimos compartir, con las demás de las asociaciones, pues las diferentes tipologías de los niños tanto con Borja Sánchez de... aunque no hayamos estado con ellos sabemos qué características y qué juegos y cómo podríamos adaptarlos a ellos. Entonces eso también te hace crecer, pienso yo." <Elementos internos $\|$ Entrevistas $\| C$ o3> - Referencia 12.

La reflexión de un alumno a partir de la retroalimentación aportada por los miembros de la entidad resalta el valor del consejo de los profesionales, asumiendo las críticas realizadas en cuanto a su propia ejecución de una forma muy constructiva.

"...cuando luego te pones a hablar con los profesionales ¿no? con los docentes que saben de esta materia pues te hacen el feedback adecuado ¿no? que se debe hacer, porque al fin y al cabo se trata de que tienes que aprender ¿no? para eso estás haciendo ese servicio, y te das cuenta de que has cometido unos errores... pero tremendos ¿no?" <Elementos internos $\|$ Entrevistas $\| C$ o4 > - Referencia 6. 
La información recibida por parte de la directora de uno de los centros colaboradores fundamentó el desarrollo de las primeras sesiones, sirviendo a los alumnos para elaborar sus propias propuestas y guiar el trabajo de los compañeros universitarios con los que debían trabajar.

"Cuando empezamos el primer contacto con la entidad hablamos con M----, nos lo explicó todo, cómo iba el centro, las dificultades que tenían todos los niños y fuimos ese mismo día a hablar con todos los grupos, a verlos a todos (...). Y allí pues ya anotábamos las impresiones que teníamos y las características de los grupos para luego pasarlas a la gente de los grupos que iban a hacer allí las sesiones, de los grupos de clase." <Elementos internos||Entrevistas ||C 05> - Referencia 2.

Las numerosas conversaciones desarrolladas durante la aplicación del servicio versaron sobre temas de gran interés práctico para el alumnado, por lo que no dudaron en incorporarlas al aprendizaje global de la experiencia realizada.

"...una cosa que no se me había ocurrido que también, yo creo que me la dijiste tú, con los niños estos que se nos iban, que pasan de todo (...) y se van y no hay manera de que jueguen, también de dejarlos un poco, de no estar todo el rato... ¿qué te pasa? ¿qué no sé qué? (...). iPues hala pues vete ya vendrás luego! No lo dejas todo el rato, toda la sesión solo ¿no? pero también dejar de hacerle un poco de caso que eso también iba bien."<Elementos internos $\|$ Entrevistas $\| C$ 06> - Referencia 10.

La reflexión de este alumno destaca la gran formación práctica que proporcionaba este programa educativo ya que, pese a toda la formación teórica recibida hasta la fecha, admitió que si no hubiera sido por esta experiencia aún no sabría cómo trabajar con los niños. Este razonamiento cuestiona la importancia relativa del conocimiento teórico frente al práctico, especialmente en el enfoque educativo por competencias.

"...todo es muy teórico. No, o sea, yo si no llega a ser por esto es que aún no sabría ni qué hacer con los niños. Porque es verdad, estamos en segundo y no sabemos aún nada, nos están mandando unidades didácticas y aún nadie se ha parado a explicar qué es una unidad didáctica. Entonces aquí es cuando de verdad lo hemos puesto en práctica y hemos tratado con niños." < Elementos internos |Entrevistas |IC o7>-Referencia 6.

Las características socioculturales de los centros formativos situados en barrios marginales pueden generar un fuerte impacto en sus docentes, más aún si hablamos de profesionales primerizos o en formación, de ahí el valor que supone tener experiencia en este tipo de entornos educativos.

"... a mí no me impactó tanto a lo mejor, porque mi madre trabaja en un cole así y yo pues me paso todos los veranos, cuando acabo las clases, en el cole. Trabaja en una guardería y está en un barrio marginal también en mi pueblo. Y a lo mejor por ese motivo no me impactó tanto porque estoy más acostumbrada a verlo (...). Y quizás me resulta más familiar." < Elementos internos ||Entrevistas ||C o8> Referencia 4 .

Conversar con los profesores de la asignatura sirvió para tener una visión más positiva de su propio desempeño tras la primera sesión, algo que pone de manifiesto la gran confianza que tenían en el profesorado y la importancia de valorar adecuadamente cada una de sus acciones.

"...hablamos con J---- y con C----, porque después de cada sesión siempre nos quedábamos un rato y reflexionábamos sobre lo que había pasado (...) nos dijeron que no había salido tan catastrófico como nosotras pensábamos (...) eso pues nos alivió un poco porque también estábamos por las familias de los 
niños, por si no volvían o por si no se habían quedado contentos." <Elementos internos $\|$ Entrevistas $\| C$ og> - Referencia 13.

La información facilitada por el profesorado sobre las necesidades educativas de los niños permitió a los alumnos hacerse una idea de cómo saldría la aplicación práctica de sus propuestas, un ejercicio de análisis mental muy importante en el ámbito de la EF pues nos permite valorar los juegos y ejercicios antes de realizarlos.

"...la gente sí que iba hacía su sesión y hablaba de las características de los niños, nosotros poníamos los juegos pero solo teníamos la información que nos daban los profesores entonces no podíamos imaginarnos mucho si saldría bien o no saldría bien ese juego. Pero con ayuda de los profesores sí que nos iban encaminando para ir haciéndonos una idea de cómo serían." <Elementos internos $\|$ Entrevistas $\| C$ 10>-Referencia 4.

Los comentarios aportados por una alumna de prácticas que coincidió con el equipo de trabajo ayudaron a desarrollar nuevos aspectos sobre la gestión de los niños. Concretamente, les llevó a analizar los aspectos sociales y relacionales del aula, una cualidad muy valiosa a la hora de realizar cualquier dinámica de grupo.

"...la chica que estaba de prácticas, al coincidir con ella también y ella estar fijándose mucho con la relación entre los niños pues también te despierta un poquito de... iostras! Y entonces empiezas a fijarte más en quién se relaciona con quién, cuando están haciendo un juego de qué manera reaccionan o si van a buscar a alguien en concreto ¿qué niño se quedaba más parado?" <Elementos internos\|Entrevistas\|C 11> - Referencia 15.

El profesor del centro educativo facilitó al alumnado el calendario de actividades a realizar, proporcionándoles información de primera mano sobre cómo se hace una programación didáctica en un entorno real. Esta situación representa una de las características básicas de los programas educativos de APS.

"...con los mayores fue él el que nos dio una programación. Y él es el que nos dice pues esta semana toca esto, esta semana toca lo otro. Hemos trabajado el equilibrio, los malabares y todo eso. Luego trabajamos los juegos tradicionales (...) ahora estamos trabajando juegos con material alternativo." <Elementos internos $\|$ Entrevistas $\| C$ 12> - Referencia 5.

A lo largo de este apartado hemos comprobado que la experiencia proporcionada a través del programa educativo de APS provocó numerosos efectos personales en el alumnado. Dichos efectos variaron notablemente en función de las características propias de cada alumno universitario. No obstante, el hecho de compartir sus impresiones personales con el resto del grupo potenció en gran medida las vivencias individuales de todos los participantes.

\section{- Aspectos sociales.}

En este segundo bloque exponemos el análisis de los aspectos de carácter social, los cuales indican los elementos, facetas y matices propios pertenecientes o relativos a la personalidad del individuo en relación con la sociedad o la comunidad. 


\section{- Conciencia social.}

La conciencia social hace alusión a la actitud moral respecto a lo comunitario, que implica reflexionar sobre las situaciones que requieren atención y actuar para mejorar la sociedad.

El comentario despectivo de un compañero universitario, hacia los niños de la entidad colaboradora, hizo aflorar la conciencia social de un alumno. Sus palabras nos ayudan a entender cómo llegó a afectarle esta situación, llegando a avergonzarle y entristecerle profundamente a nivel personal.

"iay, es que, es que no saben hacer nada! Esa frase fue delante de los niños y delante de la gente de Penyeta que estaba alrededor (...) me da un poco de vergüenza pero te lo digo, hubo un día que llegué a mi casa a lagrima viva pero porque yo no tengo esa mentalidad." < Elementos internos ||Entrevistas $\mid C$ o1>-Referencia 1.

El deseo del alumnado de atender por igual a los niños de la entidad entrañaba una gran dificultad, debido a la complejidad de elaborar propuestas adaptadas a todos los participantes. Por ello, adoptaron la estrategia de preparar actividades por grupos de competencias, una propuesta muy habitual en el ámbito de la EF donde, en ocasiones, los niveles de competencia del alumnado son muy dispares.

"...nos gustaría que todas las actividades para todos fueran súper interesantes y vamos a hacerlas con alegría y tal, pero sabemos que no se puede y entonces pues cada día a lo mejor buscamos una actividad un poco para el nivel más bajito y otra para los profesionales digamos. Y buscamos así un poco como compensar y que en cada sesión todos puedan tener su actividad." <Elementos internos $\|$ Entrevistas $\| C$ 02> - Referencia 2.

Un alumno mostró su conciencia social a través del respeto de la igualdad de género al plantear los juegos de la sesión. Este escenario se presenta muy a menudo en el ámbito de la EF donde, mayoritariamente, se han asociado ciertas tareas a cada uno de los géneros. Por ello, fomentar esta igualdad, independientemente de la actividad a realizar, tiene un gran valor educativo, especialmente al trabajar con niños en edad infantil.

"...lo que hicimos en esa sesión para formar grupos es... realizamos dos puzles uno con Superman y la Supergirl esta. Chico, chica, porque claro en las sesiones hay chicos y chicas, si no dirán... ¡ah los superhéroes son de chicos! No, los juegos son de chicos y de chicas." <Elementos internos $\|$ Entrevistas $\|$ C $03>-$ Referencia 8.

Integrar a los niños de la entidad en actividades grupales entrañaba gran dificultad. Por ello, el apoyo prestado por los familiares y los propios alumnos, al llevar más niños a las sesiones de juegos, ayudó a mejorar la socialización de los niños receptores del servicio. Igualmente, el hecho de que consideraran que participar en esa experiencia podía ser positivo para el resto de niños dice mucho en favor de su conciencia social.

"...es difícil el tema de integrar a niños de diferentes características, o sea, todos están bajo la etiqueta, por así decirlo, de niños hiperactivos pero no son todos. Porque en nuestro caso pues hay hermanos que acompañan o en algún momento ha venido algún niño de alguno de nuestro grupo simplemente por también que comparta esa experiencia y que ayude a socializar al resto." <Elementos internos $\|$ Entrevistas $\| C_{04}>$ - Referencia 5. 
El efecto de las contribuciones individuales en un trabajo de equipo destaca la importancia de estas aportaciones personales en el resultado final del grupo, planteando la posibilidad de que una participación no concienciada pudiera desvirtuar todo este sistema organizativo.

"...por ejemplo cuando hacíamos una dinámica de trabajar en grupo yo creo que eso también te aporta a ti personalmente (...) yo pensaba que si yo hacía, como aquel que dice, mi trabajo ayudaría a favorecer el trabajo en equipo. Entonces eso yo creo que también te ayuda a ti a replantearte de que si tú no colaboras lo suficiente o no haces lo que está en tus manos para aportarlo al grupo, tampoco sabes si te va a dar resultado trabajar así. Y yo creo que en eso me ha ayudado bastante." <Elementos internos\|Entrevistas\|C 05> - Referencia 15.

La necesidad de prestar un mayor apoyo humano a los centros de educación especial nació de la vivencia personal en dicho contexto social. Arraigar esta opinión en la sociedad sería de gran ayuda para mejorar la conciencia social sobre este tipo de colectivos desfavorecidos.

"Y luego he visto también que una sola... o sea, por esto que está pasando ahora ¿no? de que cada vez dan menos apoyo y que cada vez hay más niños y eso es una locura, totalmente. Porque nosotras cuando hay una persona por niño vamos muy bien, pero... (...) como futura maestra yo veo que va muy bien tener a alguien que te ayude en la clase." <Elementos internos\|Entrevistas $\mid C$ o6> - Referencia 4.

Para hacernos una idea del enorme cambio que supuso esta experiencia, en la visión del alumno sobre los niños de la entidad, debemos remitirnos al temor inicial que le generaba el servicio. Al utilizar la empatía, para ponerse en el lugar de estos niños, fue capaz de superar ese miedo, mejorando su percepción sobre este colectivo y replanteándose otros aspectos de su vida personal.

"Yo la verdad que al principio tenía miedo pero ahora me alegro de haberlo hecho porque te cambia la forma de verlo todo, porque dices... ite quejas por cosas y luego cuando te pones en la piel de ellos, es muy duro! Entonces, no sé." <Elementos internos $\|$ Entrevistas $\| C$ o7> - Referencia 1.

La reflexión del alumno sobre la aparición de conflictos en los colegios de zonas empobrecidas nos lleva a pensar que estas disputas aparecen debido al entorno social del centro educativo y no únicamente por aspectos étnicos o raciales, lo cual nos demuestra su conciencia social en esta controvertida cuestión.

"Supongo que igual que en todos los colegios. Supongo que da igual que seas de un barrio marginal que de otro, porque los problemas pueden surgir. En mi clase de toda la vida también han surgido problemas entre niños y no era porque uno era extranjero y otro no (...) pasaría aquí que en el centro de la ciudad. Igual que si fueran dos españoles." <Elementos internos||Entrevistas||C o8> - Referencia 3.

Las competencias sociales que el alumno desarrolló gracias al APS no dejan lugar a dudas del potente efecto social, ético y moral que tiene esta metodología didáctica sobre el alumnado. El hecho de que fueran ellos mismos los que reflexionaran sobre estos aprendizajes aporta un mayor significado a toda la experiencia.

"...en lo referente a trabajar mediante Aprendizaje Servicio pues también me he dado cuenta de que he desarrollado mi competencia personal e interpersonal profesional y vocacional y que... bueno $y$ también para el pensamiento social o la transformación social." < Elementos internos||Entrevistas||C og> - Referencia 11.

Otra muestra de conciencia social fue la intención de trabajar en el futuro con este tipo de colectivos desfavorecidos. La firmeza de esta decisión deja patente la visión del alumno sobre 
este grupo social, así como su propósito de ayudarles en la medida de lo posible, destacando la dificultad de esta tarea debido al gran esfuerzo psicológico que supone.

"...cuando me cogí esta carrera no sabía si cogerla en primaria para poder hacer psicología terapéutica y trabajar con niños así o coger esta y luego poder ir a algún centro y... porque también me dijeron que con esta carrera podía ir a centros con niños discapacitados y poder ayudarles (...) con estos niños la verdad es que lo que hace falta es paciencia y te tiene que gustar y ser vocacional. Porque si no te gusta puede llegar a agotarte psicológicamente mucho (...) aun asi gustándote te puedes llegar a cansar." $<$ Elementos internos $\|$ Entrevistas $\| C$ 10>- Referencia 8.

La crítica a la desigualdad existente entre la valoración de los alumnos que asisten a clase frente a los que no lo hacen, en el Grado en Maestro/a, cuestionaba la disparidad evidente entre ambos itinerarios, permitiéndonos ver su empatía por los compañeros que no podían seguir el modelo presencial. Esta reflexión sugiere la necesidad de una remodelación del sistema educativo respecto a esta cuestión.

"...hay muchos profesores, y en Magisterio sobre todo, que es como... isi no vas a clase tienes un examen hipermega X! (...) Y si vienes a clase hay otras propuestas, haces unas cosas más prácticas y tal. Hay algunos que no hacen ni examen (...) Y quizá esos extremos pues no me parecen del todo correctos. Y en magisterio quizá pasa bastante." <Elementos internos $\|$ Entrevistas $\mid C$ 11> - Referencia 11.

Un prejuicio de discriminación racial derivó en una mejora de la conciencia social de un alumno al comprobar que un niño de etnia gitana no solo no generaba menos conflictos que el resto de sus compañeros sino que era el que mejor comportamiento presentaba. La reflexión sobre la idea preconcebida de este colectivo representa un valioso aprendizaje en la sociedad multicultural en la que vivimos.

"...de los que más nos esperábamos por ser gitanos o así, de los que más nos esperábamos que fueran conflictivos son de los mejores de clase. Está el caso de S---- por ejemplo, que es gitano, y al vestir dices... ¡madre mía este, con mechas y todo, con cuatro años que tiene! Y en cambio te das cuenta que no, que es de los más buenos de clase y si tú le dices esto, hace esto y te hace caso." <Elementos internos $\|$ Entrevistas $\| C_{12}>$ - Referencia 2.

\section{- Capacidad de cooperación y ayuda.}

La cooperación y ayuda hace referencia al hecho de obrar junto a otras personas con un mismo fin, haciendo un esfuerzo y ofreciendo auxilio en el desempeño de la tarea a realizar.

La ayuda prestada por el equipo de trabajo al grupo de compañeros universitarios, y la crítica sobre la distribución del trabajo a realizar por parte de los alumnos, destacan el fuerte compromiso del alumnado con la actividad, siendo capaces de asumir labores adicionales con tal de no mermar la calidad del servicio prestado.

"...hubo dos o tres días que hemos tenido que seguir nosotras la sesión porque a lo mejor ha faltado una y decía... ¡no, es que yo solo sé mi parte, la parte de mi compañera no la sé! No hombre no, tenéis que saber las dos las dos partes." <Elementos internos \|Entrevistas\|C o1> - Referencia 2.

La experiencia realizada a través del APS no solo fomentó la maduración de destrezas relacionadas con la distribución del trabajo sino que también incentivó la mejora de habilidades sociales tan importantes como la comunicación. Este hecho nos ayuda a entender el efecto social que provocan estas vivencias en el alumnado. 
"...las compañeras fijas del APS pues también estamos aprendiendo entre nosotras a repartirnos el trabajo, a entendernos y sobre todo a hablar entre nosotras cada vez que tengamos dudas en vez de suponer que fulanita va a hacer esto y fulanita lo otro." <Elementos internos ||Entrevistas\|C 02> Referencia 2.

El aprendizaje mutuo, proporcionado a través del trabajo en equipo, ofrece la visión de que esta labor no se centra en la distribución de tareas sino en el apoyo continuo entre los miembros del equipo de trabajo. Esta perspectiva nos ayuda a entender cómo los alumnos aprendieron unos de otros a través de un comportamiento realmente cooperativo.

"...cuando tú das la idea, este da una aportación yo otra, así, así, así, así, que es de lo que se trata el trabajo en equipo, cada uno tiene unas fortalezas y unas debilidades. Entonces si a lo mejor una persona es muy buena dando ideas y otra persona es a lo mejor más... organizando los espacios y el tiempo pues yo creo que esto te hace mejorar un poquito." <Elementos internos||Entrevistas\|C 03> Referencia 22.

Un alumno destacaba la preferencia de los niños por realizar juegos de carácter cooperativo, apreciación que le hizo reflexionar sobre las posibilidades y beneficios que se pueden extraer de este tipo de tareas durante las sesiones de juegos motores y expresivos.

"...a ellos también los que les gustaban bastante eran los juegos en los que tenían que buscar, que buscar en el sentido de una manera cooperativa. A lo mejor les planteábamos que tenían que buscar pistas, por ejemplo el día que hicimos las películas (...) una pista que daba pie al siguiente juego (...). Entonces ellos de manera (...) cooperativa, cuando se encontraba a nivel de grupo." <Elementos internos $\|$ Entrevistas $\| C$ o4> - Referencia 16.

El trabajo en grupo estimula aprendizajes relativos a habilidades sociales tan importantes como la comunicación, la asertividad, el diálogo, la empatía, el respeto, etc. El hecho de que el alumno viera estos aspectos como problemas nos ayuda a entender que las experiencias de APS provocan aprendizajes ocultos sobre los que el profesorado debe incidir si quiere hacerlos conscientes para los participantes.

"...en cuanto al trabajo en equipo hay ventajas y dificultades. Las ventajas es que como somos muchas todas aportamos un poquito de cada una y eso está bien porque tú también aprendes de eso. Pero hay muchas dificultades también en cuanto a la hora, a la manera de pensar de cada una (...) siempre hay algunas que tienen pegas. Entonces tú intentas lo mejor para todos pero no siempre se queda bien y hay problemas en el grupo (...) nosotras hemos tenido un poco de dificultad en cuanto a la organización y todo." <Elementos internos $\|$ Entrevistas $\| C$ 05> - Referencia 10.

Gracias al apoyo prestado, los niños de la entidad desarrollaron su motricidad y llegaron a realizar actividades que, de otro modo, no hubieran podido alcanzar. Este logro supuso una de las mejores aportaciones que los alumnos podían ofrecer a los niños con parálisis cerebral. Al mismo tiempo, representó para el alumnado uno de los aprendizajes más valiosos respecto a la asignatura en la que se enmarcaba, vinculada a los juegos motores y expresivos en educación infantil.

"...solitos ellos no saltaban bien, es cómo que no coordinan los movimientos con el salto que tienen que dar pero si tú les coges de la mano y jugando vas andando con ellos lo hacen. Y no sé qué pasa ahí pero de haber experimentado cómo es el movimiento (...) de haberlo hecho mucho con ellos acompañados al final, al final lo saben hacer solos." <Elementos internos $\|$ Entrevistas $\| C$ o6>-Referencia 4. 
La ayuda y el trabajo de los alumnos universitarios provocaron una gran mejora en el desarrollo motor de uno de los niños. Esta exitosa situación causó una enorme alegría a los miembros del equipo de trabajo como consecuencia de la meta alcanzada en ese caso particular.

"...lo más así a lo mejor más sorprendente $G$---- que al principio, los primeros días no... o sea, no es que no se moviera es que no le notábamos ni expresión en la cara. Y el sábado antes de pascua G---- ya anduvo, con nosotras pero anduvo, entonces claro eso... isatisfacción máxima!" <Elementos internos $\|$ Entrevistas $\|$ C 07> - Referencia 3.

La falta de ayuda por parte del profesor de la entidad colaboradora propició un aprendizaje oculto a los miembros del equipo de trabajo, ya que tuvieron que enfrentarse a diversas situaciones y problemáticas que de intervenir el docente no hubieran podido afrontar.

"Al principio sí que nos resultaba extraño el tenerlo allí y que él no nos contara nada, no interactuaba con nosotras, él se sentaba y nos miraba (...). Pero ahora al final sí que nos dice... iay pues esto, aquello! (...) ¡a estas chicas no sé qué, les falta esto, tienen este problema! ¿no? Como que nos da consejos, o nos dice... ino las ayudéis a ver cómo intentan salir! Porque él a nosotras no nos ayudó y no quiere que nosotras ayudemos a los otros grupos, a ver cómo salen del jaleo." <Elementos internos $\|$ Entrevistas $\| C$ o8> - Referencia 4.

Aprender a trabajar de modo cooperativo hizo reflexionar al alumno sobre las diferentes formas de actuar en tareas grupales, además de ayudarle a mejorar sus aportaciones individuales, dos aprendizajes importantes en cualquier trabajo de grupo.

"...realizamos algunas actividades prácticas, más adelante, que también me ayudaron para darme cuenta que realmente era mejor trabajar en grupo. Por ejemplo una actividad que hicimos consistía en, por grupos, teníamos que conseguir hacer el máximo número de vasitos de papel, y el grupo que más consiguiera hacer en un tiempo determinado sería el que ganaría. Y esto lo hicimos con diferentes técnicas, digamos, y nos dimos cuenta que la mejor solución, que la mejor era la de cada uno adoptar un papel, o sea, cada uno hacer lo que mejor se le daba pero trabajando cooperativamente." $<$ Elementos internos $\|$ Entrevistas $\| C$ og $>$ - Referencia 3.

Realizar una jornada de puertas abiertas requiere una gran cooperación en su organización, además de reunir toda la ayuda posible. El éxito en una actividad tan compleja derivó en el agradecimiento y satisfacción de todos los implicados en el servicio.

"...el día de la UJI nos sirvió bastante ya que (...). Tuvimos mucha ayuda de las alumnas y ayuda de los profesores. Hicimos un recorrido por la universidad, jugamos a pádel con ellos y (...) con nuestra ayuda y todo eso salió bien el día, los profesores lo agradecieron, los niños te lo agradecían con abrazos, que querían volver, y a mí eso me llena bastante. "<Elementos internos $\|$ Entrevistas $\| C$ 10>-Referencia 6.

Gracias al programa de APS los niños de la entidad pudieron realizar algunos juegos y actividades que sin el apoyo del alumnado universitario no hubieran podido disfrutar. Esta situación demuestra el beneficio social de este proyecto educativo. Además, la reflexión del alumno sobre la dificultad del uso de gran cantidad de material o la organización de los niños por parte de un único docente, destaca la cooperación y ayuda necesarias para llevar a cabo proyectos de este tipo, cuestiones de gran relevancia si consideramos los ratios de alumnado actuales.

"Los recorridos un poco los destacaba por eso porque sí que era un poco a nivel también servicio que dábamos. Porque salir al patio puedes salir tu solo como maestro, pero esa cantidad de material a lo 
mejor de crear con aros, con cuerdas, con los bancos... pues uno solo un poco más complicado. Utilizar material novedoso como el paracaídas." <Elementos internos $\|$ Entrevistas $\| C$ 11>-Referencia 20.

La ayuda prestada por el profesor del centro colaborador para resolver un problema de comunicación posibilitó que el alumnado desarrollara las actividades planificadas con un niño de habla inglesa. El alumno también incidió en el valor de la expresión corporal para solventar problemáticas de este tipo, una forma de comunicación menos condicionada que el habla.

"...él habla inglés y a lo mejor tú le estás diciendo que haga algo y él te hace así pero luego te das cuenta de que no, no te ha entendido y $V$---- se lo dice en inglés y entonces el enseguida lo hace. Porque además es muy listo. Y a lo mejor no te está entendiendo el idioma pero ve a los demás o hace lo posible por hacer lo que tú le estás diciendo." <Elementos internos $\mid$ Entrevistas $\| C$ 12>-Referencia 1.

\section{- Coherencia y compromiso.}

La coherencia y compromiso es la actitud lógica y consecuente que vincula a una persona con una obligación o tarea contraída libremente.

La escasa vacilación de un alumno al tener que decidir su participación en el programa educativo demuestra la firmeza de su compromiso, algo que se refuerza al comprobar su intención de trabajar en el futuro en una institución de similares características, lo que ofrece mayor coherencia a su argumentación. Esta situación vuelve a resaltar el potencial de este tipo de proyectos en cuanto a la formación práctica.

"...cuando dijo las instituciones y lo que había que hacer en seguida yo dije, yo... hago la práctica. Más que nada porque yo en un futuro quiero acabar trabajando en un lugar así, en una institución así. Entonces dije pues, pues lo hago." <Elementos internos $\|$ Entrevistas $\mid C$ O1> - Referencia 1.

Este alumno valoró la posibilidad de participar en el futuro en el mismo proyecto educativo, dejando patente su coherencia y compromiso en cuanto a la actividad. Esta opinión se puede achacar al elevado nivel de satisfacción alcanzado tras la experiencia realizada.

"...si ahora me dijeran... ¿el año que viene quieres volver a hacer esto? iyo me tiraría de cabeza!" $<$ Elementos internos\|Entrevistas\|C o2> - Referencia 9.

Pese a la falta de compromiso de la entidad colaboradora, el alumnado consiguió que esta situación no perjudicara a los niños del centro ni a sus familiares, muestra de su gran responsabilidad respecto al compromiso contraído a través del servicio, otro aspecto analizado en este trabajo.

"...podíamos haber dicho, por tema de seriedad ¿no? por tema de un poco de compromiso por la asociación, podíamos haber dicho perfectamente... ipues mira se anula porque no nos habéis confirmado cuando toca y con dos niños no se puede hacer una sesión! Pero pensamos (...) ¡lo estamos haciendo para la asociación pero los niños son los implicados, o sea, los que al final acaban perdiendo y los familiares que no tienen culpa! (...) pues ivamos a lidiarla de alguna manera o de otra!" <Elementos internos $\|$ Entrevistas $\| C$ 03> - Referencia 11.

El grado de satisfacción de este alumno le llevó a plantear que no tendría reparos para participar nuevamente en esta experiencia educativa. Esto nos ayuda a entender el valor que le otorga a la vivencia realizada, animando al profesorado a continuar trabajando en esta línea para mejorar la propuesta formativa ofrecida. 
"Yo animaros a que sigáis haciendo esto porque realmente pienso que es una labor muy interesante y todos los principios son duros y de eso se trata de ir puliendo para que salga cada vez mejor. Y que en general mi conclusión es bastante positiva de lo que he hecho, lo volvería a hacer y con eso pues creo que también se dice todo." <Elementos internos $\|$ Entrevistas $\| C$ O4> - Referencia 12.

La falta de coherencia y compromiso por parte de algunos de sus compañeros hizo que este alumno hablara sobre el papel del profesorado en este tipo de programas educativos, exponiendo que debe ejercer el papel de guía en cuanto a los aspectos académicos y de mediador respecto a los posibles conflictos que puedan aparecer.

"...nosotras también estamos como en un poco de malestar en el grupo porque personas que tienen cosas que no son muy importantes se dejan de ir a Penyeta teniendo coche y pudiendo acompañar a las otras chicas que no tienen coche por cosas que no son importantes. Como que se escaquean vamos, si eso." <Elementos internos $\|$ Entrevistas $\| C$ 05> - Referencia 3.

La demanda de una mayor formación práctica en el Grado en Maestro no deja lugar a dudas en cuanto al interés de este alumno por participar en el programa formativo. Este planteamiento nos demuestra su coherencia y predisposición para comprometerse con nuevas dinámicas de este tipo en el futuro.

"...yo me apunté casi sin pensarlo porque yo que desde entré en la carrera estoy harta de decir que en magisterio debería haber práctica desde el primer año. Y me parecía pues, no sé, así un poco hipócrita también tener la oportunidad de hacer unas prácticas, estar reivindicándolo siempre y cuando me lo ofrecen no ir ¿no? Entonces que eso me parece muy buena idea." <Elementos internos\|Entrevistas ||C o6> - Referencia 1.

El compromiso del alumnado, respecto a su función como organizadores de la actividad, nos permite ver cómo procedían a lo largo del proceso educativo, guiando, informando y ayudando a sus compañeros universitarios durante toda la aplicación del servicio. Esta actitud muestra su coherencia respecto a las obligaciones contraídas a través de esta metodología.

"...cuando venían los grupos el primer día quedábamos con ellas (...) y antes de preparar las actividades pues les explicábamos más o menos... pues tenemos tantos niños y cada uno pues sus posibilidades y tal, más los juegos. Y por ejemplo pues a B---- le gusta la música, a J---- M---- la pelota grande, le explicábamos de cada uno así, lo que podían hacer y lo que les motivaba y tal. Y luego ya ese día las preparábamos en conjunto." <Elementos internos\|Entrevistas $\mid C$ O $7>$ - Referencia 3.

Pese a tener la posibilidad de distribuir su asistencia en el centro colaborador del modo que consideraran más oportuno, comprobamos cómo ningún alumno quiso reducir su presencia en el mismo. Esta plena participación destaca la coherencia y compromiso del alumnado en cuanto a su asistencia en las actividades del servicio.

"...hemos tenido muy buen rollo y muy buena relación entre todas porque lo que hacía una lo hacían todas, ibamos todas a una no le dejábamos toda la faena a una (...) intentábamos ayudar todas y al cole hemos ido todos los días todas porque todas queríamos ir." <Elementos internos ||Entrevistas |IC o8>- Referencia 2.

El alumnado consiguió motivar a sus compañeros universitarios trasladándoles su compromiso con el servicio para mejorar el nivel de las propuestas educativas a realizar. Para 
ello, llegaron incluso a entrar en el terreno personal, aludiendo a la importancia y necesidad de estos proyectos con este colectivo, muestra además de su gran conciencia social.

"...nos propusimos motivar al otro grupo contándoles todo lo que significa todo esto para las familias, para los niños, lo importante que es y lo que pensamos nosotras para ver si así se concienciaban más de todo esto y conseguían hacer mejores sesiones, realizamos juegos (...) que estuvieran más elaborados, que fueran más creativos, nosotras organizarnos mejor y todo eso." <Elementos internos $\|$ Entrevistas $\|$ Cog $>$ - Referencia 8.

La siguiente situación pone de manifiesto el compromiso del alumnado al demandar una mayor participación durante el servicio. Parte de su petición se fundamentó en poder prestar una mayor ayuda a sus compañeros universitarios, demostrando de nuevo su coherencia y compromiso con sus obligaciones.

"...nos hubiera gustado tener sesiones con cada grupo y no solo con el grupo de los pequeños porque sí con los mayores era más fácil, pero aun así nos iban surgiendo dudas a la hora de explicárselo a las chicas. Entonces nos hubiera gustado trabajar con todos y así ir aprendiendo más." <Elementos internos $\|$ Entrevistas $\| C$ 10>- Referencia 8.

El trabajo de formación y análisis sobre los niños con los que tenía que realizar el servicio no dejó lugar a dudas respecto al compromiso de actuación de este alumno, intentando aprender incluso a través del trabajo de sus compañeros. Esta conducta analítica es de gran importancia, ya que es una estrategia muy empleada en el ámbito de la EF.

"...para tenerlo más o menos controlado quiero conocerlos. Por eso también a lo mejor me gusta observar y ver cómo reaccionan frente a lo que hacemos. Entonces mirar a mis compañeras cuando ellas eran las que estaban haciendo la actividad, las que estaban dirigiéndola." <Elementos internos $\|$ Entrevistas $\| C$ 11> - Referencia 1.

La satisfacción de un alumno con el programa educativo realizado genera una valoración final tan positiva que llega a presentarse voluntario para recomendar la participación de nuevos alumnos en futuras ediciones. Esta muestra de coherencia y compromiso se ve reforzada al demandar al profesorado la continuidad del proyecto formativo por considerarlo una experiencia de gran valor, tanto a nivel profesional como personal.

"...crítica no tengo ninguna, pero lo que sí que... no dejéis de hacerlo porque sí que la verdad que es una oportunidad que yo estoy muy contenta. Y si tengo que ir a clase como vinieron el año pasado iré para animar a los de primero porque si tienen la oportunidad de hacerlo que no se lo piensen dos veces porque la verdad que... yo personalmente, no sé, pienso que me ha ayudado un montón. $Y$ eso, y te llena, es una experiencia que te llena (...) una experiencia inolvidable." <Elementos internos\|Entrevistas $\| C$ 12> - Referencia 16.

\section{- Convivencia y respeto por el bien público.}

Entendemos la convivencia y respeto por el bien público como la acción de vivir en compañía presentando una actitud de consideración y deferencia hacia otras personas y cosas, materiales o inmateriales, de propiedad comunitaria.

La demanda de un mayor respeto hacia los niños de la entidad por parte del alumnado universitario nos ayuda a comprender sus sentimientos sobre este colectivo. El alumno exigía un trato adecuado a los niños por parte de aquellos que iban a prestar el servicio, independientemente de la impresión que les despertara este grupo social. 
"Por mucho que no te gusten ese tipo de niños o que no te guste trabajar con ellos no sé un poco de respeto, pensaba yo." <Elementos internos $\|$ Entrevistas $\| C$ o1> - Referencia 4.

El autocontrol adquirido durante la experiencia, respecto a la falta de trabajo de algunos compañeros, ayudó a cambiar la forma de afrontar estas situaciones de un alumno. Un aprendizaje útil para futuras situaciones en las que deba gestionar labores grupales.

"...cuando una compañera había dicho de... por ejemplo, ;las coronitas de no sé qué las haré yo! Luego se presenta el sábado... ;ay, se me ha olvidado hacerlas! Pues antes de empezar probablemente me habría tirado encima suyo y habría habido pelea importante, porque tengo un poquito de mala leche. Pero ahora he aprendido a reservar mis energías para cosas más importantes y eso creo que me va a valer muchísimo cuando tenga que trabajar con compañeros en un cole." <Elementos internos $\|$ Entrevistas $\| C$ 02 $>$ - Referencia 4.

Pese a sufrir un contratiempo importante en la organización del servicio apreciamos cómo el alumnado hizo lo posible por salvar la actividad, no solo por ellos mismos o por los niños de la entidad sino también por el resto de compañeros universitarios, quienes de lo contrario se hubieran quedado sin poder realizar la sesión práctica. Esta acción muestra su deferencia con todos los implicados en el servicio.

"...hubo un problema una vez que solo habian en la lista dos niños y nos lo dijeron muy tarde y claro había gente de clase que tenían que estar entonces dijimos... ;ostras es que para no fastidiar a los de clase! Entonces empezamos a decir... pues yo llevaré a mis dos sobrinos, pues yo llevaré a mi primo, pues yo a mi hermano (...) Y al final nos juntamos con un montón de niños y esa sesión se salvó." <Elementos internos $\|$ Entrevistas $\|$ C o3>-Referencia 2.

La consideración de los alumnos respecto a los niños con TDAH era muy respetuosa con las características propias de este colectivo, valorando entre sus objetivos principales que se divirtieran, que participaran y que desconectaran de los problemas asociados con su situación.

"...nuestro objetivo principal era que se lo pasasen bien, que jugaran (...) que aprendieran algunas cosas en el sentido del tema de las pautas, de recibir algunas órdenes, de pues pasar dos horas entretenidas sin sentirse, o que, bueno sin que ellos estuvieran expresando los síntomas propios de su condición ¿no? Que es el trastorno este de hiperactividad y déficit de atención." < Elementos internos $\mid$ Entrevistas $\mid C$ o4>- Referencia 12.

Pese a la gran dificultad de comunicación de una niña que padecía una enfermedad con afectación neurológica el alumnado fue capaz de elaborar propuestas para que pudiera trabajar con el resto de niños. Esta acción muestra una actitud de respeto hacia sus necesidades educativas especiales, una cualidad esencial en cualquier docente.

"...hay una niña que no habla, que el contacto es mínimo si no la sabes tratar porque nosotras nos dimos cuenta en todas las sesiones que la profesora sí que sabe mucho comunicarse con ella. Pero nosotras no nos podíamos comunicar nada y todo lo que esa niña hacía era más tipo sensorial y cosas así porque tenía un síndrome de Rett. Pero bueno, ellas supieron adaptar bien todas las actividades para que esta niña también pudiera estar con el resto del grupo." < Elementos internos||Entrevistas\|C 05> - Referencia 2.

La consideración global de que la población infantil no es malintencionada por defecto llevó a un alumno a valorar que hay que tratarlos con cariño para facilitar el desarrollo de las 
propuestas a realizar. Esta reflexión representa una posición muy respetuosa, una conducta imprescindible a la hora de trabajar con cualquier colectivo de niños.

"...todo lo que he comentado antes de cómo tratarlos que se aplica para ellos pero yo creo que también se aplica para todos ¿no? el no sé, tener paciencia con ellos y entender que las cosas no las hacen por molestar. Eso es una cosa que me ha llamado mucho la atención, sobre todo con ellos, con estos niños concretamente, pero que al final yo creo que se podría tener en cuenta con todos. Que los niños no hacen las cosas por molestarte, puntualmente habrá veces en las que sí, pero que en general no hacen las cosas para molestarte a ti y que cuando los tratas bien funcionan bien." <Elementos internos\|Entrevistas\|C 06> - Referencia 21.

Debido a la falta de participación en los juegos de una niña, el alumnado intentó integrarla de forma cuidadosa para que no se sintiera forzada. Esta acción pone de manifiesto su deferencia con los niños de la entidad, intentando resolver las situaciones problemáticas de la forma más atenta posible.

"...al principio hacíamos un juego y ella se iba a la red de la portería, o sea, directa y de allí no la sacábamos (...) al principio pues también nos daba cosa, yo qué sé, abrirle los dedos para que soltara la red (...) pero luego cuando descubrimos que la música le gustaba tanto pues ya hacíamos eso, le poníamos... B---- si esta actividad la haces toda, luego en la actividad de música elegirás tú la canción (...). Y así bueno, ahora ya está siempre haciendo todo y todo bien." <Elementos internos\|Entrevistas\|C 07> - Referencia 15.

La escasa movilidad de los niños que padecían parálisis cerebral se convirtió en uno de los objetivos básicos del alumnado universitario. Su intención de ofrecer un servicio óptimo que mejorara la calidad de vida de este colectivo también destaca su capacidad para reconocer las carencias y necesidades específicas de este tipo de niños.

"...hemos hecho juegos de... sobre todo de movimiento porque creemos que es lo que más les faltaba, que desarrollaran el correr, agacharse rápido, saltar (...) la rapidez es lo que más les faltaba y hemos hecho pues eso (...) de agilidad, de que tuvieran que pensar y actuar rápido." <Elementos internos $\|$ Entrevistas $\| C$ o8> - Referencia 9.

Este alumno demandaba una mayor consideración respecto al colectivo de niños con parálisis cerebral, por parte de la sociedad en general, destacando que pese a sus limitaciones son niños con muchas capacidades. Por ello, debemos intentar tratarlos del mismo modo que al resto y no de forma condescendiente, lo cual jugaría en detrimento de su educación.

"...la verdad es que nos impactó mucho porque claro no sabíamos nada de ellos, no sabíamos cómo eran, encima eran quince, muchos vinieron con silla de ruedas y no sabíamos qué decirles, ni cómo tratarlos, ni nada porque claro no los veíamos como a unos niños normales (...) son unos niños normales, pero realmente tú lo que tienes inculcado no es eso y no lo ves así." <Elementos internos $\|$ Entrevistas $\|$ Cog $>$ - Referencia 3.

El cuidadoso modo en que el alumnado presentaba las tareas a los niños, evitando empezar una actividad hasta asegurarse de que todos los participantes la habían entendido, expresa su consideración en esta delicada cuestión. Más adelante profundizaremos en la importancia de este aspecto en el ámbito de la EF.

"En ningún momento jugábamos sin explicarles las cosas. Íbamos poco a poco y si a lo mejor tenías que estar toda la hora con el mismo juego pues lo estabas pero para el que no lo entendiera. Y ellos mismos te decían... isi, si, ya lo hemos entendido! Y se ponían a jugar y eran lo que poco a poco, viendo a sus compañeros lo iban haciendo." <Elementos internos $\|$ Entrevistas $\| C$ 10>-Referencia 8. 
El respetuoso comportamiento de los alumnos con el profesor de la entidad colaboradora nos ayuda a entender el modo en que siguieron todas sus indicaciones respecto al trabajo con los niños. Este buen entendimiento entre ambos colectivos demuestra la confianza mutua existente, destacando la importancia del valor social de este aspecto.

"...trabajamos, o sea, el objetivo principal que nos decía $V$----, como por ejemplo el equilibrio. El circuito estaba pensado exclusivamente para el equilibrio y a partir de ahí también se derivaban otras cosas y también otras actitudes, porque $V$---- nos dijo que era muy importante también con estos niños plantearnos lo que es actitudes (...) el compañerismo a la hora de esperar el turno o ayudar al compañero (...) eran actitudes de trabajo entre ellos que también se debían fomentar." < Elementos internos\|Entrevistas $\|$ C 11> - Referencia 7.

La convivencia con los niños de la entidad hizo que aparecieran algunas situaciones delicadas, pues el contraste social del centro se apreciaba en diversos hábitos y costumbres. Con la ayuda del profesorado colaborador el alumnado fue vivenciando y concienciándose de estas diferencias culturales, mejorando su comprensión respecto al colectivo de niños receptores del servicio.

"...una vez fueron a beber a la fuente y un niño vio que el agua le tocaba la cara se asustó. I----, que es la otra profesora, nos los decía... dice, a lo mejor a ti te parece una tontería el asearte, pero para ellos a lo mejor en casa no tienen esa rutina, tú no sabes (...) siempre tenemos diez minutos antes de acabar para ir a asearse y que ellos vayan cogiendo el hábito de asearse. " < Elementos internos $\mid$ Entrevistas $\mid C$ 12> - Referencia 22.

En este apartado hemos visto cómo el programa de APS propició la aparición de notables impactos sociales en el alumnado participante. Este hecho tiene una influencia directa sobre su visión particular de la sociedad y, por extensión, afecta a todos los entornos comunitarios en los que conviven. Ambas situaciones nos llevan a pensar que el efecto social de este tipo de proyectos educativos puede ser incluso mayor de lo que nos planteamos inicialmente ya que a todo esto debemos sumar la influencia sobre el resto de implicados en el servicio.

\section{- Aspectos innovadores.}

Este último bloque hace referencia a los aspectos de carácter innovador. Estos señalan los elementos, facetas y matices propios, pertenecientes o relativos a la personalidad del individuo, en relación con el potencial para descubrir, inventar y progresar.

\section{- Creatividad.}

La creatividad hace alusión a la capacidad para formar nuevas ideas o proyectos, fundándolos uno mismo.

Los alumnos pudieron desarrollar su creatividad gracias a la libertad de acción otorgada por el equipo docente del centro colaborador. Al mismo tiempo, también vemos el nivel de responsabilidad asumido durante la actividad, ya que pudieron organizarla siguiendo sus propios criterios y preferencias. 
"Luego el día de los disfraces también... nos daban banda ancha para que... poder en verdad, podíamos hacer lo que quisiéramos." <Elementos internos ||Entrevistas||C 01>- Referencia 1.

Un alumno demostró su creatividad al aprovechar un personaje familiar de una niña para motivar su participación en la sesión de juegos. Esta situación pone de manifiesto cómo fue capaz de identificar un recurso disponible a su alcance para aumentar la integración del alumnado participante, así como para mejorar el desarrollo de las tareas a realizar a través del juego simbólico dentro del ámbito de la expresión corporal.

"...también hacemos sesiones temáticas porque por ejemplo en esta que hicimos de animales la pequeñita es súper fan de Pepa Pig y entonces cuando le dijimos que era el cerdito y que podía hacer como Pepa Pig estuvo toda la sesión súper encantada yo nunca la había visto tan emocionada." $<$ Elementos internos $\|$ Entrevistas $\| C$ o2>-Referencia 1.

La importancia de ser creativo a la hora de elaborar juegos en cuanto al uso del material hizo reflexionar a un alumno sobre su capacidad para optimizar la utilización de los elementos disponibles, maximizando así sus recursos docentes pese a la limitación de estos objetos.

"...ahí nos enseñó que la importancia es de crear los juegos, de ser una persona creativa y que de cualquier material y con cualquier objetivo que tú te quieras marcar, que tú puedas sacar un juego chulo, divertido y de calidad."<Elementos internos||Entrevistas $\mid C$ o3>-Referencia 1.

El alumnado fue capaz de identificar numerosos recursos, motivadores para los niños, y de contextualizar los juegos dentro de diferentes temáticas. Con ello, consiguieron un estímulo global tremendamente atrayente para todos los participantes, mostrando su creatividad en cuanto al escenario de aplicación de las sesiones de juegos.

"La sesión que hicimos de los Oscar, que eran todo juegos referidos a películas infantiles, pues yo me encargue del juego de película para relajación y se me ocurrió hacer un juego que era lluvia de albóndigas. (...) ese día habíamos hecho una pista de automovilismo por el juego de Cars, habíamos hecho con el paracaídas los de buscando a Nemo, habíamos... un montón de juegos, pero de verdad que era para haberla visto esa sesión." <Elementos internos ||Entrevistas ||C 04> - Referencia 10/11.

La creatividad del alumno en la elaboración de las actividades propuestas, concretamente respecto al desarrollo de la expresión corporal, nos hace ver la importancia de abordar las tareas a realizar de una forma atrayente para los niños, aumentando así su motivación y participación en las mismas. Esta labor es indispensable en aquellas actividades poco motivadoras de por sí, donde este aprendizaje puede ser de gran utilidad.

"...de expresión corporal si, además de la relajación que a lo mejor les hacían convertirse en árboles por ejemplo entonces también había expresión corporal." <Elementos internos||Entrevistas||C 05> Referencia 2.

El desarrollo de una actividad de expresión corporal, que aprovechaba de forma creativa el recurso del refuerzo positivo, nos muestra cómo los alumnos fueron capaces de elaborar recompensas deseables por los niños relacionadas con la propia temática de las actividades realizadas, reforzando así el concepto globalizador de las tareas.

"...ellos tenían que como representar el animal que les había tocado, no solo con qué ruido hace sino también qué gesto hace. Y bueno muchos no sabían pero a mí me gustó mucho que entre ellos se ayudaban a hacerlo. (...) y cuando lo representaban bien, fuera ellos o fueran los demás o con ayuda de 
lo que fuera entonces luego les pintábamos la cara del animal que era... ivy, se morían de la risa jejeje!" $<$ Elementos internos $\|$ Entrevistas $\|$ C 06> - Referencia 6.

Esta propuesta de trabajo de expresión corporal fomentó notablemente la creatividad de los niños durante la actividad ya que, en algunos momentos, se les instó a plantear sus propias sugerencias en cuanto a las tareas a realizar.

"...hicimos uno de expresión que por ejemplo contábamos... iun, dos, tres! Y al principio decíamos nosotras... icasa en un, dos, tres! Y ellos, teníamos que intentar formar una casa entre todos, o también lo podían decir ellos... itristes un, dos, tres! Y entonces hacíamos la foto tristes, así no sé." <Elementos internos\|Entrevistas $\|$ C 07> - Referencia 2.

La descripción de un juego para trabajar el reconocimiento de las partes del cuerpo de forma creativa nos ayuda a entender que la estrategia escogida para desarrollar este contenido era hacerlo de forma indirecta, a través de una actividad lúdica en la que los niños se divirtieran mientras movilizaban de forma secuencial los distintos segmentos corporales.

"Con los globos que tenían que bailar. Les inflamos globos, se lo pusieron en la barriga o en la cabeza, creo que trataba las partes del cuerpo, y les decíamos una parte del cuerpo y ellos tenían que aguantar entre parejas el globo (...) e ir andando y bailar o moverse al ritmo de la música pero con el movimiento, que bailaran pero que no se les cayera."<Elementos internos $\|$ Entrevistas $\| C$ o8> - Referencia 2.

Un juego creado expresamente a partir de los objetivos de trabajo y las características de los niños participantes nos demuestra el gran valor de la creatividad en cualquier ámbito educativo, ya que proporciona al docente una fuente de recursos de trabajo inagotable. Igualmente, desarrolla la capacidad para adaptar y modificar cualquier tarea en función de las características existentes, aumentando así la calidad de las actividades a realizar.

"...uno que hemos hecho varias veces y que la verdad es que a los niños pues les ha gustado mucho era poner dos colchonetas de estas grandes ¿vale? apoyarlas contra la pared y dejar un espacio entre la pared y la colchoneta ¿vale? y entre las dos colchonetas también dejar un espacio. Entonces los niños tenían que cruzar de una parte hasta la otra y nosotras y otros niños intentar pegarles con una pelota. Y este juego la verdad es que les gustaba mucho porque ellos pues se escondían detrás de la colchoneta y ahora paso y ahora no (...) y dijimos... vale, este juego les gusta mucho pero ¿podríamos sacarle más variantes y adaptarlo? (...) Y dijimos... ipues tendrán que coger un pañuelo y llevarlo al otro lado y colocarlos en un cono y cuando el que consiga llevar más pañuelos en menos tiempo pues este será el ganador del juego!" <Elementos internos $\|$ Entrevistas $\| C$ og> - Referencia 1.

En el siguiente ejercicio el alumnado debía plantear actividades educativas adaptadas a las características de diversos tipos de niños. A través de esta tarea desarrollaron su creatividad mientras adquirían una amplia gama de propuestas de trabajo para la posterior ejecución del servicio e incluso para futuros contextos en los que tuvieran que actuar como docentes.

"...con niños hiperactivos pues hacíamos juegos relacionados con las características de los niños hiperactivos. Nos decían que inventáramos un juego con ese tipo de características y luego lo comentábamos con el resto de los compañeros. El profesor nos iba ayudando, nos decía cómo lo podíamos modificar, qué se podía hacer, qué no, los problemas que podían ocasionar. Entonces (...) a la hora de hacer las sesiones, pues cogíamos la hoja en que teníamos apuntadas las características y lo que nos iban diciendo e íbamos adaptando las sesiones a ese tipo. " < Elementos internos ||Entrevistas |IC 10>-Referencia 3 . 
Esta actividad de expresión corporal ponía de manifiesto la estrecha relación existente entre este tipo de tareas y el desarrollo de la creatividad, tanto por parte de los alumnos universitarios como de los niños receptores del servicio.

"...luego hicimos el de las estatuas (...) empezábamos un poco de... bueno, cuando esto paráis y os quedáis quietos, solo con eso. Pero luego ya era (...) vale ahora paráis pero tenéis que poneros como un animal o haciendo una figura o... y luego les preguntábamos (...) ¿y eso qué es?, y ¿eso qué es?, ¿qué estás trabajando? Y a lo mejor te decían... ¡no, soy bombero! Y tú decías... ;ah! Pero vamos no... se quedaban, no sé, ellos ponían su postura. O sea de expresión."<Elementos internos $\|$ Entrevistas $\| C$ 11> - Referencia 4 .

Actuar de forma rápida y creativa para salvar la parte final de la sesión de juegos nos hace ver cómo, en poco tiempo y con escasos recursos materiales, el alumnado elaboró un exitoso juego adaptado a las necesidades de los niños. Esta cualidad es muy valorada en cualquier ámbito de la docencia, ya que ayuda a superar muchos de los imprevistos que pueden aparecer en el transcurso de las clases.

"...cuando llegamos allí teníamos planteadas cuatro actividades. Hicimos la primera salió bien, hicimos la segunda salió bien, hicimos la tercera salió fatal (...). Hicimos la cuarta y nos estaba saliendo fatal. Y aún nos quedaban no sé si eran quince minutos. $Y$ yo le dije a $L$---- ¡mone dentro y con el material que tenemos vamos a hacer alguna actividad pero ya! (...) ¡vamos a hacer así tipo el juego de las sillas pero que en vez de que sea la silla que sea un aro y que no se vayan eliminando (...) que se vayan ayudando a que nadie se quede sin aro! Pues salimos, lo hicimos y salió superbién. Y yo se lo dije a L---- (...) hemos entrado aquí hemos cogido cuatro aros y enseguida hemos hecho una actividad. A lo mejor eso otra vez no nos lo hubiésemos ni planteado." <Elementos internos $\|$ Entrevistas $\| C$ 12>-Referencia 1.

\section{- Capacidad para identificar oportunidades.}

Entendemos la capacidad para identificar oportunidades como aptitud o cualidad que dispone a una persona para reconocer y aprovechar ocasiones o coyunturas.

El provecho que sacó el siguiente alumno de la experiencia práctica, por encima de los conocimientos teóricos adquiridos, nos permite ver que el alumnado medía su nivel de aprendizaje en base al saber hacer, otorgando un mayor valor al conocimiento práctico frente al teórico. Esta situación concuerda con la filosofía de las metodologías activas y experienciales como el APS.

"...decían... ya os daréis cuenta como con la practica será cuando... y es verdad llegó junio y yo llegué a casa y dije... ahora sí que he aprendido ahora sí que sabría manejarme en un aula o sabría qué hacer o ante alguna problemática sabría qué hacer."<Elementos internos||Entrevistas||C o1> - Referencia 3.

El beneficio extraído por este alumno al coincidir la experiencia de APS con su periodo de prácticas de final de grado, compartiendo e integrando ambas actividades, nos hace entender que el alumnado fue capaz de trasladar y aprovechar los aprendizajes adquiridos a otras áreas de actuación. Igualmente suscita la transferencia de las competencias desarrolladas a futuras situaciones laborales de similares características.

"... a nivel personal he tenido la suerte de poder hacer el APS a la vez que el prácticum y entonces lo que he aprendido de un sitio lo he ido trasladando a otro y he ido complementado un poco las dos cosas." $<$ Elementos internos\|Entrevistas $\| C$ 02> - Referencia 4. 
La consideración de que el APS es una gran oportunidad para aquellos que se forman como maestros y la matización de que debe explicarse con mayor detalle nos permite comprobar la capacidad crítica del alumnado, siendo capaz de plantear propuestas constructivas sobre esta metodología y valorándola globalmente como muy positiva para su etapa formativa.

"...yo creo que el Aprendizaje Servicio es una muy buena oportunidad para nosotros, es muy buena oportunidad porque lo he vivido, pero también creo que hay que explicarlo bien y decir... jesto es lo que hay!" <Elementos internos\|Entrevistas $\| C$ o3>- Referencia 2.

El alumnado creó una figura de control temporal para atender la necesidad de los niños de marcar adecuadamente los diferentes tiempos de la sesión. Con ello, no solo supieron responder a las necesidades propias del colectivo con el que colaboraban sino que además fueron capaces de hacerlo de una forma creativa, permitiéndoles identificar fácil y rápidamente la estructura temporal de la sesión.

"... apareció la figura del reloj, el reloj que marcaba los tiempos de lo que íbamos a hacer durante cada sesión (...). Incidimos mucho en el tema de que son niños que necesitan que las pautas estén muy claras y que sepan bien qué tienen que hacer en cada momento u otro por el tema de su déficit atencional, $y$ que tampoco sea todo, o sea, que estén muy marcados." <Elementos internos\|Entrevistas\|C o4> Referencia 4 .

La reflexión de este alumno indica que sacó beneficio de su participación mediante la adquisición de conocimientos teóricos a través de la experiencia práctica realizada. Esto nos ayuda a entender que el conocimiento teórico y el práctico se entrelazan y complementan en este tipo de actividades educativas, pudiendo fomentarse y complementarse de forma mutua, aportando así una concepción integral del aprendizaje alcanzado.

"...creo que es una buena opción escoger este itinerario porque a nivel personal te ayuda mucho en todos los sentidos, en cuanto a teoría sobre esta asignatura, que la aprendes tú por ti mismo, no hay nadie que te lo explique sino que tú con tus actuaciones en el centro aprendes de la teoría (...) creo que por muchos obstáculos que te puedas encontrar siempre tendrás como la solución porque esto te ayuda a replantearte todas las cuestiones." $<$ Elementos internos $\|$ Entrevistas $\| C$ 05>-Referencia 5.

Los alumnos universitarios aprovecharon algunas de las características propias de los niños para atenderlos y tratarlos mejor durante las clases, logrando manejar adecuadamente algunas de las dificultades propias de este tipo de niños e incluso sacando provecho de ellas para fomentar su autoestima y mejorar su nivel de compromiso en las tareas propuestas.

"...les va muy bien también que les hagas partícipes de lo que tú haces porque, por ejemplo, o sea, también aprovechar lo que ellos saben hacer. V---- que le gusta mucho ser el protagonista de todo pues yo que sé ponerlo a ayudar a recoger el material o a repartir el material. (...) entonces luego ya trabajan mejor también y juegan mejor." <Elementos internos\|Entrevistas\|C o6> - Referencia 12.

Este alumno agradeció la oportunidad de participar en el programa de APS al considerarlo muy provechoso tanto a nivel personal como profesional. Por ello, sugirió una mayor formación práctica en el Grado en Maestro/a, al mismo tiempo que reconocía el beneficio personal obtenido a través de la relación establecida con los niños de la entidad.

"...para mí ha sido perfecto. Un diez o veinte, porque con los niños es que estamos en segundo y no nos dejan hacer nada y esto y encima con ellos es que ibfff! Una unión con ellos espectacular y verles que gracias a ti, sacarles una sonrisa cuando... vienen y están tristes y empiezas con ellos y cada sonrisa de ellos te alegra el día ya o la semana." <Elementos internos||Entrevistas\|C 07> - Referencia 8. 
La explicación sobre cómo sopesó el siguiente alumno las ventajas e inconvenientes que suponía el APS, antes de aceptar la propuesta de participación, nos señala que uno de los argumentos más favorables para intervenir en estas actividades es su realismo, en este caso a través de la aplicación práctica directamente con niños. El reconocimiento de este beneficio por parte del alumnado es de gran importancia ya que es una de las aportaciones más valiosas en favor del uso de esta metodología frente a las estrategias didácticas tradicionales, facilitando un mayor provecho de la participación en este tipo de experiencias educativas.

"...cuando J---- nos comentó que podíamos hacer la asignatura de forma más práctica en un primer momento no queríamos porque sabíamos que iba a ser más faena. Pero por otro lado sí que pensábamos que sería mejor (...) porque ya no es preparar clases para los de nuestra edad sino para los niños que es lo que haremos, se supone, que en un futuro. Entonces nos gustó y además con el aliciente que eran niños que tienen problemas que es ayudar a centros (...). Entonces no dudamos en ningún momento en aceptarlo." <Elementos internos $\|$ Entrevistas $\| C$ o8> - Referencia 1.

El beneficio obtenido por el alumno, en las sesiones de preparación previas a la prestación del servicio, nos permite entender cómo le ayudaron a conocer en mayor profundidad la novedosa metodología empleada, además de aportarle herramientas de actuación para la posterior aplicación práctica.

"... antes de empezar a trabajar con los niños y todo eso realizamos una serie de sesiones más teóricas

(...) estas sesiones me sirvieron para entender mejor qué era eso del Aprendizaje Servicio (...) también aprendí pautas sobre el trabajo cooperativo, que también me han servido de mucho porque ha sido la manera que hemos tenido que trabajar." <Elementos internos $\mid$ Entrevistas $\| C$ og> - Referencia 2.

El aprendizaje de este alumno, respecto a la elaboración de tareas propias de actividad física, nos ayuda comprobar cómo se desarrollaron los contenidos de la disciplina en la que se enmarcaba el proyecto educativo. Igualmente destacó el valor de los aprendizajes obtenidos en comparación con sus experiencias prácticas anteriores, resaltando así el beneficio de la actividad realizada.

"Yo en el módulo hacia juegos más tranquilos, en un aula cerrada que tampoco podía haber mucho movimiento, entonces solo trabajabas el gateo o el saltar o andar, aquí hemos podido trabajar correr, lanzamientos, todo, no sé, hemos trabajado muchas más cosas que lo que yo trabajaba en el módulo." $<$ Elementos internos\|Entrevistas $\| C$ 10>-Referencia 8.

Ponerse en contacto con los docentes del centro colaborador, para organizar el horario de la actividad, permitió al alumno profundizar en el conocimiento de la estructura organizativa de la entidad, aprovechando la situación para reflexionar sobre la dificultad de elaborar un programa educativo real frente a la utopía de la programación teórica individual.

"...gracias a eso hablé con las tutoras de todo infantil (...) para organizar horarios y tal (...) el simple contacto de preguntar algo a una tutora de un curso te hace reflexionar en algo (...) aquí cuando programas es... todo el horario para ti, programa. Y luego te das cuenta de que en la realidad hay cosas que te atan, que tienes ciertos límites que a lo mejor a ti no se te ocurren cuando programas a nivel teórico solo." <Elementos internos $\|$ Entrevistas $\| C$ 11> - Referencia 9.

El alumnado desarrolló aspectos relacionados con el reciclaje gracias a la utilización de material alternativo en la aplicación de los juegos motores. Esta situación pone de manifiesto 
la oportunidad para trabajar temas transversales durante la aplicación del servicio, ya que nos ofrece la posibilidad de aglutinar diversos objetivos y temáticas en una misma tarea.

"...ahora con lo de los juegos con material alternativo, aparte de jugar y hacer juegos motrices y tal, ellos... por ejemplo se fabrican su propio material, por ejemplo en el béisbol se fabrican su propio bate o se fabrican... y pues no sé, trabajan también el material reciclado, trabajan muchas más cosas no sólo te centras en juegos motrices." <Elementos internos $\mid$ Entrevistas $\| C$ 12> - Referencia 4.

\section{- Iniciativa.}

Concebimos la iniciativa como la capacidad para dar principio a algo por uno mismo, adelantándose a los demás.

El deseo de los alumnos de empezar antes de lo estipulado, para tener una primera toma de contacto con los niños del centro colaborador, no solo se debía a que querían conocer previamente las características del alumnado con el que iban a trabajar sino que además también aspiraban a realizar diversas actividades en las que pudieran practicar como docentes.

"Nosotras queríamos ir una semana antes a (...) por lo menos pues a hacer nosotras actividades."

$<$ Elementos internos\|Entrevistas $\| C$ o1>-Referencia 2.

La iniciativa del siguiente alumno quedó patente al proponer una serie de actividades a realizar durante las sesiones de juegos motores. Esta acción nos lleva a comprender su predisposición para aportar ideas y sugerencias al grupo de trabajo, una cualidad indispensable a la hora desarrollar tareas de forma cooperativa.

"...propuse que hiciéramos aquí una sesión de animales y traje unas actividades y... canciones, podemos cantar esta, hicimos estas caretas, pues qué os parece si las traemos aquí." <Elementos internos||Entrevistas $\|$ C 02> - Referencia 2.

La iniciativa del alumnado de hacer una distribución de roles sirvió para aumentar el control de las distintas tareas a realizar durante el transcurso de la sesión práctica, así como para repartirse las responsabilidades existentes. Gracias a esto redujeron la aparición de malentendidos y la duplicidad de tareas en la aplicación de las actividades, dos problemas muy habituales en las actuaciones de carácter grupal.

"...se nos ocurrió es hacer roles, igual que hacemos los roles para las sesiones escritas hicimos roles en los juegos. Cada uno tenía un rol que cumplir en cada momento que durara la sesión." <Elementos internos $\|$ Entrevistas $\|$ C 03> - Referencia 5.

El deseo de participar en el programa educativo de APS sin influencias externas nos ayuda a entender que el alumnado universitario fue capaz de tomar sus propias decisiones, valorando adecuadamente sus intereses formativos por encima de las preferencias sociales o la cantidad de trabajo que suponía esta propuesta.

"...no fue una decisión condicionada por nadie, ni mucho menos, de decir... ipues vamos a cogernos esto y vamos juntos! Yo digo... jesto es lo que me interesa, lo quiero hacer así y ahí voy!" <Elementos internos $\|$ Entrevistas $\| C$ o4> - Referencia 2.

Las preguntas que el alumnado hizo a sus compañeros sobre las posibles eventualidades que pudieran aparecer durante la sesión práctica, nos ayudan a ver cómo se adelantaron a la 
manifestación de problemáticas mediante un ejercicio de análisis previo muy habitual en el ámbito de la EF.

"...cuando las chicas de los grupos de clase venían y nos presentaban la sesión, siempre nosotras intentábamos hacerles preguntas tipo... y si se da la situación de que un niño, por ejemplo, no te responde a tus órdenes o no hace lo que tú le dices ¿cómo harías para resolver eso? (...) así también, te daba un poco más de chancha a la hora de cuando ibas a hacer la sesión (...) como ya nos habíamos hecho antes estas preguntas poderlo como solucionar más rápidamente." <Elementos internos\|Entrevistas $\| C_{05}>$ - Referencia 3.

La iniciativa de un alumno, a la hora de negociar directamente con los niños la resolución de los problemas surgidos durante la sesión, nos demuestra que no era un mero agente pasivo en el proceso de toma de decisiones sino que opinó y participó en la selección y ejecución de tareas.

"...una cosa que he visto es que sí que les va muy bien que les dejes un ratito pero cuando vas con ellos... que negociar con ellos les va bien (...). Los niños es que son bastante fieles a lo que dicen. Entonces por ejemplo, yo qué sé, que quería almorzar... ivale, pues te terminas el bocadillo pero luego vienes a jugar! ¿vale? y como ya te lo ha prometido lo hace." <Elementos internos||Entrevistas\|C o6> Referencia 4.

Recomendar a unos compañeros universitarios que hablaran con el responsable del programa educativo, si les interesaba participar en el APS, demuestra la satisfacción global del alumnado con la experiencia realizada y nos ayuda a entender que consideraban que la actividad era de gran interés en el entorno educativo en el que se movían.

"...la semana pasada o la otra, bueno que vinieron los niños del Penyagolosa y vinieron chicas de primero y dijeron... iostras pues ha estado bien hoy! Y les dije... pues hablad con J---- y (...) aunque no lo tengáis o lo que sea os aseguro que él estará contento de que vengáis (...). O sea, yo las animo porque la verdad es que me ha encantado." <Elementos internos $\|$ Entrevistas $\|$ C 07> - Referencia 9.

El deseo de los alumnos de ir al centro colaborador el mayor número de días posible nos permite ver su interés y motivación de asistir a la entidad por encima de las exigencias presenciales del servicio. La participación en otras actividades similares muestra nuevamente su carácter voluntarioso e interés formativo.

"...todas queríamos ir todos los días y al final dijimos... ipues vamos todas! (...) Yo por ejemplo es por la... porque me encantan los niños y yo me lo paso muy bien, igual que cuando voy al cole de mi madre todos los viernes y en verano, voy en... los miércoles ahora. Y no me resulta ningún esfuerzo ir porque me gusta y me lo paso bien." <Elementos internos\|Entrevistas ||C o8>-Referencia 10.

Los alumnos se pusieron en contacto con el responsable de la entidad colaboradora nada más concretar el centro asociado, mostrando su interés por conocer el entorno en el que debían realizar el servicio y por obtener información de primera mano sobre las particularidades del centro, sus actividades y el tipo de niños a los que atenderían.

"...lo primero que hicimos fue llamar al responsable de la entidad, que era $T$----, y quedamos para hablar con él en sus oficinas. Y allí pues nos contó pues cómo... nos contó cómo se creó la fundación, qué era lo que hacían, qué era eso de la parálisis cerebral con los niños y todo eso." <Elementos internos $\|$ Entrevistas $\|$ C og > - Referencia 3. 
Asumir la dirección de una sesión para no perjudicar a los niños de la entidad nos ayuda a entender cómo este alumno pudo desarrollar su capacidad de improvisación y la resolución de problemas durante las actividades, dos cualidades de gran utilidad en la práctica docente.

"...ha habido gente que no le ha gustado (...) este tipo de niños. Entonces iban alli, preparaban una sesión de cualquier juego, si salía bien, bien, si no (...). En la última práctica me tocó a mí inventarme juegos en el momento ya que no iban preparadas. Entonces ahí también te da para aprender a en ese momento a solucionar los problemas y a rectificarlos." <Elementos internos\|Entrevistas $\| C$ 10> Referencia 3.

La aportación de un nuevo material por parte del alumnado, para realizar juegos con los niños, nos transmite su interés por aumentar la cantidad de recursos disponibles al aplicar las sesiones, demostrando así su afán por mejorar las condiciones del centro a través del servicio prestado.

"Introducimos globos que no tenían y quizá tampoco habían visto mucho por el cole y... me refiero que también aportamos cosas que a lo mejor allí no podían, no lo tenían como recurso o no lo utilizaban." <Elementos internos\|Entrevistas $\|$ C 11> - Referencia 2.

La rapidez con la que este alumno tomó la decisión de afiliarse, pese a la recomendación del profesorado de que lo meditara con calma, nos ayuda a ver su nivel de determinación e interés por asegurar su intervención en la propuesta de APS desde un primer momento.

"...cuando entramos en clase y J---- nos dijo que había esta posibilidad. Pues yo se lo dije a L----, y le dije... iyo no me lo pienso! Y J----, pensarlo bien. Y yo le dije enseguida, ino, yo me quiero apuntar!" $<$ Elementos internos $\|$ Entrevistas $\| C$ 12>-Referencia 2.

\section{- Capacidad para generar ideas.}

La capacidad para generar ideas es la aptitud o cualidad que dispone a una persona para producir conceptos, opiniones o juicios de valor propios, con ingenio, sobre algo o alguien.

El cambio metodológico que implicaba esta experiencia con respecto a las estrategias educativas tradicionales nos lleva a reflexionar sobre la innovación didáctica que supone este tipo de vivencias, así como sobre la importancia de la experiencia práctica en la educación por competencias, algo que adquiere mayor valor en el ámbito de la EF debido a su fuerte carácter práctico.

"...también pienso claro... yo estaba acostumbrada a tener que estudiar los apuntes, examen y ihala! $O$ si no, me lo explica un profesor, haces el examen y ihala! Y se ha acabado. Pero ya está bien de tanta letra, o sea ya era hora de que nos dieran la opción de coger, ir y hacer la práctica, es que es como, en realidad como ves... cómo funcionan las cosas. " <Elementos internos\|Entrevistas $\| C$ 01> - Referencia 9.

Comparar el centro colaborador en el que trabajó con la entidad gubernamental responsable de la educación pública comunitaria hizo reflexionar a un alumno sobre la repercusión de la situación económica actual en el sistema educativo. Por ello, planteó la posibilidad de aprovechar los recursos humanos disponibles para aumentar la calidad educativa ofrecida y mejorar la formación del profesorado.

"La entidad yo desde, o sea, cuando me puse un día a pensar de todos esos problemas que estábamos teniendo con ella, yo me lo imaginé un poco como Conselleria, de... vamos a hacer manifestaciones de no a los recortes y que mal nos tratan, y no tenemos recursos, nos falta personal, no sé qué. Pero luego 
cuando tienen a alguien con ganas de hacer algo no lo aprovechan, prefieren quejarse de cara al público (...) que aprovechar un poco lo que le pueden ofrecer gratis." <Elementos internos\|Entrevistas $\| C$ o2> - Referencia 4.

La demanda de una mayor documentación previa por parte del alumnado nos permite entender que este colectivo es un miembro activo del proceso de enseñanza-aprendizaje, capaz de reflexionar y cuestionar las estrategias utilizadas y de aportar su granito de arena para mejorar el sistema educativo, el cual no debe ser asumido como dogmático o invariable.

"...cuando empezamos a hacer el APS yo creo que tendríamos que tener un poquito más de información ¿vale? Información en cuanto a que no sea todo... que no todo sea aprendido por nosotros, que no..." $<$ Elementos internos $\|$ Entrevistas $\|$ C o3> - Referencia 11.

Al hablar sobre el sistema de evaluación utilizado en el programa de APS el alumno nos hizo ver que el cambio metodológico debe afectar a los diferentes ámbitos de la educación. Por ello, si pretendemos mejorar la calidad educativa mediante la innovación didáctica debemos ser capaces de generar estrategias de valoración adecuadas a estos nuevos retos docentes.

"El sistema de aprendizaje es muy novedoso y es muy recomendable y es muy moderno y todo lo que... vamos, todo lo que se puede decir al respecto ¿no? a nivel positivo, pero yo creo que la evaluación de este aprendizaje me parece lo más arcaico posible (...) viendo cómo se han preparado las cosas, cómo se ejecutan, cómo se gestionan, cómo se está ahí, cómo se percibe perfectamente que las cosas han tenido una preparación, un interés, un cuidado... qué necesidad hay de hacer mil fichas, de hacer examen, de hacer... no sé, las mil cosas que hay que hacer para que al fin y al cabo te den una calificación." <Elementos internos\|Entrevistas $\| C$ 04> - Referencia 30/31.

La mayor adquisición de aprendizajes prácticos en detrimento de los teóricos condujo al alumnado a meditar sobre la conexión entre estos dos tipos de aprendizajes a través de la metodología del APS. Por ello, debemos incidir en la necesidad de relacionar ambos aspectos para proporcionar al alumnado un conocimiento más consolidado, así como para hacerle consciente de su propia progresión gracias a esta propuesta educativa.

"... a nivel teórico no hemos aprendido una teoría abundante pero pienso que se ve muy compensado con la práctica (...). Si hablamos del juego espontáneo, pues sí que hemos hecho en algunos grupos juego espontáneo. Aunque no sepas exactamente la definición, llevándolo a la práctica sí que sabes de qué va, sus... como si dijéramos las características." <Elementos internos\|Entrevistas\|C 05> Referencia 4 .

La duda planteada por el siguiente alumno, sobre la importancia relativa de la inclusión y la dificultad práctica de aplicar este concepto en la realidad, partió de la base de que todos los individuos somos diferentes, por lo que recibir el mismo trato puede ser un punto de partida erróneo. Esto nos lleva a pensar que una alternativa viable para implementar esta cuestión podría ser a través del trato equivalente a todos los implicados, después de valorar las diferencias individuales de cada uno de ellos.

"Replantearse también las cosas que se escuchan porque inclusión ¿qué significa? (...) ¿qué todos juegan a lo mismo y todos igual? Pero no son todos iguales, entonces ¿qué haces? (...) porque había actividades que nosotros habían niños que teníamos que estar aparte con él, pero porque si no no se puede hacer. $Y$ entonces que vas a hacer solo juegos para ese que no sabe hacer nada y entonces los demás tienen que hacer cosas que están por debajo..." <Elementos internos\|Entrevistas\|C o6> Referencia 20. 
La mejora adquirida por trabajar con niños que presentaban unas necesidades educativas más exigentes de lo habitual pone de manifiesto la vinculación entre la experiencia aportada y el futuro desempeño laboral del alumnado, incidiendo en el valor de la actividad realizada tanto por su realismo como por el nivel de dificultad afrontado.

"... a lo mejor en nuestra clase nos podemos encontrar uno, y si llega, con parálisis. Entonces el estar pendiente de todos ahora, de ajustar tanto la ayuda (...) pero bueno que ya hemos aprendido eso y creo que luego cuando tengamos veinte niños y sean más, digamos más iguales, pero bueno, pues que a lo mejor ya estaremos un poco preparadas para esto. Porque hemos sabido aquí reaccionar y adaptarnos a ellos, y adaptarlo todo a ellos." <Elementos internos ||Entrevistas $\mid$ C $07>$ - Referencia 7.

La reflexión de un alumno sobre la disparidad existente entre dos entornos educativos similares valoraba que la falta de estimulación por parte de los familiares de los niños era la causante de las notables diferencias. Esto nos lleva a pensar que el alumnado universitario fue capaz de analizar el contexto de la experiencia del APS más allá de los límites del mismo, considerando incluso el entorno social y familiar de los niños con los que trabajó.

"...los niños de mi madre también son de etnia gitana, rumanos y hay un montón de... pero todos extranjeros y aquí también y no sé dónde está la diferencia (...) de no hablar los de aquí y aquellos hablan un montón, o aquellos están muy desarrollados y saltan y de todo lo que quieras y estos no. $Y$ creo que es por la falta que tienen de estímulo." <Elementos internos $\|$ Entrevistas $\mid C$ o8>-Referencia 4.

La valoración positiva de la experiencia realizada, pese al gran esfuerzo que supuso, nos ayuda a comprender que los alumnos fueron capaces de analizar los efectos de la metodología implementada de forma justa y no centrándose únicamente en el trabajo que conllevaba. Igualmente destacaron la labor del equipo docente, animándoles a continuar en la misma línea de trabajo.

"...la verdad es que J---- y C---- pues han hecho muy buen trabajo, que valoro mucho cómo se han portado con nosotras porque han estado ayudándonos en todo momento, y ya no como maestros sino como compañeros, mostrándonos su opinión y aconsejándonos, y la verdad es que los animo a que continúen haciendo actividades de este tipo. Porque aunque suponga más esfuerzo y sea mucha más trabajo (...) en mi opinión recompensa mucho todo lo que conlleva hacer este tipo de actividades." $<$ Elementos internos\|Entrevistas $\| C$ og $>$ - Referencia 13.

El agradecimiento mostrado por los niños de la entidad, pese a las limitaciones o problemáticas a las que se enfrentaban, nos permite ver cómo el alumnado llegó a replantearse el valor personal de los conflictos, llegando a relativizar la importancia de los problemas que se afrontan en la vida diaria.

"...con un simple detalle son más felices que a lo mejor tú que con un problema ya te haces un agujero te metes y de ahí no sales. Entonces a mi esta experiencia me ha dado, me ha ayudado a darme cuenta que aun teniendo problemas ellos siguen adelante y que siempre están felices, se divierte y que siempre te agradecen un montón lo que haces por ellos." <Elementos internos\|Entrevistas $\mid C 10>-$ Referencia 7.

La posibilidad de invertir el proceso de planificación docente, seleccionando en primer lugar las actividades a realizar y comprobando a posteriori si se alcanzaban los objetivos deseados, pone de manifiesto la capacidad crítica de este alumno respecto a uno de los procedimientos más arraigados en el proceso de enseñanza-aprendizaje. Igualmente destacó la importancia de que este supuesto no desvirtúe los beneficios educativos de los niños. 
"...sí que es verdad que planificas respecto a unos objetivos pero muchas veces las ideas te salen... te salen ideas y luego buscas, miras a ver si eso te corresponde con el objetivo ¿sabes? (...) Y es como... no, a mí me salen cosas y luego miro si eso me va bien. Y entonces eso tengo un poco de... ¿cómo lo hago? no sé ¿está bien de las dos maneras? (...) mientras el ejercicio final cumpla con lo acordado también lo considero viable." <Elementos internos $\|$ Entrevistas $\| C 11>$ - Referencia 17.

La opinión de un alumno respecto a por qué las actividades programadas no salían como esperaban, esgrimiendo la posibilidad de que los niños tuvieran un retraso en su aprendizaje, nos ayuda a apreciar que no se limitaron simplemente a realizar las actividades elaboradas sino que fueron capaces de reflexionar sobre el resultado de las mismas, buscando motivos que los justificaran y valorando opciones como la falta de estimulación o la existencia de problemas con el lenguaje para entender el fracaso de sus propuestas.

"... alguna actividad que hemos planteado que nosotros pensábamos que en cuatro años saldría o a lo mejor que sabemos que en cuatro años sale porque ya la hemos hecho anteriormente pues con ellos no salía, y eso, no sé. Igual que los de, con, que los de seis. Con los de seis muchas veces hemos hecho actividades de infantil y no salían. Yo pienso que es eso que tienen... que están un poco retrasados para la edad que tienen." <Elementos internos $\|$ Entrevistas $\| C$ 12> - Referencia 8.

\section{- Capacidad de cambio.}

La capacidad de cambio hace referencia a la aptitud o cualidad que dispone a una persona a modificar y adaptar su posición o comportamiento en función de las necesidades existentes.

Modificar el planteamiento previo de realizar diversas sesiones introductorias con los niños de la entidad, debido a la necesidad de iniciar las actividades con los compañeros universitarios lo antes posible, muestra la habilidad del siguiente alumno para adaptarse a las circunstancias y su predisposición de anteponer el beneficio común al suyo propio.

"...luego también claro tenían que ir cuatro veces mínimo cada grupo y teníamos un límite de fechas y veíamos que no nos coincidía. $O$ sea, no daba tiempo a que nosotras fuéramos durante una semana $o$ dos a hacer nosotras actividades y que luego ya engancharan los grupos. Entonces nos tocó ir la primera semana allí a Penyeta solo con los tres grupos que les tocaba esos días. O sea, no pudimos ver a más niños." <Elementos internos $\|$ Entrevistas $\| C$ o1> - Referencia 2.

El alumno aceptó un cambio espontáneo de actividad, por parte de dos niños, al considerar que la nueva tarea les aportaría un beneficio educativo mayor que continuar con el ejercicio grupal. Esta situación nos lleva a reflexionar sobre aspectos tan importantes como la inclusión y la atención a las necesidades educativas de los niños, cuestiones que cualquier educador debe tener en cuenta a la hora de ejercer su labor.

"...eso no estaba planeado porque no era parte de la sesión porque los otros estaban haciendo su sesión. Pero claro en vez de decirles de... ¡la sesión es la que están haciendo ahí, vamos a hacer todos esta sesión! Pues aproveché un poco porque eran los dos difíciles de tratar digamos y digo (...) aunque no sea lo que hagan los demás que ellos hagan algo porque están haciendo más aquí que cuando intentamos que trabajen con los demás." <Elementos internos\|Entrevistas $\| C$ O2> - Referencia 4.

Tras comprobar que el número de niños asistentes era reducido, el alumnado optó por modificar la estructura habitual y realizar una actividad conjunta con los niños de otras entidades colaboradoras. Esta acción nos ayuda a ver cómo fomentaron el desarrollo 
socioemocional de los niños a través de la socialización y la integración de distintos colectivos, aspecto de gran trascendencia en el panorama educativo.

"...hubo un día que teníamos preparado hacer algo así, y como estaban... no eran muchos niños tampoco y estaban los de Borja Sánchez y Síndrome de Down. Y propusimos de juntarnos todos (...) Entonces pusimos música y sí que estuvieron bailando los niños de APADAHCAS con los de Borja Sánchez y los de Síndrome de Down todos juntos." <Elementos internos $\|$ Entrevistas $\mid C$ o3> Referencia 17.

El cambio que un alumno introdujo en un juego, para asegurar el correcto desarrollo del mismo, demuestra una habilidad esencial para el devenir de las sesiones de EF, ya que estas demandan gran cantidad de recursos por parte del docente para ajustar, continua y correctamente, las actividades prácticas a las necesidades educativas de los niños en función de los objetivos propuestos.

"...tenían que pasarse los balones por arriba, claro nos dimos cuenta de que todo el rato los cogían los niños más altos. Pero es que claro es lógico. Entonces pues ahí al final cambiamos un poco una norma para tratar de adaptar de esa anomalía ¿no? que estaba dándose en el juego y entonces pues esos niños más altos pues entendieron que tenían que dejar participar un poco más a los otros más pequeños." <Elementos internos $\|$ Entrevistas $\| C$ o4> - Referencia 6.

El siguiente alumno fue capaz de modificar su concepción previa de inseguridad respecto a su propio desempeño, por desconocer las características de la actividad a realizar, tras conocer a los niños del centro, sus miembros y profesores. Además, no solo superó esa incertidumbre inicial sino que también ganó confianza y se planteó las futuras potencialidades de la experiencia vivida en otros entornos educativos.

"...cambió mi visión a lo largo de trabajar con todos los grupos del centro. Que al principio no me... no sabía cómo iba a reaccionar, pero que estoy muy a gusto, que ahora si tuviera que ir todos los días pues iría todos los días sin ningún problema (...) pienso que cuando trabajas con niños con necesidades especiales siempre te ayuda mucho más a la hora de planear sesiones para otros niños." < Elementos internos $\|$ Entrevistas $\|$ C 05> - Referencia 8.

El cambio de preferencia inicial a la hora de seleccionar la asociación con la que realizar el APS, en favor de varios de sus compañeros, demostró la gran empatía de este alumno con sus iguales, siendo capaz de declinar sus propias preferencias a las necesidades personales de los demás.

"...yo quería Penyeta Roja por, o sea, por razones personales y tal. Pero bueno, da igual o sea al final tenían preferencia también los que vivían lejos, que se entiende. Entonces pues Síndrome de Down no me importaba tampoco."<Elementos internos\|Entrevistas $\| C$ o6> - Referencia 1.

Modificar la estructura temporal de la sesión, eliminando el periodo del almuerzo para retrasar el inicio de la práctica, facilitó el desarrollo de las actividades además de aumentar el número de participantes. Más adelante comprobamos que esta optimización del tiempo es una cualidad fundamental en el ámbito de la EF.

"...quitamos lo del almuerzo por eso, porque a ellos les cuesta mucho y perdíamos media hora almorzando. Entonces casi era mejor empezar media hora después, que total era lo mismo, y así no venían tan cansados. Porque también nos pasaba que algunos no venían porque era demasiado pronto, (...). Entonces no sé, pues lo quitamos y las actividades ahora son más rápidas y como ya están cogidos al hilo es más dinámico." <Elementos internos $\|$ Entrevistas $\| C$ 07> - Referencia 8. 
Pese a que inicialmente temían salir del entorno habitual, por miedo a perder el control de la clase, el alumnado fue ganando la confianza suficiente como para aprovechar el patio exterior y ofrecer a los niños nuevas áreas de actuación. La optimización del espacio es otro aspecto de vital relevancia en la práctica de la EF.

"Luego al principio no queríamos sacarlos del pabellón porque $V$---- no los había sacado, y nos daba miedo salir fuera y que se nos desmadraran o que nos pasara algo. Pero cuando empezó a hacer más calorcillo después de Navidad y eso, que no llovía ni nada, empezamos a salir fuera y hacer todos los juegos fuera. " <Elementos internos $\|$ Entrevistas $\| C$ o8> - Referencia 8.

La predisposición de cambio del alumnado, respecto al trato directo con los diferentes grupos de compañeros universitarios, nos ayuda a entender que la distribución de la carga de trabajo entre los implicados en una tarea es una cuestión muy delicada si hay responsabilidades compartidas. Por ello, es fundamental desarrollar las habilidades sociales de negociación y diálogo apropiadas para llegar a acuerdos satisfactorios y equilibrados en cualquier situación.

"...como con el primer grupo no les pareció muy bien cómo habíamos repartido el trabajo pues decidimos cambiarlo, y pues preguntarles si estaban de acuerdo en hacer dos sesiones cada grupo y el que hiciera las sesiones se las pasaría al otro y las revisaría y las mejoraría y después seguían repartiéndose las fichas y en conjunto hacer la reflexión. Y les pareció bien." <Elementos internos $\|$ Entrevistas $\|$ Cog $>$ - Referencia 5.

Este alumno comentó cómo se redujo la dificultad de las actividades para que los niños pudieran realizarlas. La situación nos ayuda a comprender que la capacidad para ajustar correctamente el nivel de dificultad de las tareas es esencial en cualquier labor educativa, ya que si es muy bajo apenas producirá estímulos de mejora y si es demasiado alto se correrá el riesgo de frustrar al alumnado por tardar demasiado tiempo en alcanzarlo.

"...si por ejemplo era saltar a los aros y ellos no podían saltar a la pata coja (...) pues tú le ayudabas con una mano o cambiabas que saltaran con los dos pies. En ese momento ibas viendo cómo ellos se iban moviendo, si podían levantar una pierna, si no. Entonces si no podían moverse hacías el mismo juego pero en vez de pasar el aro saltando pues que lo pasaran solo andando o si tenían que saltar una cuerda que la pasaran con un pie primero y luego con otro." <Elementos internos $\|$ Entrevistas $\| C$ 10 $>$ Referencia 10.

Siguiendo las indicaciones del profesorado los alumnos pasaron de realizar ejercicios analíticos a modo de circuitos a otro tipo de tareas más dinámicas en forma de juegos. Dicha adaptación resalta la importancia de seleccionar correctamente las tareas en función de los niños participantes. Obviar esta cuestión aumentaría notablemente el riesgo de fracasar en nuestra labor como docentes.

"... al final lo hemos dejado más de lado quizá por los comentarios también de... jes que un circuito! Y fue como... ijolín! Nosotras lo hicimos algunas veces. También nos planteamos, nos planteó J---- creo que lo utilizáramos a modo de como refuerzo ¿no? que no fuera todos los miércoles." <Elementos internos $\|$ Entrevistas $\| C$ 11> - Referencia 1.

El profundo cambio personal experimentado por este alumno, en cuanto a su visión del colectivo con el que realizó el servicio, nos hace valorar que toda cuestión relativa a aspectos de índole cultural, racial, religiosa, etc., debe tratarse con extremada delicadeza, a fin de evitar posibles malentendidos. Por ello, consideramos que es de vital importancia que los 
docentes sean capaces de respetar las diferentes costumbres y creencias existentes en el entorno social en el que trabajan.

"...yo no soy racista pero sí que es verdad que yo antes de llegar allí, yo decía... es que árabes, (...) a mí me frenaban un poco. (...) al principio íbamos todas con coleta y con el pelo recogido. Es que a ver si nos van a pegar piojos... jtodas eh! Y... no sé, a mí me ha hecho darme cuenta de que era una tontería pero muy grande y... y no sé, y los niños... es que cuando llegas allí no te das cuenta de que son árabes no... no, son niños normales y corrientes." <Elementos internos\|Entrevistas $\| C$ 12>- Referencia 13.

\section{- Capacidad para aprender y evolucionar.}

La capacidad para aprender y evolucionar indica la aptitud o cualidad que dispone a una persona para adquirir y asimilar el conocimiento de algo, por medio del estudio o la experiencia, produciendo un progreso en su desarrollo personal o profesional.

La experiencia de APS ayudó a un alumno a aprender cómo gestionar actividades en un espacio distinto al aula. Esta situación resalta que la EF se aplica en un entorno particular diferente del contexto escolar habitual, lo cual implica unas estrategias de actuación bien diferenciadas como el tipo de tareas a realizar o la forma de coordinar a los niños.

"...sabía dentro del aula cómo manejarlos, pero en el tema... digamos más libre, en un espacio más libre que no es una clase (...) en el juego claro digamos que ellos están como más desinhibidos entonces... he aprendido a llevarlos a saber qué hacer y qué no hacer o lo que funciona o lo que no funciona... a coordinarlos." <Elementos internos\|Entrevistas $\| C$ o1 > - Referencia 4.

Este alumno destacó su evolución respecto a la capacidad de adaptarse a los imprevistos sucedidos durante la sesión, ya que el aula no es un espacio estanco en el que se puedan controlar todas las variables presentes. Por ello, es de vital importancia preparar al profesorado para afrontar y resolver las distintas eventualidades que se puedan encontrar en el transcurso de sus clases.

"...ya no me pongo tan nerviosa de esto no ha salido como yo quería y he perdido un poco la rigidez esa y de... isi esto no lo podemos hacer no lo hacemos y lo guardamos para la semana que viene! $Y$ he aprendido un poco a adaptarme sobre la marcha." <Elementos internos\|Entrevistas\|C 02> Referencia 13.

El aprendizaje adquirido por el alumno, respecto al trato directo con los niños, destaca la necesidad de adaptarse a sus particularidades individuales para mejorar su desempeño docente. La situación nos lleva a reflexionar sobre aspectos como la inclusión y la atención a las necesidades educativas de los niños, anteponiendo estas cuestiones sociales frente a algunos aspectos académicos.

"... al conocerlos tú también a ellos sabes por dónde tirar ya... ¿sabes? ya es diferente, ya dices... ibueno pues a este niño cuando está enfadado pues mejor no agobiarlo mucho! No, dejamos dos minutos, que por estar dos minutos sentado no pasa nada, y luego te acercas. $Y$ dices... ;mira vamos a jugar a otro juego que este no es de bailar! Por ejemplo, o... ieste juego es súper divertido y te va a gustar un montón! Y a lo mejor ya por ahí lo..."<Elementos internos $\|$ Entrevistas $\| C$ o3>-Referencia 36.

Pese a la falta de integración en el equipo docente, la evolución de este alumno, respecto a su capacidad de trabajar en grupo, nos ayuda a ver la importancia de esta cualidad en la labor del profesorado. Por ello, debe desempeñarse de forma conjunta con el resto de miembros 
del centro, así como con otros agentes implicados como las familias, la educación no formal, la sociedad, etc.

"... a mí en esta situación en concreto, con mi equipo de trabajo me ha costado muchísimo, muchísimo, muchísimo integrarme y trabajar y... pero también es algo que he aprendido, es decir, no todos los equipos en los que caes para trabajar tienen que... tienes que encajar (...). En este caso me ha tocado caer en un equipo en el que no me he sentido integrado y aun así creo que he salvado la situación bastante bien." <Elementos internos $\|$ Entrevistas $\| C$ o4> - Referencias 17/18.

El desarrollo de un alumno, en cuanto a su habilidad para evolucionar a partir de lo planificado con anterioridad, muestra que este aprendizaje es básico para cualquier docente ya que, por más conocimiento que se tenga de todos los factores implicados durante las sesiones prácticas, aparecen muchas situaciones e imprevistos que escapan a la planificación previa.

"...nos dimos cuenta de que todos los niños necesitaban una ayuda de una de nosotras. Entonces tú no podías llegar allí con unas cosas planificadas y tú hacer solo el papel de monitor, sino que tenías que ayudar a todos y cada uno de los niños porque todos necesitaban de tu ayuda." <Elementos internos $\|$ Entrevistas $\| C_{05}>$ - Referencia 4.

El aprendizaje del siguiente alumno en cuanto al trato directo con los niños, concretamente respecto a la forma de dirigirse a ellos, nos indica que, pese a mantener cierta libertad de elección o ejecución en las tareas propuestas, los niños deben recibir indicaciones claras y concisas, por parte del profesorado, que no den lugar a ambigüedades o confusiones.

"...otra cosa que aprendí sobre ellos también era que yo no tengo que preguntarles nada, o sea, porque yo soy muy de... ¿quieres venir a jugar? ¿vienes a no sé qué? o ¿te apetece...? (...). Y entonces pues claro que no venían (...). Pero si en vez de preguntárselo se lo afirmas, dices... ino, ven a jugar a no sé qué! Entonces vienen." <Elementos internos $\|$ Entrevistas $\| C$ 06> - Referencia 12.

La evolución experimentada en cuanto al propio desempeño a lo largo de las sesiones, provocada en gran medida por el mayor conocimiento de las características de los niños, incide notablemente tanto en el desarrollo de las clases de forma individual como a nivel global sobre todo el programa educativo, mostrando así el valor de este aprendizaje.

"Al principio pues sí que fue un poco caos porque preparábamos las sesiones y no salía nada, y no sé, pero luego ya cuando... a medida que fueron pasando los sábados y eso (...). Sabemos ya los límites de cada uno, entonces sabemos hasta dónde estirar a uno y hasta dónde quedarnos con otros. Ya sabemos adaptar las sesiones más para ellos, ajustar la ayuda en unos más que en otros y no sé, la verdad que ahora ya mejor respecto a las sesiones y eso." <Elementos internos ||Entrevistas\|C o7> Referencia 1.

La mejora del alumno, respecto a ponerse frente a los niños y dirigir las actividades a realizar en la sesión educativa, nos ayuda a comprender la importancia de perder la vergüenza o el miedo escénico a la hora de ejercer la función docente ya que, en numerosas ocasiones, se debe asumir ser el centro de atención de todas las miradas.

"En primer momento sí que era... ino, no, tú, tú, sal tú! Y las otras se escondían o no... nos daba un poco de reparo el salir y estar tú sola hablando con los niños. Claro, encima ahora ya nos da igual porque encima los conocemos y ya... no sé, les has pillado confianza y si tienes que gritarles les gritas, si tienes que reñirles les riñes, si les tienes que dar un abrazos los abrazas. "<Elementos internos $\|$ Entrevistas $\| C$ o8> - Referencia 5 . 
La experiencia del siguiente alumno le animó a continuar con sus estudios universitarios, dirigiéndolos hacia la atención de niños con necesidades educativas especiales. Esta situación nos permite descubrir la relación de este tipo de propuestas con respecto al futuro desempeño laboral del alumnado participante, proporcionándoles una vivencia personal de gran valor.

"... destacaría mucho mi aprendizaje a nivel personal (...) ha sido una experiencia fantástica y que esta experiencia pues también me ha dado muchas fuerzas para continuar estudiando esta carrera y me he dado cuenta que es realmente lo que quiero hacer y pues posiblemente sí que haga algún curso o algún máster sobre necesidades educativas especiales o para atender a niños con otras características y otras necesidades. "<Elementos internos $\|$ Entrevistas $\| C$ og $>$ - Referencia 20.

El aprendizaje del alumnado en cuanto a la aplicación de actividades propias de la EF, como juegos motores y expresivos, nos ayuda a entender que gracias a este tipo de experiencias podemos desarrollar las competencias específicas de la disciplina educativa desde la que se llevan a cabo, algo que podría ser trasladable a otros ámbitos de conocimiento o materias.

"...juegos motrices siempre hacíamos los mismos de saltar con un pie o ir a la pata coja y con esta experiencia nos ha enseñado a que hay más (...). Cómo hacer los juegos e ir aprendiendo a formular juegos de Educación Física no juegos solo para niños sin problemas, sino juegos adaptados a la Educación Física, a correr, a movimientos y no juegos de estar quietos, de relajación. Entonces hemos sabido hacer juegos más motores." <Elementos internos $\|$ Entrevistas $\| C$ 10>-Referencia 11.

La evolución de los alumnos, respecto a su capacidad para planificar y seleccionar las actividades a realizar, destaca la relación existente entre la planificación y la ejecución de tareas. Esta vinculación proporciona un feedback al profesorado sobre el camino a seguir en el proceso de enseñanza-aprendizaje, por lo que tiene gran repercusión en cualquier actividad docente.

"... a lo largo un poco de las prácticas evolucionamos nosotras como... porque vamos aprendiendo cosas y evoluciona también la manera de planificar o de los ejercicios que les planteamos. Porque vamos viendo un poco esas cosas que vas sacando, vas extrayendo y luego cuando te vuelves a sentar para planificar lo haces también teniendo en cuenta eso." <Elementos internos\|Entrevistas\|C 11> Referencia 17.

A raíz de la recomendación del profesorado, podemos ver una evolución en cuanto a la capacidad para probar ciertas actividades pese a no estar seguros de su éxito. Aunque esta propiedad puede parecer improductiva en sí misma nos ayuda a entender que es interesante formar docentes atrevidos que sean capaces de experimentar y probar cosas nuevas, todo ello con la intención de aumentar el nivel de calidad educativa a ofrecer.

"J---- nos lo decía, es que miráis mucho esto no saldrá, pues probadlo y si no sale pues ya pasáis a otra. Y eso también, yo pienso que hemos mejorado muchísimo (...) porque al principio... ino, esta no que no saldrá, esta no que no saldrá! y... yo por ejemplo hubo el caso de una actividad que no me acuerdo ahora cuál era. Pero todas decían sí, sí, sí, sí y yo estaba encabezonada que no iba a salir, que no iba a salir (...). Total que llegamos allí, hicimos la actividad y salió pero vamos... mucho mejor de lo que yo me pensaba." <Elementos internos $\|$ Entrevistas $\| C$ 12>- Referencia 4. 


\section{- Tolerancia al fracaso.}

Consideramos que la tolerancia al fracaso es la capacidad para resistir, soportar y llevar con paciencia los resultados adversos en el desempeño de una tarea o acción.

La decepción de este alumno, al comprobar la falta de implicación de sus compañeros universitarios, proviene de la consideración de que debían participar más activamente en el servicio y que les faltaban muchas cualidades para poder realizarlo correctamente, de ahí su disgusto.

"...sobre el grupo de compañeras (...). Solo llevo un año en la UJl pero creo que ha sido el mayor despago, no me esperaba para nada, esa pasividad, esa... no sé, en ningún momento noté empatía, cero, o sea cero. Pero bueno yo qué sé."<Elementos internos||Entrevistas\|C o1> - Referencia 6.

La escasa ayuda recibida por parte de la entidad colaboradora pone de manifiesto la fuerte contradicción en la postura de dicho centro, pues no estuvieron a la altura del servicio prestado. Pese a ello, el programa educativo se pudo realizar sin mayores problemas, favoreciendo igualmente a los niños del centro y a los alumnos de la universidad.

"Entonces pues no nos ayudaron mucho al principio cuando desde aqui J---- nos dijo que fuéramos a preguntarles a ellos que nos explicarían lo que habían hecho el año anterior no sé qué. Y ellos nos dijeron... ino, no, vosotros os apañáis como queráis y ya nos iremos viendo! No nos hemos vuelto a ver pero bueno." <Elementos internos $\|$ Entrevistas $\| C$ o2 $>$ - Referencia 4.

El cambio de entidad de este alumno, pese a tener una preferencia inicial bien definida, demuestra su buena voluntad por encima de sus deseos personales. Igualmente, al destacar su satisfacción final tras participar en la experiencia, comprobamos que no se vio perjudicado al aceptar el mencionado cambio.

"Primero yo elegí Borja Sánchez, porque habíamos hecho una especie de grupo y habíamos dicho... ¡bueno pues nos juntamos unos cuantos y elegimos Borja Sánchez! Pero luego faltó gente para Apadahcas y (...) levanté la mano y yo fui de las que dijo... ipues yo soy la voluntaria que se va! Y nada, estoy súper contenta, ha sido un proceso súper bonito y no estoy nada arrepentida de haberme cambiado de entidad." <Elementos internos $\|$ Entrevistas $\| C$ o3> - Referencia 1.

Al admitir el fracaso de una de las actividades vemos cómo no solo supieron sobrellevar con entereza el error cometido en su propio desempeño sino que también les sirvió para analizar de forma crítica la elaboración y selección de los juegos a realizar.

"Recuerdo el primer día que también uno de los errores muy importantes que cometimos fue que teníamos un juego pensado que (...) creímos en ese momento, que iba a ser uno de los juegos estrella de esa sesión y no funcionaba. Y no funcionaba y nosotros no nos dábamos cuenta de que no funcionaba porque lo veíamos muy claro que tenía que funcionar." <Elementos internos\|Entrevistas $\mid C$ C4> . Referencia 12.

La preocupación del alumno por empezar el servicio más tarde que el resto de sus compañeros pone de manifiesto su interés por iniciar la actividad lo antes posible, así como su motivación para ayudar al colectivo receptor del servicio de una forma apropiada.

"Luego una dificultad que sí que encontré un poco más clara es lo de empezar más tarde. Que todos los grupos empezaron a trabajar con las entidades y nosotras nos quedábamos ahí como un poco estancadas y no avanzábamos. Entonces tampoco sabíamos si cuando íbamos a comenzar lo haríamos 
bien o si no tendríamos suficiente tiempo (...) pero bueno." <Elementos internos $\|$ Entrevistas $\| C$ 05> Referencia 2.

Pese a la decepción con la entidad colaboradora, a raíz de la escasa asistencia de niños el primer día del servicio, vemos que el alumno fue capaz de extraer conclusiones positivas y aprendizajes valiosos de esa circunstancia desfavorable.

"...el primer día vino una niña jejeje. Entonces eso pues... al principio estábamos un poco enfadadas. Pero es lo mismo que con lo de la entidad, después te paras a pensarlo y la verdad es que es probable que en esa sesión haya aprendido más cosas que en otras porque... también es verdad que estabas tú y que yo he de decir que a ver las sesiones que habéis estado vosotros y os habéis puesto a hacer cosas con nosotras (...) esas veces he aprendido mucho." <Elementos internos\|Entrevistas\|C o6> Referencia 5 .

La problemática surgida con un grupo de compañeros universitarios nos permite comprobar el nivel de exigencia que el alumnado consideraba apropiado para la actividad de servicio asumida. Además de cuestionar su nivel de implicación en la tarea propuesta, también dudaban de las cualidades de estos alumnos para ejercer como maestros en el futuro.

"Con el primero sí que tuvimos un poco de jaleo porque (...) preparaban actividades muy básicas, o sea, entrar en internet y coger las actividades. No las pensaban nada, ni las adaptaban, ni hacían nada (...). $Y$ eso sí que nos fastidiaba un poco, y luego que aparte con los niños tampoco, no sé, no las veíamos que trataran muy bien a los niños. Y decíamos... ino sabemos lo que están haciendo estudiando esta carrera, pero bueno!" <Elementos internos $\|$ Entrevistas $\| C$ o7> - Referencia 7.

El fracaso de los alumnos a la hora de realizar una valoración inicial, a petición del profesor de la asignatura, nos ayuda a comprobar cómo se vieron incapaces de resolver de forma autónoma el problema que se les había planteado en una situación real. No obstante, sí que lograron asumir otras tareas como, por ejemplo, continuar con el desarrollo normal de la clase a través de los juegos motores.

"El primer día V---- nos dijo... ¡ hacerle esta prueba a dos niños! Una evaluación era, inicial (...) porque claro eran nuevos, no habían venido en todo el curso (...). Y se pusieron a llorar, no sabíamos cómo actuar, nos mirábamos, no sabíamos si cogerlos al brazo si... y no, no, tuvo que venir él, nos dijo... dar la clase vosotros y yo les haré las pruebas." <Elementos internos||Entrevistas\|C o8> - Referencia 23.

La percepción de fracaso del alumno tras realizar la primera sesión de juegos con los niños nos muestra su análisis crítico de la sesión, identificando cada uno de los errores cometidos. Por ello, pese a su valoración final en la que consideraba que habían perdido el tiempo por no lograr los objetivos esperados, comprobamos como desarrolló este aprendizaje básico para la mejora de futuras ejecuciones.

"...la sesión pues fue una catástrofe porque pues los juegos eran demasiado complejos, estaban poco adaptados a las características y a las necesidades de los niños, nosotras estábamos muy desorganizadas, después el ritmo de la sesión también era muy lento porque perdíamos mucho tiempo entre juego y juego. Y bueno, como también era el primer día pues nos costó mucho interactuar con los niños y la verdad es que algunos no hacían caso, no respetaban las normas de los juegos (...) tuve la sensación de que realmente que no habíamos aprovechado el tiempo porque realmente no había salido lo que nosotras nos habíamos planificado." <Elementos internos\|Entrevistas\|C og> - Referencia 6.

El fracaso inicial de las actividades planificadas, para el grupo de niños más pequeños, nos ayuda a entender la valoración del alumno en la que considera que dicho resultado negativo 
se debía a la mayor dependencia de este colectivo. También reflexiona sobre lo que sería una adaptación razonable de las tareas y una provocada por motivos extraordinarios como, por ejemplo, en este caso.

"...con los mayores sí, tu llevabas unas actividades y ellos ya como se mueven más no son tan dependientes como los pequeños, pues lo hacían. A lo mejor no lo hacían como tú pensabas y tenías que cambiar algunas cosas pero sí que en ese momento si había que pasar el balón, ellos sí que sabían pasarlo, si había que correr, sí que corrían detrás del balón, cosas así. Y estos niños no, estos niños estaban sentados la mayoría o en silla de ruedas, entonces... algunos con autismo, y se te iban y tenías que ir detrás y cosas así, entonces no te salía." <Elementos internos $\mid$ Entrevistas $\| C$ 10>-Referencia 12.

El conflicto sobre la gestión organizativa de la actividad nos lleva a comprender la importancia de establecer claramente cuestiones como la distribución de tareas, el nivel de responsabilidad o las figuras de autoridad, para así evitar la aparición de futuros problemas durante la aplicación del servicio en estos delicados aspectos.

"...hubo un poco de lío porque su profesora les decía una cosa y nosotros con J---- teníamos otra cosa. Entonces ellos iban haciendo también lo que querían. Entonces sentirte un poco en esa situación de que eres la responsable, porque tú coges el papel jejeje. Y que los que se supone que tienen que hacerte caso no te hacen caso, pero porque hay otros responsables por encima nuestro, que a lo mejor tampoco ha habido ahí una buena coordinación. Pues sí que hubo un poco de caos sentimental (...) Al final fue él a hablar y la autoridad de él sí que valía jejeje." <Elementos internos\|Entrevistas $\mid C$ 11>-Referencia 4.

La incapacidad del alumnado para aprenderse los nombres de origen extranjero de los niños muestra el malestar que les provocaba esta situación por miedo a que alguien pensara que se trataba de una cuestión discriminatoria. Igualmente debemos destacar su interés por resolver el conflicto para poder ofrecerles el mismo trato que al resto de niños de la entidad.

"...está J----, está S----, está M---- y esos nos los sabemos. Y claro llegamos allí y tener que a... llamar a unos por el nombre y a otros no, yo por lo menos me siento súper incómoda de no poder... me da rabia de... ijolín! (...) ver que llevo seis meses y que aún no me he aprendido todos los nombres, me da mucha rabia (...) se nos olvidan todos los nombres... son muy, son difíciles." <Elementos internos\|Entrevistas $\| C$ 12> - Referencia 10.

A lo largo de este último apartado hemos profundizado en los efectos de la experiencia de APS sobre las cualidades innovadoras del alumnado. El desarrollo de estos atributos permitió a los alumnos trabajar de forma autónoma y novedosa, incrementado notablemente sus competencias en el ámbito docente. Igualmente, comprobamos que los aspectos innovadores se vivenciaron, directa o indirectamente, junto con distintas cuestiones de carácter social y personal, reforzando así el fomento de la competencia de ES de los alumnos universitarios.

\subsection{Expresión de los datos cualitativos de forma cuantitativa}

Siguiendo las indicaciones de Creswell y Plano Clark (2007) respecto a la combinación de datos en el diseño de triangulación metodológica al aplicar los métodos mixtos, efectuamos una transformación de resultados cualitativos expresándolos de forma cuantitativa. Así pues, realizamos un análisis de la frecuencia de aparición de los aspectos relacionados con ambas 
variables en las entrevistas seleccionadas. Para ello, contabilizamos el número de citas que hacen referencia a cada uno de los aspectos que conforman la rúbrica académica y el cuestionario sobre la competencia de Emprendimiento Social, respectivamente. Esta información se presenta en gráficos, en los que podemos apreciar visualmente los registros obtenidos en cada caso. En el anexo se incluyen las tablas con los datos que corresponden a cada gráfico. Este procedimiento se ha realizado a nivel global, por categorías de aspectos y por entrevistas.

\subsubsection{Variable dependiente A: conocimientos y competencias académicas}

- Análisis global de los aprendizajes académicos.

En el gráfico 16 presentamos la información global relativa al número de referencias sobre los aprendizajes académicos de la asignatura, en cada una de las entrevistas analizadas (tabla 96 del anexo).

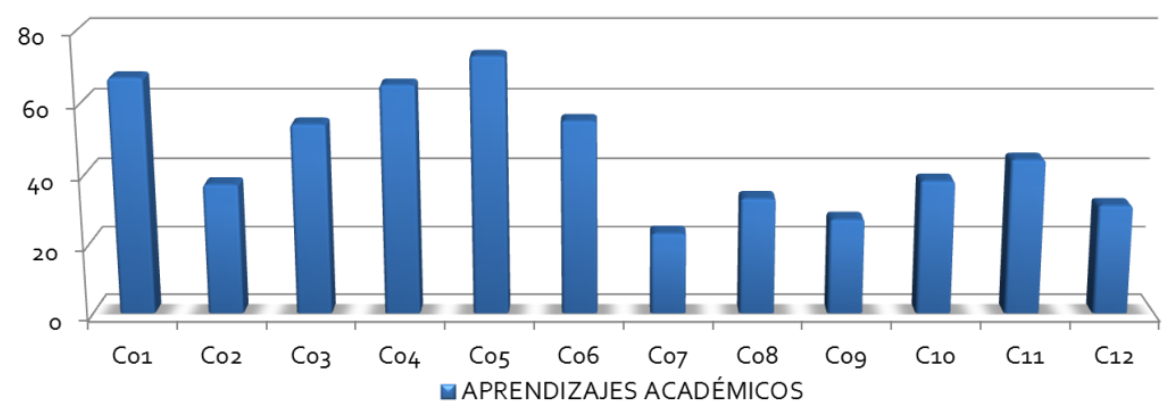

Gráfico 16. Referencias sobre aprendizajes académicos en las entrevistas (elaboración propia).

En el gráfico 17 desglosamos esta información global en función de las distintas categorías que hacen referencia a los aprendizajes académicos (tabla 97 del anexo). 


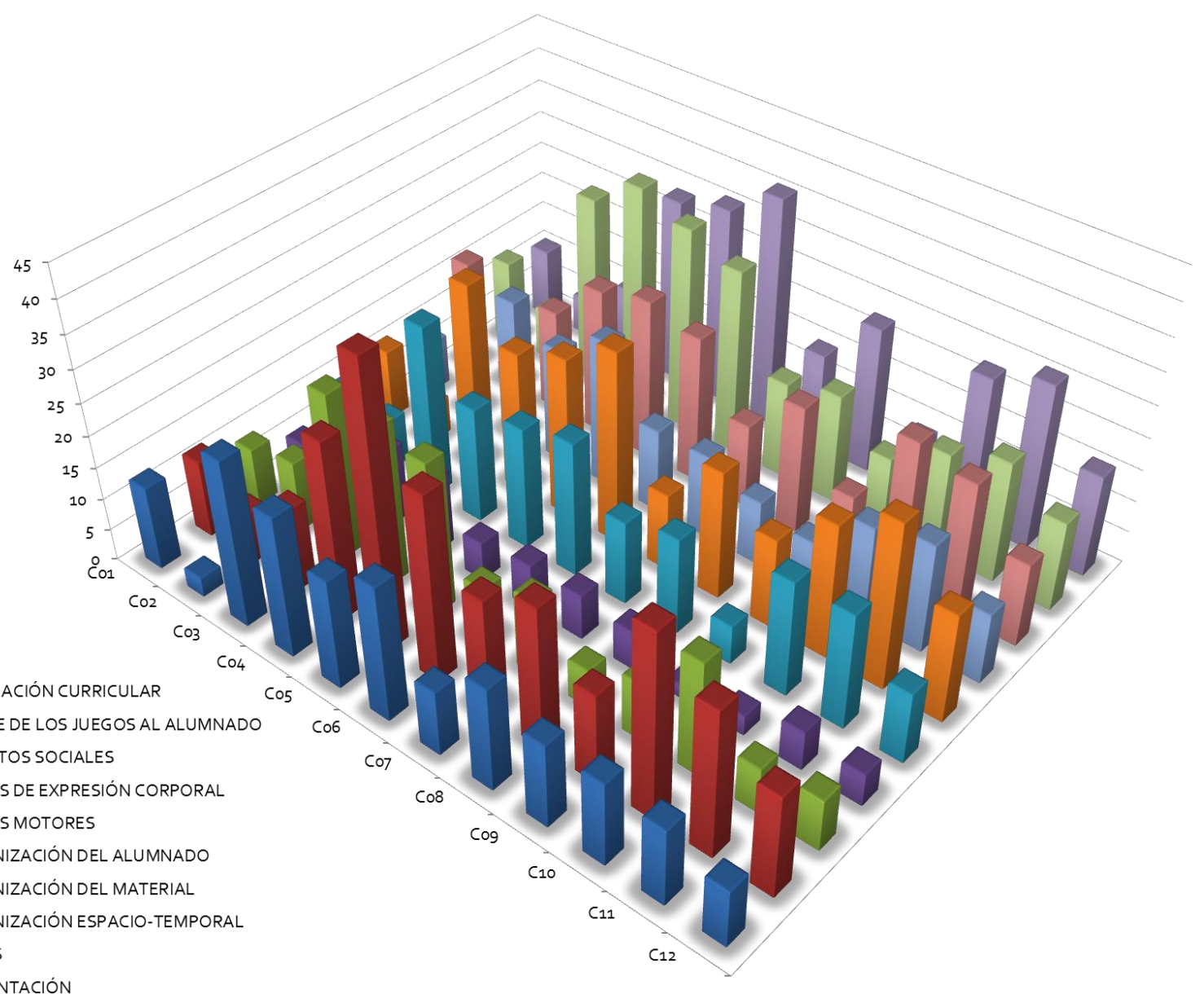

Gráfico 17. Referencias sobre aprendizajes académicos en las entrevistas por categorías (elaboración propia). 
- Análisis por categorías de los aprendizajes académicos.

\section{- Ajuste de los juegos al alumnado participante.}

El gráfico 18 expone la información relativa al ajuste de los juegos al alumnado participante en las entrevistas analizadas (tabla 98 del anexo).

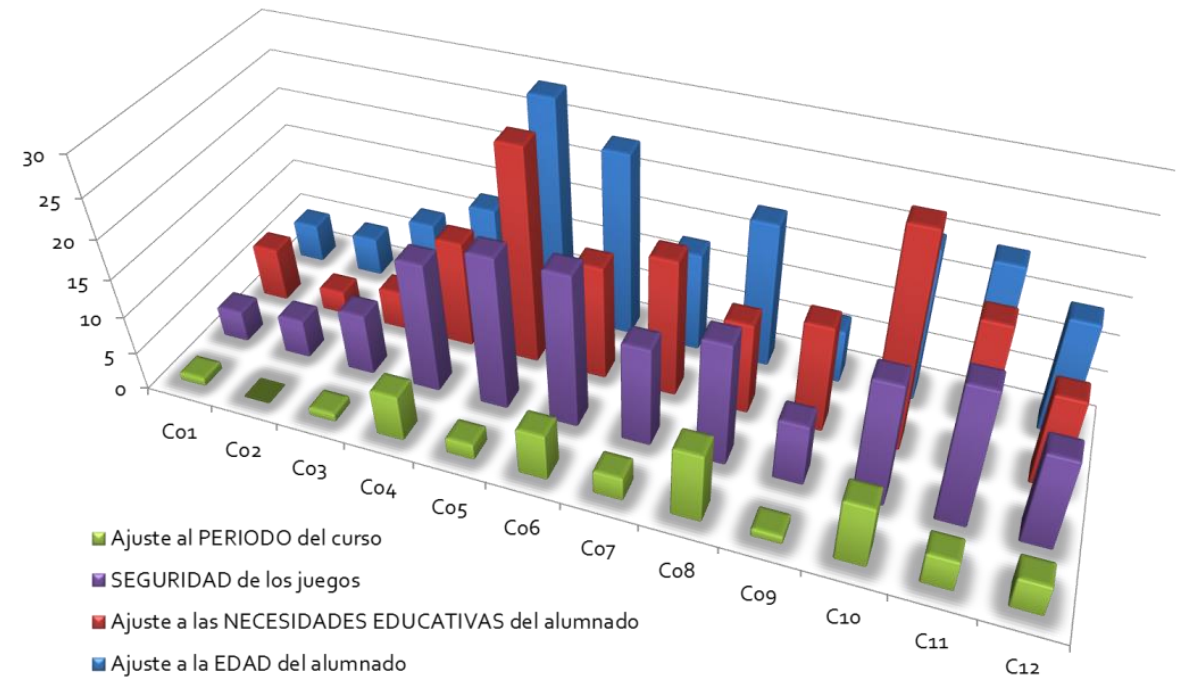

Gráfico 18. Referencias sobre el ajuste de los juegos al alumnado participante en las entrevistas (elaboración propia).

\section{- Presentación de los juegos.}

El gráfico 19 muestra los datos que hacen referencia a la presentación de los juegos en cada una de las entrevistas analizadas (tabla 99 del anexo).

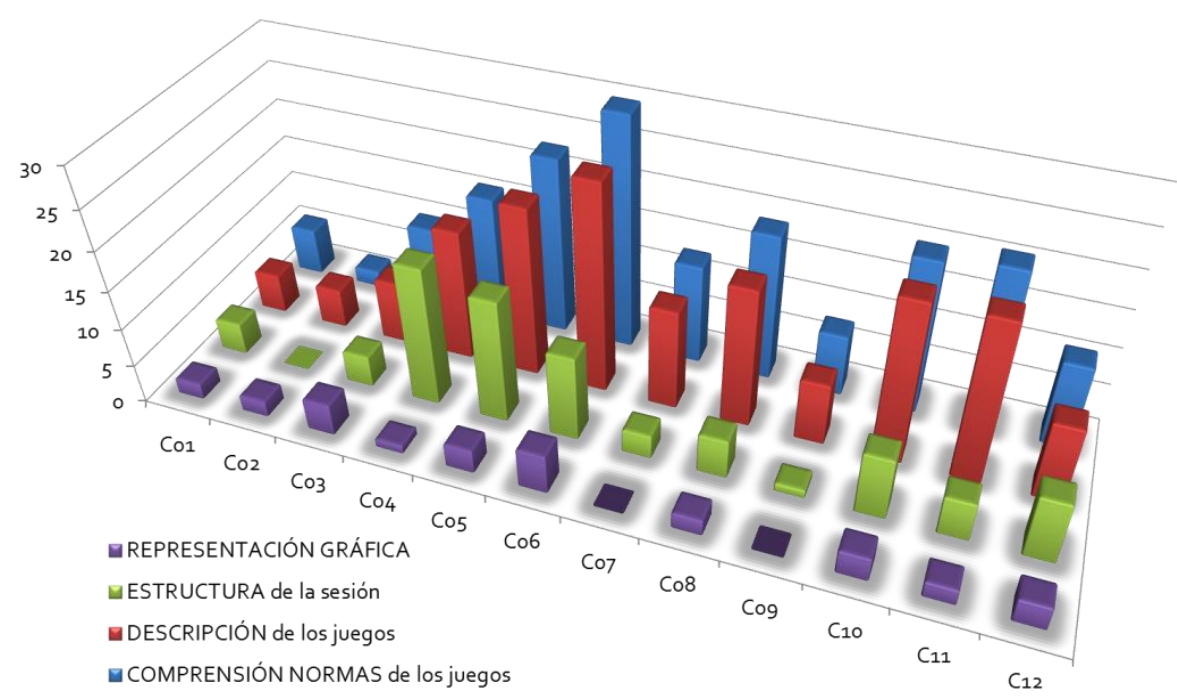

Gráfico 19. Referencias sobre la presentación de los juegos en las entrevistas (elaboración propia). 


\section{- Organización del alumnado.}

En el gráfico 20 presentamos los registros de las entrevistas analizadas en cuanto a la organización del alumnado (tabla 100 del anexo).

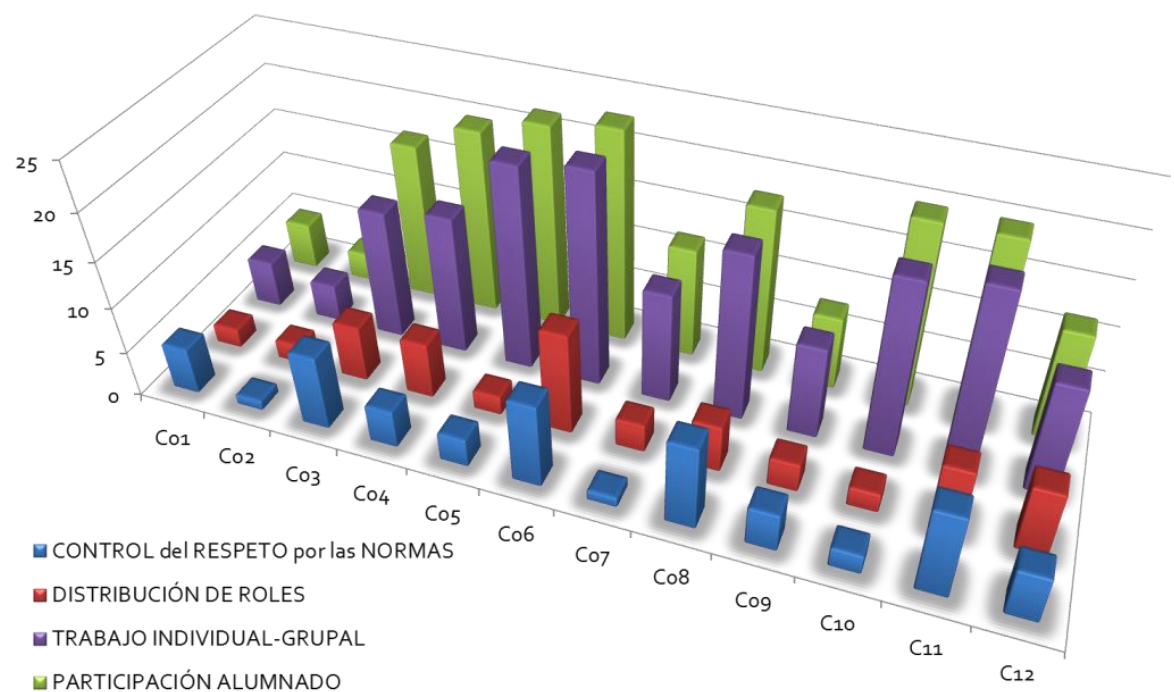

Gráfico 20. Referencias sobre la organización del alumnado en las entrevistas (elaboración propia).

\section{- Organización del material.}

El gráfico 21 expone la información relativa a la organización del material en las entrevistas analizadas (tabla 101 del anexo).

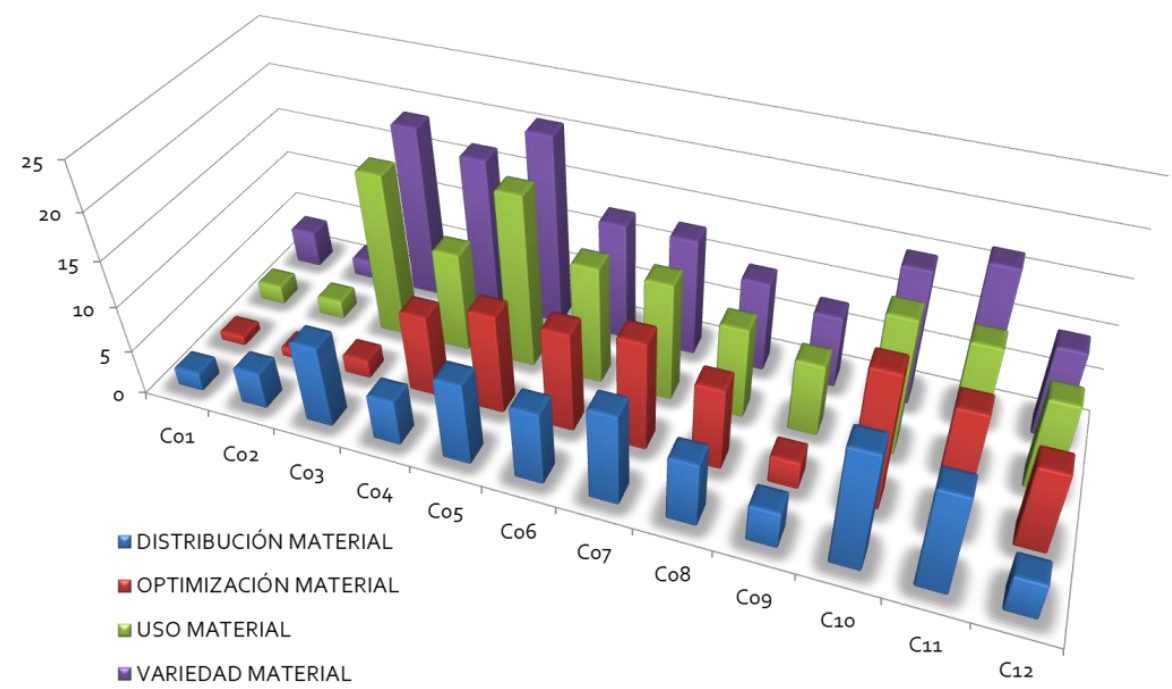

Gráfico 21. Referencias sobre la organización del material en las entrevistas (elaboración propia). 


\section{- Organización espacio/temporal.}

El gráfico 22 muestra la frecuencia de registros que hacen alusión a la organización espacio/temporal en las entrevistas (tabla 102 del anexo).

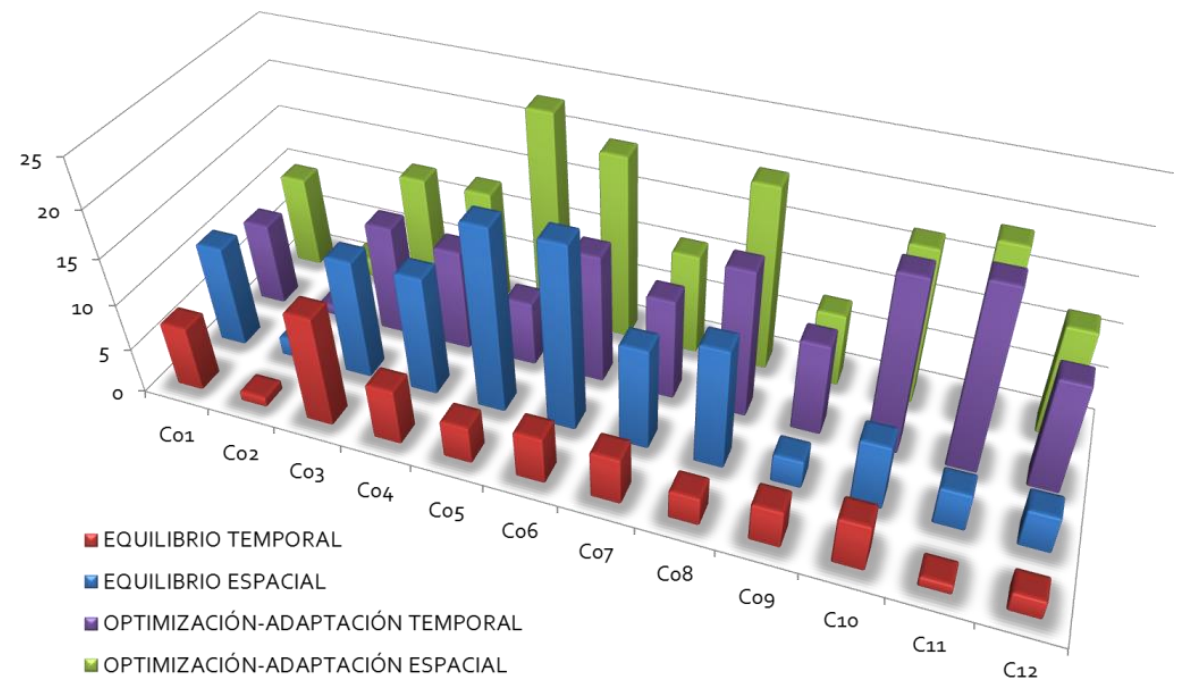

Gráfico 22. Referencias sobre la organización espacio/temporal en las entrevistas (elaboración propia).

\section{- Adecuación curricular.}

En el gráfico 23 presentamos los registros de las entrevistas analizadas en cuanto a la adecuación curricular de las actividades (tabla 103 del anexo).

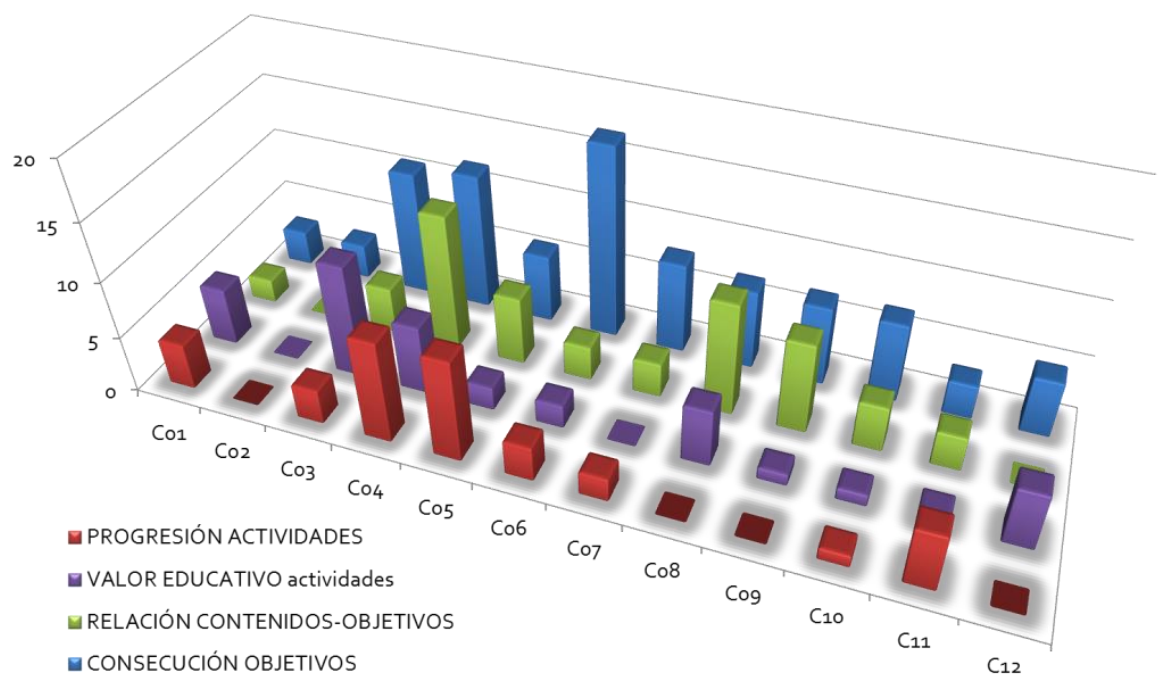

Gráfico 23. Referencias sobre la adecuación curricular de las actividades en las entrevistas (elaboración propia). 


\section{- Aspectos sociales.}

El gráfico 24 expone la información relativa a los aspectos sociales en las entrevistas analizadas (tabla 104 del anexo).

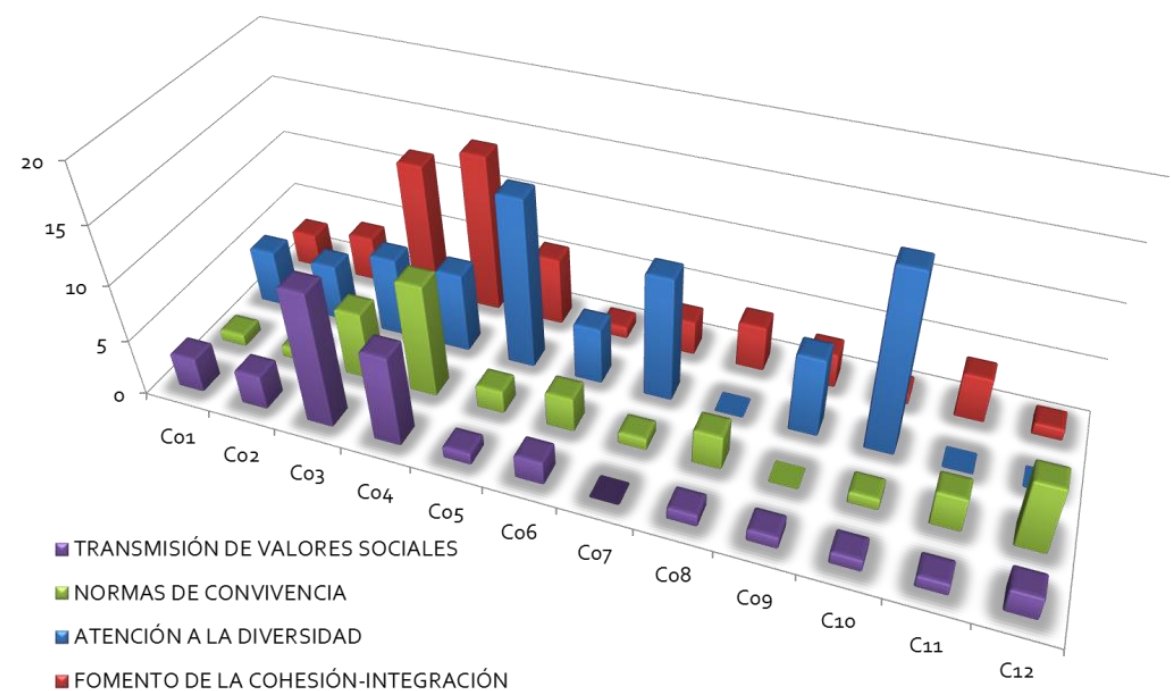

Gráfico 24. Referencias sobre aspectos sociales en las entrevistas (elaboración propia).

\section{- Juegos motores.}

El gráfico 25 muestra la frecuencia de registros que hacen alusión a los juegos motores en las entrevistas (tabla 105 del anexo).

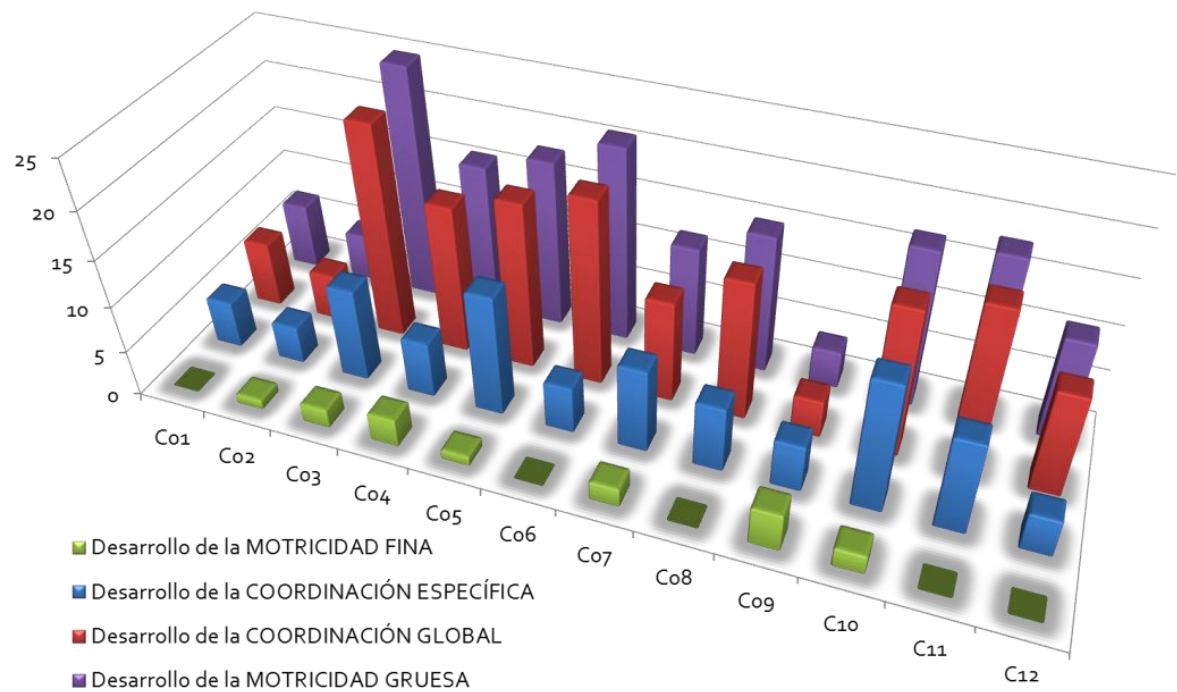

Gráfico 25. Referencias sobre juegos motores en las entrevistas (elaboración propia). 


\section{- Juegos de expresión corporal.}

En el gráfico 26 presentamos los registros de las entrevistas analizadas en cuanto a los juegos de expresión corporal (tabla 106 del anexo).

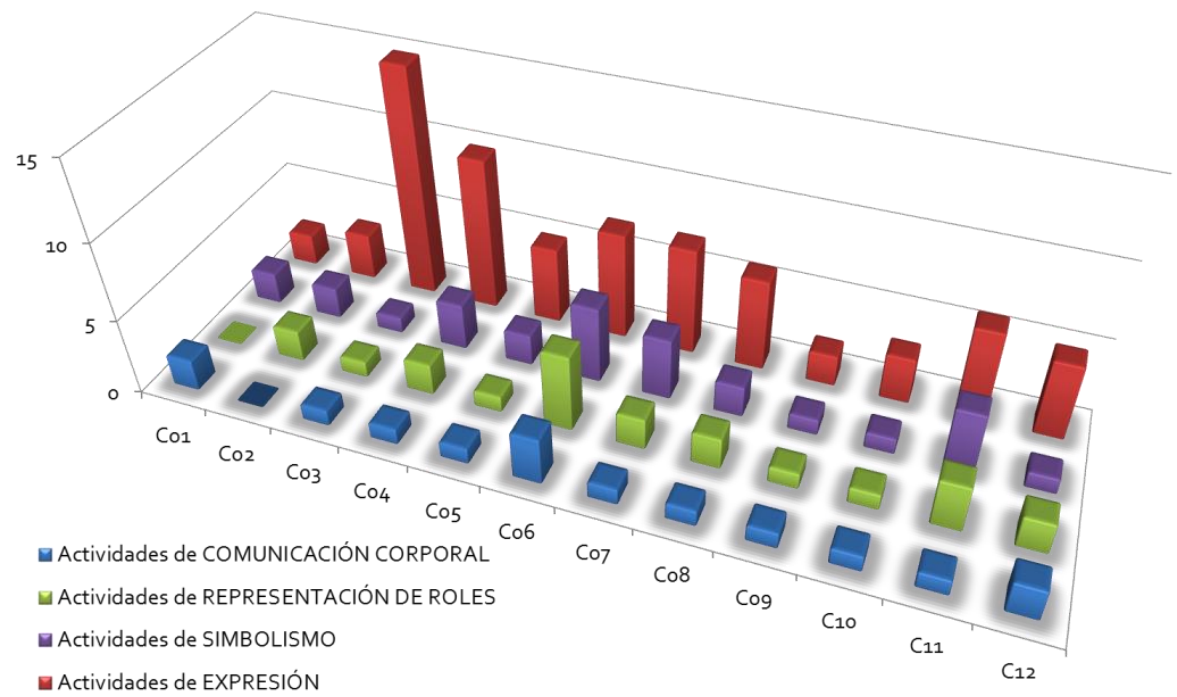

Gráfico 26. Referencias sobre juegos de expresión corporal en las entrevistas (elaboración propia).

\section{- Otros aspectos.}

El gráfico 27 expone la información relativa a otros aspectos genéricos en las entrevistas analizadas (tabla 107 del anexo).

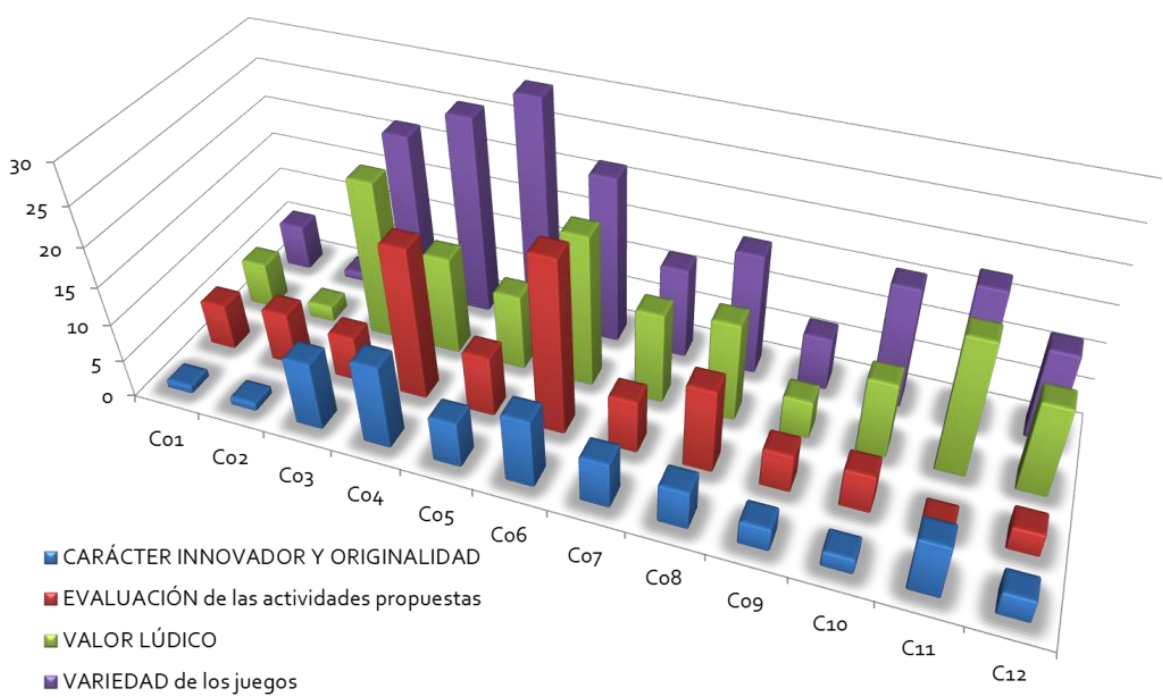

Gráfico 27. Referencias sobre otros aspectos en las entrevistas (elaboración propia). 
- Análisis por entrevistas de los aprendizajes académicos.

\section{- Entrevista Co1.}

El gráfico 28 expone la información relativa a los aprendizajes académicos en la primera entrevista analizada (tabla 108 del anexo).

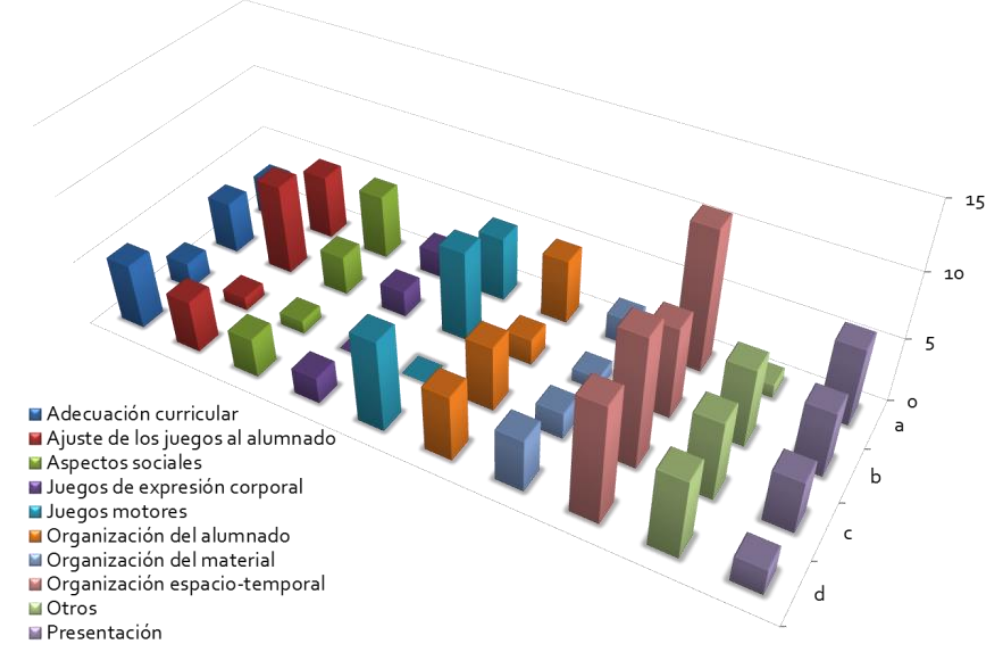

Gráfico 28. Referencias sobre aprendizajes académicos en la entrevista Co1 (elaboración propia).

\section{- Entrevista Co2.}

El gráfico 29 muestra los datos que hacen referencia a los aprendizajes académicos en la segunda entrevista analizada (tabla 109 del anexo).

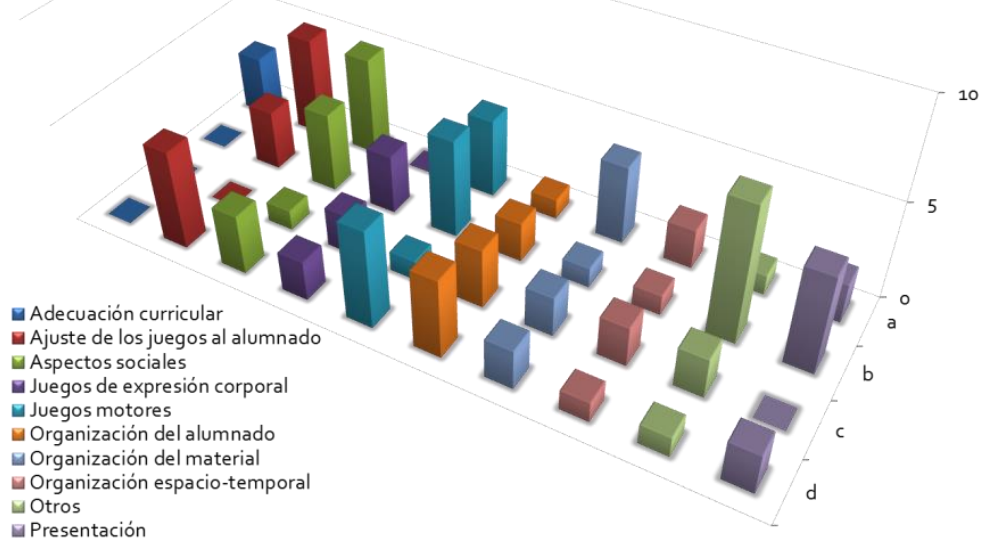

Gráfico 29. Referencias sobre aprendizajes académicos en la entrevista Co2 (elaboración propia). 


\section{- Entrevista Co3.}

En el gráfico 30 presentamos los registros de los aprendizajes académicos en la tercera entrevista (tabla 110 del anexo).

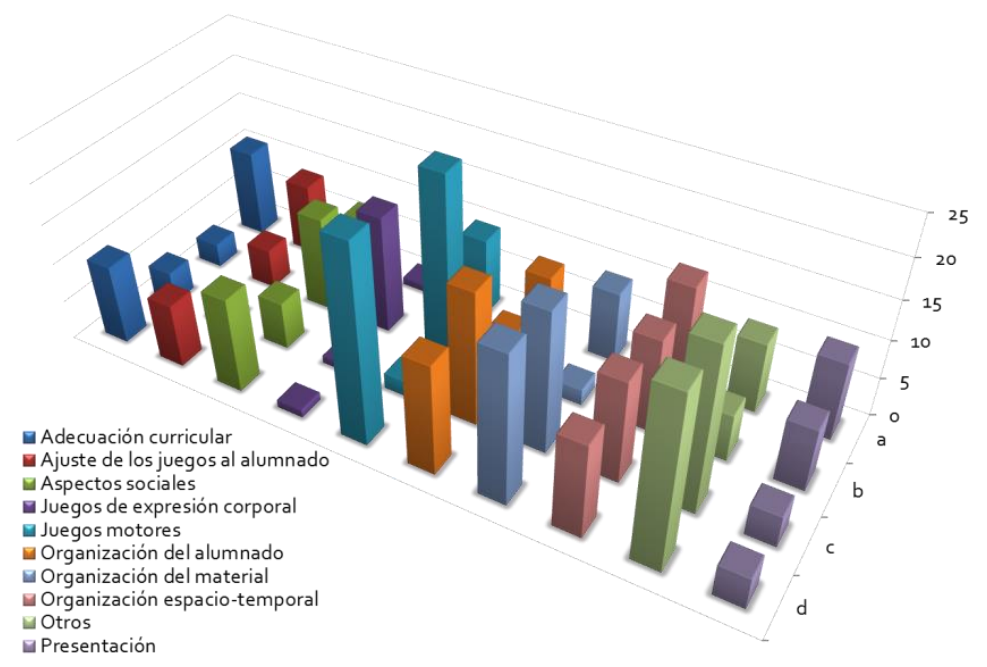

Gráfico 30. Referencias sobre aprendizajes académicos en la entrevista Co3 (elaboración propia).

\section{- Entrevista Co4.}

El gráfico 31 expone la información relativa a los aprendizajes académicos en la cuarta entrevista analizada (tabla 111 del anexo).

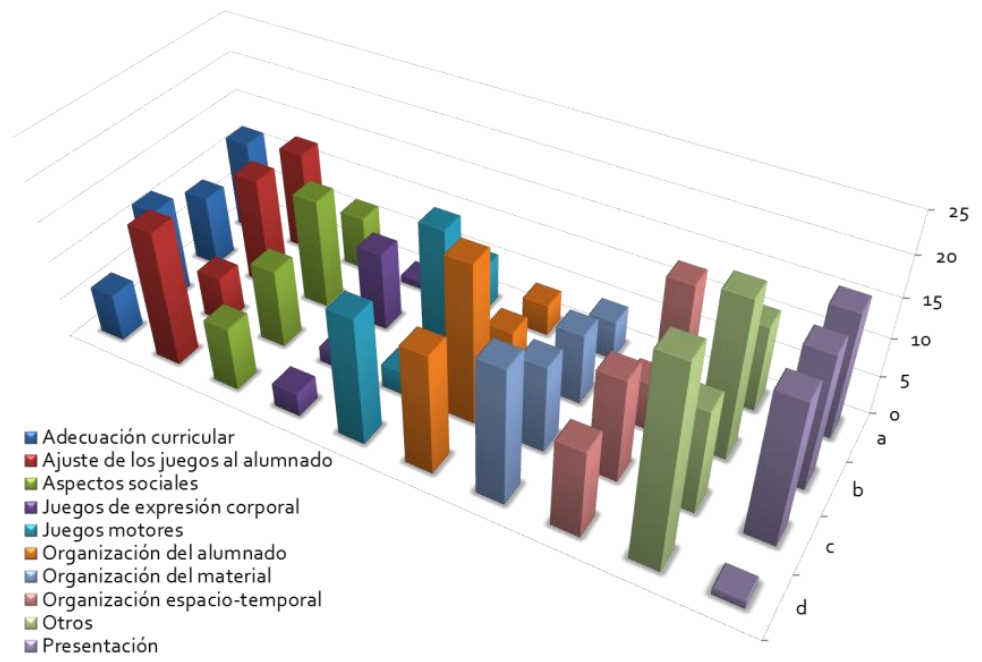

Gráfico 31. Referencias sobre aprendizajes académicos en la entrevista Co4 (elaboración propia). 


\section{- Entrevista Co5.}

El gráfico 32 muestra la frecuencia de registros que hacen alusión a los aprendizajes académicos en la quinta entrevista (tabla 112 del anexo).

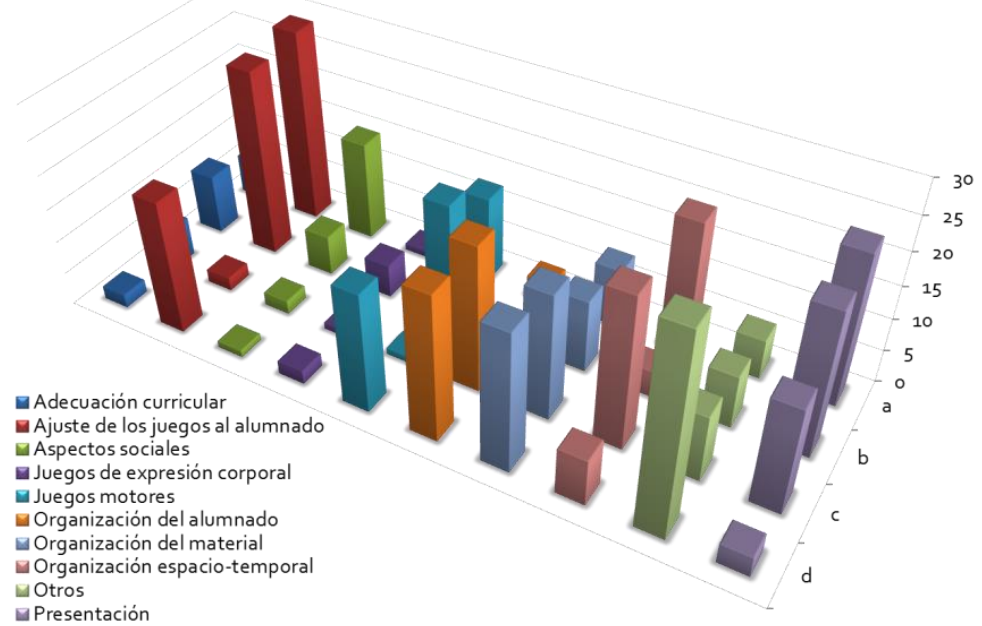

Gráfico 32. Referencias sobre aprendizajes académicos en la entrevista Co5 (elaboración propia).

\section{- Entrevista Co6.}

En el gráfico 33 presentamos los registros de los aprendizajes académicos en la sexta entrevista analizada (tabla 113 del anexo).

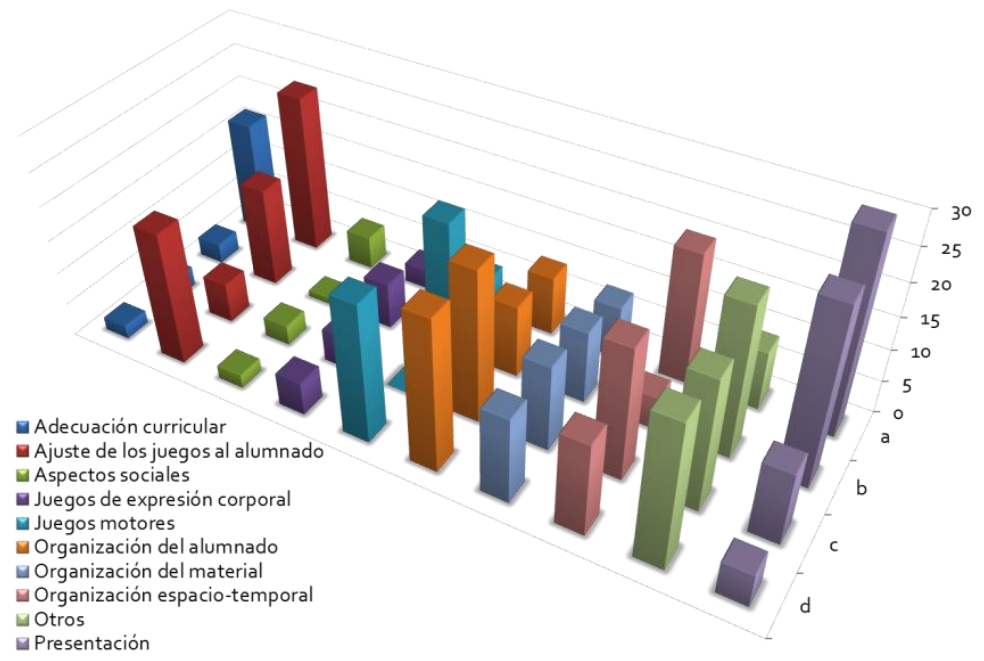

Gráfico 33. Referencias sobre aprendizajes académicos en la entrevista Co6 (elaboración propia). 


\section{- Entrevista C07.}

El gráfico 34 expone la información relativa a los aprendizajes académicos en la séptima entrevista (tabla 114 del anexo).

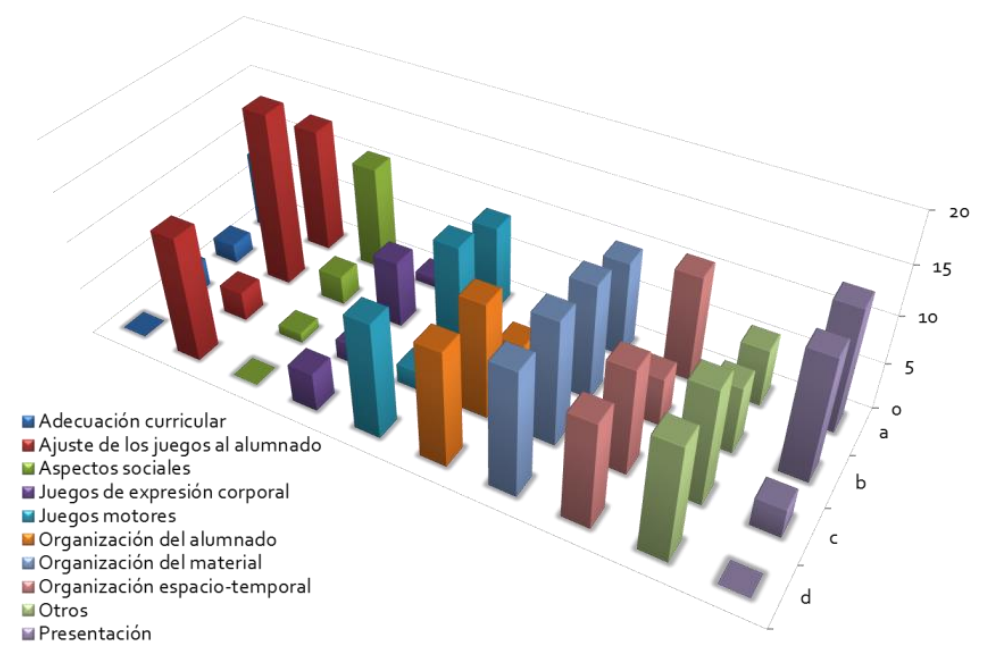

Gráfico 34. Referencias sobre aprendizajes académicos en la entrevista Co7 (elaboración propia).

\section{- Entrevista Co8.}

El gráfico 35 muestra la frecuencia de registros que hacen alusión a los aprendizajes académicos en la octava entrevista analizada (tabla 115 del anexo).

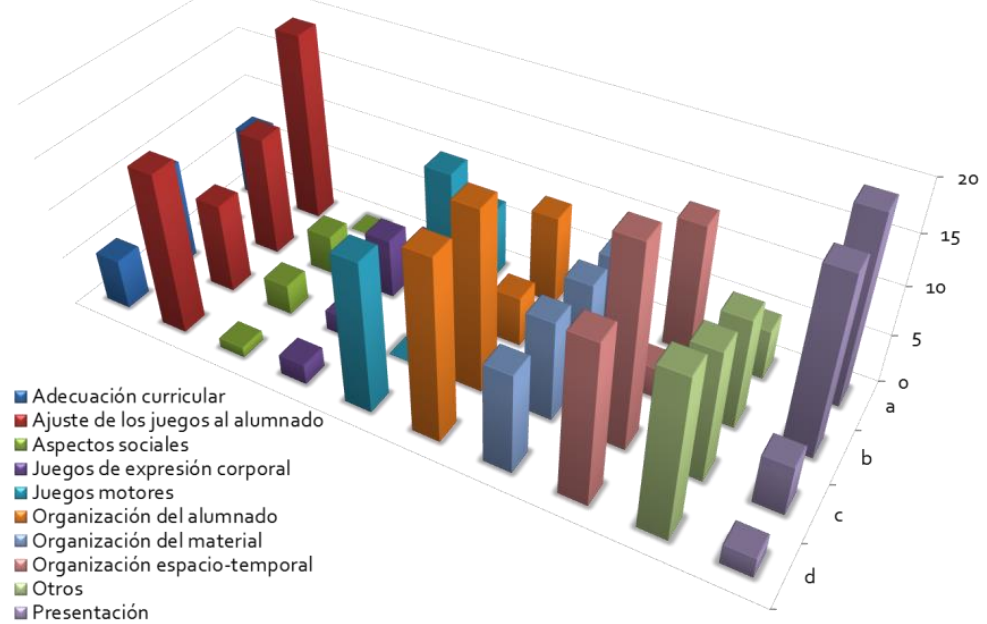

Gráfico 35. Referencias sobre aprendizajes académicos en la entrevista Co8 (elaboración propia). 


\section{- Entrevista Cog.}

En el gráfico 36 presentamos los registros de los aprendizajes académicos en la novena entrevista analizada (tabla 116 del anexo).

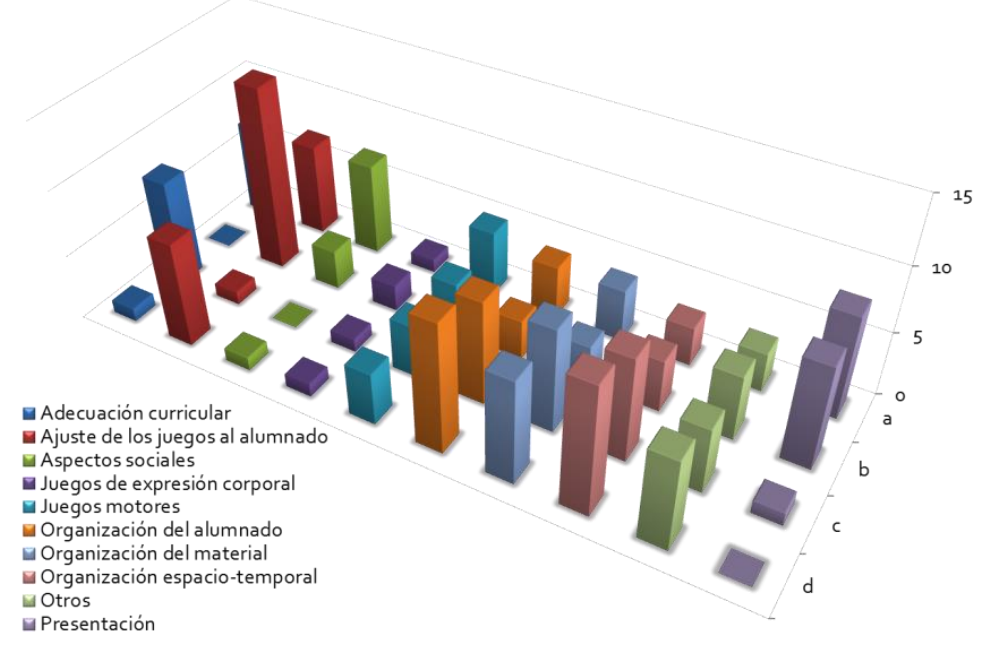

Gráfico 36. Referencias sobre aprendizajes académicos en la entrevista Cog (elaboración propia).

\section{- Entrevista C10.}

El gráfico 37 expone la información relativa a los aprendizajes académicos en la décima entrevista (tabla 117 del anexo).

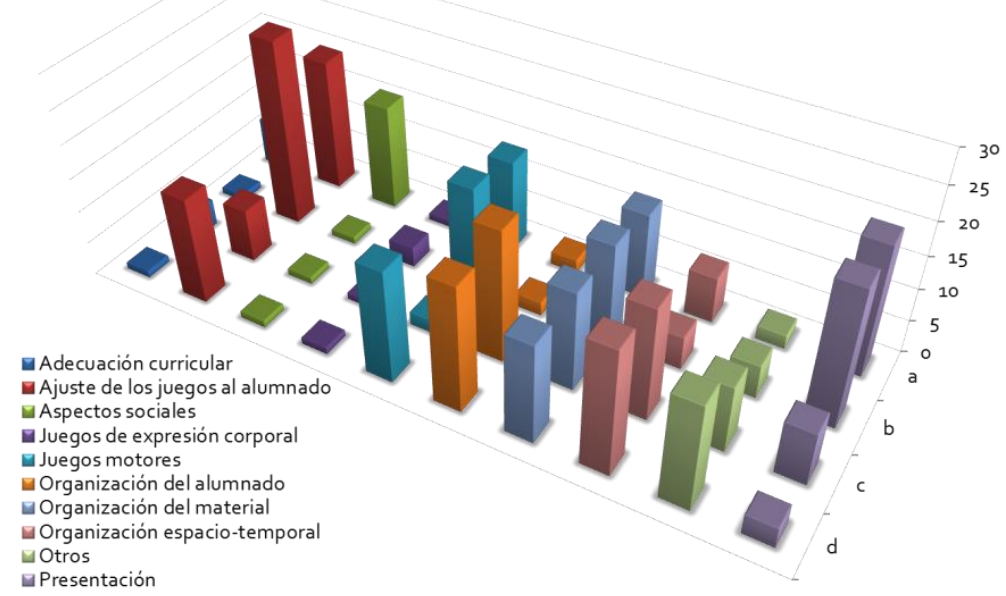

Gráfico 37. Referencias sobre aprendizajes académicos en la entrevista C10 (elaboración propia). 


\section{- Entrevista C11.}

El gráfico 38 muestra la frecuencia de registros que hacen alusión a los aprendizajes académicos en la undécima entrevista (tabla 118 del anexo).

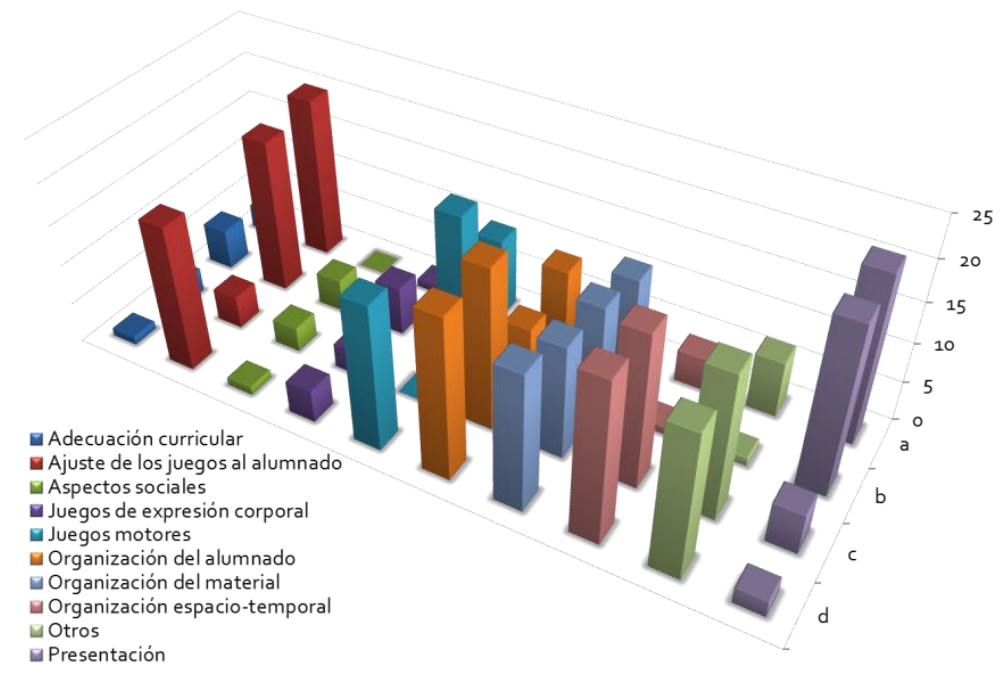

Gráfico 38. Referencias sobre aprendizajes académicos en la entrevista C 11 (elaboración propia).

\section{- Entrevista C12.}

En el gráfico 39 presentamos los registros de los aprendizajes académicos en la última entrevista analizada (tabla 119 del anexo).

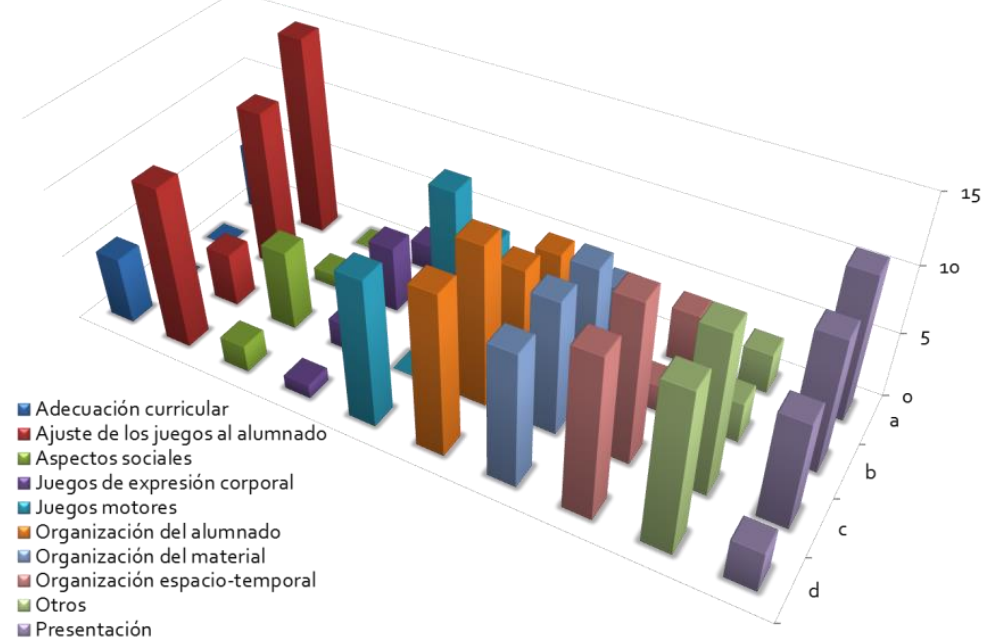

Gráfico 39. Referencias sobre aprendizajes académicos en la entrevista $C_{12}$ (elaboración propia). 


\subsubsection{Variable dependiente B: competencia de Emprendimiento Social}

\section{- Análisis global de la competencia de Emprendimiento Social.}

En el gráfico 40 presentamos la información global relativa al número de referencias sobre la competencia de ES en las entrevistas analizadas (tabla 120 del anexo).

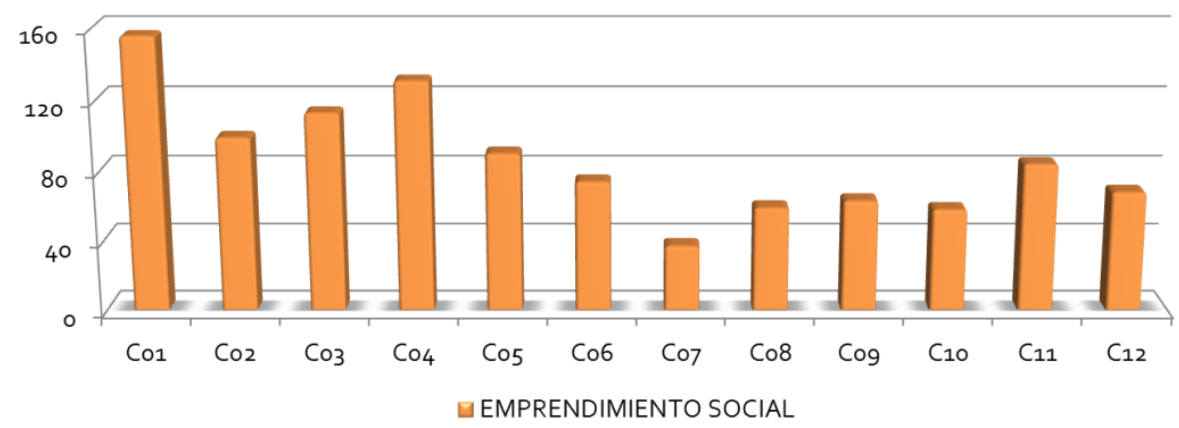

Gráfico 40. Referencias sobre la competencia de Emprendimiento Social en las entrevistas (elaboración propia).

En el gráfico 41 desglosamos esta información global en función de las categorías que conforman la competencia de ES (tabla 121 del anexo). Debemos aclarar en este punto que para poder comparar estos registros se normalizaron los datos obtenidos, ya que cada categoría de esta variable se asocia a un número diferente de aspectos: categoría de aspectos personales (6), categoría de aspectos sociales (4) y categoría de aspectos innovadores (7).

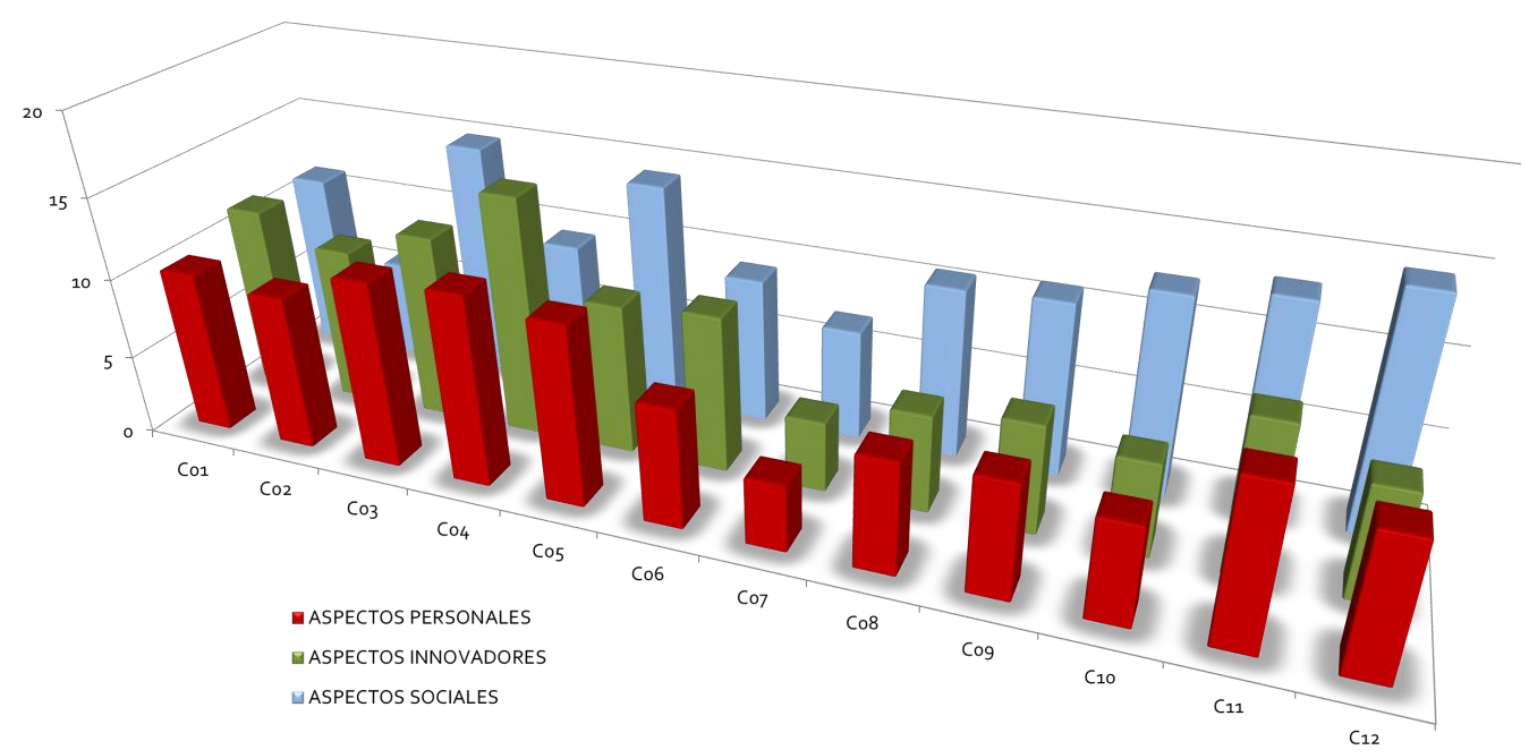

Gráfico 41. Referencias sobre la competencia de Emprendimiento Social en las entrevistas por categorías (elaboración propia). 
- Análisis por categorías de la competencia de Emprendimiento Social.

\section{- Aspectos personales.}

El gráfico 42 expone la información relativa a los aspectos personales en las entrevistas analizadas (tabla 122 del anexo).

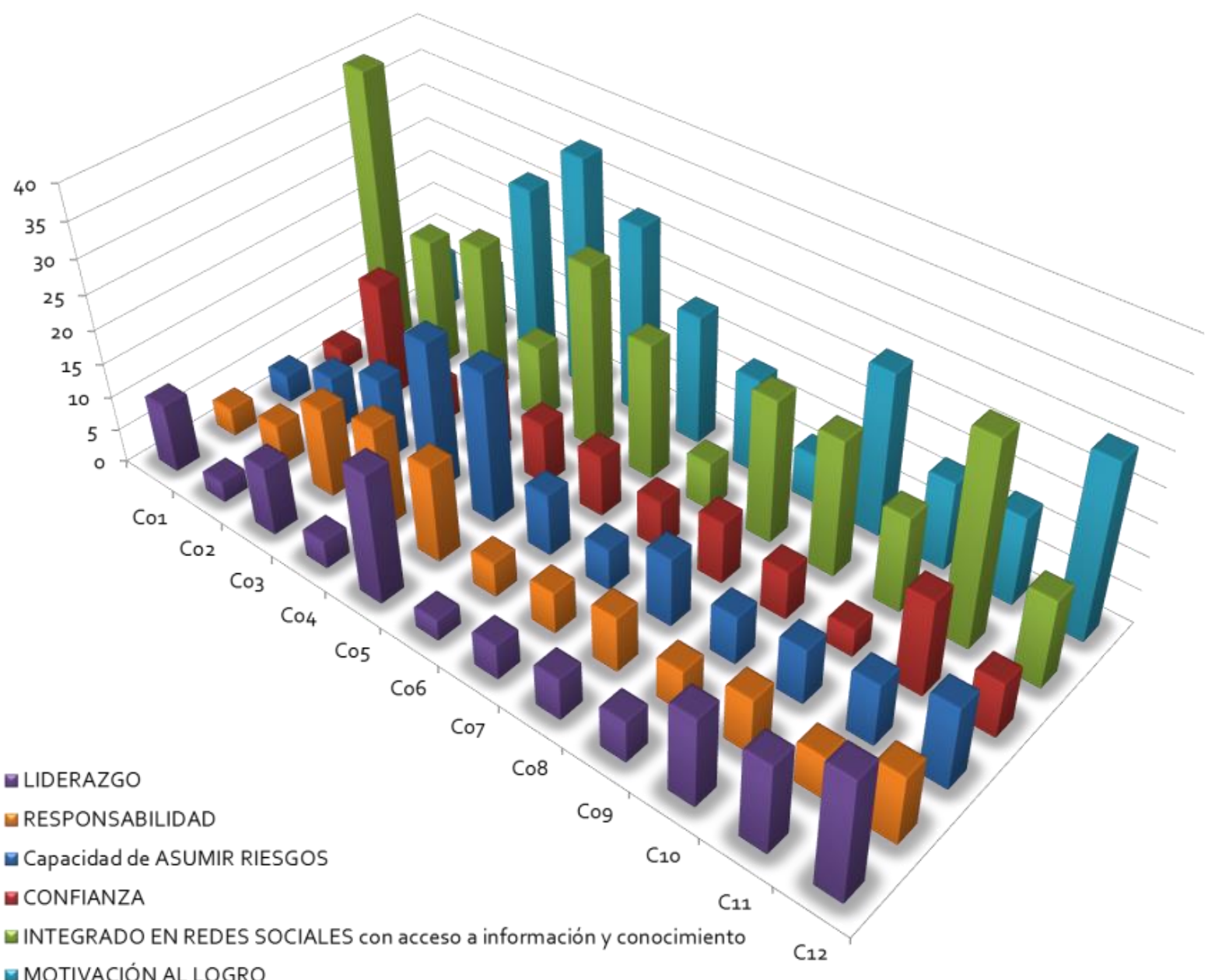

Gráfico 42. Referencias sobre los aspectos personales del Emprendimiento Social en las entrevistas (elaboración propia). 


\section{- Aspectos sociales.}

El gráfico 43 muestra los datos que hacen referencia a los aspectos sociales en cada una de las entrevistas analizadas (tabla 123 del anexo).

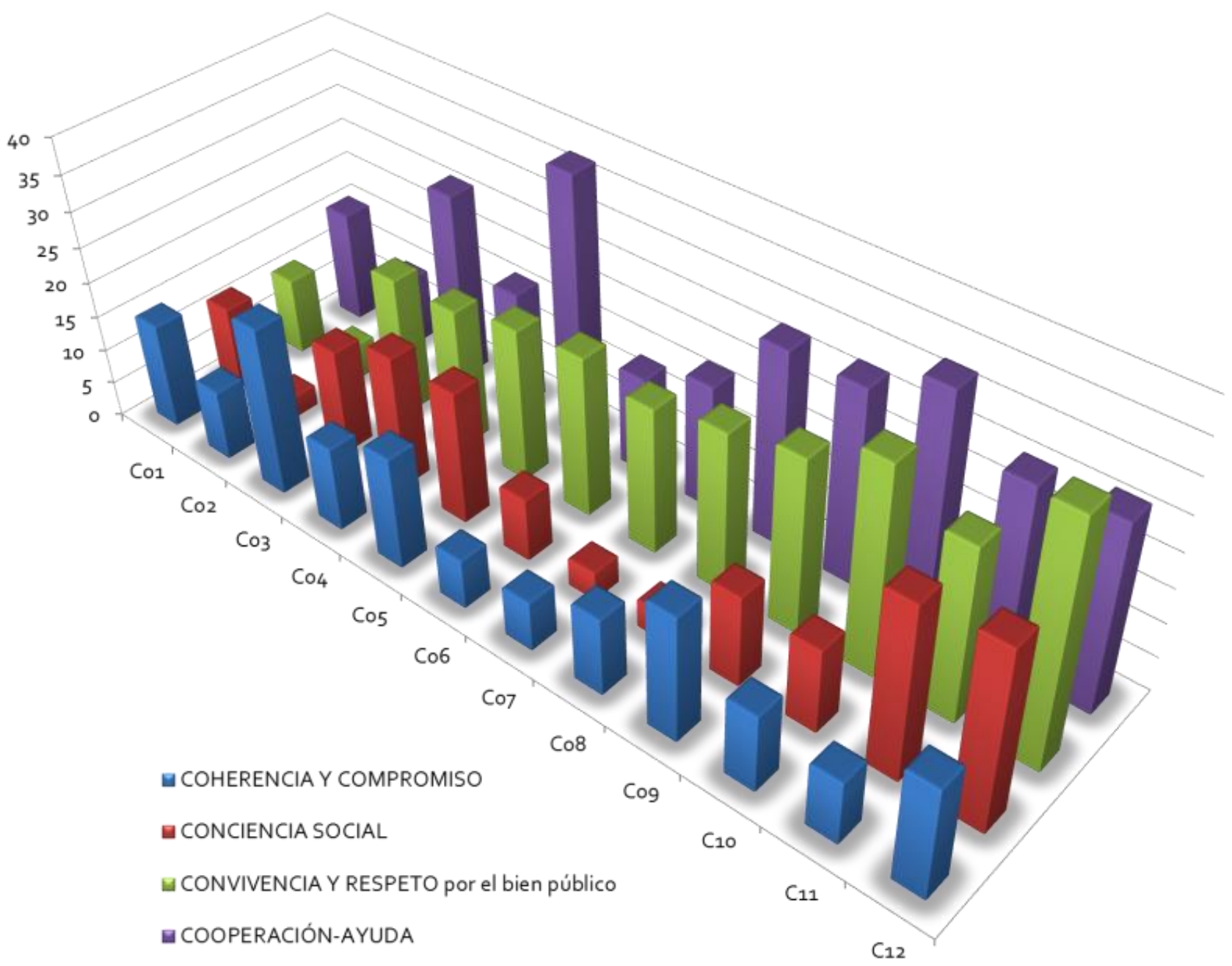

Gráfico 43. Referencias sobre los aspectos sociales del Emprendimiento Social en las entrevistas (elaboración propia). 


\section{- Aspectos innovadores.}

En el gráfico 44 presentamos los registros de las entrevistas analizadas en cuanto a los aspectos innovadores (tabla 124 del anexo).

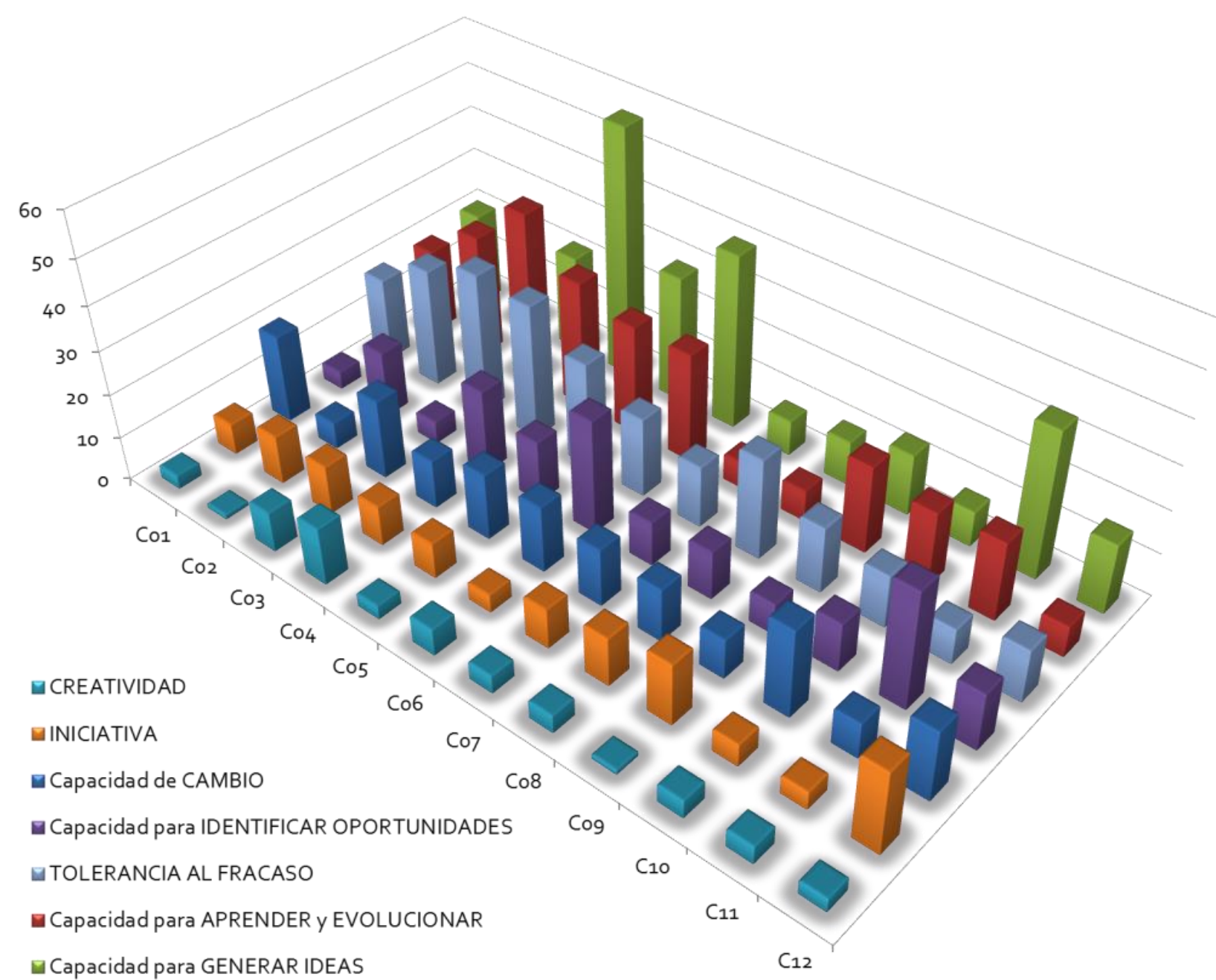

Gráfico 44. Referencias sobre los aspectos innovadores del Emprendimiento Social en las entrevistas (elaboración propia).

\section{- Análisis por entrevistas de la competencia de Emprendimiento Social.}

Seguidamente, para facilitar el entendimiento de los siguientes gráficos, especificamos las claves que hacen referencia a cada aspecto analizado. Aspectos personales: capacidad para asumir riesgos (a), confianza (b), integración en redes sociales con acceso a información y conocimiento (c), liderazgo (d), motivación al logro (e) y responsabilidad (f). Aspectos sociales: coherencia y compromiso (a), conciencia social (b), convivencia y respeto por el bien público (c) y capacidad de cooperación y ayuda (d). Aspectos innovadores: capacidad de cambio (a), capacidad para aprender 
y evolucionar (b), capacidad para generar ideas (c), capacidad para identificar oportunidades (d), creatividad (e), iniciativa $(f)$ y tolerancia al fracaso $(g)$.

\section{- Entrevista Co1.}

El gráfico 45 expone la información relativa a la competencia de ES en la primera entrevista analizada (tabla 125 del anexo).

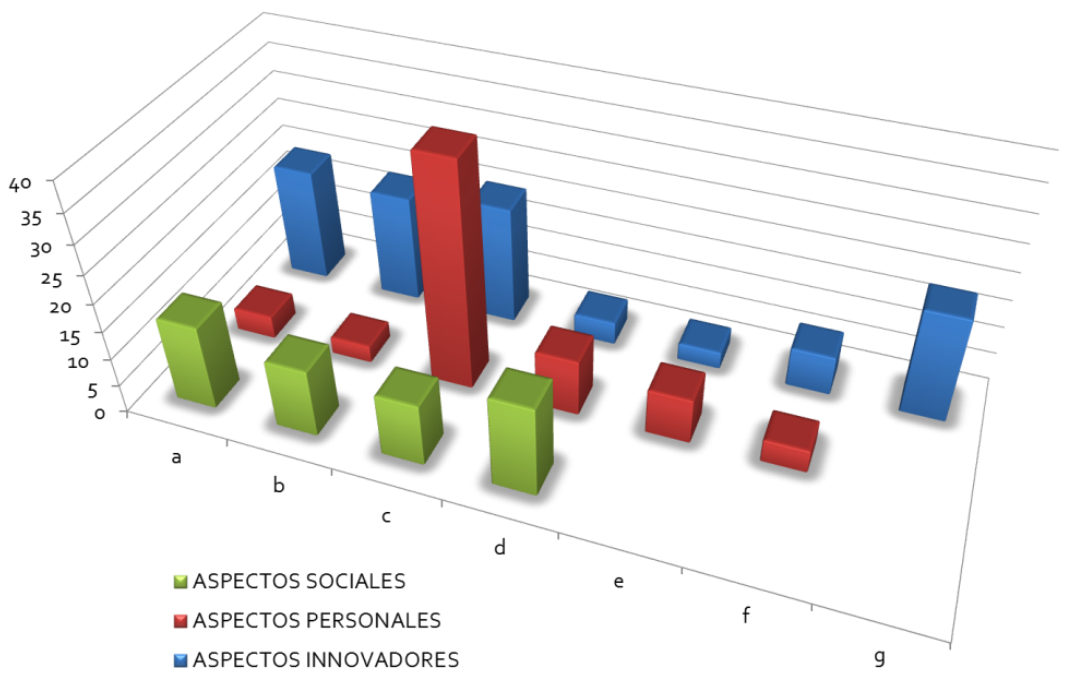

Gráfico 45. Referencias sobre la competencia de Emprendimiento Social en la entrevista Co1 (elaboración propia).

\section{- Entrevista Co2.}

El gráfico 46 muestra los datos que hacen referencia a la competencia de ES en la segunda entrevista analizada (tabla 126 del anexo).

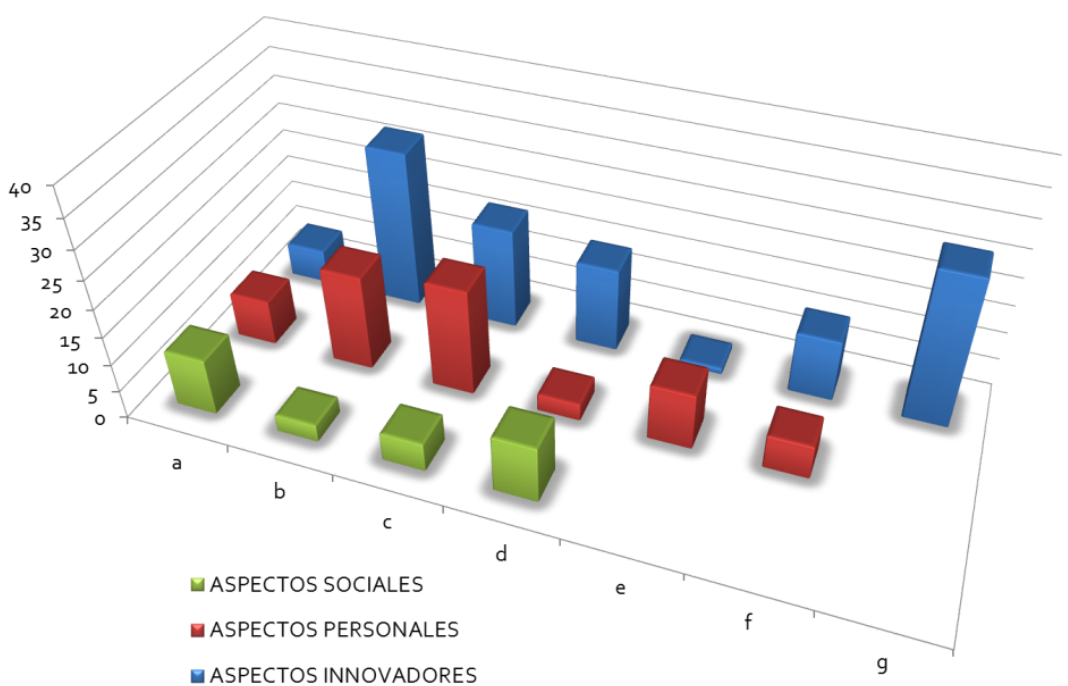

Gráfico 46. Referencias sobre la competencia de Emprendimiento Social en la entrevista Co2 (elaboración propia). 


\section{- Entrevista Co3.}

En el gráfico 47 presentamos los registros de la competencia de ES en la tercera entrevista (tabla 127 del anexo).

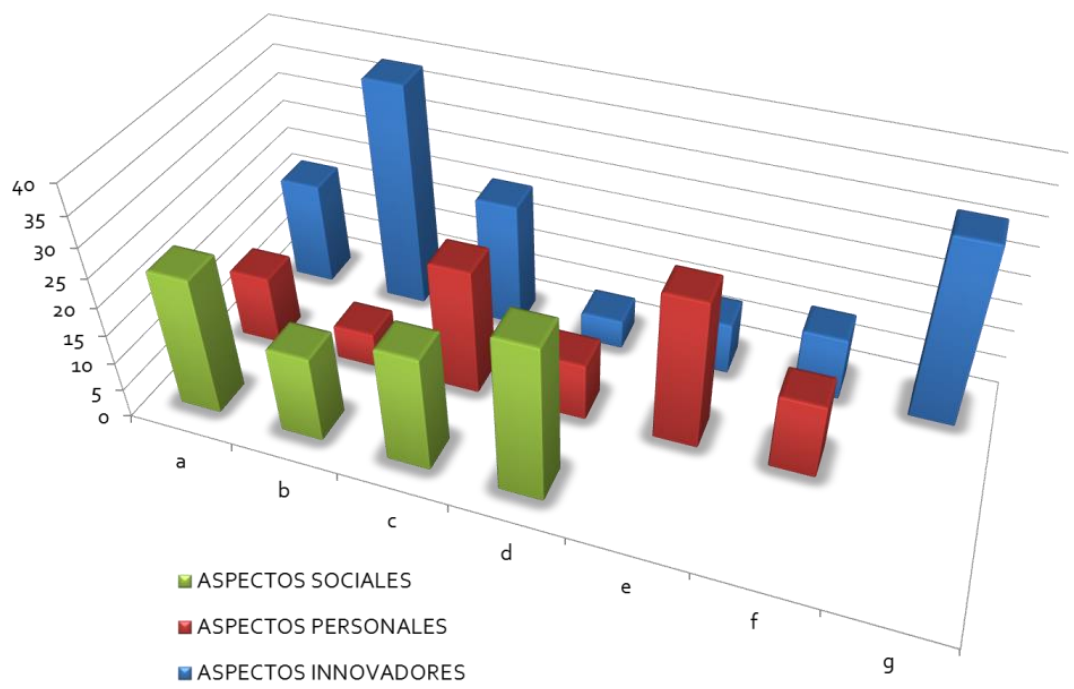

Gráfico 47. Referencias sobre la competencia de Emprendimiento Social en la entrevista Co3 (elaboración propia).

\section{- Entrevista Co4.}

El gráfico 48 expone la información relativa a la competencia de ES en la cuarta entrevista analizada (tabla 128 del anexo).

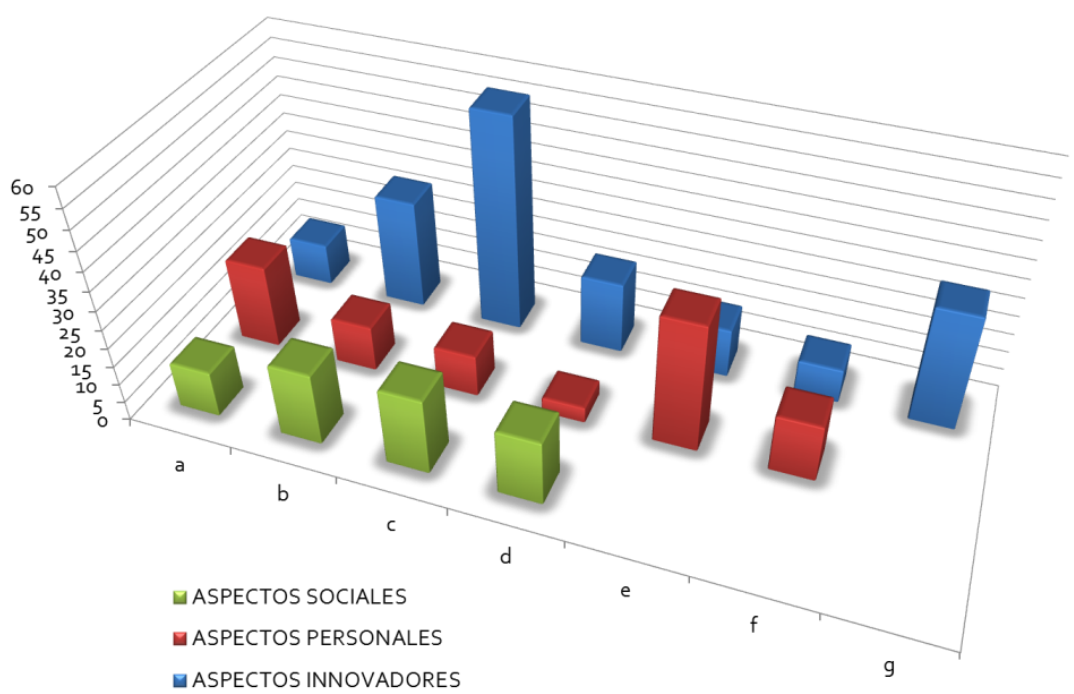

Gráfico 48. Referencias sobre la competencia de Emprendimiento Social en la entrevista Co4 (elaboración propia). 


\section{- Entrevista Co5.}

El gráfico 49 muestra la frecuencia de registros que hacen alusión a la competencia de ES en la quinta entrevista (tabla 129 del anexo).

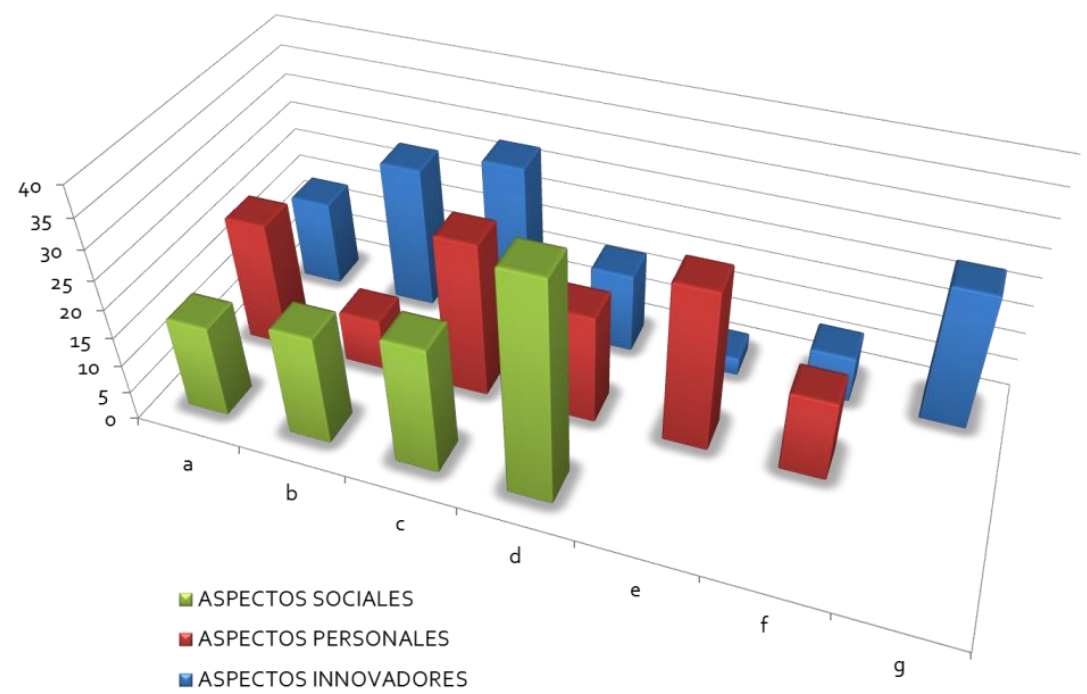

Gráfico 49. Referencias sobre la competencia de Emprendimiento Social en la entrevista Co5 (elaboración propia).

\section{- Entrevista Co6.}

En el gráfico 50 presentamos los registros de la competencia de ES en la sexta entrevista analizada (tabla 130 del anexo).

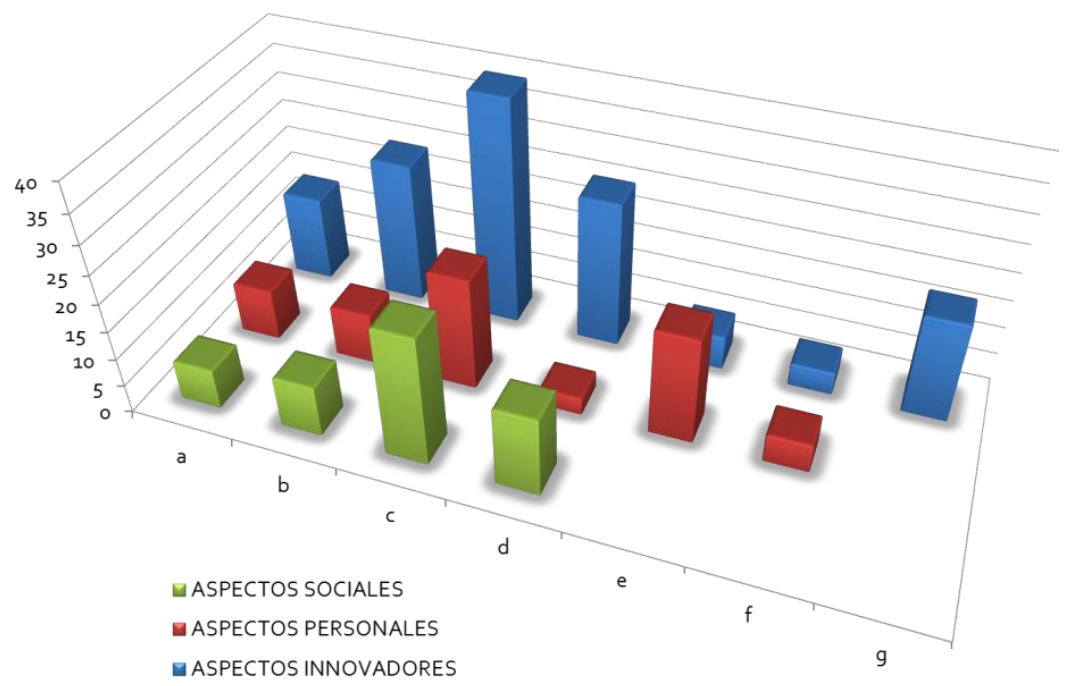

Gráfico 50. Referencias sobre la competencia de Emprendimiento Social en la entrevista Co6 (elaboración propia). 


\section{- Entrevista Co7.}

El gráfico 51 expone la información relativa a la competencia de ES en la séptima entrevista (tabla 131 del anexo).

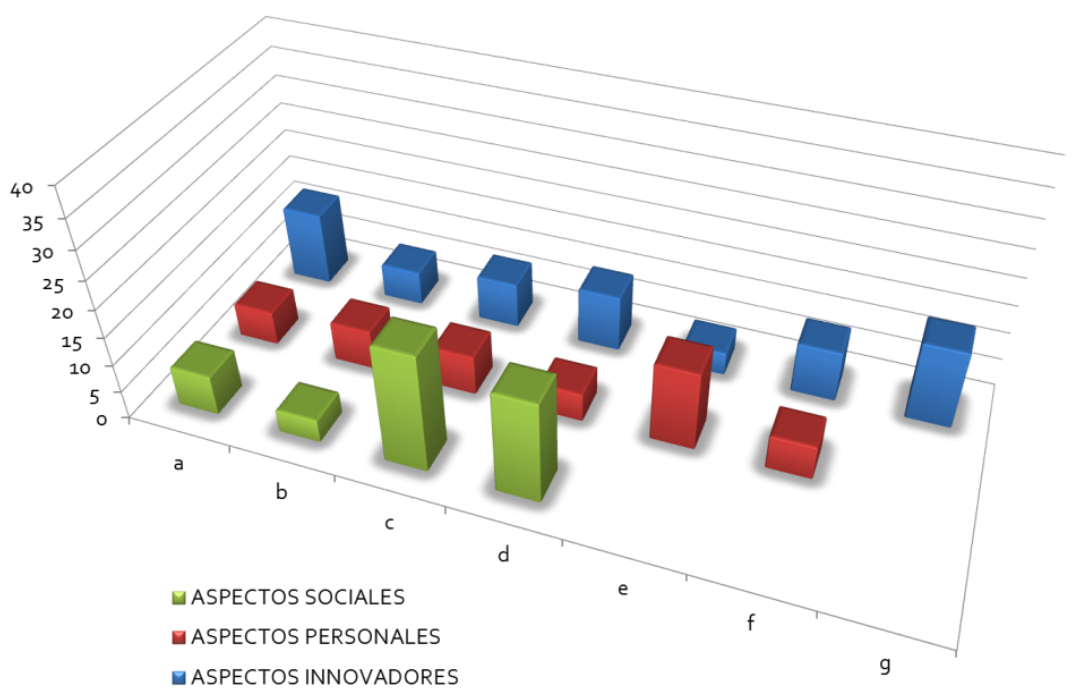

Gráfico 51. Referencias sobre la competencia de Emprendimiento Social en la entrevista Co7 (elaboración propia).

\section{- Entrevista Co8.}

El gráfico 52 muestra la frecuencia de registros que hacen alusión a la competencia de ES en la octava entrevista analizada (tabla 132 del anexo).

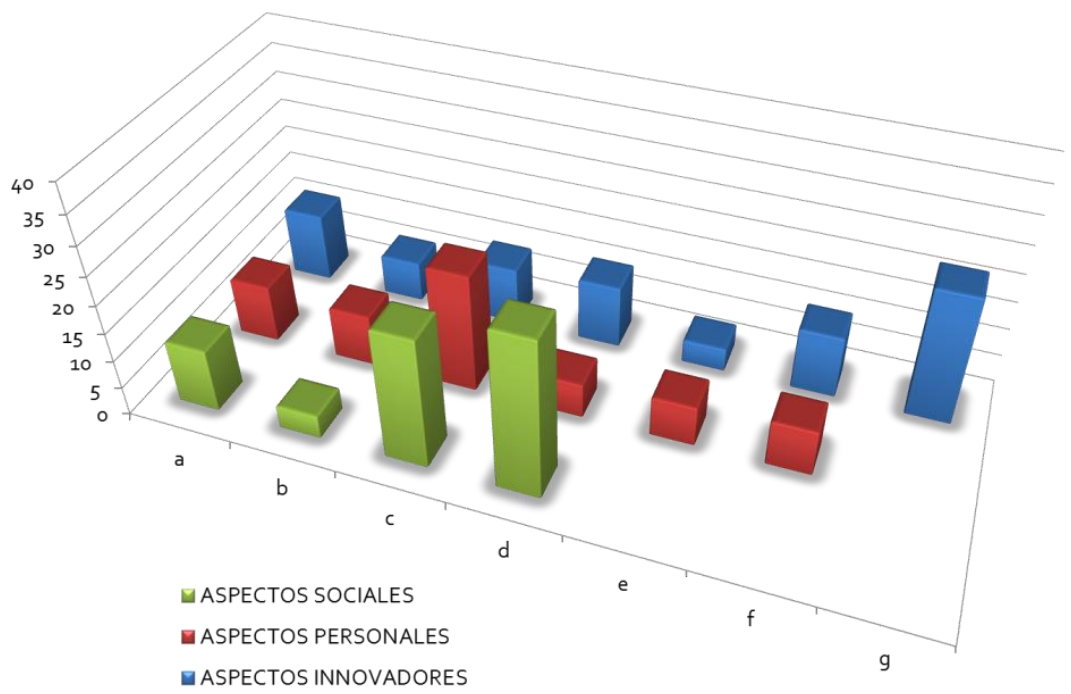

Gráfico 52. Referencias sobre la competencia de Emprendimiento Social en la entrevista Co8 (elaboración propia). 


\section{- Entrevista Cog.}

En el gráfico 53 presentamos los registros de la competencia de ES en la novena entrevista analizada (tabla 133 del anexo).

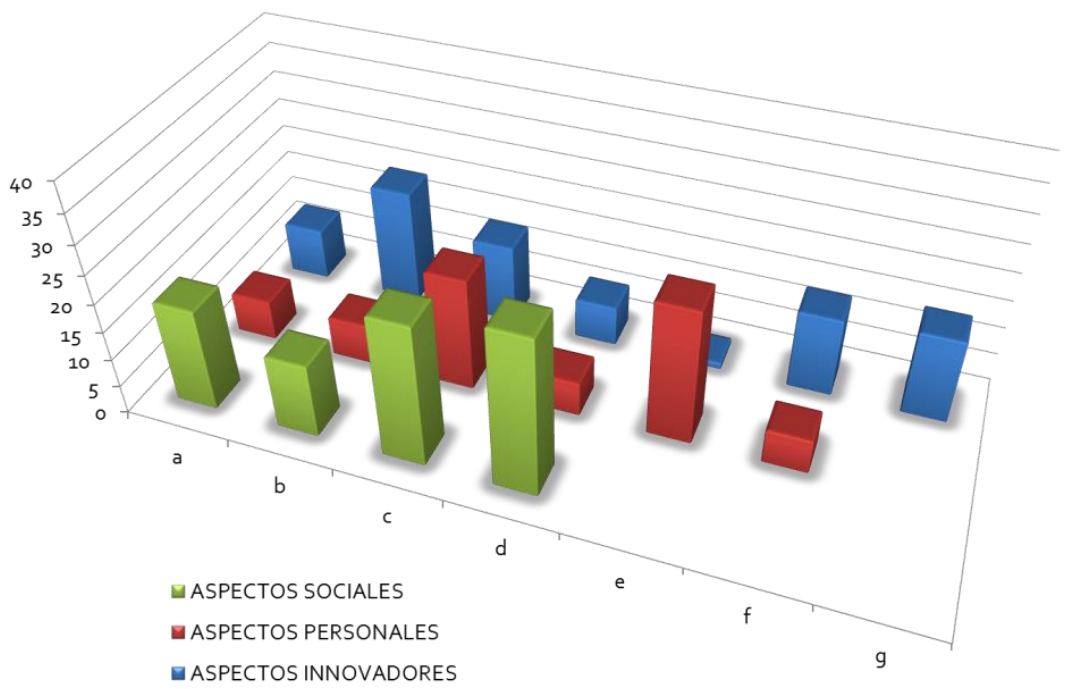

Gráfico 53. Referencias sobre la competencia de Emprendimiento Social en la entrevista Cog (elaboración propia).

\section{- Entrevista C10.}

El gráfico 54 expone la información relativa a la competencia de ES en la décima entrevista (tabla 134 del anexo).

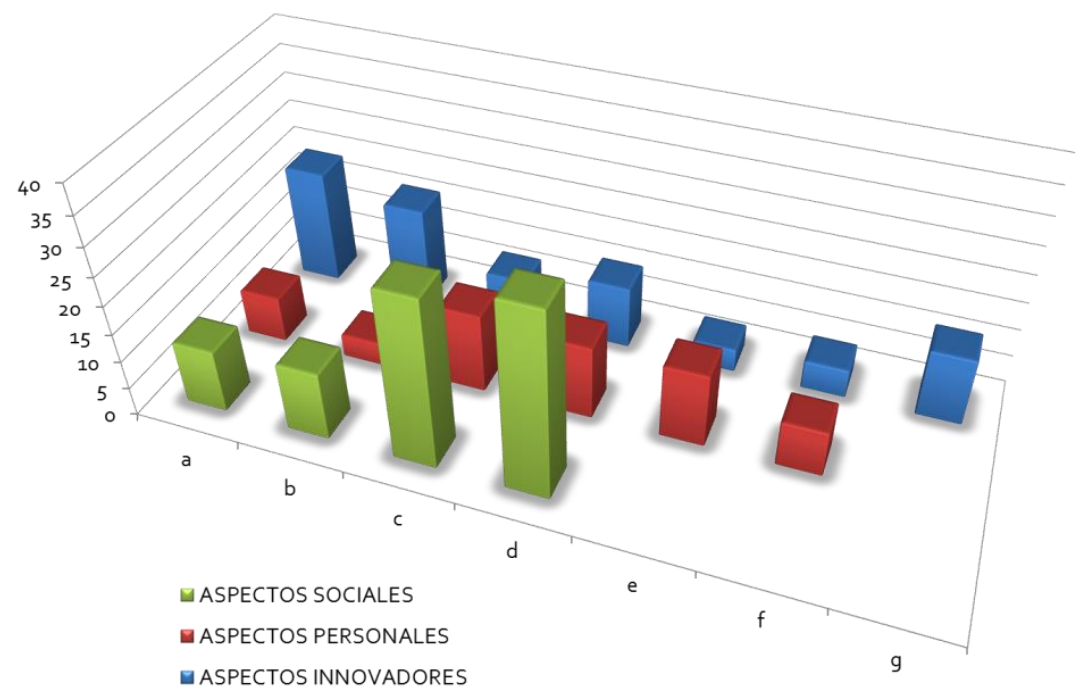

Gráfico 54. Referencias sobre la competencia de Emprendimiento Social en la entrevista C10 (elaboración propia). 


\section{- Entrevista C11.}

El gráfico 55 muestra la frecuencia de registros que hacen alusión a la competencia de ES en la undécima entrevista (tabla 135 del anexo).

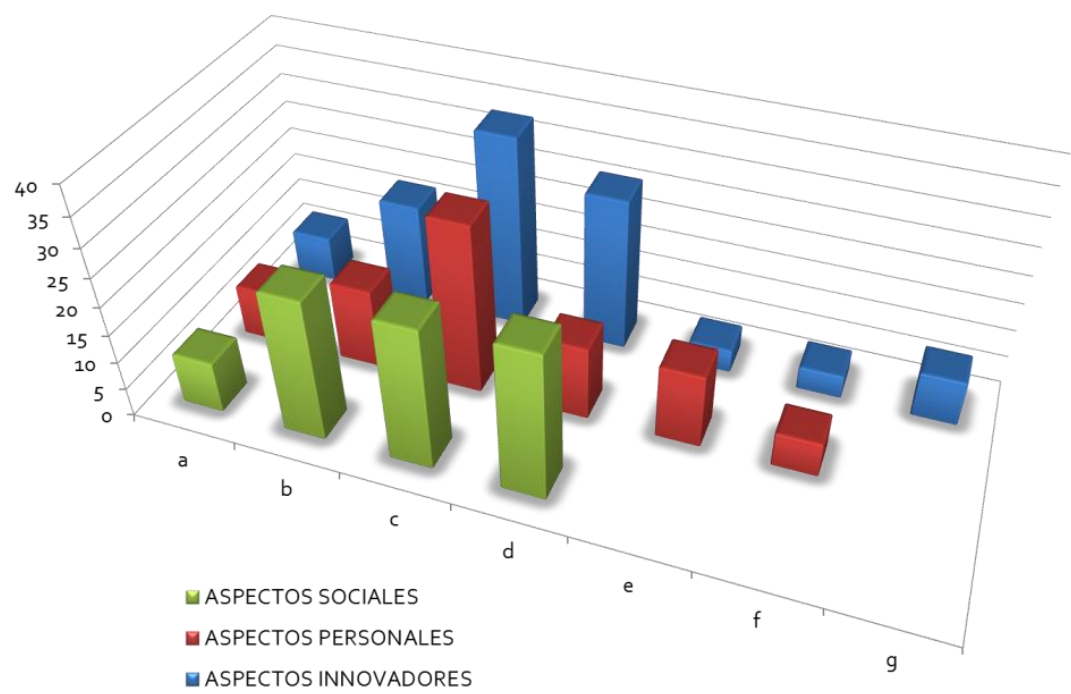

Gráfico 55. Referencias sobre la competencia de Emprendimiento Social en la entrevista C11 (elaboración propia).

\section{- Entrevista C12.}

En el gráfico 56 presentamos los registros de la competencia de ES en la última entrevista analizada (tabla 136 del anexo).

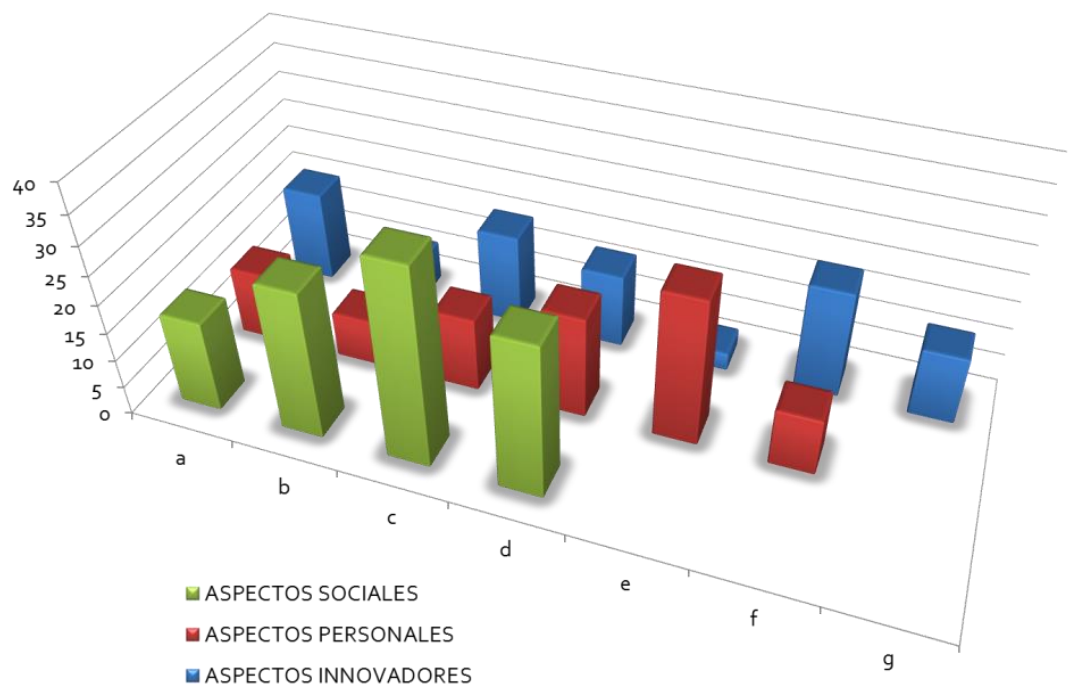

Gráfico 56. Referencias sobre la competencia de Emprendimiento Social en la entrevista C12 (elaboración propia). 


7. Discusión

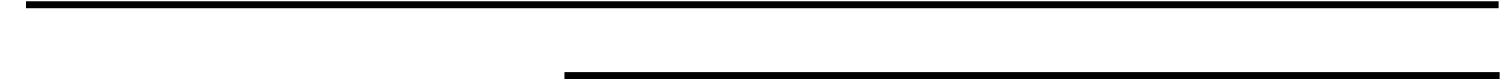



Para clarificar la estructura de este capítulo empezamos recordando la vinculación entre el objetivo principal de la investigación, los objetivos del programa de APS aplicado y las variables dependientes de nuestro estudio con las preguntas e hipótesis de investigación. En la tabla 47, presentamos esquemáticamente la relación entre estos elementos.

Tabla 47. Relación entre el objetivo principal de la investigación, los objetivos del programa de APS, las variables dependientes y las preguntas e hipótesis de investigación (elaboración propia).

\begin{tabular}{|c|c|c|c|}
\hline $\begin{array}{c}\text { OBJETIVO } \\
\text { PRINCIPAL DE LA } \\
\text { INVESTIGACIÓN }\end{array}$ & $\begin{array}{l}\text { OBJETIVOS DEL } \\
\text { PROGRAMA DE } \\
\text { APS }\end{array}$ & $\begin{array}{c}\text { VARIABLES } \\
\text { DEPENDIENTES }\end{array}$ & $\begin{array}{l}\text { PREGUNTAS DE } \\
\text { INVESTIGACIÓN }\end{array}$ \\
\hline & $\begin{array}{l}\text { Desarrollar los } \\
\text { aprendizajes del } \\
\text { alumnado sobre } \\
\text { los contenidos de } \\
\text { la asignatura } \\
\text { "Fundamentos de } \\
\text { la Expresión } \\
\text { Corporal, Juegos } \\
\text { Motrices en } \\
\text { Educación } \\
\text { Infantil", } \\
\text { incrementando su } \\
\text { competencia } \\
\text { docente en este } \\
\text { ámbito }\end{array}$ & $\begin{array}{c}\text { Variable } \\
\text { Dependiente A: } \\
\text { conocimientos y } \\
\text { competencias } \\
\text { del alumnado } \\
\text { sobre los } \\
\text { contenidos } \\
\text { académicos de la } \\
\text { asignatura } \\
\text { "Fundamentos } \\
\text { de la Expresión } \\
\text { Corporal, Juegos } \\
\text { Motrices en } \\
\text { Educación } \\
\text { Infantil" }\end{array}$ & $\begin{array}{c}\mathrm{P}_{1} \text { : ¿El programa } \\
\text { de APS } \\
\text { implementado } \\
\text { aumenta los } \\
\text { conocimientos y } \\
\text { competencias de } \\
\text { la asignatura } \\
\text { "Fundamentos } \\
\text { de la Expresión } \\
\text { Corporal, Juegos } \\
\text { Motrices en } \\
\text { Educación } \\
\text { Infantil" en el } \\
\text { alumnado } \\
\text { participante? }\end{array}$ \\
\hline
\end{tabular}

\section{Diseñar y evaluar los resultados de la aplicación de un programa de APS en la asignatura "Fundamentos de la Expresión Corporal, Juegos Motrices en Educación Infantil"}

Fomentar el Emprendimiento Social del alumnado a través del desarrollo de los distintos aspectos de carácter personal, social e innovador que lo conforman

\section{HIPÓTESIS DE INVESTIGACIÓN}

$\mathrm{H}_{1}$ : La aplicación del programa de APS A producirá en el alumnado del Grupo Experimental I una mejora estadísticamente significativa $(p<0,05)$ en sus conocimientos académicos y competencias sobre los contenidos de la asignatura "Fundamentos de la Expresión Corporal, Juegos Motrices en Educación Infantil", que diferirá y será superior a la obtenida por el Grupo Control

$\mathrm{H}_{2}$ : La aplicación del programa de APS B producirá en el alumnado del Grupo Experimental II una mejora estadísticamente significativa $(p<0,05)$ en sus conocimientos académicos y competencias sobre los contenidos de la asignatura "Fundamentos de la Expresión Corporal, Juegos Motrices en Educación Infantil", que diferirá y será superior a la obtenida por el Grupo Control

$\mathrm{H}_{3}$ : La aplicación del programa de APS A producirá en el alumnado del Grupo Experimental I una mejora estadísticamente significativa $(p<0,05)$ en sus conocimientos académicos y competencias sobre los contenidos de la asignatura "Fundamentos de la Expresión Corporal, Juegos Motrices en Educación Infantil", que diferirá y será superior a la obtenida por el Grupo Experimental II

$\mathrm{H}_{4}$ : La aplicación del programa de APS A producirá en el alumnado del Grupo Experimental I una mejora estadísticamente significativa $(p<0,05)$ respecto a su competencia de Emprendimiento Social, que diferirá y será superior a la obtenida por el Grupo Control

$\mathrm{H}_{5}$ : La aplicación del programa de APS B producirá en el alumnado del Grupo Experimental II una mejora estadísticamente significativa $(p<0,05)$ respecto a su competencia de Emprendimiento Social, que diferirá y será superior a la obtenida por el Grupo Control

$\mathrm{H}_{6}$ : La aplicación del programa de APS A producirá en el alumnado del Grupo 
Experimental I una mejora estadísticamente significativa $(p<0,05)$ respecto a su competencia de Emprendimiento Social, que diferirá y será superior a la obtenida por el Grupo Experimental II

La conexión entre los distintos elementos de esta tabla determinan las principales líneas de trabajo de esta investigación: el desarrollo de los aprendizajes académicos y el fomento de la competencia de ES del alumnado. La discusión de los resultados está dividida en base a estos dos aspectos. La elaboración de ambos apartados sigue el siguiente proceso: exposición de los resultados más relevantes en los distintos análisis realizados, comparación de los resultados con publicaciones de referencia, exposición de resultados adicionales, rechazo o aceptación de las hipótesis de investigación vinculadas a la variable abordada y respuesta de la pregunta de investigación relacionada con dicha variable. La discusión de los resultados integra los registros obtenidos en el análisis cuantitativo y cualitativo, respectivamente, y la expresión cuantitativa de los resultados cualitativos, siguiendo así las indicaciones de Creswell y Plano Clark (2007) respecto a la aplicación de los métodos mixtos. Como ya hemos indicado, la diferencia entre estos dos últimos tipos de resultados radica en que, mientras el estudio cualitativo analiza la importancia y profundidad de los comentarios del alumnado, la expresión cuantitativa de los resultados cualitativos incide en el número de ocasiones que se cita cada uno de los aspectos analizados. Después de discutir los resultados de las dos variables presentamos las futuras líneas de investigación.

\subsection{Discusión de los resultados para la variable A}

Los resultados expuestos en el análisis cuantitativo de nuestra investigación revelan que los tres grupos participantes obtuvieron mejoras significativas en cuanto a los contenidos y competencias de la asignatura. Por otra parte, el análisis cualitativo presenta el desarrollo de valiosos aprendizajes, en las distintas categorías de la rúbrica, derivados de la prestación del servicio. Esto nos ayuda a entender el notable avance del alumnado en cada uno de los aspectos analizados gracias a su participación en el programa de APS implementado. El progreso académico de los grupos vinculados con el APS concuerda con lo expuesto en varios trabajos teóricos de referencia en este campo (Billig, 2000, 2002; Bransford et al., 2004; Butin, 2003, 2006; Chambers y Lavery, 2012; Eyler et al., 2001; Eyler y Giles, 1999; Seban, 2013), así como en diversos meta-análisis sobre los efectos del uso de esta metodología (Celio et al., 2011; Cervantes y Meaney, 2013; Conway et al., 2009; Furco, 2004; White, 2001; Yorio y Ye, 2012).

Al observar los registros del Postest en los distintos grupos analizados comprobamos que los miembros del Grupo Control son los que obtienen mejores puntuaciones, seguidos por el alumnado del Grupo Experimental I, mientras que el Grupo Experimental II es el que peores datos recoge. La 
comparación de estos registros no revela diferencias significativas entre los resultados del Postest de los dos Grupos Experimentales. Por otra parte, pese a la existencia de diferencias significativas en los registros del Postest respecto a los Grupos Experimentales I y II comparados con el Grupo Control, en favor de este último, el contraste por categorías de la rúbrica muestra que dichas diferencias solo se mantienen en tres de los diez bloques de resultados, los que hacen referencia a la adaptación curricular, los aspectos sociales y los juegos de expresión corporal. La expresión cuantitativa de los resultados cualitativos refuerza esta valoración ya que estas tres categorías se encuentran entre las cuatro menos citadas a lo largo de las entrevistas analizadas. Este hecho nos lleva a pensar que dichos aspectos tienen un peor desarrollo a través del APS por lo que deberíamos prestar especial atención a su evolución en futuras intervenciones. Por otra parte, las categorías con mejores puntuaciones, tanto en el análisis cuantitativo como en la expresión cuantitativa de los resultados cualitativos, hacen alusión al ajuste de los juegos al alumnado, la presentación de los juegos, la organización del alumnado, la organización espacio/temporal y la categoría de "otros aspectos". Esta situación guarda relación con los registros de la investigación de Galvan y Parker (2011), donde destacan que el mayor resultado de la aplicación del APS con futuros maestros de EF se obtiene en el desarrollo de habilidades fundamentales para realizar una enseñanza efectiva, relacionadas con la gestión y la instrucción de las clases. Por su parte, la frecuencia de comentarios en las distintas entrevistas analizadas presenta unos datos muy parecidos, situación que nos ayuda a entender que el programa de APS provocó un efecto muy similar en los distintos alumnos participantes.

Seguidamente analizamos en profundidad los resultados del Grupo Experimental I, en base a la agrupación de aprendizajes académicos establecida, para tener un mayor conocimiento del impacto del programa de APS sobre el alumnado en esta cuestión.

Como hemos visto en el capítulo anterior, la categoría que hace referencia al ajuste de los juegos al alumnado es una de las que mayores puntuaciones recibe en el análisis cuantitativo, y la más citada en las entrevistas, lo que nos ayuda a ver el fuerte impacto del APS sobre los aspectos que la conforman. El análisis cualitativo revela numerosas mejoras en cuanto a la capacidad del alumnado para adaptar los juegos a las características de los receptores del servicio. Esta situación nos permite valorar que fueron capaces de tratar adecuadamente la información necesaria para desempeñar su labor de forma satisfactoria, aprendizaje que coincide con lo expuesto por varios autores en cuanto a los efectos de la aplicación del APS (Batchelder y Root, 1994; Eyler y Giles, 1999; Melchior y Orr, 1995; Osborne, Hammerich et al., 1998; Supik, 1996). Los resultados cuantitativos muestran, mayoritariamente, un avance del alumnado en cuanto al ajuste de las actividades a la edad de los participantes, el periodo del curso y la seguridad de las actividades, indicando registros más discretos respecto a las adaptaciones para cubrir las necesidades educativas de los niños. Además, el estudio cualitativo revela notables y numerosos avances en este aspecto, situación que se corresponde con los resultados descritos por Galvan y Parker (2011). En nuestro caso se mejoró específicamente la atención de las necesidades educativas especiales de niños con diversidad funcional a través del APS, un aprendizaje académico que tiene un precedente en el trabajo de Miller (2012). Asimismo, el cuidado por aplicar actividades que no entrañaran riesgo 
para los niños participantes coincide con lo expuesto por Domangue y Carson (2008) en cuanto a la mejora de la seguridad en las actividades propuestas.

La presentación de las actividades constituye una de las categorías con mejores puntuaciones, tanto en el análisis cuantitativo como en el número de citas de las entrevistas, especialmente en cuanto a la descripción de las actividades y la comprensión de las normas. Esta situación señala una mayor fluidez y efectividad del alumnado al explicar las actividades, coincidiendo con varios trabajos sobre la aplicación del APS en docentes de EF (Massey-Stokes y Meaney, 2006; Meaney et al., 2008; Miller, 2012) y una mejor implantación de las normas, resultado descrito en el estudio de Himelein el al. (2010). Por otra parte, el progreso en cuanto a la estructura de la sesiones se erige como otro aprendizaje importante a través de la mejora en las técnicas y protocolos de aplicación de las actividades de EF, situación que corrobora lo expuesto por Galvan y Parker (2011) y LaMaster (2001). Finalmente, el uso adecuado de la representación gráfica fue el aspecto con peores puntuaciones en el estudio cuantitativo y el menos citado en las entrevistas. No obstante, la profundidad de los comentarios del análisis cualitativo y el hecho de que sea el elemento que experimenta un mayor incremento de puntuaciones entre el Pretest y el Postest nos da una idea de la importante mejora del alumnado en esta cuestión.

La organización del alumnado representa la categoría mejor valorada en el análisis cuantitativo y se encuentra entre las más citadas en las entrevistas. Ambas situaciones apuntan a una notable mejora en cuanto al trato directo con los niños, resultado que coincide con lo expuesto en el trabajo de Himelein et al. (2010). Dentro de esta categoría, la participación del alumnado es el aspecto con mayores puntuaciones, demostrando la mejora del alumnado universitario en despertar el interés y motivación de los niños, un aprendizaje académico muy expuesto en la bibliografía (Baldwin et at., 2007; Galvan y Parker, 2011; LaMaster, 2001, Williams y Kovacs, 2001). La frecuencia de citas en las entrevistas otorga un gran protagonismo a la promoción de actividades individuales y grupales; sin embargo, el estudio cuantitativo apunta a un desarrollo más equilibrado del resto de aspectos de esta categoría. Por otra parte, el análisis cualitativo destaca el avance en la gestión del comportamiento de los participantes, logrando que se cumplan las normas establecidas, situación que concuerda con los trabajos de Domangue y Carson (2008), Meaney et al. (2009) y Robinson y Meyer (2012).

En cuanto a la organización del material, tanto el análisis cuantitativo como el número de referencias en las entrevistas indican unos registros más discretos en esta categoría. Pese a ello, los datos indican una notable mejoría entre los registros del Pretest y el Postest respecto a la optimización y distribución del material, mientras que la frecuencia de citas desvela una gran cantidad de comentarios sobre su uso y variedad. Por su parte, el estudio cualitativo revela importantes aprendizajes en todos estos aspectos y destaca la notable relación de sus elementos con la categoría de organización espacio/temporal. Esta situación nos lleva a ver la mejora de los alumnos en las competencias de gestión y organización (Conrad y Hedin, 1989; National Youth Leadership Council, 2004; Yorio y Ye, 2014), en este caso referidas a los recursos materiales. Este aprendizaje está vinculado con su avance en la competencia para desarrollar actividades, la gestión 
de tareas, la autoeficacia, la improvisación y la resolución de problemas, progresos que ya han sido descritos en diversos estudios de APS en EF (Himelein et al., 2010; Miller, 2012; Meaney et al., 2009). Por último, la mejora en cuanto a la optimización de materiales en maestros de EF coincide con lo expuesto en el trabajo de Pechak y Thompson (2011).

La categoría que hace referencia a la organización espacio/temporal obtiene unas puntuaciones notables tanto en el estudio cuantitativo como en la frecuencia de comentarios de las entrevistas. Al igual que en la categoría anterior, el análisis cualitativo revela la interrelación de los distintos elementos de este bloque tanto entre ellos como con las dos categorías previas, la organización del alumnado y la organización del material. Centrándonos en los dos aspectos que la conforman comprobamos que los registros más destacables hacen referencia a la gestión del espacio. No obstante, los aspectos relativos a la gestión del tiempo presentan un mayor progreso entre el Pretest y el Postest cuantitativos. Como anteriormente, la mejora en esta categoría también es debida al progreso del alumnado universitario en sus competencias de gestión y organización, en este caso aplicadas sobre los aspectos espaciales y temporales de las actividades.

La adecuación curricular es una de las categorías con peores registros tanto en el número de referencias de las entrevistas como en el análisis cuantitativo. No obstante, el estudio cualitativo desvela la mejora de los distintos elementos de este bloque en relación a diferentes aprendizajes académicos como el fomento del desarrollo motor, el componente lúdico de los juegos o la organización y participación del alumnado. Esta situación destapa el progreso en la competencia para elaborar un programa educativo en base al currículum y la capacidad para definir objetivos, coincidiendo con los resultados de otros trabajos sobre esta temática (Baldwin et at., 2007; Williams y Kovacs, 2001). Analizando en profundidad los elementos de esta categoría comprobamos que el estudio cuantitativo registra unas puntuaciones más notables en cuanto al valor educativo y la progresión de las actividades; en cambio, la frecuencia de citas de las entrevistas indica una mayor importancia de la relación contenidos-objetivos y la consecución de estos últimos. Por su parte, el análisis cualitativo señala que la consecución de objetivos hace especial referencia al aspecto motor y lúdico de las actividades e incide en el valor educativo del servicio prestado, llegando a desarrollar en los niños aprendizajes que no son propios del área de EF como la mejora del lenguaje. Estos aprendizajes permiten al alumnado plantear propuestas educativas acordes a los requerimientos académicos establecidos y promover otros aprendizajes adicionales a través de la práctica de la EF, cualidades que serán de gran utilidad en su futuro desempeño como docentes.

Al igual que en la categoría anterior, los aspectos sociales obtuvieron unos valores poco notables, tanto en el estudio cuantitativo como en el número de citas de las entrevistas. Sin embargo, el análisis cualitativo revela importantes aprendizajes sociales, tanto por parte de los niños receptores del servicio como por los alumnos universitarios. Esta situación se ve reforzada en el análisis de la variable $\mathrm{B}$ al abordar el estudio de los aspectos sociales relativos a la competencia de ES. Por su parte, los datos cuantitativos indican una mejora muy similar en cuanto a la transmisión de valores sociales, el establecimiento de normas de convivencia y el fomento de la cohesión-integración del grupo, obteniendo unos valores más discretos respecto a la labor del 
alumnado universitario en cuanto a la atención a la diversidad en las actividades realizadas. Sin embargo, analizando el número de referencias en las entrevistas vemos que este aspecto es el que más veces nombraron los alumnos, lo que nos hace pensar que no pasó tan desapercibido. Además, las mejoras descritas en el análisis cualitativo respecto a la diversidad, la inclusión, la solidaridad, el aspecto social de la educación, los valores de justicia social y el crecimiento personal y social, tanto en el colectivo universitario como en los niños receptores del servicio, como señalaron los alumnos entrevistados, nos ayudan a comprender el fuerte impacto social del APS, algo que guarda relación con distintos trabajos que abordan esta temática (Baldwin et al., 2007; Miller, 2012; Tapia, 2008). Finalmente, dentro de la transmisión de valores sociales, queremos resaltar la adecuada gestión del afán competitivo de los niños como un aprendizaje académico muy importante y necesario en el ámbito de la EF, situación que coincide con el trabajo de Domangue y Carson (2008).

La categoría que analiza la aplicación de los juegos motores presenta unas puntuaciones muy notables, tanto en el análisis cuantitativo como en la frecuencia de citas de las entrevistas. Ambos estudios indican que los registros sobre el fomento de la motricidad gruesa y la coordinación global de los niños, a través de las actividades propuestas por el alumnado universitario, son los más destacables. De este modo, apreciamos la mejora de los alumnos en su capacidad para elaborar propuestas y actividades que desarrollen estos aspectos motrices básicos de la $E F$, algo de especial relevancia en Educación Infantil. Por otra parte, la obtención de unos registros menos elevados en cuanto al diseño de tareas que estimulen la coordinación específica y, particularmente, respecto al fomento de la motricidad fina de los niños, destaca la dificultad de desarrollar estas competencias docentes mediante el programa de APS implementado, por lo que deberemos prestar especial atención en futuras aplicaciones para incentivar adecuadamente dichas competencias en los alumnos universitarios. Por su parte, el análisis cualitativo revela profundos comentarios sobre el gran desarrollo motor fomentado en los niños participantes, cubriendo así una de las premisas más importantes del servicio. Todo esto nos lleva a pensar en la gran mejora del alumnado universitario en la elaboración de actividades y juegos para estimular la motricidad de los niños. Además, la aparición de estos resultados supone un novedoso referente en cuanto al estudio de los efectos del APS en futuros docentes de EF, pues debido a la especificidad del programa educativo no se han encontrado resultados similares en la bibliografía sobre esta temática.

El bloque que aborda la aplicación de juegos de expresión corporal es el que menos citas registra en las entrevistas analizadas y uno de los que peores registros obtiene en el análisis cuantitativo. Por otra parte, el estudio cualitativo desvela que el alumnado universitario profundizó en menor medida en el conocimiento y aplicación de este tipo de actividades en comparación con aquellas de carácter motor. Pese a ello, esta categoría es la que presenta una mayor progresión de registros entre el Pretest y el Postest, descubriendo así el aprendizaje académico más notable de esta experiencia. Estos datos cuantitativos apuntan a una mejora conjunta de los distintos elementos de esta categoría; no obstante, el número de referencias sobre el desarrollo de la expresión es sensiblemente superior al resto de aspectos de este bloque, situación que se refuerza al revisar la profundidad de los comentarios expuestos en el análisis cualitativo. Así pues, el desarrollo de este aprendizaje permitirá al alumnado elaborar propuestas que estimulen distintos 
aspectos relacionados con la expresión corporal, elemento de especial interés en el caso que nos ocupa por su gran relevancia en la EF infantil. Igualmente, la mejora en la capacidad para diseñar juegos, tanto motores como expresivos, supone un valor añadido en el contexto de nuestro trabajo pues representa una herramienta educativa muy potente en esta área de conocimiento. Como en el caso anterior, los resultados de esta categoría representan un importante antecedente en este tipo de estudios, ya que tampoco se han encontrado resultados similares al respecto en la bibliografía.

La última categoría de la rúbrica, denominada "otros aspectos", analiza diferentes aprendizajes académicos y es una de las mejor valoradas, tanto en el análisis cuantitativo como en el número de citas de las entrevistas. Por su parte, el estudio cualitativo desvela la interrelación de los aspectos de esta categoría, carácter innovador y originalidad, valor lúdico, variedad de los juegos y evaluación de las actividades propuestas, con distintos elementos de la rúbrica como la participación del alumnado, la consecución de objetivos, el ajuste a las necesidades educativas de los participantes, la variedad de materiales, etc., hecho que refuerza la inclusión de los distintos elementos de esta categoría como aprendizajes académicos a valorar. El análisis cuantitativo muestra una importante mejora global entre las puntuaciones del Pretest y el Postest, lo que indica la gran progresión del alumnado en los aspectos de este bloque. Estos avances en la capacidad para elaborar tareas educativas originales, innovadoras y variadas son de gran relevancia en cualquier ámbito docente, pues representan una inagotable fuente de recursos para enriquecer las propuestas de los futuros docentes. Por otra parte, ser capaz de desarrollar actividades con un elevado componente recreativo supone un aprendizaje de especial interés en la enseñanza de la EF, más aún al tratar con niños en edad infantil, ya que este aspecto tiene un efecto muy positivo en la motivación del alumnado. Finalmente, queremos destacar que la evaluación de las propuestas se desarrolló gracias a una mejora del pensamiento crítico y reflexivo de los alumnos universitarios, coincidiendo con lo expuesto en otros trabajos sobre esta temática (Galvan y Parker, 2011; Pechak y Thompson, 2011). Esta cualidad es de vital importancia, pues establece las bases para mejorar el desempeño del alumnado a través del análisis y la discusión de lo establecido.

Otro resultado destacable respecto a los aprendizajes académicos de la rúbrica es la gran interrelación entre los distintos aspectos analizados. Este hecho, manifestado en las dos vertientes de nuestra investigación, cuantitativa y cualitativa, nos lleva a pensar que el APS facilita la consecución de un aprendizaje global que integra en una misma propuesta educativa el desarrollo de los distintos conocimientos teórico-prácticos a desarrollar, como apunta el estudio de Wilkinson et al. (2013).

Tras analizar los resultados académicos relativos a las categorías de la rúbrica, a continuación presentamos la discusión sobre la mejora de otros aprendizajes vinculados con la temática de la asignatura, extraídos del estudio cualitativo. En primer lugar queremos destacar la gran cantidad de elementos que han aparecido en este análisis y que no se encontraban entre los objetivos iniciales de nuestra propuesta. Esta situación nos hace pensar en la multitud de aprendizajes que podríamos ubicar en el currículum oculto de este tipo de proyectos educativos. 
Entre estos aprendizajes destaca el valor de la experiencia en un entorno real. Este hecho representa uno de los beneficios básicos del APS y opinamos que puede tener mayor importancia si cabe en la EF por tratarse de una materia eminentemente práctica. Así pues, entendemos que la diferencia entre hacer prácticas simuladas con los compañeros de clase y trabajar directamente con niños en sesiones reales es más que notable, hecho que supone una importante mejora en la formación de los futuros maestros al permitirles aplicar procesos de investigación-acción y reflexión de forma directa sobre la práctica real, potenciando enormemente sus aprendizajes en este sentido. Además, la realidad de este contexto educativo también estimuló el desarrollo de aprendizajes propios de la EF, situación que concuerda con los resultados de varios trabajos sobre esta temática (Baldwin et al., 2007; Bishop y Driver, 2007; Robinson y Meyer, 2012).

Esta aplicación del programa de APS en un entorno real facilitó el desarrollo de una amplia diversidad de experiencias educativas, lo que representa otra mejora académica de gran relevancia. De este modo, el uso de nuevas estrategias de enseñanza, la interacción con los padres de los niños, la elaboración de nuevas y variadas propuestas y la práctica en diversos entornos educativos y con distintos tipos de niños representaron valiosos aprendizajes para el alumnado participante, algo que coincide con lo expuesto por Domangue y Carson (2008) y Massey-Stokes y Meaney (2006). Esta variedad de situaciones conlleva un enorme incremento en las vivencias prácticas del alumnado, enriqueciendo notablemente su formación y mejorando su disposición para afrontar de forma exitosa nuevos y diferentes contextos educativos en el futuro.

Asimismo, el alumnado universitario valoró positivamente el trabajo específico con este tipo de niños, al considerar que sus alteraciones motrices aumentaban la exigencia de la práctica educativa, un comentario que también aparece en el estudio de Bishop y Driver (2007). Esta situación les obligó a estar más atentos y receptivos durante las sesiones prácticas, hecho que representa una clara fuente de aprendizajes, irreproducibles mediante las metodologías tradicionales. Igualmente, su apreciación destaca la conveniencia del entorno educativo utilizado en el programa de APS implementado, apuntando que puede ser un campo de actuación idóneo para la aplicación de este tipo de proyectos educativos en el ámbito de la EF.

Los comentarios de las entrevistas también destacan una influencia positiva del programa de APS sobre la vocación profesional del alumnado, un efecto académico similar al descrito en el trabajo de Miller (2012). Esta situación tiene una notable incidencia en el futuro laboral de los alumnos, llegando incluso a esclarecerlo en algunos casos particulares, lo que coincide con lo expuesto por Himelein et al. (2010).

Pese a expresarlo inicialmente en forma de crítica, el alumnado también destacó el hecho de que la independencia otorgada en el servicio aumentó sus competencias al no encontrarse bajo el manto protector del profesorado, una consideración que aporta un nuevo valor a los aprendizajes académicos adquiridos mediante esta metodología didáctica, como señalan Domangue y Carson (2008). Este hecho, ligado a la responsabilidad y a la resolución de problemas derivados de las situaciones de aprendizaje a las que se somete al alumnado, implica que no respondan 
directamente frente el profesorado, sino frente a otros agentes implicados como los propios niños con los que están trabajando, sus familiares o los miembros de las entidades colaboradoras, recibiendo así un feedback externo y directo de su labor como docentes.

Otros comentarios interesantes relativos a cuestiones académicas hacen referencia a la importancia del aprendizaje recíproco promovido entre los niños receptores del servicio y los alumnos universitarios, y el desarrollo de aprendizajes significativos a través de esta práctica pedagógica. Ambas situaciones concuerdan con lo expuesto en estudios similares en los trabajos de Baldwin et al. (2007) y Miller (2012), respectivamente. Así pues, mientras los niños de las entidades desarrollaron su motricidad, mejoraron su socialización y se divirtieron a través de las sesiones de juegos motores y expresivos, el alumnado universitario potenció sus competencias docentes, adquirió experiencias prácticas de gran valor y aprendió a tratar a niños con necesidades educativas especiales, entre otros aprendizajes, situación que pone de manifiesto el claro beneficio de este tipo de experiencias educativas para los principales colectivos implicados. Igualmente, las características del propio contexto de aplicación de estas propuestas suponen un valor añadido en todos estos aprendizajes, pues al aumentar su significado fomentan su adquisición por parte del alumnado.

Pese a todos los aprendizajes descritos, el estudio cuantitativo revela unas puntuaciones globalmente superiores en el Grupo Control respecto a los Grupos Experimentales en el Postest, lo que apunta a unos registros finales menores en estos colectivos. Esta no es una situación novedosa en la aplicación del APS en EF, pues en el trabajo de Galvan y Parker (2011) se considera que la progresión curricular del alumnado fue escasa debido a su preocupación por enfrentarse a una práctica real. No obstante, podemos resaltar que, de los 40 ítems de la rúbrica académica, el Grupo Experimental I mejoró sus registros en el Postest en 36 de ellos, respecto al Pretest, y el Grupo Experimental II en 33. Además, debemos considerar que esta metodología fomenta la adquisición nuevos y valiosos aprendizajes académicos para el alumnado, representando un valor añadido respecto a los planteamientos iniciales. Igualmente se estimula el desarrollo de numerosos aspectos sociales y cívicos, estableciendo así la promoción de ciudadanos preparados para vivir en sociedad. Esta concepción es básica para entender la educación como una forma de mejorar la comunidad en que vivimos y no únicamente como un espacio de formación de futuros profesionales cualificados donde apenas importa su desarrollo ético o moral, una visión acorde al concepto de RSU.

Por otra parte, es posible que la evaluación de los contenidos y competencias de la asignatura a través de un supuesto teórico-práctico favoreciera a los alumnos del Grupo Control al estar más acostumbrados a enfrentarse con este tipo de planteamientos a lo largo de la asignatura. En cambio, el alumnado de los Grupos Experimentales pudo ver alterada su capacidad para responder a nuestros requerimientos sobre los aprendizajes académicos adquiridos en la implementación del APS, por estar menos familiarizados con dicho sistema de evaluación en la temática de la asignatura. Esta situación nos anima a desarrollar, en el futuro, estrategias de valoración alternativas para estimar el desarrollo de las competencias docentes del alumnado en este tipo de 
proyectos, como bien defienden Guzmán y Marín (2011) y Lleixà et al. (2008), lo que nos ayudaría a avanzar en este campo de estudio.

Tras lo expuesto, podemos decir que los resultados del estudio cuantitativo y el análisis de la frecuencia de comentarios cualitativos, tanto en global como en las distintas entrevistas, presentan unos resultados muy similares. Por su parte, el estudio cualitativo nos proporciona información de gran relevancia para comprender en profundidad cómo se han desarrollado los aprendizajes, aportando matices de gran valor sobre los progresos académicos. Asimismo, entendemos que los resultados académicos obtenidos en esta investigación están en consonancia con los trabajos teóricos de referencia y las principales revisiones sobre el APS, así como con diversos estudios sobre los efectos de esta metodología en el campo docente de la EF. Igualmente, también se aportan nuevos y destacables resultados sobre diversos aspectos de gran interés en relación con la variable A.

Finalmente, tomamos las siguientes decisiones en cuanto a las hipótesis iniciales relacionadas con el desarrollo de los aprendizajes académicos de la asignatura:

- Aceptamos parcialmente la $\mathrm{H}_{1}$ ya que el alumnado del Grupo Experimental I obtuvo una mejora estadísticamente significativa $(p<0,05)$ respecto a sus conocimientos $y$ competencias académicas sobre los contenidos de la asignatura "Fundamentos de la Expresión Corporal, Juegos Motrices en Educación Infantil", que difiere pero no es superior a la obtenida por el Grupo Control.

- Aceptamos parcialmente la $\mathrm{H}_{2}$ ya que el alumnado del Grupo Experimental Il obtuvo una mejora estadísticamente significativa $(p<0,05)$ respecto a sus conocimientos y competencias académicas sobre los contenidos de la asignatura "Fundamentos de la Expresión Corporal, Juegos Motrices en Educación Infantil", que difiere pero no es superior a la obtenida por el Grupo Control.

- Aceptamos parcialmente la $\mathrm{H}_{3}$ ya que el alumnado del Grupo Experimental I obtuvo una mejora estadísticamente significativa $(p<0,05)$ respecto a sus conocimientos $y$ competencias académicas sobre los contenidos de la asignatura "Fundamentos de la Expresión Corporal, Juegos Motrices en Educación Infantil", pero no difiere de la obtenida por el Grupo Experimental II.

De igual modo, los resultados de nuestro estudio nos permiten responder positivamente a la pregunta de investigación $\mathrm{P}_{1}$ pues su análisis indica que el programa de Aprendizaje Servicio implementado aumentó los conocimientos y competencias de la asignatura "Fundamentos de la Expresión Corporal, Juegos Motrices en Educación Infantil" en el alumnado participante. 


\subsection{Discusión de los resultados para la variable B}

Los resultados expuestos en el análisis cuantitativo de nuestra investigación revelan que los tres grupos participantes obtuvieron mejoras significativas respecto a la competencia de ES. Por otra parte, el análisis cualitativo presenta el desarrollo de valiosos aprendizajes en las distintas categorías del cuestionario, algo que nos ayuda a ver el notable avance del alumnado participante en el programa de APS en cada uno de los elementos analizados. Este efecto positivo sobre los rasgos personales que definen la competencia de ES concuerda con lo expuesto en varios trabajos teóricos y meta-análisis de referencia en este campo, donde se describe el desarrollo de los aspectos personales, sociales e innovadores que la conforman (Billig, 2000, 2002; Butin, 2003, 2006; Celio et al., 2011; Chambers y Lavery, 2012; Conway et al., 2009; Eyler et al., 2001; Eyler y Giles, 1999; Furco, 2004; Seban, 2013; Tapia 2008; White, 2001; Yorio y Ye, 2012).

Pese a que no existen diferencias significativas entre los registros del Postest en los distintos grupos analizados, comprobamos que los miembros del Grupo Experimentales I son los que obtienen mejores puntuaciones, seguidos por el alumnado del Grupo Experimental II, mientras que el Grupo Control es el que peores datos recoge. Cabe destacar que esta ordenación se mantiene mayoritariamente en todo el estudio cuantitativo, tanto en el análisis por categorías (social, personal e innovadora) como por aspectos característicos del ES (liderazgo, motivación al logro, capacidad para asumir riesgos, etc.). Comparando los registros obtenidos en los distintos ítems del cuestionario, comprobamos que aquellos que valoran los aspectos sociales son los que mejores puntuaciones reciben, seguidos por los que hacen referencia a los aspectos innovadores y por último encontramos los ítems relativos a los aspectos personales, situación que coincide con los resultados de Celio et al. (2011), Conway et al. (2009), Furco (2004) y Yorio y Ye (2012). Esta situación apunta que la experiencia realizada fomenta en mayor medida las habilidades sociales de los participantes, un aspecto de gran relevancia en nuestro caso al tratarse de estudiantes del Grado en Maestro/a, lo que les permitirá ser más sensibles y atentos con las necesidades y requerimientos de sus futuros alumnos. Esta ordenación de los resultados cuantitativos se repite en todos los Grupos analizados, Experimental I, Experimental II y Control, y presenta idéntica distribución en la expresión cuantitativa de los resultados cualitativos, donde los aspectos sociales vuelven a ser los más destacados, seguidos por los aspectos innovadores y los personales, con unos registros igualmente notables. Por otra parte, la frecuencia de comentarios en las distintas entrevistas analizadas también presenta unos datos semejantes, situación que indica que el programa educativo provocó un efecto muy similar en todos los alumnos del Grupo Experimental I entrevistados. Finalmente, cabe destacar que se registraron unas elevadísimas puntuaciones en todos los ítems del cuestionario, hecho que también tiene un claro reflejo en la frecuencia de citas de las entrevistas, lo que indica el notable impacto del programa de APS sobre la competencia de ES del alumnado.

Seguidamente analizamos en profundidad los resultados del Grupo Experimental I, en base a la categorización de los distintos aspectos de la competencia de ES establecida, para tener un mayor conocimiento del impacto del programa de APS sobre el alumnado en esta cuestión. 
Aunque el liderazgo se encuentra entre los menos citados en las entrevistas, su puntuación final supera la valoración media en la escala Likert utilizada, de 1 a 5 , y obtiene una de las mayores progresiones en la comparación entre el Pretest y el Postest cuantitativo. Esta situación se ve reforzada por el estudio cualitativo donde aparecen valiosas situaciones en las que el alumnado tuvo que dirigir diversas actividades, tanto con los niños como con sus compañeros universitarios. Todo ello nos ayuda a ver el importante efecto del programa de APS aplicado sobre este rasgo personal, algo que está en consonancia con los trabajos de Ammon et al. (2002) y Billig (2002) y las revisiones de White (2001) y Celio et al. (2011). Este aprendizaje es de gran relevancia en cualquier ámbito docente ya que el maestro debe liderar y guiar el proceso de enseñanza-aprendizaje para facilitar y orientar el desarrollo de sus alumnos, especialmente en el ámbito de la Educación Infantil por tratarse de un colectivo que necesita mayor apoyo para poder trabajar de forma autónoma.

La motivación al logro representa uno de los aspectos con mejores registros cuantitativos y se encuentra entre los más citados en la frecuencia de comentarios de las entrevistas. Además, el estudio cualitativo revela el deseo del alumnado por mejorar sus competencias docentes vinculadas con la temática de la asignatura, una actitud muy similar a la descrita en otros trabajos en cuanto al incremento de la motivación respecto al aprendizaje y el interés de desarrollo profesional (Follman, 1998; Gallini y Moely, 2003; Hatcher et al., 2002). Por otra parte, las entrevistas también destacan que la intención del alumnado de ayudar a los niños y prestar un servicio de calidad, así como la mejora en la actitud de los participantes respecto a las actividades a realizar, estimularon directa e indirectamente dicha motivación al logro de los alumnos universitarios. Este último apunte señala la interrelación de este aspecto personal con la capacidad de cooperación y ayuda, correspondiente a la categoría de aspectos sociales, lo que indica la mejora conjunta de ambas cualidades a través de este tipo de propuestas educativas.

Aunque el número de citas sobre la capacidad para asumir riesgos es moderado, esta categoría se encuentra entre los aspectos con mejores resultados en el estudio cuantitativo. Por su parte, el análisis cualitativo desvela la buena predisposición del alumnado para responsabilizarse de situaciones desconocidas o que presentan un elevado grado de incertidumbre. La mayor parte de estos casos están relacionados con su participación en el programa de APS, una metodología innovadora de la que apenas tenían referencias previas, y con el trato directo con los niños con necesidades educativas especiales. Ambas situaciones hacen una clara alusión a la responsabilidad asumida por el alumnado, demostrando así la interrelación entre estas dos cualidades personales a través del fomento de la capacidad para asumir riesgos de forma responsable. Por otra parte, este aprendizaje supone una mejora notable en la formación de futuros maestros, pues su labor demanda la aplicación de nuevas y diferentes estrategias de enseñanza que estimulen el desarrollo de los alumnos, como se defiende en el presente trabajo. La aparición de estos resultados supone un novedoso referente en cuanto al estudio de los efectos del APS en el ámbito de la EF, pues no se han encontrado resultados similares en la bibliografía sobre esta temática.

La confianza registra unas valoraciones cuantitativas menos notables, situándose en una posición intermedia respecto al resto de elementos analizados. Esta situación tiene un reflejo en el 
análisis de comentarios ya que se encuentra entre los aspectos menos citados en las entrevistas. Pese a ello, el hecho de que siga registrando unas puntuaciones cuantitativas muy elevadas en el Postest y que la diferencia entre el Prestest y el Postest se encuentre entre las más destacables, nos indica la importante mejora del alumnado en este aspecto. Esta no es una situación novedosa, pues ya ha sido descrita en otros trabajos sobre APS (White, 2001) y en distintos estudios sobre los efectos de esta metodología en futuros docentes de EF (Miller, 2012; Robinson y Meyer, 2012). Además, los resultados del estudio cualitativo descubren la mejora de este aspecto tanto a nivel personal como en cuanto a su labor docente. La adquisición de esta seguridad personal y profesional en su propio desempeño representa una cualidad esencial en la función del profesorado, pues es necesaria para afrontar de forma adecuada las distintas eventualidades que pueden surgir durante el desarrollo de las clases.

Pese a situarse entre los aspectos menos comentados en las entrevistas, la responsabilidad representa otro de los elementos con mejores registros cuantitativos. Por su parte, el análisis cualitativo aporta diferentes situaciones en las que el alumnado debía gestionar nuevas y complejas situaciones, mayoritariamente respecto a la preparación y prestación del servicio. Además, la conexión de esta cualidad con la capacidad para asumir riesgos, la capacidad de cooperación y ayuda o la coherencia y compromiso nos ayudan a ver el notable efecto del programa educativo en este apartado. Este hecho coincide con numerosos trabajos sobre APS al describir una mejora en la responsabilidad social y personal (Follman, 1998; Kirby, 2002; Weiler et al., 1998), responsabilidad social y ciudadana (Ammon et al., 2002; Covitt, 2002; Levine y Lopez, 2002; Westheimer y Kahne, 2004), responsabilidad cívica (Celio et al., 2011) o en la capacidad de asumir responsabilidades (Conrad y Hedin, 1989; National Youth Leadership Council, 2004). En el ámbito de la EF también encontramos trabajos que describen esta mejora en la responsabilidad social y cívica del alumnado a través del APS (Miller, 2012; Pechak y Thompson, 2011) e incluso en trabajos relacionados con el desarrollo del ES (Maistry y Ramdhani, 2010), reforzando la inclusión de este aspecto en nuestro estudio. El desarrollo de este aprendizaje es doblemente importante en la labor del profesorado. En primer lugar, por la gran cantidad de obligaciones que demanda la función docente respecto al trato con los niños, el ajuste de las actividades al currículum establecido, la relación con los familiares de los alumnos, la mediación en los conflictos que puedan aparecer, etc.; $y$, en segundo lugar, por la necesidad de responder de forma adecuada y coherente a las demandas existentes en todas estas situaciones.

Estar integrado en redes sociales con acceso a información y conocimiento supone uno de los aspectos con peores registros cuantitativos, pese a seguir obteniendo unas puntuaciones en el Postest considerablemente superiores a la valoración media de la escala utilizada. Este hecho viene respaldado por un gran número de alusiones en las entrevistas analizadas y la importancia de los comentarios extraídos en el estudio cualitativo. Estos hacen referencia a la relación de los alumnos con distintos colectivos como el profesorado, los compañeros universitarios, los miembros de las entidades y los niños receptores del servicio y sus familiares, demostrando así su integración en distintas redes sociales para mejorar su desempeño en el programa de APS. Todo ello expresa el notable avance del alumnado gracias a su participación en propuestas que requieren la acción 
conjunta del centro educativo y la comunidad, algo que concuerda con lo expuesto por Kim y Billig (2003). Esta cualidad será de gran ayuda en su futuro desempeño laboral ya que, por un lado, incrementará sus recursos para mejorar la calidad de su docencia y, por otro, les permitirá estar acostumbrados al contacto social con los diversos agentes implicados en el proceso de enseñanzaaprendizaje.

Aunque la conciencia social registra una cantidad moderada de comentarios en las entrevistas, este aspecto obtiene unas valoraciones notablemente elevadas en el análisis cuantitativo. Además, el estudio cualitativo revela un valioso impacto sobre este elemento social, especialmente en lo relativo a la atención de las necesidades educativas especiales de los niños receptores del servicio. Estos resultados están en consonancia con numerosos estudios sobre los efectos del APS (Covitt, 2002; Furco, 2004; Perry y Katula, 2001) y con diversos trabajos aplicados en EF (Pechak y Thompson, 2011), principalmente respecto a la concienciación social sobre la prevención de la obesidad infantil (Himelein et al., 2010; Hodges y Videto, 2008; Massey-Stokes y Meaney, 2006). Por otra parte, el trabajo de Maistry y Ramdhani (2010) desarrolla un programa educativo relacionado con el ES para concienciar al alumnado sobre la responsabilidad social, un planteamiento muy acorde con nuestro trabajo. Este aprendizaje supone un valor añadido en la formación de los futuros maestros, pues además de ayudarles a reflexionar y actuar sobre las situaciones que requieren atención para mejorar la sociedad, les permite transmitir esos valores sociales al resto de la comunidad a través de sus alumnos.

La capacidad de cooperación y ayuda es otro aspecto con destacables puntuaciones cuantitativas y el más citado en las entrevistas, situaciones que indican el importante impacto del programa de APS en esta cuestión. Por su parte, el análisis cualitativo señala el desarrollo de esta capacidad gracias al perfeccionamiento de diversas habilidades sociales como la comunicación, la cual hemos asociado en el apartado anterior con el aprendizaje académico de la presentación de los juegos, y la mejora del servicio prestado a través de la acción conjunta de los alumnos universitarios y el profesorado. Todo ello denota un aumento de la competencia para trabajar en equipo de forma cooperativa, coincidiendo con los trabajos de Conrad y Hedin (1989), Melchior y Orr (1995) y el National Youth Leadership Council (2004), en general, y el estudio de Galvan y Parker (2011) en un caso concreto con futuros docentes de EF.

Pese a registrar una cantidad moderada de comentarios en las entrevistas, la coherencia y compromiso del alumnado vuelve a situarse entre los aspectos mejor valorados en los resultados del estudio cuantitativo. Este hecho viene fuertemente respaldado por el análisis cualitativo donde se aprecia el desarrollo de este rasgo social en relación a la prestación del servicio, el deseo de participar nuevamente en propuestas similares o el futuro desempeño laboral del alumnado. Esta mejora ya ha sido descrita en numerosos trabajos, asociada a distintas visiones de compromiso: comunitario (Furco, 2004; Youniss et al., 1999), cívico (Celio et al., 2011), académico (Billig, 2002; Eyler et al., 2001) y social (González y Montes, 2004; Tapia, 2006). Igualmente, también existen importantes referentes en esta línea en cuanto al fomento del compromiso del alumnado de EF a través de programas de APS (LaMaster, 2001; Robinson y Meyer, 2012). 
La convivencia y respeto por el bien público representa el aspecto que mayor puntuación obtiene en el análisis cuantitativo y el segundo más citado en las entrevistas, lo que nos ofrece una primera idea del enorme impacto del APS en esta cuestión social. Por su parte, el estudio cualitativo desvela el desarrollo de esta cualidad esencialmente ligado a la actitud de comprensión y deferencia del alumnado universitario respecto a los niños de las entidades, como sucede en el estudio de Galvan y Parker (2011). No obstante, el fomento de este aspecto también se estimuló a través del contacto con el resto de colectivos implicados como los compañeros de clase (Furco, 2004), el profesorado y los familiares de los receptores del servicio (White, 2001), la comunidad en general (Celio et al., 2011) o la escuela como entidad educativa (Gallini y Moely, 2003; Hatcher et al., 2002; Stephens, 1995). Todo ello revela la relación de este aspecto con la conciencia social, respaldando el desarrollo de esta esta valiosa actitud para vivir en sociedad.

El aspecto innovador que hace referencia a la creatividad es claramente el que menos comentarios genera en las entrevistas analizadas y uno de los peor valorados en el estudio cuantitativo, por lo que podemos considerar que se encuentra entre los menos fomentados mediante la implementación del programa de APS. Pese a ello, presenta unas puntuaciones ampliamente superiores a la valoración media, lo que coincide con el análisis cualitativo al descubrir importantes avances en esta cuestión, especialmente referidos a la elaboración y aplicación de nuevas y diferentes propuestas prácticas. Además, también se indica la influencia de la creatividad en la capacidad para generar ideas, otro aspecto innovador del ES analizado en este trabajo. El trabajo de White (2001) describe la estimulación de esta cualidad, aunque su desarrollo se limita a la capacidad del alumnado para "crear diferencias" en la comunidad, por lo que no concuerda plenamente con el enfoque de nuestra investigación. Esta cualidad creativa adquiere gran relevancia en la formación del profesorado, ya que representa una inagotable fuente de recursos para enriquecer sus propuestas didácticas al permitirles elaborar tareas educativas originales, innovadoras y variadas, como hemos indicado anteriormente.

La capacidad para identificar oportunidades registra un número de citas moderado y una de las puntuaciones cuantitativas más bajas. No obstante, estos datos siguen siendo destacablemente superiores a la valoración media, lo que viene reforzado por el estudio cualitativo donde se indica que el alumnado aprovechó satisfactoriamente su participación en este programa educativo, tanto a nivel personal como en el aspecto académico o profesional. De igual modo, se valora positivamente la prestación del servicio como medio para aportar una mejora a la sociedad, incidiendo en la capacidad del alumnado para apreciar posibilidades de cambio social, desarrollo personal e interpersonal y desarrollo de la ciudadanía participativa, coincidiendo con lo expuesto por Eyler y Giles (1999). Además, esta cualidad no solo les permitirá reconocer y aprovechar distintas oportunidades en el ámbito social, sino que también les ayudará a trasladar los beneficios de su desarrollo a su labor como maestros, mejorando así su competencia para ejercer como docentes.

El aspecto que hace referencia a la iniciativa obtiene una de las puntuaciones más bajas tanto en el estudio cuantitativo como en la frecuencia de comentarios de las entrevistas. Pese a ello, estos 
datos no son tan negativos ya que sigue obteniendo unos registros superiores a la valoración media y presenta uno de los mayores avances entre el Prestest y el Postest, lo que nos ayuda a ver el importante progreso en este aspecto. Además, el análisis cualitativo indica que los alumnos universitarios desarrollaron su iniciativa gracias a la implementación del servicio, especialmente en cuanto a la aplicación de sesiones de juegos motores y expresivos. Este efecto apunta a una mejora de la iniciativa personal y las competencias de organización y gestión, de acuerdo con lo expuesto por Conrad y Hedin (1989) y el National Youth Leadership Council (2004), en nuestro caso vinculadas con el trato del alumnado, el material, el espacio y el tiempo.

La capacidad para generar ideas presenta unos destacables registros cuantitativos apoyados por una gran cantidad de referencias en las entrevistas analizadas. Por su parte, el estudio cualitativo señala que este aspecto se mejoró gracias al fomento de la capacidad de reflexión del alumnado, valorando mayoritariamente cualidades sobre el ámbito educativo en general y las propuestas de APS en particular. La mayor parte de antecedentes sobre los impactos del APS en este aspecto inciden en la mejora del pensamiento crítico y reflexivo (Eyler y Giles, 1999; White, 2001; Yorio y Ye, 2012) y la capacidad para analizar valoraciones a través del juicio ético y la argumentación (Tapia, 2008), por lo que están en consonancia con los resultados de nuestro trabajo.

La capacidad de cambio muestra unas puntuaciones más moderadas, tanto en el análisis cuantitativo como en el número de citas de las entrevista, aunque debemos apuntar que ambos datos registran cifras notablemente elevadas. El estudio cualitativo nos permite ver la buena predisposición del alumnado en este aspecto, especialmente en lo relativo a los procesos de aplicación de las actividades y su percepción de los receptores del servicio. Estas cuestiones hacen referencia a cambios en la competencia docente del alumnado y las creencias o actitudes sobre diversos estereotipos preconcebidos, situación que concuerda con diversos estudios sobre esta temática en el ámbito de la EF (Meaney et al., 2008; Pechak y Thompson, 2011; Williams y Kovacs; 2001). Igualmente, el desarrollo de esta cualidad está ligado al fomento de la capacidad para generar ideas, lo que explica los cambios de opinión del alumnado sobre el proceso pedagógico, como sucede en los trabajos de Maistry y Ramdhani (2010) y Sharra (2005) respecto al fomento del ES.

La capacidad para aprender y evolucionar supone otro aspecto con notables registros, tanto en el estudio cuantitativo como en la frecuencia de comentarios de las entrevistas. El análisis cualitativo nos ayuda a comprender que esta aptitud supone una mejora de las competencias del alumnado a nivel personal, social y profesional, con una notable influencia de los aspectos relativos a la capacidad de cambio y la motivación al logro, y mostrando una relación directa con los aprendizajes académicos de la asignatura anteriormente analizados. Estos avances implican un desarrollo personal e interpersonal, un aumento de las habilidades sociales, una mejora de la ciudadanía participativa y un progreso académico y profesional importantes, coincidiendo con lo expuesto por Eyler y Giles (1999) y White (2001). 
Finalmente, la tolerancia al fracaso obtiene una de las valoraciones más elevadas, tanto en la cantidad de referencias en las entrevistas como en el análisis cuantitativo. Estos datos vienen reforzados por los resultados cualitativos donde se indica la mejora del alumnado para afrontar diferentes conflictos o situaciones desfavorables a lo largo de la prestación del servicio. Todo ello apunta al notable efecto del APS en esta cualidad, situación que está en consonancia con lo expuesto en numerosos trabajos sobre esta temática (Batchelder y Root, 1994; Covitt, 2002; Leming, 2001; McMahon et al., 1998; Morgan y Streb, 1999; Scales y Blyth, 1997). Debemos puntualizar que estos estudios hacen referencia a esta mejora utilizando el término de resiliencia.

Otro resultado destacable es la gran interrelación entre los distintos aspectos del ES analizados. Este hecho, patente en los dos enfoques de análisis, cuantitativo y cualitativo, nos lleva a pensar que el ES se desarrolla de una forma global y no a través del fomento individual de las diversas cualidades que lo conforman, como podría sugerir la selección inicial de estos elementos. Pese a ello, se aprecia una mayor incidencia sobre los aspectos sociales del ES frente a los personales e innovadores, situación que se debe a que están en mayor consonancia con el enfoque didáctico del APS a raíz de la prestación del servicio a la comunidad.

Tras analizar los resultados relativos a las categorías del cuestionario sobre ES, seguidamente presentamos la discusión sobre la mejora de otros aspectos de carácter personal, social e innovador, extraídos del estudio cualitativo. En primer lugar queremos destacar la gran cantidad de elementos que han aparecido en este análisis y que no se encontraban entre los objetivos iniciales de nuestra propuesta. Esta situación nos permite ver que el impacto de este tipo de proyectos sobre las cualidades personales, sociales e innovadoras del alumnado son aún mayores de lo que imaginamos.

Entre estos aspectos destaca el cambio de opinión de los alumnos universitarios sobre los niños receptores del servicio, una situación claramente relacionada con la capacidad de cambio. Inicialmente gran parte de los alumnos universitarios no tenían una imagen muy positiva de los niños y sus familiares, considerando que sería difícil trabajar y tratar con ellos. No obstante, el paso de las sesiones les aportó la información necesaria para comprender su situación y concienciarse de sus necesidades, modificando su percepción sobre este colectivo e incluso indicando que no existían tantas diferencias con cualquier otro grupo de niños. El desarrollo de esta actitud es de gran importancia para su futuro laboral, pues les ayuda a iniciar la práctica docente sin mostrar prejuicios previos. Este cambio positivo en la perspectiva del alumnado sobre los receptores del servicio ya ha sido descrito en diferentes estudios sobre los efectos del APS en general (Conway et al., 2009) y en el ámbito de la EF en particular (Baldwin et at., 2007; Meaney et al., 2009; Pechak y Thompson, 2011; Wilkinson et al., 2013), lo que demuestra la conveniencia de estas propuestas educativas para tratar aspectos sociales dentro de una actividad académica.

Otro aspecto de gran importancia es la satisfacción final del alumnado participante. El sentimiento de felicidad y alegría expresado por los alumnos en las entrevistas nos permite ver la gran aceptación de este tipo de propuestas, tanto desde el punto de vista académico como 
personal. Esta situación coincide con lo expuesto por Miller (2012) y tiene una incidencia directa sobre la actitud del alumnado respecto a la escuela y el aprendizaje (Celio et al., 2011). En ocasiones, el grado de satisfacción del alumnado fue tan elevado que incluso agradecieron la oportunidad de participar en la experiencia de APS, suceso que concuerda con otros trabajos sobre esta temática en EF (Himelein et al., 2010). Por todo ello, consideramos que el profesorado debe aprovechar esta metodología para ofrecer a sus alumnos nuevos y atractivos proyectos educativos que estimulen su desarrollo en multitud de ámbitos.

La promoción de diversos valores éticos y morales a través de la prestación del servicio supone otra cuestión de notable interés. Este hecho incide en la vertiente educativa de la formación del alumnado frente a la mera instrucción, una cuestión de gran relevancia en cualquier nivel o disciplina educativa. Además, esta situación adquiere mayor importancia si cabe en este caso al tratarse de futuros docentes, por lo que también les servirá para trasladarla posteriormente a sus alumnos. Teniendo en consideración las características del contexto en el que se realizó el servicio, se entiende que sea un entorno adecuado para incentivar el desarrollo de este tipo de aspectos, especialmente de aquellos de carácter social. Por todo ello, no es de extrañar que ya se hayan descrito resultados similares en cuanto a la promoción de valores éticos y morales a través del APS (Yorio y Ye, 2012). Concretamente, queremos destacar el desarrollo de la empatía, gracias a la cual el alumnado mejoró su percepción de los niños receptores del servicio y sus necesidades, situación que coincide con los resultados de Baldwin et al. (2007) y Meaney et al. (2008). Este aprendizaje permite que los estudiantes del Grado en Maestro/a estén en mejor disposición para comprender las necesidades y requerimientos de su alumnado en el futuro. Además, matizamos que el fomento de este aspecto se logró evitando despertar un sentimiento de compasión por los receptores del servicio, ya que en los periodos de reflexión se expuso el hecho de que sentirse apenados por los niños podía jugar en contra de sus propios intereses. Por ello, en la medida de lo posible, los alumnos universitarios intentaron tratarlos como a cualquier otro colectivo de niños.

Por último queremos resaltar el fomento de otros aspectos personales, sociales e innovadores que están en consonancia con otros trabajos sobre la temática de nuestro trabajo, como la mejora en la comprensión de la diversidad (Baldwin et al., 2007), el desarrollo de las habilidades interpersonales (Billig, 2002; Yates y Youniss, 1996), la superación de las dudas e inseguridades iniciales respecto al trato con los niños y el refuerzo del sentimiento de la efectividad del alumnado (Miller, 2012), la conexión de la práctica con los contenidos desarrollados en las clases de preparación (Baldwin et al., 2007) y la promoción de la independencia docente y el activismo con intención de incentivar la innovación y provocar un cambio social (Sharra, 2005). Todo ello apunta a que el programa de APS desarrollado ofrece grandes oportunidades en la formación de los futuros maestros de EF, integrando sus conocimientos en la sociedad y preparándolos mediante tareas desafiantes que otorgan una valiosa experiencia a través del servicio a la comunidad (Konukman y Schneider, 2012). Además, el hecho que fueran los propios alumnos los que expresaran estas consideraciones supone un valor añadido, ya que pone de manifiesto su capacidad crítica y reflexiva sobre la formación recibida, demandando una mayor presencia de propuestas innovadoras frente a la educación tradicional. 
Tras lo expuesto, podemos decir que los resultados del análisis cuantitativo y el estudio sobre la frecuencia de comentarios cualitativos, tanto en global como en las distintas entrevistas, presentan unos registros muy similares. Por su parte, el estudio cualitativo nos aporta información de gran relevancia para comprender en profundidad cómo se han desarrollado estos aspectos, aportando matices de gran valor sobre los progresos personales, sociales e innovadores. Asimismo, entendemos que los resultados personales, sociales e innovadores obtenidos en esta investigación están en consonancia con los trabajos teóricos de referencia y las principales revisiones sobre el APS, diversos estudios sobre los efectos de esta metodología en el campo docente de la EF y varias investigaciones sobre el desarrollo del ES. Igualmente, también se aportan nuevos y destacables resultados sobre diversos aspectos de gran interés en relación con la variable $B$.

Finalmente, tomamos las siguientes decisiones en cuanto a las hipótesis iniciales vinculadas al fomento de la competencia de ES:

- Aceptamos parcialmente la $\mathrm{H}_{4}$ ya que el alumnado del Grupo Experimental I obtuvo una mejora estadísticamente significativa $(p<0,05)$ respecto a su competencia de Emprendimiento Social, pero no difiere de la obtenida por el Grupo Control.

- Aceptamos parcialmente la $\mathrm{H}_{5}$ ya que el alumnado del Grupo Experimental II obtuvo una mejora estadísticamente significativa $(p<0,05)$ respecto a su competencia de Emprendimiento Social, pero no difiere de la obtenida por el Grupo Control.

- Aceptamos parcialmente la $\mathrm{H}_{6}$ ya que el alumnado del Grupo Experimental I obtuvo una mejora estadísticamente significativa $(p<0,05)$ respecto a su competencia de Emprendimiento Social, pero no difiere de la obtenida por el Grupo Experimental II.

De igual modo, los resultados de nuestro estudio nos permiten responder positivamente a la pregunta de investigación $\mathrm{P}_{2}$ pues su análisis indica que el programa de Aprendizaje Servicio implementado desarrolló la competencia de Emprendimiento Social en el alumnado participante.

\subsection{Futuras líneas de investigación}

Como hemos apuntado en la discusión de los aprendizajes académicos, una de nuestras posibles líneas de investigación en el futuro puede ser el desarrollo de nuevas estrategias de valoración de las experiencias de APS, por ejemplo a través de la aplicación práctica de la rúbrica creada. Con ello reduciríamos el distanciamiento entre el desarrollo de las competencias del alumnado y su evaluación. Igualmente, nos planteamos la utilización de esta herramienta en otros ámbitos educativos relacionados con la docencia de la EF, para así comprobar su utilidad como instrumento de valoración genérico en este campo. 
Otra futura línea de trabajo es la implementación del cuestionario sobre la competencia de ES en diferentes programas de APS y con otras metodologías innovadoras. Esto nos permitiría contrastar el fomento de esta competencia en otras áreas de conocimiento, mediante la aplicación del APS y otras estrategias didácticas igualmente innovadoras.

También nos planteamos abrir una línea de investigación, en consonancia con los trabajos de Galvan y Parker (2011), que analice los efectos del APS tanto en el alumnado que presta el servicio como en los receptores del mismo, ya que predominantemente los estudios sobre esta metodología se centran exclusivamente en la perspectiva de los proveedores del servicio (Domangue y Carson, 2008; Meaney et al., 2008). Este nuevo planteamiento nos permitiría conocer en mayor profundidad el enorme impacto social de estas propuestas educativas, en nuestro caso respecto a los niños y niñas de las entidades colaboradoras.

Nuestra última sugerencia propone estudiar los efectos de esta metodología de una forma progresiva, analizando la adquisición de conocimientos y el desarrollo de competencias por parte del alumnado, a través de la observación continua a lo largo del proceso de enseñanza-aprendizaje. 


8. Conclusiones

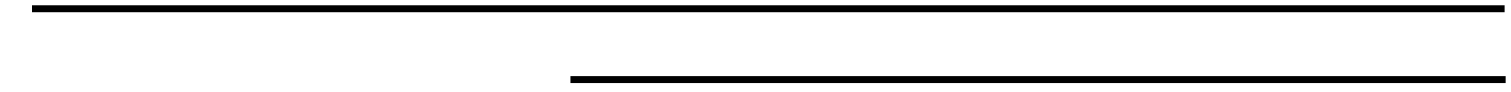



A la vista de lo expuesto en los resultados y discusión de este trabajo, en este capítulo sintetizamos las principales conclusiones de nuestro estudio.

1. La aplicación del programa de Aprendizaje Servicio produjo una mejora significativa en los conocimientos y competencias académicas del alumnado participante sobre los contenidos de la asignatura "Fundamentos de la Expresión Corporal, Juegos Motrices en Educación Infantil".

2. La aplicación del programa de Aprendizaje Servicio produjo una mejora significativa respecto a la competencia de Emprendimiento Social del alumnado participante.

3. Los resultados obtenidos en esta investigación, respecto al desarrollo de los conocimientos y competencias académicas y el fomento de la competencia de Emprendimiento Social, están en consonancia con los trabajos teóricos de referencia y las principales revisiones sobre el Aprendizaje Servicio, así como con diversos estudios sobre los efectos de esta metodología en el campo docente de la Educación Física y el fomento del Emprendimiento Social en el ámbito educativo. Asimismo, se aportan nuevos y destacables resultados sobre diversos aspectos de gran interés en la temática de investigación.

4. Existe una gran interrelación entre los distintos aprendizajes académicos analizados y entre los diferentes aspectos que conforman el Emprendimiento Social, poniendo de manifiesto que los elementos de ambos conceptos se desarrollan de forma conjunta.

5. La aplicación del programa de Aprendizaje Servicio provocó un notable impacto en el alumnado participante, desarrollando numerosos aprendizajes académicos y aspectos de carácter personal, social e innovador adicionales. 

9. Conclusions (English version) 

After showing the results and discussion of this work, in this chapter we summarize the main findings of our study.

1. The application of the Service Learning program produced a significant improvement in the student's academic knowledge and competences about the contents of the subject "Basis of Body Language, Motor Games in Early Childhood Education".

2. The application of the Service Learning program produced a significant improvement over the Social Entrepreneurship student's competence.

3. The results obtained in this research, regarding the development of knowledge and academic competences and the promotion of the Social Entrepreneurship competence, are in agreement with the theoretical reference works and major reviews about Service Learning as well as various studies on the effects of this methodology in teaching Physical Education and promoting Social Entrepreneurship in Education. Moreover, we provide new and outstanding results about several aspects with great interest in our field.

4. There is a strong interrelationship among the academic learning aspects analysed and among the Social Entrepreneurship features, showing that the elements of both concepts are developed jointly.

5. The application of the Service Learning program caused a significant impact on students, developing a relevant academic learning and additional personal, social, and innovative aspects. 

10. Referencias bibliográficas 

Aguirre, A. (1995). Etnografía. Metodología cualitativa en la investigación sociocultural. Barcelona: Marcombo.

Aguirre, R., De Pelekais, C., \& Paz, A. (2012). Responsabilidad social: compromiso u obligación universitaria. TELOS. Revista de Estudios Interdisciplinarios En Ciencias Sociales, 14(1), 11-20.

Aldeanueva, I. (2011). Responsabilidad Social en la Universidad: estudio de casos y propuesta de despliegue. (Doctoral Dissertation, Universidad de Málaga). Retrieved from http://riuma.uma.es/xmlui/bitstream/handle/10630/4687/TDR_ALDEANUEVA_SERRANO.pdf ?sequence $=6$

Aldous, D., \& Brown, D. (2010). Framing bodies of knowledge within the "acoustics" of the school: exploring pedagogical transition through newly qualified Physical Education teacher $\begin{array}{llll}\text { experiences. Sport, Education and Society, 15(4), 429. } & \text { 41-42. }\end{array}$ http://doi.org/10.108o/13573322.2010.514737

Ali, A., Topping, K. J., \& Tariq, R. H. (2009). Entrepreneurial inclinations of prospective teachers. New Horizons in Education, 57(2), 1-16.

Ali, A., Topping, K. J., \& Tariq, R. H. (2010). Entrepreneurial attributes among postgraduate students of a Pakistani university. US-China Education Review, 7(5), 66-77.

Aliaga, C., \& Schalk, A. (2010). E2: Empleabilidad Temprana Y Emprendimiento. Dos grandes desafíos en la formación superior en chile. Calidad En La Educación, (33), 319-337.

Allen, E. I., Langowitz, N., \& Minniti, M. (2006). Global Entrepreneurship Monitor. 2006 Report on Women and Entrepreneurship. The Global Entrepreneurship Research Association. Retrieved from http://www.babson.edu/Academics/centers/blank-center/globalresearch/gem/Documents/gem-2006-women-entrepreneurship-report.pdf

Allen, J. P., Kuperminc, G., Philliber, S., \& Herre, K. (1994). Programmatic prevention of adolescent problem behaviors: The role of autonomy, relatedness, and volunteer service in the teen outreach program. American Journal of Community Psychology, 22(5), 617-638. http://doi.org/10.1007/BF02506896

Allin, L., \& Humberstone, B. (2006). Exploring careership in outdoor education and the lives of women outdoor educators. Sport, Education and Society, 11(2), 135-153. http://doi.org/10.1080/13573320600640678

Alonso, F. J. (2004). Adquisición de actitudes de responsabilidad social a través de un programa de voluntariado. (Doctoral Dissertation, Universitat de València). Retrieved from http://www.tdx.cat/bitstream/handle/10803/10301/alonso.pdf?sequence=1

Alonso, P. (2008). La formación en competencias del profesorado de Magisterio en la especialidad de Educación Física. Educar, (42), 63-77. 
Alter, K. (2004). Social enterprise typology. Washington, DC: Virtue Ventures LLC. Retrieved from http://www.globalcube.net/clients/philippson/content/medias/download/SE_typology.pdf

Álvarez, S., Pérez, A., \& Suárez, M. L. (2008). Hacia un enfoque de la educación en competencias. Consejería de Educación y Ciencia Dirección General de Políticas Educativas y Ordenación Académica - Servicio de Evaluación, Calidad y Ordenación Académica. Gobierno del $\begin{array}{llll}\text { Principado de } & \text { Asturias. } & \text { Retrieved }\end{array}$ http://www.educastur.es/media/publicaciones/enfoquemail.pdf

Álvarez-Rojo, Víctor; Romero, S., Gil-Flores, J., Rodríguez-Santero, J., Clares, J., Asensio, I., DelFrago, R., ... Salmeron-Vilchez, P. (2011). Necesidades de formación del profesorado universitario para la adaptación de su docencia al Espacio Europeo de Educación Superior (EEES). Relieve. Revista Electrónica de Investigación Y Evaluación Educativa, 17(1), 1-22. Retrieved from http://www.uv.es/RELIEVE/v17n1/RELIEVEv17nı_1.htm

Alvord, S. H., Brown, L. D., \& Letts, C. W. (2004). Social Entrepreneurship and Societal Transformation: An Exploratory Study. The Journal of Applied Behavioral Science, 40(3), 260282. http://doi.org/10.1177/0021886304266847

Ammon, M. S., Furco, A., Chi, B., \& Middaugh, E. (2002). Service-learning in California: A profile of the CalServe service-learning partnerships, 1997-2000. Berkeley, CA: University of California, Service-Learning Research and Development Center.

Andersen, S. M. (1998). Service Learning: A National Strategy for Youth Development. Washington, DC: George Washington University. Retrieved from http://www.gwu.edu/ ccps/documents/1998ServiceLearning.pdf

Andrade, H. G. (2000). Using Rubrics to Promote Thinking and Learning. Educational Leadership, 57(5), 13-18. Retrieved from http://www.ascd.org/publications/educationalleadership/feboo/vol57/numo5/Using-Rubrics-to-Promote-Thinking-and-Learning.aspx

ANECA. Agencia Nacional de Evaluación de la Calidad y Acreditación. (2005a). Libro Blanco. Título de Grado en Ciencias de la Actividad Física y del Deporte. Madrid: Omán Impresores. Retrieved from http://www.aneca.es/var/media/150296/libroblanco_deporte_def.pdf

ANECA. Agencia Nacional de Evaluación de la Calidad y Acreditación. (2005b). Libro Blanco. Título de Grado en Magisterio. Madrid: Omán Impresores. Retrieved from http://www.aneca.es/var/media/150404/libroblanco_juno5_magisterio1.pdf

Anguera, M. T., Camerino, O., Castañer, M., \& Sánchez-Algarra, P. (2014). Mixed methods en la investigación de la actividad física y el deporte. Revista de Psicología Del Deporte, 23(1), 123130.

Aponte, C. (2007). Propuesta de indicadores de evaluación de la función de Proyección Social / Extensión Universitaria / Interacción en la Educación Superior. Asociación Colombiana de 
Universidades

(ASCUN).

Retrieved

from http://dars.pucp.edu.pe/2011/publicaciones_documentos/Propuesta_e_Indicadores_de_Evalu acion_de_la_Func_Social.pdf

Aramburuzabala, P., \& García, R. (2012). El Aprendizaje-Servicio en la formación de maestros. In VII CIDUI: La universidad: una institución de la sociedad. Barcelona.

Arnold, P. J. (1991). Educación física, movimiento y currículum. Madrid: Ediciones Morata.

Astin, A. W., \& Sax, L. J. (1998). How undergraduates are affected by service participation. Journal of College Student Development, 39(3), 251-263.

Austin, J., Stevenson, H. H., \& Wei-Skillern, J. (2003). Social Enterprise Series No. 28-Social Entrepreneurship and Commercial Entrepreneurship: Same, Different, or Both? (No. 04-029). Harvard Business School.

Austin, J., Stevenson, H., \& Wei-Skillern, J. (2006). Social and Commercial Entrepreneurship: Same, Different, or Both? Entrepreneurship Theory and Practice, 30(1), 1-22. http://doi.org/10.1111/j.1540-6520.2006.00107.x

Ausubel, D. P. (1960). The use of advance organizers in the learning and retention of meaningful verbal material. Journal of Educational Psychology, 51(1), 267-272. http://doi.org/10.1037/hoo46669

Ausubel, D. P. (1963). The Psychology of Meaningful Verbal Learning. New York, NY: Grune \& Stratton.

Ausubel, D. P. (1978). In defense of advance organizers: A reply to the critics. Review of Educational Research, 48(2), 251-257. http://doi.org/10.3102/00346543048002251

Ausubel, D. P., Novak, J. D., \& Hanesian, H. (1978). Educational Psychology: A Cognitive View (2nd ed.). New York, NY: Holt, Rinehart \& Winston.

Babcock, B. (Ed.). (2000). Learning from Experience: A Collection of Service-Learning Projects Linking Academic Standards to Curriculum. Milwaukee, WI: Wisconsin Department of Public Instruction.

Bacq, S., \& Janssen, F. (2011). The multiple faces of social entrepreneurship: A review of definitional issues based on geographical and thematic criteria. Entrepreneurship \& Regional Development: An International Journal, 23(5-6), 373-403. http://doi.org/10.1080/08985626.2011.577242

Baldwin, S. C., Buchanan, A. M., \& Rudisill, M. E. (2007). What Teacher Candidates Learned About Diversity, Social Justice, and Themselves From Service-Learning Experiences. Journal of Teacher Education, 58(4), 315-327. http://doi.org/10.1177/0022487107305259

Barber, K. (Ed.). (1998). The Canadian Oxford dictionary. Toronto: Oxford University Press. 
Baron, D. P. (2007). Corporate social responsibility and social entrepreneurship. Journal of Economics \& Management Strategy, 16(3), 683-717. http://doi.org/10.1111/j.1530$9134.2007 .00154 \cdot x$

Barrachina, J., \& Blasco, J. E. (2012). Análisis del desarrollo de las competencias básicas en el currículum de la Educación Física en la ESO en la Marina Baixa. Un estudio de caso. Apunts. Educación Física Y Deportes, 4(110), 36-44. http://doi.org/10.5672/apunts.2014og83.es.(2012/4).110.04

Batchelder, T. H., \& Root, S. (1994). Effects of an undergraduate program to integrate academic learning and service: cognitive, prosocial cognitive, and identity outcomes. Journal of Adolescence, 17(4), 341-355. http://doi.org/10.1006/jado.1994.1031

Batlle, R. (2009). El servicio en el aprendizaje servicio. In J. M. Puig (Ed.), Aprendizaje servicio (APS) Educación y compromiso cívico (pp. 71-90). Barcelona: Graó.

Bazeley, P. (2009). Editorial: Integrating Data Analyses in Mixed Methods Research. Journal of Mixed Methods Research, 3(3), 203-207. http://doi.org/10.1177/1558689809334443

Belisle, C., \& Linard, M. (1996). Quelles nouvelles compétences des acteurs de la formation dans le contexte des TIC? Education Permanente, (127), 19-47.

Beltrán, J., Íñigo, E., \& Mata, A. (2014). La responsabilidad social universitaria, el reto de su construcción permanente. RIES. Revista Iberoamericana de Educación Superior, 5(14), 3-18.

Bentz, V. M., \& Shapiro, J. J. (1998). Mindful Inquiry in Social Research. London: Sage Publications.

Bernadowski, C., Perry, R., \& Del Greco, R. (2013). Improving perservice teachers' self-efficacy through service learning: Lessons learned. International Journal of Instruction, 6(2), 67-86.

Bertaux, D. (1997). Les Récits de vie: perspective ethnosociologique. Paris: Éditions Nathan.

Bichi, R. (2002). L'intervista biografica. Una prospettiva metodologica. Milano: Vita e Pensiero.

Billig, S. H. (2000). Research on K-12 School-Based Service-Learning: The Evidence Builds. Phi Delta Kappan, 81(9), 658-664.

Billig, S. H. (2002). Support for K-12 Service-Learning Practice: A Brief Review of the Research. Educational Horizons, 80(4), 184-189.

Billig, S. H. (2004). Heads, hearts, hands: The research on K-12 service-learning. In J. C. Kielsmeier, M. Neal, \& M. McKinnon (Eds.), Growing to greatness: The state of service-learning project (pp. 12-25). St. Paul, MN: National Youth Leadership Council.

Billig, S. H. (2009). Does quality really matter: Testing the new $\mathrm{K}-12$ service learning standards for quality practice. In B. E. Moely, S. H. Billig, \& B. A. Holland (Eds.), Advances in service-learning 
research: Vol. 9. Creating our identities in service-learning and community engagement (pp. 131157). Charlotte, NC: Information Age Publishers.

Billig, S. H., Root, S., \& Jesse, D. (2005). The Impact of Participation in ServiceLearning on High School Students' Civic Engagement (The Center for Information \& Research on Civic Learning \& Engagement No. CIRCLE WORKING PAPER 33). Denver, CO.

Birky, B. (2012). Rubrics: A Good Solution for Assessment. Strategies: A Journal for Physical and Sport Educators, 25(7), 19-21. http://doi.org/10.1080/08924562.2012.10590978

Bishop, J., \& Driver, S. (2007). Implementing Service-Learning in Undergraduate Adapted Physical Education. Journal of Physical Education, Recreation \& Dance (JOPERD), 78(8), 15-19. http://doi.org/10.1080/07303084.2007.10598071

Blázquez, D., \& Bofill, A. (2009). Estrategias didácticas para la enseñanza de la Educación Física en base a competencias. In D. Blázquez \& E. M. Sebastiani (Eds.), Enseñar por competencias en Educación Física (pp. 139-162). Barcelona: INDE.

Blázquez, D., \& Sebastiani, E. M. (Eds.). (2009). Enseñar por competencias en Educación Física. Barcelona: INDE.

Blyth, D. A., Saito, R., \& Berkas, T. (1997). A quantitative study of the impact of service-learning programs. In A. S. Waterman (Ed.), Service learning: Applications from research (pp. 39-56). Hillsdale, NJ: Lawrence Erlbaum Associates.

BOE 106. Ley Orgánica de Educación 2/2006 de 3 de mayo, Pub. L. No. 7899 (2006). Retrieved from http://www.boe.es/boe/dias/2006/05/04/pdfs/A17158-17207.pdf

BOE 295. Ley Orgánica para la Mejora de la Calidad Educativa 8/2013 de 9 de diciembre, Pub. L. No. 12886 (2013). Retrieved from http://www.boe.es/boe/dias/2013/12/10/pdfs/BOE-A-201312886.pdf

BOE 297. Real Decreto $1707 / 2011$, de 18 de noviembre, por el que se regulan las prácticas académicas externas de los estudiantes universitarios, Pub. L. No. 19362 (2011). Retrieved from http://www.boe.es/boe/dias/2011/12/10/pdfs/BOE-A-2011-19362.pdf

Boissin, J. P., Castagnos, J. C., \& Deschamps, B. (2006). Motivations and drawbacks concerning entrepreneurial action: a study of French PhD students. In A. Fayolle \& H. Klandt (Eds.), International Entrepreneurship: Education Issues and Newness (pp. 263-276). Cheltenham, UK: Edward Elgar Publishing.

Boks, C., \& Diehl, J. C. (2006). Integration of sustainability in regular courses: experiences in industrial design engineering. Journal of Cleaner Production, 14(9-11), 932-939. http://doi.org/10.1016/j.jclepro.2005.11.038 
Bolívar, A., Domingo, J., \& Fernández, M. (1998). La investigación biográfico-narrativa en educación. Guía para indagar en el campo. Granada: Grupo Force.

Boned, C. J., Rodríguez, G., Mayorga, J. I., \& Merino, Á. (2004). Competencias profesionales del Licenciado en Ciencias de la Educación Física y el Deporte. In III Congreso de la Asociación española de Ciencias del Deporte: Hacia la Convergencia Europea. Valencia. Retrieved from http://cienciadeporte.eweb.unex.es/congreso/04 val/pdf/C142.pdf

Borins, S. F. (2000). Loose Cannons and Rule Breakers, or Enterprising Leaders? Some Evidence About Innovative Public Managers. Public Administration Review, 6o(6), 498-507. http://doi.org/10.1111/0033-3352.00113

Bornstein, D. (2004). How to Change the World: Social Entrepreneurs and the Power of New Ideas. Oxford: Oxford University Press.

Borrero, C., \& Contreras, L. C. (2009). Evaluación de competencias en entornos virtuales. In J. I. Aguaded \& M. C. Fonseca (Eds.), Huellas de innovación docente en las aulas universitarias (pp. 77-86). La Coruña: Netbiblo.

Boschee, J. (1995). Social entrepreneurship. Across the Board, 32(3), 20-25.

Boschee, J. (1998). Merging Mission and Money: A Board Member's Guide to Social Entrepreneurship. The National Center for Nonprofit Boards. Retrieved from http://www.socialent.org/pdfs/MergingMission.pdf

Boschee, J., \& McClurg, J. (2003). Towards A Better Understanding of Social Entrepreneurship: Some Important Distinctions. Retrieved from http://www.caledonia.org.uk/papers/SocialEntrepreneurship.pdf

Bosma, N., \& Harding, R. (2007). Global Entrepreneurship Monitor. GEM 2006 Results. The Global Entrepreneurship Research Association. Retrieved from http://www.babson.edu/Academics/centers/blank-center/globalresearch/gem/Documents/gem-2006-global-report.pdf

Boss, J. A. (1994). The Effect of Community Service Work on the Moral Development of College Ethics Students. Journal of Moral Education, 23(2), 183-198. http://doi.org/10.1080/0305724940230206

Boyd, B. K., Gove, S., \& Hitt, M. A. (2005). Construct measurement in strategic management research: illusion or reality? Strategic Management Journal, 26(3), 239-257. http://doi.org/10.1002/smj.444

Boyle, M. E. (2007). Learning to Neighbor? Service-learning in Context. Journal of Academic Ethics, 5(1), 85-104. http://doi.org/10.1007/s10805-007-9045-5 
Brannen, J. (2005). Mixing Methods: The Entry of Qualitative and Quantitative Approaches into the Research Process. International Journal of Social Research Methodology, 8(3), 173-184. http://doi.org/10.1080/13645570500154642

Bransford, J. D., Brown, A. L., \& Cocking, R. R. (Eds.). (2004). How People Learn Brain, Mind, Experience, and School (Expanded E). Washington, DC: National Academy Press.

Bricall, J. M. (2000). Conferencia de Rectores de las Universidades Españolas (CRUE). Informe Universidad 2000. Barcelona: Biblioteca Digital de la OEl. Retrieved from http://www.oei.es/oeivirt/bricall.htm

Brown, D. (1999). Complicity and Reproduction in Teaching Physical Education. Sport, Education and Society, 4(2), 143-159. http://doi.org/10.1080/1357332990040203

Brown, D., \& Evans, J. (2004). Reproducing Gender? Intergenerational Links and the Male PE Teacher as a Cultural Conduit in Teaching Physical Education. Journal of Teaching in Physical Education, 23(1), 48-70.

Bruner, J. (1991). Actos de significado. Más allá de la revolución cognitiva. Madrid: Alianza.

Bruyat, C., \& Julien, P. A. (2001). Defining the field of research in entrepreneurship. Journal of Business Venturing, 16(2), 165-180.

Buchta, K. (2012). The Competences of Physical Education Students. Unified Versus Two-Tier University Studies. Polish Journal of Sport and Tourism, (19), 151-154. http://doi.org/10.2478/v10197-012-0015-0

Bunk, G. (1994). La transmisión de las competencias en la formación y perfeccionamiento profesionales de la RFA. Revista Europea de Formación Profesional, (1), 8-14.

Buscà, F., \& Capllonch, M. (2008). De las competencias básicas a las competencias profesionales transversales. Aportaciones desde el ámbito de la educación física. Tándem. Didáctica de La Educación Física, (26), 34-51.

Bustos, C., \& Inciarte, A. (2012). Dimensión comunitaria de la responsabilidad social universitaria. Opción, (68), 367-379.

Butin, D. W. (2003). Of What Use Is It? Multiple Conceptualizations of Service Learning Within Education. Teachers College Record, 105(9), 1674-1692. http://doi.org/10.1046/j.1467$9620.2003 .00305 . x$

Butin, D. W. (2006). The Limits of Service-Learning in Higher Education. The Review of Higher Education, 29(4), 473-498. http://doi.org/10.1353/rhe.2006.0025

Bygrave, W. D., \& Quill, M. (2007). Global entrepreneurship monitor. 2006 financing report. The Global Entrepreneurship Research Association. Retrieved from 
http://www.babson.edu/Academics/centers/blank-center/globalresearch/gem/Documents/gem-2006-financing-report.pdf

Caballero, J. A. (2013). La contribución del área de educación física a las competencias básicas: opinión de los docentes. EmásF. Revista Digital de Educación Física, (21), 41-58.

Calahorro, F., Lara, A. J., \& Torres-Luque, G. (2010). Competencias básicas en educación física: identificación y desarrollo. Arte Y Movimiento, (2), 31-39.

Camerino, O., Castañer, M., \& Anguera, M. T. (Eds.). (2012). Mixed Methods Research in the Movement Sciences. Case studies in sport, physical education and dance. New York, NY: Routledge.

CANADIAN CENTRE FOR SOCIAL ENTREPRENEURSHIP (CCSE). (2001). Social Entrepreneurship $\begin{array}{lllll}\text { Discussion. } & \text { Naper } & \text { No. } & \text { Retrieved from }\end{array}$ http://citeseerx.ist.psu.edu/viewdoc/download;jsessionid=3ED60368F9oC $56 C_{04} E_{04}{ }_{435} E_{4} E_{7}$ Co15?doi=10.1.1.194:4683\&rep=rep1\&type=pdf

Cano, E. (2005). Cómo mejorar las competencias de los docentes. Guía para la autoevaluación y el desarrollo de las competencias del profesorado. Barcelona: Graó.

Capella, C., Gil, J., Chiva, Ò., \& Corbatón, R. (2015). Promoción del emprendimiento social y la competencia docente en la aplicación de juegos motores y expresivos utilizando el aprendizaje servicio en Educación Física. RIDAS, Revista Iberoamericana de Aprendizaje Servicio, (1), 138143. http://doi.org/10.1344/RIDAS2015.1.9

Capella, C., Gil, J., Chiva, Ò., \& Martí, M. (2015). Diseño y validación de una rúbrica para valorar la competencia docente en la didáctica de juegos motores y expresión corporal en educación infantil. Ágora Para La Educación Física Y El Deporte, 2(17), 148-167.

Capella, C., Gil, J., \& Martí, M. (2014). La metodología del aprendizaje-servicio en la educación física. Apunts. Educación Física Y Deportes, 2(116), 33-43. http://doi.org/10.5672/apunts.2014og83.es.(2014/2).116.03

Capella, C., Gil, J., Martí, M., \& Chiva, Ò. (2015). Estudio de caso múltiple con historias de vida en el Grado de Educación Infantil: Aprendizaje-servicio en la didáctica de la Educación Física. Profesorado. Revista de Currículum Y Formación Del Profesorado, 19(1), 334-348.

Capella, C., Gil, J., Martí, M., \& Ruiz-Bernardo, M. P. (in press). Creación y validación de un cuestionario para medir el emprendimiento social desarrollado mediante programas de aprendizaje-servicio en Educación Física. Pedagogia Social Revista Interuniversitaria.

Carbonell, J., \& Carrillo, I. (2010). Prácticas de cooperación en planes de formación inicial. La educación en valores como vivencia. In M. Martínez (Ed.), Aprendizaje Servicio y Responsabilidad Social de las Universidades (pp. 151-176). Barcelona: Ediciones Octaedro. 
Carrington, S. (2011). Service-Learning Within Higher Education: Rhizomatic Interconnections Between University And The Real World. Australian Journal of Teacher Education, 36(6), 1-14. http://doi.org/10.14221/ajte.2011v36n6.3

Carson, R. L., \& Raguse, A. L. (2014). Systematic Review of Service-Learning in Youth Physical Activity Settings. Quest, (66), 57-95. http://doi.org/10.1080/00336297.2013.814578

Casilla, D., \& Camacho, H. (2012). Evaluación de la responsabilidad social universitaria. Opción, (69), $452-465$.

Casson, M. C. (1982). The Entrepreneur: An Economic Theory. Oxford: Martin Robertson.

Castañer, M., Camerino, O., \& Anguera, M. T. (2013). Métodos mixtos en la investigación de las ciencias de la actividad física y el deporte. Apunts. Educación Física Y Deportes, 2(112), 31-36. http://doi.org/10.5672/apunts.2014-0983.es.(2013/2).112.01

Castejón, F. J. (2010). Indicadores de calidad en la enseñanza de Educación física. In C. González \& T. LLeixà (Eds.), Educación Física. Investigación, innovación y buenas prácticas (pp. 59-76). Barcelona: Graó.

Castejón, F. J. (2013). La evaluación de las competencias del profesorado de educación física. Dificultades y propuestas. Tándem. Didáctica de La Educación Física $(43), 49-58$.

Castillo, E., \& Sáenz-López, P. (2007). Hábitos relacionados con la práctica de actividad física de las alumnas de la Universidad de Huelva a través de historias de vida. Profesorado. Revista de Currículum Y Formación Del Profesorado, 11(2), 1-18. Retrieved from http://www.ugr.es/ recfpro/rev112ART7.pdf

Catford, J. (1998). Social entrepreneurs are vital for health promotion but they need supportive environments too. Health Promotion International, 13(2), 95-97.

Cazers, G. (2009). Life Histories of Three Exemplary American Physical Educators. (Doctoral Dissertation, The University of Alabama).

Cazers, G., \& Curtner-Smith, M. (2013). Legacy of a Pioneer African American Educator. Research Quarterly for Exercise and Sport, 84(1), 39-51. http://doi.org/10.1080/02701367.2013.762290

Cazers, G., \& Curtner-Smith, M. (2014). Life History of Karen. A Physical Education Educator with an Impairment. Palaestra, 28(2), 47-53

Cejas, M. F. (2005). La Formación por competencias: Una visión estratégica en la gestión de personas. Visión Gerencial, 4(1), 11-22.

Celio, C. I., Durlak, J., \& Dymnicki, A. (2011). A Meta-analysis of the Impact of Service-Learning on Students. Journal of Experiential Education, 34(2), 164-181. http://doi.org/10.5193/JEE34.2.164 
CENTRO DE DESARROLLO EMPRENDEDOR DEL INSTITUTO DE ESTUDIOS EMPRESARIALES DE MONTEVIDEO (IEEM). (2007). El emprendedurismo en los universitarios: Una opción cada día más real. Montevideo. Retrieved from http://noticias.universia.edu.uy/vidauniversitaria/noticia/2007/04/16/125305/emprendedurismo-universitarios-opcion-cada-diamas-real.html

CEENTRO PROMOTOR DEL APRENDIZAJE SERVICIO DE CATALUÑA. (2015). Què és I'APS? Retrieved March 6, 2015, from http://www.aprenentatgeservei.org/index.php?cm=02

CENTROS EUROPEOS DE EMPRESAS INNOVADORAS (CEEI). (2012). Test del perfil emprendedor. Retrieved from http://ceeivalencia.emprenemjunts.es/index.php?op $=65 \& \mathrm{tFM}=70$

Certo, S. T., \& Miller, T. (2008). Social entrepreneurship: Key issues and concepts. Business Horizons, 51(4), 267-271. http://doi.org/10.1016/j.bushor.2008.02.009

Cervantes, C. M., \& Meaney, K. S. (2013). Examining Service-Learning Literature in Physical Education Teacher Education: Recommendations for Practice and Research. Quest, 65(3), 332-353. http://doi.org/10.1080/00336297.2013.773533

Chambers, D. J., \& Lavery, S. (2012). Service-learning: A valuable component of pre-service teacher education. Australian Journal of Teacher Education, 37(4), 128-137.

Chell, E., Haworth, J. M., \& Brearley, S. A. (1991). The Entrepreneurial Personality: Concepts, Cases, and Categories. London: Routledge.

Chiva, Ò., Corbatón, R., Gil, J., \& Zorrilla, L. (2015). Efecto de un programa de aprendizaje-servicio sobre el clima motivacional en la asignatura «Actividad físico-deportiva y salud». Tándem. Didáctica de La Educación Física, (48), 47-55.

Chiva, Ò., \& Gil, J. (2012). Rubrics as tool for assessment of applications for service-learning in the teaching of Physical Education: A practical Proposal. In E. M. Sebastiani \& J. Cabedo (Eds.), Together for Physical Education. Scientific Communications of the 7th FIEP European Congress (pp. 572-576). Barcelona: Fédération Internationale d'Éducation Physique.

Chiva, Ò., Gil, J., \& Hernando, C. (2014). Innovación metodológica en la universidad. Aprendizaje servicio en la didáctica de la expresión corporal y los juegos motrices. Tándem. Didáctica de La Educación Física, (44), 41-48.

Choi, N., \& Majumdar, S. (2014). Social entrepreneurship as an essentially contested concept: Opening a new avenue for systematic future research. Journal of Business Venturing, 29(3), 363-376. http://doi.org/10.1016/j.jbusvent.2013.05.001

Chomsky, N., García-Albea, J. E., Gómez, J. L., Domènech, A., \& Comas, D. (2002). Los límites de la globalización. Barcelona: Editorial Ariel. 
Cieza, J. A. (2010). El compromiso y la participación comunitaria de los centros escolares. Un nuevo espacio-tiempo de intervención socioeducativa. Pedagogía Social. Revista Interuniversitaria, 17, 123-136. http://doi.org/10.7179/psri

Claus, J., \& Ogden, C. (Eds.). (1999). Service Learning for Youth Empowerment and Social Change. New York, NY: Peter Lang.

Collier, D., Hidalgo, F. D., \& Maciuceanu, A. O. (2006). Essentially contested concepts: Debates and applications. Journal of Political Ideologies, 11(3), 211-246. http://doi.org/10.1080/13569310600923782

Collins, C. J., Hanges, P. J., \& Locke, E. A. (2004). The Relationship of Achievement Motivation to Entrepreneurial Behavior: A Meta-Analysis. Human Performance, 17(1), 95-117. http://doi.org/10.1207/S15327043HUP1701_5

Conrad, D., \& Hedin, D. (1989). High school community service: A review of research and programs. Madison, WI: National Center on Effective Secondary Schools.

CONSEJO DE LA UNIÓN EUROPEA Y EL PARLAMENTO EUROPEO. (2006) Recommendation of the European Parliament and the Council of 18 December 2006 on key competencies for lifelong learning, Official Journal of the European Union 10-18. Retrieved from http://eurlex.europa.eu/LexUriServ/LexUriServ.do?uri=OJ:L:2006:394:0010:0018:en:PDF

Contín, I., \& Larraza, M. (2010). Actividad Emprendedora Rural y Urbana: el Caso de Navarra. Revista Internacional de Estudios Vascos, 1(55), 39-60.

Contreras, O. R. (2012). Las competencias del profesor de educación física. In O. R. Contreras (Ed.), Las competencias del profesor de educación física (pp. 11-30). Barcelona: INDE.

Conway, J. M., Amel, E. L., \& Gerwien, D. P. (2009). Teaching and Learning in the Social Context: A Meta-Analysis of Service Learning's Effects on Academic, Personal, Social, and Citizenship $\begin{array}{llll}\text { Outcomes. Teaching of } & \text { 233-245. }\end{array}$ http://doi.org/10.1080/00986280903172969

Cook, B., Dodds, C., \& Mitchell, W. (2003). Social entrepreneurship. False premises and dangerous forebodings. Australian Journal of Social Issues, 38(1), 57-72.

Corduras, A. (2006). La motivación para emprender en España. Ekonomiaz: Revista Vasca de Economía, 2(62), 12-39.

Cornwall, J. R. (1998). The entrepreneur as building block for community. Journal of Developmental Entrepreneurship, 3(2), 141-148.

Corominas, E., Tesouro, M., Capell, D., Teixidó, J., Pèlach, J., \& Cortada, R. (2006). Percepciones del profesorado ante la incorporación de las competencias genéricas en la formación universitaria. Revista de Educación, 341, 301-336. 
Corradi, C. (1991). Text, Context and Individual Meaning: Rethinking Life Stories in a Hermeneutic Framework. Discourse \& Society, 2(1), 105-118. http://doi.org/10.1177/0957926591002001006

Covin, J. G., \& Slevin, D. P. (1986). The development and testing of an organizational-level entrepreneurship scale. In R. Ronstadt, J. A. Hornaday, R. Peterson, \& K. H. Vesper (Eds.), Frontiers of Entrepreneurship Research (pp. 628-639). Wellesley, MA: Babson College.

Covitt, B. A. (2002). Motivating environmentally responsible behavior through service-learning. In S. H. Billig \& A. Furco (Eds.), Advances in service-learning research: Vol. 2. Service-learning through a multidisciplinary lens (pp. 177-197). Greenwich, CT: Information Age Publishers.

Creswell, J. W. (2007). Qualitative Inquiry \& Research Design. Choosing among five approaches (2nd ed.). Thousand Oaks, CA: Sage Publications.

Creswell, J. W., \& Plano Clark, V. L. (2007). Designing and Conducting Mixed Methods Research. Thousand Oaks, CA: Sage Publications.

CUADERNOS DE PEDAGOGÍA. (2007). Monográfico dedicado a las competencias básicas, (370).

Cummings, T. G. (2007). Quest for an Engaged Academy. Academy of Management Review, 32(2), 355-36o. http://doi.org/10.5465/AMR.2007.24349184

Dacin, M. T., Dacin, P. A., \& Tracey, P. (2011). Social Entrepreneurship: A Critique and Future Directions. Organization Science, 22(5), 1203-1213. http://doi.org/10.1287/orsc.1100.0620

Dahlsrud, A. (2008). How corporate social responsibility is defined: an analysis of 37 definitions. Corporate Social Responsibility and Environmental Management, 15(1), 1-13. http://doi.org/10.1002/csr.132

De la Calle, C. (2010). La formación de la Responsabilidad Social del Universitario: un estudio empírico. (Doctoral Dissertation, Universidad Complutense de Madrid). Retrieved from http://eprints.ucm.es/10187/1/T31406.pdf

De la Calle, C., García, J. M., \& Giménez, P. (2007). La formación de la responsabilidad social en la universidad. Revista Complutense de Educación, 18(2), 47-66.

De la Cerda, M., Graell, M., Martín, X., Muñoz, Á., \& Puig, J. M. (2009). Aprendizaje servicio: ejemplos y definiciones. In J. M. Puig (Ed.), Aprendizaje servicio (APS) Educación y compromiso cívico (pp. 15-32). Barcelona: Graó.

De la Cerda, M., Martín, X., \& Puig, J. M. (2010). Amigos y amigas de lectura. Una experiencia de aprendizaje servicio en la formación de profesionales de la educación. In M. Martínez (Ed.), Aprendizaje Servicio y Responsabilidad Social de las Universidades (pp. 129-150). Barcelona: Ediciones Octaedro. 
De la Cruz, C., \& Sasia, P. M. (2008). La Responsabilidad de la Universidad en el proyecto de construcción de una sociedad. Educación Superior Y Sociedad, 13(2), 17-52.

De la Vega, I., Coduras, A., Cruz, C., Justo, R., \& González, I. (2006). Global Entrepreneurship Monitor. Informe ejecutivo GEM España. Madrid: Instituto de la Empresa. Retrieved from http://www.gem-spain.com/wp-content/uploads/2015/03/Informes antiguos/GEM2006.pdf

De Pablo, I., Santos, B., \& Bueno, Y. (2004). Las dimensiones del perfil del emprendedor: Contraste empírico con emprendedores de éxito. In S. Roig, D. Ribeiro, V. R. Torcal, A. De la Torre, \& E. Cerver (Eds.), El Emprendedor Innovador y la Creación de Empresas de I+D+l (pp. 813-830). València: Universitat de València.

Dean, M. A., Shook, C. L., \& Payne, G. T. (2007). The Past, Present, and Future of Entrepreneurship Research: Data Analytic Trends and Training. Entrepreneurship Theory and Practice, 31(4), 601618. http://doi.org/10.1111/j.1540-6520.2007.00190.x

DECLARACIÓN DE TALLOIRES. (2005). Sobre las responsabilidades cívicas sociales y las funciones cívicas de la educación Superior. Talloires. Retrieved from http://talloiresnetwork.tufts.edu/wpcontent/uploads/DECLARACIONDETALLOIRES.pdf

Decter, M. H. (2009). Comparative review of UK-USA industry-university relationships. Education + Training, 51(8/9), 624-634. http://doi.org/10.1108/00400910911005190

Dees, J. G. (1998a). Enterprising nonprofits. Harvard Business Review, 76(1), 55-67.

Dees, J. G. (1998b). The Meaning of "Social Entrepreneurship." Kansas City, MO and Palo Alto, CA: Kauffman Foundation and Stanford University. Retrieved from http://sehub.stanford.edu/sites/default/files/TheMeaningofsocialEntrepreneurship.pdf

Dees, J. G. (2003). Social Entrepreneurship is About Innovation and Impact, Not Income. The Skoll Foundation's Social Edge. The CASEconnection Newsletter. Retrieved from https://centers.fuqua.duke.edu/case/wpcontent/uploads/sites/7/2015/02/Article_Dees_SEisAboutInnovationandImpactNotIncome_20 03.pdf

Defourny, J., \& Nyssens, M. (2010). Conceptions of Social Enterprise and Social Entrepreneurship in Europe and the United States: Convergences and Divergences. Journal of Social Entrepreneurship, 1(1), 32-53. http://doi.org/10.1080/19420670903442053

Del Pozo, P. (2012). La rúbrica y los flashes en la evaluación de la expresión corporal. Emásf. Revista Digital de Educación Física, 17, 38-47. Retrieved from http://emasf.webcindario.com/La_rublica_y_los_flashes_en_la_evaluacion_de_la_expresion_ corporal.pdf 
Del Rincón, D., Arnal, J., Latorre, A., \& Sans, A. (1995). Técnicas de investigación en ciencias sociales. Madrid: Dykinson.

Delors, J. (Ed.). (1996). La educación encierra un tesoro. Informe a la UNESCO de la Comisión Internacional sobre la Educación para el Siglo XXI. Paris: Ediciones UNESCO.

Demazière, D., \& Dubar, C. (1997). Analyser les entretiens biographiques. L'exemple des récits d'insertion. Paris: Éditions Nathan.

Denzin, N. K. (1970). The research act: A Theoretical Introduction to Sociological Methods. New Jersey, NY: Aldine Transaction.

Denzin, N. K. (1989). Interpretive Biography (Qualitative Research Methods). Newbury Park, CA: Sage Publications.

Devís, J., \& Sparkes, A. C. (1999). Burning the Book: A Biographical Study of a Pedagogically Inspired Identity Crisis in Physical Education. European Physical Education Review, 5(2), 135152. http://doi.org/10.1177/1356336X990052005

Devís, J., \& Sparkes, A. C. (2004). La crisis de identidad de un estudiante universitario de educación física. La reconstrucción de un estudio biográfico. In A. Sicilia \& J. M. Fernández-Balboa (Eds.), La otra cara de la investigación. Reflexiones desde la educación física (pp. 83-108). Sevilla: Wanceulen.

Dey, P. (2006). The rhetoric of social entrepreneurship: paralogy and new language games in academic discourse. In C. Steyaert \& D. Hjorth (Eds.), Entrepreneurship as social change. A Third Movements in Entrepreneurship Book (pp. 121-142). Northampton, MA: Edward Elgar Publishing.

Dey, P., \& Steyaert, C. (2010). The politics of narrating social entrepreneurship. Journal of Enterprising Communities: People and Places in the Global Economy, 4(1), 85-108. http://doi.org/10.1108/17506201011029528

Díaz, A. (2008). La responsabilidad social de la universidad en la promoción del capital social para el desarrollo sustentable. (Master's Thesis, Universidad de Carabobo). Retrieved from http://www.eumed.net/libros-gratis/2008b/402/

Díaz, J., Campos, M., Pérez, C. M., Guerras, A., Casado, M. V., Feltrer, J., ... Bilbao, A. (2008). El desarrollo de las competencias básicas a través de la Educación Física. Efdeportes. Revista Digital, (118). Retrieved from http://www.efdeportes.com/efd118/desarrollo-de-lascompetencias-basicas-a-traves-de-la-educacion-fisica.htm

Ding, C. S., \& Hershberger, S. L. (2002). Assessing Content Validity and Content Equivalence Using Structural Equation Modeling. Structural Equation Modeling: A Multidisciplinary Journal, 9(2), 283-297. http://doi.org/10.1207/S15328007SEMogo2_7 
Dixon, R., Meier, R. L., Brown, D. C., \& Custer, R. L. (2005). The critical entrepreneurial competencies required by intructors from institution-based entreprises: A Jamaican study. Journal of Industrial Teacher Education, 42(4), 25-51.

DOCV 5734. Decreto 38/2008, de 28 de marzo, por el que se establece el currículo del segundo ciclo de la Educación Infantil en la Comunitat Valenciana, Pub. L. No. 3838 (2008). Retrieved from http://www.docv.gva.es/datos/2008/04/03/pdf/2008_3838.pdf

Domangue, E., \& Carson, R. L. (2008). Preparing Culturally Competent Teachers : Service-Learning and Physical Education Teacher Education. Journal of Teaching in Physical Education, (27), 347367.

Dowling, F. J. (1996). Life Events and Curriculum Change: The Life History of a Norwegian Physical Educator. European Physical Education Review, 2(1), 41-53. http://doi.org/10.1177/1356336X9600200105

Dowling, F. J. (1998). Tales of Norwegian Physical Education Teachers: A Life History Analysis. (Doctoral Dissertation, Norwegian University of Sport and Physical Education).

Dowling, F. J. (2001). Sharing Stories about the Dialectics of Self and Structure in Teacher Socialization: Revisiting a Norwegian Physical Educator's Life History. European Physical Education Review, 7(1), 44-6o. http://doi.org/10.1177/1356336X010071001

Duarte, R., Torres, C., \& Nieto, N. (2010). Historia de vida de una deportista paralímpica colombiana. Revista Educación Física Y Deporte, 29(1), 95-101.

Dyson, B., Placek, J. H., Graber, K. C., Fisette, J. L., Rink, J., Zhu, W., ... Park, Y. (2011). Development of PE Metrics Elementary Assessments for National Physical Education Standard 1. Measurement in Physical Education and Exercise Science, 15(2), 100-118. http://doi.org/10.1080/1091367X.2011.568364

Eberly, D. (1988). National Service. A promise to keep. Rochester, NY: John Alden Books.

Echeverría, B. (2002). Gestión de la competencia de acción profesional. Revista de Investigación Educativa, 20(1), 7-43.

Elliott, J. (1993). El cambio educativo desde la investigación-acción. Madrid: Morata.

Emerson, J., \& Twersky, F. (1996). New social entrepreneurs: The success, challenge and lessons of non-profit enterprise creation. A Progress Report on the Planning and Startup of Non-Profit Businesses. San Francisco, CA: Roberts Foundation Homeless Economic Development Fund.

Enciso-Congote, J. D. (2010). El emprendimiento y el bien común: ¿competencias complementarias o excluyentes? Educación Y Educadores, 13(1), 63-76. 
Escobar, J., \& Cuervo, Á. (2008). Validez De Contenido y Juicio de Expertos: Una Aproximación a su Utilización. Avances En Medición, 6(1), 27-36.

Espíritu, R. (2011). Actitud emprendedora en los estudiantes universitarios: un análisis de factores explicativos en la Comunidad de Madrid. (Doctoral Dissertation, Universidad Complutense de Madrid). Retrieved from http://eprints.ucm.es/12803/1/T32967.pdf

Eyler, J. S. (2000). What do we most need to know about the impact of service-learning on student learning. Michigan Journal of Community Service Learning, (Fall), 11-17.

Eyler, J. S., \& Giles, D. E. (1999). Where's the learning in service-learning? San Francisco: Jossey Bass.

Eyler, J. S., Giles, D. E., \& Schmiede, A. (1996). A practitioner's guide to reflection in service- learning: Student voices and reflections. Nashville, TN: Vanderbilt University Press.

Eyler, J. S., Giles, D. E., Stenson, C. M., \& Gray, C. J. (2001). At A Glance: What We Know about The Effects of Service-Learning on College Students, Faculty, Institutions and Communities, 19932000: Third Edition. Nashville, TN: Vanderbilt University Press.

Fernández, C., Delpiano, C., \& De Ferari, J. M. (2006). Responsabilidad Social Universitaria: Una manera de ser universidad. Teoría y práctica en la experiencia chilena. Santiago de Chile: Gráfica Funny. Retrieved from http://rsuniversitaria.org/web/images/stories/memoria/UCP 2006.pdf

Fernández-Balboa, J. M. (2008). ¿Debemos contribuir a la convergencia europea a través de un modelo de formación de futuros docentes por competencias? Tándem. Didáctica de La Educación Física, (26), 19-33.

Ferrer, V., Cabrera, O. E., Alegre, R. M., Montané, A., Sánchez, C., \& Alaiz, E. (2014). El perfil del emprendedor social del estudiantado de los Grados de Educación Social, Pedagogía y Trabajo Social en la Universidad de Barcelona. REIRE. Revista d'Inovació I Recerca En Educació, 7(1), 1129. http://doi.org/10.1344/reire2014.7.1712

Ferrer-Balas, D., Adachi, J., Banas, S., Davidson, C. I., Hoshikoshi, A., Mishra, A., ... Ostwald, M. (2008). An international comparative analysis of sustainability transformation across seven universities. International Journal of Sustainability in Higher Education, 9(3), 295-316. http://doi.org/10.1108/14676370810885907

Folgueiras, P., Luna, E., \& Puig, G. (2013). Aprendizaje y servicio: estudio del grado de satisfacción de estudiantes universitarios. Revista de Educación, (362), 159-185. http://doi.org/10.4438/1988-592X-RE-2011-362-157

Follman, J. (1998). Florida Learn and Serve: 1996-97 Outcomes and Correlations with 1994-95 and 1995-96. Tallahassee, FL: Florida State University, Center for Civic Education and Service.

Foot, P. (1978). Virtues and Vices and Other Essays in Moral Philosophy. Oxford: Oxford University Press. 
Fowler, A. (2000). NGDOs as a moment in history: Beyond aid to social entrepreneurship or civic innovation? Third World Quarterly, 21(4), 637-654. http://doi.org/10.1080/713701063

Fraile, A., \& Hernández-Álvarez, J. L. (2006). La formación del maestro de educación física en la encrucijada entre los marcos legislativos y las necesidades sociales. AULA De Innovación Educativa, (157), 65-71.

Fry, J. M. (1997). Dealing with the Powers that Be. Sport, Education and Society, 2(2), 141-162. http://doi.org/10.1080/1357332970020201

Furco, A. (1996). Service-Learning: A balanced approach to experiential education. In Cooperative Education Association (Ed.), Expanding Boundaries: Serving and Learning (pp. 2-6). Washington, DC: Corporation for National Service.

Furco, A. (2002). High School Service-Learning and the Preparation of Students for College: An Overview of Research. In E. Zlotkowski (Ed.), Service-Learning and the First-Year Experience: Preparing Students for Personal Success and Civic Responsibility (pp. 3-14). Columbia, SC: University of South Carolina, National Resource Center for The First-Year Experience and Students in Transition.

Furco, A. (2004). Impacto de los proyectos de aprendizaje-servicio. In A. González \& R. Montes (Eds.), Actas del 7mo. Seminario Internacional "Aprendizaje y Servicio Solidario" (pp. 19-26). Buenos Aires: Programa Nacional Educación Solidaria. Unidad de Programas Especiales. Ministerio de Educación, Ciencia y Tecnología. Retrieved from http://repositorio.educacion.gov.ar/dspace/bitstream/handle/123456789/94404/ELo01174.pdf ?sequence $=1$

Furco, A., \& Root, S. (2010). Research Demonstrates the Value of Service Learning. Phi Delta Kappan, 91(5), 16-20.

Gaete, R. (2011). La responsabilidad social universitaria como desafío para la gestión estratégica de la Educación Superior: el caso de España. Revista de Educación, (355), 109-133.

Gallego, B. (2008). La investigación biográfico-narrativa en un estudio sobre la situación de las mujeres en el deporte. Revista de Investigación Educativa, 26(1), 121-140.

Gallie, W. B. (1956). Essentially Contested Concepts. Proceedings of the Aristotelian Society, 56, 167198.

Gallini, S. M., \& Moely, B. E. (2003). Service-Learning and Engagement, Academic Challenge, and Retention. Michigan Journal of Community Service Learning, (Fall), 5-14.

Gallo, A. M. (2004). 5 Simple steps to Designing a Rubric. Strategies. A Journal for Physical and Sport Educators, 17(5), 21-24. 
Galvan, C., \& Parker, M. (2011). Investigating the Reciprocal Nature of Service-Learning in Physical Education Teacher Education. Journal of Experiential Education, 34(1), 55-70.

García, A. (2011). Construyendo una lógica educativa en los juegos en Educación Física Escolar: "El juego bueno." Ágora Para La Educación Física Y El Deporte, 13(1), 35-54.

García, R., Gozálvez, V. E., Vázquez, V., \& Escámez, J. (2010). Repensando la Educación: cuestiones y debates para el siglo XXI. Valencia: Brief Ediciones.

Garde, R. (2013). Revelación online de información sobre Responsabilidad Social Universitaria: propuesta de un modelo e incentivos de divulgación. (Doctoral Dissertation, Universidad de Granada). Retrieved from http://digibug.ugr.es/bitstream/10481/30839/1/22560282.pdf

Garde, R., Rodríguez, M. P., \& López, A. M. (2013). Divulgación online de información de responsabilidad social en las universidades españolas. Revista de Educación, (Número extraordinario), 177-209. http://doi.org/10.4438/1988-592X-RE-2013-EXT-246

Gartner, W. B. (1985). A Conceptual Framework for Describing the Phenomenon of New Venture Creation. The Academy of Management Review, 10(4), 696-706. http://doi.org/10.1177/026327602761899255

Gaut, B. (2000). "Art" as a cluster concept. In N. Carroll (Ed.), Theories of art today (pp. 25-44). Madison, WI: University of Wisconsin Press.

George, D., \& Mallery, P. (2014). IBM SPSS Statistics 21 Step by Step: A Simple Guide and Reference (13th ed.). New Jersey, NY: Pearson Higher Education.

Gessa, A., \& Toledano, N. (2011). Turismo, emprendimiento y sostenibilidad en los espacios naturales protegidos. El Caso de Andalucía, España. Estudios Y Perspectivas En Turismo, 20, 1154-1174.

Ghazali, Z., Ibrahim, N. A., \& Zainol, F. A. (2013). Factors Affecting Entrepreneurial Intention among UniSZA Students. Asian Social Science, 9(1), 85-93. http://doi.org/10.5539/ass.vgn1p85

Ghiglione, R., Matalon, B., \& Bacri, N. (1985). Les dires analysés: l'analyse propositionelle du discours. Saint-Denis: Presses Universitaires de Vincennes.

Gibbons, M., Limoges, C., Nowonty, H., Schawartzman, S., Scott, P., \& Trown, M. (1997). La nueva producción del conocimiento: La dinámica de la ciencia y la investigación en las sociedades contemporáneas. Barcelona: Ediciones Pomares-Corredor. Retrieved from https://ia700704.us.archive.org/2/items/LaNuevaProduccionDelConocimiento/1997gibbonslec .pdf

Gil, J. (2012). El Aprendizaje-Servicio en la enseñanza superior: una aplicación en el ámbito de la Educación Física. (Doctoral Dissertation, Universitat Jaume I de Castellón). Retrieved from http://repositori.uji.es/xmlui/bitstream/handle/10234/74758/jgilgomez.pdf?sequence=2 
Gil, J., \& Chiva, Ò. (2014). Una experiencia de aprendizaje-servicio en la asignatura «Bases anatómicas y fisiológicas del movimiento» del Área de Didáctica de la Expresión Corporal. Retos. Nuevas Tendencias En Educación Física, Deporte Y Recreación, (26), 122-127.

Gil, J., Chiva, Ò., \& Martí, M. (2014). El aprendizaje de contenidos de educación física en la universidad mediante aprendizaje servicio. Un estudio cuantitativo y cualitativo. Tándem. Didáctica de La Educación Física, (44), 15-25.

Gil, J., Francisco, A., \& Moliner, L. (2012). La Educación Física y el Aprendizaje Servicio: abriendo el entorno natural a la escuela. Tándem. Didáctica de La Educación Física, (38), 95-100.

Giles, D. E., \& Eyler, J. S. (1994). The impact of a college community service laboratory on students' personal, social, and cognitive outcomes. Journal of Adolescence, 17(4), 327-339. http://doi.org/10.1006/jado.1994.1030

Gimeno, J. (1991). El currículum: una reflexión sobre la práctica. Madrid: Ediciones Morata.

González, A., \& Montes, R. (Eds.). (2004). Aprendizaje y servicio solidario en la Educación Superior y en los sistemas educativos latinoamericanos. In Actas del 7mo. Seminario Internacional "Aprendizaje y Servicio Solidario." Buenos Aires: Programa Nacional Educación Solidaria. Unidad de Programas Especiales. Ministerio de Educación, Ciencia y Tecnología. Retrieved from http://repositorio.educacion.gov.ar/dspace/bitstream/handle/123456789/94404/ELo01174.pdf ?sequence $=1$

González, C. (2006). La qualitat de l'àrea d'educació física. El cas dels centres que imparteixen l'educació secundària obligatòria de la ciutat de Barcelona. (Doctoral Dissertation, Universitat de Barcelona). Retrieved from http://diposit.ub.edu/dspace/handle/2445/43054

González, J. F. (2009). La formación para la participación ciudadana dentro y fuera de la escuela. Perspectivas desde Bogotá. Investigación en la escuela, (68), 63-72.

González, J., Sánchez, P., \& Jornet, J. M. (2011). Estudio de validación por jueces de una escala para medir la competencia de compromiso en universitarios. In XV Congreso Nacional - I Internacional de Modelos de Investigación Educativa (pp. 21-23). Madrid. Retrieved from http://www.uv.es/innovamide/archivos/2011_AIDIPE.pdf

González, J., \& Wagenaar, R. (Eds.). (2003). Tuning Educational Structures in Europe. Informe Final. Bilbao: Universidad de Deusto.

González, R., \& Zúñiga, A. (2011). Método CEPCES para la Evaluación del Potencial Emprendedor. Journal of Technology Management \& Innovation, 6(1), 77-97.

Goodson, I. F. (Ed.). (2004). Historias de vida del profesorado. Barcelona: Ediciones Octaedro. 
Gortari, A. (2004). El aprendizaje-servicio en el MERCOSUR y América Latina. El Servicio Social obligatorio en la Universidad mexicana. In A. González \& R. Montes (Eds.), Actas del 7 mo. Seminario Internacional "Aprendizaje y Servicio Solidario" (pp. 111-113). Buenos Aires: Programa Nacional Educación Solidaria. Unidad de Programas Especiales. Ministerio de Educación, Ciencia y Tecnología. Retrieved from http://repositorio.educacion.gov.ar/dspace/bitstream/handle/123456789/94404/ELo01174.pdf ?sequence $=1$

Graña, F., \& Fornoni, M. (2002). Líneas y Recomendaciones de Política de Servicios Universitarios para la Creación de Empresas. In III Seminario Internacional de la Red Motiva. San José.

Gray, M. J., Ondaatje, E. H., Fricker, R., Campbell, N., Rosenblatt, K., Geschwind, S., ... Klein, S. P. (1998). Coupling Service and Learning in Higher Education: The Final Report of the Evaluation of the Learn and Serve America, Higher Education Program. Santa Monica, CA: RAND Corporation.

Gronski, R., \& Pigg, K. (2000). University and Community Collaboration: Experiential Learning in Human Services. American Behavioral Scientist, 43(5), 781-792. http://doi.org/10.1177/00027640021955595

Grundy, S. (1991). Producto o praxis del currículum. Madrid: Ediciones Morata.

Guzmán, A., \& Trujillo, M. A. (2008). Emprendimiento Social. Revisión de Literatura. Estudios Gerenciales, 24(109), 105-125.

Guzmán, I., \& Marin, R. (2011). La competencia y las competencias docentes: reflexiones sobre el concepto y la evaluación. Revista Electrónica Interuniversitaria de Formación Del Profesorado, 14(1), 151-163. Retrieved from http://www.aufop.com/aufop/uploaded_files/articulos/1301588498.pdf

Hamilton, S. F., \& Zeldin, R. S. (1987). Learning Civics in the Community. Curriculum Inquiry, 17(4), 407-420. http://doi.org/10.2307/1179597

Hammond, C., \& Churchman, D. (2008). Sustaining academic life: A case for applying principles of social sustainability to the academic profession. International Journal of Sustainability in Higher Education, 9(3), 235-245. http://doi.org/10.1108/14676370810885862

Harding, R. (2004). Social Enterprise: The New Economic Engine? Business Strategy Review, 15(4), 39-43. http://doi.org/10.1111/j.0955-6419.2004.00338.x

Harris, M. L., Gibson, S. G., \& Taylor, S. R. (2007). Examining the Impact of Small Business Institute Participation on Entrepreneurial Attitudes. Journal of Small Business Strategy, 18(2), 57-75.

Harwood, A. M., \& Radoff, S. A. (2009). Reciprocal benefits of mentoring: Results of a middle school-university collaboration. In B. E. Moely, S. H. Billig, \& B. A. Holland (Eds.), Advances in 
service-learning research: Vol. 9. Creating our identities in service-learning and community engagement (pp. 131-158). Charlotte, NC: Information Age Publishers.

Hatcher, J. A., Bringle, R. G., \& Muthiah, R. (2002). The role of service learning on retention of firstyear students. In American Association of Higher Education National Conference. Chicago, IL.

Haugh, H. (2005). A research agenda for social entrepreneurship. Social Enterprise Journal, 1(1), 112.

Hernández, F. (2011). Las historias de vida en el marco del giro narrativo en la investigación en Ciencias Sociales: los desafíos de poner biografías en contexto. In F. Hernández, J. M. Sancho, \& J. I. Rivas (Eds.), Historias de Vida en Educación. Biografías en contexto (pp. 13-22). Barcelona: ESBRINA - RECERCA, Universitat de Barcelona. Retrieved from http://diposit.ub.edu/dspace/handle/2445/15323

Hernández, J. L., \& Martínez, V. (2008). La Educación Física en la Educación Secundaria en el marco de la nueva Ley Orgánica de Educación: análisis y reflexiones. Revista Española de Educación Física Y Deporte, (8), 11-26.

Herrera, H. (2009). Investigación sobre redes sociales y emprendimiento: revisión de la literatura y agenda futura. Revista Innovar, 19(33), 19-33.

Hervani, A., \& Helms, M. M. (2004). Increasing Creativity in Economics: The Service Learning Project. Journal of Education for Business, 79(5), 267-274. http://doi.org/10.3200/JOEB.79.5.267-274

Hibbert, S. A., Hogg, G., \& Quinn, T. (2002). Consumer response to social entrepreneurship: The case of the Big Issue in Scotland. International Journal of Nonprofit \& Voluntary Sector Marketing, 7(3), 288-301. http://doi.org/10.1002/nvsm.186

Hill, T. L., Kothari, T. H., \& Shea, M. (2010). Patterns of Meaning in the Social Entrepreneurship Literature: A Research Platform. Journal of Social Entrepreneurship, 1(1), 5-31. http://doi.org/10.1080/19420670903442079

Himelein, M., Passman, L., \& Phillips, J. M. (2010). College Teaching and Community Outreaching: Service Learning in an Obesity Prevention Program. American Journal of Health Education, 41(6), 368-378. http://doi.org/10.1080/19325037.2010.10599166

Hodges, B. C., \& Videto, D. M. (2008). Service Learning: Creating Visibility and Advocacy for Health Education. American Journal of Health Education, 39(1), 44-54. http://doi.org/10.1080/19325037.2008.10599013

Hoogendoorn, B., Pennings, E., \& Thurik, R. (2010). What Do We Know About Social Entrepreneurship: An Analysis of Empirical Research. Rotterdam: Erasmus Research Institute of Management (ERIM). Erasmus University. Retrieved from http://hdl.handle.net/1765/16558 
Howard, J. P. F. (Ed.). (1993). Praxis I: A Faculty Casebook on Community Service Learning. Ann Arbor, MI: University of Michigan. Office of Community Service Learning Press.

Huberman, M., Thompson, Ch. L., \& Weiland, S. (2000). Perspectivas en la carrera del profesor. In B. J. Biddle, T. L. Good, \& I. F. Goodson (Eds.), La enseñanza y los profesores I. La profesión de enseñar (pp. 19-98). Barcelona: Paidós Ibérica.

Huefner, J. C., Hunt, H. K., \& Robinson, P. B. (1996). A comparison of four scales predicting entrepreneurship. Academy of Entrepreneurship Journal, 1(2), 56-80.

ISTITUTO PER LO SVILUPPO DELLA FORMAZIONE PROFESSIONALE DEI LAVORATORI (ISFOL). (1997). Unità capitalizzabili e crediti formativi. Metodologie e strumenti di lavoro. Milano: Franco Angeli.

Jacoby, B. (Ed.). (1996). Service-learning in Higher Education. Concepts and Practices. San Francisco: Jossey Bass.

Jiménez, I. (2001). El ejercicio profesional de las titulaciones del deporte. Barcelona: Bosch.

Jiménez, J. R. (2007). Competencias Básicas. P@K-EN-REDES. Revista Digital Del Centro Del Profesorado de Alcalá de Guadaíra, 1(1). Retrieved from http://www.redescepalcala.org/inspector/DOCUMENTOS Y LIBROS/COMPETENCIAS/COMPETENCIAS BASICAS (JOSE RAMON JIMENEZ).pdf

Jones, G. R. (1983). Life history methodology. In G. Morgan (Ed.), Beyond method. Strategies for social research (pp. 147-159). Beverly Hills, CA: Sage Publications.

Kafati, K. (2012). Cuestionario para medir la capacidad emprendedora. Instituto Nacional de $\begin{array}{llll}\text { Formación Profesional. } & \text { Retrieved from }\end{array}$ https://www.google.es/url?sa=t\&rct=j\&q=\&esrc=s\&source=web\&cd=1\&cad=rja\&uact=8\&ved= oahUKEwi6kv7ig63KAhWC1RoKHTbjB44OFggfMAA\&url=https://foliesvillaverde.files.wordpr ess.com/2013/o4/cuestionario-para-medir-la-capacidad-emprendedora.doc\&usg=AFQjC

Kahne, J., \& Westheimer, J. (2002). The limits of efficacy: Educating citizens for democratic action. In Annual Meeting of the American Political Science Association. Boston, MA: Educational Resources Information Center Document Reproduction Service.

Karlsson, H. (2011). Summer Entrepreneur an Activity for stimulating Entrepreneurship Among Youths: A Case Study in a Swedish County. US-China Education Review, 1(5), 715-725.

Keay, J. (2006). Collaborative learning in physical education teachers' early-career professional development. Physical Education \& Sport Pedagogy, 11(3), 285-305. http://doi.org/10.1080/17408980600986322

Kerlinger, F. N. (1986). Foundations of Behavioral Research (3rd ed.). New York, NY: Harcourt Brace Jovanovich College Publishers. 
Kim, W., \& Billig, S. H. (2003). Colorado Learn and Serve Evaluation. Research Report. Denver, CO: RMC Research Corporation.

Kirby, D. (2002). Effective approaches to reducing adolescent unprotected sex, pregnancy, and childbearing. Journal of Sex Research, 39(1), 51-57. http://doi.org/10.1080/00224490209552120

Kirby, D. A., \& Ibrahim, N. (2011). The case for (social) entrepreneurship education in Egyptian universities. Education + Training, 53(5), 403-415. http://doi.org/10.1108/00400911111147712

Kliksberg, B. (2009). Los desafíos éticos pendientes en un mundo paradojal: el rol de la universidad. Revista Del CLAD Reforma Y Democracia, (43), 63-82.

Klute, M. M., \& Billig, S. H. (2002). The impact of service-learning on MEAP: A large-scale study of Michigan Learn and Serve grantees. Denver, CO: RMC Research Corporation.

Konukman, F., \& Schneider, R. C. (2012). Academic Service Learning in PETE: Service for community in the 21st century. Strategies, (Semptember/October), 15-18.

Kovač, M., Sloan, S., \& Starc, G. (2008). Competencies in physical education teaching: Slovenian teachers' views and future perspectives. European Physical Education Review, 14(3), 299-323. http://doi.org/10.1177/1356336Xo8095668

Kraft, R. J., \& Sakofs, M. (1985). The Theory of Experiential Education. Boulder, CO: Association for Experiential Education.

Kramer, M. (2000). Make it last forever: The institutionalization of service learning in America. Washington, DC: Corporation for National Service.

LaMaster, K. J. (2001). Enhancing Preservice Teachers Field Experiences through the Addition of a Service-Learning Component. The Journal of Experiential Education, 24(1), 27-33. http://doi.org/10.1177/105382590102400107

Lämsä, A. M., Vehkaperä, M., Puttonen, T., \& Pesonen, H. L. (2008). Effect of Business Education on Women and Men Students' Attitudes on Corporate Responsibility in Society. Journal of Business Ethics, 82(1), 45-58. http://doi.org/10.1007/s10551-007-9561-7

Lanzas, A. M., Lanzas, V. E., \& Castaño, J. C. (2006). Modelo administrativo para una unidad de emprendimiento en instituciones públicas de educación superior, caso Universidad Tecnológica de Pereira. Scientia Et Technica, 12(30), 239-249.

Lasprogata, G. A., \& Cotten, M. N. (2003). Contemplaing "Enterprise": The Business and Legal Challenges of Social Enterpreneurship. American Business Law Journal, 41(1), 67-114. http://doi.org/10.1111/j.1744-1714.2003.tboooo2.x

Lavega, P. (2008). Educación Física y mercado laboral. Competencias profesionales. Cultura, Ciencia Y Deporte, 3(8), 123-131. 
Le Boterf, G. (2000). Ingeniería de las competencias. Barcelona: Gestión 2000.

Leadbeater, C. (1997). The rise of the social entrepreneur. Lodon: Demos. Retrieved from http://www.demos.co.uk/files/theriseofthesocialentrepreneur.pdf

Ledic, J., Culum, B., Nuzdic, S., \& Jancec, L. (2008). What Role Do Croatian Higher Institution Play? A Study on University Civic Mission. In 4th International Barcelona Conference on Higher Education. Higher education and citizenship, participation and democracy. Barcelona: GUNI. Global University Network for Innovation. Retrieved from http://files.eric.ed.gov/fulltext/ED525692.pdf

Lee, L. S., \& Lai, C. C. (2010). An Exploratory Survey of Prospective Childcare Givers' Entrepreneurial Potential in Taiwan. In International Conference on Business and Information (BA/2010) (pp. 1-11). Kitakyushu. Retrieved from http://files.eric.ed.gov/fulltext/ED510783.pdf

Leming, J. S. (1998). Some critical thoughts about the teaching of critical thinking. The Social Studies, 89(2), 61-66.

Leming, J. S. (2001). Integrating a structured ethical reflection curriculum into high school community service experiences: Impact on students' sociomoral development. Adolescence, 36(141), 33-45.

Levine, P., \& Lopez, M. H. (2002). Youth Voter Turnout has Declined, by Any Measure. College Park, MD: CIRCLE. The Center for Information \& Research on Civic Learning \& Engagement. Retrieved from http://civicyouth.org/research/products/Measuring_Youth_Voter_Turnout.pdf

Lévy-Leboyer, C. (1996). La gestión de las competencias. Barcelona: Gestión 2000.

Lewis, E. (1980). Public Entrepreneurship: Toward a Theory of Bureaucratic Political Power. Bloomington, IN: Indiana University Press.

Light, P. C. (2006). Reshaping Social Entrepreneurship. Stanford Social Innovation Review, (Fall), 4751.

Light, P. C. (2008). The Search for Social Entrepreneurship. Washington, DC: Brookings Institution Press.

Light, P. C. (2009). Social Entrepreneurship Revisited. Stanford Social Innovation Review, (Summer), 21-22. Retrieved from http://ssir.org/images/articles/2009SU_First_Person_Light2.pdf

LLeixà, T. (2007). Educación física y competencias básicas. Contribución del área a la adquisición de las competencias básicas del currículo. Tándem. Didáctica de La Educación Física, (23), 31-37.

Lleixà, T., Robert, M., \& Batalla, A. (2008). La evaluación de competencias en la formación del profesorado de educación física. El caso del blaagaard seminarium de copenhague. Revista Fuentes, 8, 116-124. 
Lleixà, T., Torralba, M. A., \& Abrahão, S. R. (2010). Evaluación de competencias en Educación Física: Investigación-acción para el diseño de procedimientos de evaluación en la Etapa Primaria. Movimento, 16(4), 33-51.

Llopart, X. (1997). La gestión de los recursos humanos en base a competencias. (Doctoral Dissertation, Universitat de Barcelona). Retrieved from http://www.tesisenred.net/bitstream/handle/10803/1481/06.XLP_6de17.pdf?sequence=6

Loli, A. E., Dextre, E., Del Carpio, J., \& La Jara, E. (2010). Actitudes de creatividad y emprendimiento en estudiantes de la Universidad Nacional de Ingeniería y su relación con algunas variables socio demográficas. Revista de Investigación En Psicología, 13(2), 139-151.

López, J. (2006). Las competencias básicas del currículo en la LOE. In A. Jiménez \& M. A. Lou (Eds.), Actas del V Congreso Internacional "Educación y Sociedad". La educación: retos del siglo XXI. Granada: Ilustre Colegio Oficial de Doctores y Licenciados en Ciencias y en Letras de Granada, Almería y Jaén.

López, V. M., García-Peñuela, A., Pérez, D., López, E. M., \& Monjas, R. (2004). Las historias de vida en la formación inicial del profesorado de Educación Física. Revista Internacional de Medicina $Y$ Ciencias de La Actividad Física Y El Deporte, 4(13), 45-57. Retrieved from http://cdeporte.rediris.es/revista/revista13/evaluavida.pdf

Lozano, J. M. (2009). La empresa ciudadana como empresa responsable y sostenible. Madrid: Editorial Trotta.

Lozano, R. (2010). Diffusion of sustainable development in universities' curricula: an empirical example from Cardiff University. Journal of Cleaner Production, 18(7), 637-644. http://doi.org/10.1016/j.jclepro.2009.07.005

Lozano, R., Lukman, R., Lozano, F. J., Huisingh, D., \& Lambrechts, W. (2013). Declarations for sustainability in higher education: becoming better leaders, through addressing the university system. Journal of Cleaner Production, 48, 10-19. http://doi.org/10.1016/j.jclepro.2011.10.006

Lozano, R., \& Peattie, K. (2011). Assessing Cardiff University's Curricula Contribution to Sustainable Development Using the STAUNCH(RTM) System. Journal of Education for Sustainable Development, 5(1), 115-128. http://doi.org/10.1177/097340821000500114

Luchs, K. P. (1981). Selected changes in urban high school students after participation in community based learning and service activities. (Doctoral Dissertation, University of Maryland). Retrieved from http://digitalcommons.unomaha.edu/cgi/viewcontent.cgi?article=1066\&context=slcedt

Lund, J. L. (2000). Creating Rubrics for Physical Education. Reston, VA: National Association for Sport and Physical Education. 
Lund, J. L. (2006). NASPE/NCATE Report Preparation for the Accreditation Process. Journal of Physical Education, Recreation \& Dance (JOPERD), 77(3), 13-31. http://doi.org/10.108o/07303084.2006.10597839

Maclntyre, A. (2007). After Virtue: A Study in Moral Theory (3rd ed.). Notre Dame, IN: University of Notre Dame Press. Retrieved from http://www3.nd.edu/ undpress/excerpts/Po1162-ex.pdf

Macke, D., \& Markley, D. (2003). Entrepreneur Self Test. Tools for energizing entrepreneurship. Lincoln, NE: Center for Rural Entrepreneurship. Retrieved from http://www.slideshare.net/miteshtake/entrepreneur-self-test-118kb

Mair, J., Battilana, J., \& Cardenas, J. (2012). Organizing for Society: A Typology of Social Entrepreneuring Models. Journal of Business Ethics, 111(3), 353-373. http://doi.org/10.1007/s10551-012-1414-3

Mair, J., \& Martí, I. (2006). Social entrepreneurship research: A source of explanation, prediction, and delight. Journal of World Business, 41(1), 36-44. http://doi.org/10.1016/j.jwb.2005.09.002

Maistry, S. M., \& Ramdhani, J. (2010). Integrating social responsibility into an entrepreneurship education program: A case study. US-China Education Review, 7(4), 23-29.

Markus, G. B., Howard, J. P. F., \& King, D. C. (1993). Integrating Community Service and Classroom Instruction Enhances Learning: Results From an Experiment. Educational Evaluation and Policy Analysis, 15(4), 410-419.

Marrewijk, M. (2003). Concepts and Definitions of CSR and Corporate Sustainability: Between Agency and Communion. Journal of Business Ethics, 44(2/3), 95-105. http://doi.org/10.2307/25075020

Martí, J. J., \& Martí-Vilar, M. (2013). Una década de Responsabilidad Social Universitaria en Iberoamérica. Revista Española Del Tercer Sector, (25), 145-162.

Martí, J. J., Martí-Vilar, M., \& Almerich, G. (2014). Responsabilidad social universitaria: influencia de valores y empatía en la autoatribución de comportamientos socialmente responsables. Revista Latinoamericana de Psicología, 46(3), 160-168.

Martin, R. L., \& Osberg, S. (2007). Social entrepreneurship: The case for definition. Stanford Social Innovation Review, (Spring), 29-39. Retrieved from http://www.ssireview.org/images/articles/2007SP_feature_martinosberg.pdf

Martín, X. (2009). La pedagogía del aprendizaje servicio. In J. M. Puig (Ed.), Aprendizaje servicio (APS) Educación y compromiso cívico (pp. 107-126). Barcelona: Graó.

Martínez, C., Mavárez, R. J., Rojas, L. A., \& Carvallo, B. (2008). La responsabilidad social universitaria como estrategia de vinculación con su entorno social. Frónesis. Revista de Filosofía Jurídica, Social Y Política, 15(3), 81-103. 
Martínez, D., Mora, J. G., \& Vila, L. E. (2007). Entrepreneurs, the Self-employed and Employees amongst Young European Higher Education Graduates. European Journal of Education, 42(1), 99-117. http://doi.org/10.1111/j.1465-3435.2007.00285.x

Martínez, M. (Ed.). (2010). Aprendizaje Servicio y Responsabilidad Social de las Universidades. Barcelona: Ediciones Octaedro.

Martínez, M. (2015). Educación y Ciudadanía Activa. Retrieved March 12, 2015, from http://www.oei.es/valores2/mmartinez.htm

Martínez-Odría, A. (2005). Service-Learning o Aprendizaje-Servicio: Una propuesta de incorporación curricular del voluntariado. (Doctoral Dissertation, Universidad de Navarra).

Massetti, B. L. (2008). The Social Entrepreneurship Matrix as a "Tipping Point" for Economic Change. E:CO Emergence: Complexity and Organization, 10(3), 1-8.

Massey-Stokes, M., \& Meaney, K. S. (2006). Understanding our service-learning community: An exploratory study of parent, teacher and student perceptions about childhood obesity. The Health Educator, 38(2), 53-60.

Maynes, N., Hatt, B., \& Wideman, R. (2013). Service Learning as a Practicum Experience in a PreService Education Program. Canadian Journal of Higher Education, 43(1), 80-99.

Mazón, V. (Ed.). (2010). Programación de la educación física basada en competencias. Primaria (6 volúmenes). Barcelona: INDE.

McGrath, R. G. (2003). Connecting the Study of Entrepreneurship and Theories of Capitalist Progress An Epilogue. In Z. J. Acs \& D. B. Audretsch (Eds.), Handbook of Entrepreneurship Research. An Interdisciplinary Survey and Introduction (pp. 515-531). New York, NY: SpringerVerlag.

McMahon, R. (1998). Service learning: Perceptions of pre-service teachers. In Annual Meeting of the Mid-South Educational Research Association. New Orleans, LA: Educational Resources Information Center Document Reproduction Service.

Meaney, K. S., Bohler, H. R., Kopf, K., Hernandez, L., \& Scott, L. S. (2008). Service-Learning and Pre-Service Educators' Cultural Competence for Teaching: An Exploratory Study. Journal of Experiential Education, 31(2), 189-208. http://doi.org/10.1177/105382590803100206

Meaney, K. S., Griffin, K., \& Bohler, H. (2009). Service-Learning: A Venue for Enhancing Pre-Service Educators' Knowledge Base for Teaching. International Journal for the Scholarship of Teaching and Learning, 3(2), Article 21.

Meaney, K. S., Hart, M. A., \& Griffin, K. L. (2009). Fun \& Fit, Phase I. A Program for Overweight African American and Hispanic American Children from Low-Income Families. Journal of 
Physical Education, Recreation \& Dance (JOPERD), 80(6), 35-39. http://doi.org/10.1080/07303084.2009.10598338

Meaney, K. S., Housman, J., Cavazos, A., \& Wilcox, M. L. (2012). Examining Service-Learning in a Graduate Physical Education Teacher Education Course. Journal of the Scholarship of Teaching and Learning, 12(3), 108-124.

Melchior, A. (1999). Summary Report: National Evaluation of Learn and Serve America. Waltham, MA: Center for Human Resources. The Heller School Brandeis University.

Melchior, A. (2000). Costs and Benefits of Service Learning. The School Administrator, 57(7), 26-31.

Melchior, A., \& Bailis, L. N. (2002). Impact of service-learning on civic attitudes and behaviors of middle and high school youth: Findings from three national evaluations. In A. Furco \& S. H. Billig (Eds.), Advances in service learning research: Vol. 1. Service-learning: The essence of the pedagogy (pp. 201-222). Greenwich, CT: Information Age Publishers.

Melchior, A., \& Orr, L. (1995). Final Report: National Evaluation of Serve America. Washington, DC: Corporation for National and Community Service.

Mertens, D. M. (1998). Research methods in education and psychology. Integrating diversity with quantitative and qualitative approaches. Thousand Oaks, CA: Sage Publications.

Meyer, S. (2006). Texas center for service-learning: Evaluation of K-12 SCP and CHESP programs. Denver, CO: RMC Research Corporation.

Miller, M. (2012). The role of service-learning to promote early childhood physical education while examining its influence upon the vocational call to teach. Physical Education \& Sport Pedagogy, 17(1), 61-77. http://doi.org/10.1080/17408981003712810

MINISTERIO DE CIENCIA E INNOVACIÓN. (2009). Estrategia Universidad 2015. Universidades para el progreso, el bienestar y la competitividad. Madrid. Retrieved from http://www.redtcue.es/biblioteca/ecosistema/5-estrategia-universidad-2015/file

MINISTERIO DE EDUCACIÓN Y CIENCIA. (2007). PISA 2006. Programa para la Evaluación Internacional de Alumnos de la OCDE. Informe Español. Madrid: Secretaría general técnica. Subdirección General de Información y Publicaciones.

MINISTERIO DE INDUSTRIA COMERCIO Y TURISMO \& MINISTERIO DE EDUCACIÓN Y CIENCIA. (2003). El espíritu emprendedor motor de futuro. Guía del profesor. Madrid: Secretaría General de Educación y Formación Profesional. Retrieved from http://www.oei.es/etp/espiritu_emprendedor_motor_futuro_guia_profesor.pdf

Miranda, M. D., Lara, A. J., Zagalaz, M. L., \& Cachón, J. (2011). Cómo abordar las competencias básicas desde el área de Educación Física. TRANCES: Revista de Transmisión Del Conocimiento Educativo Y de La Salud, 3(2), 269-283. 
Mohnsen, B. (2006). Assessment and Grading in Physical Education. Strategies: A Journal for Physical and Sport Educators, 20(2), 24-28. http://doi.org/10.1080/08924562.2006.10590709

Molina, J. P., \& Antolín, L. (2008). Las competencias básicas en Educación Física: Una valoración crítica. Cultura, Ciencia Y Deporte, 3(8), 81-86.

Moraleda, M., González, A., \& García-Gallo, J. (2004). AECS: Actitudes y Estrategias Cognitivas Sociales (2nd ed.). Madrid: TEA Ediciones.

Morgan, W., \& Streb, M. (1999). How quality service-learning develops civic values. Bloomington, IN: Indiana University, Center for Participation and Citizenship.

Morgan, W., \& Streb, M. (2001). Building Citizenship: How Student Voice in Service-Learning Develops Civic Values. Social Science Quarterly, 82(1), 154-169.

Moriano, J. A., Palací, F., \& Morales, J. F. (2006). El perfil psicosocial del emprendedor universitario. Revista de Psicología Del Trabajo Y de Las Organizaciones, 22(1), 75-99.

Morse, J. M. (1991). Approaches to Qualitative-Quantitative Methodological Triangulation. Nursing Research, 40(2), 120-123. http://doi.org/10.1097/00006199-199103000-00014

Mort, G. S., Weerawardena, J., \& Carnegie, K. (2003). Social entrepreneurship: towards conceptualisation. International Journal of Nonprofit and Voluntary Sector Marketing, 8(1), 7688

Mosston, M., \& Ashworth, S. (1993). La enseñanza de la Educación Física. La reforma de los estilos de enseñanza. Barcelona: Hispano Europea.

Moya, J. (Coord) (Ed.). (2008). Proyecto Atlántida. De las competencias básicas al currículum integrado. Madrid: 10 Sistemas de comunicación. Retrieved from http://www.proyectoatlantida.eu/wordpress/wp-content/uploads/2015/01/Competencias.pdf

Mulder, K. F. (2010). Don't preach. Practice! Value laden statements in academic sustainability education. International Journal of Sustainability in Higher Education, 11(1), 74-85. http://doi.org/10.1108/14676371011010066

Muñoz, J. C. (2007). La Educación Física en la Ley Orgánica de Educación. Efdeportes. Revista Digital, (105). Retrieved from http://www.efdeportes.com/efd105/la-educacion-fisica-en-laley-organica-de-educacion.htm

NATIONAL YOUTH LEADERSHIP COUNCIL. (2004). Growing to Greatness 2004. The State of Service-Learning Project. Saint Paul, MN: State Farm Companies Foundation.

NATIONAL YOUTH LEADERSHIP COUNCIL. (2008). K-12 Service-Learning Standards for Quality Practice. Saint Paul, MN: National Youth Leadership Council. 
Navarro, V. (2011). Aplicaciones pedagógicas del diseño de juegos motores de reglas en Educación Física. Ágora Para La Educación Física Y El Deporte, 13(1), 15-34.

Navarro, V., \& Jiménez, F. (2012). La mejora en la evaluación formativa de maestros de educación física través de un instrumento de metaevaluación didáctica. RICYDE. Revista Internacional de Ciencias Del Deporte, 8(27), 63-79. http://doi.org/10.5232/ricyde2012.02705

Navío, A. (2005). Propuestas Conceptuales en torno a la Competencia Profesional. Revista de Educación, 337, 213-234.

Neave, G. (1998). Autonomía, Responsabilidad Social y Libertad Académica. Paris: Asociación Internacional de Universidades. Retrieved from http://unesdoc.unesco.org/images/0011/001135/113549so.pdf

Newman, J. (2008). Service learning as an expression of ethics. New Directions for Higher Education, 2008(142), 17-24. http://doi.org/10.1002/he.300

Nicholls, A. (Ed.). (2008). Social Entrepreneurship: New Models of Sustainable Social Change. Oxford: Oxford University Press.

Nicholls, A. (2010). The Legitimacy of Social Entrepreneurship: Reflexive Isomorphism in a PreParadigmatic Field. Entrepreneurship Theory and Practice, 34(4), 611-633. http://doi.org/10.1111/j.1540-6520.2010.00397.x

Nicholls, A., \& Cho, A. H. (2008). Social entrepreneurship: the structuration of a field. In A. Nicholls (Ed.), Social Entrepreneurship: New Models of Sustainable Social Change (pp. 99-118). Oxford: Oxford University Press.

Nicolaides, A. (2006). The implementation of environmental management towards sustainable universities and education for sustainable development as an ethical imperative. International Journal of Sustainability in Higher Education, 7(4), 414-424. http://doi.org/10.1108/14676370610702217

Norasmah, O., Norashidah, H., \& Hariyaty, A. W. (2012). Readiness towards entrepreneurship education: Students and Malaysian universities. Education + Training, 54(8/9), 697-708. http://doi.org/10.1108/00400911211274837

Nóvoa, A. (2003). Textos, imágenes y recuerdos. Escritura de nuevas historias de la educación. In T. S. Popkewitz, B. D. Franklin, \& M. A. Pereira (Eds.), Ensayos críticos sobre conocimiento y escolarización (pp. 61-84). Barcelona: Ediciones Pomares-Corredor.

Núñez, M., \& Alonso, I. (2009). La Responsabilidad Social en el mapa estratégico de las universidades públicas. Pecvnia, 9, 157-180. http://doi.org/10.18002/pec.voig.666

O’Donnell, L., Stueve, A., San Doval, A., Duran, R., Haber, D., Atnafou, R., ... Piessens, P. (1999). The effectiveness of the Reach for Health Community Youth Service learning program in 
reducing early and unprotected sex among urban middle school students. American Journal of Public Health, 89(2), 176-181.

Orrego, C. I. (2009). La fenomenología y el emprendimiento. Pensamiento \& Gestión, (27), 235 252.

Osborne, R. E., Hammerich, S., \& Hensley, C. (1998). Student effects of Service-Learning: Tracking Change Across a Semester. Michigan Journal of Community Service Learning, 5(1), 5-13.

Osborne, R. E., Weadick, K., \& Penticuff, J. (1998). Service learning: From process to impact. In R. G. Bringle \& D. K. Duffy (Eds.), With Service in Mind: Concepts and Models for Service-Learning in Psychology (pp. 128-141). Washington, DC: American Association for Higher Education.

Ostrander, S. A. (2007). The Growth of Donor Control: Revisiting the Social Relations of Philanthropy. Nonprofit and Voluntary Sector Quarterly, 36(2), 356-372. http://doi.org/10.1177/0899764007300386

Pacenza, M. I., \& Silva, Y. F. (2013). Análisis bibliométrico sobre responsabilidad social universitaria. Psychology, Society \& Education, 5(2), 125-138.

Pacheco, J. J. (2011). El desarrollo de la competencia motriz en la educación física escolar. El caso de canarias. Acción Motriz., (7), 30-37. Retrieved from http://www.accionmotriz.com/documentos/revistas/articulos/7_completa.pdf

Palmer, T. B., \& Short, J. C. (2008). Mission Statements in U.S. Colleges of Business: An Empirical Examination of Their Content With Linkages to Configurations and Performance. Academy of $\begin{array}{lllll}\text { Management Learning \& } \quad \text { Education, } & \text { 454-470. }\end{array}$ http://doi.org/10.5465/AMLE.2008.35882187

Palos, J. (2009). ¿Por qué hacer actividades de aprendizaje servicio? In J. M. Puig (Ed.), Aprendizaje servicio (APS) Educación y compromiso cívico (pp. 151-161). Barcelona: Graó.

Pamphilon, B. (1999). The Zoom Model: A Dynamic Framework for the Analysis of Life Histories. Qualitative Inquiry, 5(3), 393-410. http://doi.org/10.1177/107780049900500306

Pascual, C. (2003). La historia de vida de una educadora de profesores de Educación Física: su desarrollo personal y profesional. Ágora Para La Educación Física Y El Deporte, (2-3), 23-38.

Pavié, A. (2011). Formación docente: hacia una definición del concepto de competencia profesional docente. Revista Electrónica Interuniversitaria de Formación Del Profesorado, 14(1), 67-80. Retrieved from http://www.aufop.com/aufop/uploaded_files/articulos/1301587967.pdf

Pazo, C. I., \& Tejada, J. (2012). Las competencias profesionales en Educación Física. Retos. Nuevas Tendencias En Educación Física, Deporte Y Recreación, 2(22), 5-8. 
Pechak, C., \& Thompson, M. (2011). Going global in physical therapist education: International service-learning in US-based programmes. Physiotherapy Research International, 16(4), 225236. http://doi.org/10.1002/pri.501

Peredo, A. M., \& McLean, M. (2006). Social entrepreneurship: A critical review of the concept. Journal of World Business, 41(1), 56-65. http://doi.org/10.1016/j.jwb.2005.10.007

Pérez, Á. I. (2007). Cuadernos de Educación de Cantabria. La naturaleza de las competencias básicas y sus aplicaciones pedagógicas. Consejería de Educación de Cantabria. Retrieved from http://www.educantabria.es/docs/info_institucional/publicaciones/2007/Cuadernos_Educacio n_1.PDF?phpMyAdmin=DxoCAdBIc\%2CANuNIkvc-WZcMiFvc

Pérez, M. P. (2008). Competencias adquiridas por los futuros docentes desde la formación inicial. Revista de Educación, 347, 343-367.

Pérez, V., Devís, J., Smith, B. M., \& Sparkes, A. C. (2011). La investigación narrativa en la educación física y el deporte: qué es y para qué sirve. Movimento, 17(1), 11-38.

Pérez-Tornero, J. M. (Ed.). (2000). Comunicación y educación en la sociedad de la información. Nuevos lenguajes y conciencia crítica. Barcelona: Paidós Ibérica.

Perrini, F., \& Vurro, C. (2006). Social Entrepreneurship: Innovation and Social Change Across Theory and Practice. In J. Mair, J. Robinson, \& K. Hockerts (Eds.), Social Entrepreneurship (pp. 57-85). Basingstoke: Palgrave Macmillan.

Perry, J. L., \& Katula, M. C. (2001). Does Service Affect Citizenship? Administration \& Society, 33(3), 330-365. http://doi.org/10.1177/00953990122019794

Phoenix, C., \& Sparkes, A. C. (2007). Sporting bodies, ageing, narrative mapping and young team athletes: an analysis of possible selves. Sport, Education and Society, 12(1), 1-17. http://doi.org/10.1080/13573320601081468

Pissanos, B. W., \& Allison, P. C. (1996). Continued Professional Learning: A Topical Life History. Journal of Teaching in Physical Education, 16(1), 2-19.

Polo, I. (2010). Las rúbricas como instrumentos de apoyo. La evaluación de las competencias básicas en la asignatura de Educación Física. Tándem. Didáctica de La Educación Física, (32), 106-119.

Prabhu, G. N. (1999). Social entrepreneurial leadership. Career Development International, 4(3), 140145. http://doi.org/10.1108/13620439910262796

Puig, J. M., Batlle, R., Bosch, C., \& Palos, J. (2007). Aprendizaje servicio. Educar para la ciudadanía. Barcelona: Ministerio de Educación y Ciencia y Editorial Octaedro. 
Puig, J. M., Gijón, M., Martín, X., \& Rubio, L. (2011). Aprendizaje-servicio y Educación para la Ciudadanía. Revista de Educación, (Número extraordinario), 45-67.

Pujadas, J. J. (1992). El método biográfico: el uso de las historias de vida en ciencias sociales. Madrid: Centro de Investigaciones Sociológicas.

Pujadas, J. J. (2000). El método biográfico y los géneros de la memoria. Revista de Antropología Social, 9, 127-158.

Queiroz, M. I. P. (1991). Relatos orais: do "indizível" ao "dizível." In M. I. P. Queiroz (Ed.), Variações sobre a técnica do gravador no registro da informação viva (pp. 1-26). São Paulo: Editorial T.A. Queiroz.

Ram, B. S., \& Selvaraj, M. (2012). Impact of computer based online entrepreneurship distance education in India. Turkish Online Journal of Distance Education. IETC, 13(3), 247-259. Retrieved from http://tojde.anadolu.edu.tr/makale_goster.php?id=798

Ramalho, B. L., \& Beltrán, J. (2012). Universidad y sociedad: la pertinencia de educación superior para una ciudadanía plena. Revista Lusófona de Educação, 21(21), 33-52.

Ramiro, J., Sánchez-Bañuelos, F., \& García-Ferrando, M. (1998). Libro blanco, I+D en el deporte. Madrid: Consejo Superior de Deportes.

Ramos, C. (2010). Hacia una cultura de Responsabilidad Social Universitaria. Centro de Investigación de Ciencias Administrativas Y Gerenciales, 7(2), 97-113.

Rauch, A., \& Frese, M. (2000). Psychological approaches to entrepreneurial success: A general model and an overview of findings. In C. L. Cooper \& I. T. Robertson (Eds.), International review of industrial and organizational psychology (pp. 101-142). Chichester, UK: John Wiley \& Sons.

Rauch, A., \& Frese, M. (2007). Let's Put the Person Back into Entrepreneurship Research: A MetaAnalysis on the Relationship between Business Owners' Personality Traits, Business Creation, and Success. European Journal of Work and Organizational Psychology, 16(4), 352-385. http://doi.org/10.1080/13594320701595438

Raymond, H. (1968). Analyse de contenu et entretien non-directif: application au symbolisme de I' habitat. Revue Française de Sociologie, 9(2), 167-179. Retrieved from http://www.persee.fr/docAsPDF/rfsoc_0035-2969_1968_num_9_2_1378.pdf

Rees, T., Smith, B., \& Sparkes, A. C. (2003). The influence of social support on the lived experiences of spinal cord injured sportsmen. The Sport Psychologist, 17(2), 135-156.

Reyno, M. (2006). Responsabilidad Social Empresarial (RSE) como ventaja competitiva. (Master's Thesis, Universidad Técnica Federico Santa María). Retrieved from http://www.eumed.net/libros-gratis/2008c/436/\#indice 
Riba, C. E. (2007). La metodologia qualitativa en l'estudi del comportament. Barcelona: UOC.

Rich, E. (2003). "The problem with girls": liberal feminism, "equal opportunities" and gender inequality in physical education. British Journal of Teaching Physical Education, 34(1), 46-49.

Roberts, D., \& Woods, C. (2005). Changing the world on a shoestring: The concept of social entrepreneurship. University of Auckland Business Review, 7(1), 45-51.

Roberts, N., \& King, P. (1989). Public Entrepreneurship: A Typology. Monterey, CA: Naval Postgraduate School. Retrieved from http://calhoun.nps.edu/bitstream/handle/10945/29055/publicentrepreneoorobe.pdf?sequence $=1$

Robinson, D. B., \& Meyer, M. (2012). Health education and interactive drama: Findings from a service learning project. Health Education Journal, 71(2), 219-228. http://doi.org/10.1177/0017896911398811

Robinson, P. B., Stimpson, D. V, Huefner, J. C., \& Hunt, H. K. (1991). An Attitude Approach to the Prediction of Entrepreneurship. Entrepreneurship Theory and Practice, 15(4), 13-31.

Rodríguez, A., \& Fustes, S. (2013). Las Rúbricas en Educación Física. Revista de Educación Física, $29(3), 14-18$.

Rodríguez, G., Gil, J., \& García, E. (1996). Metodología de la investigación cualitativa. Málaga: Ediciones Aljibe.

Rodríguez, V. J., \& Larrota, S. Y. (2012). Responsabilidad Social y Emprendimiento en la formación de los estudiantes de la Universidad de La Salle de Bogotá D.C. Punto de Vista, 3(5), 49-75.

Romero, C. (2004). Argumentos sobre la formación inicial de los docentes en educación física. Profesorado. Revista de Currículum Y Formación Del Profesorado, 8(1), 1-20. Retrieved from http://www.ugr.es/ recfpro/rev81ART5.pdf

Romero, C. (2009). Definición de módulos y competencias del maestro con mención en educación física. Revista Internacional de Medicina Y Ciencias de La Actividad Física Y Del Deporte, 9(34), 179-200.

Romero, C., Zagalaz, M. L., Romero, M. N., \& Martínez, E. J. (2011). Importancia de las competencias profesionales de los Maestros en Educación Física expresadas por los estudiantes. Retos. Nuevas Tendencias En Educación Física, Deporte Y Recreación, 1(19), 63-68.

Roper, J., \& Cheney, G. (2005). Leadership, learning and human resource management. The meanings of social entrepreneurship today. Corporate Governance, 5(3), 95-104. http://doi.org/10.1108/14720700510604733 
Rosales, C. (2013). Competencias específicas curriculares que ha de adquirir el estudiante del título de Grado de Maestro. Profesorado. Revista de Currículum Y Formación Del Profesorado, 17(3), 73-90.

Rovegno, I., \& Bandhaver, D. (1997). Psychological Dispositions That Facilitated and Sustained the Development of Knowledge of a Constructivist Approach to Physical Education. Journal of Teaching in Physical Education, 16(2), 136-154.

Rubio, L. (2009). El aprendizaje en el aprendizaje servicio. In J. M. Puig (Ed.), Aprendizaje servicio (APS) Educación y compromiso cívico (pp. 91-105). Barcelona: Graó.

Ruiz, J. I., \& Ispizua, M. A. (1989). La descodificación de la vida cotidiana. Métodos de investigación cualitativa. Bilbao: Universidad de Deusto.

Ruiz-Pérez, L. M. (1995). Competencia motriz. Elementos para comprender el aprendizaje motor en educación física escolar. Madrid: Gymnos.

Sagawa, S., \& Segal, E. (2000). Common Interest, Common Good: Creating Value Through Business and Social Sector Partnerships. California Management Review, 42(2), 105-122. http://doi.org/10.2307/41166035

Saggers, B., \& Carrington, S. (2008). Outcomes of a service-learning program for pre-service teachers: links to Butin's conceptual model. Teaching Education, 19(1), 57-71. http://doi.org/10.1080/10476210701860057

Saldaña, D. E., \& Coutiño, R. S. (2010). Universidad y emprendimiento social: El caso del Tecnológico de Monterrey. ICADE. Revista Cuatrimestral de Las Facultades de Derecho Y Ciencias Económicas Y Empresariales, (80), 265-290.

Salicetti, A., Campos, C., Jiménez, J., Carpio, E., \& Smith, D. (2013). Construcción y validación de un instrumento de evaluación de estrategias metodológicas aplicadas a la Educación Física. Ágora Para La Educación Física Y El Deporte, 3(15), 210-227.

Sánchez, J. C. (2010). Evaluación de la Personalidad Emprendedora: Validez Factorial del Cuestionario de Orientación Emprendedora (COE). Revista Latinoamericana de Psicología, $42(1), 41-52$.

Sánchez, J. C., \& Gutiérrez, A. (2011). Entrepreneurship research in Spain: Developments and distinctiveness. Psicothema, 23(3), 458-463.

Sánchez-Bañuelos, F. (1996). La actividad física orientada hacia la salud. Madrid: Biblioteca Nueva.

Santamarina, C., \& Marinas, J. M. (1995). Historias de vida e historia oral. In J. M. Delgado \& J. Gutiérrez (Eds.), Métodos y técnicas cualitativas de investigación en ciencias sociales (pp. 259287). Madrid: Síntesis. 
Sarramona, J. (2004). Las competencias básicas en la educación obligatoria. Barcelona: CEAC.

Sarrate, M. L., García, J. L., \& Pérez, G. (2013). Exigencias profesionales del animador/a: Competencias clave. Pedagogia Social Revista Interuniversitaria, (22), 75-89. http://doi.org/10.7179/PSRI

Scales, P. C., \& Blyth, D. A. (1997). Effects of service learning on youth: What we know and what we need to know. Generator, Winter, 6-9.

Scales, P. C., Blyth, D. A., Berkas, T. H., \& Kielsmeier, J. C. (2000). The Effects of Service-Learning on Middle School Students' Social Responsibility and Academic Success. The Journal of Early Adolescence, 20(3), 332-358.

Schempp, P. G. (1993). Constructing Professional Knowledge: A Case Study of an Experienced High School Teacher. Journal of Teaching in Physical Education, 13(1), 2-13.

Schmitt-Rodermund, E. (2004). Pathways to successful entrepreneurship: Parenting, personality, early entrepreneurial competence, and interests. Journal of Vocational Behavior, 65(3), 498518. http://doi.org/10.1016/j.jvb.2003.10.007

Seban, D. (2013). The impact of the type of projects on preservice teachers' conceptualization of service learning. Teaching and Teacher Education, 32, 87-97. http://doi.org/10.1016/j.tate.2013.01.009

Sebastiani, E. M. (2007a). Las competencias del profesor de Educación Física en el Espacio Europeo de Educación Superior (EEES). INDEref. Revista de Educación Física. Retrieved from http://www.inderef.com/content/view/91/110/

Sebastiani, E. M. (2007b). Les competències professionals del professor d'Educació Física de Secundària a Catalunya. Una proposta de categories per a la seva anàlisi. (Doctoral Dissertation, Universitat Ramon Llull). Retrieved from http://www.tdx.cat/bitstream/handle/10803/9229/TESI_DOCTORAL_E_SEBASTIANI.pdf?seq vence $=1$

Seelos, C., \& Mair, J. (2005). Social entrepreneurship: Creating new business models to serve the poor. Business Horizons, 48(3), 241-246. http://doi.org/10.1016/j.bushor.2004.11.006

Selamé, T. (1999). Emprendimiento juvenil. Santiago de Chile: Instituto Nacional de la Juventud.

SENATE \& HOUSE OF REPRESENTATIVES 3127. National and Community Service Act of 1990 November 16, Pub. L. No. 101-610 (1990). Retrieved from http://www.nationalservice.gov/sites/default/files/page/Service_Act_09_11_13.pdf

Serap, M. G., \& Eker, T. (2007). Corporate Identity of a Socially Responsible University - A Case from the Turkish Higher Education Sector. Journal of Business Ethics, 76(1), 55-68. http://doi.org/10.1007/s10551-006-9274-3 
Shaffer, B. (1993). Service-Learning: An Academic Methodology. Stanford, CA: Stanford University Department of Education.

Sharir, M., \& Lerner, M. (2006). Gauging the success of social ventures initiated by individual social entrepreneurs. Journal of World Business, 41(1), 6-20. http://doi.org/10.1016/j.jwb.2005.09.004

Sharra, S. (2005). From Entrepreneurship to Activism: Teacher Autobiography, Peace and Social Justice in Education. Current Issues in Comparative Education, 8(1), 7-17.

Shaw, E., Shaw, J., \& Wilson, M. (2002). Unsung entrepreneurs: Entrepreneurship for social gain. Durham, UK: University of Durham Business School. The Barclays Centre for Entrepreneurship.

Shook, J. R. (2000). Dewey's Empirical Theory of Knowledge and Reality. Nashville, TN: Vanderbilt University Press.

Short, J. C., Ketchen, D. J., \& Palmer, T. B. (2002). The Role of Sampling in Strategic Management Research on Performance: A Two-Study Analysis. Journal of Management, 28(3), 363-385. http://doi.org/10.1177/014920630202800306

Short, J. C., Moss, T. W., \& Lumpkin, G. T. (2009). Research in Social Entrepreneurship: past contributions and future opportunities. Strategic Entrepreneurship Journal, 3(2), 161-194. http://doi.org/10.1002/sej

Short, J. C., Payne, G. T., \& Ketchen, D. J. (2008). Research on Organizational Configurations: Past Accomplishments and Future Challenges. Journal of Management, 34(6), 1053-1079. http://doi.org/10.1177/0149206308324324

Shumer, R. (1994). Community-based learning: humanizing education. Journal of Adolescence, 17(4), 357-367. http://doi.org/10.1006/jado.1994.1032

Simpeh, K. N. (2011). Entrepreneurship theories and Empirical research: A Summary Review of the Literature. European Journal Of Business and Management, 3(6), 1-9.

Singer, R. N. (1986). El aprendizaje de las acciones motrices en el deporte. Barcelona: Hispano Europea.

Skjong, R., \& Wentworth, B. (2001). Expert Judgement and Risk Perception. In International Offshore and Polar Engineering Conference. Stavanter: The International Society of Offshore and Polar Engineers. Retrieved from http://research.dnv.com/skj/Papers/SkjWen.pdf

Slater, S. F., \& Narver, J. C. (1995). Market Orientation and the Learning Organization. Journal of Marketing, 59(3), 63-74. http://doi.org/10.2307/1252120

Sleeper, R. W. (2001). The Necessity of Pragmatism: John Dewey's Conception of Philosophy. Chicago, IL: University of Illinois Press. 
Snow, C. C., \& Thomas, J. B. (1994). Field research methods in strategic management: contributions to theory building and testing. Journal of Management Studies, 31(4), 457-480. http://doi.org/10.1111/j.1467-6486.1994.tboo626.x

Sparkes, A. C. (1993). Challenging technical rationality in physical education teacher education: the potential of a life history approach. Physical Education Review, 16(2), 107-121.

Sparkes, A. C. (1994a). Life histories and the issue of voice: reflections on an emerging relationship. International Journal of Qualitative Studies in Education, $7(2)$, $165-183$. http://doi.org/10.1080/0951839940070205

Sparkes, A. C. (1994b). Self, Silence and Invisibility as a Beginning Teacher: A life history of lesbian experience. British Journal of Sociology of Education, 15(1), 93-118. http://doi.org/10.1080/0142569940150106

Sparkes, A. C. (2003). Investigación narrativa en la Educación Física y el Deporte. Ágora Para La Educación Física Y El Deporte, (2-3), 51-60.

Sparkes, A. C., \& Devís, J. (2008). Investigación narrativa y sus formas de análisis: una visión desde la educación física y el deporte. In W. Moreno (Ed.), Educación cuerpo y ciudad. El cuerpo en las interacciones e instituciones sociales (pp. 43-68). Medellin: Funámbulos.

Sparkes, A. C., \& Templin, T. J. (1992). Life histories and physical education teachers: Exploring the meanings of marginality. In A. C. Sparkes (Ed.), Research in physical education and sport: Exploring alternative visions (pp. 118-145). London: Falmer Press.

Sparkes, A. C., Templin, T. J., \& Schempp, P. G. (1993). Exploring Dimensions of Marginality: Reflecting on the Life Histories of Physical Education Teachers. Journal of Teaching in Physical Education, 12(4), 386-398.

Spear, R. (2006). Social entrepreneurship: a different model? International Journal of Social Economics, 33(5/6), 399-410. http://doi.org/10.1108/03068290610660670

Stanton, T. K., Giles, D. E., \& Cruz, N. I. (1999). Service-learning. A Movement's Pioneers Reflect on its Origins, Practice, and Future. San Francisco: Jossey Bass.

Stephens, J. C., Hernández, M. E., Román, M., Graham, A. C., \& Scholz, R. W. (2008). Higher education as a change agent for sustainability in different cultures and contexts. International Journal of Sustainability in Higher Education, 9(3), 317-338. http://doi.org/10.1108/14676370810885916

Stephens, L. S. (1995). The complete guide to learning through community service. Grades K-9. Boston, MA: Allyn \& Bacon. 
Stewart, W. H., \& Roth, P. L. (2001). Risk propensity differences between entrepreneurs and managers: A meta-analytic review. Journal of Applied Psychology, 86(1), 145-153. http://doi.org/10.1037/0021-9010.86.1.145

Stewart, W. H., \& Roth, P. L. (2004). Data Quality Affects Meta-Analytic Conclusions: A Response to Miner and Raju (2004) Concerning Entrepreneurial Risk Propensity. Journal of Applied Psychology, 89(1), 14-21. http://doi.org/10.1037/0021-9010.89.1.14

Stupik, J. (1996). Valued Youth Partnerships: Programs in Caring. San Antonio, TX: Intercultural Research and Development Association.

Suskie, L. (2004). Assessing student learning: A common sense guide. Bolton, MA: Anker Publishing.

Switzer, G. E., Simmons, R. G., Dew, M. A., Regalski, J. M., \& Wang, C. H. (1995). The Effect of a School-Based Helper Program on Adolescent Self-Image, Attitudes, and Behavior. The Journal of Early Adolescence, 15(4), 429-455. http://doi.org/10.1177/0272431695015004003

Sykes, H. (1998). Turning the Closets Inside/Out: Towards a Queer-Feminist Theory in Women's Physical Education. Sociology of Sport Journal, 15(2), 154-173.

Sykes, H. (2001a). Pedagogies and Life Histories of Non-Heterosexual Physical Educators. In Annual Meeting of the American Educational Research Association (p. 25). Seattle, WA: Educational Resources Information Center Document Reproduction Service.

Sykes, H. (2001b). Understanding and overstanding: Feminist-poststructural life histories of physical education teachers. International Journal of Qualitative Studies in Education, 14(1), 1331. http://doi.org/10.1080/0269172001009744

Sykes, H., \& Goldstein, T. (2004). From performed to performing ethnography: translating life history research into anti-homophobia curriculum for a teacher education program. Teaching Education, 15(1), 41-61. http://doi.org/10.1080/1047621042000179989

Tan, W. L., Williams, J., \& Tan, T. M. (2005). Defining the "Social" in "Social Entrepreneurship": Altruism and Entrepreneurship. International Entrepreneurship and Management Journal, 1(3), 353-365. http://doi.org/10.1007/s11365-005-2600-x

Tapia, M. N. (2001). La solidaridad como pedagogía. El aprendizaje-servicio en la escuela (2nd ed.). Buenos Aires: Ciudad Nueva.

Tapia, M. N. (2006). Aprendizaje y servicio solidario en el sistema educativo y las organizaciones juveniles. Buenos Aires: Ciudad Nueva.

Tapia, M. N. (2008). Aprendizaje y servicio solidario en la misión de la Educación Superior. In A. González \& R. Montes (Eds.), El Aprendizaje-Servicio en la Educación Superior. Una mirada analítica desde los protagonistas (1st ed., pp. 11-34). Editorial Universitaria de Buenos Aires. 
Tapia, M. N. (2010). Calidad académica y responsabilidad social: el aprendizaje servicio como puente entre dos culturas universitarias. In M. Martínez (Ed.), Aprendizaje Servicio y Responsabilidad Social de las Universidades (pp. 27-56). Barcelona: Ediciones Octaedro.

Teddlie, C., \& Tashakkori, A. (2010). Overview of contemporary issues in mixed methods research. In A. Tashakkori \& C. Teddlie (Eds.), Handbook of Mixed Methods in Social \& Behavioral Research (2nd ed., pp. 1-41). Thousand Oaks, CA: Sage Publications.

Tejada, J. (2005). El trabajo por competencias en el prácticum: cómo organizarlo y cómo evaluarlo. REDIE Revista Electrónica de Investigación Educativa, 7(2). Retrieved from http://www.redalyc.org/articulo.oa?id=15507211

Templin, T. J., Sparkes, A. C., Grant, B. C., \& Schempp, P. G. (1994). Matching the Self: The Paradoxical Case and Life History of a Late Career Teacher/Coach. Journal of Teaching in Physical Education, 13(3), 274-294.

THE ORGANISATION FOR ECONOMIC CO-OPERATION AND DEVELOPMENT (OECD). (1999). Social Enterprises. Paris: OECD.

Thompson, J. (2002). The world of the social entrepreneur. International Journal of Public Sector Management, 15(5), 412-431. http://doi.org/10.1108/09513550210435746

Thompson, J., Alvy, G., \& Lees, A. (2000). Social entrepreneurship - a new look at the people and the potential. Management Decision, 38(5), 328-338. http://doi.org/10.1108/00251740010340517

Thompson, J., \& Doherty, B. (2006). The diverse world of social enterprise: A collection of social enterprise stories. International Journal of Social Economics, 33(5/6), 361-375. http://doi.org/10.1108/03068290610660643

Thorburn, M. (2011). "Still game": an analysis of the life history and career disappointments of one veteran male teacher of physical education in Scotland. Educational Review, 63(3), 329-343. http://doi.org/10.1080/00131911.2011.571762

Titlebaum, P., Williamson, G., Daprano, C., Baer, J., \& Brahler, J. (2004). Annotated History of Service Learning 1862-2002. Dayton, $\mathrm{OH}$ : University of Dayton.

Todd, Z., Nerlich, B., \& McKeown, S. (2004). Introduction. In Z. Todd, B. Nerlich, S. McKeown, \& D. D. Clarke (Eds.), Mixing Methods in Psychology. The integration of qualitative and quantitative methods in theory and practice (pp. 2-15). Hove, UK: Psychology Press. Taylor \& Francis Group.

Torres, C., \& Lorenzo, M. (2004). Aportaciones de las Historias de Vida en la investigación sobre el valor formativo de los clubes deportivos infantiles y juveniles: un estudio de caso. Revista de Investigación Educativa, 22(1), 61-88. 
Tracey, P., \& Phillips, N. (2007). The Distinctive Challenge of Educating Social Entrepreneurs: A Postscript and Rejoinder to the Special Issue on Entrepreneurship Education. Academy of $\begin{array}{llll}\text { Management Learning } \quad \text { \& } \quad \text { Education, } & \text { 264-271. }\end{array}$ http://doi.org/10.5465/AMLE.2007.25223465

Ubah, A. C., Onwuasoanya, P., \& Eze, J. (2012). Perceived Impact of Guidance and Counseling Services on the Development of Entrepreneurial Skills for Sustainable Livelihood among Students. US-China Education Review, 2(12), 1044-1051.

UNITED NATIONS EDUCATIONAL SCIENTIFIC AND CULTURAL ORGANIZATION (UNESCO). (2009). Conferencia Mundial sobre la Educación Superior: La nueva dinámica de la educación superior y la investigación para el cambio social y el desarrollo. Paris. Retrieved from http://www.unesco.org/education/WCHE200g/comunicado_es.pdf

Vaca, M. J. (2008). Contribución de la educación física escolar a las competencias básicas señaladas en la LOE para la educación primaria. Tándem. Didáctica de La Educación Física, (26), 52-61.

Vallaeys, F. (2005). Breve marco teórico de Responsabilidad Social Universitaria. Monterrey. Retrieved from http://rsuniversitaria.org/web/images/stories/BreveMarcoTeodelaResponsabilidadSocialUniv. pdf

Vallaeys, F. (2007). Responsabilidad social universitaria. Propuesta para una definición madura y eficiente (Programa para la Formación en Humanidades). Monterrey. Retrieved from http://www.responsable.net/sites/default/files/responsabilidad_social_universitaria_francois_ vallaeys.pdf

Vallaeys, F., De la Cruz, C., \& Sasia, P. M. (2009). Responsabilidad Social Universitaria. Manual de primeros pasos. México, DF: McGraw-Hill Interamericana.

Valls, N., Villa, A., Martínez, S., \& Hernando, A. (2009). Emprendimiento Social Juvenil. 18 buenas prácticas. (Fundación Bertelsmann, Ed.). Barcelona: CEGE.

Valor, C., \& Hurtado, I. (Eds.). (2009). Las empresas españolas y la responsabilidad social corporativa. La contribución a los objetivos de desarrollo del milenio. Madrid: Catarata.

Van De Ven, A. H., \& Johnson, P. E. (2006). Knowledge for Theory and Practice. Academy of Management Review, 31(4), 802-821. http://doi.org/10.5465/AMR.2006.22527385

Van de Ven, A. H., Sapienza, H. J., \& Villanueva, J. (2007). Entrepreneurial pursuits of self- and collective interests. Strategic Entrepreneurship Journal, 1(3-4), 353-370. http://doi.org/10.1002/sej.34

Vargas, F. (2004). Competencias clave y aprendizaje permanente. Montevideo: Cinterfor. 
Velasco, R. (2012). Emprendimiento un estado de la investigación. In J. L. García (coord.) (Ed.), Empresas y empresarios en la economía global (Vol. 21, pp. 53-62). Almería: Mediterráneo Económico. Fundación Cajamar.

Vicente, M. (2011). Escuela y educación física en el contexto de la enseñanza por competencias. Reflexiones genealógicas desde la pedagogía crítica. Cultura, Ciencia Y Deporte, 6(18), 161170.

Vila, E. S., \& Martín, V. M. (2014). A río revuelto, ganancia de pescadores. Usos y abusos en torno a la empleabilidad vista desde la responsabilidad social de las universidades. Procedia - Social and Behavioral Sciences, 139, 42-47. http://doi.org/10.1016/j.sbspro.2014.08.018

Villa, A., Campo, L., Arranz, S., Villa, O., \& García, A. (2013). Valoración del profesorado de magisterio sobre el aprendizaje basado en competencias implantado. Profesorado. Revista de Currículum Y Formación Del Profesorado, 17(3), 35-55.

Villa, A., \& Poblete, M. (Eds.). (2007). Aprendizaje basado en competencias. Una propuesta para la evaluación de las competencias genéricas. Bilbao: Universidad de Deusto y Ediciones Mensajero.

Villar, J. (2010). Responsabilidad Social Universitaria: nuevos paradigmas para una educación liberadora y humanizadora de las personas y las sociedades. Responsabilidad Social, (4), 27-37. Retrieved from http://www.unrc.edu.ar/unrc/psc/pdfs/biblio/2. Javier Villar.pdf

Vygotsky, L. S. (1978). Mind in Society: The Development of Higher Psychological Processes. Cambridge, MA: Harvard University Press.

Waddock, S. A. (1988). Building Successful Social Partnerships. Sloan Management Review, 29(4), 17-23.

Waddock, S. A., \& Post, J. E. (1991). Social Entrepreneurs and Catalytic Change. Public Administration Review, 51(5), 393-401. http://doi.org/10.2307/976408

Wallace, S. L. (1999). Social entrepreneurship: The role of social purpose enterprises in facilitating community economic development. Journal of Developmental Entrepreneurship, 4(2), 153-174.

Wang, J., \& Rairigh, R. M. (2006). Using Instructional Rubrics in Physical Education. Teaching Elementary Physical Education, 17(3), 37-41.

Warren, J. L. (2012). Does Service-Learning Increase Student Learning?: A Meta-Analysis. Michigan Journal of Community Service Learning, (Spring), 56-61.

Wedgwood, N. (2005). Just one of the boys? A life history case study of a male physical education teacher. Gender and Education, 17(2), 189-201. http://doi.org/10.1080/0954025042000301456 
Weerawardena, J., \& Mort, G. S. (2006). Investigating social entrepreneurship: A multidimensional model. Journal of World Business, 41(1), 21-35. http://doi.org/10.1016/j.jwb.2005.09.001

Weiler, D., LaGoy, A., Crane, E., \& Rovner, A. (1998). An evaluation of $K$-12 service-learning in California: Phase II final report. Emeryville, CA: RPP International with the Search Institute.

Welch, S., \& Comer, J. (1988). Quantitative Methods for Public Administration: Techniques and Applications. Mishawaka, IN: Dorsey Press.

Westheimer, J., \& Kahne, J. (2004). What Kind of Citizen? The Politics of Educating for Democracy. American Educational Research Journal, 41(2), 237-269. http://doi.org/10.3102/00028312041002237

White, A. E. (2001). A meta-analysis of service learning research in middle and high schools. (Doctoral Dissertation, University of North Texas). Retrieved from http://digitalcommons.unomaha.edu/cgi/viewcontent.cgi?article=1050\&context=slcedt

Wilkinson, S., Harvey, W. J., Bloom, G. A., Joober, R., \& Grizenko, N. (2013). Student teacher experiences in a service-learning project for children with attention-deficit hyperactivity disorder. Physical Education \& Sport Pedagogy, 18(5), 475-491. http://doi.org/10.1080/17408989.2012.690385

Williams, K., \& Kovacs, C. (2001). Balance and Mobility Training for Older Adults: An Undergraduate Service-Learning Experience. Journal of Physical Education, Recreation \& Dance (JOPERD), 72(3), 54-58. http://doi.org/10.1080/07303084.2001.10605853

Williams, L., \& Rink, J. (2003). Chapter 5: Teacher Competency Using Observational Scoring Rubrics. Journal of Teaching in Physical Education, 22(5), 552-572.

Wolf, K., \& Stevens, E. (2007). The role of Rubrics in Advancing and Assessing Student Learning. The Journal of Effective Teaching, 7(1), 3-14.

WRITING@CSU. (2015). Definition of Service-Learning. Retrieved March 5, 2015, from http://writing.colostate.edu/guides/teaching/service_learning/definition.cfm

Wurr, A. J. (2002). Text-Based Measures of Service-Learning Writing Quality. Reflections: A Journal of Writing, Service Learning and Community Literacy, 2(2), 40-55.

Yániz, C. (2008). Las competencias en el currículo universitario: implicaciones para diseñar el aprendizaje y para la formación del profesorado. REDU. Revista de Docencia Universitaria, 6(1), Monográfico de Formación centrada en competencias. Retrieved from http://redu.net/redu/index.php/REDU/article/view/59/pdf

Yates, M., \& Youniss, J. (1996). A developmental perspective on community service in adolescence. Social Development, 5(1), 85-111. 
Yorio, P. L., \& Ye, F. (2012). A meta-analysis on the effects of service-learning on the social, personal, and cognitive outcomes of learning. Academy of Management Learning and Education, 11(1), 9-27. http://doi.org/10.5465/amle.2010.0072

Youniss, J., Mclellan, J. A., Su, Y., \& Yates, M. (1999). The Role of Community Service in Identity Development: Normative, Unconventional, and Deviant Orientations. Journal of Adolescent Research, 14(2), 248-261. http://doi.org/10.1177/0743558499142006

Zabalza, M. Á. (2005). Competencias docentes. In Conferencia en la Pontificia Universidad Javeriana de Cali. Retrieved from http://www.academica.mx/sites/default/files/adjuntos/8802/lectura2competencias-docentes.miguel_angel_zabalza.pdf

Zabalza, M. Á. (2011). El Practicum en la formación universitaria: estado de la cuestión. Revista de Educación, (354), 21-43.

Zagalaz, M. L., Cachón, J., \& Lara, A. J. (2008). La educación física en primaria a partir de la ley orgánica de educación (LOE, 2006). Especial atención a la enseñanza por competencias. Jaén: Formación Continuada LOGOSS.

Zahra, S. A., Gedajlovic, E., Neubaum, D. O., \& Shulman, J. M. (2009). A typology of social entrepreneurs: Motives, search processes and ethical challenges. Journal of Business Venturing, 24(5), 519-532. http://doi.org/10.1016/j.jbusvent.2008.04.007

Zamorano, D. (2011). La elaboración de aprendizajes/indicadores de evaluación desde el área de Educación Física. Programando desde un enfoque competencial. Lecturas: Educación Física $Y$ Deportes, Revista Digital., (163). Retrieved from http://www.efdeportes.com/efd163/evaluacion-desde-el-area-de-educacion-fisica.htm

Zamorano, D. (2012). Una propuesta para la estructura de la programación didáctica de Educación Física en educación primaria desde el enfoque de las competencias básicas Introducción. Lecturas: Educación Física Y Deportes. Revista Digital, (165). Retrieved from http://www.efdeportes.com/efd165/estructura-de-la-programacion-de-educacion-fisica.htm

Zapatero, J. A., González, M. D., \& Campos, A. (2013). La evaluación por competencias en educación física: modelos e instrumentos de evaluación utilizados por el profesorado. Ágora Para La Educación Física Y El Deporte, 3(15), 180-196.

Zhao, H., \& Seibert, S. E. (2006). The Big Five Personality Dimensions and Entrepreneurial Status: A Meta-Analytical Review. Journal of Applied Psychology, 91(2), 259-271. http://doi.org/10.1037/0021-9010.91.2.259 


11. Anexo

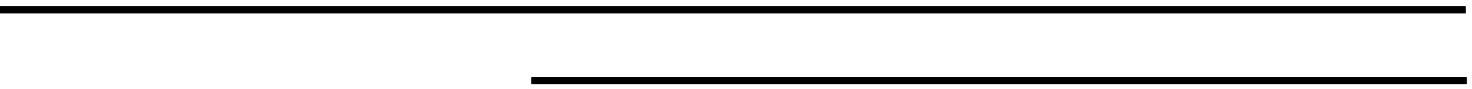



Tabla 48. Estadísticos descriptivos de la prueba piloto de la rúbrica (elaboración propia).

\begin{tabular}{|c|c|c|c|}
\hline Ítem & n Válidos & Media & Desviación típica \\
\hline a1 & 160 & 2,83 & 892 \\
\hline b1 & 160 & 2,80 & 671 \\
\hline $\mathrm{C} 1$ & 160 & 2,63 & ,707 \\
\hline $\mathrm{d}_{1}$ & 160 & 2,69 & 959 \\
\hline a2 & 160 & 3,10 & 803 \\
\hline b2 & 160 & 2,81 & 892 \\
\hline C2 & 160 & 3,12 &, 638 \\
\hline$d_{2}$ & 160 & 1,28 & 614 \\
\hline a3 & 160 & 2,85 &, 684 \\
\hline$b_{3}$ & 160 & 2,50 &, 682 \\
\hline C3 & 160 & 2,74 &, 763 \\
\hline d3 & 160 & 2,93 &, 539 \\
\hline$a_{4}$ & 160 & 2,73 &, 663 \\
\hline b4 & 160 & 2,76 & 601 \\
\hline C4 & 160 & 2,11 &, 484 \\
\hline$d_{4}$ & 160 & 2,39 &, 614 \\
\hline a5 & 160 & 2,34 & 801 \\
\hline b5 & 160 & 2,33 & 799 \\
\hline C5 & 160 & 3,05 &, 524 \\
\hline$d_{5}$ & 160 & 3,06 & ,498 \\
\hline a6 & 160 & 2,52 & ,644 \\
\hline b6 & 160 & 2,50 &, 624 \\
\hline c6 & 160 & 2,14 &, 460 \\
\hline d6 & 160 & 2,46 & 613 \\
\hline a7 & 160 & 2,42 & ,668 \\
\hline b7 & 160 & 2,71 & 688 \\
\hline C7 & 160 & 2,68 & 628 \\
\hline d7 & 160 & 2,76 & ,731 \\
\hline a8 & 160 & 3,19 & 731 \\
\hline b8 & 160 & 3,29 & ,578 \\
\hline c8 & 160 & 3,28 &, 585 \\
\hline $\mathrm{d} 8$ & 160 & 2,80 & 680 \\
\hline ag & 160 & 1,37 & 579, \\
\hline bg & 160 & 1,47 & 717 \\
\hline c9 & 160 & 1,46 & ,613 \\
\hline dg & 160 & 1,44 & 651 \\
\hline a10 & 160 & 2,58 & 658 \\
\hline b10 & 160 & 2,64 & ,544 \\
\hline C10 & 160 & 2,45 &, 632 \\
\hline $\mathrm{d}_{10}$ & 160 & 2,08 & ,371 \\
\hline
\end{tabular}

Tabla 49. Análisis de los ítems si se elimina algún elemento en la rúbrica. Estadísticos total-elemento (elaboración propia).

\begin{tabular}{|ccccc|}
\hline Ítem & $\begin{array}{c}\text { Media de la escala si se } \\
\text { elimina el elemento }\end{array}$ & $\begin{array}{c}\text { Varianza de la escala si se } \\
\text { elimina el elemento }\end{array}$ & $\begin{array}{c}\text { Correlación elemento- } \\
\text { total corregida }\end{array}$ & $\begin{array}{c}\text { Alfa de Cronbach si se } \\
\text { elimina el elemento }\end{array}$ \\
\hline a1 & 98,45 & 144,677 & 1413 & 1906 \\
b1 & 98,48 & 148,000 & 1361 & 1906 \\
C1 & 98,66 & 144,755 & 1534 & 1904 \\
d1 & 98,59 & 145,878 & 1325 &, 908 \\
a2 & 98,18 & 147,281 & 1329 & 1907 \\
b2 & 98,47 & 142,062 & 1540 & 1904 \\
C2 & 98,16 & 145,646 & 1538 &, 904 \\
d2 & 100,01 & 152,547 &, 094 & 1910
\end{tabular}




\begin{tabular}{|c|c|c|c|c|}
\hline a3 & 98,43 & 145,857 &, 485 & 905 \\
\hline b3 & 98,78 & 143,757 & 619 & 903 \\
\hline C3 & 98,54 & 142,904 &, 595 & 903 \\
\hline$d_{3}$ & 98,35 & 148,657 &, 410 & 906 \\
\hline$a_{4}$ & 98,56 & 144,626 &, 582 & 904 \\
\hline$b_{4}$ & 98,53 & 147,861 &, 418 & 906 \\
\hline $\mathrm{C} 4$ & 99,18 & 150,108 &, 338 & 907 \\
\hline$d_{4}$ & 98,89 & 146,485 &, 503 & 905 \\
\hline a5 & 98,94 & 144,663 & ,469 & , \\
\hline$b_{5}$ & 98,95 & 144,413 &, 484 & 905 \\
\hline $\mathrm{C} 5$ & 98,23 & 148,330 &, 450 & 905 \\
\hline $\mathrm{d}_{5}$ & 98,22 & 148,650 &, 449 & ,906 \\
\hline$a 6$ & 98,76 & 143,792 &, 656 & 903 \\
\hline b6 & 98,78 & 144,637 &, 620 & 903 \\
\hline$c 6$ & 99,14 & 148,509 &, 501 & 905 \\
\hline d6 & 98,82 & 143,168 &, 736 & ,902 \\
\hline a7 & 98,86 & 149,214 &, 287 & 907 \\
\hline b7 & 98,58 & 147,202 &, 400 & 906 \\
\hline $\mathrm{C7}$ & 98,60 & 147,977 & 391 & 906 \\
\hline d7 & 98,52 & 147,597 & 350 & 907 \\
\hline a8 & 98,09 & 149,703 &, 229 & 908 \\
\hline b8 & 97,99 & 150,038 &, 280 & 907 \\
\hline c8 & 98,00 & 149,635 & 305 & 907 \\
\hline $\mathrm{d} 8$ & 98,48 & 148,566 & 320 & 907 \\
\hline ag & 99,91 & 148,294 &, 405 & 906 \\
\hline bg & 99,81 & 149,323 &, 257 & 908 \\
\hline $\mathrm{cg}$ & 99,83 & 148,950 &, 335 & ,907 \\
\hline dg & 99,84 & 148,573 &, 337 & 907 \\
\hline a10 & 98,70 & 144,060 &, 623 & 903 \\
\hline b10 & 98,64 & 146,042 & 609 & 904 \\
\hline $\mathrm{C} 10$ & 98,83 & 146,770 &, 468 & 905 \\
\hline $\mathrm{d}_{10}$ & 99,20 & 153,519 &, 074 & ,909 \\
\hline
\end{tabular}

Tabla 50. Extracción de factores comunes de la prueba piloto de la rúbrica. Varianza total explicada (elaboración propia).

\begin{tabular}{|c|c|c|c|c|c|c|c|}
\hline \multirow{2}{*}{ 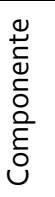 } & \multicolumn{3}{|c|}{ Autovalores iniciales } & \multicolumn{3}{|c|}{$\begin{array}{l}\text { Sumas de las saturaciones al cuadrado } \\
\text { de la extracción }\end{array}$} & \multirow{2}{*}{$\begin{array}{c}\text { Suma de las } \\
\text { saturaciones al } \\
\text { cuadrado de la rotación }^{\mathrm{a}} \\
\text { Total }\end{array}$} \\
\hline & Total & \% varianza & $\%$ acumulado & Total & $\%$ varianza & $\%$ acumulado & \\
\hline 1 & 9,728 & 24,320 & 24,320 & 9,728 & 24,320 & 24,320 & 6,159 \\
\hline 2 & 3,477 & 8,692 & 33,012 & 3,477 & 8,692 & 33,012 & 3,617 \\
\hline 3 & 2,839 & 7,097 & 40,108 & 2,839 & 7,097 & 40,108 & 4,224 \\
\hline 4 & 2,528 & 6,319 & 46,427 & 2,528 & 6,319 & 46,427 & 4,283 \\
\hline 5 & 2,191 & 5,478 & 51,906 & 2,191 & 5,478 & 51,906 & 4,402 \\
\hline 6 & 1,817 & 4,542 & 56,448 & 1,817 & 4,542 & 56,448 & 2,824 \\
\hline 7 & 1,681 & 4,203 & 60,650 & 1,681 & 4,203 & 60,650 & 3,843 \\
\hline 8 & 1,403 & 3,508 & 64,158 & 1,403 & 3,508 & 64,158 & 3,924 \\
\hline 9 & 1,238 & 3,094 & 67,252 & 1,238 & 3,094 & 67,252 & 1,523 \\
\hline 10 & 1,206 & 3,015 & 70,268 & 1,206 & 3,015 & 70,268 & 3,609 \\
\hline 11 & 1,111 & 2,777 & 73,045 & & & & \\
\hline 12 & 1,022 & 2,556 & 75,601 & & & & \\
\hline 13 & ,939 & 2,347 & 77,948 & & & & \\
\hline 14 & ,819 & 2,046 & 79,995 & & & & \\
\hline 15 &, 771 & 1,927 & 81,922 & & & & \\
\hline 16 &, 734 & 1,836 & $83,75^{8}$ & & & & \\
\hline
\end{tabular}




\begin{tabular}{|llll|}
17 & 1598 & 1,496 & 85,253 \\
18 & 1559 & 1,397 & 86,651 \\
19 & 1539 & 1,348 & 87,999 \\
20 & 1502 & 1,255 & 89,254 \\
21 &, 474 & 1,185 & 90,439 \\
22 & 1442 & 1,105 & 91,544 \\
23 & 1416 & 1,039 & 92,584 \\
24 & 1368 & 1920 & 93,504 \\
25 & 1331 &, 827 & 94,330 \\
26 & 1322 &, 804 & 95,135 \\
27 &, 295 & 1736 & 95,871 \\
28 &, 263 &, 657 & 96,528 \\
29 &, 246 &, 616 & 97,144 \\
30 &, 205 &, 512 & 97,656 \\
31 &, 194 &, 484 & 98,140 \\
32 &, 173 &, 432 & 98,572 \\
33 &, 147 &, 368 & 98,941 \\
34 &, 120 &, 300 & 99,241 \\
35 &, 091 &, 228 & 99,469 \\
36 &, 082 &, 206 & 99,675 \\
37 &, 056 &, 139 & 99,813 \\
38 &, 034 &, 084 & 99,898 \\
39 &, 025 &, 063 & 99,961 \\
40 &, 016 &, 039 & 100,000 \\
\hline
\end{tabular}

Tabla 51. Estadísticos descriptivos de la prueba piloto del cuestionario (elaboración propia).

\begin{tabular}{|cccc|}
\hline Ítem & n Válidos & Media & Desviación típica \\
\hline i1 & 188 & 3,40 &, 917 \\
i2 & 188 & 2,63 &, 986 \\
i3 & 188 & 4,18 &, 708 \\
i4 & 188 & 4,22 &, 606 \\
i5 & 188 & 4,16 &, 760 \\
i6 & 188 & 3,55 &, 741 \\
i7 & 188 & 3,66 &, 679 \\
i8 & 188 & 3,93 &, 697 \\
i9 & 188 & 3,87 &, 666 \\
i10 & 188 & 4,27 &, 634 \\
i11 & 188 & 4,12 &, 768 \\
i12 & 188 & 3,87 &, 986 \\
i13 & 188 & 3,22 &, 896 \\
i14 & 188 & 3,73 &, 881 \\
i15 & 188 & 4,35 &, 656 \\
i16 & 188 & 4,64 &, 572 \\
i17 & 188 & 4,32 &, 626 \\
i18 & 188 & 4,59 &, 610 \\
i19 & 188 & 3,69 &, 740 \\
i20 & 188 & 3,62 &, 663 \\
i21 & 188 & 3,72 &, 603 \\
i22 & 188 & 3,06 & 1,058 \\
i23 & 188 & 2,77 & 1,177 \\
i24 & 188 & 3,96 &, 636 \\
i25 & 188 & 3,87 &, 752 \\
i26 & 188 & 3,52 &, 705 \\
i27 & 188 & 3,50 &, 742 \\
i28 & 188 & 3,77 &, 905 \\
& & &
\end{tabular}




\begin{tabular}{llll} 
i29 & 188 & 4,19 &, 581 \\
i30 & 188 & 4,19 &, 590 \\
\hline
\end{tabular}

Tabla 52. Análisis de los ítems si se elimina algún elemento en el cuestionario. Estadísticos total-elemento (elaboración propia).

\begin{tabular}{|c|c|c|c|c|}
\hline Ítems & $\begin{array}{l}\text { Media de la } \\
\text { escala si se } \\
\text { elimina el } \\
\text { elemento }\end{array}$ & $\begin{array}{l}\text { Varianza de la } \\
\text { escala si se } \\
\text { elimina el } \\
\text { elemento }\end{array}$ & $\begin{array}{c}\text { Correlación } \\
\text { elemento-total } \\
\text { corregida }\end{array}$ & $\begin{array}{c}\text { Alfa de } \\
\text { Cronbach si se } \\
\text { elimina el } \\
\text { elemento }\end{array}$ \\
\hline i1 & 111,17 & 74,859 & 330 & 803 \\
\hline i2 & 111,95 & 75,462 &, 262 & ,807 \\
\hline i3 & 110,39 & 75,128 &, 432 & 799 \\
\hline$i_{4}$ & 110,35 & 76,625 & ,371 & ,802 \\
\hline i5 & 110,41 & 76,863 &, 262 & 806 \\
\hline i6 & 111,03 & 75,791 &, 356 & ,802 \\
\hline i7 & 110,91 & 74,838 & ,479 & ,798 \\
\hline i8 & 110,65 & 75,266 &, 428 & ,800 \\
\hline ig & 110,70 & 74,905 &, 484 & ,798 \\
\hline i10 & 110,30 & 75,421 &, 464 & 799 \\
\hline i11 & 110,45 & 75,789 & 341 & ,803 \\
\hline i12 & 110,71 & 77,096 & 165 & 812 \\
\hline i13 & 111,36 & 76,295 &, 245 & ,807 \\
\hline i14 & 110,85 & 76,024 & 269 & 806 \\
\hline i15 & 110,23 & 75,193 &, 466 & 799 \\
\hline i16 & 109,93 & 77,840 & ,274 & ,805 \\
\hline i17 & 110,25 & 75,718 &, 443 & 800 \\
\hline i18 & 109,99 & 76,888 & 343 & ,803 \\
\hline i19 & 110,89 & 75,287 & 397 & 801 \\
\hline i20 & 110,95 & 76,313 & 361 & ,802 \\
\hline$i 21$ & 110,86 & 76,124 &, 422 & ,801 \\
\hline i22 & 111,51 & 78,347 & , 078 & 817 \\
\hline i23 & 111,80 & 80,277 &,- 035 &, 826 \\
\hline i24 & 110,62 & 76,804 & ,334 & ,803 \\
\hline$i 25$ & 110,71 & 75,213 & ,395 & ,801 \\
\hline i26 & 111,05 & 76,254 &, 340 & ,803 \\
\hline$i 27$ & 111,07 & 75,438 &, 383 & 801 \\
\hline i28 & 110,80 & 75,175 &, 315 & ,804 \\
\hline i29 & 110,38 & 76,548 & 398 & ,802 \\
\hline i3o & 110,38 & 75,906 &, 455 & 800 \\
\hline
\end{tabular}

Tabla 53. Extracción de factores comunes tras el paso de la prueba piloto del cuestionario, varianza total explicada (elaboración propia).

\begin{tabular}{|c|c|c|c|c|c|c|c|}
\hline \multirow{2}{*}{ 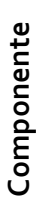 } & \multicolumn{3}{|c|}{ Autovalores iniciales } & \multicolumn{3}{|c|}{$\begin{array}{c}\text { Sumas de las saturaciones al cuadrado } \\
\text { de la extracción }\end{array}$} & \multirow{2}{*}{$\begin{array}{c}\text { Suma de las saturaciones al } \\
\text { cuadrado de la rotación }{ }^{\text {a }} \\
\text { Total }\end{array}$} \\
\hline & Total & \% varianza & $\%$ acumulado & Total & $\%$ varianza & $\%$ acumulado & \\
\hline 1 & 5,820 & 19,401 & 19,401 & 5,820 & 19,401 & 19,401 & 4,829 \\
\hline 2 & 2,545 & 8,485 & 27,886 & 2,545 & 8,485 & 27,886 & 2,604 \\
\hline 3 & 2,114 & 7,045 & 34,931 & 2,114 & 7,045 & 34,931 & 4,108 \\
\hline
\end{tabular}




\begin{tabular}{|cccc|}
4 & 1,836 & 6,119 & 41,050 \\
5 & 1,621 & 5,404 & 46,455 \\
6 & 1,491 & 4,969 & 51,424 \\
7 & 1,337 & 4,456 & 55,879 \\
8 & 1,207 & 4,023 & 59,902 \\
9 & 1,089 & 3,632 & 63,534 \\
10 & 1961 & 3,204 & 66,738 \\
11 & 1946 & 3,153 & 69,891 \\
12 & 1873 & 2,910 & 72,801 \\
13 & 1762 & 2,541 & 75,343 \\
14 & 1741 & 2,471 & 77,814 \\
15 &, 662 & 2,208 & 80,022 \\
16 & 1652 & 2,174 & 82,196 \\
17 & 1544 & 1,815 & 84,010 \\
18 & 1527 & 1,758 & 85,768 \\
19 & 1490 & 1,632 & 87,401 \\
20 & 1473 & 1,577 & 88,977 \\
21 & 1453 & 1,509 & 90,487 \\
22 & 1440 & 1,467 & 91,954 \\
23 & 1388 & 1,293 & 93,247 \\
24 & 1367 & 1,224 & 94,470 \\
25 & 1335 & 1,118 & 95,588 \\
26 & 1307 & 1,024 & 96,613 \\
27 &, 298 & 1992 & 97,605 \\
28 & 1254 & 1,846 & 98,451 \\
29 & 1240 & 1802 & 99,253 \\
30 &, 224 & 1,747 & 100,000 \\
\hline
\end{tabular}

Tabla 54. Análisis de fiabilidad de los datos de la variable A (elaboración propia).

\section{Alfa de Cronbach $\mathrm{N}$ de elementos} 955 40

Tabla 55. Estadísticos descriptivos de los datos de la variable A para el Grupo Experimental I en el Pretest (elaboración propia).

\begin{tabular}{|lrrrrrr|}
\hline & N & Mínimo & Máximo & Media & Desv. típ. & Varianza \\
\hline a1 & 28 & 1 & 4 & 2,54 &, 793 &, 628 \\
b1 & 28 & 1 & 4 & 2,61 &, 786 &, 618 \\
C1 & 28 & 2 & 4 & 2,54 &, 637 &, 406 \\
d1 & 28 & 1 & 4 & 2,57 & 1,034 & 1,069 \\
a2 & 28 & 1 & 5 & 3,18 &, 863 &, 745 \\
b2 & 28 & 1 & 5 & 3,00 &, 981 &, 963 \\
C2 & 28 & 2 & 4 & 3,11 &, 685 &, 470 \\
d2 & 28 & 1 & 3 & 1,21 &, 568 &, 323 \\
a3 & 28 & 2 & 4 & 2,93 &, 604 &, 365 \\
b3 & 28 & 1 & 4 & 2,50 &, 745 &, 556 \\
C3 & 28 & 1 & 4 & 2,82 &, 819 &, 671 \\
d3 & 28 & 2 & 4 & 2,93 &, 466 &, 217 \\
a4 & 28 & 2 & 4 & 2,64 &, 559 &, 312 \\
b4 & 28 & 2 & 4 & 2,71 &, 600 &, 360 \\
C4 & 28 & 2 & 3 & 2,04 &, 189 &, 036 \\
d4 & 28 & 2 & 4 & 2,57 &, 573 &, 328
\end{tabular}




\begin{tabular}{|c|c|c|c|c|c|c|}
\hline a5 & 28 & 1 & 4 & 2,46 &, 838 & ,702 \\
\hline b5 & 28 & 1 & 4 & 2,39 & ,786, & 618 \\
\hline C5 & 28 & 3 & 4 & 3,21 &, 418 & 175, \\
\hline$d_{5}$ & 28 & 3 & 4 & 3,21 & ,418 & 175 \\
\hline a6 & 28 & 2 & 4 & 2,68 &, 548 &, 300 \\
\hline b6 & 28 & 2 & 4 & 2,68 &, 548 & ,300 \\
\hline c6 & 28 & 1 & 3 & 2,11 & ,416 & 173 \\
\hline d6 & 28 & 1 & 3 & 2,57 & ,573 &, 328 \\
\hline a7 & 28 & 2 & 4 & 2,32 & 612 & ,374 \\
\hline b7 & 28 & 2 & 4 & 2,54 & ,744 & ,554 \\
\hline C7 & 28 & 2 & 4 & 2,54 & 693 & 1480 \\
\hline d7 & 28 & 2 & 4 & 2,61 & ,786, & 618 \\
\hline a8 & 28 & 2 & 5 & 3,50 & ,793 & ,630 \\
\hline b8 & 28 & 2 & 4 & 3,57 & ,573 &, 328 \\
\hline c8 & 28 & 2 & 4 & 3,54 & ,576 &, 332 \\
\hline d8 & 28 & 2 & 4 & 2,75 & ,645 & ,417 \\
\hline a9 & 28 & 1 & 3 & 1,57 &, 742 & ,550 \\
\hline b9 & 28 & 1 & 4 & 1,71 & ,937, & 878 \\
\hline c9 & 28 & 1 & 3 & 1,61 & ,685 & ,470 \\
\hline dg & 28 & 1 & 3 & 1,54 & ,744 & ,554 \\
\hline a10 & 28 & 2 & 4 & 2,71 & 659, &, 434 \\
\hline b10 & 28 & 2 & 4 & 2,61 &, 567 &, 321 \\
\hline C10 & 28 & 1 & 3 & 2,25 &, 518 & ,269 \\
\hline $\mathrm{d}_{10}$ & 28 & 2 & 3 & 2,07 & ,262 & o69, \\
\hline $\mathrm{N}$ válido (según lista) & 28 & & & & & \\
\hline
\end{tabular}

Tabla 56. Estadísticos descriptivos de los datos de la variable A para el Grupo Experimental II en el Pretest (elaboración propia).

\begin{tabular}{|c|c|c|c|c|c|c|}
\hline & $\mathbf{N}$ & Mínimo & Máximo & Media & Desv. típ. & Varianza \\
\hline a1 & 65 & 1 & 4 & 3,05 & 943 & ,888 \\
\hline b1 & 65 & 1 & 4 & 2,91 & ,605 &, 366 \\
\hline $\mathrm{C} 1$ & 65 & 1 & 4 & 2,72 &, 740 & ,547 \\
\hline d1 1 & 65 & 1 & 4 & 2,68 & , 986 & 972 \\
\hline a2 & 65 & 2 & 4 & 2,92 & ,735 &, 541 \\
\hline b2 & 65 & 1 & 4 & 2,58 & ,864 &, 747 \\
\hline C2 & 65 & 2 & 4 & 3,06 &, 704 &, 496 \\
\hline$d_{2}$ & 65 & 1 & 3 & 1,25 & 531 &, 282 \\
\hline a3 & 65 & 1 & 4 & 2,86 &, 726 &, 527 \\
\hline$b_{3}$ & 65 & 1 & 4 & 2,43 &, 728 &, 530 \\
\hline C3 & 65 & 1 & 4 & 2,71 &, 765 &, 585 \\
\hline$d_{3}$ & 65 & 2 & 4 & 2,97 &, 585 & 343 \\
\hline a4 & 65 & 1 & 4 & 2,78 & 649 &, 422 \\
\hline b4 & 65 & 2 & 4 & 2,88 &, 573 &, 328 \\
\hline $\mathrm{C}_{4}$ & 65 & 1 & 5 & 2,18 & ,635 &, 403 \\
\hline$d_{4}$ & 65 & 1 & 4 & 2,60 &, 703 & ,494 \\
\hline a5 & 65 & 1 & 4 & 2,18 & 846 & ,715 \\
\hline$b_{5}$ & 65 & 1 & 4 & 2,18 & 827 & ,684 \\
\hline C5 & 65 & 1 & 4 & 2,97 & , 499 & 249 \\
\hline$d_{5}$ & 65 & 1 & 4 & 2,98 &, 515 &, 265 \\
\hline a6 & 65 & 1 & 4 & 2,55 & ,708 &, 501 \\
\hline b6 & 65 & 2 & 4 & 2,51 & ,664 &, 441 \\
\hline c6 & 65 & 1 & 5 & 2,23 & ,606 &, 368 \\
\hline d6 & 65 & 1 & 4 & 2,51 & ,664 &, 441 \\
\hline a7 & 65 & 1 & 4 & 2,43 & ,684 &, 468 \\
\hline b7 & 65 & 2 & 5 & 2,65 & ,779 & ,607 \\
\hline
\end{tabular}




\begin{tabular}{|lllllll}
$c 7$ & 65 & 2 & 4 & 2,58 &, 659 &, 434 \\
d7 & 65 & 2 & 5 & 2,72 &, 857 &, 735 \\
a8 & 65 & 2 & 4 & 3,03 &, 706 &, 499 \\
b8 & 65 & 1 & 4 & 3,18 &, 583 & 1340 \\
c8 & 65 & 1 & 4 & 3,18 & 1583 & 1340 \\
d8 & 65 & 2 & 4 & 2,85 &, 667 &, 445 \\
a9 & 65 & 1 & 3 & 1,35 &, 598 & 1357 \\
b9 & 65 & 1 & 3 & 1,42 &, 705 & 1497 \\
c9 & 65 & 1 & 3 & 1,46 &, 639 &, 409 \\
d9 & 65 & 1 & 4 & 1,49 &, 732 & 1535 \\
a10 & 65 & 2 & 4 & 2,51 &, 640 & 1410 \\
b10 & 65 & 2 & 4 & 2,69 &, 528 &, 279 \\
c10 & 65 & 1 & 4 & 2,42 & 1583 & 1340 \\
d10 & 65 & 1 & 4 & 2,08 &, 444 &, 197 \\
N válido (según lista) & 65 & & & & & \\
\hline
\end{tabular}

Tabla 57. Estadísticos descriptivos de los datos de la variable A para el Grupo Control en el Pretest (elaboración propia).

\begin{tabular}{|c|c|c|c|c|c|c|}
\hline & $\mathbf{N}$ & Mínimo & Máximo & Media & Desv. típ. & Varianza \\
\hline a1 & 67 & 1 & 4 & 2,75 & 841 & 707, \\
\hline b1 & 67 & 1 & 4 & 2,78 & ,670 &, 449 \\
\hline $\mathrm{C} 1$ & 67 & 1 & 4 & 2,57 & ,701 &, 492 \\
\hline$d_{1}$ & 67 & 1 & 4 & 2,75 & 910 & 829 \\
\hline a2 & 67 & 1 & 5 & 3,24 & 818 & ,669 \\
\hline b2 & 67 & 1 & 5 & 2,96 & 843 &, 710 \\
\hline C2 & 67 & 2 & 4 & 3,18 &, 548 & ,301 \\
\hline $\mathrm{d} 2$ & 67 & 1 & 3 & 1,33 & ,705 & ,497 \\
\hline a3 & 67 & 1 & 4 & 2,81 & ,680 &, 462 \\
\hline b3 & 67 & 2 & 4 & 2,57 & 609 &, 370 \\
\hline C3 & 67 & 2 & 5 & 2,75 &, 746 &, 556 \\
\hline$d_{3}$ & 67 & 2 & 4 & 2,90 & 526 &, 277 \\
\hline$a_{4}$ & 67 & 1 & 4 & 2,70 & ,718 &, 516 \\
\hline b4 & 67 & 2 & 4 & 2,66 & ,617 &, 380 \\
\hline $\mathrm{C}_{4}$ & 67 & 1 & 4 & 2,06 & 385 & 148 \\
\hline$d_{4}$ & 67 & 1 & 4 & 2,10 & 394 &, 156 \\
\hline a5 & 67 & 1 & 4 & 2,45 &, 724 &, 524 \\
\hline$b_{5}$ & 67 & 1 & 4 & 2,45 &, 764 &, 584 \\
\hline C5 & 67 & 1 & 4 & 3,06 & ,574 &, 330 \\
\hline$d_{5}$ & 67 & 2 & 4 & 3,07 &, 502 &, 252 \\
\hline$a 6$ & 67 & 2 & 4 & 2,42 &, 607 &, 368 \\
\hline b6 & 67 & 2 & 4 & 2,42 &, 607 &, 368 \\
\hline c6 & 67 & 2 & 3 & 2,07 &, 265 & , 070 \\
\hline $\mathrm{d} 6$ & 67 & 1 & 4 & 2,37 & ,573 &, 328 \\
\hline a7 & 67 & 2 & 4 & 2,45 & 681 &, 463 \\
\hline b7 & 67 & 2 & 4 & 2,84 & ,539, & ,291 \\
\hline C7 & 67 & 2 & 4 & 2,84 & 539 & 291 \\
\hline d7 & 67 & 2 & 4 & 2,87 & 548 & 300 \\
\hline a8 & 67 & 2 & 4 & 3,22 & ,692 & ,479 \\
\hline b8 & 67 & 2 & 4 & 3,28 &, 545 & 297 \\
\hline c8 & 67 & 2 & 4 & 3,27 &, 566 & 321 \\
\hline d8 & 67 & 2 & 4 & 2,78 & ,714 & , 510 \\
\hline ag & 67 & 1 & 2 & 1,30 &, 461 &, 213 \\
\hline bg & 67 & 1 & 3 & 1,42 & ,607 &, 368 \\
\hline c9 & 67 & 1 & 3 & 1,39 & ,549 &, 302 \\
\hline dg & 67 & 1 & 3 & 1,34 & ,509 & ,259 \\
\hline a10 & 67 & 1 & 5 & 2,60 & 676 &, 456 \\
\hline
\end{tabular}




\begin{tabular}{|lllllll|} 
b10 & 67 & 2 & 4 & 2,60 &, 552 &, 305 \\
c10 & 67 & 2 & 5 & 2,57 & 1701 & 1492 \\
d10 & 67 & 2 & 4 & 2,09 & 1336 & 113 \\
N válido (según lista) & 67 & & & & & \\
\hline
\end{tabular}

Tabla 58. Estadísticos descriptivos de los datos de la variable A para el Grupo Experimental I en el Postest (elaboración propia).

\begin{tabular}{|c|c|c|c|c|c|c|}
\hline & $\mathrm{N}$ & Mínimo & Máximo & Media & Desv. típ. & Varianza \\
\hline a1 & 28 & 2 & 5 & 3,57 & ,742 &, 550 \\
\hline b1 & 28 & 3 & 4 & 3,54 &, 508 &, 258 \\
\hline C1 & 28 & 1 & 5 & 2,71 & 1,084 & 1,175 \\
\hline$d_{1}$ & 28 & 1 & 4 & 3,07 & 539 & 291 \\
\hline a2 & 28 & 2 & 5 & 3,25 & ,701 & ,491 \\
\hline b2 & 28 & 2 & 5 & 3,18 &, 723 &, 522 \\
\hline $\mathrm{C} 2$ & 28 & 2 & 4 & 3,07 &, 466 &, 217 \\
\hline$d 2$ & 28 & 1 & 5 & 2,71 & 1,049 & 1,101 \\
\hline a3 & 28 & 2 & 4 & 3,39 & ,629 & 396 \\
\hline b3 & 28 & 2 & 4 & 3,18 &, 548 & 300 \\
\hline C3 & 28 & 2 & 4 & 3,07 &, 539 &, 291 \\
\hline$d_{3}$ & 28 & 2 & 4 & 3,14 &, 525 & 275 \\
\hline$a_{4}$ & 28 & 1 & 5 & 2,96 & 962 & 925 \\
\hline$b_{4}$ & 28 & 1 & 5 & 3,04 & 881 &, 776 \\
\hline C4 & 28 & 2 & 4 & 2,75 & ,701 & ,491 \\
\hline$d_{4}$ & 28 & 2 & 4 & 3,04 & ,576 &, 332 \\
\hline a5 & 28 & 2 & 4 & 3,11 & ,786 &, 618 \\
\hline$b_{5}$ & 28 & 2 & 4 & 3,00 & ,770 & ,593 \\
\hline C5 & 28 & 2 & 5 & 3,32 & ,723 &, 522 \\
\hline$d_{5}$ & 28 & 2 & 4 & 3,25 & ,645 &, 417 \\
\hline a6 & 28 & 1 & 5 & 2,21 & 1,197 & 1,434 \\
\hline b6 & 28 & 1 & 4 & 2,29 & 976 & 952 \\
\hline$c 6$ & 28 & 1 & 4 & 2,36 & 911 & 831 \\
\hline d6 & 28 & 1 & 4 & 2,64 & ,826 & ,683 \\
\hline a7 & 28 & 1 & 5 & 2,43 & 1,345 & 1,810 \\
\hline b7 & 28 & 2 & 4 & 2,89 & ,737 & ,544 \\
\hline C7 & 28 & 2 & 4 & 2,96 & ,693 & ,480 \\
\hline$d_{7}$ & 28 & 2 & 4 & 3,04 & ,576 &, 332 \\
\hline a8 & 28 & 1 & 5 & 2,71 & 1,049 & 1,101 \\
\hline b8 & 28 & 3 & 5 & 3,71 & 535 & 286 \\
\hline c8 & 28 & 2 & 5 & 3,68 & ,612 & ,374 \\
\hline d8 & 28 & 2 & 4 & 2,86 & ,756 & ,571 \\
\hline a9 & 28 & 2 & 4 & 2,75 & ,752 & 565 \\
\hline bg & 28 & 2 & 4 & 2,57 & ,742 &, 550 \\
\hline $\mathrm{Cg}$ & 28 & 2 & 4 & 2,79 & ,738 &, 545 \\
\hline dg & 28 & 2 & 4 & 2,64 & ,731 & ,534 \\
\hline a10 & 28 & 2 & 4 & 3,18 & 670 &, 448 \\
\hline b10 & 28 & 2 & 4 & 3,18 & 670 &, 448 \\
\hline C10 & 28 & 2 & 4 & 3,07 &, 604 & 365 \\
\hline$d_{10}$ & 28 & 2 & 4 & 2,71 & 659 &, 434 \\
\hline $\mathrm{N}$ válido (según lista) & 28 & & & & & \\
\hline
\end{tabular}


Tabla 59. Estadísticos descriptivos de los datos de la variable A para el Grupo Experimental II en el Postest (elaboración propia).

\begin{tabular}{|c|c|c|c|c|c|c|}
\hline & $\mathbf{N}$ & Mínimo & Máximo & Media & Desv. típ. & Varianza \\
\hline a1 & 68 & 1 & 4 & 3,65 &, 567 &, 321 \\
\hline$b_{1}$ & 68 & 3 & 4 & 3,49 &, 503 &, 254 \\
\hline $\mathrm{C} 1$ & 68 & 1 & 4 & 2,37 &, 827 & ,684 \\
\hline$d_{1}$ & 68 & 2 & 5 & 3,26 &, 638 &, 406 \\
\hline a2 & 68 & 2 & 5 & 3,25 &, 720 &, 519 \\
\hline b2 & 68 & 1 & 4 & 3,04 & ,721 &, 520 \\
\hline$C 2$ & 68 & 2 & 4 & 3,16 &, 563 & 317 \\
\hline$d 2$ & 68 & 1 & 5 & 2,47 & 1,139 & 1,298 \\
\hline a3 & 68 & 2 & 5 & 3,44 &, 608 & ,370 \\
\hline$b_{3}$ & 68 & 2 & 5 & 3,26 &, 563 & 317 \\
\hline C3 & 68 & 2 & 5 & 3,32 &, 558 &, 312 \\
\hline$d_{3}$ & 68 & 2 & 5 & 3,24 & 576 &, 332 \\
\hline$a_{4}$ & 68 & 1 & 5 & 2,84 & 971 & 944 \\
\hline b4 & 68 & 1 & 5 & 2,72 & 1,063 & 1,130 \\
\hline C4 & 68 & 1 & 4 & 2,71 &, 734 & ,539 \\
\hline$d_{4}$ & 68 & 1 & 5 & 2,88 &, 764 &, 583 \\
\hline a5 & 68 & 1 & 5 & 3,16 & 891 & ,794 \\
\hline$b_{5}$ & 68 & 1 & 5 & 3,09 &, 842 & ,709 \\
\hline C5 & 68 & 2 & 5 & 3,28 & ,709 &, 503 \\
\hline$d_{5}$ & 68 & 2 & 5 & 3,29 & ,670 &, 450 \\
\hline a6 & 68 & 1 & 5 & 2,37 & 1,105 & 1,221 \\
\hline b6 & 68 & 1 & 5 & 2,44 & 998 & 996 \\
\hline c6 & 68 & 1 & 4 & 2,60 & 933 & 870 \\
\hline$d 6$ & 68 & 1 & 5 & 2,82 & 929 & ,864 \\
\hline a7 & 68 & 1 & 5 & 2,12 & 1,030 & 1,061 \\
\hline b7 & 68 & 1 & 4 & 2,91 &, 824 & ,679 \\
\hline C7 & 68 & 1 & 4 & 2,96 & ,781 & ,610 \\
\hline d7 & 68 & 1 & 5 & 3,01 & 837 & ,701 \\
\hline a8 & 68 & 1 & 4 & 2,35 & ,787 & ,620 \\
\hline b8 & 68 & 1 & 5 & 3,63 & 751 &, 564 \\
\hline c8 & 68 & 2 & 5 & 3,71 &, 648 &, 420 \\
\hline d8 & 68 & 1 & 4 & 2,74 &, 840 &, 705 \\
\hline ag & 68 & 1 & 5 & 2,82 & 929 & ,864 \\
\hline bg & 68 & 1 & 5 & 2,74 & 891 & ,795 \\
\hline c9 & 68 & 1 & 5 & 2,74 &, 822 & ,675 \\
\hline dg & 68 & 1 & 5 & 2,72 & ,770 & ,592 \\
\hline a10 & 68 & 1 & 5 & 3,07 &, 852 &, 726 \\
\hline b10 & 68 & 2 & 4 & 3,07 & 698 &, 487 \\
\hline C10 & 68 & 1 & 4 & 2,96 &, 742 &, 550 \\
\hline $\mathrm{d}_{10}$ & 68 & 2 & 4 & 2,85 & ,758 & ,575 \\
\hline $\mathrm{N}$ válido (según lista) & 68 & & & & & \\
\hline
\end{tabular}

Tabla 6o. Estadísticos descriptivos de los datos de la variable A para el Grupo Control en el Postest (elaboración propia).

\begin{tabular}{|llllrrr|}
\hline & N & Mínimo & Máximo & Media & Desv. típ. & Varianza \\
\hline a1 & 77 & 2 & 5 & 3,48 &, 598 & 1358 \\
b1 & 77 & 2 & 5 & 3,43 & 1594 & 1353 \\
C1 & 77 & 2 & 5 & 3,23 & 1705 & 1497 \\
d1 & 77 & 2 & 5 & 3,29 &, 535 &, 286 \\
a2 & 77 & 2 & 5 & 3,45 &, 836 &, 699 \\
b2 & 77 & 2 & 5 & 3,49 & 1719 & 1516 \\
c2 & 77 & 2 & 5 & 3,49 &, 700 &, 490
\end{tabular}




\begin{tabular}{|c|c|c|c|c|c|c|}
\hline $\mathrm{d} 2$ & 77 & 2 & 4 & 3,10 & , 347 & 121 \\
\hline a3 & 77 & 3 & 5 & 3,36 & ,511 &, 261 \\
\hline b3 & 77 & 3 & 5 & 3,31 & ,494 & ,244 \\
\hline C3 & 77 & 3 & 5 & 3,35 & 556 & 310 \\
\hline$d_{3}$ & 77 & 3 & 5 & 3,32 &, 498 & 248 \\
\hline$a_{4}$ & 77 & 2 & 4 & 3,23 & ,535 & ,287 \\
\hline b4 & 77 & 3 & 4 & 3,26 &, 441 & 195, \\
\hline C4 & 77 & 2 & 4 & 2,66 & 661 & ,437 \\
\hline$d_{4}$ & 77 & 2 & 5 & 3,29 & ,559 &, 312 \\
\hline a5 & 77 & 2 & 4 & 3,08 & ,644 &, 415 \\
\hline b5 & 77 & 2 & 5 & 3,21 & 614 & , 377 \\
\hline C5 & 77 & 2 & 4 & 3,27 &, 504 &, 254 \\
\hline$d_{5}$ & 77 & 3 & 4 & 3,30 & 461 & ,212 \\
\hline a6 & 77 & 1 & 5 & 3,04 & 979 & 959, \\
\hline b6 & 77 & 2 & 5 & 3,00 & 843 & ,711 \\
\hline c6 & 77 & 2 & 5 & 3,03 & ,725 & 526 \\
\hline d6 & 77 & 2 & 5 & 3,13 & 695 &, 483 \\
\hline a7 & 77 & 1 & 5 & 3,14 & 683 &, 466 \\
\hline b7 & 77 & 3 & 5 & 3,29 & ,535 & 286 \\
\hline C7 & 77 & 3 & 5 & 3,26 &, 523 & ,274 \\
\hline d7 & 77 & 3 & 5 & 3,27 & ,529 & ,280 \\
\hline a8 & 77 & 3 & 4 & 3,49 &, 503 & ,253 \\
\hline b8 & 77 & 3 & 4 & 3,45 & ,501 & 251 \\
\hline c8 & 77 & 3 & 4 & 3,47 & ,502 &, 252 \\
\hline d8 & 77 & 3 & 4 & 3,48 &, 503 & ,253 \\
\hline ag & 77 & 2 & 5 & 3,06 & ,592 & 351 \\
\hline bg & 77 & 2 & 5 & 3,16 & ,630 & ,396 \\
\hline c9 & 77 & 2 & 4 & 3,09 & ,518 & ,268 \\
\hline dg & 77 & 2 & 4 & 3,06 & 546 & ,298 \\
\hline a10 & 77 & 2 & 5 & 3,16 & 650 &, 423 \\
\hline b10 & 77 & 2 & 5 & 3,25 & ,491 & 241 \\
\hline C10 & 77 & 2 & 5 & 3,19 & ,539 & 290 \\
\hline $\mathrm{d}_{10}$ & 77 & 2 & 5 & 2,64 & 687 & ,471 \\
\hline N válido (según lista) & 77 & & & & & \\
\hline
\end{tabular}

Tabla 61. Prueba de Kolmogorov-Smirnov para las medias de los datos de la variable A (elaboración propia).

\begin{tabular}{|c|c|c|c|c|c|c|c|}
\hline & & Pre exp I & Pre exp II & Pre control & Post exp I & Post exp II & Post control \\
\hline $\mathrm{N}$ & & 40 & 40 & 40 & 40 & 40 & 40 \\
\hline Parámetros & Media & 2,5663 & 2,5183 & 2,5320 & 2,9755 & 2,9638 & 3,2315 \\
\hline normales ${ }^{a, b}$ & Desviación típica &, 54142 &, 51349 &, 55249 & ,35703 & ,37971 & 19857 \\
\hline & Absoluta &, 156 & 174 & 170 & ,097 & , 077 & ,097 \\
\hline extremas & Positiva &, 095 & , 102 & , 103 &, 083 &, 053 &, 096 \\
\hline & Negativa &,- 156 &,- 174 &,- 170 &,- 097 &,- 077 &,- 097 \\
\hline Z de Kolmogoro & v-Smirnov & 985 & 1,101 & 1,073 & 611 &, 487 &, 613 \\
\hline $\begin{array}{l}\text { Sig. asintót. (bil } \\
\text { a. La distribució }\end{array}$ & $\begin{array}{l}\text { teral) } \\
\text { de contraste es }\end{array}$ & trmal. & 177 &, 200 & ,849 & (972 & 846 \\
\hline
\end{tabular}




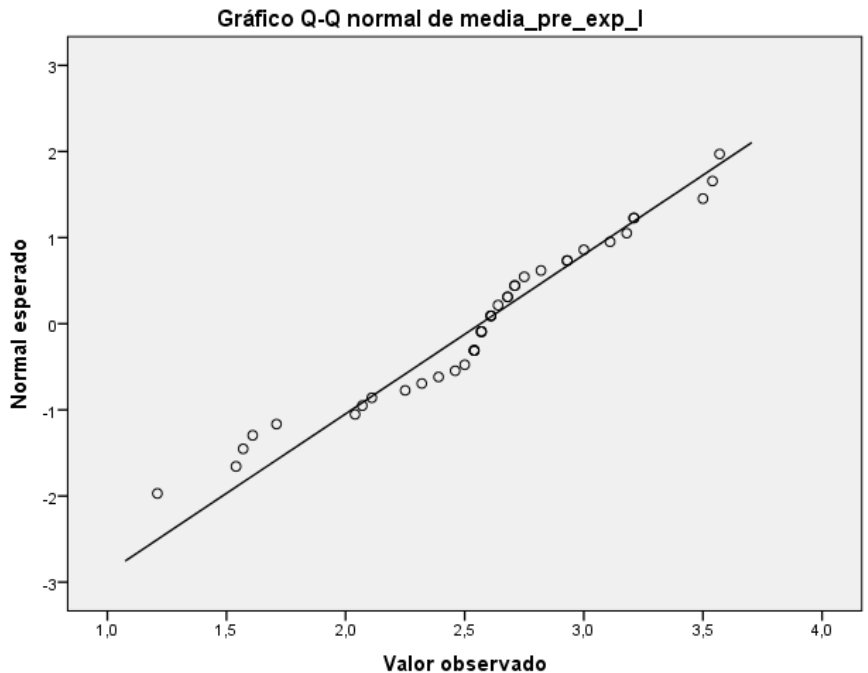

Gráfico 57. Normalidad de la muestra del Grupo Experimental I en el Pretest para la variable A (elaboración propia).

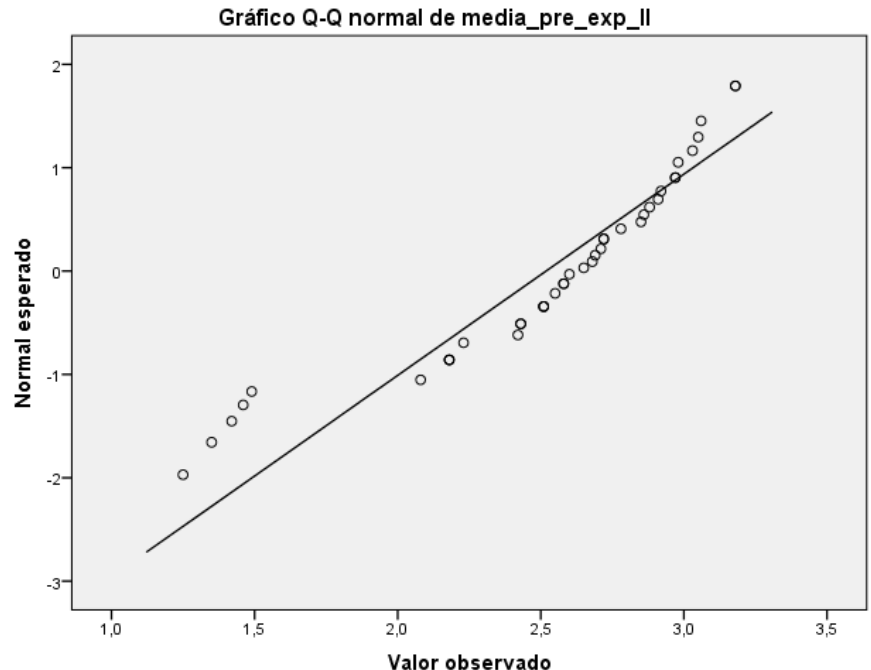

Gráfico 58. Normalidad de la muestra del Grupo Experimental II en el Pretest para la variable A (elaboración propia). 


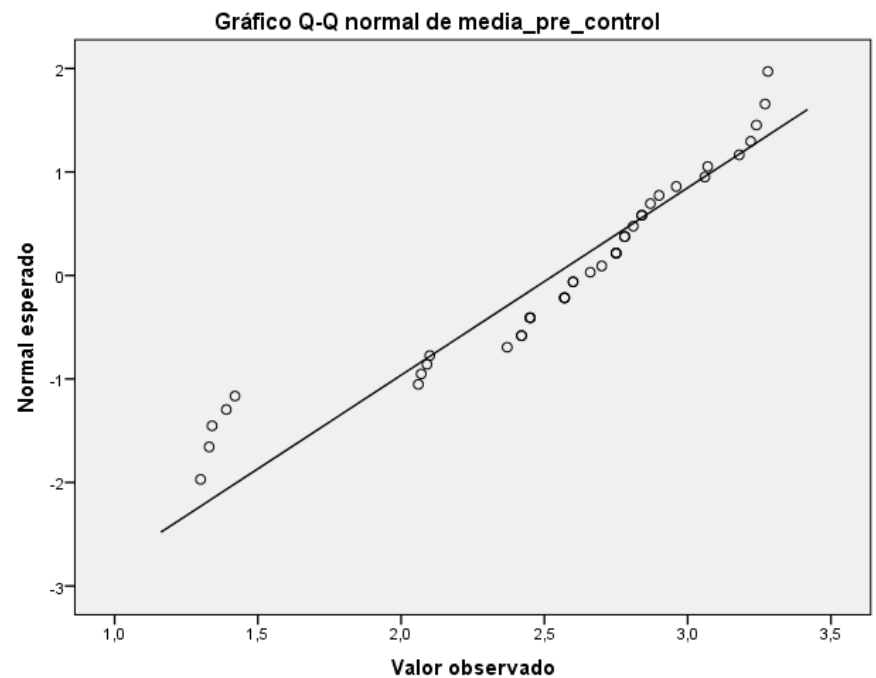

Gráfico 59. Normalidad de la muestra del Grupo Control en el Pretest para la variable A (elaboración propia).

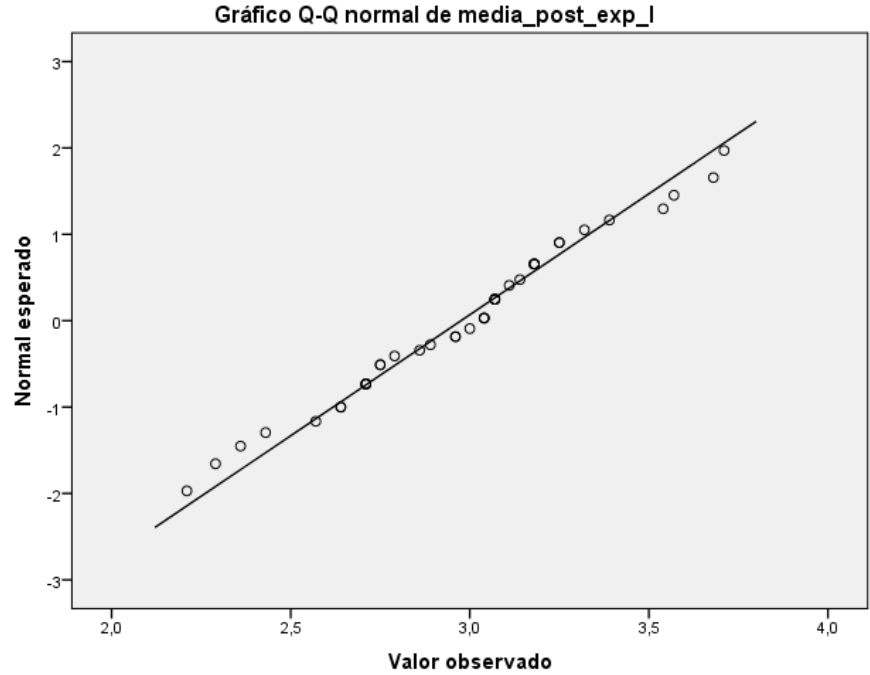

Gráfico 6o. Normalidad de la muestra del Grupo Experimental I en el Postest para la variable A (elaboración propia). 


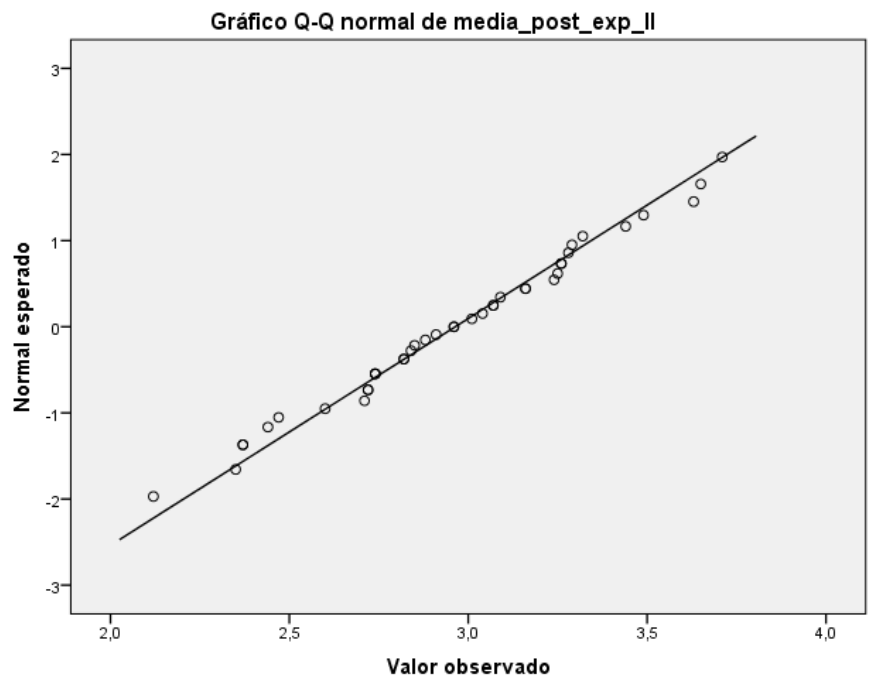

Gráfico 61. Normalidad de la muestra del Grupo Experimental Il en el Postest para la variable A (elaboración propia).

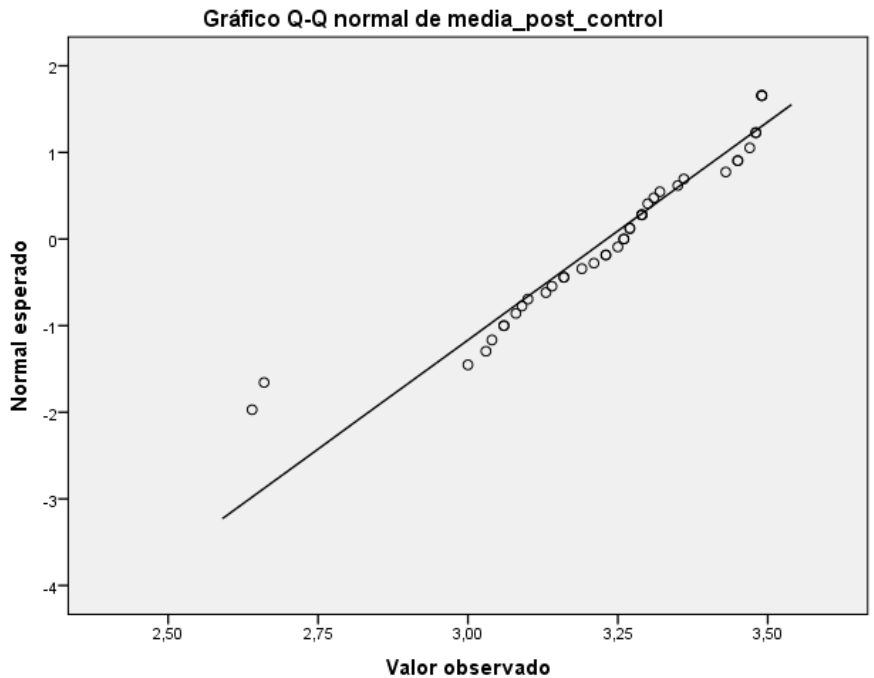

Gráfico 62. Normalidad de la muestra del Grupo Control en el Postest para la variable A (elaboración propia). 
Tabla 62. Prueba de Levene para las medias de los datos de la variable A en el Pretest (elaboración propia).

\begin{tabular}{|c|c|c|c|c|c|c|c|c|c|c|}
\hline & & $\begin{array}{l}\text { Prueb } \\
\text { Levene } \\
\text { iguald } \\
\text { varian }\end{array}$ & $\begin{array}{l}\text { de } \\
\text { ara la } \\
\text { d de } \\
\text { zas }\end{array}$ & & & Prueba 1 & $\overline{\Gamma \text { para la igua }}$ & dad de medi & & \\
\hline & & $\mathrm{F}$ & Sig. & $\mathbf{t}$ & gl & $\begin{array}{c}\text { Sig. } \\
\text { (bilateral) }\end{array}$ & $\begin{array}{l}\text { Diferencia } \\
\text { de medias }\end{array}$ & $\begin{array}{l}\text { Error típ. } \\
\text { de la } \\
\text { diferencia }\end{array}$ & $\begin{array}{r}95 \% \text { Int } \\
\text { confian } \\
\text { difer }\end{array}$ & $\begin{array}{l}\text { rvalo de } \\
\text { a para la } \\
\text { encia }\end{array}$ \\
\hline & & & & & & & & & Inferior & Superior \\
\hline Pre exp I & $\begin{array}{l}\text { Se han asumido } \\
\text { varianzas iguales }\end{array}$ &, 000 & 988 & 407 & 78 &, 685 &, 04800 & ,11798 & -18689 & 28289 \\
\hline Pre exp II & $\begin{array}{l}\text { No se han asumido } \\
\text { varianzas iguales }\end{array}$ & & &, 407 & 77,782 &, 685 &, 04800 & ,11798 &,- 18690 &, 28290 \\
\hline Pre exp I & $\begin{array}{l}\text { Se han asumido } \\
\text { varianzas iguales }\end{array}$ & 149 &, 700 &, 280 & 78 &, 780 &, 03425 & ,12231 &,- 20925 & ,27775 \\
\hline Pre control & $\begin{array}{l}\text { No se han asumido } \\
\text { varianzas iguales }\end{array}$ & & &, 280 & 77,968 &, 780 &, 03425 & 12231 &,- 20925 & ,27775 \\
\hline Pre exp II & $\begin{array}{l}\text { Se han asumido } \\
\text { varianzas iguales }\end{array}$ & 180 & ,673 &,- 115 & 78 & 909 &,- 01375 & 11926 &,- 25118 &, 22368 \\
\hline Pre control & $\begin{array}{l}\text { No se han asumido } \\
\text { varianzas iguales }\end{array}$ & & &,- 115 & 77,586 & ,909 &,- 01375 & ,11926 &,- 25120 &, 22370 \\
\hline
\end{tabular}

Tabla 63. Prueba de Levene para las medias de los datos de la variable A en el Postest (elaboración propia).

\begin{tabular}{|c|c|c|c|c|c|c|c|c|c|c|}
\hline & & \multicolumn{2}{|c|}{$\begin{array}{c}\text { Prueba de } \\
\text { Levene para la } \\
\text { igualdad de } \\
\text { varianzas }\end{array}$} & \multirow{3}{*}{$\mathrm{t}$} & \multicolumn{4}{|c|}{ Prueba T para la igualdad de medias } & \multirow{2}{*}{\multicolumn{2}{|c|}{$\begin{array}{c}95 \% \text { Intervalo de } \\
\text { confianza para la } \\
\text { diferencia }\end{array}$}} \\
\hline & & \multirow[t]{2}{*}{$\mathbf{F}$} & \multirow[t]{2}{*}{ Sig. } & & \multirow[t]{2}{*}{ gl } & \multirow[t]{2}{*}{$\begin{array}{c}\text { Sig. } \\
\text { (bilateral) }\end{array}$} & \multirow[t]{2}{*}{$\begin{array}{l}\text { Diferencia } \\
\text { de medias }\end{array}$} & \multirow[t]{2}{*}{$\begin{array}{l}\text { Error típ. } \\
\text { de la } \\
\text { diferencia }\end{array}$} & & \\
\hline & & & & & & & & & Inferior & Superior \\
\hline Post exp I & $\begin{array}{l}\text { Se han asumido } \\
\text { varianzas iguales }\end{array}$ & 252 & 617 & 143 & 78 & 887 & 01175 &, 08241 &,- 15232 & 17582 \\
\hline Post exp II & $\begin{array}{l}\text { No se han asumido } \\
\text { varianzas iguales }\end{array}$ & & & 143 & 77,706 & ,887 &, 01175 &, 08241 &,- 15232 &, 17582 \\
\hline Post exp I & $\begin{array}{l}\text { Se han asumido } \\
\text { varianzas iguales }\end{array}$ & 11,155 &, 001 & $-3,963$ & 78 &, 000 &,- 25600 & ,06459 &,- 38460 &,- 12740 \\
\hline Post control & $\begin{array}{l}\text { No se han asumido } \\
\text { varianzas iguales }\end{array}$ & & & $-3,963$ & 61,020 &, 000 &,- 25600 &, 06459 &,- 38516 &,- 12684 \\
\hline Post exp II & $\begin{array}{l}\text { Se han asumido } \\
\text { varianzas iguales }\end{array}$ & 15,164 &, 000 & $-3,952$ & 78 &, 000 &,- 26775 & ,06775 &,- 40263 &,- 13287 \\
\hline Post control & $\begin{array}{l}\text { No se han asumido } \\
\text { varianzas iguales }\end{array}$ & & & $-3,952$ & 58,846 &, 000 &,- 26775 & , 06775 &,- 40333 &,- 13217 \\
\hline
\end{tabular}

Tabla 64. Prueba de Kruskal-Wallis para las medias de los datos de la variable A en el Pretest (elaboración propia).

\begin{tabular}{|lr|}
\hline & \multicolumn{2}{c|}{ Pre todos } \\
\hline Chi-cuadrado &, 022 \\
gl & 2 \\
Sig. asintót. &, 989 \\
\hline
\end{tabular}


Tabla 65. Prueba de Wilcoxon para las medias de los datos de la variable A en el Pretest-Postest (elaboración propia).

\begin{tabular}{|lrrr|}
\hline & $\begin{array}{c}\text { Post exp I } \\
\text { Pre exp I }\end{array}$ & $\begin{array}{r}\text { Post exp II } \\
\text { Pre exp II }\end{array}$ & $\begin{array}{r}\text { Post control } \\
\text { Pre control }\end{array}$ \\
\hline Z & $-4,510^{\mathrm{b}}$ & $-4,483^{\mathrm{b}}$ & $-5,512^{\mathrm{D}}$ \\
Sig. asintót. (bilateral) &, 000 &, 000 &, 000 \\
b. Basado en los rangos negativos. & & & \\
\hline
\end{tabular}

Tabla 66. Prueba de Kruskal-Wallis para las medias de los datos de la variable A en el Postest (elaboración propia).

\begin{tabular}{|lr|}
\hline & Post todos \\
\hline Chi-cuadrado & 18,487 \\
gl & 2 \\
Sig. asintót. &, 000 \\
\hline
\end{tabular}

Tabla 67. Prueba de U de Mann-Whitney para las medias de los datos de la variable A en el Postest del Grupo Experimental I y el Grupo Experimental II (elaboración propia).

\begin{tabular}{|lr|}
\hline & Post exp I - Post exp II \\
\hline U de Mann-Whitney & 798,500 \\
W de Wilcoxon & 1618,500 \\
Z &,- 014 \\
Sig. asintót. (bilateral) &, 988 \\
\hline
\end{tabular}

Tabla 68. Prueba de U de Mann-Whitney para la media de los datos de la variable A en el Postest del Grupo Experimental I y el Grupo Control (elaboración propia).

\begin{tabular}{|lr|}
\hline & Post exp I - Post control \\
\hline U de Mann-Whitney & 401,000 \\
W de Wilcoxon & 1221,000 \\
Z & $-3,841$ \\
Sig. asintót. (bilateral) &, 000 \\
\hline
\end{tabular}

Tabla 69. Prueba de U de Mann-Whitney para las medias de los datos de la variable A en el Postest del Grupo Experimental Il y el Grupo Control (elaboración propia).

\begin{tabular}{|lr|}
\hline & Post exp II - Post control \\
\hline U de Mann-Whitney & 427,000 \\
W de Wilcoxon & 1247,000 \\
Z & $-3,590$ \\
Sig. asintót. (bilateral) &, 000 \\
\hline
\end{tabular}


Tabla 70. Prueba de Kruskal-Wallis para las medias de la categoría ajuste de los juegos al alumnado en el Postest (elaboración propia).

\begin{tabular}{|lr|}
\hline & Ajuste juegos Post todos \\
\hline Chi-cuadrado &, 038 \\
gl & 2 \\
Sig. asintót. &, 981 \\
\hline
\end{tabular}

Tabla 71. Prueba de Kruskal-Wallis para las medias de la categoría presentación de los juegos en el Postest (elaboración propia).

\begin{tabular}{|lr|}
\hline & Presentación Post todos \\
\hline Chi-cuadrado & 4,270 \\
gl & 2 \\
Sig. asintót. &, 118 \\
\hline
\end{tabular}

Tabla 72. Prueba de Kruskal-Wallis para las medias de la categoría organización del alumnado en el Postest (elaboración propia).

\begin{tabular}{|lr|}
\hline & Organización alumnado Post todos \\
\hline Chi-cuadrado & 2,499 \\
gl & 2 \\
Sig. asintót. &, 287 \\
\hline
\end{tabular}

Tabla 73. Prueba de Kruskal-Wallis para las medias de la categoría organización del material en el Postest (elaboración propia).

\begin{tabular}{|lr|}
\hline & Organización material Post todos \\
\hline Chi-cuadrado & 3,242 \\
gl & 2 \\
Sig. asintót. & 198 \\
\hline
\end{tabular}

Tabla 74. Prueba de Kruskal-Wallis para las medias de la categoría organización espacio/tiempo en el Postest (elaboración propia).

\begin{tabular}{|lr|}
\hline & Organización espacio/tiempo Post todos \\
\hline Chi-cuadrado & 115 \\
gl & 2 \\
Sig. asintót. &, 944 \\
\hline
\end{tabular}


Tabla 75. Prueba de Kruskal-Wallis para la medias de las categoría adaptación curricular en el Postest (elaboración propia).

\begin{tabular}{|lr|}
\hline & Adaptación curricular Post todos \\
\hline Chi-cuadrado & 8,346 \\
gl & 2 \\
Sig. asintót. &, 015 \\
\hline
\end{tabular}

Tabla 76. Prueba de Kruskal-Wallis para las medias de la categoría aspectos sociales en el Postest (elaboración propia).

\begin{tabular}{|lr|}
\hline & Aspectos sociales Post todos \\
\hline Chi-cuadrado & 7,420 \\
gl & 2 \\
Sig. asintót. &, 024 \\
\hline
\end{tabular}

Tabla 77. Prueba de Kruskal-Wallis para las medias de la categoría juegos motores en el Postest (elaboración propia).

\begin{tabular}{|lr|}
\hline & Juegos motores Post todos \\
\hline Chi-cuadrado &, 087 \\
$\mathrm{gl}$ & 2 \\
Sig. asintót. &, 958 \\
\hline
\end{tabular}

Tabla 78. Prueba de Kruskal-Wallis para las medias de la categoría juegos de expresión en el Postest (elaboración propia).

\begin{tabular}{|lr|}
\hline & Juegos expresión Post todos \\
\hline Chi-cuadrado & 7,592 \\
gl & 2 \\
Sig. asintót. &, 022 \\
\hline
\end{tabular}

Tabla 79. Prueba de Kruskal-Wallis para las medias de la categoría otros aprendizajes académicos en el Postest (elaboración propia).

\begin{tabular}{|lr|}
\hline & Otros Post todos \\
\hline Chi-cuadrado & 1,683 \\
gl & 2 \\
Sig. asintót. &, 431 \\
\hline
\end{tabular}


Tabla 8o. Prueba de Pearson para las medias de los datos de la variable A por categorías de ítems en el Postest (elaboración propia).

\begin{tabular}{|c|c|c|c|c|c|c|c|c|c|c|c|}
\hline & & $\begin{array}{c}\text { Ajuste } \\
\text { alumnado } \\
\text { Post }\end{array}$ & $\begin{array}{c}\text { Presentación } \\
\text { Post }\end{array}$ & $\begin{array}{l}\text { Organización } \\
\text { alumnado } \\
\text { Post }\end{array}$ & $\begin{array}{c}\text { Organización } \\
\text { material } \\
\text { Post }\end{array}$ & $\begin{array}{c}\text { Organización } \\
\text { espacio/tiempo } \\
\text { Post }\end{array}$ & $\begin{array}{l}\text { Adecuación } \\
\text { Curricular } \\
\text { Post }\end{array}$ & $\begin{array}{l}\text { Aspectos } \\
\text { sociales } \\
\text { Post }\end{array}$ & $\begin{array}{c}\text { Juegos } \\
\text { motores } \\
\text { Post }\end{array}$ & $\begin{array}{l}\text { Juegos } \\
\text { expresión } \\
\text { corporal } \\
\text { Post }\end{array}$ & $\begin{array}{l}\text { Otros } \\
\text { Post }\end{array}$ \\
\hline & $\begin{array}{l}\text { Correlación } \\
\text { Pearson }\end{array}$ & 1 &, $419^{*}$ & $.556^{* \pi}$ & $1484^{*}$ & $378^{* \pi}$ & $.516^{* \pi}$ &, $411^{* \pi}$ & $317^{*}$ & $1338^{* \pi}$ & $1521^{* \pi}$ \\
\hline $\begin{array}{l}\text { Ajuste alumnado } \\
\text { Post }\end{array}$ & $\begin{array}{l}\text { Sig. } \\
\text { (bilateral) }\end{array}$ & &, 000 &, 000 &, 000 &, 000 &, 000 &, 000 &, 000 &, 000 &, 000 \\
\hline & $\begin{array}{l}\mathrm{N} \\
\text { Correlación } \\
\text { de Pearson }\end{array}$ & .173 & $\begin{array}{r}173 \\
1\end{array}$ & $1719^{* *}$ & $.585^{173}$ & $1343^{* *}$ &, $561^{173}$ & $1530^{173}$ & $1544^{* \star}$ & $1393^{173}$ &, $482^{173}$ \\
\hline $\begin{array}{l}\text { Presentación } \\
\text { Post }\end{array}$ & $\begin{array}{l}\text { Sig. } \\
\text { (bilateral) }\end{array}$ &, 000 & &, 000 &, 000 &, 000 &, 000 &, 000 &, 000 &, 000 &, 000 \\
\hline Organización & $\begin{array}{l}\mathrm{N} \\
\text { Correlación } \\
\text { de Pearson }\end{array}$ &, $556^{* *}$ & $.519^{173}$ & $\begin{array}{r}173 \\
1\end{array}$ & $.573^{* *}$ & $1500^{* *}$ & $1573^{* *}$ & $.433^{* *}$ & $1367^{* *}$ & $1373^{173}$ &, $602^{* *}$ \\
\hline $\begin{array}{l}\text { alumnado } \\
\text { Post }\end{array}$ & $\begin{array}{l}\text { Sig. } \\
\text { (bilateral) }\end{array}$ &, 000 &, 000 & &, 000 &, 000 &, 000 &, 000 &, 000 & , 000 &, 000 \\
\hline Organización & $\begin{array}{l}\mathrm{N} \\
\text { Correlación } \\
\text { de Pearson }\end{array}$ &, $484^{* *}$ &, $585^{173}$ & $1573^{173}$ & $\begin{array}{r}173 \\
1\end{array}$ &, $\begin{array}{r}173 \\
, 418^{* *}\end{array}$ & .173 & $\begin{array}{r}173 \\
, 521^{* *}\end{array}$ &, $450^{173}$ &, $404^{173}$ &, $619^{173}$ \\
\hline $\begin{array}{l}\text { material } \\
\text { Post }\end{array}$ & $\begin{array}{l}\text { Sig. } \\
\text { (bilateral) }\end{array}$ &, 000 &, 000 &, 000 & &, 000 &, 000 &, 000 & , 000 &, 000 &, 000 \\
\hline Organización & $\begin{array}{l}\mathrm{N} \\
\text { Correlación } \\
\text { de Pearson }\end{array}$ & $\begin{array}{r}173 \\
1378^{* *}\end{array}$ & $1343^{173}$ & $1500^{173}$ &, $418^{* *}$ & $\begin{array}{r}173 \\
1\end{array}$ & $.502^{173}$ &, $283^{173}$ &, $270^{173}$ &, $442^{173}$ &, $563^{173}$ \\
\hline $\begin{array}{l}\text { espacio/tiempo } \\
\text { Post }\end{array}$ & $\begin{array}{l}\text { Sig. } \\
\text { (bilateral) }\end{array}$ &, 000 &, 000 &, 000 &, 000 & &, 000 &, 000 & , 000 &, 000 & , 000 \\
\hline Adecuación & $\begin{array}{l}\mathrm{N} \\
\text { Correlación } \\
\text { de Pearson }\end{array}$ & $\begin{array}{r}173 \\
.516^{* *}\end{array}$ &, $561^{* *}$ & $.573^{173}$ & $.1773^{* *}$ &, $502^{173}$ & $\begin{array}{r}173 \\
1\end{array}$ &, $482^{173}$ &, $460^{* *}$ &, $482^{173}$ &, $604^{173}$ \\
\hline $\begin{array}{l}\text { curricular } \\
\text { Post }\end{array}$ & $\begin{array}{l}\text { Sig. } \\
\text { (bilateral) }\end{array}$ &, 000 &, 000 &, 000 &, 000 &, 000 & &, 000 &, 000 &, 000 &, 000 \\
\hline Aspectos & $\begin{array}{l}\mathrm{N} \\
\text { Correlación } \\
\text { de Pearson }\end{array}$ &, $4171^{* *}$ & $1530^{* *}$ & $.433^{* *}$ &, $521^{* *}$ &, $283^{* *}$ &, $482^{* *}$ & $\begin{array}{r}173 \\
1\end{array}$ &, $572^{* *}$ &, $225^{* *}$ & $365^{173}$ \\
\hline $\begin{array}{l}\text { sociales } \\
\text { Post }\end{array}$ & $\begin{array}{l}\text { Sig. } \\
\text { (bilateral) }\end{array}$ &, 000 &, 000 &, 000 &, 000 &, 000 &, 000 & & , 000 &, 003 &, 000 \\
\hline Juegos & $\begin{array}{l}\mathrm{N} \\
\text { Correlación } \\
\text { de Pearson }\end{array}$ &, $317^{* *}$ & $174^{* *}$ & $.367^{* *}$ &, $450^{173}$ &, $270^{* *}$ &, $460^{173}$ &, $572^{173}$ & $\begin{array}{r}173 \\
1\end{array}$ & $1313^{* *}$ &, $444^{173}$ \\
\hline $\begin{array}{l}\text { motores } \\
\text { Post }\end{array}$ & $\begin{array}{l}\text { Sig. } \\
\text { (bilateral) }\end{array}$ &, 000 &, 000 &, 000 &, 000 &, 000 &, 000 &, 000 & &, 000 &, 000 \\
\hline $\begin{array}{l}\text { Juegos } \\
\text { expresión }\end{array}$ & $\begin{array}{l}\mathrm{N} \\
\text { Correlación } \\
\text { de Pearson }\end{array}$ &, $338^{* *}$ & $1393^{173}$ &, $373^{173}$ &, $404^{173}$ &, $142^{173}$ &, $482^{173}$ &, $225^{173}$ & $1313^{* *}$ & $\begin{array}{r}173 \\
1\end{array}$ &, $524^{173}$ \\
\hline corporal & $\begin{array}{l}\text { Sig. } \\
\text { (bilateral) }\end{array}$ &, 000 &, 000 &, 000 &, 000 &, 000 &, 000 &, 003 &, 000 & &, 000 \\
\hline & $\begin{array}{l}\mathrm{N} \\
\text { Correlación } \\
\text { de Pearson }\end{array}$ &, $521^{173}$ &, $482^{173}$ &, $602^{173}$ &, $619^{173}$ &, $563^{173}$ &, $604^{173}$ & $.365^{173}$ & $.444^{* *}$ &, $524^{173}$ & $\begin{array}{r}173 \\
1\end{array}$ \\
\hline Post & $\begin{array}{l}\text { Sig. } \\
\text { (bilateral) }\end{array}$ &, 000 &, 000 &, 000 &, 000 &, 000 &, 000 &, 000 &, 000 & , 000 & \\
\hline **. La correlación & $\begin{array}{l}\mathrm{N} \\
\text { es significativ }\end{array}$ & $\begin{array}{r}173 \\
\text { nivel } 0,01(b\end{array}$ & teral). & 173 & 173 & 173 & 173 & 173 & 173 & 173 & 173 \\
\hline
\end{tabular}

Tabla 81. Análisis de fiabilidad de los datos de la variable B (elaboración propia).

Alfa de Cronbach $\mathrm{N}$ de elementos

$827 \quad 30$


Tabla 82. Estadísticos descriptivos de los datos de la variable B para el Grupo Experimental I en el Pretest (elaboración propia).

\begin{tabular}{|c|c|c|c|c|c|c|}
\hline & $\mathbf{N}$ & Mínimo & Máximo & Media & Desv. típ. & Varianza \\
\hline i1 & 28 & 1 & 5 & 3,36 & 1,129 & 1,275 \\
\hline i2 & 28 & 1 & 5 & 2,36 & 1,026 & 1,053 \\
\hline i3 & 28 & 2 & 5 & 4,21 & 630 & 397 \\
\hline$i_{4}$ & 28 & 3 & 5 & 4,29 &, 659 &, 434 \\
\hline i5 & 28 & 2 & 5 & 4,11 & ,737 &, 544 \\
\hline i6 & 28 & 2 & 4 & 3,57 & ,573 &, 328 \\
\hline i7 & 28 & 2 & 5 & 3,50 & ,745 &, 556 \\
\hline i8 & 28 & 2 & 5 & 3,79 & 833 & 693 \\
\hline ig & 28 & 2 & 5 & 3,71 & 854 & ,730 \\
\hline i10 & 28 & 4 & 5 & 4,36 &, 488 &, 238 \\
\hline i11 & 28 & 3 & 5 & 4,18 &, 612 &, 374 \\
\hline i12 & 28 & 2 & 5 & 3,89 & ,916 & 840 \\
\hline i13 & 28 & 1 & 5 & 3,32 & 1,056 & 1,115 \\
\hline i14 & 28 & 3 & 5 & 4,18 &, 863 &, 745 \\
\hline i15 & 28 & 4 & 5 & 4,36 &, 488 &, 238 \\
\hline i16 & 28 & 4 & 5 & 4,71 &, 460 &, 212 \\
\hline i17 & 28 & 4 & 5 & 4,32 &, 476 & 226 \\
\hline i18 & 28 & 4 & 5 & 4,71 &, 460 &, 212 \\
\hline i19 & 28 & 2 & 5 & 3,54 & 793 &, 628 \\
\hline i2o & 28 & 2 & 4 & 3,25 & 518 & 269 \\
\hline$i 21$ & 28 & 3 & 5 & 3,64 & 559 &, 312 \\
\hline$i 22$ & 28 & 1 & 5 & 3,07 & 1,184 & 1,402 \\
\hline i23 & 28 & 1 & 5 & 2,89 & 1,315 & 1,729 \\
\hline i24 & 28 & 3 & 5 & 4,00 & 609 & 370 \\
\hline$i 25$ & 28 & 2 & 5 & 3,64 & 870 &, 757 \\
\hline i26 & 28 & 2 & 5 & 3,50 & 793 &, 630 \\
\hline$i 27$ & 28 & 2 & 5 & 3,32 &, 863 &, 745 \\
\hline i28 & 28 & 2 & 5 & 3,96 & 793 &, 628 \\
\hline i29 & 28 & 2 & 5 & 4,07 &, 604 & 365 \\
\hline i3o & 28 & 3 & 5 & 4,18 &, 548 & 300 \\
\hline N válido (según lista) & 28 & & & & & \\
\hline
\end{tabular}

Tabla 83. Estadísticos descriptivos de los datos de la variable B para el Grupo Experimental II en el Pretest (elaboración propia).

\begin{tabular}{|lrrrrrr|}
\hline & N & Mínimo & Máximo & Media & Desv. típ. & Varianza \\
\hline i1 & 59 & 1 & 5 & 3,32 &, 918 &, 843 \\
i2 & 59 & 1 & 5 & 2,63 & 1,032 & 1,065 \\
i3 & 59 & 4 & 5 & 4,54 &, 502 &, 252 \\
i4 & 59 & 2 & 5 & 4,24 &, 678 &, 460 \\
i5 & 59 & 2 & 5 & 3,98 &, 900 &, 810 \\
i6 & 59 & 1 & 5 & 3,47 &, 704 &, 495 \\
i7 & 59 & 2 & 5 & 3,59 &, 698 &, 487 \\
i8 & 59 & 3 & 5 & 4,03 &, 454 &, 206 \\
i9 & 59 & 2 & 5 & 4,08 &, 624 &, 389 \\
i10 & 59 & 3 & 5 & 4,12 &, 528 &, 279 \\
i11 & 59 & 3 & 5 & 4,19 &, 572 &, 327 \\
i12 & 59 & 2 & 5 & 4,05 &, 879 &, 773 \\
i13 & 59 & 2 & 5 & 3,36 &, 737 &, 544 \\
i14 & 59 & 1 & 5 & 3,49 &, 954 &, 909 \\
i15 & 59 & 2 & 5 & 4,29 &, 645 &, 416 \\
i16 & 59 & 3 & 5 & 4,54 &, 536 &, 287
\end{tabular}




\begin{tabular}{|c|c|c|c|c|c|c|}
\hline i17 & 59 & 3 & 5 & 4,44 &, 534 &, 285 \\
\hline i18 & 59 & 2 & 5 & 4,51 & 679 &, 461 \\
\hline i19 & 59 & 2 & 5 & 3,49 & ,598, &, 358 \\
\hline i2o & 59 & 1 & 5 & 3,41 & 790, & 625 \\
\hline i21 & 59 & 1 & 5 & 3,64 & 688, & ,475 \\
\hline i22 & 59 & 1 & 5 & 2,95 & 1,151 & 1,325 \\
\hline i23 & 59 & 1 & 5 & 2,66 & 1,212 & 1,469 \\
\hline i24 & 59 & 3 & 5 & 4,03 & ,556 & 309 \\
\hline$i 25$ & 59 & 3 & 5 & 3,97 & ,718 & , 516 \\
\hline i26 & 59 & 1 & 5 & 3,51 & ,774 & 599, \\
\hline i27 & 59 & 1 & 5 & 3,39 & 695 &, 483 \\
\hline i28 & 59 & 2 & 5 & 3,71 & 966, & 933 \\
\hline i29 & 59 & 3 & 5 & 4,10 & 635 &, 403 \\
\hline i3o & 59 & 1 & 5 & 4,19 & 754 &, 568 \\
\hline $\mathrm{N}$ válido (según lista) & 59 & & & & & \\
\hline
\end{tabular}

Tabla 84. Estadísticos descriptivos de los datos de la variable B para el Grupo Control en el Pretest (elaboración propia).

\begin{tabular}{|lrrrrrr|}
\hline & N & Mínimo & Máximo & Media & Desv. típ. & Varianza \\
\hline i1 & 68 & 1 & 5 & 3,41 &, 833 &, 694 \\
i2 & 68 & 1 & 5 & 2,54 &, 984 &, 968 \\
i3 & 68 & 2 & 5 & 4,12 &, 681 &, 464 \\
i4 & 68 & 3 & 5 & 4,10 &, 650 &, 422 \\
i5 & 68 & 2 & 5 & 4,01 &, 801 &, 642 \\
i6 & 68 & 2 & 5 & 3,50 &, 801 &, 642 \\
i7 & 68 & 2 & 5 & 3,60 &, 694 &, 482 \\
i8 & 68 & 2 & 5 & 3,96 &, 584 &, 341 \\
i9 & 68 & 3 & 5 & 4,07 &, 555 &, 308 \\
i10 & 68 & 2 & 5 & 4,26 &, 638 &, 406 \\
i11 & 68 & 1 & 5 & 3,93 &, 798 &, 636 \\
i12 & 68 & 1 & 5 & 3,94 &, 862 &, 743 \\
i13 & 68 & 1 & 5 & 3,29 &, 793 &, 629 \\
i14 & 68 & 2 & 5 & 3,54 &, 742 &, 550 \\
i15 & 68 & 3 & 5 & 4,26 &, 563 &, 317 \\
i16 & 68 & 317 \\
i17 & 68 & 5 & 4,59 &, 553 &, 306 \\
i18 & 3 & 5 & 4,28 &, 514 &, 264 \\
i19 & 3 & 5 & 4,49 &, 611 &, 373 \\
i20 & 68 & 5 & 3,57 &, 719 &, 517 \\
i21 & 68 & 3 & 5 & 3,49 &, 658 &, 433 \\
i22 & 68 & 1 & 5 & 3,56 &, 583 &, 340 \\
i23 & 68 & 5 & 2,63 &, 929 &, 863 \\
i24 & 1 & 5 & 3,16 & 1,154 & 1,332 \\
i25 & 68 & 2 & 3,90 &, 550 &, 303 \\
i26 & 68 & 5 & 3,88 &, 659 &, 434 \\
i27 & 68 & 5 & 3,43 &, 834 &, 696 \\
i28 & 68 & 5 & 3,24 &, 813 &, 660 \\
i29 & 68 & 5 & 3,54 &, 999 &, 998 \\
i30 & 1 & 5 & 4,00 &, 623 &, 388 \\
N válido (según lista) & 68 & 3 & 5 & 4,12 &, 587 &, 344 \\
\hline & 68 & 2 & & & & \\
\hline
\end{tabular}


Tabla 85. Estadísticos descriptivos de los datos de la variable B para el Grupo Experimental I en el Postest (elaboración propia).

\begin{tabular}{|c|c|c|c|c|c|c|}
\hline & $\mathbf{N}$ & Mínimo & Máximo & Media & Desv. típ. & Varianza \\
\hline i1 & 28 & 2 & 5 & 3,54 & 962 & ,925 \\
\hline i2 & 28 & 2 & 5 & 2,93 & 900 & 810 \\
\hline i3 & 28 & 3 & 5 & 4,61 & 567 & 321 \\
\hline$i_{4}$ & 28 & 3 & 5 & 4,39 &, 629 &, 396 \\
\hline i5 & 28 & 3 & 5 & 4,43 & ,573 &, 328 \\
\hline i6 & 28 & 3 & 5 & 3,93 & ,539 &, 291 \\
\hline i7 & 28 & 2 & 5 & 3,79 & ,738 &, 545 \\
\hline i8 & 28 & 3 & 5 & 4,25 & ,701 & ,491 \\
\hline ig & 28 & 3 & 5 & 4,14 & 591 &, 349 \\
\hline i10 & 28 & 4 & 5 & 4,54 & 508 &, 258 \\
\hline $\mathrm{i} 11$ & 28 & 3 & 5 & 4,25 &, 518 &, 269 \\
\hline $\mathrm{i} 12$ & 28 & 1 & 5 & 3,86 & 1,079 & 1,164 \\
\hline $\mathrm{i} 13$ & 28 & 1 & 5 & 3,21 & 1,031 & 1,063 \\
\hline i14 & 28 & 3 & 5 & 3,68 & ,772 & ,597 \\
\hline i15 & 28 & 3 & 5 & 4,32 & ,612 &, 374 \\
\hline $\mathrm{i} 16$ & 28 & 3 & 5 & 4,71 &, 535 &, 286 \\
\hline i17 & 28 & 4 & 5 & 4,50 &, 509 &, 259 \\
\hline i18 & 28 & 4 & 5 & 4,86 & 356 &, 127 \\
\hline i19 & 28 & 2 & 5 & 3,75 & 799 &, 639 \\
\hline $\mathrm{i} 20$ & 28 & 2 & 5 & 3,75 & 799 &, 639 \\
\hline $\mathrm{i} 21$ & 28 & 3 & 5 & 3,82 & ,723 &, 522 \\
\hline $\mathrm{i} 22$ & 28 & 1 & 5 & 3,54 & 1,105 & 1,221 \\
\hline i23 & 28 & 1 & 5 & 3,25 & ,967 & ,935 \\
\hline $\mathrm{i} 24$ & 28 & 3 & 5 & 4,00 &, 471 &, 222 \\
\hline $\mathrm{i} 25$ & 28 & 3 & 5 & 4,04 &, 637 &, 406 \\
\hline i26 & 28 & 2 & 5 & 3,71 &, 854 &, 730 \\
\hline $\mathrm{i} 27$ & 28 & 3 & 5 & 3,61 & ,737 &, 544 \\
\hline $\mathrm{i} 28$ & 28 & 2 & 5 & 3,86 & 848 &, 720 \\
\hline i29 & 28 & 3 & 5 & 4,43 &, 573 &, 328 \\
\hline iзo & 28 & 3 & 5 & 4,36 &, 559 &, 312 \\
\hline N válido (según lista) & 28 & & & & & \\
\hline
\end{tabular}

Tabla 86. Estadísticos descriptivos de los datos de la variable B para el Grupo Experimental II en el Postest (elaboración propia).

\begin{tabular}{|lrrrrrr|}
\hline & N & Mínimo & Máximo & Media & Desv. típ. & Varianza \\
\hline i1 & 61 & 1 & 5 & 3,36 & 1,017 & 1,034 \\
i2 & 61 & 1 & 5 & 2,62 &, 897 &, 805 \\
i3 & 61 & 3 & 5 & 4,30 &, 558 &, 311 \\
i4 & 61 & 2 & 5 & 4,18 &, 671 &, 450 \\
i5 & 61 & 2 & 5 & 4,31 &, 743 &, 551 \\
i6 & 61 & 2 & 5 & 3,74 &, 794 &, 630 \\
i7 & 61 & 2 & 5 & 3,69 &, 765 &, 585 \\
i8 & 61 & 2 & 5 & 4,03 &, 730 &, 532 \\
i9 & 61 & 3 & 5 & 4,11 &, 661 &, 437 \\
i10 & 61 & 2 & 5 & 4,38 &, 582 &, 339 \\
i11 & 61 & 2 & 5 & 4,07 &, 704 &, 496 \\
i12 & 61 & 2 & 5 & 3,79 &, 859 &, 737 \\
i13 & 61 & 2 & 5 & 3,41 &, 901 &, 813 \\
i14 & 61 & 1 & 5 & 3,66 &, 814 &, 663 \\
i15 & 61 & 2 & 5 & 4,30 &, 558 &, 311 \\
i16 & 61 & 3 & 5 & 4,57 &, 590 &, 349
\end{tabular}




\begin{tabular}{|c|c|c|c|c|c|c|}
\hline i17 & 61 & 4 & 5 & 4,43 & ,499 & ,249 \\
\hline $\mathrm{i} 18$ & 61 & 3 & 5 & 4,57 &, 562 &, 315 \\
\hline i19 & 61 & 2 & 22 & 3,89 & 2,457 & 6,037 \\
\hline i2o & 61 & 2 & 5 & 3,51 & 649 &, 421 \\
\hline$i 21$ & 61 & 2 & 5 & 3,79 & 609 & ,370 \\
\hline$i 22$ & 61 & 1 & 5 & 3,11 & 1,212 & 1,470 \\
\hline$i 23$ & 61 & 1 & 5 & 3,11 & 1,318 & 1,737 \\
\hline i24 & 61 & 2 & 5 & 3,97 & ,576 &, 332 \\
\hline$i 25$ & 61 & 2 & 5 & 4,03 & ,752 & ,566 \\
\hline i26 & 61 & 2 & 5 & 3,64 & 708 &, 501 \\
\hline$i 27$ & 61 & 2 & 5 & 3,48 & 673 &, 454 \\
\hline i28 & 61 & 1 & 5 & 3,87 & 1,040 & 1,083 \\
\hline i29 & 61 & 2 & 5 & 4,23 & 693 &, 480 \\
\hline i3o & 61 & 2 & 5 & 4,21 & 733 & ,537 \\
\hline $\mathrm{N}$ válido (según lista) & 61 & & & & & \\
\hline
\end{tabular}

Tabla 87. Estadísticos descriptivos de los datos de la variable B para el Grupo Control en el Postest (elaboración propia).

\begin{tabular}{|c|c|c|c|c|c|c|}
\hline & $\mathbf{N}$ & Mínimo & Máximo & Media & Desv. típ. & Varianza \\
\hline i1 & 65 & 1 & 5 & 3,51 & 812 &, 660 \\
\hline i2 & 65 & 1 & 5 & 2,74 & 923 & 852 \\
\hline i3 & 65 & 3 & 5 & 4,31 &, 528 &, 279 \\
\hline$i_{4}$ & 65 & 2 & 5 & 4,25 & ,730 &, 532 \\
\hline i5 & 65 & 2 & 5 & 4,22 & ,739 &, 547 \\
\hline i6 & 65 & 2 & 5 & 3,72 &, 650 &, 422 \\
\hline i7 & 65 & 2 & 5 & 3,74 & 853 &, 727 \\
\hline i8 & 65 & 2 & 5 & 4,00 & ,750 &, 563 \\
\hline ig & 65 & 2 & 5 & 4,09 & ,723 &, 523 \\
\hline i10 & 65 & 2 & 5 & 4,15 & 690 &, 476 \\
\hline i11 & 65 & 2 & 5 & 4,02 &, 800 & 640 \\
\hline$i_{12}$ & 65 & 1 & 5 & 3,98 &, 875 &, 765 \\
\hline i13 & 65 & 2 & 5 & 3,48 & 709 &, 503 \\
\hline i14 & 65 & 1 & 5 & 3,38 & 842 & ,709 \\
\hline i15 & 65 & 3 & 5 & 4,26 & ,594 &, 352 \\
\hline i16 & 65 & 3 & 5 & 4,57 &, 585 &, 343 \\
\hline i17 & 65 & 3 & 5 & 4,34 & 567 &, 321 \\
\hline i18 & 65 & 3 & 5 & 4,46 &, 686 &, 471 \\
\hline i19 & 65 & 2 & 5 & 3,82 & ,748 & ,559 \\
\hline $\mathrm{i} 20$ & 65 & 2 & 5 & 3,54 & ,752 &, 565 \\
\hline i21 & 65 & 2 & 5 & 3,68 & ,687 &, 472 \\
\hline$i 22$ & 65 & 1 & 5 & 3,20 & 1,078 & 1,163 \\
\hline i23 & 65 & 1 & 5 & 3,45 & 1,031 & 1,063 \\
\hline i24 & 65 & 2 & 5 & 3,98 & 673 &, 453 \\
\hline i25 & 65 & 2 & 5 & 3,85 & 815 &, 663 \\
\hline i26 & 65 & 2 & 5 & 3,65 & 818 & ,670 \\
\hline$i 27$ & 65 & 2 & 5 & 3,66 & ,735 & 1540 \\
\hline i28 & 65 & 1 & 5 & 3,71 & 1,114 & 1,241 \\
\hline i29 & 65 & 2 & 5 & 4,05 & ,717 &, 513 \\
\hline iзo & 65 & 2 & 5 & 4,06 & ,747 & ,559 \\
\hline N válido (según lista) & 65 & & & & & \\
\hline
\end{tabular}


Tabla 88. Prueba de Kolmogorov-Smirnov para las medias de los datos de la variable B (elaboración propia).

\begin{tabular}{|c|c|c|c|c|c|c|c|}
\hline & Pre exp I & Pre exp II & Pre control & Post exp I & Post exp II & Post control \\
\hline \multicolumn{2}{|l|}{$\bar{N}$} & 30 & 30 & 30 & 30 & 30 & 30 \\
\hline \multirow{2}{*}{$\begin{array}{l}\text { Parámetros } \\
\text { normales }^{a, b}\end{array}$} & Media & 3,7997 & 3,7973 & 3,7470 & 4,0020 & 3,8787 & 3,8623 \\
\hline & Desviación típica &, 53785 &, 52012 &, 48780 &, 46964 &, 46407 &, 40078 \\
\hline \multirow{3}{*}{$\begin{array}{l}\text { Diferencias más } \\
\text { extremas }\end{array}$} & Absoluta &, 094 &, 163 & 141 & 101 & ,094 & ,115 \\
\hline & Positiva &, 082 & ,077 &, 085 &, 085 &, 068 &, 053 \\
\hline & Negativa &,- 094 &,- 163 &,- 141 &,- 101 &,- 094 &,- 115 \\
\hline \multicolumn{2}{|c|}{ Z de Kolmogorov-Smirnov } & 513 & 895 & ,771 &, 555 &, 518 &, 632 \\
\hline \multicolumn{2}{|c|}{ Sig. asintót. (bilateral) } & $\begin{array}{l}\text { '955 } \\
\text { rmal. }\end{array}$ &, 400 & ,592 & 918 & 952 & 819 \\
\hline
\end{tabular}

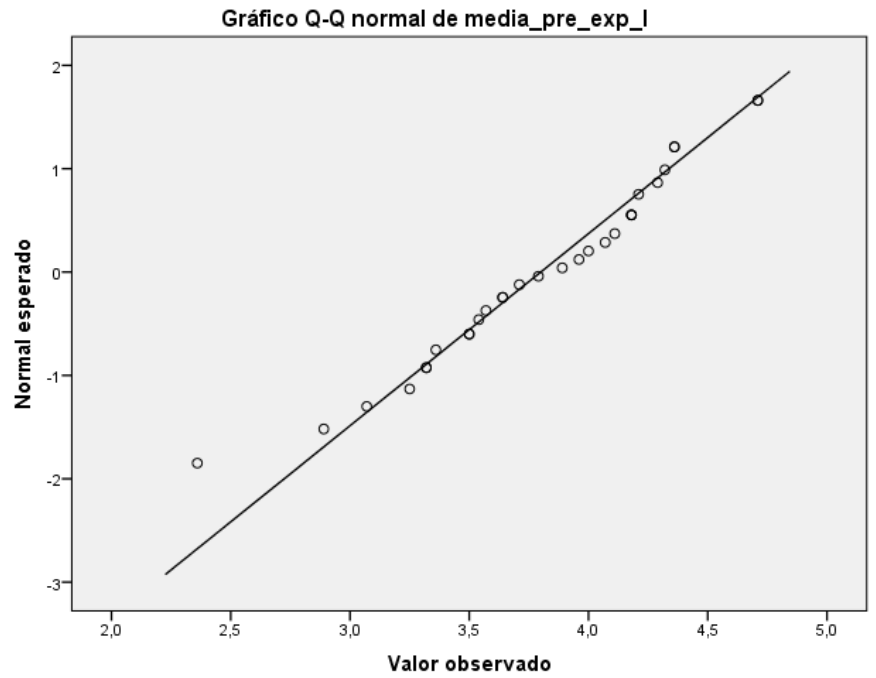

Gráfico 63. Normalidad de la muestra del Grupo Experimental I en el Pretest para la variable B (elaboración propia).

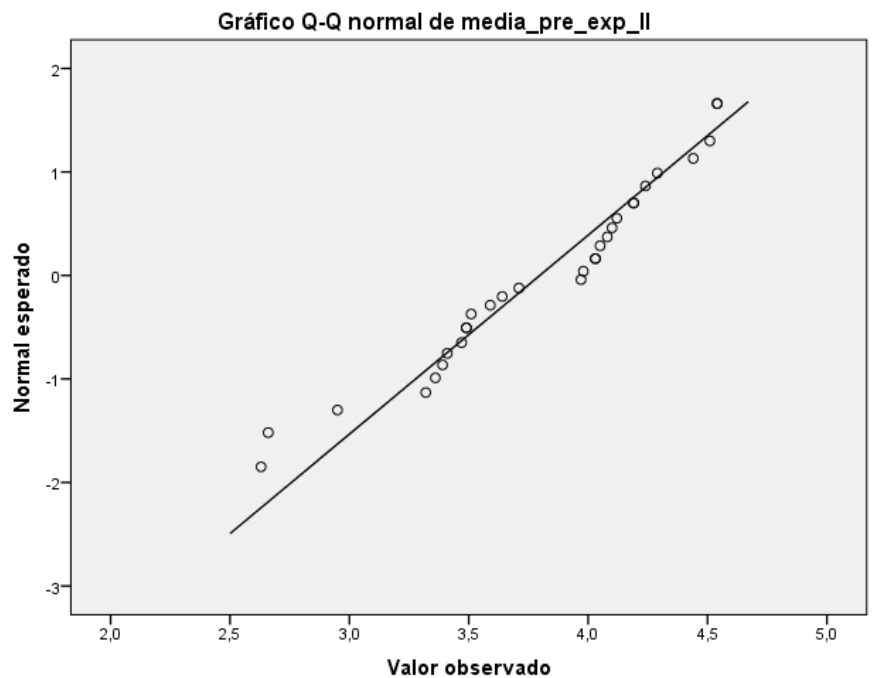

Gráfico 64. Normalidad de la muestra del Grupo Experimental Il en el Pretest para la variable B (elaboración propia). 


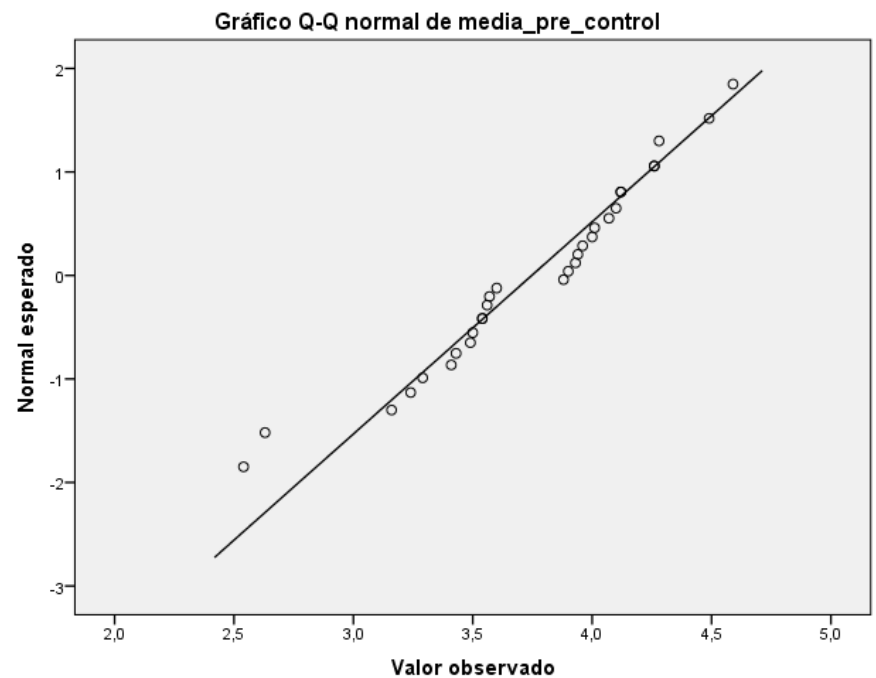

Gráfico 65. Normalidad de la muestra del Grupo Control en el Pretest para la variable B (elaboración propia).

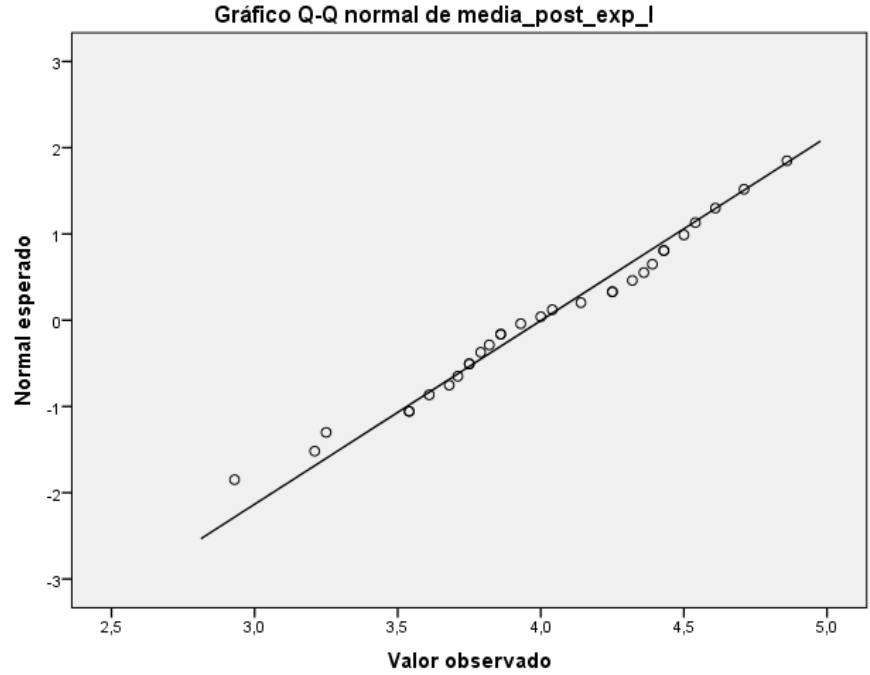

Gráfico 66. Normalidad de la muestra del Grupo Experimental I en el Postest para la variable B (elaboración propia). 


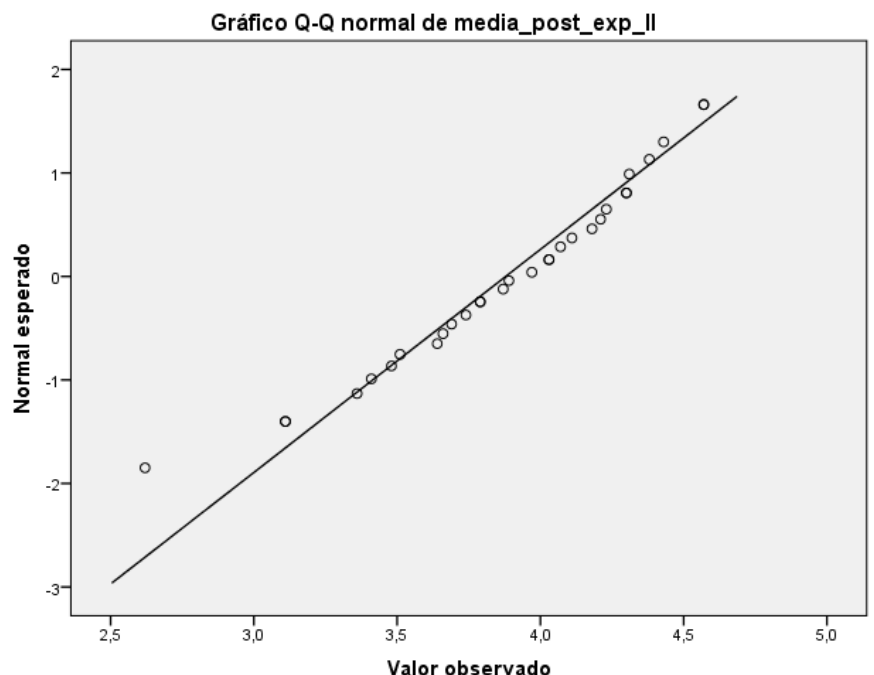

Gráfico 67. Normalidad de la muestra del Grupo Experimental Il en el Postest para la variable B (elaboración propia).

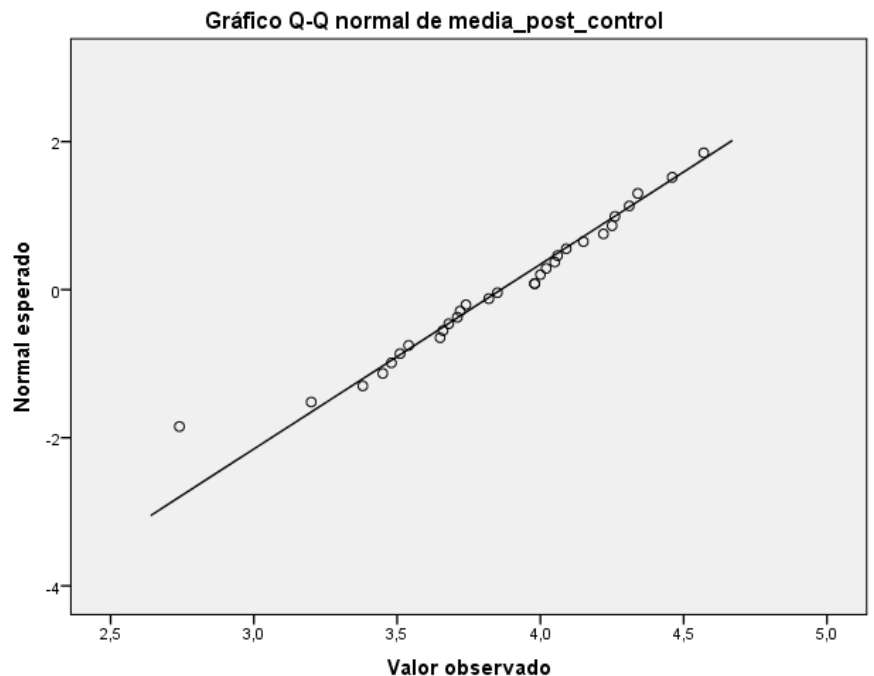

Gráfico 68. Normalidad de la muestra del Grupo Control en el Postest para la variable B (elaboración propia). 
Tabla 89. Prueba de Levene para las medias de los datos de la variable B en el Pretest (elaboración propia).

\begin{tabular}{|c|c|c|c|c|c|c|c|c|c|c|}
\hline & & $\begin{array}{l}\text { Prueb } \\
\text { Leven } \\
\text { la igu } \\
\text { de vari }\end{array}$ & $\begin{array}{l}\text { a de } \\
\text { para } \\
\text { ldad } \\
\text { anzas }\end{array}$ & & & Prueba & T para la igu & aldad de mec & lias & \\
\hline & & $\mathbf{F}$ & Sig. & $t$ & gl & $\begin{array}{c}\text { Sig. } \\
\text { (bilateral) }\end{array}$ & $\begin{array}{l}\text { Diferencia } \\
\text { de medias }\end{array}$ & $\begin{array}{l}\text { Error típ. } \\
\text { de la } \\
\text { diferencia }\end{array}$ & $\begin{array}{r}95 \% \text { Int } \\
\text { confian } \\
\text { dife }\end{array}$ & $\begin{array}{l}\text { ervalo de } \\
\text { za para la } \\
\text { encia }\end{array}$ \\
\hline & & & & & & & & & Inferior & Superior \\
\hline Pre exp I & $\begin{array}{l}\text { Se han asumido } \\
\text { varianzas iguales }\end{array}$ &, 000 & ,995 &, 017 & 58 & 986 & ,00233 & 13660 &,- 27111 & 27577 \\
\hline Pre exp II & $\begin{array}{l}\text { No se han asumido } \\
\text { varianzas iguales }\end{array}$ & & &, 017 & 57,935 & 986 &, 00233 & 13660 &,- 27111 &, 27578 \\
\hline Pre exp I & $\begin{array}{l}\text { Se han asumido } \\
\text { varianzas iguales }\end{array}$ &, 265 & 609 & ,397 & 58 & ,693 &, 05267 & 13257 &,- 21270 &, 31803 \\
\hline Pre control & $\begin{array}{l}\text { No se han asumido } \\
\text { varianzas iguales }\end{array}$ & & & 397 & 57,455 & ,693 &, 05267 & 13257 &,- 21275 &, 31808 \\
\hline Pre exp II & $\begin{array}{l}\text { Se han asumido } \\
\text { varianzas iguales }\end{array}$ &, 307 &, 582 &, 387 & 58 & ,700 &, 05033 & 13019 &,- 21027 & 31093 \\
\hline Pre control & $\begin{array}{l}\text { No se han asumido } \\
\text { varianzas iguales }\end{array}$ & & &, 387 & 57,763 & ,700 &, 05033 & 13019 &,- 21029 & 31096 \\
\hline
\end{tabular}

Tabla 9o. Prueba de Levene para las medias de los datos de la variable B en el Postest (elaboración propia).

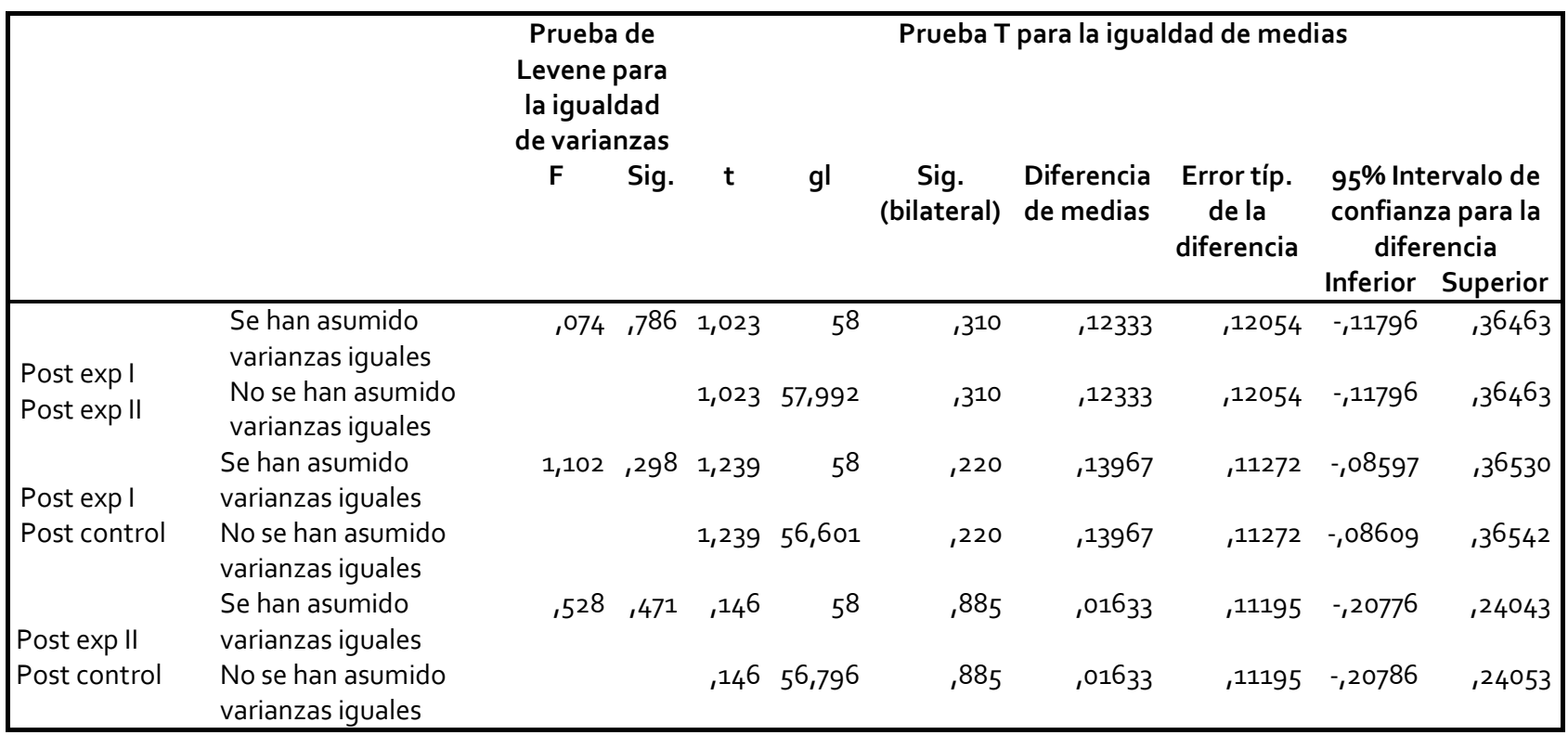

Tabla 91. Prueba ANOVA para las medias de los datos de la variable B en el Pretest (elaboración propia).

\begin{tabular}{|lrrrr|}
\hline Pre todos & Suma de cuadrados & gl Media cuadrática & F & Sig. \\
\hline Inter-grupos &, 053 & 2 & $, 027,100,905$ \\
Intra-grupos & 23,13587 &, 266 & \\
Total & 23,188 & 89 & & \\
\hline
\end{tabular}


Tabla 92. Prueba $T$ de muestras relacionadas para las medias de los datos de la variable $B$ en el Pretest-Postest (elaboración propia).

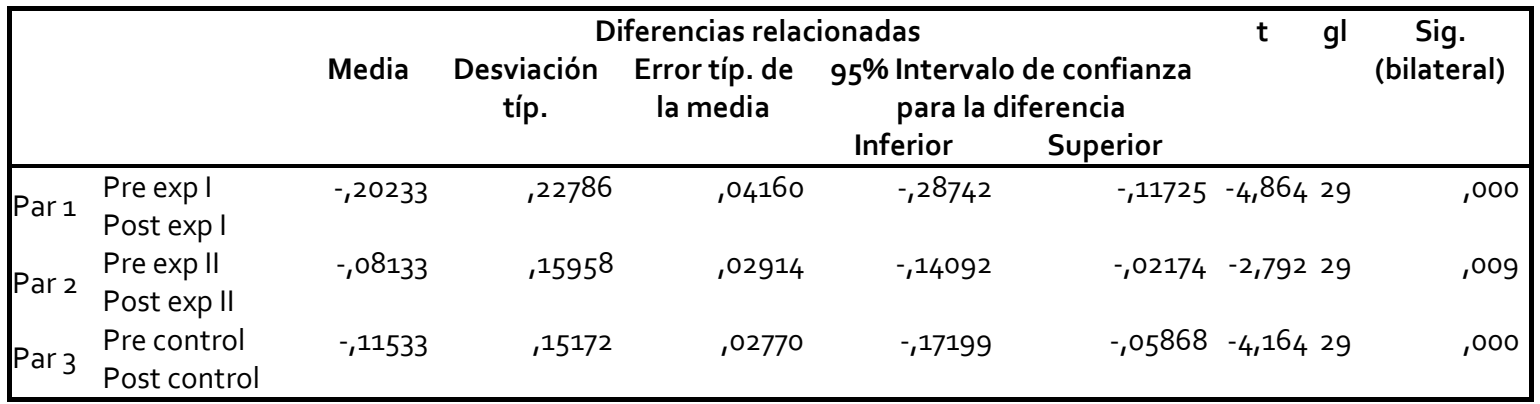

Tabla 93. Prueba ANOVA para las medias de los datos de la variable B en el Postest (elaboración propia).

\begin{tabular}{|lrrrr|}
\hline Post todos & Suma de cuadrados & gl Media cuadrática & F & Sig. \\
\hline Inter-grupos & 1350 & 2 & $175,880,419$ \\
Intra-grupos & 17,300 & 87 & 199 & \\
Total & 17,650 & 89 & & \\
\hline
\end{tabular}

Tabla 94. Prueba de Pearson para las medias de los datos de la variable B por categorías de aspectos en el Postest (elaboración propia).

\begin{tabular}{|c|c|c|c|c|}
\hline & & Personales post & es post & es post \\
\hline & Correlación de Pearson & 1 &, $457^{* \pi x}$ & $625^{* \pi}$ \\
\hline Personales post & Sig. (bilateral) & &, 000 &, 000 \\
\hline & $\mathrm{N}$ & 154 & 154 & 154 \\
\hline & Correlación de Pearson &, $457^{* \star}$ & 1 & $1440^{* *}$ \\
\hline Sociales post & Sig. (bilateral) &, 000 & &, 000 \\
\hline & $\mathrm{N}$ & 154 & 154 & 154 \\
\hline & Correlación de Pearson &, $625^{* *}$ &, $440^{* \star}$ & 1 \\
\hline Innovadores post & Sig. (bilateral) &, 000 &, 000 & \\
\hline & $\mathrm{N}$ & 154 & 154 & 154 \\
\hline
\end{tabular}


Tabla 95. Prueba de Pearson para las medias de los datos de la variable B por aspectos característicos del Emprendimiento Social en el Postest (elaboración propia).

\begin{tabular}{|c|c|c|c|c|c|c|c|c|c|c|c|c|c|c|c|c|c|c|}
\hline & & $\begin{array}{l}\text { Liderazgo } \\
\text { Post }\end{array}$ & $\begin{array}{l}\text { Motivación } \\
\text { logro } \\
\text { Post }\end{array}$ & $\begin{array}{c}\text { Asumir } \\
\text { riesgos } \\
\text { Post }\end{array}$ & $\begin{array}{l}\text { Confianza } \\
\text { Post }\end{array}$ & $\begin{array}{l}\text { Responsabilidad } \\
\text { Post }\end{array}$ & $\begin{array}{l}\text { Integrado } \\
\text { redes } \\
\text { sociales } \\
\text { Post }\end{array}$ & $\begin{array}{l}\text { Conciencia } \\
\text { social } \\
\text { Post }\end{array}$ & $\begin{array}{c}\text { Cooperación } \\
\text { ayuda } \\
\text { Post }\end{array}$ & $\begin{array}{l}\text { Coherencia } \\
\text { compromiso } \\
\text { Post }\end{array}$ & $\begin{array}{l}\text { Convivencia } \\
\text { respeto } \\
\text { bien } \\
\text { público } \\
\text { Post }\end{array}$ & $\begin{array}{l}\text { Creatividad } \\
\text { Post }\end{array}$ & $\begin{array}{c}\text { Identificar } \\
\text { oportunidades } \\
\text { Post }\end{array}$ & $\begin{array}{l}\text { Iniciativa } \\
\text { Post }\end{array}$ & $\begin{array}{c}\text { Generar } \\
\text { ideas } \\
\text { Post }\end{array}$ & $\begin{array}{l}\text { Capacidad } \\
\text { cambio } \\
\text { Post }\end{array}$ & $\begin{array}{l}\text { Aprender } \\
\text { evolucionar } \\
\text { Post }\end{array}$ & $\begin{array}{c}\text { Tolerancia } \\
\text { fracaso } \\
\text { Post }\end{array}$ \\
\hline & $\begin{array}{l}\text { Correlación } \\
\text { de Pearson }\end{array}$ & 1 & 100 &, $244^{* \prime \prime}$ &, $232^{\text {*27 }}$ &,- 038 &, $232^{\pi *}$ & 108 & 140 &, 051 &, 026 & 154 &, $258^{* \pi}$ & $179^{*}$ & ,077 &, $208^{* 7}$ &, 085 &, 069 \\
\hline $\begin{array}{l}\text { Liderazgo } \\
\text { Post }\end{array}$ & $\begin{array}{l}\text { Sig. } \\
\text { (bilateral) }\end{array}$ & &, 216 &, 002 &, 004 & ,643 & ,004 & 181 & ,083 &, 526 &, 752 & ,057 & ,001 &, 026 &, 344 & , 010 &, 295 & 398 \\
\hline & $\mathrm{N}$ & 154 & 154 & 154 & 154 & 154 & 154 & 154 & 154 & 154 & 154 & 154 & 154 & 154 & 154 & 154 & 154 & 154 \\
\hline Motivación & $\begin{array}{l}\text { Correlación } \\
\text { de Pearson }\end{array}$ & 100 & 1 &, $412^{* *}$ &, $673^{* *}$ &, $274^{* *}$ &, 132 &, $220^{* \star}$ & $166^{*}$ &, $317^{* *}$ & $294^{* \star}$ &, $283^{* *}$ & $369^{* *}$ & ,133 & $1338^{* *}$ & $1399^{* *}$ & $1424^{* *}$ &, $273^{* *}$ \\
\hline $\begin{array}{l}\text { logro } \\
\text { Post }\end{array}$ & $\begin{array}{l}\text { Sig. } \\
\text { (bilateral) }\end{array}$ &, 216 & &, 000 &, 000 &, 001 & ,104 &, 006 &, 040 & , 000 &, 000 & , 000 &, 000 & 101 &, 000 &, 000 &, 000 &, 001 \\
\hline Asumir & $\begin{array}{l}\mathrm{N} \\
\text { Correlación } \\
\text { de Pearson }\end{array}$ & $\begin{array}{l}154 \\
, 244^{4 *}\end{array}$ & $\begin{array}{l}154 \\
, 412^{* *}\end{array}$ & $\begin{array}{r}154 \\
1\end{array}$ & $\begin{array}{l}154 \\
.406^{* *}\end{array}$ & $\begin{array}{l}154 \\
, 145\end{array}$ & $\begin{array}{r}154 \\
, 164^{*}\end{array}$ &, $213^{* *}$ & $\begin{array}{l}154 \\
174^{*}\end{array}$ & $\begin{array}{l}154 \\
, 163^{*}\end{array}$ & $\begin{array}{l}154 \\
, 265^{* *}\end{array}$ & $\begin{array}{l}154 \\
, 271^{* *}\end{array}$ & $1335^{154}$ & $\begin{array}{r}154 \\
, 069\end{array}$ & $\begin{array}{l}154 \\
, 213^{* *}\end{array}$ & $1320^{* *}$ &, $358^{* \star}$ & $\begin{array}{r}154 \\
, 418^{* *}\end{array}$ \\
\hline $\begin{array}{l}\text { riesgos } \\
\text { Post }\end{array}$ & $\begin{array}{l}\text { Sig. } \\
\text { (bilateral) }\end{array}$ &, 002 &, 000 & &, 000 & ,073 &, 043 &, 008 &, 031 &, 043 & ,001 & ,001 &, 000 &, 398 &, 008 &, 000 &, 000 &, 000 \\
\hline & $\begin{array}{l}\mathrm{N} \\
\text { Correlación } \\
\text { de Pearson }\end{array}$ & $\begin{array}{l}154 \\
, 232^{2^{*}}\end{array}$ & , $673^{154}$ & $\begin{array}{l}154 \\
, 406^{* *}\end{array}$ & $\begin{array}{r}154 \\
1\end{array}$ & $\begin{array}{r}154 \\
, 128\end{array}$ & $\begin{aligned} 154 \\
, 239^{* *}\end{aligned}$ & $\begin{array}{r}154 \\
130\end{array}$ & $\begin{array}{r}154 \\
1122\end{array}$ & $\begin{aligned} & 154 \\
&, 216^{* *}\end{aligned}$ & $\begin{array}{l}154 \\
, 180^{*}\end{array}$ & $\begin{array}{l}154 \\
189\end{array}$ & $\begin{array}{r}154 \\
, 376^{* *}\end{array}$ & $\begin{array}{r}154 \\
, 089\end{array}$ &, $299^{154}$ & $\begin{array}{l}154 \\
.435^{*}\end{array}$ & $\begin{array}{l}154 \\
396^{* *}\end{array}$ & $\begin{array}{l}154 \\
164^{*}\end{array}$ \\
\hline $\begin{array}{l}\text { Confianza } \\
\text { Post }\end{array}$ & $\begin{array}{l}\text { Sig. } \\
\text { (bilateral) }\end{array}$ &, 004 &, 000 &, 000 & & ,113 & ,003 & 107 & ,130 & ,007 &, 025 & , 019 & , 000 &, 272 &, 000 &, 000 &, 000 &, 043 \\
\hline & $\begin{array}{l}\mathrm{N} \\
\text { Correlación } \\
\text { de Pearson }\end{array}$ & $\begin{array}{r}154 \\
-, 038\end{array}$ & $\begin{array}{l}154 \\
, 274^{* *}\end{array}$ & $\begin{array}{r}154 \\
1145\end{array}$ & $\begin{array}{r}154 \\
, 128\end{array}$ & $\begin{array}{r}154 \\
1\end{array}$ & $\begin{array}{r}154 \\
, 122\end{array}$ & $\begin{aligned} & 154 \\
&, 220^{* *}\end{aligned}$ & $\begin{array}{l}154 \\
1305^{* *}\end{array}$ & $\begin{array}{r}154 \\
, 44^{* *}\end{array}$ & $\begin{array}{l}154 \\
1399^{\star \star}\end{array}$ & $\begin{array}{l}154 \\
, 213^{* *}\end{array}$ & $\begin{array}{l}154 \\
, 177^{*}\end{array}$ & $\begin{array}{r}154 \\
-, 022\end{array}$ & $\begin{aligned} & 154 \\
&, 222^{* *}\end{aligned}$ & $\begin{aligned} & 154 \\
&, 231^{* *}\end{aligned}$ & $\begin{array}{l}154 \\
, 293^{* *}\end{array}$ & $\begin{array}{r}154 \\
1346^{* *}\end{array}$ \\
\hline $\begin{array}{l}\text { Responsabilidad } \\
\text { Post }\end{array}$ & $\begin{array}{l}\text { Sig. } \\
\text { (bilateral) }\end{array}$ & 643 &, 001 & , 073 & 113 & & ,132 &, 006 & , 000 & , 000 &, 000 & ,008 &, 028 &, 790 &, 006 &, 004 &, 000 &, 000 \\
\hline Integrado & $\begin{array}{l}\mathrm{N} \\
\text { Correlación } \\
\text { de Pearson }\end{array}$ & $\begin{array}{l}154 \\
, 232^{* *}\end{array}$ & $\begin{array}{r}154 \\
132\end{array}$ & $\begin{array}{l}154 \\
164^{*}\end{array}$ & $\begin{array}{l}154 \\
, 239^{* *}\end{array}$ & $\begin{array}{r}154 \\
122\end{array}$ & $\begin{array}{r}154 \\
1\end{array}$ & $\begin{array}{l}154 \\
167^{*}\end{array}$ & $\begin{array}{l}154 \\
1397^{* *}\end{array}$ & $\begin{array}{r}154 \\
, 085\end{array}$ & $\begin{array}{r}154 \\
, 246^{* \pi}\end{array}$ & $\begin{array}{r}154 \\
, 142\end{array}$ & $\begin{array}{l}154 \\
162^{*}\end{array}$ &, $233^{154}$ & $\begin{array}{l}154 \\
185^{*}\end{array}$ & $\begin{array}{l}154 \\
, 271^{* \star}\end{array}$ & $\begin{array}{l}154 \\
, 070\end{array}$ & $\begin{array}{l}154 \\
, 144\end{array}$ \\
\hline $\begin{array}{l}\text { redes } \\
\text { sociales } \\
\text { Post }\end{array}$ & $\begin{array}{l}\text { Sig. } \\
\text { (bilateral) }\end{array}$ &, 004 & ,104 &, 043 &, 003 & 132 & & ,038 &, 000 & ,295 & ,002 & ,079 &, 044 &, 004 &, 022 & , 001 & 389 &, 074 \\
\hline Conciencia & $\begin{array}{l}\mathrm{N} \\
\text { Correlación } \\
\text { de Pearson }\end{array}$ & $\begin{array}{r}154 \\
, 108\end{array}$ & $\begin{array}{r}154 \\
, 220 *\end{array}$ & $\begin{aligned} 154 \\
213^{* *}\end{aligned}$ & $\begin{array}{r}154 \\
, 130\end{array}$ & $\begin{aligned} 154 \\
, 220^{* *}\end{aligned}$ & $\begin{array}{l}154 \\
, 167^{*}\end{array}$ & $\begin{array}{r}154 \\
1\end{array}$ & $\begin{aligned} & 154 \\
&, 439 * *\end{aligned}$ & $\begin{aligned} 154 \\
, 232^{* *}\end{aligned}$ & $\begin{array}{r}154 \\
, 283^{* *}\end{array}$ & $\begin{array}{r}154 \\
, 056\end{array}$ & $\begin{array}{l}154 \\
163^{*}\end{array}$ & $\begin{array}{l}154 \\
183^{*}\end{array}$ & $\begin{array}{l}154 \\
, 277^{* *}\end{array}$ & $\begin{array}{r}154 \\
101\end{array}$ & $\begin{array}{r}154 \\
, 094\end{array}$ & $\begin{array}{l}154 \\
164^{*}\end{array}$ \\
\hline $\begin{array}{l}\text { social } \\
\text { Post }\end{array}$ & $\begin{array}{l}\text { Sig. } \\
\text { (bilateral) }\end{array}$ & ,181 & ,006 & ,008 & 107 & ,006 &, 038 & &, 000 &, 004 &, 000 &, 490 &, 043 &, 023 &, 000 &, 213 &, 245 &, 042 \\
\hline & $\mathrm{N}$ & 154 & 154 & 154 & 154 & 154 & 154 & 154 & 154 & 154 & 154 & 154 & 154 & 154 & 154 & 154 & 154 & 154 \\
\hline Cooperación & $\begin{array}{l}\text { Correlación } \\
\text { de Pearson }\end{array}$ & 140 & $166^{*}$ & $174^{*}$ & 122 & $1305^{\circ}$ & $1397^{*}$ &, $439^{x}$ & 1 & $.325^{*}$ &, $273^{*}$ & $175^{*}$ & 156 &, 036 &, $398^{* *}$ &, $252^{2 \pi}$ & $215^{\text {K }}$ &, $241^{* *}$ \\
\hline $\begin{array}{l}\text { ayuda } \\
\text { Post }\end{array}$ & $\begin{array}{l}\text { Sig. } \\
\text { (bilateral) }\end{array}$ &, 083 &, 040 &, 031 & ,130 & , 000 & ,000 & , 000 & & ,000 & ,001 & ,030 &, 054 & ,661 & , 000 &, 002 & ,007 &, 003 \\
\hline & $\mathrm{N}$ & 154 & 154 & 154 & 154 & 154 & 154 & 154 & 154 & 154 & 154 & 154 & 154 & 154 & 154 & 154 & 154 & 154 \\
\hline $\begin{array}{l}\text { Coherencia } \\
\text { compromiso }\end{array}$ & $\begin{array}{l}\text { Correlación } \\
\text { de Pearson }\end{array}$ &, 051 &, $317^{* *}$ & $163^{*}$ &, $216^{*}$ &, $448^{* *}$ &, 085 &, $232^{* *}$ & $1325^{* *}$ & 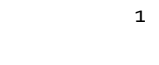 &, $290^{*}$ &, $223^{* *}$ & ,125 & ,011 & $1325^{* *}$ &, $273^{* *}$ &, $261^{* * *}$ &, $261^{* *}$ \\
\hline $\begin{array}{l}\text { compromiso } \\
\text { Post }\end{array}$ & $\begin{array}{l}\text { Sig. } \\
\text { (bilateral) }\end{array}$ &, 526 &, 000 &, 043 & , 007 & , 000 & ,295 &, 004 & , 000 & &, 000 &, 005 &, 123 & ,893 & , 000 &, 001 & ,001 & ,001 \\
\hline
\end{tabular}




\begin{tabular}{|c|c|c|c|c|c|c|c|c|c|c|c|c|c|c|c|c|c|c|}
\hline $\begin{array}{l}\text { Convivencia } \\
\text { respeto }\end{array}$ & $\begin{array}{l}\mathrm{N} \\
\text { Correlación } \\
\text { de Pearson }\end{array}$ & $\begin{array}{r}154 \\
, 026\end{array}$ & $\begin{array}{l}154 \\
, 294^{* *}\end{array}$ & $\begin{array}{l}154 \\
265^{4 *}\end{array}$ & $\begin{array}{r}154 \\
, 180^{*}\end{array}$ & $\begin{array}{l}154 \\
1399^{* *}\end{array}$ & $\begin{array}{r}154 \\
, 246^{6 *}\end{array}$ & $\begin{array}{l}154 \\
283^{* *} \\
,\end{array}$ & $\begin{array}{l}1254 \\
.273^{* *}\end{array}$ & $\begin{array}{l}1544 \\
, 290^{* *}\end{array}$ & $\begin{array}{r}154 \\
1\end{array}$ & $\begin{array}{l}154 \\
, 170^{*}\end{array}$ & $\begin{array}{l}154 \\
, 205^{*}\end{array}$ & $\begin{array}{r}154 \\
, 042\end{array}$ & $\begin{array}{l}154 \\
1402^{* *}\end{array}$ & $\begin{array}{l}154 \\
262^{2+4} \\
,\end{array}$ & $\begin{array}{l}154 \\
1384\end{array}$ & $\begin{array}{r}154 \\
, 370^{* *}\end{array}$ \\
\hline $\begin{array}{l}\text { bien } \\
\text { público }\end{array}$ & $\begin{array}{l}\text { Sig. } \\
\text { (bilateral) }\end{array}$ &, 752 & ,000 & ,001 &, 025 & , 000 & ,002 & , 000 & ,001 & , 000 & & ,035 & ,011 & ,609 &, 000 & ,001 & ,000 & , 000 \\
\hline Post & $\begin{array}{l}\mathrm{N} \\
\text { Correlación } \\
\text { de Pearson }\end{array}$ & $\begin{array}{r}154 \\
, 154\end{array}$ & $\begin{array}{l}154 \\
, 283^{* *}\end{array}$ & $\begin{array}{r}154 \\
, 271^{4 *}\end{array}$ & $\begin{array}{l}154 \\
, 189^{*}\end{array}$ & $\begin{array}{l}154 \\
213^{* *} \\
,\end{array}$ & $\begin{array}{l}154 \\
, 142\end{array}$ & $\begin{array}{l}154 \\
, 056\end{array}$ & $\begin{array}{r}154 \\
, 175^{*}\end{array}$ & $\begin{array}{l}154 \\
223^{4 *} \\
,\end{array}$ & $\begin{array}{l}154 \\
, 170^{*}\end{array}$ & $\begin{array}{r}154 \\
1\end{array}$ & $\begin{array}{l}154 \\
277^{* *} \\
,\end{array}$ & $\begin{array}{l}154 \\
, 072\end{array}$ & $\begin{array}{l}154 \\
284 \\
284\end{array}$ & $\begin{array}{l}154 \\
, 202^{*}\end{array}$ & $\begin{array}{l}154 \\
208^{8 *}\end{array}$ & $\begin{array}{l}154 \\
, 223^{* *}\end{array}$ \\
\hline $\begin{array}{l}\text { Creatividad } \\
\text { Post }\end{array}$ & $\begin{array}{l}\text { Sig. } \\
\text { (bilateral) }\end{array}$ & ,057 &, 000 & , 001 & ,019 & ,008 & ,079 & ,490 &, 030 & ,005 & ,035 & & , 000 &, 372 &, 000 & ,012 & ,010 &, 006 \\
\hline Identificar & $\begin{array}{l}\text { N } \\
\text { Correlación } \\
\text { de Pearson }\end{array}$ & $\begin{array}{r}154 \\
, 25^{8 * *}\end{array}$ & $\begin{array}{l}154 \\
369^{* *}\end{array}$ & $\begin{array}{l}154 \\
.335^{5 *}\end{array}$ & $\begin{array}{l}154 \\
.376^{6 *}\end{array}$ & $\begin{array}{l}154 \\
, 177^{*}\end{array}$ & $\begin{array}{l}154 \\
, 162^{*}\end{array}$ & $\begin{array}{l}154 \\
, 163^{*}\end{array}$ & $\begin{array}{r}154 \\
, 156\end{array}$ & $\begin{array}{l}154 \\
, 125\end{array}$ & $\begin{array}{l}154 \\
, 205^{*}\end{array}$ & $\begin{array}{l}154 \\
, 277^{7 *}\end{array}$ & $\begin{array}{r}154 \\
1\end{array}$ & $\begin{array}{r}154 \\
, 064\end{array}$ & $\begin{array}{l}154 \\
219^{*} \\
2\end{array}$ & $\begin{array}{l}154 \\
, 453^{* *}\end{array}$ & $\begin{array}{l}154 \\
.33^{2 *}\end{array}$ & $\begin{array}{r}154 \\
, 246^{* *}\end{array}$ \\
\hline $\begin{array}{l}\text { oportunidades } \\
\text { Post }\end{array}$ & $\begin{array}{l}\text { Sig. } \\
\text { (bilateral) }\end{array}$ & ,001 & ,000 & , 000 & , 000 &, 028 & ,044 &, 043 &, 054 & ,123 & ,011 & , 000 & &, 429 & ,006 & , 000 & , 000 & ,002 \\
\hline & $\begin{array}{l}\mathrm{N} \\
\text { Correlación }\end{array}$ & $\begin{array}{l}154 \\
179^{*}\end{array}$ & 154 & 154 & $\begin{array}{l}154 \\
084\end{array}$ & 154 & 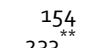 & 154 & 154 & 154 & 154 & 154 & 154 & 154 & 154 & 154 & 154 & 154 \\
\hline $\begin{array}{l}\text { Iniciativa } \\
\text { Post }\end{array}$ & $\begin{array}{l}\text { Correlación } \\
\text { de Pearson } \\
\text { Sig. } \\
\text { (bilateral) }\end{array}$ & $\begin{array}{l}, 179 \\
, 026\end{array}$ & 101 & $\begin{array}{l}, 069 \\
, 398\end{array}$ & $\begin{array}{l}, 089 \\
, 272\end{array}$ & $\begin{array}{l}-, 022 \\
, 790\end{array}$ & $\begin{array}{l}, 233 \\
, 004\end{array}$ & $\begin{array}{l}183 \\
, 023\end{array}$ & $\begin{array}{l}, 036 \\
, 661\end{array}$ & $\begin{array}{l}, 011 \\
, 893\end{array}$ & $\begin{array}{l}, 042 \\
, 609\end{array}$ & $\begin{array}{l}, 072 \\
, 372\end{array}$ & $\begin{array}{l}, 064 \\
, 429\end{array}$ & 1 & $\begin{array}{l}, 217 \\
, 007\end{array}$ & $\begin{array}{l}104 \\
, 197\end{array}$ & $\begin{array}{l}, 019 \\
, 812\end{array}$ & $\begin{array}{l}, 077 \\
, 340\end{array}$ \\
\hline Generar & $\begin{array}{l}\mathrm{N} \\
\text { Correlación } \\
\text { de Pearson }\end{array}$ & $\begin{array}{l}154 \\
, 077\end{array}$ & $\begin{array}{r}154 \\
.33^{* *}\end{array}$ & $\begin{array}{l}154 \\
213^{4 \times} \\
,\end{array}$ & $\begin{array}{l}154 \\
1299^{\circ *}\end{array}$ & $\begin{array}{r}154 \\
, 222^{* *}\end{array}$ & $\begin{array}{l}154 \\
, 185^{5}\end{array}$ & $\begin{array}{l}154 \\
, 277^{4.4}\end{array}$ & $\begin{array}{r}154 \\
.398^{* *}\end{array}$ & $\begin{array}{l}154 \\
1325^{5 *}\end{array}$ & $\begin{array}{l}154 \\
, 402^{* *}\end{array}$ & $\begin{array}{l}154 \\
284 \\
, 284\end{array}$ & $\begin{array}{l}154 \\
219 \\
, 219^{* *}\end{array}$ & $\begin{array}{l}154 \\
217^{*} \\
,\end{array}$ & $\begin{array}{r}154 \\
1\end{array}$ & $\begin{array}{l}154 \\
1347^{7}\end{array}$ & $\begin{array}{l}154 \\
2277^{* *}\end{array}$ & $\begin{array}{r}154 \\
, 380^{* *}\end{array}$ \\
\hline $\begin{array}{l}\text { ideas } \\
\text { Post }\end{array}$ & $\begin{array}{l}\text { Sig. } \\
\text { (bilateral) }\end{array}$ &, 344 & ,000 & ,008 & , 000 & ,006 &, 022 & ,000 & ,000 & ,000 &, 000 & ,000 & ,006 & ,007 & & ,000 & ,001 & , 000 \\
\hline Capacidad & $\begin{array}{l}\mathrm{N} \\
\text { Correlación } \\
\text { de Pearson }\end{array}$ & $\begin{array}{r}154 \\
, 208^{* *}\end{array}$ & $\begin{array}{l}154 \\
1399^{* *}\end{array}$ & $\begin{array}{r}154 \\
1320^{*+5}\end{array}$ & $\begin{array}{l}154 \\
.435^{4}\end{array}$ & $\begin{array}{r}154 \\
, 231^{* *}\end{array}$ & $\begin{array}{l}154 \\
.271^{1 *} \\
\end{array}$ & $\begin{array}{l}154 \\
101\end{array}$ & $\begin{array}{r}154 \\
, 25^{* *}\end{array}$ & $\begin{array}{l}154 \\
, 273^{-44}\end{array}$ & $\begin{array}{r}154 \\
, 262^{* *}\end{array}$ & $\begin{array}{l}154 \\
, 202^{*}\end{array}$ & $\begin{array}{l}154 \\
.453^{* \pi}\end{array}$ & $\begin{array}{r}154 \\
, 104\end{array}$ & $\begin{array}{l}154 \\
1347^{*}\end{array}$ & $\begin{array}{r}154 \\
1\end{array}$ & $\begin{array}{l}154 \\
.417 \\
\end{array}$ & $\begin{array}{l}154 \\
1317^{* *}\end{array}$ \\
\hline $\begin{array}{l}\text { cambio } \\
\text { Post }\end{array}$ & $\begin{array}{l}\text { Sig. } \\
\text { (bilateral) }\end{array}$ & ,010 & ,000 & ,000 & , 000 & ,004 & ,001 &, 213 &, 002 & ,001 & ,001 & ,012 & ,000 & 197 & ,000 & & ,000 & , 000 \\
\hline Aprender & $\begin{array}{l}\mathrm{N} \\
\text { Correlación } \\
\text { de Pearson }\end{array}$ & $\begin{array}{r}154 \\
, 085\end{array}$ & $\begin{array}{l}154 \\
1424^{2}\end{array}$ & $\begin{array}{r}154 \\
135^{8^{* 4}}\end{array}$ & $\begin{array}{l}154 \\
396^{6 *}\end{array}$ & $\begin{array}{l}154 \\
1293^{\text {t.t }}\end{array}$ & $\begin{array}{l}154 \\
, 070\end{array}$ & $\begin{array}{l}154 \\
, 094\end{array}$ & $\begin{array}{l}154 \\
215^{4.4}\end{array}$ & $\begin{array}{l}154 \\
261^{4} \\
, 2\end{array}$ & $\begin{array}{r}154 \\
1384\end{array}$ & $\begin{array}{l}154 \\
208^{5 *}\end{array}$ & $\begin{array}{l}154 \\
1332^{2+4}\end{array}$ & $\begin{array}{l}154 \\
, 019\end{array}$ & $\begin{array}{l}154 \\
, 277^{4.5}\end{array}$ & $\begin{array}{l}154 \\
6417^{4.4}\end{array}$ & $\begin{array}{r}154 \\
1\end{array}$ & $\begin{array}{l}154 \\
, 551^{*} \\
.\end{array}$ \\
\hline $\begin{array}{l}\text { evolucionar } \\
\text { Post }\end{array}$ & $\begin{array}{l}\text { Sig. } \\
\text { (bilateral) }\end{array}$ & ,295 & , 000 & , 000 & , 000 & ,000 & , 389 &, 245 & ,007 & ,001 &, 000 & ,010 & ,000 &, 812 & ,001 & ,000 & & , 000 \\
\hline Tolerancia & $\begin{array}{l}\mathrm{N} \\
\text { Correlación } \\
\text { de Pearson }\end{array}$ & $\begin{array}{l}154 \\
, 069\end{array}$ & $\begin{array}{l}154 \\
, 273^{*}\end{array}$ & $\begin{array}{l}154 \\
4418^{4}\end{array}$ & $\begin{array}{c}154 \\
164_{4}\end{array}$ & $\begin{array}{l}154 \\
1346^{4 *}\end{array}$ & $\begin{array}{l}154 \\
, 144\end{array}$ & $\begin{array}{l}154 \\
, 164^{4}\end{array}$ & $\begin{array}{l}154 \\
241^{1.4}\end{array}$ & $\begin{array}{l}154 \\
261^{2.4}\end{array}$ & $\begin{array}{l}154 \\
, 377^{*}\end{array}$ & $\begin{array}{l}154 \\
1223^{2.4}\end{array}$ & $\begin{array}{l}154 \\
, 246^{6 *}\end{array}$ & $\begin{array}{l}154 \\
, 077\end{array}$ & $\begin{aligned} & 154 \\
&, 380^{* *}\end{aligned}$ & $\begin{array}{l}154 \\
317^{7 *}\end{array}$ & $\begin{array}{l}154 \\
155^{1+4}\end{array}$ & $\begin{array}{r}154 \\
1\end{array}$ \\
\hline $\begin{array}{l}\text { fracaso } \\
\text { Post }\end{array}$ & $\begin{array}{l}\text { Sig. } \\
\text { (bilateral) }\end{array}$ &, 398 & , 001 & ,000 & ,043 & ,000 & ,074 &, 042 &, 003 & ,001 &, 000 & ,006 & ,002 & 1340 &, 000 & ,000 & ,000 & \\
\hline $\begin{array}{l}\text { **. La correlación } \\
\text { *. La correlación }\end{array}$ & $\begin{array}{l}\text { N } \\
\text { es significativ } \\
\text { es significante }\end{array}$ & $\begin{array}{l}154 \\
\text { ivel } 0,0 \\
\text { el } 0,05\end{array}$ & $\begin{array}{l}154 \\
\text { ateral). } \\
\text { eral). }\end{array}$ & 154 & 154 & 154 & 154 & 154 & 154 & 154 & 154 & 154 & 154 & 154 & 154 & 154 & 154 & 154 \\
\hline
\end{tabular}


Tabla 96. Referencias sobre aprendizajes académicos en las entrevistas (elaboración propia).

\begin{tabular}{|cc|}
\hline ENTREVISTA & APRENDIZAJES ACADÉMICOS \\
\hline C01 & 67 \\
C02 & 37 \\
C03 & 54 \\
C04 & 65 \\
C05 & 73 \\
C06 & 55 \\
C07 & 23 \\
C08 & 33 \\
Co9 & 27 \\
C10 & 38 \\
C11 & 44 \\
C12 & 31 \\
\hline
\end{tabular}

Tabla 97. Referencias sobre aprendizajes académicos en las entrevistas por categorías (elaboración propia).

\begin{tabular}{|c|c|c|c|c|c|c|c|c|c|c|c|c|}
\hline & Co1 & $\mathrm{Co2}$ & $\mathrm{Co3}$ & $\mathrm{Co} 4$ & Co5 & Co6 & $\mathrm{Co} 7$ & Co8 & Cog & $\mathrm{C}_{10}$ & $\mathrm{C}_{11}$ & $\mathrm{C}_{12}$ \\
\hline $\begin{array}{l}\text { Ajuste de los juegos } \\
\text { al alumnado }\end{array}$ & 12 & 8 & 13 & 28 & 44 & 29 & 18 & 22 & 14 & 29 & 23 & 16 \\
\hline Presentación & 11 & 6 & 11 & 29 & 31 & 36 & 15 & 23 & 9 & 23 & 26 & 16 \\
\hline $\begin{array}{l}\text { Organización del } \\
\text { alumnado }\end{array}$ & 11 & 6 & 29 & 22 & 25 & 30 & 12 & 20 & 14 & 21 & 26 & 17 \\
\hline $\begin{array}{l}\text { Organización del } \\
\text { material }\end{array}$ & 8 & 6 & 22 & 18 & 23 & 13 & 13 & 10 & 8 & 15 & 17 & 11 \\
\hline $\begin{array}{l}\text { Organización } \\
\text { espacio-temporal }\end{array}$ & 17 & 3 & 16 & 23 & 25 & 23 & 13 & 20 & 10 & 23 & 21 & 13 \\
\hline $\begin{array}{l}\text { Adecuación } \\
\text { curricular }\end{array}$ & 13 & 3 & 26 & 22 & 17 & 21 & 10 & 16 & 13 & 13 & 12 & 9 \\
\hline Aspectos sociales & 9 & 11 & 26 & 25 & 24 & 9 & 12 & 6 & 9 & 18 & 7 & 8 \\
\hline Juegos motores & 9 & 8 & 27 & 18 & 19 & 21 & 13 & 15 & 6 & 18 & 18 & 11 \\
\hline $\begin{array}{l}\text { Juegos de expresion } \\
\text { corporal }\end{array}$ & 5 & 3 & 12 & 12 & 6 & 7 & 7 & 6 & 2 & 3 & 6 & 5 \\
\hline Otros & 13 & 8 & 30 & 35 & 32 & 29 & 15 & 17 & 11 & 16 & 19 & 14 \\
\hline
\end{tabular}

Tabla 98. Referencias sobre el ajuste de los juegos al alumnado participante en las entrevistas (elaboración propia).

\begin{tabular}{|ccccc|}
\hline ENTREVISTA & EDAD & PERIODO DEL CURSO & NECESIDADES EDUCATIVAS & SEGURIDAD \\
\hline C01 & 5 & 1 & 7 & 4 \\
C02 & 5 & 0 & 3 & 5 \\
C03 & 9 & 1 & 5 & 8 \\
C04 & 13 & 6 & 14 & 17 \\
C05 & 29 & 2 & 28 & 20 \\
C06 & 24 & 6 & 15 & 20 \\
C07 & 13 & 3 & 18 & 13 \\
C08 & 19 & 9 & 12 & 16 \\
Co9 & 7 & 1 & 14 & 8 \\
C10 & 20 & 8 & 28 & 16 \\
C11 & 20 & 4 & 19 & 18 \\
C12 & 15 & 4 & 12 & 12 \\
\hline
\end{tabular}


Tabla 99. Referencias sobre la presentación de los juegos en las entrevistas (elaboración propia).

\begin{tabular}{|ccccc|}
\hline ENTREVISTA & DESCRIPCIÓN & $\begin{array}{c}\text { ESTRUCTURA DE } \\
\text { LA SESIÓN }\end{array}$ & $\begin{array}{c}\text { COMPRENSIÓN DE } \\
\text { LAS NORMAS }\end{array}$ & $\begin{array}{c}\text { REPRESENTACIÓN } \\
\text { GRÁFICA }\end{array}$ \\
\hline C01 & 5 & 4 & 6 & 2 \\
C02 & 5 & 0 & 2 & 2 \\
C03 & 8 & 4 & 10 & 4 \\
C04 & 17 & 18 & 16 & 1 \\
C05 & 22 & 16 & 23 & 3 \\
C06 & 27 & 11 & 30 & 5 \\
C07 & 13 & 3 & 13 & 0 \\
C08 & 18 & 5 & 19 & 2 \\
Co9 & 8 & 1 & 8 & 0 \\
C10 & 21 & 8 & 20 & 3 \\
C11 & 21 & 5 & 21 & 2 \\
C12 & 10 & 8 & 11 & 3 \\
\hline
\end{tabular}

Tabla 100. Referencias sobre la organización del alumnado en las entrevistas (elaboración propia).

\begin{tabular}{|ccccc|}
\hline ENTREVISTA & $\begin{array}{c}\text { PARTICIPACIÓN } \\
\text { ALUMNADO }\end{array}$ & $\begin{array}{c}\text { DISTRIBUCIÓN DE } \\
\text { ROLES }\end{array}$ & $\begin{array}{c}\text { TRABAJO } \\
\text { INDIVIDUAL-GRUPAL }\end{array}$ & $\begin{array}{c}\text { CONTROL DEL } \\
\text { RESPTO POR LAS } \\
\text { NORMAS }\end{array}$ \\
\hline C01 & 5 & 2 & 5 & 5 \\
C02 & 3 & 2 & 4 & 1 \\
C03 & 17 & 6 & 14 & 8 \\
C04 & 20 & 6 & 15 & 4 \\
C05 & 22 & 2 & 22 & 3 \\
C06 & 23 & 11 & 23 & 9 \\
C07 & 12 & 3 & 12 & 1 \\
C08 & 18 & 5 & 18 & 9 \\
Co9 & 8 & 3 & 10 & 4 \\
C10 & 20 & 2 & 19 & 2 \\
C11 & 20 & 7 & 20 & 9 \\
C12 & 12 & 7 & 12 & 5 \\
\hline
\end{tabular}

Tabla 101. Referencias sobre la organización del material en las entrevistas (elaboración propia).

\begin{tabular}{|ccccc|}
\hline ENTREVISTA & USO & VARIEDAD & OPTIMIZACIÓN & DISTRIBUCIÓN \\
\hline C01 & 2 & 4 & 1 & 2 \\
C02 & 2 & 2 & 1 & 4 \\
C03 & 18 & 19 & 2 & 9 \\
C04 & 11 & 17 & 9 & 5 \\
C05 & 19 & 21 & 11 & 9 \\
C06 & 13 & 13 & 11 & 8 \\
C07 & 13 & 13 & 12 & 10 \\
C08 & 10 & 10 & 9 & 7 \\
Co9 & 8 & 8 & 3 & 4 \\
C10 & 15 & 15 & 15 & 13 \\
C11 & 14 & 17 & 13 & 11 \\
C12 & 10 & 10 & 9 & 4 \\
\hline
\end{tabular}


Tabla 102. Referencias sobre la organización espacio/temporal en las entrevistas (elaboración propia).

\begin{tabular}{|ccccc|}
\hline ENTREVISTA & $\begin{array}{c}\text { OPTIMIZACIÓN- } \\
\text { ADAPTACIÓN } \\
\text { TEMPORAL }\end{array}$ & $\begin{array}{c}\text { EQUILIBRIO } \\
\text { TEMPORAL }\end{array}$ & $\begin{array}{c}\text { OPTIMIZACIÓN- } \\
\text { ADAPTACIÓN } \\
\text { ESPACIAL }\end{array}$ & $\begin{array}{c}\text { EQUILIBRIO } \\
\text { ESPACIAL }\end{array}$ \\
\hline C01 & 9 & 7 & 10 & 11 \\
C02 & 1 & 1 & 2 & 2 \\
C03 & 12 & 12 & 13 & 13 \\
C04 & 11 & 6 & 13 & 13 \\
C05 & 7 & 4 & 23 & 20 \\
C06 & 14 & 5 & 20 & 20 \\
C07 & 11 & 5 & 11 & 11 \\
C08 & 16 & 3 & 20 & 13 \\
C09 & 10 & 4 & 8 & 3 \\
C10 & 19 & 5 & 17 & 7 \\
C11 & 20 & 1 & 19 & 4 \\
C12 & 12 & 2 & 12 & 4 \\
\hline
\end{tabular}

Tabla 103. Referencias sobre la adecuación curricular de las actividades en las entrevistas (elaboración propia).

\begin{tabular}{|ccccc|}
\hline ENTREVISTA & $\begin{array}{c}\text { RELACIÓN } \\
\text { CONTENIDOS-OBJETIVOS }\end{array}$ & $\begin{array}{c}\text { CONSECUCIÓN } \\
\text { OBJETIVOS }\end{array}$ & $\begin{array}{c}\text { PROGRESIÓN } \\
\text { ACTIVIDADES }\end{array}$ & $\begin{array}{c}\text { VALOR } \\
\text { EDUCATIVO }\end{array}$ \\
\hline C01 & 2 & 3 & 4 & 5 \\
Co2 & 0 & 3 & 0 & 0 \\
C03 & 4 & 11 & 3 & 10 \\
Co4 & 12 & 12 & 9 & 6 \\
Co5 & 6 & 6 & 9 & 2 \\
Co6 & 3 & 17 & 3 & 2 \\
Co7 & 3 & 8 & 2 & 0 \\
Co8 & 10 & 7 & 0 & 5 \\
Co9 & 8 & 7 & 0 & 1 \\
C10 & 4 & 7 & 1 & 1 \\
C11 & 3 & 3 & 5 & 1 \\
C12 & 0 & 5 & 0 & 5 \\
\hline
\end{tabular}

Tabla 104. Referencias sobre aspectos sociales en las entrevistas (elaboración propia).

\begin{tabular}{|ccccc|}
\hline ENTREVISTA & $\begin{array}{c}\text { ATENCIÓN A LA } \\
\text { DIVERSIDAD }\end{array}$ & $\begin{array}{c}\text { TRANSMISIÓN } \\
\text { DE VALORES } \\
\text { SOCIALES }\end{array}$ & $\begin{array}{c}\text { NORMAS DE } \\
\text { CONVIVENCIA }\end{array}$ & $\begin{array}{c}\text { FOMENTO DE } \\
\text { LA COHESIÓN- } \\
\text { INTEGRACIÓN }\end{array}$ \\
\hline C01 & 5 & 3 & 1 & 3 \\
C02 & 5 & 3 & 1 & 4 \\
C03 & 7 & 12 & 6 & 12 \\
C04 & 7 & 8 & 10 & 14 \\
C05 & 15 & 1 & 2 & 6 \\
C06 & 5 & 2 & 3 & 1 \\
C07 & 11 & 0 & 1 & 3 \\
C08 & 0 & 1 & 3 & 4 \\
Co9 & 7 & 1 & 0 & 3 \\
C10 & 16 & 1 & 1 & 1 \\
C11 & 0 & 1 & 3 & 4 \\
C12 & 0 & 2 & 6 & 1 \\
\hline
\end{tabular}


Tabla 105. Referencias sobre juegos motores en las entrevistas (elaboración propia).

\begin{tabular}{|ccccc|}
\hline ENTREVISTA & $\begin{array}{c}\text { MOTRICIDAD } \\
\text { FINA }\end{array}$ & $\begin{array}{c}\text { MOTRICIDAD } \\
\text { GRUESA }\end{array}$ & $\begin{array}{c}\text { COORDINACIÓN } \\
\text { GLOBAL }\end{array}$ & $\begin{array}{c}\text { COORDINACIÓN } \\
\text { ESPECÍFICA }\end{array}$ \\
\hline C01 & 0 & 7 & 7 & 5 \\
C02 & 1 & 5 & 5 & 4 \\
C03 & 2 & 26 & 23 & 10 \\
C04 & 3 & 16 & 16 & 6 \\
C05 & 1 & 18 & 18 & 13 \\
C06 & 0 & 21 & 20 & 5 \\
C07 & 2 & 12 & 11 & 9 \\
C08 & 0 & 15 & 15 & 7 \\
Co9 & 4 & 4 & 4 & 5 \\
C10 & 2 & 17 & 16 & 14 \\
C11 & 0 & 18 & 18 & 10 \\
C12 & 0 & 11 & 11 & 4 \\
\hline
\end{tabular}

Tabla 106. Referencias sobre juegos de expresión corporal en las entrevistas (elaboración propia).

\begin{tabular}{|ccccc|}
\hline ENTREVISTA & $\begin{array}{c}\text { REPRESENTACIÓN } \\
\text { DE ROLES }\end{array}$ & SIMBOLISMO & EXPRESIÓN & $\begin{array}{c}\text { COMUNICACIÓN } \\
\text { CORPORAL }\end{array}$ \\
\hline C01 & 0 & 2 & 2 & 2 \\
C02 & 2 & 2 & 3 & 0 \\
C03 & 1 & 1 & 15 & 1 \\
C04 & 2 & 3 & 10 & 1 \\
C05 & 1 & 2 & 5 & 1 \\
C06 & 5 & 5 & 7 & 3 \\
C07 & 2 & 4 & 7 & 1 \\
C08 & 2 & 2 & 6 & 1 \\
Co9 & 1 & 1 & 2 & 1 \\
C10 & 1 & 1 & 3 & 1 \\
C11 & 3 & 4 & 6 & 1 \\
C12 & 2 & 1 & 5 & 2 \\
\hline
\end{tabular}

Tabla 107. Referencias sobre otros aspectos en las entrevistas (elaboración propia).

\begin{tabular}{|ccccc|}
\hline ENTREVISTA & $\begin{array}{c}\text { CARÁCTER } \\
\text { INNOVADORY } \\
\text { ORIGINALIDAD }\end{array}$ & VALOR LÚDICO & $\begin{array}{c}\text { VARIEDAD DE } \\
\text { LOS JUEGOS }\end{array}$ & $\begin{array}{c}\text { EVALUACIÓN } \\
\text { DE LAS } \\
\text { ACTIVIDADES }\end{array}$ \\
\hline C01 & 1 & 6 & 6 & 6 \\
C02 & 1 & 2 & 1 & 7 \\
C03 & 9 & 21 & 22 & 6 \\
C04 & 11 & 13 & 26 & 20 \\
C05 & 6 & 10 & 31 & 8 \\
C06 & 9 & 20 & 22 & 23 \\
C07 & 6 & 12 & 12 & 7 \\
C08 & 5 & 13 & 16 & 11 \\
Co9 & 3 & 5 & 7 & 5 \\
C10 & 2 & 10 & 16 & 5 \\
& & & &
\end{tabular}




\begin{tabular}{lllll}
$C_{11}$ & 7 & 18 & 18 & 1 \\
$C_{12}$ & 3 & 12 & 12 & 3 \\
\hline
\end{tabular}

Tabla 108. Referencias sobre aprendizajes académicos en la entrevista Co1 (elaboración propia).

\begin{tabular}{|lcccc|}
\hline \multicolumn{1}{|c}{ ENTREVISTA Co1 } & a & b & c & d \\
\hline Ajuste de los juegos al alumnado & 5 & 7 & 1 & 4 \\
Presentación & 6 & 5 & 4 & 2 \\
Organización del alumnado & 5 & 2 & 5 & 5 \\
Organización del material & 2 & 1 & 2 & 4 \\
Organización espacio/temporal & 11 & 7 & 10 & 9 \\
Adecuación curricular & 3 & 4 & 2 & 5 \\
Aspectos sociales & 5 & 3 & 1 & 3 \\
Juegos motores & 5 & 7 & 0 & 7 \\
Juegos de expresión corporal & 2 & 2 & 0 & 2 \\
Otros & 1 & 6 & 6 & 6 \\
\hline
\end{tabular}

Tabla 109. Referencias sobre aprendizajes académicos en la entrevista Co2 (elaboración propia).

\begin{tabular}{|lcccc|}
\hline \multicolumn{1}{|c}{ ENTREVISTA Co2 } & a & b & c & d \\
\hline Ajuste de los juegos al alumnado & 5 & 3 & 0 & 5 \\
Presentación & 2 & 5 & 0 & 2 \\
Organización del alumnado & 1 & 2 & 3 & 4 \\
Organización del material & 4 & 1 & 2 & 2 \\
Organización espacio/temporal & 2 & 1 & 2 & 1 \\
Adecuación curricular & 3 & 0 & 0 & 0 \\
Aspectos sociales & 5 & 4 & 1 & 3 \\
Juegos motores & 4 & 5 & 1 & 5 \\
Juegos de expresión corporal & 0 & 3 & 2 & 2 \\
Otros & 1 & 7 & 2 & 1 \\
\hline
\end{tabular}

Tabla 110. Referencias sobre aprendizajes académicos en la entrevista Co3 (elaboración propia).

\begin{tabular}{|lcccc|}
\hline \multicolumn{1}{|c}{ ENTREVISTA Co3 } & a & b & c & d \\
\hline Ajuste de los juegos al alumnado & 9 & 5 & 1 & 8 \\
Presentación & 10 & 8 & 4 & 4 \\
Organización del alumnado & 8 & 6 & 17 & 14 \\
Organización del material & 9 & 2 & 18 & 19 \\
Organización espacio/temporal & 13 & 12 & 13 & 12 \\
Adecuación curricular & 11 & 3 & 4 & 10 \\
Aspectos sociales & 7 & 12 & 6 & 12 \\
Juegos motores & 10 & 23 & 2 & 26 \\
Juegos de expresión corporal & 1 & 15 & 1 & 1 \\
Otros & 9 & 6 & 21 & 22 \\
\hline
\end{tabular}


Tabla 111. Referencias sobre aprendizajes académicos en la entrevista Co4 (elaboración propia).

\begin{tabular}{|lcccc|}
\hline \multicolumn{1}{|c}{ ENTREVISTA Co4 } & a & b & c & d \\
Ajuste de los juegos al alumnado & 13 & 14 & 6 & 17 \\
Presentación & 16 & 17 & 18 & 1 \\
Organización del alumnado & 4 & 6 & 20 & 15 \\
Organización del material & 5 & 9 & 11 & 17 \\
Organización espacio/temporal & 13 & 6 & 13 & 11 \\
Adecuación curricular & 12 & 9 & 12 & 6 \\
Aspectos sociales & 7 & 14 & 10 & 8 \\
Juegos motores & 6 & 16 & 3 & 16 \\
Juegos de expresión corporal & 1 & 10 & 2 & 3 \\
Otros & 11 & 20 & 13 & 26 \\
\hline
\end{tabular}

Tabla 112. Referencias sobre los aprendizajes académicos en la entrevista Co5 (elaboración propia).

\begin{tabular}{|lcccc|}
\hline \multicolumn{1}{|c}{ ENTREVISTA Co5 } & $\mathrm{a}$ & $\mathrm{b}$ & $\mathrm{c}$ & $\mathrm{d}$ \\
\hline Ajuste de los juegos al alumnado & 29 & 28 & 2 & 20 \\
Presentación & 23 & 22 & 16 & 3 \\
Organización del alumnado & 3 & 2 & 22 & 22 \\
Organización del material & 9 & 11 & 19 & 21 \\
Organización espacio/temporal & 20 & 4 & 23 & 7 \\
Adecuación curricular & 6 & 9 & 6 & 2 \\
Aspectos sociales & 15 & 6 & 2 & 1 \\
Juegos motores & 13 & 18 & 1 & 18 \\
Juegos de expresión corporal & 1 & 5 & 1 & 2 \\
Otros & 6 & 8 & 10 & 31 \\
\hline
\end{tabular}

Tabla 113. Referencias sobre aprendizajes académicos en la entrevista Co6 (elaboración propia).

\begin{tabular}{|lcccc|}
\hline \multicolumn{1}{|c}{ ENTREVISTA Co6 } & $\mathrm{a}$ & $\mathrm{b}$ & $\mathrm{c}$ & $\mathrm{d}$ \\
\hline Ajuste de los juegos al alumnado & 24 & 15 & 6 & 20 \\
Presentación & 30 & 27 & 11 & 5 \\
Organización del alumnado & 9 & 11 & 23 & 23 \\
Organización del material & 8 & 11 & 13 & 13 \\
Organización espacio/temporal & 20 & 5 & 20 & 14 \\
Adecuación curricular & 17 & 3 & 3 & 2 \\
Aspectos sociales & 5 & 1 & 3 & 2 \\
Juegos motores & 5 & 20 & 0 & 21 \\
Juegos de expresión corporal & 3 & 7 & 5 & 5 \\
Otros & 9 & 23 & 20 & 22 \\
\hline
\end{tabular}

Tabla 114. Referencias sobre aprendizajes académicos en la entrevista Co7 (elaboración propia).

\begin{tabular}{|lcccc|}
\hline \multicolumn{1}{|c}{ ENTREVISTA Co7 } & a & b & c & d \\
\hline Ajuste de los juegos al alumnado & 13 & 18 & 3 & 13 \\
Presentación & 13 & 13 & 3 & 0 \\
Organización del alumnado & 1 & 3 & 12 & 12 \\
Organización del material & 10 & 12 & 13 & 13 \\
Organización espacio/temporal & 11 & 5 & 11 & 11 \\
Adecuación curricular & 8 & 2 & 3 & 0
\end{tabular}




\begin{tabular}{|lcccc|} 
Aspectos sociales & 11 & 3 & 1 & 0 \\
Juegos motores & 9 & 11 & 2 & 12 \\
Juegos de expresión corporal & 1 & 7 & 2 & 4 \\
Otros & 6 & 7 & 12 & 12 \\
\hline
\end{tabular}

Tabla 115. Referencias sobre aprendizajes académicos en la entrevista Co8 (elaboración propia).

\begin{tabular}{|lcccc|}
\hline \multicolumn{1}{|c}{ ENTREVISTA Co8 } & a & b & c & d \\
\hline Ajuste de los juegos al alumnado & 19 & 12 & 9 & 16 \\
Presentación & 19 & 18 & 5 & 2 \\
Organización del alumnado & 9 & 5 & 18 & 18 \\
Organización del material & 7 & 9 & 10 & 10 \\
Organización espacio/temporal & 13 & 3 & 20 & 16 \\
Adecuación curricular & 7 & 0 & 10 & 5 \\
Aspectos sociales & 0 & 4 & 3 & 1 \\
Juegos motores & 7 & 15 & 0 & 15 \\
Juegos de expresión corporal & 1 & 6 & 2 & 2 \\
Otros & 5 & 11 & 13 & 16 \\
\hline
\end{tabular}

Tabla 116. Referencias sobre aprendizajes académicos en la entrevista Cog (elaboración propia).

\begin{tabular}{|lcccc|}
\hline \multicolumn{1}{|c}{ ENTREVISTA Cog } & $\mathrm{a}$ & $\mathrm{b}$ & $\mathrm{c}$ & $\mathrm{d}$ \\
\hline Ajuste de los juegos al alumnado & 7 & 14 & 1 & 8 \\
Presentación & 8 & 8 & 1 & 0 \\
Organización del alumnado & 4 & 3 & 8 & 10 \\
Organización del material & 4 & 3 & 8 & 8 \\
Organización espacio/temporal & 3 & 4 & 8 & 10 \\
Adecuación curricular & 7 & 0 & 8 & 1 \\
Aspectos sociales & 7 & 3 & 0 & 1 \\
Juegos motores & 5 & 4 & 4 & 4 \\
Juegos de expresión corporal & 1 & 2 & 1 & 1 \\
Otros & 3 & 5 & 5 & 7 \\
\hline
\end{tabular}

Tabla 117. Referencias sobre aprendizajes académicos en la entrevista C10 (elaboración propia).

\begin{tabular}{|lcccc|}
\hline \multicolumn{1}{|c}{ ENTREVISTA C10 } & $\mathrm{a}$ & $\mathrm{b}$ & $\mathrm{c}$ & $\mathrm{d}$ \\
\hline Ajuste de los juegos al alumnado & 20 & 28 & 8 & 16 \\
Presentación & 20 & 21 & 8 & 3 \\
Organización del alumnado & 2 & 2 & 20 & 19 \\
Organización del material & 13 & 15 & 15 & 15 \\
Organización espacio/temporal & 7 & 5 & 17 & 19 \\
Adecuación curricular & 7 & 1 & 4 & 1 \\
Aspectos sociales & 16 & 1 & 1 & 1 \\
Juegos motores & 14 & 16 & 2 & 17 \\
Juegos de expresión corporal & 1 & 3 & 1 & 1 \\
Otros & 2 & 5 & 10 & 16 \\
\hline
\end{tabular}


Tabla 118. Referencias sobre aprendizajes académicos en la entrevista C11 (elaboración propia).

\begin{tabular}{|lcccc|}
\hline \multicolumn{1}{|c}{ ENTREVISTA C11 } & $\mathrm{a}$ & $\mathrm{b}$ & $\mathrm{c}$ & $\mathrm{d}$ \\
\hline Ajuste de los juegos al alumnado & 20 & 19 & 4 & 18 \\
Presentación & 21 & 21 & 5 & 2 \\
Organización del alumnado & 9 & 7 & 20 & 20 \\
Organización del material & 11 & 13 & 14 & 17 \\
Organización espacio/temporal & 4 & 1 & 19 & 20 \\
Adecuación curricular & 3 & 5 & 3 & 1 \\
Aspectos sociales & 0 & 4 & 3 & 1 \\
Juegos motores & 10 & 18 & 0 & 18 \\
Juegos de expresión corporal & 1 & 6 & 3 & 4 \\
Otros & 7 & 1 & 18 & 18 \\
\hline
\end{tabular}

Tabla 119. Referencias sobre aprendizajes académicos en la entrevista C12 (elaboración propia).

\begin{tabular}{|lcccc|}
\hline \multicolumn{1}{|c}{ ENTREVISTA C12 } & a & b & c & d \\
\hline Ajuste de los juegos al alumnado & 15 & 12 & 4 & 12 \\
Presentación & 11 & 10 & 8 & 3 \\
Organización del alumnado & 5 & 7 & 12 & 12 \\
Organización del material & 4 & 9 & 10 & 10 \\
Organización espacio/temporal & 4 & 2 & 12 & 12 \\
Adecuación curricular & 5 & 0 & 0 & 5 \\
Aspectos sociales & 0 & 1 & 6 & 2 \\
Juegos motores & 4 & 11 & 0 & 11 \\
Juegos de expresión corporal & 2 & 5 & 2 & 1 \\
Otros & 3 & 3 & 12 & 12 \\
\hline
\end{tabular}

Tabla 120. Referencias sobre la competencia de Emprendimiento Social en las entrevistas (elaboración propia).

\begin{tabular}{|cc|}
\hline ENTREVISTA & $\begin{array}{c}\text { COMPETENCIA DE } \\
\text { EMPRENDIMIENTO SOCIAL }\end{array}$ \\
\hline C01 & 156 \\
C02 & 99 \\
C03 & 113 \\
C04 & 131 \\
Co5 & 90 \\
Co6 & 74 \\
C07 & 37 \\
Co8 & 59 \\
Co9 & 63 \\
C10 & 58 \\
C11 & 84 \\
C12 & 68 \\
\hline
\end{tabular}


Tabla 121. Referencias sobre la competencia de Emprendimiento Social en las entrevistas por categorías (elaboración propia).

\begin{tabular}{|c|c|c|c|c|c|c|c|c|c|c|c|c|}
\hline & Co1 & $\mathrm{Co2}$ & $\mathrm{Co} 3$ & $\mathrm{Co} 4$ & $\mathrm{Co} 5$ & Co6 & $\mathrm{Co} 7$ & Co8 & $\operatorname{Cog}$ & $C_{10}$ & $C_{11}$ & $\mathrm{C}_{12}$ \\
\hline ASPECTOS PERSONALES & 10,17 & 9,67 & 11,67 & 12,00 & 11,33 & 7,50 & 4,17 & 7,00 & 7,17 & 6,17 & 10,00 & 8,50 \\
\hline ASPECTOS SOCIALES & 11,25 & 6,25 & 15,00 & 9,50 & 14,25 & 9,25 & 7,00 & 10,75 & 11,00 & 12,50 & 13,25 & 14,75 \\
\hline ASPECTOS INNOVADORES & 11,57 & 9,86 & 11,71 & 15,14 & 9,43 & 9,86 & 4,43 & 6,14 & 6,86 & 5,86 & 9,57 & 7,00 \\
\hline
\end{tabular}

Tabla 122. Referencias sobre aspectos personales del Emprendimiento Social en las entrevistas (elaboración propia).

\begin{tabular}{|c|c|c|c|c|c|c|}
\hline ENTREVISTA & LIDERAZGO & CONFIANZA & RESPONSABILIDAD & $\begin{array}{c}\text { MOTIVACIÓN } \\
\text { AL LOGRO }\end{array}$ & $\begin{array}{c}\text { CAPACIDAD } \\
\text { PARA } \\
\text { ASUMIR } \\
\text { RIESGOS }\end{array}$ & $\begin{array}{l}\text { INTEGRADO EN } \\
\text { REDES SOCIALES } \\
\text { CON ACCESO A } \\
\text { INFORMACIÓN Y } \\
\text { CONOCIMIENTO }\end{array}$ \\
\hline $\mathrm{Co1}$ & 10 & 3 & 4 & 8 & 4 & 40 \\
\hline $\mathrm{Co2}$ & 3 & 17 & 6 & 10 & 8 & 19 \\
\hline $\mathrm{Co3}$ & 10 & 6 & 13 & 26 & 12 & 22 \\
\hline $\mathrm{Co} 4$ & 4 & 12 & 15 & 34 & 22 & 11 \\
\hline Co5 & 19 & 9 & 14 & 28 & 22 & 27 \\
\hline Co6 & 3 & 9 & 5 & 19 & 9 & 20 \\
\hline Co7 & 5 & 7 & 6 & 14 & 6 & 7 \\
\hline Co8 & 6 & 9 & 8 & 7 & 10 & 21 \\
\hline $\operatorname{Cog}$ & 6 & 7 & 6 & 24 & 7 & 20 \\
\hline$C_{10}$ & 13 & 4 & 8 & 13 & 8 & 14 \\
\hline $\mathrm{C}_{11}$ & 13 & 14 & 6 & 13 & 9 & 30 \\
\hline $\mathrm{C}_{12}$ & 18 & 8 & 10 & 26 & 12 & 13 \\
\hline
\end{tabular}

Tabla 123. Referencias sobre aspectos sociales del Emprendimiento Social en las entrevistas (elaboración propia).

\begin{tabular}{|ccccc|}
\hline ENTREVISTA & $\begin{array}{c}\text { COHERENCIAY } \\
\text { COMPROMISO }\end{array}$ & $\begin{array}{c}\text { CONCIENCIA } \\
\text { SOCIAL }\end{array}$ & $\begin{array}{c}\text { CONVIVENCIA Y RESPETO } \\
\text { POR EL BIEN PÚBLICO }\end{array}$ & $\begin{array}{c}\text { CAPACIDAD DE } \\
\text { COOPERACIÓN-AYUDA }\end{array}$ \\
\hline C01 & 15 & 12 & 11 & 16 \\
C02 & 10 & 3 & 5 & 10 \\
C03 & 24 & 15 & 20 & 27 \\
C04 & 12 & 19 & 20 & 17 \\
C05 & 16 & 19 & 22 & 38 \\
C06 & 7 & 9 & 23 & 14 \\
C07 & 7 & 4 & 21 & 18 \\
C08 & 11 & 4 & 23 & 28 \\
Co9 & 18 & 13 & 25 & 28 \\
C10 & 11 & 12 & 30 & 33 \\
C11 & 9 & 25 & 25 & 26 \\
C12 & 16 & 26 & 35 & 27 \\
\hline
\end{tabular}


Tabla 124. Referencias sobre aspectos innovadores del Emprendimiento Social en las entrevistas (elaboración propia).

\begin{tabular}{|c|c|c|c|c|c|c|c|}
\hline ENTREVISTA & INICIATIVA & CREATIVIDAD & $\begin{array}{l}\text { CAPACIDAD } \\
\text { PARA } \\
\text { GENERAR } \\
\text { IDEAS }\end{array}$ & $\begin{array}{l}\text { CAPACIDAD PARA } \\
\text { IDENTIFICAR } \\
\text { OPORTUNIDADES }\end{array}$ & $\begin{array}{l}\text { CAPACIDAD } \\
\text { DE CAMBIO }\end{array}$ & $\begin{array}{c}\text { CAPACIDAD } \\
\text { PARA } \\
\text { APRENDER Y } \\
\text { EVOLUCIONAR }\end{array}$ & $\begin{array}{l}\text { TOLERANCIA } \\
\text { AL FRACASO }\end{array}$ \\
\hline C01 & 7 & 3 & 21 & 4 & 20 & 19 & 19 \\
\hline $\mathrm{Co2}$ & 11 & 1 & 18 & 15 & 6 & 28 & 27 \\
\hline $\mathrm{Co} 3$ & 11 & 9 & 22 & 5 & 18 & 39 & 32 \\
\hline $\mathrm{Co} 4$ & 9 & 13 & 57 & 19 & 11 & 29 & 31 \\
\hline $\operatorname{Co5}$ & 8 & 3 & 29 & 14 & 15 & 25 & 24 \\
\hline Co6 & 4 & 6 & 40 & 26 & 15 & 25 & 18 \\
\hline $\mathrm{Co7}$ & 9 & 4 & 8 & 10 & 13 & 6 & 14 \\
\hline Co8 & 11 & 4 & 10 & 11 & 12 & 7 & 23 \\
\hline Cog & 14 & 1 & 14 & 7 & 9 & 20 & 15 \\
\hline$C_{10}$ & 5 & 4 & 8 & 11 & 20 & 17 & 12 \\
\hline$C_{11}$ & 4 & 4 & 34 & 27 & 8 & 18 & 8 \\
\hline$C_{12}$ & 19 & 3 & 16 & 13 & 16 & 7 & 12 \\
\hline
\end{tabular}

Tabla 125. Referencias sobre la competencia de Emprendimiento Social en la entrevista Co1 (elaboración propia).

\begin{tabular}{|lccccccc|}
\hline \multicolumn{1}{|c}{ ENTREVISTA Co1 } & a & b & c & d & e & f & g \\
\hline Aspectos personales & 4 & 3 & 40 & 10 & 8 & 4 & \\
Aspectos sociales & 15 & 12 & 11 & 16 & & & \\
Aspectos innovadores & 20 & 19 & 21 & 4 & 3 & 7 & 19 \\
\hline
\end{tabular}

Tabla 126. Referencias sobre la competencia de Emprendimiento Social en la entrevista Co2 (elaboración propia).

\begin{tabular}{|lccccccc|}
\hline \multicolumn{1}{|c}{ ENTREVISTA Co2 } & a & b & c & d & e & f & g \\
\hline Aspectos personales & 8 & 17 & 19 & 3 & 10 & 6 & \\
Aspectos sociales & 10 & 3 & 5 & 10 & & & \\
Aspectos innovadores & 6 & 28 & 18 & 15 & 1 & 11 & 27 \\
\hline
\end{tabular}

Tabla 127. Referencias sobre la competencia de Emprendimiento Social en la entrevista Co3 (elaboración propia).

\begin{tabular}{|lccccccc|}
\hline \multicolumn{1}{|c}{ ENTREVISTA Co3 } & a & b & c & d & e & f & g \\
\hline Aspectos personales & 12 & 6 & 22 & 10 & 26 & 13 & \\
Aspectos sociales & 24 & 15 & 20 & 27 & & & \\
Aspectos innovadores & 18 & 39 & 22 & 5 & 9 & 11 & 32 \\
\hline
\end{tabular}

Tabla 128. Referencias sobre la competencia de Emprendimiento Social en la entrevista Co4 (elaboración propia).

\begin{tabular}{|lccccccc|}
\hline \multicolumn{1}{|c}{ ENTREVISTA Co4 } & a & b & c & d & e & f & g \\
\hline Aspectos personales & 22 & 12 & 11 & 4 & 34 & 15 & \\
Aspectos sociales & 12 & 19 & 20 & 17 & & & \\
Aspectos innovadores & 11 & 29 & 57 & 19 & 13 & 9 & 31 \\
\hline
\end{tabular}


Tabla 129. Referencias sobre la competencia de Emprendimiento Social en la entrevista Co5 (elaboración propia).

\begin{tabular}{|lccccccc|}
\hline \multicolumn{1}{|c}{ ENTREVISTA C05 } & a & b & c & d & e & f & g \\
\hline Aspectos personales & 22 & 9 & 27 & 19 & 28 & 14 & \\
Aspectos sociales & 16 & 19 & 22 & 38 & & & \\
Aspectos innovadores & 15 & 25 & 29 & 14 & 3 & 8 & 24 \\
\hline
\end{tabular}

Tabla 130. Referencias sobre la competencia de Emprendimiento Social en la entrevista Co6 (elaboración propia).

\begin{tabular}{|lccccccc|}
\hline \multicolumn{1}{|c}{ ENTREVISTA Co6 } & a & b & c & d & e & f & g \\
\hline Aspectos personales & 9 & 9 & 20 & 3 & 19 & 5 & \\
Aspectos sociales & 7 & 9 & 23 & 14 & & & \\
Aspectos innovadores & 15 & 25 & 40 & 26 & 6 & 4 & 18 \\
\hline
\end{tabular}

Tabla 131. Referencias sobre la competencia de Emprendimiento Social en la entrevista Co7 (elaboración propia).

\begin{tabular}{|lccccccc|}
\hline \multicolumn{1}{|c}{ ENTREVISTA Co7 } & a & b & c & d & e & f & g \\
\hline Aspectos personales & 6 & 7 & 7 & 5 & 14 & 6 & \\
Aspectos sociales & 7 & 4 & 21 & 18 & & & \\
Aspectos innovadores & 13 & 6 & 8 & 10 & 4 & 9 & 14 \\
\hline
\end{tabular}

Tabla 132. Referencias sobre la competencia de Emprendimiento Social en la entrevista Co8 (elaboración propia).

\begin{tabular}{|lccccccc|}
\hline \multicolumn{1}{|c}{ ENTREVISTA Co8 } & a & b & c & d & e & f & g \\
\hline Aspectos personales & 10 & 9 & 21 & 6 & 7 & 8 & \\
Aspectos sociales & 11 & 4 & 23 & 28 & & & \\
Aspectos innovadores & 12 & 7 & 10 & 11 & 4 & 11 & 23 \\
\hline
\end{tabular}

Tabla 133. Referencias sobre la competencia de Emprendimiento Social en la entrevista Cog (elaboración propia).

\begin{tabular}{|lccccccc|}
\hline \multicolumn{1}{|c}{ ENTREVISTA Cog } & a & b & c & d & e & f & g \\
\hline Aspectos personales & 7 & 7 & 20 & 6 & 24 & 6 & \\
Aspectos sociales & 18 & 13 & 25 & 28 & & & \\
Aspectos innovadores & 9 & 20 & 14 & 7 & 1 & 14 & 15 \\
\hline
\end{tabular}

Tabla 134. Referencias sobre la competencia de Emprendimiento Social en la entrevista C10 (elaboración propia).

\begin{tabular}{|lccccccc|}
\hline \multicolumn{1}{|c}{ ENTREVISTA C10 } & a & b & c & d & e & f & g \\
\hline Aspectos personales & 8 & 4 & 14 & 13 & 13 & 8 & \\
Aspectos sociales & 11 & 12 & 30 & 33 & & & \\
Aspectos innovadores & 20 & 17 & 8 & 11 & 4 & 5 & 12 \\
\hline
\end{tabular}


Tabla 135. Referencias sobre la competencia de Emprendimiento Social en la entrevista C11 (elaboración propia).

\begin{tabular}{|lccccccc|}
\hline \multicolumn{1}{|c}{ ENTREVISTA C11 } & a & b & c & d & e & f & g \\
\hline Aspectos personales & 9 & 14 & 30 & 13 & 13 & 6 & \\
Aspectos sociales & 9 & 25 & 25 & 26 & & & \\
Aspectos innovadores & 8 & 18 & 34 & 27 & 4 & 4 & 8 \\
\hline
\end{tabular}

Tabla 136. Referencias sobre la competencia de Emprendimiento Social en la entrevista C12 (elaboración propia).

\begin{tabular}{|lccccccc|}
\hline \multicolumn{1}{|c}{ ENTREVISTA C12 } & a & b & c & d & e & f & g \\
\hline Aspectos personales & 12 & 8 & 13 & 18 & 26 & 10 & \\
Aspectos sociales & 16 & 26 & 35 & 27 & & & \\
Aspectos innovadores & 16 & 7 & 16 & 13 & 3 & 19 & 12 \\
\hline
\end{tabular}

